\title{
Financial instruments in the OECD model tax convention
}

Citation for published version (APA):

Weissbrodt, J. (2018). Financial instruments in the OECD model tax convention. [Doctoral Thesis, Maastricht University]. Maastricht University. https://doi.org/10.26481/dis.20181123jw

Document status and date:

Published: 01/01/2018

DOI:

10.26481/dis.20181123jw

Document Version:

Publisher's PDF, also known as Version of record

\section{Please check the document version of this publication:}

- A submitted manuscript is the version of the article upon submission and before peer-review. There can be important differences between the submitted version and the official published version of record.

People interested in the research are advised to contact the author for the final version of the publication, or visit the DOI to the publisher's website.

- The final author version and the galley proof are versions of the publication after peer review.

- The final published version features the final layout of the paper including the volume, issue and page numbers.

Link to publication

\footnotetext{
General rights rights.

- You may freely distribute the URL identifying the publication in the public portal. please follow below link for the End User Agreement:

www.umlib.nl/taverne-license

Take down policy

If you believe that this document breaches copyright please contact us at:

repository@maastrichtuniversity.nl

providing details and we will investigate your claim.
}

Copyright and moral rights for the publications made accessible in the public portal are retained by the authors and/or other copyright owners and it is a condition of accessing publications that users recognise and abide by the legal requirements associated with these

- Users may download and print one copy of any publication from the public portal for the purpose of private study or research.

- You may not further distribute the material or use it for any profit-making activity or commercial gain

If the publication is distributed under the terms of Article $25 \mathrm{fa}$ of the Dutch Copyright Act, indicated by the "Taverne" license above, 


\title{
Financial Instruments in the OECD Model Tax Convention
}

\author{
Jan Weissbrodt
}


Lay-out: Much2Proof - Maastricht - Leiden

(C) 2018 J. Weissbrodt

ISBN/EAN: 978-94-028-1249-7

Behoudens de in of krachtens de Auteurswet gestelde uitzonderingen mag niets uit deze uitgave worden verveelvoudigd, opgeslagen in een geautomatiseerd gegevensbestand, of openbaar gemaakt, in enige vorm of op enige wijze, hetzij elektronisch, mechanisch, door fotokopieën, opnamen of enige andere manier, zonder voorafgaande schriftelijke toestemming van de uitgever.

Voor zover het maken van reprografische verveelvoudigingen uit deze uitgave is toegestaan op grond van artikel $16 \mathrm{~h}$ Auteurswet dient men de daarvoor wettelijk verschuldigde vergoedingen te voldoen aan de Stichting Reprorecht (Postbus 3051, 2130 KB Hoofddorp, www.reprorecht.nl). Voor het overnemen van (een) gedeelte(n) uit deze uitgave in bloem-lezingen, readers en andere compilatiewerken (art. 16 Auteurswet) kan men zich wenden tot de Stichting PRO (Stichting Publicatie- en Reproductierechten Organisatie, Postbus 3060, 2130 KB Hoofddorp, www.stichting-pro.nl).

No part of this book may be reproduced in any form, by print, photoprint, microfilm or any other means without written permission from the publisher. 


\title{
Financial Instruments in the OECD Model Tax Convention
}

\author{
DISSERTATION
}

to obtain the degree of Doctor at

Maastricht University on the authority of the Rector Magnificus

Prof. dr. Rianne M. Letschert

in accordance with the decision of the Board of Deans,

to be defended in public

on Friday $23^{\text {rd }}$ of November 2018 at 10.00 hours

by

Jan Weissbrodt

born in Berlin, Germany

in 1979 
Supervisor:

Co-supervisors:

Assessment Committee:
Prof. dr. Rainer G. Prokisch

Prof. dr. Hans van den Hurk

Prof. dr. Raymond Luja (Chair)

Dr. Marcel Schaper

Prof. dr. Alexander Brüggen

Prof. dr. Marjaana Helminen

Prof. dr. Madeleine Simonek 


\section{Contents}

$\begin{array}{lll}\text { II Abbreviations } & \text { IX }\end{array}$

1 Introduction $\quad 1$

1.1 Subject 1

1.1.1 Problem 1

1.1.2 Objective 2

1.1.3 Relevance 3

1.2 Scope $\quad 5$

1.3 Approach 6

1.4 Sources of law and their relevance $\quad 8$

1.4.1 Preliminary remarks 8

1.4.2 OECD Commentaries on the OECD MTC 11

1.4.3 UN Commentaries on the UN MTC 16

$\begin{array}{ll}\text { 1.4.4 US tax law } & 16\end{array}$

$\begin{array}{ll}\text { 1.4.5 EU tax law } & 17\end{array}$

1.4.6 IAS / IFRS 20

2 Basic principles, systematic context and potential differentiators of financial instruments 23

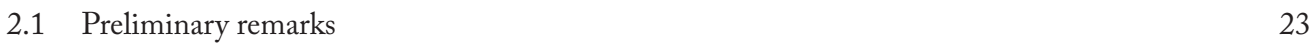

2.2 Analysis and discussion of basic principles $\quad 23$

2.2.1 Preliminary remarks 23

2.2.2 Asset versus transaction 24

$\begin{array}{lll}2.2 .3 & \text { Risk } & 28\end{array}$

2.2.4 Substance versus form 33

2.2.4.1 Genuine versus derivative concepts 33

2.2.4.2 Abuse as a derivative concept 34

2.2.4.3 Limitations of the genuine substance over principle $\quad 37$

$\begin{array}{ll}\text { 2.2.4.4 Conclusions } & 41\end{array}$

2.2.5 Aggregation versus disaggregation 41

2.2.5.1 Preliminary remarks 41

2.2.5.2 Definition and scope $\quad 42$

2.2.5.3 Options as building blocks 45

2.2.5.4 Aggregation must be applied restrictively 48

2.2.5.5 What can be learned from the IAS/IFRS 51

2.2.5.6 What can be learned from finance theory 59

$\begin{array}{lll}2.2 .5 .7 & \text { Conclusions } & 65\end{array}$

2.3 Analysis and discussion of the systematic context 68

$\begin{array}{lll}\text { 2.3.1 Preliminary remarks } & 68\end{array}$

2.3.2 Relations between the distributive articles $\quad 69$ 
$\begin{array}{lll}\text { 2.3.3 Beneficial ownership } & 70\end{array}$

2.3.3.1 Preliminary remarks $\quad 70$

$\begin{array}{lll}\text { 2.3.3.2 Definition and scope } & 70\end{array}$

2.3.3.3 Asset- and transaction-related aspect $\quad 74$

$\begin{array}{ll}\text { 2.3.3.4 Interim conclusions } & 77\end{array}$

$\begin{array}{lll}\text { 2.3.3.5 Operationalisation } & 81\end{array}$

2.3.3.6 Limitations 85

2.3.4 Realisation 88

2.3.4.1 Definition and legal basis 88

2.3.4.2 The relevance of the terms 'paid' and 'from' 90

2.3.4.3 The relevance of the term 'arising' 92

2.3.4.4. The relevance of the term 'alienation' 94

2.3.4.5 Deemed income $\quad 97$

$\begin{array}{ll}\text { 2.3.4.6 Conclusions } & 104\end{array}$

2.4 Analysis and discussion of potential differentiators 104

$\begin{array}{ll}\text { 2.4.1 Preliminary remarks } & 104\end{array}$

2.4.2 Rights and obligations 106

$\begin{array}{lll}\text { 2.4.2.1 Preliminary remarks } & 106\end{array}$

$\begin{array}{lll}2.4 .2 .2 & \text { Reciprocity } & 106\end{array}$

$\begin{array}{lll}2.4 .2 .3 \text { Control } & 109\end{array}$

2.4.2.4 Voluntariness, laterality and self-execution $\quad 112$

$\begin{array}{lll}2.4 .3 & \text { Time aspects } & 115\end{array}$

2.4.3.1 Preliminary remarks 115

$\begin{array}{ll}\text { 2.4.3.2 Maturity of principal } & 116\end{array}$

$\begin{array}{ll}\text { 2.4.3.3 Maturity of remuneration } & 117\end{array}$

$\begin{array}{lll}2.4 .4 & \text { Payment profile } & 118\end{array}$

$\begin{array}{ll}\text { 2.4.4.1 Preliminary remarks } & 118\end{array}$

$\begin{array}{ll}\text { 2.4.4.2 Absence of any income } & 118\end{array}$

$\begin{array}{ll}\text { 2.4.4.3 Participation in profits and losses } & 119\end{array}$

2.4.4.4 Time value of money 122

$\begin{array}{lll}2.4 .5 & \text { Risks and opportunities } & 127\end{array}$

$\begin{array}{ll}\text { 2.4.5.1 Preliminary remarks } & 127\end{array}$

$\begin{array}{ll}\text { 2.4.5.2 Subordination } & 128\end{array}$

$\begin{array}{ll}\text { 2.4.5.3 Coverage and collateral } & 130\end{array}$

$\begin{array}{ll}\text { 2.4.5.4 Termination risk } & 134\end{array}$

$\begin{array}{ll}\text { 2.4.5.5 Conclusions } & 144\end{array}$

2.4.6 Origin of funds 145

$\begin{array}{ll}\text { 2.4.6.1 Preliminary remarks } & 145\end{array}$

$\begin{array}{lll}\text { 2.4.6.2 Liquidation of assets } & 145\end{array}$

$\begin{array}{ll}\text { 2.4.6.3 Business profits } & 147\end{array}$ 
3 Analysis and discussion of the relevant distributive articles

3.1 Preliminary remarks

3.2 Dividends

3.2.1 Structure of the provision $\quad 154$

3.2.2 Shares and the like 156

$\begin{array}{lll}3.2 .3 \text { Corporate rights } & 159\end{array}$

3.2.4 Participating in profits 163

3.2.5 Other rights 168

3.2.6 Not being debt-claims 171

$\begin{array}{lll}3.3 & \text { Interest } & 172\end{array}$

$\begin{array}{lll}\text { 3.3.1 Structure of the provision } & 172\end{array}$

$\begin{array}{lll}\text { 3.3.2 } & \text { Debt-claims } & 173\end{array}$

$\begin{array}{ll}3.3 .3 \text { Of every kind } & 180\end{array}$

3.3.4 Accrued interest 184

3.4 Capital gains $\quad 186$

3.4.1 Structure of the provision 186

$\begin{array}{ll}3.4 .2 \text { Alienation } & 187\end{array}$

3.5 Other income 195

$\begin{array}{lll}\text { 3.5.1 Structure of the provision } & 195\end{array}$

$\begin{array}{lll}\text { 3.5.2 Gamble } & 196\end{array}$

4 Summary of conclusions $\quad 199$

5 Classification of selected types of financial instruments 213

5.1 Preliminary remarks 213

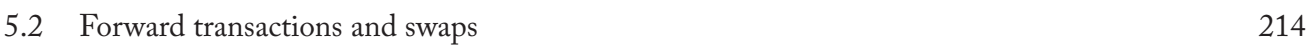

$\begin{array}{lll}5.2 .1 & \text { Structure } & 214\end{array}$

$\begin{array}{lll}5.2 .2 & \text { Optionality } & 215\end{array}$

$\begin{array}{lll}5.2 .3 \text { Seriality } & 219\end{array}$

$\begin{array}{ll}\text { 5.2.4 Underlying } & 220\end{array}$

$\begin{array}{lll}5.2 .5 & \text { Settlement } & 222\end{array}$

$\begin{array}{lll}\text { 5.2.6 Conclusions } & 224\end{array}$

$\begin{array}{lll}5.3 & \text { Convertibles } & 224\end{array}$

$\begin{array}{lll}\text { 5.3.1 } & \text { Structure } & 224\end{array}$

$\begin{array}{lll}\text { 5.3.2 Disaggregation } & 226\end{array}$

$\begin{array}{lll}\text { 5.3.3 Redemption obligation } & 227\end{array}$

$\begin{array}{lll}\text { 5.3.4 Termination risk } & 229\end{array}$

$\begin{array}{lll}\text { 5.3.5 Remuneration } & 231\end{array}$

$\begin{array}{lll}\text { 5.3.6 Self-execution } & 232\end{array}$

5.3.7 Conclusions 234

5.4 Other debt-based financial instruments 235

5.4.1 Structure 235

$\begin{array}{lll}\text { 5.4.2 Linkers } & 235\end{array}$

$\begin{array}{lll}\text { 5.4.3 Linkers on debt-specific risks } & 238\end{array}$ 
$\begin{array}{lll}\text { 5.4.4 } & \text { Replicated debts } & 240\end{array}$

5.4.5 Negative interest $\quad 242$

5.5 Other equity-based financial instruments 244

$\begin{array}{lll}\text { 5.5.1 Structure } & 244\end{array}$

$\begin{array}{lll}\text { 5.5.2 Redeemability } & 244\end{array}$

$\begin{array}{lll}\text { 5.5.3 Preference in the remuneration } & 245\end{array}$

$\begin{array}{lll}\text { 5.5.4 Preference in the event of liquidation } & 248\end{array}$

$\begin{array}{lll}\text { 5.5.5 Preference in membership rights } & 249\end{array}$

$\begin{array}{lll}\text { 5.5.6 Conclusions } & 250\end{array}$

$\begin{array}{lll}5.6 & \text { Strips } & 250\end{array}$

$\begin{array}{lll}\text { 5.6.1 Structure } 250 & 250\end{array}$

5.6.2 The relevance of the separate capital 251

5.6.3 The conflict between termination and remuneration risk 253

$\begin{array}{lll}5.7 & \text { Non-cash based financial instruments } & 257\end{array}$

$\begin{array}{lll}5.7 .1 & \text { Structure } & 257\end{array}$

$\begin{array}{ll}\text { 5.7.2 Determination of the operation } & 257\end{array}$

$\begin{array}{lll}\text { 5.7.3 Relevant risk types } & 260\end{array}$

$\begin{array}{lll}\text { 5.7.4 Synergetic effects } & 261\end{array}$

$\begin{array}{lll}\text { 5.7.5 The relevant level } & 262\end{array}$

5.7.6 Securities lending transactions 265

$\begin{array}{llr}6 & \text { General discussion } & 267\end{array}$

$\begin{array}{ll}\text { III Bibliography } & 273\end{array}$

$\begin{array}{ll}\text { IV Materials } & 283\end{array}$

$\begin{array}{llr}\text { V Illustrations } & 291\end{array}$

$\begin{array}{ll}\text { Valorisation Addendum } & 293\end{array}$

$\begin{array}{ll}\text { Curriculum Vitae } & 297\end{array}$ 


\section{Abbreviations}

A.A.R. Authority for Advance Rulings

Art. Article(s)

AS Aksjeselskap

BEPS Base Erosion and Profit Shifting

BC (IAS / IFRS) Basis for Conclusions

BNB Beslissingen in belastingzaken / Nederlandse Belastingrechtspraak

BStB1 Bundessteuerblatt

BV Besloten vennootschap met beperkte aansprakelijkheid

CDO Collateralised debt obligation(s)

Chap. Chapter(s)

CLN Credit-linked note(s)

CoCo Contingent convertible bond(s)

C.T.C. Canada Tax Cases

CPEC Convertible preferred equity certificate(s)

D.C. District of Columbia

DECS Dividend enhanced convertible securities

DO Dissenting Opinion

DStR Deutsches Steuerrecht

DTC Double Tax Convention(s) on Income and on Capital

EBIT Earnings before Interest and Taxes

EBITDA Earnings before Interest, Taxes, Depreciation and Amortisation

EC European Community

ECJ European Court of Justice

EEC European Economic Community

e.g. $\quad$ exemplī grātiā

EMIR European Market Infrastructure Regulation

et al. et alii / et aliae / et alia

etc. et cetera

et seq. et sequens

et seqq. et sequentia

EU European Union

FCA Federal Court of Australia

HCA High Court of Australia

IAS International Accounting Standards

IBFD International Bureau of Fiscal Documentation

ICJ International Court of Justice

i.e. id est

IE (IAS / IFRS) Illustrative Examples

IFA International Fiscal Association

IFRIC (IFRS) International Financial Reporting Interpretations Committee 
IFRS International Financial Reporting Standards

IG (IAS / IFRS) Guidance on Implementing

ILS Insurance-linked security(s)

Inc. Incorporated

IWB Internationale Wirtschaftsbriefe

Jr. Junior

KPMG Klynveld, Peat, Marwick \& Goerdeler

Ltd. Limited

MTC Model Tax Convention on Income and on Capital

$\mathrm{n} / \mathrm{a} \quad$ Not applicable

No. Number(s)

NWB Neue Wirtschaftsbriefe

OECD Organisation for Economic Co-operation and Development

OEEC Organisation for European Economic Co-operation

p. Page(s)

Par. Paragraph(s)

PERCS Preferred equity redemption cumulative stock

PT Perseroan Terbatas

Ref. Reference(s)

SCRIP Substitute Cash Redeem in Person

SFAS Statement(s) of (US) Financial Accounting Standards

Sec. Section(s)

SIC (IAS) Standing Interpretations Committee

TARN Targeted accrual redemption note(s)

TFEU Treaty on the Functioning of the European Union, Lisbon, 13 December 2007, available online at http://eur-lex.europa.eu (last retrieved on 15 September 2017)

UN United Nations

US / USA United States of America

VCLT Vienna Convention on the Law of Treaties, Vienna, 23 May 1969, available online at http://treaties.un.org (last retrieved on 15 September 2017)

Vol. Volume(s)

vs. versus 


\section{Chapter 1}

\section{Introduction}

\subsection{Subject}

\subsubsection{Problem}

Financial instruments are legal contracts evidencing financial transactions. Financial transactions can be understood in a narrow purposive sense of particularly providing finance capital (e.g. equity yielding dividends and debt yielding interest) or in a broader, objective sense of generally dealing with cash and/or cashequivalents (e.g. also including capital gains). While the OECD MTC deals with income from both forms of financial transactions, it requires them to be classified into its various distributive articles. Obviously the aspect of applying a legal framework to contracts is not a particular issue of financial instruments but rather of any tax case. The peculiarity of financial instruments is, however, that they extract or separate economic attributes such as cash flows or risks from any real asset. In other words: it is this economic purity which allows financial instruments, as opposed to physical transactions, to transform those economic attributes from the underlying assets into a "piece of paper" and to market and transact them between taxpayers under considerably low frictions (e.g. transaction costs, timing, legal restrictions, etc.). And it is this very reason which makes finance capital an extraordinarily mobile economic factor. Even facing the specific complexity of the OECD MTC as what is called in this study a collective tax law, it is therefore not so much the legal but rather the economic aspect of financial instruments that is detached from that legal aspect in such an exceptional manner that it challenges the traditional real-economic fundamentals of any legal framework dealing with economic situations. Thinking this to its end raised quite early doubts towards the principal capability and expedience of an income tax law system to tackle these challenges ${ }^{1}$.

\footnotetext{
1 David Hasen, p. 399 et seq. and 481; Duncan, James A., Tax Treatment of hybrid Financial Instruments in cross-border Transactions General Report, Series IFA Cahiers 2000, Vol. 85a, p. 21; Achim Pross, p. 172 and 181; Anthony Polito, p. 762; Shaviro, Daniel, Risk-Based Rules and the Taxation of Capital Income, Tax Law Review 1995, Vol. 50, Issue 4, p. 645, 690, 704 and 708; David Weisbach, p. 492 and 495; Warren, Alvin C. Jr., Financial Contract Innovation and Income Tax Policy, Harvard Law Review 1993, Vol. 107, Issue 2, p. 461 , 482 and 491 et seq.; Edward Kleinbard, financial innovations, p. 1361 et seqq.; Edward Kleinbard, debt, p. 946.
} 
These challenges include, for instance ${ }^{2}$ :

- Financial transactions, both in the narrow and the broader sense mentioned above ${ }^{3}$ are flexible and can be tailor-made in the sense that they can be replicated by each other and/or artificially synthesised.

- As a result, the basic principles of realisation, its methods (e.g. accrual versus cash flow basis) and its date are placed at disposal, as are, consequently, the general rules of attribution.

- In addition, financial transactions are capable of compensating or synergising compound effects (e.g. hedges), so that the amounts of income are not necessarily predetermined.

- Furthermore, the source of income is highly flexible in terms of replaceability and mobility.

- In transferring or exchanging not only cash-equivalents as positive assets but also risks as negative assets, financial instruments present unique issues with respect to "in lieu of" payments.

3 Due to the strong dualism between the legal form and the economic substance in tax law, many financial instruments or transactions appear to be ambiguous and impervious to a distinct classification. These ambiguities, which already emerge in domestic tax laws, become even more critical in the law of DTC. Domestic laws often try to constitute a closed and cohesive system that may resolve or alleviate these conflicts, for instance by subsidiarity rules, fall-back provisions or tests ${ }^{4}$. Due to their segregated structure of income types or schedules, DTC, however, provide only the four possible Art. 10, 11, 13 and 21 OECD MTC, which lead to considerably different legal consequences. In addition, the question of which level of law is relevant and decisive (e.g. DTC itself, protocol, domestic law, treaty override, binding or non-binding memorandum of consultations, etc.) for each and every single criterion leads to another level of complexity when interpreting and applying DTC. For these reasons, qualification conflicts must be acknowledged as very likely to occur in the field of financial tax law, fostering entire repeals (e.g. the OECD Multilateral Convention ${ }^{5}$ ) or at least secondary law and derivative concepts (e.g. "abuse"). Such derivative concepts, however, presuppose genuine concepts (e.g. definitions) as their precondition instead of creating them as their result. In casuistically alleviating the cursory symptoms rather than dealing with the actual root causes in an abstract manner, those responses eventually erode primary law and thus subvert legal certainty as a whole.

\subsubsection{Objective}

4 The intention and objective of this study is to develop a tie-breaking test in order to distinguish:

(1) Shares yielding dividends pursuant to Art. 10(3) OECD MTC and debt-claims yielding interest pursuant to Art. 11(3) OECD MTC from each other;

(2) The group of these finance transactions in the narrow sense from those in the broader sense ${ }^{6}$, i.e. capital gains pursuant to Art. 13(5) OECD MTC; and

(3) The group of these specific financial transactions from the general residual of other income pursuant to Art. 21(1) OECD MTC.

\footnotetext{
OECD, ST/SG/AC.8/2001/CRP.8, p. 17 et seqq., par. 47 et seqq.

See par. 1 .

4 Similarly: Michael Lang, hybrids, p. 128.

5 OECD, Multilateral Convention to implement Tax Treaty related Measures to prevent BEPS, Paris, 2017.

6 See par. 1.
} 
5 Closed-end tax law systems such as domestic tax laws typically adhere to other and/or additional purposes than tax treaties and thus apply other and/or additional principles ${ }^{7}$. In contrast, the aspired OECD MTC tie-breaking test shall - as much as possible - have the following properties or characteristics ${ }^{8}$ :

\section{Logical requirements to the tie-breaking test}

- Coherence: The test criteria or differentiators form a logical and systematic structure.

- Consistency: Equal or comparable inputs (i.e. cases of financial instruments or transactions) harmonically and consequently result in equal or comparable outputs (i.e. legal classifications) respectively.

- Universality: The test is capable of processing the greatest possible diversity of inputs.

- Completeness: The test is gapless in the sense that it is capable of always resulting in an output (i.e. legal classification).

- Mutual exclusivity: The output from the test is unique or otherwise clearly and distinctly determined without any overlap or ambiguity.

\section{Legal requirements to the tie-breaking test}

- Justifiability: The test criteria or differentiators shall each be supported by the current state and findings of jurisprudential research and discourse. In addition, they shall also integrate dissenting opinions wherever possible.

- Autonomy: All test criteria or differentiators and consequently also the outputs from the test are independent from domestic laws.

- Objectivity: All test criteria or differentiators and consequently also the outputs from the test are also independent from domestic terminology.

\section{Technical requirements to the tie-breaking test}

- Resilience: All test criteria or differentiators and, consequently, also the outputs from the test are robust and stable, even when viewed from different perspectives.

- Operationalisability: The test shall be easy to apply, as it will use publicly available or otherwise easily identifiable information wherever possible.

\subsubsection{Relevance}

It has been estimated that presently there exist around 3,000 DTC worldwide ${ }^{9}$. This represents an estimated coverage of nominal ca. $7 \%{ }^{10}$ of all possible combinations of jurisdictions under international law, but of real ca. $80 \%$ in terms of their accumulated share of the global economic power ${ }^{11}$. Given the economic significance of

\footnotetext{
7 Illustrative: Brunson, Samuel D., Elective Taxation of Risk-Based Financial Instruments: A Proposal, Houston Business and Tax Law Journal 2007, Vol. 8, Issue 1, p. 15 et seqq.

8 Illustrative: OECD, ST/SG/AC.8/2001/CRP.8, p. 25 et seq., par. 89 et seqq.

9 Institute of Chartered Accountants in England and Wales, www.icaew.com/en/library/key-resources/double-tax-treaties (last retrieved on 15 September 2017).

10 Calculation based on a maximum of 208 jurisdictions under international law (Auswärtiges Amt der Bundesrepublik Deutschland, Länderverzeichnis für den amtlichen Gebrauch in der Bundesrepublik Deutschland, 23 February 2017, Auswärtiges Amt der Bundesrepublik Deutschland, Berlin, 2017).

11 Calculation based on International Monetary Fund, World Economic Outlook Database (Gross Domestic Product) 2016, International Monetary Fund, Washington D.C., 2016, and World Bank, World Bank national Accounts Data and OECD National Accounts Data Files (Gross Domestic Product) 2016, World Bank, Washington D.C., 2016.
} 
the OECD member jurisdictions, the OECD MTC's longstanding history ${ }^{12}$ and its significant international acceptance and conformity ${ }^{13}$, the OECD MTC may safely be recognised as the world's leading and most influential standard template for the negotiation of DTC. As such, it has extended its impact far beyond the OECD area $^{14}$.

This importance of the OECD MTC has grown gradually over decades. For instance, as recently as 1955 only 70 DTC had been signed ${ }^{15}$. It is nevertheless remarkable that its originators and their successors seem to have taken comparatively little effort into systematically (re-)defining the key terms in the relevant distributive articles and/or into conceptually developing respective tie-breaking tests ${ }^{16}$. In particular, the widely cited original documents of OEEC/OECD Working Parties No.1,11,12 and 14 dating between 1957 and 1974 do not contain abstract bottom-up considerations with respect to those fundamental terms. Instead, they provide first of all casuistic top-down analyses of the various domestic tax law systems and financial instruments encountered at that time. In addition, they provide the corresponding effects of the tax burden and tax revenue allocation. It must be taken seriously that the OECD MTC's international acceptance strongly depends on such effects ${ }^{17}$. However, it appears that the key terms and their remarkably rudimentary definitions were considered to be clear and proven, and were derived ${ }^{18}$ or even taken from other DTC already present at that time ${ }^{19}$. This is even more evident as many of today's financial instruments were invented later ${ }^{20}$. In this historical context the important doctrine must be $\operatorname{seen}^{21}$ that:

(1) "In view of the great differences between the laws of OECD Member countries, it is impossible to define 'dividends' fully and exhaustively." 22

(2) "In the course of the revision of the 1963 Draft Convention, a thorough study has been undertaken to find a solution which does not refer to domestic laws. This study has led to the conclusion that, in view of the still remaining dissimilarities between Member countries in the field of company law and taxation law, it did not appear to be possible to work out a definition of the concept of dividends that would be independent of domestic laws." ${ }^{23}$

For one thing, these occurrences and developments are the historical root cause for the consequent legal uncertainties we face at present. On the other hand, the understanding of the abstract grounds and interdependencies in terms of economic and financial theory has grown significantly in recent years. This has

\footnotetext{
12 For a comprehensive overview see May, Nicolás in Thomas Ecker, p. 419 et seqq.

13 OECD Commentaries 2014, introduction, p. I-4, par. 13.

14 OECD Commentaries 2014, introduction, p. I-4, par. 14.

OECD Commentaries 2014, introduction, p. I-1, par. 4.

6 See par. 4.

17 OEEC Council, Fourth Report of the Fiscal Committee, ref. C(61)97, Paris, 1961, p. 12 et seqq.

Exemplary also Anthony Polito, p. 778.

19 May, Nicolás in Thomas Ecker, p. 425 et seq.; OEEC (Working Party No. 12 of the Fiscal Committee), Second Report on the Taxation of Dividends, ref. FC/WP12(60)4, Paris, 1960, p. 12.

20 Harris, Peter A. in IBFD Commentaries on Art. 10 OECD MTC, sec. 5.1.2.4.2.

21 OECD, CFA/WP1(73)2, p. 6, par. 9, p. 10, par. 19, and p. 14, sec. A.

22 OEEC (Working Party No. 12 of the Fiscal Committee), Second Report on the Taxation of Dividends, ref. FC/WP12(60)4, Paris, 1960, p. 15.

23 OECD Commentaries 2014 on Art. 10 OECD MTC, p. C(10)-9 et seq., par. 23, tracing back to OECD Commentaries 1977 on Art. 10 OECD MTC, par. 23. The author has been unable to locate this study (equally: Hans Pijl, hybrid debts, sec. 2.2.2.), even on request to the OECD.
} 
given rise to a pervasive and increasing innovation and sophistication of modern financial instruments ${ }^{24}$. In other words: On the one hand, the traditional legal income tax framework is limited per se in its capabilities to tackle the specific economic challenges of financial instruments ${ }^{25}$. On the other hand, these have been simultaneously elaborated to very adept standards. As a consequence, these two developments finally led to today's significant divergence in the dualism between the rule of law and its economic subject. In addition, the technique of financial engineering has not only professionalised but also internationalised. Accordingly, the OECD MTC has to cope with a vast diversity of financial instruments ${ }^{26}$ and transactions arising from and thus embodying the peculiarities of a large number of unprecedentedly transparent and accessible jurisdictions. Lastly, the specific character of the OECD MTC as a collective and increasingly global but basically not yet multilateral tax law makes its adaptations and enhancements comparably inertial and causes its leverage and implementation to be time-consuming. These conditions have contributed - and will continue to do so - to the fairly acute situation into which the cross-border taxation of financial instruments and transactions has evolved.

\subsection{Scope}

The exclusive subject of this study is the OECD MTC. Particular DTC as parts of their respective domestic tax laws and their supplementary agreements (e.g. protocols, memorandum of consultations, etc.) as well as similar tax-related treaties under international law (e.g. those on exchange of information, judicial or administrative assistance, etc.) are not its focus. Other collective tax laws are not the subject of this study. However, they may be consulted as sources of inspiration in the sense of comparative law depending on specific criteria for relevance and appropriateness. These criteria are outlined in section 1.4.

10 More specifically, this study concentrates on the constitutive ${ }^{27}$ paragraphs within those distributive articles of chap. III, which are relevant for the income from financial instruments and transactions in the broader sense. These are Art. 10(3), 11(3), 13(5) and 21(1) OECD MTC ${ }^{28}$. Transactions such as letting and leasing, royalties and annuities, betting and gambling or those in the context of ("framed" or "wrapped") activities to be classified into other schedules of the OECD MTC taxonomy (e.g. business or employment) shall not be considered to be financial instruments in this sense. Notably, any justification for such exclusion of these legal transactions from the economic nature and context of financial instruments ${ }^{29}$ would actually require an equally thorough and in-depth analysis. This was, however, far too extensive for the envisaged volume of this study and therefore dispensed with. Within those constitutive paragraphs, this study concentrates only on the substantive core of genuine concepts within the object of taxation (definitions). Any precedent matter (e.g. taxpayer, tax domicile, etc.) as well as any derivative concept (e.g. "abuse") or otherwise situative aspect (e.g. related parties) or subsequent consideration (e.g. legal consequences, appropriateness, procedural law, etc.) are

\footnotetext{
${ }^{24}$ OECD, ST/SG/AC.8/2001/CRP.8, p. 8, par. 1 et seqq.

25 See par. 1.

${ }^{26}$ Duncan, James A., Tax Treatment of hybrid Financial Instruments in cross-border Transactions - General Report, Series IFA Cahiers 2000, Vol. 85a, p. 31.

27 Marjaana Helminen, dividend concept, p. 55.

28 See par. 4.

29 See par. 1.
} 
entirely left aside. This implies the working assumption that the subjective intention of the involved parties coincides with the objective observables, i.e. the arm's length principle.

11 This study takes the perspective of the investor as the relevant recipient of the income. However, the classification of financial instruments and transactions may also be seen as depending in some way on the classification of the issuer (e.g. company versus partnership). As stated before, this study focusses on the general object of taxation and not on subjective aspects (e.g. hybrid entities, collective investment schemes) ${ }^{30}$, which are outside the scope of this work. This may be especially relevant where these subjective aspects preselect or narrow that object of taxation. The following topics are not the primary subject of this study but appear to be closely connected with it. Hence, they turn out to be either indispensible for avoiding the actual constriction of this study's subject towards meaninglessness or at least helpful for its understanding. These topics are:

- the category of capital pursuant to chap. IV of the OECD MTC;

- questions of subjective attribution, particularly beneficial ownership ${ }^{31}$;

- matters relating to the nature, recognition and determination of income;

- time aspects.

12 Finally, this study takes the English language version of the OECD MTC and the OECD Commentaries as its basis.

\subsection{Approach}

13 As stated before, previous developments led to the current impasse in the interpretation and application of the OECD MTC with respect to financial instruments and transactions. ${ }^{32}$ In this context, the history and analysis of previous studies gives the impression that the literal or textual element of interpretation is close to having reached its limitations of capability. It nevertheless leaves a number of essential issues open or ambiguous. In order to gain additional jurisprudential insights, the methodology in this study is therefore to put the focus more on the systematic element of interpretation. Owing to the specific nature of financial instruments and transactions, this approach promises to lead comparably deeper into their economic conceptual grounds. In other words: from the author's point of view, the aforementioned peculiarities of financial instruments ${ }^{33}$ provide an adequate justification for the conclusion that the disentanglement of their structural mechanisms must play a significant role in the interpretation and application of the said provisions. Nevertheless, the results will be carefully embedded in the findings made so far by also integrating dissenting opinions wherever possible. In this sense, this study shall therefore represent a complementary rather than an alternative approach.

\footnotetext{
$30 \quad$ See par. 10.

31 Comprehensively: Joanna Wheeler, missing keystone, sec. 2.4., 2.5. and 3.

32 See par. 7 et seq.

33 See par. 1.
} 
14 Facing that more or less exhausted literal or textual interpretability and applicability ${ }^{34}$, especially of autonomous terms, the history and analysis of relevant case law also conveys the impression that the competent courts tend to seek salvation in methodologically referring to their respective domestic tax laws quite early. In particular, they seem to neglect first considering all possibilities to resolve the issue on the treaty level itself. In other words: Art. 3(2) OECD MTC is actually given extensive prevalence by undervaluing its important exception of "unless the context otherwise requires". In doing so, however, the purpose, intention and function of the OECD MTC are frustrated. In fact, they foster selective repeals and thus eventually exacerbate the problem of potential qualification conflicts. This study is an attempt to tap the full potential of an autonomous interpretation of those terms, to the extent that it is in line with methodological requirements and jurisprudential appropriateness. Within this scope, it is consequently an important part of its approach to distinctly identify the limitations of the autonomous towards the domestic interpretation, by strictly focussing on the former and not on the latter (e.g. including the question which of the involved domestic tax laws applies).

15 This study strictly follows a descriptive purpose in the sense that it attempts to respect and interpret the OECD MTC as it actually is (de lege lata). This means in particular that it does not follow a normative purpose in the sense that it indicates any evaluative suggestion beyond the OECD MTC as it actually is (de lege ferenda). Nevertheless, some sections employ findings from the normative field of tax policy making. It is important to note that the use of these findings remains however confined to their descriptive discoveries and concepts regarding inherent structural rationales and interrelationships within collective tax law systems in general. In particular, it also does not encompass their specific normative conclusions regarding needs and recommendations for action. Admittedly, those conceptual insights are also taken into account for the systematic way of interpretation in this study, in so far as any interpretation results should naturally be able to solve the present and ideally also potential legal conflicts actually identified by the research area of tax policy making. However, this consideration is strictly limited to the extent that it is in line with methodological admissibility and jurisprudential justifiability. It is also carefully embedded in the descriptive findings made so far. In this sense, the methodological way and spirit of interpretation in this study may be said to take a progressive approach.

16 That said, it turns out that a meaningful discussion and treatment of financial instruments and transactions under the OECD MTC may not be constricted to the narrow delimitation between the isolated terms of dividends pursuant to Art. 10(3) OECD MTC, interest pursuant to Art. 11(3) OECD MTC, capital gains pursuant to Art. 13(5) OECD MTC and/or other income pursuant to Art. 21(1) OECD MTC. Instead, additional aspect in the context between these terms must be taken into account in this discussion ${ }^{35}$. This is caused by the many systematic connections and conceptual interdependencies between all these legal aspects ${ }^{36}$ on the one side and the specific economic detachment of financial instruments and transactions ${ }^{37}$ on the other, and, consequently, to their exceptional capability to arbitrarily convert and address these aspects. In other words: it could be said that financial instruments and transactions are in a sense an "organic topic", which cannot be reasonably described by individually picking out certain isolated aspects. Rather than following

\footnotetext{
$34 \quad$ See par. 13.

35 See par. 11.

36 See par. 14.

37 See par. 1.
} 
such a classical, analytical approach, this study attempts to make a compromise between these two techniques. It starts with a holistic or synthetic view that considers the relevant "shades" between the pure concepts. Only subsequently does it take the reductive or analytical view that dives into the details of these concepts.

17 Interpreting such a comprehensive as well as strongly entangled and interdependent system from the fairly few words in Art. 10(3), 11(3), 13(5) and 21(1) OECD MTC may also present a formidable challenge. In order to improve legibility and comprehensibility, this study takes a "funnel approach": it starts with the general and fundamental aspects and basic principles ${ }^{38}$, which are embedded in the systematic legal setting afterwards ${ }^{39}$. In the course of the study, the findings are condensed or broken down to potential differentiators ${ }^{40}$ and only then are they interpretatively tested against the concrete legal texts ${ }^{41}$. Finally, the study ends with a practice section applying the abstract-theoretical findings to a number of specific groups of financial instruments and transactions ${ }^{42}$. The order of the sub-sections therein follows the logical dependencies found among them.

\subsection{Sources of law and their relevance}

\subsubsection{Preliminary remarks}

18 The purpose of this section is to give a brief overview of the selection of legal sources being worth of consideration and their potential relevance for this study. These legal sources may generally be categorised into two groups. On the one hand, those being either legally binding or at least admissible for the purpose of legally interpreting the OECD MTC (interpretational legal sources). On the other hand those without such more or less binding character but rather representing a source of inspiration (inspirational legal sources). These two categories have in common that they must be of a collective character in the sense of a multinational or multi-jurisdictional compromise across, and must be beyond the heterogeneous peculiarities of individual (domestic) or cultural (regional) tax laws or even entire tax systems. Multi-jurisdictional in this sense is independent of and may not be confused with the term multilateral, which merely describes the formal organisational mode of constituting and maintaining a collective law. A multi-jurisdictional law can be multilateral (e.g. the OECD Multilateral Convention ${ }^{43}$ ) or bilateral (e.g. OECD MTC/DTC). Obviously, the borderline between collective and non-collective tax laws is fluid. There might be domestic tax laws with a collective character that is stronger than a homogeneous multi-jurisdictional tax law. Even the OECD MTC itself may be seen as being "locally biased" in that it embodies and represents the peculiarities of the developed countries, i.e. their capital-exporting national economics. In that, collective tax laws - as opposed to domestic tax laws - are no closed-end systems: they reach a new generic quality by sharing a number of similar conceptual problems. The objective of this section is therefore to briefly analyse some collective tax laws by quality and scope of their comparability criteria. This would require a more comprehensive and detailed comparability analysis, but such an analysis would be far too extensive to be given here. Instead, the crucial aspect and the added scientific value of the respective collective tax law - even though it is not being legally

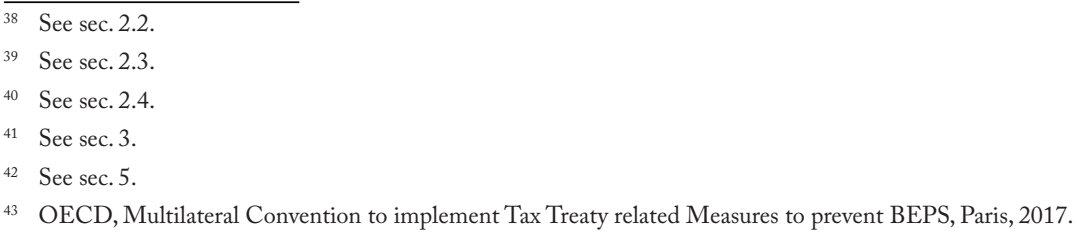


binding - is to what extent its fundamental principles are compatible and fit into those of the OECD MTC. These coincidences are the fixation points, on which the conceptual framework built in this study is pinned. For these reasons, the following legal sources have been excluded from the analysis and are not consulted in this study:

- Domestic tax laws, except where these have an extraordinary collective character;

- Particular DTC as part of just two domestic tax laws;

- MTC of individual jurisdictions as being "locally biased" (e.g. US MTC);

- MTC of multiple jurisdictions with a homogeneous tax law culture (e.g. Nordic MTC).

19 The practice of international taxation is an allocation conflict between the jurisdictions over the tax revenues available for distribution. In this conflict it can be observed that it is naturally the jurisdiction of residence that is urged to avoid double taxation by crediting the tax that has already been withheld by the source jurisdiction. Therefore, the main purpose and function of DTC pursuant to Art. 31(1) VCLT is to strike a balance between the two contracting jurisdictions by limiting the allocation of taxation rights to the source jurisdictions (limiting effect or function of DTC). To serve this function, the terms used in the treaty need to be associated with a unique and common meaning pursuant to Art.31(4) VCLT in order to avoid qualification conflicts, which would necessarily occur where the contracting jurisdictions interpreted the DTC from their domestic perspectives ${ }^{44}$. Being in line with the international law principles of interpretation pursuant to Art. 31 et seqq. VCLT, this is the reason why DTC in particular and the OECD MTC in general are basically to be interpreted autonomously (primacy of the autonomous interpretation), especially as regards parts serving its tax-limiting function. In other words: the treaty purpose, intention and function require a restrained or cautious invocation of domestic tax law ${ }^{45}$.

20 The autonomous interpretation leads to the problem that each of its attempts to define a term or figure may tend to exacerbate the interpretation problem in the triangle between the treaty and the two domestic tax laws by creating more and more terms with the need of interpretation ${ }^{46}$. This was one practical reason why there is an exception to the primacy of the autonomous interpretation in Art. 3(2) OECD MTC that gives prevalence to domestic tax law for the interpretation of terms not being defined in the OECD MTC therein ("lex fori") ${ }^{47}$. However, pursuant to the express wording of Art. 3(2) OECD MTC this exception applies only "unless the context otherwise requires"48. Due to this limiting insertion, the significance or relevance of Art. 3(2) OECD MTC is controversial ${ }^{49}$. Nevertheless, pursuant to the international law principles of interpretation ${ }^{50}$

44 Wassermeyer, Franz in Wassermeyer Commentaries, p. 284, par. 86; Michael Lang, interpretation, p. 288 et seq.; Huerta, Adalbertos Ramos in Eva Burgstaller, p. 21, 28 and 31; Michael Lang, hybrids, p. 22 et seq.; Klaus Vogel Commentaries 1997, p. 208 et seq., par. 60; Rainer Prokisch, interpretation, p. 52; OECD, Consolidated List of outstanding Points concerning the OECD Draft Convention on Income and Capital, ref. TFD/FC/218, Paris, 1967, p. 29, sec. A. In other words: the autonomous interpretation prevents misconceptions where the two contracting jurisdictions use the same term but each with a different understanding of its content.

45 Peter Hongler, p. 207.

46 Similarly: Caroline Poiret, sec. 2.7.

47 Wassermeyer, Franz in Wassermeyer Commentaries, p. 271, par. 71 et seq; Vogel, Klaus / Prokisch, Rainer, Interpretation of Double Taxation Conventions - General Report, Series IFA Cahiers 1993, Vol. 78a, p. 72.

48 The additional exception of separate authorities' agreements inserted by the OECD MTC Draft Update, p. 11, par. 8, is not relevant for the scope of this study (see par. 14).

49 For an overview see Michael Lang, hybrids, p. 24 et seqq.; Dürrschmitt, Daniel in Vogel / Lehner, p. 549 et seqq., par. 116a et seqq.; Wassermeyer, Franz in Wassermeyer Commentaries, p. 271, par. 71, and p. 281, par. 82. The relation between the autonomous and the domestic interpretation was much more controversial prior to the 1995 update to OECD MTC, adopted on 21 September 1995.

$50 \quad$ See par. 19. 
the majority of commentators ${ }^{51}$ came to the consensus view that this context is to be understood in a broad sense. In particular, the domestic interpretation is not permissible where the OECD MTC provides a closed or exhaustive definition ${ }^{52}$, where domestic tax law would make parts of the OECD MTC inapplicable Or $^{53}$ where the term in question has a general meaning (i.e. is no terminus technicus) ${ }^{54}$. This conclusion of the majority opinion is in line with the aforementioned purpose, intention and function of the OECD MTC outbalancing the aforementioned possible problem of exacerbation by the autonomous interpretation. Anything else would only relegate the interpretation and application problem of qualification conflicts to the mutual agreement procedure ${ }^{55}$.

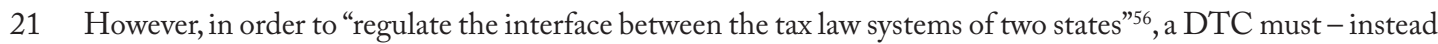
of being detached or distant - necessarily be linked with the domestic tax law by certain "connecting factors" ${ }^{\text {" }}$. These are references to items which represent facts or precursory matters from the treaty perspective. ${ }^{58}$ In other words: the domestic tax law first needs to constitute a taxable event. Only afterwards is this taxable event subject to the treaty's subsequent function of assessing and - where necessary - limiting the taxation. ${ }^{59}$ Those connecting factors, which are regularly interpreted domestically rather than autonomously, are typically references to the taxpayer and the tax base (e.g. company, profit, income, assets, etc.). ${ }^{60}$

22 Having set their general scope and role in this section, the potential international sources of tax law, be they legally binding or interpretational or inspirational ${ }^{61}$, shall now be introduced in a nutshell.

51 Avery Jones, John F. in IBFD Commentaries on The Scope of Art. 3(2) of the OECD Model, sec. 8.1.; Reimer, Ekkehart/Rust, Alexander in Klaus Vogel Commentaries 2015, p. 207, par. 111, and p. 212, par. 123; Wassermeyer, Franz in Wassermeyer Commentaries, p. 271, par. 71, and p. 282, par. 82; Michael Lang, introduction, p. 45, par. 74, p. 57, par. 117, and p. 57, par. 119; Peter Hongler, p. 210; Michael Lang, interpretation, p. 288 et seq.; Huerta, Adalbertos Ramos in Eva Burgstaller, p. 31; Klaus Vogel Commentaries 1997, p. 214 , par. 72.

52 Dürschmitt, Daniel in Vogel / Lehner, p. 546, par. 101 and 107; Reimer, Ekkehart/Rust, Alexander in Klaus Vogel Commentaries 2015, p. 208, par. 114, and p. 213, par. 126; Wassermeyer, Franz in Wassermeyer Commentaries, p. 271, par. 71 et seq., and p. 280 et seq., par. 81; Fehér, Tamás in Eva Burgstaller, p. 235; Klaus Vogel Commentaries 1997, p. 211, par. 63; all with explicit references to Art. 10(3) and 11(3) OECD MTC.

53 Reimer, Ekkehart/Rust, Alexander in Klaus Vogel Commentaries 2015, p. 218, par. 124; Dürrschmitt, Daniel in Vogel / Lehner, p. 551, par. $116 \mathrm{c}$.

${ }^{54}$ Avery Jones, John F. in IBFD Commentaries on The Scope of Art. 3(2) of the OECD Model, sec. 7.2.2.; Dürrschmitt, Daniel in Vogel / Lehner, p. 544, par. 98; Wassermeyer, Franz in Wassermeyer Commentaries, p. 272, par. 71, and p. 282, par. 82; Huerta, Adalbertos Ramos in Eva Burgstaller, p. 23 et seq.; Dutch Hoge Raad der Nederlanden, judgement ref. 33267, 1999; Klaus Vogel Commentaries 1997, p. 210, par. 62 .

55 OECD, Consolidated List of outstanding Points concerning the OECD Draft Convention on Income and Capital, ref. TFD/FC/218, Paris, 1967, p. 29, sec. A.

56 Joanna Wheeler, attribution, p. 487.

57 Michael Lang, introduction, p. 46, par. 76.

58 Michael Lang, hybrids, p. 26.

59 OECD Commentaries 2014 on Art. 1 OECD MTC, p. C(1)-20, par. 9.2, and p. C(1)-32, par. 22.1.

${ }^{60}$ Wassermeyer, Franz in Wassermeyer Commentaries, p. 271, par. 71, and p. 282, par. 82; Michael Lang, introduction, p. 46, par. 77; Michael Lang, interpretation, p. 289; Michael Lang, hybrids, p. 31 et seqq.; Klaus Vogel Commentaries 1997, p. 215, par. 73.

61 See par. 18. 


\subsubsection{OECD Commentaries on the OECD MTC}

23 The legal character of the OECD Commentaries ${ }^{62}$ evolved into a complex matter while being identified by OECD in the mid $1990 \mathrm{~s}^{63}$ and was increasingly disputed during the 2000s decade. Apart from contradictory provisions in the OECD materials ${ }^{64}$, the following points in the field of general international law emerged as the key questions ${ }^{65}$.

\section{How can jurisdictions passively enter into legal obligations?}

24 Pursuant to Art. 31(2)(a) VCLT, the context for the interpretation of an international treaty comprises any relating agreement - including tacit ones - which were made between the parties in connection with the conclusion of that treaty. In earlier boundary dispute judgements, the ICJ ${ }^{66}$ had established and developed the concepts of acquiescence and estoppel ("speak or act" ${ }^{\prime 7}$ ). Acquiescence means the tacit or implied consent by silence, especially when called for reaction. In contrast, estoppel means the tacit or implied consent by continuously practicing the status quo, especially when benefitting from it. This raised the question as to whether a jurisdiction might implicitly accept the OECD Commentaries as a tacit agreement with legally binding effect ${ }^{68}$, especially where this jurisdiction did not make any reservation ${ }^{69}$ or observation ${ }^{70}$ to the Commentaries, as is the common practice ${ }^{71}$.

\section{When does a treaty negotiation start to touch international law?}

25 As the general rule pursuant to Art.31(1) VCLT, a treaty shall also be interpreted in good faith in accordance with the ordinary meaning to be given to the terms of the treaty in their context. Even if acquiescence and estoppel would not bind the jurisdiction to the OECD Commentaries as a tacit agreement (hard law) ${ }^{72}$, in a particular DTC negotiation this jurisdiction may still appear to its counterparty as being committed to the OECD Commentaries (soft law). The reason is that the OECD Commentaries are part of the OECD's institutional framework. This appearance was in question to create such context or good faith, either entirely by legitimate expectations of the counterparty or selectively to the extent that the wording of the OECD MTC has been used - at least where a different understanding has not been established pursuant to Art. 31(4) VCLT ${ }^{73}$. This appearance may be even more crucial where this jurisdiction is an OECD member and depends on that jurisdiction's role within the OECD's institutional framework (e.g. voting policy, initiatives, membership in working groups or statutory bodies, reservations and/or observations, etc.).

\footnotetext{
62 The role of the OECD Reports will not be dealt with further. For this study the authors follows the view that the OECD Reports do not have a legally binding character (Provodová, Katerina in Thomas Ecker, p. 158).

63 Rainer Prokisch, OECD Commentaries; Rainer Prokisch, interpretation, p. 52 et seq.

64 For an overview see Gómez-Ballina, Rodrigo in Schilcher / Weninger, p. 98 - 102.

65 Conference Position Paper: The Quest of the Holy Grail in International Tax Law - The legal Status of the Commentaries on the OECD MTC in Frank Engelen, p. 262.

${ }^{66}$ In particular: Fisheries case; Temple of Preah Vihear; North Sea Continental Shelf; Gulf of Maine; Maritime Frontier Dispute.

67 Engelen, Frank in Frank Engelen, p. 70.

68 Engelen, Frank in Frank Engelen, p. 65.

69 OECD Commentaries 2014, introduction, p. I-10, par. 31.

70 OECD Commentaries 2014, introduction, p. I-9 et seq., par. 30. On the legal effects of observations see, Guglielmo Maisto, observations.

71 Engelen, Frank in Frank Engelen, p. 61.

72 See par. 24.

73 Rainer Prokisch, interpretation, p. 54.
} 


\section{Do the OECD Commentaries represent international customary law?}

26 The ICJ shall apply international conventions, which establish rules and international custom, as evidence of a general practice accepted as law. ${ }^{74}$ Irrespective of the international treaty law governed by the VCLT, the question was raised whether the OECD Commentaries may represent another source of international law (i.e. customary law).

\section{Who is the addressee of the OECD Commentaries?}

27 Primarily, a DTC is an international treaty between two jurisdictions. However, at least one of its purposes and functions was also the protection of the rights of the taxpayer, who is in so far the object of the treaty and its interested third party. ${ }^{75}$ In this respect, a DTC was a "hybrid system" inducing the jurisdiction to act ambiguously while balancing its own interests against those of the taxpayer. ${ }^{76}$ But even though a DTC granted those protection rights directly to the taxpayer ${ }^{77}$, he was allowed to claim the OECD Commentaries only for the application of a particular DTC as the subject to the jurisdictions' legislative procedure and its courts' interpretation. This dual purpose ${ }^{78}$ made it unclear whether the addressee of the OECD Commentaries is either the jurisdiction's government in its negotiator and executor role, the legislator in its approver role, the courts in their interpreters role, or the taxpayer in his role as an interested stakeholder.

28 The majority of commentators ${ }^{79}$ came nevertheless to the consensus view that the OECD Commentaries have no legally binding effect. Their arguments were primarily the following:

- The concepts of acquiescence and estoppel applied only "where there is a duty or a need to speak" ${ }^{80}$ Since recommendations ${ }^{81}$ were legally not binding ${ }^{82}$ regardless of their subject, they were not accessible to constitute a tacit agreement.

- But even if acquiescence and estoppel applied, a positive intention to enter into a legally binding agreement would be further required in any case. ${ }^{83}$ However, all OECD members themselves proclaimed their common understanding and intention not to do so. ${ }^{84}$ This intention was established objectively and not merely subjectively, ${ }^{85}$ and it was supported by the fact that the OECD Commentaries have never been

\footnotetext{
74 Art. 38(1)(a) and (b) of the ICJ Statutes, The Hague, 18 April 1946, available online at www.icj-cij.org (last retrieved on 15 September 2017).

75 Ward, David A. in Frank Engelen, p. 89; Pijl, Hans in Frank Engelen, p. 108; David Ward, interpretation, p. 53.

76 Pijl, Hans in Frank Engelen, p. 109 and 128.

77 Pijl, Hans in Frank Engelen, p. 107; Rainer Prokisch, OECD Commentaries, p. 6.

78 Rainer Prokisch, interpretation, p. 57.

79 Among others: Mellinghoff, Rudolf in Franz Wassermeyer, Festgabe, p. 35 et seq.; Michael Lang, introduction, p. 48, par. 83; Sven-Eric Bärsch, p. 98; Peter Hongler, p. 220; Ward, David A. in Frank Engelen, p. 73; Pijl, Hans in Frank Engelen, p. 97, 112, 124 and 129; Gómez-Ballina, Rodrigo in Schilcher/Weninger, p. 109, and Schmitt, Marcus in Schilcher/Weninger, p. 121; Weiss, Friedl in Erasmus-Koen, Monica/Douma, Sjoerd, Legal status of the OECD Commentaries - in search of the holy grail of international tax law, Bulletin for International Taxation 2007, Vol. 61, No. 8, p. 347; David A. Ward, The Role of the Commentaries on the OECD Model in the Tax Treaty Interpretation Process, in Bulletin for International Taxation 2006, Vol. 60, No. 3, p. 100; David Ward, interpretation, p. 113; Wattel / Marres, interpretation, p. 234; Michael Lang, hybrids, p. 26 and 54.

80 Ward, David A. in Frank Engelen, p. 74; Pijl, Hans in Frank Engelen, p. 125.

81 In particular, the Recommendations 1997 , sec. I.2.

82 Ward, David A. in Frank Engelen, p. 74; Pijl, Hans in Frank Engelen, p. 112.

83 Ward, David A. in Frank Engelen, p. 81 and 87, with reference to North Sea Continental Shelf; Pijl, Hans in Frank Engelen, p. 112.

84 Ward, David A. in Frank Engelen, p. 74.

85 Ward, David A. in Frank Engelen, p. 80, with reference to Qatar vs. Bahrain.
} 
registered pursuant to Art. 102 of the UN Charter. ${ }^{86}$ In addition, none of the OECD members applying the dualistic concept has ever deemed it necessary to transform the OECD Commentaries into their domestic tax laws. ${ }^{87}$

- The assumption that the OECD members were committed to the OECD Commentaries was prejudicial ${ }^{88}$ and could be observed neither theoretically nor practically ${ }^{89}$. In addition, the OECD Commentaries as a general framework could not be subject of the context or good faith, as they were not made between the parties in connection with the conclusion of a particular DTC ${ }^{90}$. Finally, the concept of good faith as such was a mere interpretation aid and did not transmute something non-binding into binding international law ${ }^{91}$.

- In the absence of the two constituent or qualifying elements of a consistent practice and a common conviction and acceptance on its legally binding nature ("opinio iuris sive necessitatis"), the OECD Commentaries did not represent international customary law either. ${ }^{92}$ Instead, they rather represent a supplementary means of interpretation pursuant to Art. 32 VCLT.

- Finally, there were also good practical reasons such as flexible adaptations to new developments why OECD chose the Commentaries not to be legally binding. ${ }^{93}$

29 Accordingly, the OECD Commentaries formed the legal context to a particular DTC in the sense of an aid or assistance in interpreting and applying it at the point in time when it was negotiated ${ }^{94}$ They did not represent a legal but rather a political commitment (“comply or explain”), encouraged by political measures (such as peer review, peer pressure, etc.). ${ }^{95}$ As such, they were primarily addressed to the jurisdiction's government in its role as the negotiator and executor.

30 The author shares this view. In the sense of a contextual element of interpretation, the OECD Commentaries are linked as a logical subset to the OECD MTC, which itself undisputedly represents a legally unbinding recommendation. As such, the OECD Commentaries cannot go beyond the OECD MTC in the sense of being stronger. This remains true even if the OECD MTC as a recommendation has been followed in a particular DTC negotiation, no matter how closely the two are linked. In other words: no matter how

86 UN, Charter of the UN, New York, 26 June 1945, available online at www.un.org (last retrieved on 15 September 2017); Ward, David A. in Frank Engelen, p. 75.

87 Ward, David A. in Frank Engelen, p. 81.

88 Ward, David A. in Frank Engelen, p. 76; Pijl, Hans in Frank Engelen, p. 125, David Ward, interpretation, p. 51.

89 Ward, David A. in Frank Engelen, p. 76, 82 and 87; Pijl, Hans in Frank Engelen, p. 119; David Ward, interpretation, p. 41 and 48.

90 Mellinghoff, Rudolf in Franz Wassermeyer, Festgabe, p. 36, par. 4, and p. 47, par. 39; Michael Lang, introduction, p. 48, par. 84; Ward, David A. in Frank Engelen, p. 82; Ellis, Maarten J., The Influence of the OECD Commentaries on Treaty Interpretation - Response to Prof. Dr. Klaus Vogel, Bulletin for International Taxation 2000, Vol. 54, No. 12, p. 618; Rainer Prokisch, interpretation, p. 53.

91 David Ward, interpretation, p. 48.

92 Avery Jones, John F. in IBFD Commentaries on Issues in the Application of International Law Interpretation Principles to Tax Treaties, sec. 5.2.5.; Mellinghoff, Rudolf in Franz Wassermeyer, Festgabe, p. 37, par. 10 et seqq.; Pijl, Hans in Frank Engelen, p. 98; Gómez-Ballina, Rodrigo in Schilcher / Weninger, p. 109; Weiss, Friedl in Erasmus-Koen, Monica / Douma, Sjoerd, Legal status of the OECD Commentaries - in search of the holy grail of international tax law, Bulletin for International Taxation 2007, Vol.61, No. 8, p. 347; David Ward, interpretation, p. 41 and 51; Czech Nejvyšš Sprárni Soud, judgement ref. 2Afs 108/2004-106, 2005; Supreme Court of Canada, judgement ref. 23940, 1995, par. 44; High Court of Australia, judgement ref. [1990] HCA 37, 1990.

93 Ward, David A., in Frank Engelen, p. 83; Pijl, Hans in Frank Engelen, p. 103.

94 Mellinghoff, Rudolf in Franz Wassermeyer, Festgabe, p. 36, par. 5, p. 42, par. 24 et seqq., and p. 47, par. 39; Wassermeyer, Franz in Wassermeyer Commentaries, p. 277, par. 78; Michael Lang, introduction, p. 51, par. 95; Peter Hongler, p. 222; Michael Lang, interpretation, p. 285 et seq.; Hans Pijl, hybrid debts, introduction; Ward, David A., in Frank Engelen, p. 85 and 93; David Ward, commentaries, p. 101; David Ward, interpretation, p. 42, 80 and 110. On the particular question regarding the static or dynamic interpretation see par. 33 et seqq.

95 Pijl, Hans in Frank Engelen, p. 96, 120 and 124. 
often the recipient (i.e. OECD member) follows a recommendation (i.e. OECD MTC for the purpose of a particular DTC), it remains a recommendation with all its supplements (i.e. OECD Commentaries). As such, it shares the same fate (i.e. it is unbinding) and leaves the ultimate decision with that recipient at all times without ever turning into any kind of obligation.

31 Beyond these arguments, the question to what extent a mere involvement or engagement of a member within the OECD's institutional framework may prejudge a particular DTC negotiation leads to the subsequent problem of the OECD's institutional framework as being more of a bilateral or multilateral nature.

Example 1: Art. 6(2) of the OECD Convention ${ }^{96}$ allows a majority's resolution to not apply to a member that abstained from voting. This possibility to evade the organisational power in the same way as such abstention from voting was an "escape from democracy" is exceptional for multilateral frameworks. It actually leads to a state of "rights without obligations", making it typically difficult or perhaps even impossible for the multilateral framework to exist.

Bilateral in this sense means a clear separation between the OECD and its members, with no soft legal obligations between them. Multilateral means the OECD and its members to be incorporated into one municipal entity imposing hard legal obligations to its members. This point becomes even more crucial, as a second aspect of ambiguity relates to the fact that the OECD appears to coalesce both the "legislative" and the executive function in itself (and maybe even the "judicative" function as well) ${ }^{97}$. The two aspects combined show the possible spectrum between a non-committal network acting as a neutral counsellor on the one hand and a community of duties acting as "judge and hangman" on the other, in which the OECD as a standard setter to legal tax developments may be reflected. This could be seen as the institutional background why the OECD Commentaries form the legal context only to those DTCs negotiated at that respective point in time. In fact, only for those DTCs the OECD could be said to have acted in its "legislative" role. And perhaps it was this aspect that Maarten J. Ellis meant when he said: "The fact that the Commentary is now changed so frequently $[\ldots]$ makes it less valuable and certainly less authoritative" 98 .

32 Accordingly, today's majority of commentators explicitly or implicitly take the position that the OECD's institutional framework is basically of a bilateral nature, at least as regards its recommendations. ${ }^{99}$ In fact, this was also the original intention of the OECD MTC ${ }^{100}$. However, it seems that the remarkable dynamic of international tax developments nowadays and the consequential authority of the OECD in this field may change that actual view, and that this might have even been one driver for the OECD's BEPS action item

\footnotetext{
96 OECD, Convention on the OECD, Paris, 14 December 1960, available online at www.oecd.org (last retrieved on 15 September 2017).

97 OECD, Peer Review - An OECD Tool for Co-operation and Change, 2003, p. 15; similarly: Schmitt, Marcus in Schilcher/Weninger, p. 120; David Ward, commentaries, p. 101.

98 Ellis, Maarten J., The Influence of the OECD Commentaries on Treaty Interpretation - Response to Prof. Dr. Klaus Vogel, Bulletin for International Taxation 2000, Vol. 54, No. 12, p. 618.

99 See footnote 79 .

${ }^{100}$ League of Nations, Document C.216.M.85, ref. C.216.M.85, London, 1927, p. 8; Report presented by the General Meeting of Government Experts on Double Taxation and Tax Evasion, ref. C.562.M.178.1928.II., Geneva, 1928, p. 5.
} 
No. 15, according to which the OECD Multilateral Convention ${ }^{101}$ has been introduced in order "to modify existing bilateral tax treaties"102.

33 In sum, this generally means that the historical interpretation, the conflict between static and dynamic interpretation and the dependencies between these two aspects deserve careful consideration when consulting the OECD Commentaries. Above all, there must be a clear and strict separation between the interpretation of the OECD MTC as such and the interpretation of a particular DTC.

34 Being subject to the domestic practice of interpretation and unless otherwise agreed in that particular DTC ${ }^{103}$, the academic literature ${ }^{104}$ de facto tends to support a static approach:

- Amplifications to existing provisions (e.g. by adding new examples or new arguments) shall be treated similarly to the opinions of other well-regarded commentators.

- Interpretations and further developments, especially those that fill gaps, shall also be treated similarly to the opinions of other well-regarded commentators. But they shall be treated with special attention and great care to the independent consideration of whether they represent a fair and legitimate interpretation.

- Reversions of existing provisions shall be ignored or discarded for the purpose of the interpretation of that particular DTC, the reason being that they would otherwise not enjoy democratic legitimacy. In addition, they infringe the principle of non-retroactivity pursuant to Art. 28 VCLT.

35 In contrast to this interpretation of a particular DTC, the working material for the interpretation of the OECD MTC is, however, the latest available version of the OECD Commentaries. It is obvious and clear in itself that the OECD Commentaries represent a dynamic interpretation of the OECD MTC, i.e. the latest available version of the OECD Commentaries applies as the end point of a dynamic interpretation of the OECD MTC. Given that each version of the OECD Commentaries forms the legal context to a particular DTC at the point in time it was negotiated, a renewal of an assumed DTC identical to the OECD MTC has ceteris paribus no space for being anything other than the result from a change of the OECD Commentaries. But even if the OECD Commentaries represented a static interpretation of the OECD MTC, this would lead to the same methodological approach for this study: it implied the case of a particular DTC following the OECD MTC that was negotiated as per today, i.e. the latest available version of the OECD Commentaries applied again but now as the starting point of a static interpretation of the OECD MTC. As a conclusion for the further course of this study, the latest available version of the OECD Commentaries is relevant for the dynamic interpretation of the actual OECD MTC ${ }^{105}$. Complementary to the interpretation of a particular

\footnotetext{
${ }_{101}$ OECD, Multilateral Convention to implement Tax Treaty related Measures to prevent BEPS, Paris, 2017.

102 OECD, Developing a Multilateral Instrument to Modify Bilateral Tax Treaties, Action 15 - 2015 Final Report, Paris, 5 October 2015, p. 11.

${ }^{103}$ Some DTCs contain specific rules which explicitly allow the dynamic interpretation by referring to the OECD Commentaries and their later changes.

${ }^{104}$ Among others: Avery Jones, John F. in IBFD Commentaries on Issues in the Application of International Law Interpretation Principles to Tax Treaties, sec. 5.1.; Wassermeyer, Franz in Wassermeyer Commentaries, p. 277, par. 78; Mellinghoff, Rudolf in Franz Wassermeyer, Festgabe, p. 42, par. 24 et seqq.; Michael Lang, introduction, p. 53, par. 102; Peter Hongler, p. 222; Hans Pijl, hybrid debts, introduction; Ward, David A. in Frank Engelen, p. 86; Schmitt, Marcus in Schilcher/Weninger, p. 137; David Ward, commentaries, p. 101; David Ward, interpretation, p. 110; Wattel / Marres, interpretation, p. 224, 229 and 232; Klaus Vogel, interpretation, p. 616; Michael Lang, later commentaries, p. 9; Ault, Hugh J., The Role of the OECD Commentaries in the Interpretation of Tax Treaties, Intertax 1994, Vol. 22, No. 4, p. 148.

105 OECD MTC Draft Update; Paris, 11 July 2017; OECD, MTC (full version), Paris, 15 July 2014.
} 
DTC, older versions of the OECD Commentaries may serve the historical interpretation of the OECD MTC in so far as existing provisions had been amplified.

\subsubsection{UN Commentaries on the UN MTC}

36 While not being legally binding to the OECD MTC, the UN Commentaries ${ }^{106}$ and the UN MTC ${ }^{107}$ as a collective tax law are undoubtedly inspirational sources of law ${ }^{108}$. In fact, Art. 10(3) $)^{109}, 11(3)^{110}, 13(6)^{111}$ and 21(1) ${ }^{112}$ UN MTC reproduce their equivalents of Art. 10(3), 11(3) and 13(5) OECD MTC in an identical wording. Accordingly, the UN Commentaries explicitly refer directly to the respective passages within the OECD Commentaries. The reason is that "the similarities between these two leading Models reflect the importance of achieving consistency where possible." ${ }^{113}$ Insofar, the added value of the UN Commentaries on the UN MTC for the interpretation and application of the OECD MTC appears to be fairly limited. By derogation from this basic principle, only the UN Commentaries on Art.11(3) UN MTC provide some additions and amendments with respect to Islamic financial instruments. These are consulted later in this study in the context of interpreting the term interest pursuant to Art. 11(3) OECD MTC ${ }^{114}$.

\subsubsection{US tax law}

37 The US federal tax law is an exception from the general principle of this study to exclude domestic tax laws as typically closed-end systems ${ }^{115}$ from being a source of interpretation or inspiration. The reason for this is that the legal development in the US has historically taken a different route than in most other countries, in that the private and corporate law is a matter of the particular member states rather than of the federal state ${ }^{116}$. The federal tax law, for which the private and corporate law principally is a precursory field of law, has to cope with a large number of varying tax law rules and systems among these particular member states, making the need for tax law concepts evident. From this perspective, the varying legal systems of the particular member states are themselves closed-end systems, making it conceptually pointless to graft another legal system onto them in a conventional and satisfactory manner. In order to still ensure compatibility and consistency, the US federal tax law instead took the unconventional approach of developing independent universal standards to evaluate the material outcome of these varying legal systems of the particular member states, rather than to attach to its formal ways and means. In the absence of any other material reference, these standards - known as "tests" - are predominantly based on economic criteria. In other words: the US federal tax law works in a way that it legally goes beyond its precursory fields of law. It employs tests to evaluate their material economic

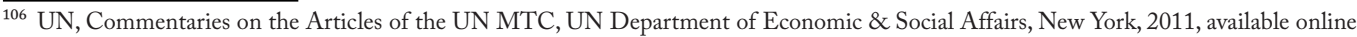
at www.un.org (last retrieved on 15 September 2017).

${ }^{107}$ UN, Model Double Taxation Convention between Developed and Developing Countries, UN Department of Economic \& Social Affairs, New York, 2011, available online at www.un.org (last retrieved on 15 September 2017).

108 See par. 18.

${ }^{109}$ UN Commentaries on Art. 10 UN MTC, p. 176, par. 1, and p. 184, par. 14.

${ }^{110}$ UN Commentaries on Art. 11 UN MTC, p. 192, par. 1, and p. 198, par. 19.

${ }^{111}$ UN Commentaries on Art. 13 UN MTC, p. 225, par. 1, and p. 236, par. 17.

${ }^{112}$ UN Commentaries on Art. 21 UN MTC, p. 299, par. 1 and 3.

${ }^{113}$ Introduction to the UN MTC, p. vi, par. 2.

114 See par. 292.

${ }^{115}$ Duncan, James A., Tax Treatment of hybrid Financial Instruments in cross-border Transactions - General Report, Series IFA Cahiers 2000, Vol. 85a, p. 21 et seq. See also par. 18.

116 Zimmer, Frederik, Form and Substance in Tax Law - General Report, Series IFA Cahiers 2002, Vol. 87a, p. 25.
} 
substance for a legal transaction, which is then legally codified back into the federal tax law. By doing so, it tackles the same conceptual difficulties and therefore is of the same collective nature as the OECD MTC.

38 As a consequence, the US federal tax law has evolved to a jurisdiction with exceptionally strong doctrines for dealing with a large variety of legal concepts ${ }^{117}$. Accordingly, there has also emerged a natural convergence between the concepts of the US federal tax law and the US accounting law, which is known as one of the most significant influencing factor of the IAS/IFRS ${ }^{118}$.

39 Undoubtedly, the US federal tax law is an inspirational source of $\mathrm{law}^{119}$ and in this study no attempts shall be made to create or advocate a legally binding character to the OECD MTC. Having accepted this, the US federal tax law might nevertheless allow valuable insights into its subjacent concepts in order to establish a maximum of inherent consistency and systematology in the treatment of financial instruments and transactions under the OECD MTC with a minimum of assumptions or preconditions.

\subsubsection{EU tax law}

40 Sources of EU tax law, which might potentially be of interest for this study, are:

(1) the Parent-Subsidiary Directive, originally introduced in $1990^{120}$ but replaced in $2011^{121}$ and last amended in $2015^{122}$. It governs the elimination of double taxation on European inter-company profit distributions.

(2) the Interest and Royalties Directive, introduced in $2003^{123}$ and currently in discussion for being replaced ${ }^{124}$. It governs the elimination of double taxation on European inter-company interest payments and royalties.

(3) the Anti Tax Avoidance Directive, introduced in $2016^{125}$ and currently in discussion for being amended ${ }^{126}$. It governs measures against tax avoidance (e.g. thin capitalisation rules, exit taxation, controlled foreign company rules and hybrid mismatches).

(4) the Savings Directive, introduced in $2003^{127}$ but de facto repealed in $2015^{128}$. It governed an exchange of information among the EU member states on received interest income. As this directive has already expired, it is out of scope for this study.

41 At these respective times, the EU had 12 (1990), 15 (2003) and 28 (2016) member states with multiple diverse legal cultures and tax law systems. Without pre-empting a comparability analysis ${ }^{129}$, the EU tax law

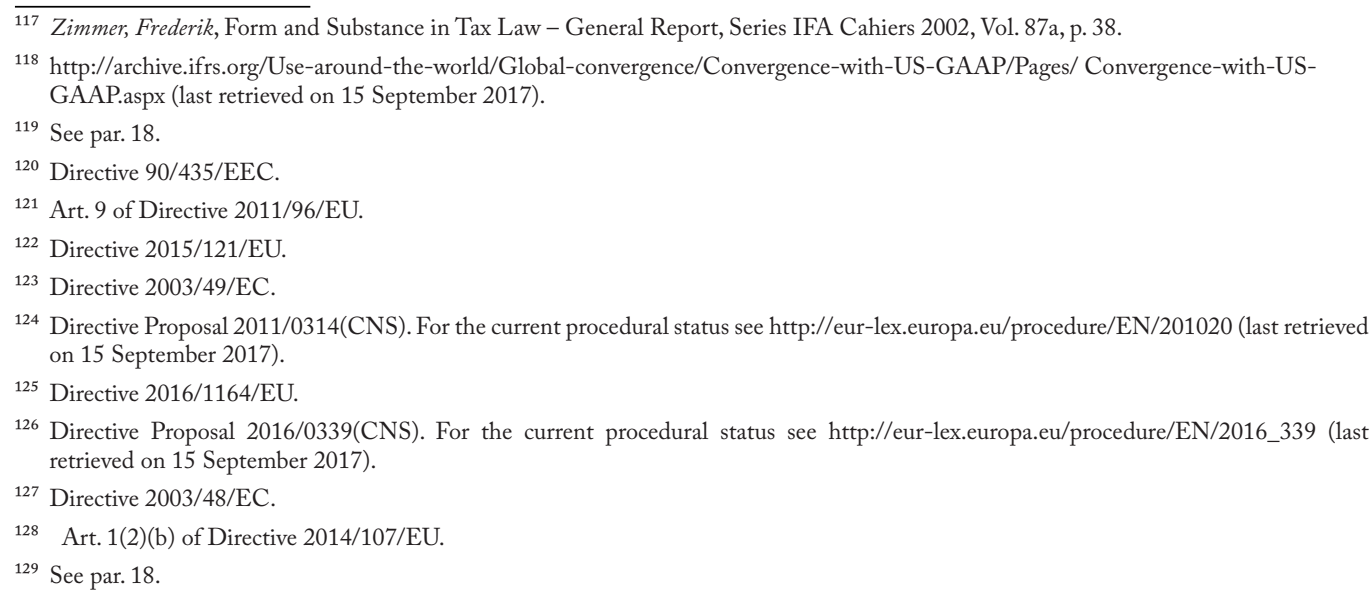


could be seen in this light as not "locally biased" and thus as a collective tax law. This particularly applies to the non-harmonised tax matters at those times, which gave the very reason for such integration initiatives. On the one hand, the EU tax law is no direct interpretational source of law ${ }^{130}$ for this study and no attempts shall be made in this study to create or advocate a legally binding character towards the OECD MTC. On the other hand, neither is it an inspirational source of law for this study, for the following reasons:

42 The Parent-Subsidiary Directive ${ }^{131}$ applies its relevant term of a profit distribution only to qualified minimum holdings of $10 \%{ }^{132}$, which corresponds with the qualified minimum holding concept of $25 \%$ in Art. $10(2)$ (a) OECD MTC. However, the 10\% qualified minimum holdings criterion reflects the tax-wise borderline between the EU rights ${ }^{133}$ in regards to the freedom of establishment pursuant to Art. 49 TFEU et seqq. and the free movement of capital pursuant to Art. 63 TFEU et seqq. In contrast, the $25 \%$ qualified minimum holdings criterion is intended as a compromise between the source jurisdiction's right to tax the profits of the company as the source and the residence jurisdiction's right to tax those of its holder ${ }^{134}$. Apart from this intentional and functional difference, the two concepts have in common that they eventually include - and even particularly focus on - dual-character investors (e.g. related parties), which can provide equity and debt capital simultaneously. In that, their subjective scope, however, is narrower. Their objective scope or understanding of what a dividend or profit distribution shall be must necessarily be broader than those of Art. 10(3) OECD $\mathrm{MTC}^{135}$. This is made obvious for instance by the fact that the two concepts also incorporate aspects of tax groups (e.g. profit-transfer agreements) and anti-abuse considerations ${ }^{136}$ (e.g. hidden profit distributions). As the further analysis in this study will show, Art.10(2) OECD MTC is open in so far as it refers to parts of Art. 10(3) OECD MTC being explicitly interpreted domestically. ${ }^{137}$ In contrast, the Parent-Subsidiary Directive employs an integrated and cohesive term profit distribution. Consequently, it incorporates also derivative dividend concepts ${ }^{138}$ - be it domestic ones or autonomous ones or both - rather than solely the genuine one as the exclusive focus of this study ${ }^{139}$. In addition, the replacement of the Parent-Subsidiary Directive in $2011^{140}$ was also intended to implement the OECD's BEPS action item No. 2 on what is considered

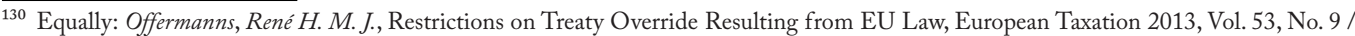
Special Issue, sec. 2; Kemmeren, Eric C. C. M., Double Tax Conventions on Income and Capital and the EU: Past, Present and Future, EC Tax Review 2012, Vol. 21, Issue 3, p. 160; Fernandes, Sandra Martinho et al., A comprehensive Analysis of Proposals to amend the Interest and Royalties Directive, European Taxation 2011, Vol. 51, No. 9 / 10 / 11, sec. 3.3.2.3.; similarly: Jakob Bundgaard, hybrids, p. 192; Jakob Bundgaard, EU Tax Directives, sec. 2.2.; ECJ, judgement ref. C-101/05, 2007, par. 37; ECJ, judgement ref. C-446/04, 2006, par. 170; ECJ, judgement ref. C-336/96, 1998

131 See par. 40(1).

132 Art. 3(1) of Directive 2011/96/EU.

${ }^{133}$ ECJ, judgement ref. C-282/04 and C-283/04, 2006; ECJ, judgement ref. C-492/04, 2007.

134 OECD Commentaries 2014 on Art. 10 OECD MTC, p. C(10)-2 et seq., par. 10, and p. C(23)-21, par. 50.

135 Equally: Jakob Bundgaard, hybrids, p. 190; Sven-Eric Bärsch, p. 115 et seqq.; Terra, Ben J. M. / Wattel, Peter Jacob, European Tax Law, 6th edition, Wolters Kluwer (Law \& Business), Alphen aan den Rijn, 2012, p. 631 et seq.; Jakob Bundgaard, EU Tax Directives, sec. 3.1.2.1.; Marjaana Helminen, dividend concept, p. 171; Bell, Susan, Cross-border Repatriation of Dividends: tax neutral in the European Union?, Derivatives \& Financial Instruments 2005, Vol. 7, No. 1, p. 22 et seq.; Guglielmo Maisto, Parent-Subsidiary Directive, p. 177; Marjaana Helminen, Parent-Subsidiary Directive, p. 162 and 166; de Hosson, Fred C., The Parent-Subsidiary Directive, Intertax 1990, Vol. 18, Issue 10, p. 433 et seq.

${ }^{136}$ For instance, Art. 1(3) of Directive 2015/121/EU.

${ }^{137}$ See par. 271

${ }^{138}$ See par. 3.

139 See par. 10.

140 See par. 40(1).
} 
"hybrid mismatch arrangements"141. The result is that its scope of application ${ }^{142}$ was actually limited by being selectively suspended, which makes particularly "hybrid" loans, as one of the very key subjects of this study, ${ }^{143}$ eventually its "blind spot". For these reasons, the Parent-Subsidiary Directive cannot expediently be used as an inspirational source of law for the interpretation of the genuine dividend concept pursuant to Art. 10(3) OECD MTC, which must instead be resilient to stand also against non-dual character investors.

43 Furthermore, the Interest and Royalties Directive ${ }^{144}$ applies its relevant term of interest only to qualified minimum holdings of $25 \%{ }^{145}$, which is in discussion to be reduced to $10 \%{ }^{146}$ in order to correspond to the Parent-Subsidiary Directive ${ }^{147}$. Basically, the term interest "is based on that used in Article 11 of the 1996 OECD Model Tax Convention on income and on capital, with the exception of income from government securities which is not relevant to this Directive" ${ }^{148}$. However, "the Directive applies not only to the payments of interest or royalties as defined under paragraph 1 but also to all payments regarded by Member States as such, either under a Double Taxation Convention in force between the Member State where the interest or royalties arise and the Member State of the beneficial owner or, in the absence of such a Convention, on the basis of the national tax legislation of the Member State where the interest or royalties arise." ${ }^{149}$ Apart from likewise focussing on dual-character investors ${ }^{150}$, the term interest employed by the Interest and Royalties Directive is thus eventually broader than that of Art. 11(3) OECD MTC ${ }^{151}$. It actually incorporates at least also domestic concepts ${ }^{152}$ - be they genuine ones or derivative ones or both - instead of solely an autonomous one as the exclusive focus of this study ${ }^{153}$. For this reason, the Interest and Royalties Directive is equally not used as an inspirational source of law for the interpretation of the genuine interest concept pursuant to Art. 11(3) OECD MTC, which is exclusively to be interpreted autonomously ${ }^{154}$.

44 Apart from likewise incorporating the above-mentioned derivative concepts, the Anti Tax Avoidance Directive ${ }^{155}$ particularly defines its potentially relevant term of hybrid mismatches explicitly as "situations [... with ...] any of the following outcomes" ${ }^{156}$. Obviously, the Directive refers thus to the legal consequences of

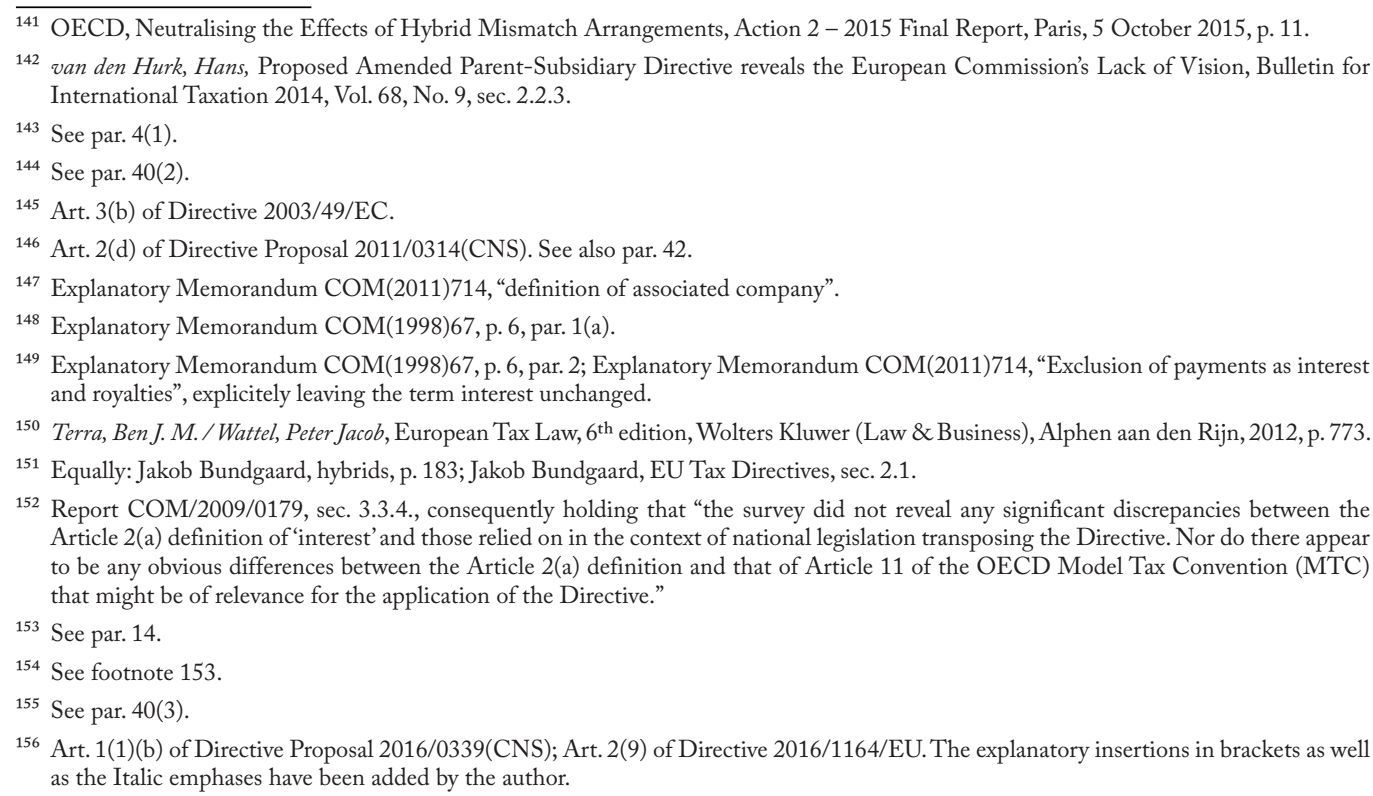


financial instruments or transactions instead of to their legal grounds as the exclusive focus of this study ${ }^{157}$. In other words: the Directive leaves the fundamental schedule or box structure and the respective classification of income from financial instruments actually untouched, and merely suspends, rather than amends, the general rules selectively. In that, it actually limits their scopes of application in the same way the Parent-Subsidiary Directive was enriched by derivative anti-abuse measures in $2011,{ }^{158}$ and leaves particularly debt-equity "hybrids"159 as one of the very key subjects of this study eventually a "blind spot". Insofar, it takes a top-down approach and therefore represents secondary law. For these reasons, the Anti Tax Avoidance Directive can also not expediently be used as an inspirational source of law for the interpretation of the genuine concepts of dividends pursuant to Art. 10(3) OECD MTC, interest pursuant to Art. 11(3) OECD MTC and capital gains pursuant to Art. 13(5) OECD MTC as sources of primary law, which instead require a bottom-up approach.

\subsubsection{IAS / IFRS}

45 The IAS/IFRS are undoubtedly an inspirational source of law ${ }^{160}$ and no attempts shall be made in this study to create or advocate a legally binding character to the OECD MTC ${ }^{161}$. True, some jurisdiction apply the IAS/IFRS as their mandatory accounting standard by simultaneously grafting their domestic tax law onto the accounting law ${ }^{162}$. However, in the universal context of the OECD MTC as a collective tax law, this may not lead to generalisations ${ }^{163}$ (e.g. to taxpayers such as private individuals, which are not subject of those accounting laws). Having accepted this, the IAS/IFRS might nevertheless allow valuable insights by drawing constructive analogies or by investigating some perceptions on universal or hidden structural rationales, which may to a certain extent be transferable to the OECD MTC ${ }^{164}$. The reason is not only that the IAS/IFRS are a collective law as well that necessitates to ignore the domestic peculiarities of precursory fields of law. In other words: the IAS/IFRS do likewise need to "make themselves a generic opinion on what has happened" without recurring to the domestic laws ${ }^{165}$. The peculiarity essentially is that this legal assessment by the IAS/ IFRS is - by its material nature - economically driven due to their specific purpose, function and intention. Hence, where it comes to economic aspects or concepts (such as substance over form, risk, correlations, etc.), the IAS/IFRS are considerably closer to the problem ${ }^{166}$ allowing to draw insightful parallels to the interpretation of the OECD MTC.

46 Among others, the IAS/IFRS particularly address the following fields relevant for this study:

(1) IAS 39 deals with the special aspect of the recognition of financial instruments. In 2001 the IAS Board adopted IAS 39 that had originally been issued by its predecessor organisation, the IAS Committee,

\footnotetext{
157 See par. 10 .

158 See par. 42.

159 Art. 1(3) of Directive Proposal 2016/0339(CNS); Art. 9 of Directive 2016/1164/EU.

${ }^{160}$ See par. 18.

${ }^{161}$ OECD, Taxation of new Financial Instruments, OECD, Paris, 1994, p. 27 et seqq.

162 OECD, BEPS Action No. 2 - Neutralising the Effects of Hybrid Mismatch Arrangements (Final Report), 5 October 2015, OECD, Paris, 2015, p. 35, par. 63.

163 OECD, ST/SG/AC.8/2001/CRP.8, p. 27 et seq., par. 99 et seqq.

164 Similarly: Laukkanen, Antti, Taxation of Investment Derivatives, IBFD, Amsterdam, 2007, p. 416; OECD, ST/SG/AC.8/2001/CRP.8, p. 28, par. 102 .

165 See par. 18.

${ }^{166}$ Kaeser, Christian/Wassermeyer, Franz in Wassermeyer Commentaries, p. 1308, par. 112; Peters, M.J., IFRS, Tax Accounting and Derivatives, Derivatives \& Financial Instruments 2010, Vol. 12, No. 2a / Special Issue; OECD, ST/SG/AC.8/2001/CRP.8, p. 28 , par. 102.
} 
in 1999 with the intention to replace IAS 39 in its entirety by IFRS $9^{167}$. In 2006 the IAS Board had joined ${ }^{168}$ a long-term project of the US Financial Accounting Standards Board on "financial instruments with characteristics of equity" (formerly "liabilities and equity") ${ }^{169}$ and pursued it independently since $2012^{170}$. This long-term project ${ }^{171}$ was divided into the three successive phases of (1) classification and measurement, (2) impairment and (3) hedge accounting. The first two of these topics are complete to-date by being entirely carved-out and relocated from IAS 39 to IFRS 9. The third one becomes effective as per 2018, i.e. the topic of hedge accounting is still provided in both IAS 39 providing the old and IFRS 9 the new rules. In the meantime, the transition rules basically provide the right to elect between the hedge accounting rules of IAS 39 and IFRS $9^{172}$, particularly in regards to portfolio hedging ${ }^{173}$ that is not yet included in IFRS 9 but rather subject of a research project ${ }^{174}$. At the same time, IFRS 9 also incorporated IFRIC 9, which dealt with embedded derivatives. As IAS 39 will expire soon, this study focuses on the new hedge accounting rules pursuant to IFRS 9 only. Therefore, IAS 39 is out of scope and IFRS 9 in scope of this study ${ }^{175}$. IFRS 9 deals with the holder's perspective ${ }^{176}$ on financial instruments in general. Its most relevant features are the classification of financial instruments into financial assets and financial liabilities as well as the provisions in terms of embedded derivatives and hedge accounting.

(2) IAS $32^{177}$, though from the issuer's perspective ${ }^{178}$, deals with the special aspect of the presentation of financial instruments. In 2005 IAS 32 also incorporated SIC-5, which dealt with the classification of financial instruments, and SIC draft interpretation D34, which dealt with financial instruments and rights redeemable by the holder. The most relevant feature of IAS 32 is the classification of financial instruments into equity and liability.

(3) IFRS $7^{179}$ deals with the special aspect of the disclosure of financial instruments and also incorporates some of the requirements allocated from IAS 32 and IAS 39 when released in 2005. Its most relevant features are the provisions in terms of risks, embedded derivatives and hedge accounting.

(4) IFRS $4{ }^{180}$, though from the issuer's perspective ${ }^{181}$, deals with the special aspect of insurance contracts. Although not the primary focus for this study, the classification of risks and the provisions in terms of unbundling insurance and deposit components are relevant features.

\footnotetext{
${ }_{167}$ IAS 32, introduction.

${ }^{168}$ IAS Board, Financial Instruments with Characteristics of Equity - Discussion Paper, IAS Board, London, 2008, p. 4, par. 3 et seqq.

${ }^{169}$ For an overview see www.fasb.org/project/fi_with_characteristics_of_equity.shtml (last retrieved on 15 September 2017).

${ }_{170}$ www.iasplus.com/en/projects/research/short-term/fice (last retrieved on 15 September 2017).

${ }^{171}$ For an overview see http://archive.ifrs.org/current-projects/iasb-projects/financial-instruments-a-replacement-of-ias-39-financialinstruments-recognitio (last retrieved on 15 September 2017) and www.iasplus.com/en/projects/major/financial-instruments (last retrieved on 15 September 2017).

172 IFRS 9.7.2.21.

${ }^{173}$ IFRS 9.6.1.3.

${ }^{174}$ IFRS 9.IN10 and 9.BC6.87 et seqq. See also par. 47.

${ }^{175}$ Legal status as per 1 January 2018 (IFRS 9.7.1.1).

${ }^{176}$ IAS 32.AG30; IFRS 9.2.1(d).

${ }^{177}$ Legal status as per 1 January 2017.

${ }^{178}$ IAS 32.2.

${ }^{179}$ Legal status as per 1 January 2017.

${ }^{180}$ Legal status as per 1 January 2017.

${ }^{181}$ IFRS 4.1.
} 
(5) IFRIC $2^{182}$ interprets IAS 32 and IFRS 9 by applying their principles to members' shares in co-operative entities and similar instruments. Its most relevant feature is the provision of generic similarity or comparability criteria for certain features and circumstances, in which they affect the classification as liabilities or equity.

47 In addition, there are two research projects by the IAS Board on-going to date, which address further fields relevant for this study:

- Macro bedge accounting ${ }^{183}$ in the context of a comprehensive financial instruments project, dealing with dynamic risk management and portfolio hedging; and

- Financial instruments with characteristics of equity ${ }^{184}$ in the context of a comprehensive conceptual framework project.

48 By their structure, the IAS/IFRS typically comprise the Standard itself, including one or more Appendixes, a Basis for Conclusion (BC) outlining the backgrounds and considerations behind the Standards and a Guidance on Implementing (IG) suggesting possible ways to apply the Standards and accompanying Illustrative Examples (IE). In contrast to the OECD MTC, all of these auxiliary materials state individually whether or not they are an integral part of the Standard. Only materials being an integral part of the Standards have the mandatory or legally binding character of constitutive "law" 185 . However, the other auxiliary materials are - even though they are regarded to have the same interpretative value as the opinions of other well-regarded commentators - nevertheless de facto requirements ${ }^{186}$.

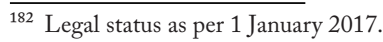

${ }^{183}$ For an overview see www.iasplus.com/en/projects/major/macro-hedge-accounting (last retrieved on 15 September 2017). See also par. 46(1).

${ }^{184}$ For an overview see www.iasplus.com/en/projects/research/short-term/fice (last retrieved on 15 September 2017).

${ }^{185}$ IAS 8.9.

${ }^{186}$ Diana Doege, p. 39, with further citations.
} 


\section{Chapter 2}

\section{Basic principles, systematic context and potential differentiators of financial instruments}

\subsection{Preliminary remarks}

49 The purpose of this section is to explore and discuss the abstract-theoretical mechanisms of financial instruments and transactions. Its intention is to prepare their various implications and aspects ${ }^{187}$ for the subsequent analysis of the relevant distributive articles, which follows in section $3 .{ }^{188}$ On the one hand, this examination in particular is necessarily characterised by leading comparably deeper into the economic grounds ${ }^{189}$. On the other hand, this is compensated by correspondingly shedding light on their structural links to the relevant legal concepts. According to the "funnel approach" taken in this study and in order to improve its legibility and comprehensibility ${ }^{190}$, this section starts with the basic principles ${ }^{191}$, which are embedded into the systematic legal context afterwards ${ }^{192}$. In the further course of the section, the findings will eventually be condensed and broken down to potential differentiators ${ }^{193}$ as the final objective of this section.

\subsection{Analysis and discussion of basic principles}

\subsubsection{Preliminary remarks}

50 The purpose of this section is to outline a clear and distinct understanding of selected fundamental principles or concepts and their various aspects and implications on the classification of the income types of financial instruments and transactions. One objective is to present the author's view of these principles. Another objective is to further concretise these principles in order to derive and identify some general guidelines, which indicate their principal applicability and scope as well as their intensity to potential fields of differentiators.

\footnotetext{
187 See par. 16.

188 See par. 10.

189 See par. 13.

190 See par. 17.

191 See sec. 2.2.

192 See sec. 2.3.

193 See sec. 2.4.
} 
51 In the absence of any express wording, most of these principles or concepts cannot methodologically be interpreted literally or textually, but only indirectly from inherent and implicit interdependencies within the OECD MTC. That is also the reason why the following considerations take the liberty of transferring some structural findings and parallels from other inspirational disciplines to the OECD MTC. While the methodological justification of such transfer might in certain cases be subject of legitimate debates, the author's intention to put them up for discussion is primarily to draw additional insights or conclusions and to establish a maximum of inherent consistency and systematology in the treatment of financial instruments and transactions with a minimum of assumptions or preconditions. Like the inspirational source of law, the crucial aspect and the scientific value added by those disciplines is, even though not legally binding, to see to what extent their structural findings and parallels are compatible and fit into those of the OECD MTC. These coincidences are those fixation points on which the conceptual framework built in this section of this study is pinned ${ }^{194}$.

\subsubsection{Asset versus transaction}

52 In the context of a systematic interpretation, the income types of financial instruments can generally be approached by either the asset or the transaction. Generally speaking, transactions are economically reciprocal arrangements or exchanges of benefits described by an economic operation and an economic return. Financial transactions are transactions of monetary benefits ${ }^{195}$. On the other hand, financial assets are the result of financial transactions ${ }^{196}$. While the asset-based approach derives the income classification indirectly from its source or origin, the transaction-based approach derives it directly from the effective operation:

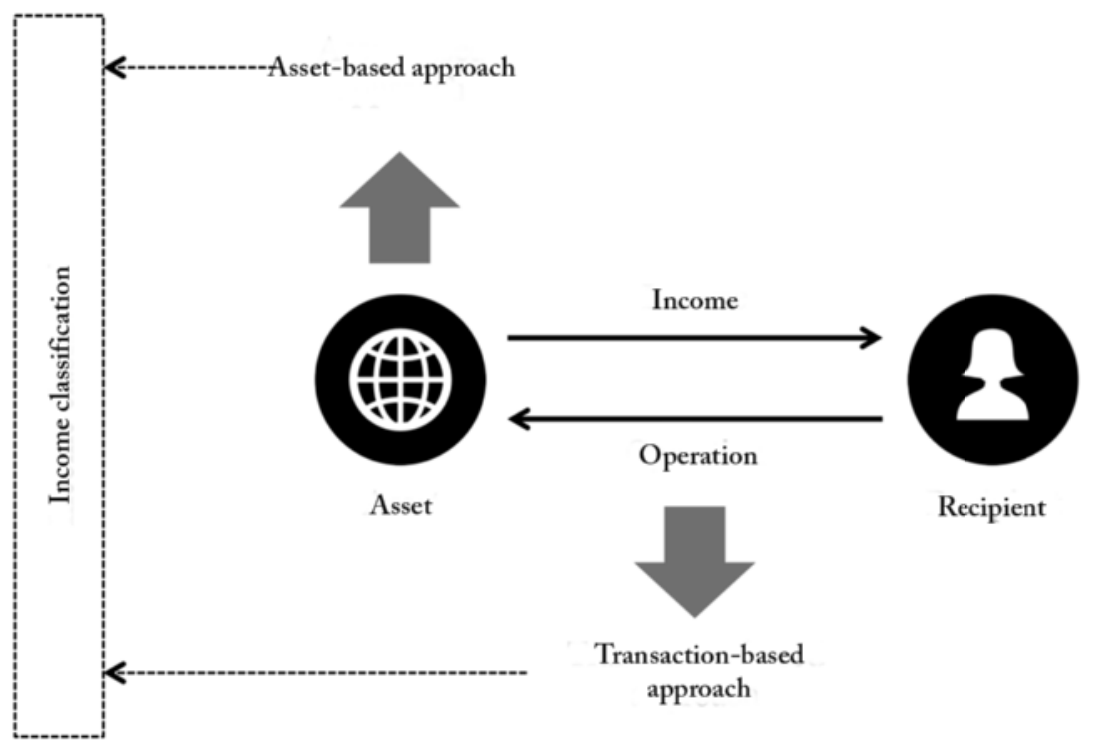

Illustration 1: Asset-based approach versus transaction-based approach

\footnotetext{
194 See par. 18.

195 See par. 1.

${ }^{196}$ IAS 32.11 and 32.AG3 et seqq., defining certain financial assets as rights as a class of specific monetary financial objects.
} 
As a demonstration, a dividend may be defined either asset-based as income from shares or transaction-based as income from the provision or contribution of equity. An interest may be defined either asset-based as income from bonds or transaction-based as income from the provision or contribution of debt capital.

53 As a starting point, assets and transactions are principally independent of each other, since assets can be subject of various transactions. That is why the asset-based approach apparently leads to the literal imprecision that also income types other than dividends may be seen as being obtained from shares (e.g. the capital gain when selling them) and income types other than interest may be seen as being obtained from bonds (e.g. the compensation when lending them). Consequently, the asset-based approach requires and implies as additional information an assignment or reconciliation of transactions, which are admissible or accessible to the asset in order to make the income classification clear and meaningful. ${ }^{197}$ As an illustration, whether a hammer is a tool or turns into a weapon depends solely on its usage or the action. In other words: it could be said that the asset-based approach is not cohesive in that it merely indicates the transaction implicitly but not addresses it explicitly. Continuing with the previous demonstration ${ }^{198}$, the phrase income from shares actually means income from the provision or contribution of equity in the form of shares and the phrase income from bonds actually means income from the provision or contribution of debt capital in the form of bonds. This literal or textual interpretation is methodically solved by gap filling: those other income types from transactions not admissible or accessible to the asset in order to yield dividends or interest are said to be not genuinely obtained from the asset itself but derivatively from that other transaction ${ }^{199}$. For instance, a capital gain is said not to have been obtained from the share but from the sale of the share or with the share, and a compensation is said not to have been obtained from the bond but from the lending of the bond or with the bond.

54 In other words: the asset-based approach turns the principal independence of assets and transactions into a one-way predetermination or dependency of the transaction by or from the asset, but not vice versa. Not only does the asset-based approach thus imply and require the transaction-based approach by way of that textual but also systematic interpretation; another difference between the two is that the latter makes it possible to analyse the income types of financial instruments in a more consistent way: the concepts of dividends and interest can actually be examined by using both approaches. But the asset-based approach is not practicable when it comes to the concept of capital gains, which already is a transaction itself (i.e. the sale). ${ }^{200}$ Hence, following the asset-based approach would lead to a dualism of methods.

55 The reason for this is that the asset is a static reference ${ }^{201}$ in the sense of a particular state. In contrast, the transaction is a dynamic reference in the sense of a change of that state ${ }^{202}$, which is closer to the nature and object of an income tax ${ }^{203}$. In this sense, the said assignment or reconciliation ${ }^{204}$ could be seen as an

\footnotetext{
${ }^{197}$ Harris, Peter $A$. in IBFD Commentaries on Art. 10 OECD MTC, sec. 5.1.3.2.4., touching this point in the context of OECD Commentaries 2014 on Art. 10 OECD MTC, p. C(10)-10 et seq., par. 25.

198 See par. 52.

199 See examples at Harris, Peter A. in IBFD Commentaries on Art. 10 OECD MTC, sec. 5.1.2.5.6, and Reimer, Ekkehart in Klaus Vogel Commentaries 2015, p. 1050, par. 6.

200 Equally: Ismer, Roland / Blank, Alexander in Klaus Vogel Commentaries 2015, p. 161, par. 44. See also examples in par. 53.

201 Similarly: David Hariton, equity and debt, p. 502.

202 See Illustration 1 on p. 24.

${ }^{203}$ Ismer, Roland in Vogel/Lehner, p. 474, par. 38.

204 See par. 53.
} 
"adapter" between the static reference asset and the dynamic reference transaction to make the two approaches compatible with each other. Although it should be kept in mind that the OECD MTC not only applies to taxes on income but also to those on capital, for the purpose of an income tax the asset is an impracticable reference.

56 As stated before ${ }^{205}$, financing of any kind is economically a reciprocal arrangement or an exchange of benefits described by an economic operation (i.e. the provision or contribution of capital) and an economic return (i.e. the income). In this respect, the difference between dividends and interest is less an economic one than an aspect of the legal or organisational form. ${ }^{206}$ For tax purposes, the substance of a transaction is determined by the operation (condition) and assessed by the return (amount). This is why the main advantage of the transaction-based approach is its straight or more direct access to the substance of the income types.

Side note: Apart from practical means ${ }^{207}$, the economic substitutability of debt and equity was the reason why Art. 9 of the Mexico Draft MTC covered both dividends and interest as one income from movable capita ${ }^{208}$. The background of splitting the income from movable capital into dividends and interest and of taxing them differently was the idea that "dividends were to be taxed in the country where the capital from which they were derived was invested - i.e., put into productive use" 209 . In contrast, "interest [was to be taxed in] the country from which capital originated had a prior right to tax such interest wherever the capital was invested" Although this is an economic consideration as well, it is no micro-economic one referring to the substance of the transaction but a macro-economic one referring to the tax burden and tax revenue allocation.

57 Admittedly, following the pure transaction-based approach would be insufficient for the analysis of the income types of financial instruments. The reason for this is that there is obviously more than one provision in the OECD MTC dealing with income from financial transactions. Ergo, the transaction-based approach requires an object to which it refers (i.e. the asset) as well. However, it shall be emphasised that the reason and purpose for that object in the asset-based approach is a different one than in the transaction-based approach. In the asset-based approach this purpose, apart from the matter of course that, first and foremost, the location of the source or situs of the asset constitutes a cross-border situation, is to derive the income classification from the object. In the transaction-based approach, however, the purpose is to identify and classify the object itself according to the system of the OECD MTC ${ }^{211}$. For instance, there is a difference in the system of the

206 Jieyin Tang, substance vs. form, sec. 5.1.; Wolfgang Schön, comparative analysis, p. 163 et seq.; Sven-Eric Bärsch, p. 76; Peter Hongler, p. 269; Marjaana Helminen, dividend concept, p. 163 et seq. and p. 167; David Weisbach, p. 494; Emmerich, Adam O., Hybrid Instruments and the Debt-Equity Distinction in Corporate Taxation, University of Chicago Law Review 1985, Vol. 52, Issue 1, p. 122 et seq.; League of Nations (Economic and Financial Commission), Report on Double Taxation submitted to the Financial Committee - Economic and Financial Commission Report by the Experts on Double Taxation, ref. E.F.S.73. F.19, Vol. 4, sec. 1, Geneva, 1923, p. 37, sec. II, par. V(c).

207 Fuentes Hernandez, Daniel in Thomas Ecker, p. 447.

${ }^{208}$ League of Nations, Annex to London and Mexico Model Tax Conventions Commentary and Text, Geneva, November 1946, available online at http://adc.library.usyd.edu.au (last retrieved on 15 September 2017), p. 24.

${ }^{209}$ League of Nations, Annex to London and Mexico Model Tax Conventions Commentary and Text, Geneva, November 1946, available online at http://adc.library.usyd.edu.au (last retrieved on 15 September 2017), p. 25.

${ }^{210}$ League of Nations, Annex to London and Mexico Model Tax Conventions Commentary and Text, Geneva, November 1946, available online at http://adc.library.usyd.edu.au (last retrieved on 15 September 2017), p. 26.

${ }^{211}$ Marjaana Helminen, dividend concept, p. 72.
} 
OECD MTC between the incomes from financing a company or a partnership depending on whether or not the corporate level has already been taxed. ${ }^{212}$ The illustration that both company and partnership can be financed by equity and debt makes plain that the purpose of classifying the income using the asset-based approach is independent of the purpose of classifying the object using the transactions-based approach ${ }^{213}$. Or in other words: the object (i.e. the asset) carries one single bit of information in the transaction-based approach (i.e. on itself for tax-systematic purposes) but two bits of information in the asset-based approach (i.e. on itself for tax-systematic purposes and on the income classification).

58 In summary, the transaction-based approach decomposes the object into the asset-related and the transactionrelated bit of information. This transaction-related bit, which determines the substance of the transaction, is the underlying operation. Contrarily, the asset-related bit of information is important for tax-systematic purposes. Both components are required for the income classification, but the asset-based approach separates source and transaction only implicitly, requiring additional information, while the transaction-based approach does so explicitly, without requiring such additional information ${ }^{214}$. In contrast to the transaction-based approach for capital gains, the OECD MTC has obviously taken the asset-based approach (arising rule) 215 $^{215}$ for dividends and interest ${ }^{216}$. For other income the approach is not relevant due to its character as a residuary provision, which covers the remainder of any further income - be it from an asset or a transaction - and therefore does not need to be decomposed. However, while both approaches lead to the same results, the transaction-based approach provides more information, a deeper understanding and maybe new perspectives going beyond the asset-based approach. It opens or disentangles the implied dependencies between asset (source) and transaction (operation), and eventually provides more transparency. In this sense, the transactionbased approach is no substitute for the asset-based approach but rather an enlargement and breakdown. For these systematic reasons, as an interim conclusion the transaction-based approach emerges as the more practicable one for the further course of this study.

\footnotetext{
${ }_{212}$ Harris, Peter $A$. in IBFD Commentaries on Art. 10 OECD MTC, sec. 1.1.2.2.

${ }^{213}$ In result equally: Joanna Wheeler, attribution, p. 478.

${ }^{214}$ The OEEC (Working Party No. 12 of the Fiscal Committee), Report on the Taxation of Dividends, ref. FC-WP12(58)1part1, Paris, 1958, p. 18, already mentions the two components explicitly: "The essential condition is that there must be on the one hand an independent legal entity (payments by partnerships of individuals are thus excluded), and on the other hand a relationship founded on a contract of association and giving a right to participate in the profits." Similarly: Kaeser, Christian/Wassermeyer, Franz in Wassermeyer Commentaries, p. 1307, par. 110.

215 Laukkanen, Antti, Taxation of Investment Derivatives, IBFD, Amsterdam, 2007, p. 236; Carmine Rotondaro, redemption, p. 266; Klaus Vogel Commentaries 1997, p. 1072, par. 11; analogously: IAS 32.36; IFRIC 2.11.

${ }_{216}$ As regards to interest, the OECD Commentaries 2014 on Art. 11 OECD MTC seem to modify the asset-based approach taken by the OECD MTC: unlike dividends, the OECD Commentaries 2014 on Art. 11 OECD MTC also refer to the creditor as an object additional to debt-claims as the source of income. The reason is probably given in OECD Commentaries 2014 on Art. 11 OECD MTC, p. C(11)-1, par. 1: "Unlike dividends, interest does not suffer economic double taxation that is, it is not taxed both in the hands of the debtor and in the hands of the creditor." In other words: shares, which represent the legal but not the economic source of income, are logically set between the recipient or beneficial owner and the issuer as an additional level of taxation. In contrast, debt-claims, which represent both the legal and the economic source of income, induce a more direct relationship between the two. In this respect, the OECD Commentaries 2014 deduce the object of the income types of financial transactions from the tax subjectivity of the issuer by applying an economic perspective. Although this appears to be consistent and may open new perspectives in other respects, for the discussion here it still remains an asset-based approach (i.e. it makes no difference whether the static reference is the asset or its issuer) and therefore has no further impact on the question of which approach this study will purposively take.
} 


\subsubsection{Risk}

\section{The nature and role of risk}

59 Financial instruments "can be and are used to allocate among the contracting parties various risks relating to changes in market value" ${ }^{217}$. In other words: risk as such cannot be resolved but only transferred or reallocated (e.g. by way of hedging). On the one hand, this gives rise to the reasonable assumption that the concept of risk plays an important role in the tax treatment of financial instruments. On the other hand, risk is linked to and is naturally limited by the question of aggregation and disaggregation ${ }^{218}$, as diversification is a portfolio-based concept $\mathrm{t}^{219}$. Hence, assuming rational taxpayers means, as a final consequence, to consider any asset and transaction as being part of their net risk mitigation strategy, and calls for a total consolidation ${ }^{220}$. However, this potential significance of the risk concept with regard to financial instruments conflicts with and is limited by the fact that the OECD MTC is generally based on a classification of asset and income types or schedules (position-by-position or item-by-item approach) ${ }^{221}$.

60 Risk is typically understood as a potential loss (positive risk, i.e. a hazard) or gain (negative risk, i.e. a chance). The economical difference between the two is that the latter is a positive asset calling for compensation from the buyer (e.g. the option holder) to the seller. In contrast, the former is a negative asset calling for reverse compensation from the seller (e.g. the option writer) to the buyer. According to economical understanding, the so-called value at risk as the standard measure for financial instruments ${ }^{222}$ is the result of two aspects: (1) uncertainty of information on the existence (probability) and/or the interdependencies (effect) of factors or determinants influencing a specific event and (2) an objective value of that event. ${ }^{223}$ The first aspect implies that risk is an ex-ante or forward-looking heuristic concept in the stochastical sense, as opposed to ex-post or backward-looking concepts in the statistical or empirical sense, so that later changes never affect the past but only the future. This is why, in particular, the actual occurrence of that ex-post event does not change the ex-ante nature of the risk as such ${ }^{224}$ but merely lets it materialise.

Example 2: A credit risk from a debt-claim does not retroactively turn into a business risk only because it has become dependent on it due to a sudden business crisis, i.e. the actual frustration of the forward-looking going-concern assumption ${ }^{225}$.

\footnotetext{
217 Shaviro, Daniel, Risk-Based Rules and the Taxation of Capital Income, Tax Law Review 1995, Vol. 50, Issue 4, p. 659; similarly: IAS 32.AG16; Steinberg, Lerwis R., Colloquium on Financial Instruments: Commentary, Tax Law Review 1995, Vol. 50, Issue 4, New York University School of Law, New York, 1995, p. 725.

218 See sec. 2.2.5.

219 As will be shown in more detail later (see par. 102). Similarly: IFRS 9.BC6.178.

220 Steinberg, Lewis R., Colloquium on Financial Instruments: Commentary, Tax Law Review 1995, Vol. 50, Issue 4, New York University School of Law, New York, 1995, p. 726; critically: Brooks, John R. II, Taxation, Risk, and Portfolio Choice: The Treatment of Returns to Risk under a Normative Income Tax, Tax Law Review 2013, Vol. 66, Issue 3, p. 269 et seqq.

221 See par. 58.

${ }^{222}$ KPMG Deutsche TreuhandGesellschaft Aktiengesellschaft Wirtschaftsprüfungsgesellschaft, Offenlegung von Finanzinstrumenten und Risikoberichterstattung nach IFRS 7: Analyse der Offenlegungsvorschriften für Finanzinstrumente nach IFRS 7 sowie zum Kapital nach IAS 1, Schäffer-Poeschel, Stuttgart, 2007, p. 156 et seq.

${ }^{223}$ Brooks, John R. II, Taxation, Risk, and Portfolio Choice: The Treatment of Returns to Risk under a Normative Income Tax, Tax Law Review 2013, Vol. 66, Issue 3, p. 281.

${ }^{224}$ In this sense, however: Sven-Eric Bärsch, p. 233; Ceryak, David V., Using Risk Analysis to Classify Junk Bonds as Equity for Federal Income Tax Purposes, Indiana Law Journal 1990, Vol. 66, Issue 1, p. 289.

${ }^{225}$ IAS 32.30, IFRS 9.B5.5.27
} 
In contrast to those qualitative changes of the financial instrument (e.g. modifications or re-negotiations) giving rise to its re-classification ${ }^{226}$, such quantitative changes are rather subject of its re-evaluation ${ }^{227}$. The second aspect makes clear that it is the quantitative value itself, or its changes, which is at risk. Namely, it comprises no other uncertainties such as the timing or value changes, which are - to a certain extent predictable or expectable ${ }^{228}$. Further, the objective value has to be distinguished from its subjective assessment. For instance, an objective value at risk can be assessed differently by taxpayers with higher and lower risk tolerances.

61 This very general understanding of risk can naturally be interpreted and (de-)composed in countless varieties. The purpose and objective of this section is therefore to set a terminological base and to structure these various terms in order to hold a stringent vocabulary for the further course of this study.

\section{Absolute versus relative risk}

62 Theoretically, risk can be either equal or not equal to zero. However, in fact there is no absolutely riskless state (e.g. market risk, systematic risk, etc.), which is why finance theory operates with relative risk. In the absence of a better alternative, the state with the lowest absolute risk (e.g. deposit at the central bank) is relatively "riskless" compared to any other available state. However, such a comparative approach is necessarily impacted by environmental influences, making the determination of the relatively riskless state fluent and the attribution or allocation of the root cause for a change of absolute risks impossible.

Example 3: The interest-change risk is the hazard that the absolute market (i.e. environmental) interest rate changes, so that the absolute interest rate of a particular interest-bearing financial instrument (e.g. a straight bond) changes relatively ${ }^{229}$. However, the market interest rate risk is also affected by the expected inflation risk. Consequently, an inflation-linked note may be considered as "riskless" where the ex-ante inflation expectations have ex-post been met or underestimated. And it may be considered "risky" where these expectations have been overestimated or where there is a significant time lag between the coupon payment and the underlying ${ }^{230}$.

\section{Objective versus subjective risk}

63 Subjective risks are those affecting only one individual taxpayer or contracting legal party (i.e. gross risk from an isolated view). In contrast, inter-subjective or objective risks are those affecting more than one taxpayer or contracting legal party (i.e. net risk from a consolidated view).

Example 4: Where two parties are contracting in a win-lose situation (i.e. a conflict of interests, e.g. a bet against each other), the subjective risk is positive and the objective risk is zero (zero-sum wagers). Where, however, the two parties are contracting in a win-win situation (i.e. an incorporation of interests, e.g. a bet of both against a third party), both the

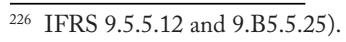

227 IFRS 9.5.5.9.

${ }^{228}$ David Hasen, p. 406.

${ }^{229}$ IFRS 9.BC6.503

${ }^{230}$ Haufe, IFRS, p. 1712, par. 166 et seqq.
} 
subjective and the objective risks are positive. Hence, the risk profile of one or all contracting parties allows conclusions to the incentives of the transaction and therefore indications to its legal character.

Although likewise subjective, this relational aspect must however be separated from the evaluative aspect of risk assessment ${ }^{231}$. For instance, an individual taxpayer may assess a positive subjective risk as negative due to his risk-aversion.

\section{Symmetric versus asymmetric risk}

64 Objective risks can be either symmetric or asymmetric ${ }^{232}$. The value of a symmetric risk is always zero (e.g. forward), whereas the value of an asymmetric risk is always positive ${ }^{233}$ (e.g. option). The zero value of symmetric risks does not, however, mean that it is riskless ${ }^{234}$ but only that the positive risk goes equally in both directions of the contract.

\section{Formal versus material risk}

65 At first glance, it seems inconceivable to understand an economical or mathematical parameter such as risk in a formal way, which is why "law" is not even listed as a practice area for the term risk in most encyclopaedias. However, special fields of private law show that risk may be defined formally, perhaps as an occurrence where the contracting parties agree it to be by convention (e.g. insurance contract law). This raises, for instance, the question as to whether a hazard which is contractually agreed as but is virtually possible or impossible to materialise can be considered a risk.

Example 5: A "deep-in-the-money option" or "deep-out-of-the-money option" (also referred to as "low exercise price option") has a strike price set in a way that the risk is close to zero and the success is de facto certain. As a consequence, the price of the underlying is virtually carved-out or substituted by that strike price.

\section{Legal versus non-legal risks}

66 Legal risks "are hazards that arise when the confidence in a certain legal situation is frustrated"235. Or in other words: legal risks are mainly rooted in the legal relationships as such. In particular, they comprise uncertainties with regard to laws and their tools (especially contracts), including their enforceability. ${ }^{236}$ Non-legal risks are any other hazards. Where a risk cannot be attributed to any legally contracting party ${ }^{237}$, it cannot possibly be a legal risk. For instance, market risk is the residual objective risk after a total consolidation of all market

\footnotetext{
${ }^{231}$ See par. 60.

${ }^{232}$ Dana Doege, p. 18.

${ }^{233}$ IFRS 9.B4.3.3; Kuhn / Hachmeister, p. 61, par. 47 et seq., and p. 708, par. 29.

234 See par. 62.

${ }^{235}$ Fuchs, Florian, Close-out Netting, Collateral und systemisches Risiko: Rechtsansätze zur Minderung der Systemgefahr im außerbörslichen Derivatehandel, Schriften zum Unternehmens- und Kapitalmarktrecht No. 6, 2013, p. 22 (translated by the author), with further citations.

${ }^{236}$ Kolbrenner, Scott Marc, Derivaties Design and Taxation, Virginia Tax Review 1995, Vol. 15, Issue 2, p. 237.

237 See par. 62.
} 
participants $^{238}$ (i.e. a total diversification of all investments on the market) and therefore cannot possibly represent a legal risk.

\section{Underwriting versus timing risk}

67 Underwriting risk - also referred to as "intrinsic risk" 339 or "underlying risk" - is a hazard that refers to ex-ante unpredictable changes in the substance of a present value (if-at-all probability) ${ }^{240}$. Elements such as assets or transactions bearing also underwriting risk are called risk-based.

Side note: Underwriting risk must not be identical with insurance ris ${ }^{241}$, which might be more comprehensive by also encompassing some timing risks ${ }^{242}$. In addition, the key differentiator of insurance risk - as opposed to underwriting risk - is that it is (1) specific to the insured ${ }^{243}$ in the sense of a physical adverse effect beyond a mere uncertain event ${ }^{244}$ and (2) limited to insurable interests as specific events onl $y^{245}$. In other words: although both bear underwriting risks, an insurance is a specific type of a guarantee ${ }^{246}$ and pays only in case of a material adverse effect. Hence, it is not an asset, whereas a financial instrument pays in any case ${ }^{247}$ and is therefore an asset ${ }^{248}$.

68 In contrast, timing risk is a hazard that merely refers to changes in the ex-ante predictable or expectable ${ }^{249}$ timing of value changes (accrual or dissipate uncertainty) ${ }^{250}$. Elements such as assets or transactions bearing only timing risk are called time-based.

Side note: Timing risk must not be identical with financial ris $k^{251}$, which is the complement to insurance risk and might therefore be more comprehensive by also encompassing some underlying risks.

69 The borderline between underlying and timing risk is fluid. On the one hand, there is a nexus between risk and timing, in that the risk or probability that the event occurs ${ }^{252}$ is the higher the longer the respective time period is. The reason behind is the law of large numbers, according to which the relative frequency of

\footnotetext{
${ }_{238}$ Ceryak, David V., Using Risk Analysis to Classify Junk Bonds as Equity for Federal Income Tax Purposes, Indiana Law Journal 1990, Vol. 66, Issue 1, p. 286.

239 IFRS 9.6.2.4(a), 9.6.5.15 and 9.B6.5.29.

240 Appendix C to SFAS 113, par. 121 (IFRS 4.BC19); IFRS 4.BC35 and $4 . \mathrm{BC} 37$ may be understood to the contrary but draws upon practical considerations only.

241 Appendix A of IFRS 4.

242 IFRS 4.B2(b).

${ }^{243}$ IFRS 4.B9.

${ }^{244}$ IFRS 4.B14 and 4.BC56.

245 IFRS BC.29.

${ }^{246}$ IFRS 9.B2.5(a) and 4.BC67.

${ }^{247}$ IFRS 32.AG8, 4.BC60, 9.B2.5(b) and 9.BC6.519.

${ }^{248}$ Haufe, IFRS, p. 1736 et seq., par. 232; Kubn / Hachmeister, p. 21, par. 138.

249 See par. 60.

${ }^{250}$ IFRS 4.BC19; David Miller, p. 516 et seqq.; Appendix C to SFAS 113, par. 121.

251 Appendix A of IFRS 4.

${ }^{252}$ IAS Board, portfolio hedging, p. 87, par. 8.6(b).
} 
uncertain events stabilises around a constant value that is virtually certain to occur. On the other hand, there is a strong subjective aspect with regard to the predictability, as the following example illustrates ${ }^{253}$.

Example 6: There is a difference between the cases of a retroactive insurance, in which the parties are (1) ignorant or (2) aware of the fact that the insured event has already occurred ${ }^{254}$. In the first case (1) the insurer takes the risk as his own by only calculating the event's value at risk into his premium (i.e. probability of less than 100\%), keeping the insurance a shift of underwriting risk. In the second case (2) the insurer will calculate the value of the entire event into his premium (i.e. probability equal to $100 \%$ ), diminishing the transaction to a mere shift of money (timing risk).

In addition, the underwriting risk necessarily also implies the timing risk (but not vice versa) ${ }^{255}$. Where the occurrence of the event is at all uncertain, this obviously includes its timing as well. That is why underwriting risk can replicate and be converted into timing risk (but not vice versa), as the following example illustrates ${ }^{256}$ :

Example 7: Where the value paid out from an excess insurance is higher than the value of the adverse effect from the entire event itself and thus overcompensates its prospected probability, the value at risk is re-equalised to the value of the entire event, leaving eventually only timing risk as a remainder.

Consequently, it is either a question of whether to disaggregate ${ }^{257}$ the risk ${ }^{258}$ or a matter of degree, how much timing risk is critical to turn it entirely from underwriting into timing risk ${ }^{259}$.

70 The difference between underwriting and timing risk is however key for the axiomatic delimitation of financing, for instance from insurances or bets. Insurance is first of all the taking of underwriting risk as own risk ${ }^{260}$ in order to pool and distribute it according to the law of large numbers ${ }^{261}$. This means that any transfer or conduit of underwriting risk, such as by way of hedges, reinsurances or securitisations, diminishes the transaction to a mere shift of money (timing risk).

Side note: From the IAS/IFRS insurance perspective, this axiom ${ }^{262}$ appears to be problematic. As pooling merely helps to ensure a greater predictability, in the long run there are no uncertain risks but only certain events. Consequently, it could even be said that there is actually no such thing as an "insurance" but only financing. A "distribution" of risk is nothing else than transfer

\footnotetext{
${ }^{253}$ IFRS $4 . B 3$ et seq.

${ }^{254}$ David Miller, p. 517; IFRS 4.B12.

255 IFRS 9.B6.5.34; IAS Board, December 2016, 5B, p. 8, par. 28.

256 IFRS 4.B13; David Miller, p. 521.

257 See sec. 2.2.5.

${ }^{258}$ IFRS 4.DO10.

${ }^{259}$ Analogously for insurance risk versus financial risk: IFRS 4.B10.

${ }^{260}$ IFRS 4.B8 and 4.B11.

${ }^{261}$ Frank Angermann, p. 10; Dana Doege, p. 21; David Miller, p. 530.

262 IFRS 4.BC29.
} 
of risk, at least back to the insured party by way of calculating it into the premium. This is why there are considerable overlaps between insurance contracts pursuant to IFRS 4 and financial instruments pursuant to IFRS $9^{263}$.

To this extent, a bet is a negative insurance in the sense of granting a chance (i.e. taking a negative underwriting risk $\left.^{264}\right)^{265}$. In contrast, financing is to take timing risk as own risk in order to pool and distribute it by way of transforming lots and maturities.

Side note: From the IAS/IFRS perspective, this axiom appears to be problematic as well, in that it is only theoretically possible to separate timing risk (i.e. financing) from underwriting risk (i.e. insurance). In practice, however, there is no absolutely riskless state ${ }^{266}$ in the sense of a pure timing risk, so that financing actually bears underwriting risk ${ }^{267}$ (e.g. business risk, credit risk, etc.) as well. This underwriting risk from a financial transaction may even resemble the underwriting risk from an insurance transaction ${ }^{268}$. For instance, the shareholder of an insurance company bears in fact the underwriting risk from the insurance business. This is why there are considerable overlaps between financial instruments pursuant to IFRS 9 and insurance contracts pursuant to IFRS $4^{269}$.

\subsubsection{Substance versus form}

\subsubsection{Genuine versus derivative concepts}

71 As stated earlier ${ }^{270}$, DTC are "hybrid systems" with the dual purpose of representing international agreements between two jurisdictions (horizontal binding effect) and fields of the public tax law governing the relation between these jurisdictions and its taxpayers (vertical binding effect). As regards the latter, on the one hand, a DTC has to integrate itself as a coherent element into the whole legal system of its jurisdiction. It basically respects the instruments and legal relations granted by other fields of that legal system ("form"), in particular the private and corporate law but also to other fields of the public law (e.g. accounting law). Although these precursory fields of law may themselves adhere more to substantive than to formal concepts, the legal form is nevertheless bound by these fields of the law. On the other hand, it has to reassess and - where necessary -subordinate these instruments and legal relations under its own normative purposes and auxiliary conditions. One of these is the equal or neutral treatment of comparable patterns ("substance") in order to avoid distortions and to find public acceptance owed to the expropriative character of tax law. That is why tax law is actually a legal model of economic facts: while its material content is economically induced or driven, its formal application and procedural requirements are subject to legal methodologies. In this inherent conflict,

\footnotetext{
${ }^{263}$ IFRS 4.4(d).

${ }^{264}$ See par. 60.

${ }^{265}$ Equally: IFRS 4.BC26; contrary: Kuhn/Hachmeister, p. 20, par. 111, classifying bets into the IAS/IFRS category of derivatives (see par. 96 et seqq.).

266 See par. 62.

${ }^{267}$ IFRS 9.BC6.524 et seq.

${ }^{268}$ IFRS 9.B5.7.14 and 9.B5.7.15(b).

${ }^{269}$ IFRS 9.2.1(e) and 9.BC6.390 et seqq.

270 See par. 27.
} 
tax law has "to balance the rule of law and the legality principle on the one hand and the equality of taxpayers and the efficiency of the tax collection on the other."271

72 In this context, the purpose and objective of this section is to identify general guidelines indicating the principal applicability and the scope of when, where and to what extent the aspect of substance prevails over the aspect of form for particular fields of attributes. As a starting point, substance over form is a general and implicit principle of interpretation (bottom-up induction) rather than an explicit legal directive (top-down deduction). It can only be derived indirectly from particular terms or provisions within the OECD MTC. It applies methodologically to both steps of applying the tax law: the case-by-case assessment or subsumption of facts or attributes from precursory fields of law ("look-through") and the abstract interpretation of the OECD MTC as the tax law itself. ${ }^{272}$ In both ways it can be considered as certain that the legal form is the baseline. ${ }^{273}$ This is not only a result of Art. 31(1) VCLT ${ }^{274}$ and the general policy that tax law has to respect the instruments and legal relations granted by other fields of the legal system ${ }^{275}$. It was also the original intention of the OECD MTC ${ }^{276}$. The form is the determination or construct of a relationship (path), whereas the substance is an evaluation of its result (destination). This is why concepts of substance are subsequent matters arising from the tax law itself. Their application requires additional qualifying elements or measures within the tax law going beyond the determining or constructive attributes from precursory fields of law ${ }^{277}$. In this sense it could be said that the conflict between substance and form is not acted out on the same logical level. A solution through the form actually represents a transparency of the tax law in that it lets the legal result from the precursory fields of law "pass". In contrast, a solution through the substance actually represents an opacity of the tax law, in that it replaces the legal result from the precursory fields of law by its own.

\subsubsection{Abuse as a derivative concept}

73 The most prominent and omnipresent example or use case of the general substance over form principle is the concept of treaty abuse as a construct to prevent taxpayers from actually "writing their own tax ticket"278. However, the substance over form principle goes far beyond this, as it touches "the viability of the fundamental rules and classifications on which income tax systems and international tax agreements are currently based"279. In particular, this includes the object of taxation, aspects of ownership or questions of character and source as well as of timing and amount of the income. Accordingly, the scope of the general substance over form principle must be split up into its specific use case of abuse and the remainder ${ }^{280}$. This necessity predominantly follows from systematic considerations: even allowing or applying both approaches in the

\footnotetext{
271 Zimmer, Frederik, Form and Substance in Tax Law - General Report, Series IFA Cahiers 2002, Vol. 87a, p. 21.

272 Wheatcroft, George Shorrock Ashcombe, The Interpretation of Tax Laws with special Reference to Form and Substance - General Report, Series IFA Cahiers 1965, Vol. 50a, p. 8, 10 et seq. and 14.

${ }^{273}$ Equally: Jieyin Tang, substance vs. form, sec. 5.2.; Marjaana Helminen, dividend concept, p. 166; IFA, $54^{\text {th }}$ IFA Congress, Munich 2000 Summaries of Discussion on Subjects I and II, Bulletin for International Taxation 2001, Vol. 55, No. 2, p. 81.

${ }^{274}$ Hans Pijl, interest, sec. 6.2.3.

275 See par. 71.

${ }^{276}$ Among others: League of Nations, Document C.216.M.85, ref. C.216.M.85, London, 1927, p. 14.

277 Hensel, Albert in Paul Krüger, calling the tax law an "unavoidable extension to the fact of the private law" (p. 235, translated by the author) and "a special field grafted onto the private law" (p. 242, translated by the author).

${ }^{278}$ William Plumb, p. 455; similarly: Harris, Peter A., Corporate Tax Law: Structure, Policy and Practice, Cambridge University Press, Cambridge, 2013, p. 191.

${ }^{279}$ OECD, ST/SG/AC.8/2001/CRP.8, p. 31, p. 4

${ }^{280}$ See par. 10.
} 
OECD MTC simultaneously (i.e. substance over form and form over substance) may resolve the problem of qualification conflicts but it would raise the new one of determining the applicable distributive provision. Equally important is that, to the author's understanding, there must be a difference between genuine legal concepts on the one hand (e.g. a definition) and derivative or situative legal concepts on the other (e.g. abuse). Any confusion of the two types may result in methodological and/or logical errors (e.g. circular reasoning, cum hoc ergo propter hoc, etc.). Pursuant to the laws of logic, treating a derivative legal concept like a genuine legal concept presupposes that the latter already exists. Or in other words: the exception is determined by the general principle. The difference between the two types is that genuine legal concepts are exogenous, whereas derivative or situative legal concepts are endogenous in that they are derived from genuine legal concepts. While both types typically trigger the same legal consequences, they are nevertheless different from each other.

Example 8: A shareholder loan can only be treated like a dividend, if the understanding of what a dividend is already exists. The shareholder loan may be treated like a dividend but still remains a loan.

For these reasons it must be clear whether a particular criterion of a provision or term either affects the genuine legal concept itself (fact) or merely employs its legal consequence analogously (notion). The following illustration visualises this understanding:

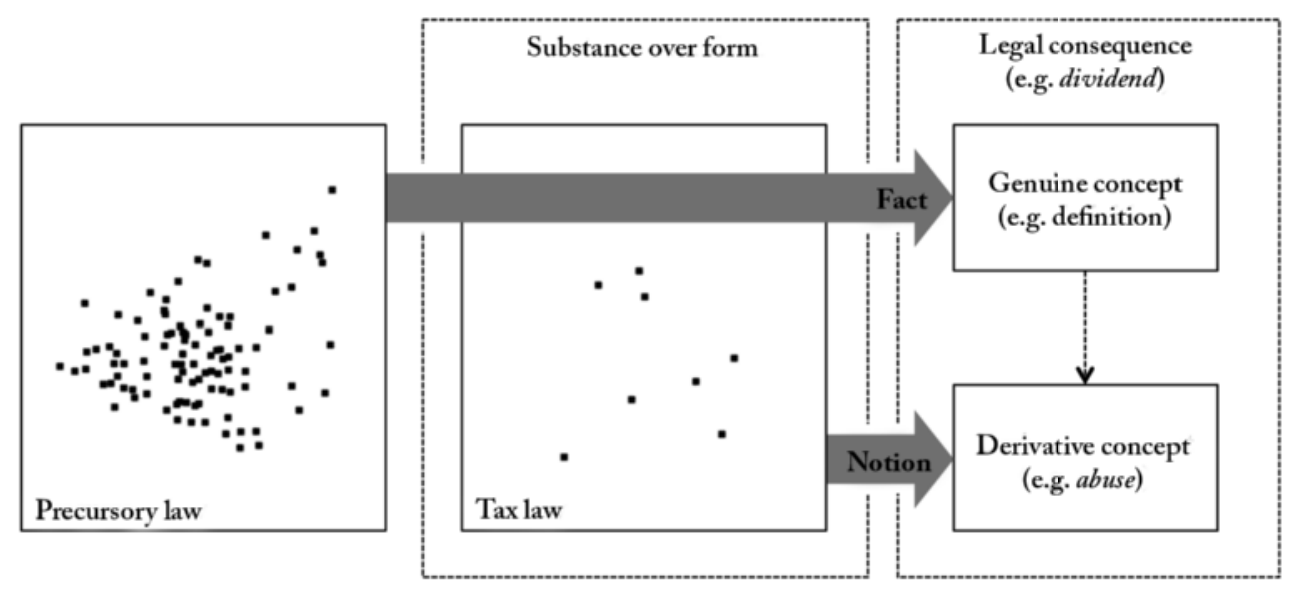

- Criterion / attribute

Illustration 2: Genuine and derivative legal concepts under the substance over form principle

More challenging than the abstract need to distinguish abusive and non-abusive concepts is, however, the identification or location of the concrete point or reference at which a particular legal criterion of a provision or term is clustered into the one concept or the other. The assessment reference to draw this red line can often not be the purpose, intention or function of the respective provision or term. While it should be possible to grasp the purpose, intention and function of each legal provision or term in the OECD MTC by way of 
interpretation, it seldom reveals whether it is intended to impact a genuine legal concept as such or to merely trigger its legal consequence ${ }^{281}$. The answer may be easy in cases where a provision or term recurs to another one or is explicitly worded as a notion. But it can be challenging in cases where the reason for the provision or term is to complement another one, especially where both terms are embedded into the same provision.

Example 8 (continued): It may be ambiguous whether the reclassification of the shareholder loan into "functional equity" is intended to impact the genuine legal definition of a dividend as such or to merely trigger its legal consequence.

Example 9: It may be ambiguous whether penalty charges for late payment pursuant to Art.11(2) OECD MTC are not considered interest by excluding them from its genuine legal definition or whether they are considered interest but merely excluded from its legal consequence ${ }^{282}$.

The selection of an appropriate assessment reference to draw a common line in the sense of "one size fits all" is even more difficult in the treaty context. As stated before, a particular provision or term of the OECD MTC must be capable of dealing with terms and meanings in multiple jurisdictions ${ }^{283}$ which employ diverse genuine and derivative legal concepts themselves. A particular criterion in the OECD MTC may be regarded as part of a genuine legal concept (e.g. a definition) by one jurisdiction but as part of a derivative or situative legal concept (e.g. abuse) by another jurisdiction, because they are different closed-end systems ${ }^{284}$.

Example 9 (continued): Pursuant to their respective domestic tax law systems, one jurisdiction may consider penalty charges for late payment still a part of the genuine interest definition, while another may see such charges as an anti-abusive provision.

75 This problem leads to the philosophical issue of what, at a global scale, is considered as "normal". This question is far too general and its answer so extensive that a satisfactory answer cannot be given here. With respect to the scope of this study, according to which the concept of treaty abuse shall not be analysed in more detail ${ }^{285}$, it is sufficient to hold the following key points:

(1) It follows from the legality principle ${ }^{286}$ that any concept of abuse must be made explicitly and in written form $^{287}$, i.e. may not be deduced by way of interpretation and particularly not by analogy. The reason is that "abuse begins exactly where the art of interpretation starts to fail" 288 .

(2) From the fact that concepts of substance are subsequent matters requiring additional qualifying elements within the OECD MTC itself ${ }^{289}$ it can further be concluded that there is no space for any treaty abuse where the OECD MTC adopts terms from precursory fields of law. This also includes abusive concepts

\footnotetext{
281 Similarly: Hensel, Albert in Paul Krüger, p. 242.

${ }^{282}$ French Conseil d'État, judgement ref. 215124, 2001.

283 See par. 19 et seqq.

284 See par. 18.

${ }^{285}$ See par. 10.

286 See par. 71.

${ }^{287}$ Hensel, Albert in Paul Krüger, p. 223 - 247 and 262 et seq., comprehensively and in detail deducing and justifying this aspect as well as systematically distinguishing and explaining the other legal principles and their incapability of constituting anti-abuse concepts.

${ }^{288}$ Hensel, Albert in Paul Krüger, p. 244 et seq. (translated by the author).

289 See par. 72.
} 
pursuant to domestic tax laws as the only precursory fields of law for a DTC ${ }^{290}$. In other words: only terms which are exclusively created by the OECD MTC or which are also employed by domestic tax law but interpreted autonomously, come potentially into question for representing an abusive concept.

(3) When breaking these terms into their particular attributes, another separation line is the distinction between misuses of legal options from misuses of economic options. Abuse is defined only as the misuse of legal options in the absence of economic reasons ${ }^{291}$. In turn, there is no space for any abuse where there is at least also a minimum of economic reasons as a falsifier ${ }^{292}$. It follows further that if the abusive concept, which is a specific and more restrictive use case, already fails due to economic reasons, the general and less restrictive substance over form principle must fail even more. ${ }^{293}$ That is why the two concepts are necessarily related in such a way that the specific use case of abuse replaces the general substance over form principle instead of subordinating to it. The general substance over form principle is no "fall-back" for the specific concept of treaty abuse in the sense of a residuary provision. Or in other words: abuse is constituted by distinct qualifiers going beyond the general substance over form principle. As a consequence, attributes of a term with a multi-purpose or ambiguity of serving both the abusive and the non-abusive function nevertheless belong only to the latter. Where a mixed case does not - in its entirety - outweigh the attributes of a term towards abuse, it is typically split up quantitatively into an abusive part and a non-abusive part.

Example 8 (continued): The shareholder loan may be quantitatively disaggregated into a nonabusive part to the extent that it is still at arm's length (i.e. interest) and the remainder as an abusive part (i.e. dividend).

As a consequence, attributes of terms not unambiguously belonging to the abuse concept require a cautious invocation of the substance over form principle. Or in other words: in cases of doubt, in favour of the legal form.

\subsubsection{Limitations of the genuine substance over principle}

The previous analyses have explained the principal necessity of delimitating and carving-out the specific aspect of treaty abuse from the general concept of substance over form. In the following chapters the remaining genuine legal concept of substance over form will be analysed in order to identify those general guidelines indicating the weighting of substance or form for particular attributes of financial instruments. In this context, some comments ${ }^{294}$ may initially be suggest applying the substance over form principle in a particularly progressive manner to financial instruments as a specific pattern or box of transactions. The argument behind this is that they are exceptionally flexible by allowing constructions and combinations in a way that any specified set of discrete economic attributes can be replicated or separated in a variety of legal forms at the free disposition of the contracting counterparties. ${ }^{295}$ That is why financial instruments in particular were suspected of eliciting to tax planning and tax avoidance. However, not only would it in practice be prejudicial

\footnotetext{
290 See par. 21.

291 Jieyin Tang, substance vs. form, sec. 3.1.; Hensel, Albert in Paul Krüger, p. 277.

292 Argumentum e contrario.

${ }^{293}$ Argumentum a minori ad maius.

${ }^{294}$ Warren, Alvin C. Jr., Financial Contract Innovation and Income Tax Policy, Harvard Law Review 1993, Vol. 107, Issue 2, p. 465.

295 Sven-Eric Bärsch, p. 82; OECD, ST/SG/AC.8/2001/CRP.8, p. 2 and 25, par. 89; Duncan, James A., Tax Treatment of hybrid Financial Instruments in cross-border Transactions - General Report, Series IFA Cahiers 2000, Vol. 85a, p. 21.
} 
at worst and impossible at best to find financial instruments which do not at least have economic (non-tax) purposes as well ${ }^{296}$. But also in theory, such a progressive approach was flawed: it is the legal form which gives a financial instrument certain attributes (e.g. default or credit or solvency or liquidity risk, hereafter referred to as "default risk" in general and "credit risk" for debts) and therefore significant features of its individual economic substance or profile ${ }^{297}$. In addition, even more important than these technical arguments is it to hold that no indications can be found in the OECD MTC for such a specific pattern or box for financial instruments. Instead, the OECD MTC is generally based on a classification of asset and income types or schedules (vertical position-by-position approach) ${ }^{298}$, regardless of whether or not they arise from financial instruments ${ }^{299}$ (horizontal pattern approach). That is why those comments in favour of a progressive application of the substance over form principle to financial instruments are intended to be understood in a normative or tax-political rather than a descriptive or interpretative way. In other words: any normative need for future action or abstract considerations on tax policies, which may be motivated by the comparatively low frictions of financial instruments, is not the same as and incompatible with the descriptive interpretation and application of the existing OECD MTC ${ }^{300}$.

77 Instead, the position could be taken that financial instruments, including "classic" financial instruments such as shares or straight bonds ${ }^{301}$, are based on or derived from the value of something else ${ }^{302}$ and therefore are predominantly evidence of relative legal claims ${ }^{303}$. In other words: "It is these contractual rights, not the economic substance that make financial instruments differ from each other" ${ }^{\text {"304, }}$, so that "an effort to apply the economic substance principle to 'everything' will in effect cause it to apply to nothing" 305 . It appears that this difference has also been recognised by the IAS/IFRS. Although applying substance over form as the general principle for all assets ${ }^{306}$ including financial instruments ${ }^{307}$, the IAS/IFRS nevertheless require a contract ${ }^{308}$ as a necessary minimum condition (conditio sine qua non) ${ }^{309}$. Statutory or otherwise public financial assets and

${ }_{296}$ Jieyin Tang, substance vs. form, sec. 3.1., with further citations; OECD, ST/SG/AC.8/2001/CRP.8, p. 31, par. 116; Duncan, James A., Tax Treatment of hybrid Financial Instruments in cross-border Transactions - General Report, Series IFA Cahiers 2000, Vol. 85 a, p. 22 et seq.; Ferguson, Bradford L., The Rationales for the Rules: How to think about Derivatives in the Tax World, Taxes: The Tax Magazine 1994, Vol. 72, Issue 12, p. 998.

${ }^{297}$ Circular reasoning. David Hasen, p. 408 et seq., 445 and 469; Ceryak, David V., Using Risk Analysis to Classify Junk Bonds as Equity for Federal Income Tax Purposes, Indiana Law Journal 1990, Vol. 66, Issue 1, p. 282.

298 See par. 59.

${ }^{299}$ Jieyin Tang, substance vs. form, sec. 5.2.; IFA, 54th IFA Congress, Munich 2000 Summaries of Discussion on Subjects I and II, Bulletin for International Taxation 2001, Vol. 55, No. 2, p. 82.

300 See par. 15.

301 See par. 56.

${ }^{302}$ Huang, Peter H., A Normative Analysis of New Financially Engineered Derivatives, Southern California Law Review 2000, Vol. 73, Issue 3, p. 503 et seq.; Plambeck, Charles T. / Rosenbloom, H. David / Ring, Diane M., Tax aspects of derivative Financial Instruments - General Report, Series IFA Cahiers 1995, Vol. 80b, p. 661; Baer, Robert, Understanding Derivatives and Financial Instruments, Taxes: The Tax Magazine 1994, Vol. 72, Issue 12, p. 930.

303 OECD, ST/SG/AC.8/2001/CRP.8, p. 14, par. 31 et seq.; Anthony Polito,p. 772 et seq.; Plambeck, Charles T. / Rosenbloom, H. David/Ring, Diane M., Tax aspects of derivative Financial Instruments - General Report, Series IFA Cahiers 1995, Vol. 80b, p. 660; Shaviro, Daniel, Risk-Based Rules and the Taxation of Capital Income, Tax Law Review 1995, Vol. 50, Issue 4, p. 657 et seq

304 Jieyin Tang, substance vs. form, sec. 5.1.

${ }^{305}$ David Hariton, substance, p. 34.

306 IAS / IFRS Framework 4.44

${ }^{307}$ IAS 32.15 and 32.18 .

${ }^{308}$ IAS 32.11 and 32.13 .

${ }^{309}$ Haufe, IFRS, p. 1647, par. 3, and p. 1665, par. 48; Nguyen, Tristan, Bilanzielle Abbildung von Finanzderivaten und Sicherungsgeschäften: Hedge Accounting nach HGB und IAS / IFRS, Munich, 2007, p. 23. 
liabilities are not considered a contract in this sense ${ }^{310}$, which might give rise to differences between IAS/IFRS and the OECD MTC. However, the explicit reference to a contract is nevertheless an unmistakable indication of the legal form as the baseline for financial instruments. The author shares this view, which is why a first interim conclusion for the further course of this study is that the existence of financial instruments as an asset or transaction requires a cautious invocation of the substance over form principle $^{311}$.

78 As regards aspects of risk, it was stated on the one hand that even such economical or mathematical parameter as risk could principally be interpreted in a legal way ${ }^{312}$, on the other hand it could be the legal form which gives a financial instrument certain risk attributes ${ }^{313}$. Although such legal risk attributes may be subject of another financial instrument (e.g. an insurance or credit "derivative"), this other financial instrument in itself bears new legal risks ${ }^{314}$. As risks cannot be resolved but only transferred or re-allocated ${ }^{315}$, it is this legal transfer that is causing new legal risks and makes the idea of "resolving legal risks" even more doubtful (i.e. both self-contradiction and circular reasoning). This is why transferring legal hazards is methodologically not a matter of risk but rather of aggregation and disaggregation ${ }^{316}$. According to the author's point of view, the question to which extent the substance prevails over the form must therefore depend to a considerable extent on the source or origin of the risk. The more a risk is rooted in the relationship to the contracting counterparty as the subject, which the taxpayer is legally related with (i.e. the existence of financial instruments as an asset or transaction ${ }^{317}$ ), the more the focus must naturally tend to the legal form. This should not be misunderstood prejudicially, in that the internal risk from the financial instrument is to be split up into its separate components or aspects (e.g. multiple credit risks of serial contracting parties), which is the subject of section 2.4.5. It only means that the external risks are to be typified or allocated (e.g. credit risk versus market risk). Apart from that, the focus must naturally tend more to the economic substance. As a consequence, an occurrence contractually agreed as uncertain but in actuality either almost certain or virtually impossible to materialise cannot be considered a risk ${ }^{318}$.

79 Within the scope of this study ${ }^{319}$, aspects with regard to the payment profile of financial instruments lead first of all to realisation issues and to subjacent questions on the nature of an income tax. In the context of the OECD MTC, which does not only apply to taxes on income but also to those on capital ${ }^{20}$, this materialises in the systematic distinction between income pursuant to chap. III of the OECD MTC and capital pursuant to chap. IV of the OECD MTC. This fundamental question touches the theory of tax types and cannot be examined in more detail here. Instead, it is sufficient to hold: while the former "fruit and tree doctrine" 321

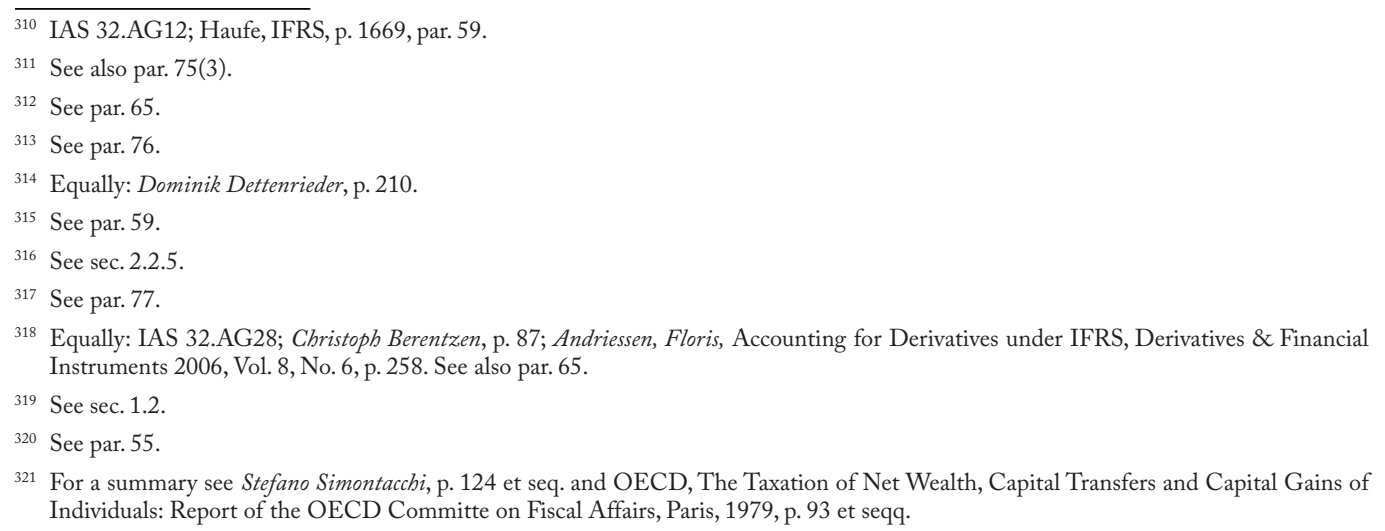


revolved around the axiomatic distinction between income and capital gains (i.e. the asset as the source of that income), the actual Schanz-Haig-Simons concept ${ }^{322}$ rather calls for common grounds between the two. If the existence of financial instruments as an asset already requires a cautious invocation of the substance over form principle $^{323}$, this must be even more true for the existence of the income or transaction itself ${ }^{324}$. The reason is that the asset as the source requires and implies the income or transaction ${ }^{325}$. Accordingly it is the law which splits economic capital or wealth into legal capital and legal income. That is why for the initial determination of whether or not there is a payment, the legal form must play a decisive role. For the subsequent question of what may be considered a payment or not (e.g. payments in kind), however, the economic substance is of higher importance.

80 In terms of rights and obligations from financial instruments as another field of possible criteria for the classification of financial instruments, it is beyond question that the legal form is of essential importance for the way of interpretation. This follows directly from the preceding findings ${ }^{326}$ that the substance over form principle can methodologically only apply in an evaluative way to the abstract interpretation of the OECD MTC as the tax law itself and to the case-by-case subsumption of facts or attributes as the results from precursory fields of law, but can never touch these facts or attributes themselves. This is why a provision or term in the context of tax law, which picks up a wording from a precursory field of non-tax law, may be understood synonymously as long as there are clear indications that its economic interpretation demands another meaning. For this, the mere purpose, intention and function of the tax law are not sufficient ${ }^{327}$. Or in other words: "Considering [...] a 'factual obligation' is close to nonsense" 328.

81 Finally, as regards aspects of time, at a first glance it seems impossible to interpret such physical parameters in different ways. However, some financial instruments (e.g. demand deposits, short-term call money, netting agreements, perpetuations, etc.) illustrate that time may also be defined formally, perhaps as a potential or theoretical feasibility to legally terminate the transaction at any time. This raises, for instance, the question as to whether or not a period being contractually agreed but which virtually never comes into effect can be considered a duration. The issue bears a nexus with the aspect of temporal aggregation and disaggregation ${ }^{329}$ : it strongly depends on the question whether such novation by way of expiry or renunciation of the formal termination right constitutes a new financial instrument (substitution) ${ }^{330}$. In other words: aspects of time are interdependent with the financial instrument's existence as such, bearing an inextricable nexus with each other in a reciprocal relationship. From the finding ${ }^{331}$ that the existence of financial instruments tends to

\footnotetext{
322 "Income is the money value of the net accretion to one's economic power between two points of time." (Haig, Robert Murray, The Federal Income Tax, Columbia University Press, New York, 1921, p. 7)

323 See par. 77.

${ }^{324}$ Argumentum a maiore ad minus.

325 See par. 53 et seq.

326 See par. 72.

327 Hensel, Albert in Paul Krüger, on p. 241 et seq. accurately denying a concept of "fiscal economic terms" (translated by the author), and on p. 242 and 264 summarising that tax law cannot be triggered by economic but only by legal facts, in that the former must be transformed into the latter.

328 Gutmann, Daniel in Michael Lang, beneficial ownership, p. 343. See however the term constructive obligation in IAS 37.10, which remarkably does not apply to financial instruments (Haufe, IFRS, p. 1649, par. 9).

329 See sec. 2.2.5.

${ }^{330}$ Similarly: IFRS 9.BC6.334.

331 See par. 77.
} 
follow the form rather than the substance, it follows in the author's view that aspects of time had to be basically interpreted pursuant to domestic tax law as well. Ergo, the principle of substance over form does not apply to this extent ${ }^{332}$. However, aspects of time become particularly important in interaction with other aspects $^{333}$. That is why these other aspects, including their relative importance and intensity, are to be taken into particular consideration for the question to what extent the substance may eventually still prevail over the form ${ }^{334}$.

Example 10: The time lag between the legal commitment and the effective settlement might be relevant for distinguishing spot and forward transactions ${ }^{335}$. The time period for transferring assets or partial rights temporarily might be relevant for determining or allocating ownership. The timing characteristics between two or more transactions or components might be relevant for aggregating or disaggregating them. The duration of a transaction might be relevant for its classification.

\subsubsection{Conclusions}

82 The purpose and objective of this section was to identify general guidelines indicating the applicability and scope of when, where and to what extent the aspect of substance prevails over the aspect of form for particular fields of attributes of financial instruments. ${ }^{336}$ The findings have, on the one hand, validated the natural intuition that fields of attributes determining legal states as the legal building blocks of financial instruments (e.g. rights and obligations) mainly follow the form. In contrast, fields of attributes economically assessing the results from these legal states (e.g. risk) mainly follow the substance. On the other hand, there are fields interacting with both aspects (e.g. time). A particular criterion of a provision or term from such a field must be interpreted on an individual basis. Finally, this section has disentangled the interdependency between the legal form and the economic substance in both methodological ways of applying the tax law: the case-by-case assessment or subsumption of facts or attributes from precursory fields of law (e.g. risk profile by legal form) and the abstract interpretation of the OECD MTC as the tax law itself (e.g. "fiscal economic terms").

\subsubsection{Aggregation versus disaggregation}

\subsubsection{Preliminary remarks}

83 The purpose and objective of this section is to identify general guidelines indicating the principal applicability and to determine when, where and to what extent financial instruments which imply the transactions ${ }^{337}$ shall be either aggregated or disaggregated under the OECD MTC, or neither. Starting with the circumscription of the terminological understanding and scope of the two schemes, the section proceeds with the introduction of a theoretical base model for this study of a total disaggregation into options. Then, some first conclusions are drawn from this base model with regard to the specific aspect of aggregation. This done, the section

\footnotetext{
332 Contrary: IFRS 9.B5.5.39, applying in so far a more progressive substance over form principle at least to some particular types of undrawn commitments, which is however due to the IAS/IFRS-specific and thus non-transferrable purposes.

333 Similarly: Wheeler, Joanna in IBFD Commentaries on Time in Tax Treaties, sec. 5.

334 See also par. 75(3).

335 Appendix to IFRS 9, regular way purchase or sale.

336 See par. 72.

${ }^{337}$ See par. 53 et seq.
} 
continues with an in-depth analysis of both the IAS/IFRS and finance theory in order to draw further conclusions from them in regards to disaggregation. The final conclusions bring all these aspects together.

\subsubsection{Definition and scope}

84 Aggregation - also referred to as "integration", "amalgamation" or "bundling" - means the conjoined or pooled treatment of more than one financial instrument or transaction as one consolidated unit according to its economic substance (i.e. typically the predominant component ${ }^{338}$ ). As the logical complement, disaggregation - also referred to as "bifurcation", "fragmentation" or "unbundling" - means the breaking or deconstruction of one financial instrument or transaction into its qualitative components and separate treatment according to their economic substance. Alternatively, disaggregation can also be understood in the quantitative sense of a proportion or layer of the entire financial instrument ${ }^{339}$ (i.e. a proportion or layer of all its qualitative components ${ }^{340}$ ), which is however not the primary focus of this study.

85 On the one hand, both schemes of aggregation and disaggregation are expressions of, and therefore apply only to, the extent of the substance over form principle. As such, they actually ignore the legal form ${ }^{341}$ and can be dealt with only on the treaty level. Especially the disaggregation scheme finds its systematic justification in treating a combination of financial instruments or transactions similarly as if these were held or realised separately ${ }^{342}$. On the other hand, the approach of aggregation and disaggregation can be understood in two ways: in a narrow sense it means the composition or decomposition of "derivative" financial instruments (e.g. structured products) or transactions (e.g. composite options strategies) and their separate or consolidated treatment. In the broader sense it refers to the interpretation of particular legal characteristics of "classic" financial instruments such as shares or debt-claims. The former is a methodology for the case-by-case assessment or subsumption of factual attributes in order to concretely apply the law (i.e. refers to the object of the legal issue). In contrast, the latter is a methodology for identifying the legal attributes in order to abstractly interpret the law (i.e. refers to the target of the legal issue) ${ }^{343}$. These boundaries are blurred, since another objective of the interpretation is to determine the legal object. Illustrated by an example, "hybrid" financial instruments coalesce both the applicative and the interpretative aspect in themselves. However, for the further course of this study it is sufficient to hold, but also important to emphasise, the principal different ways of understanding the general approach of aggregation and disaggregation: aggregation and disaggregation in the narrow sense are best practices and pre-steps in order to prepare the case for the subsequent interpretation by way of aggregation and disaggregation in the broader sense ${ }^{344}$. The IFRS seem to make this distinction as well: the applicative aspect is subject of IFRS 7 and $9^{345}$, whereas the interpretative aspect is subject of a

\footnotetext{
338 Duncan, James A., Tax Treatment of hybrid Financial Instruments in cross-border Transactions - General Report, Series IFA Cahiers 2000, Vol. 85a, p. 30.

339 IFRS 9.B6.3.16.

${ }^{340}$ For an overview see Dominik Dettenrieder, p. 132 et seqq.

${ }^{341}$ Equally: IAS 32.BC22; Diana Doege, p. 48. See also par. 77 et seqq.

${ }^{342}$ David Weisbach, p. 507 et seqq.; IAS 32.BC29; critically: Jieyin Tang, bifurcation or integration, sec. 5.1.

343 See par. 72.

344 "Although the debate has been framed in theoretical terms, it generally has turned on practical considerations. The case has not been made on normative grounds for the theoretical superiority of either a complete bifurcation or integration approach." (Deborab Huffman Schenk, equity derivatives, p. 580).

345 See par. 46(1) and 46(3).
} 
fundamental research project in the context of the IFRS framework ${ }^{346}$. While the latter methodologically applies in any case, the predominant question here is whether or not the financial instrument as the legal object is to be composed or decomposed. The difference is clarified by the example of a straightforward share and a structured product or hedge, which are all objects of the legal problem of classifying them into the distributive articles of the OECD MTC. Interpreting these provisions abstractly raises the same questions of analytically and/or contextually identifying their legal attributes (i.e. the aggregation and disaggregation in the broader sense). However, applying these provisions concretely to the structured product and the hedge seems - in contrast to the straightforward share - to raise the particular question of whether or not it has to be composed (hedge) or decomposed (structured product) and treated respectively.

86 In this study, aggregation and disaggregation are understood in the narrow sense. For the further course the applicative or preparatory aspect of aggregation and disaggregation in this narrow sense is analysed in this section, whereas the interpretative aspect of aggregation and disaggregation in the broader sense is subject of sections 2.4 and 3. The following illustration visualises this understanding:

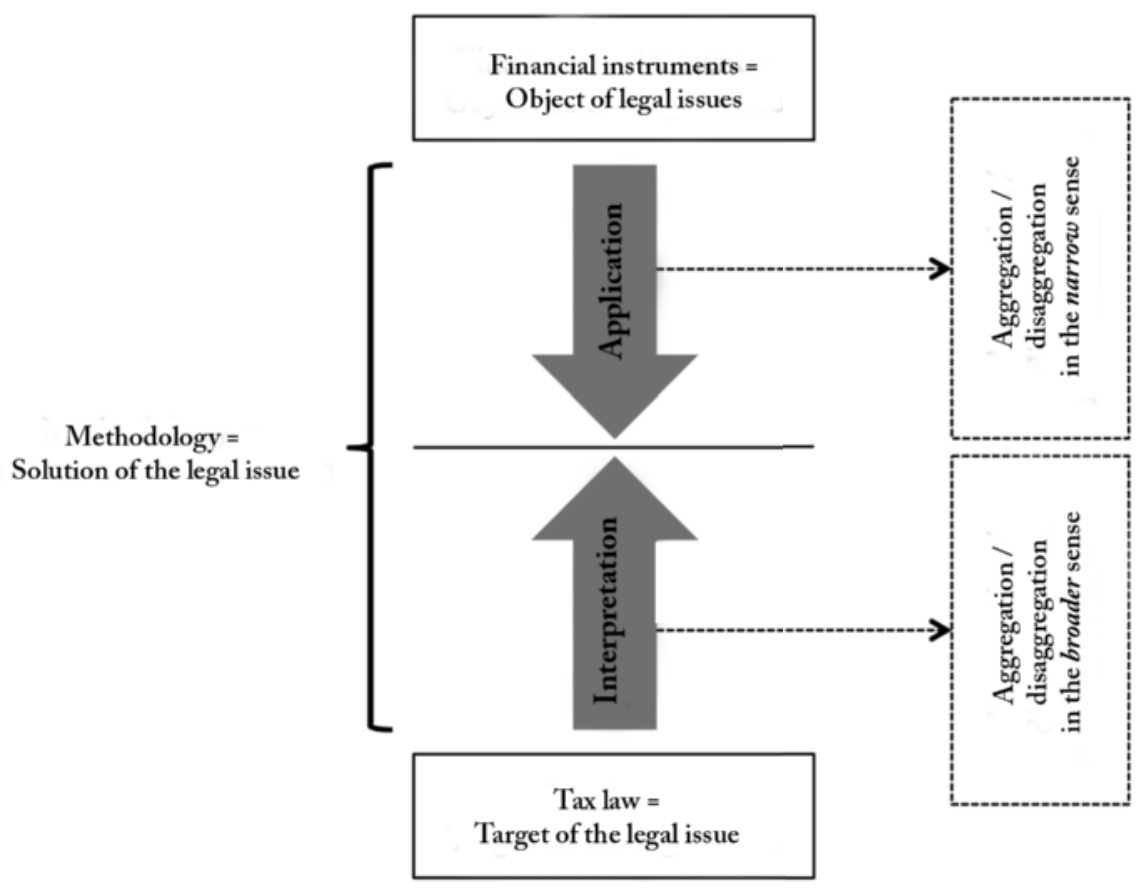

Illustration 3: Aggregation and disaggregation in the narrow versus in the broader sense

87 The common method of aggregation and disaggregation (in the narrow sense) is drawing analogies. This is why their scopes are naturally limited: as a matter of principle, analogies always require and presume

346 See par. 47. 
benchmarks, which can themselves not likewise be derived by analogies. This leads to the problem what such benchmark shall be. Aggregation and disaggregation are best practices ${ }^{347}$, but in practice any financial instrument is likewise object of the same legal question that still needs to be answered by drawing that analogy. That is why the distinction between genuine and derivative legal concepts ${ }^{348}$, which refer only to the target of the legal issue, may not lead to the conclusion that there are also genuine and derivative objects of that legal issue. By the example of a straightforward share and a structured product or hedge ${ }^{349}$, the pre-classification of the former into some kind of benchmark ("genuine financial instrument") and of the latter into something other ("derivative financial instrument") would be a circular reasoning. Starting from the same legal problem of classifying both into Art. 10(3), 11(3), 13(5) or 21(1) OECD MTC, the one does not differ in any way from the other. In other words: while the distinction of the income types of financial instruments is real, the distinction of "classic", "hybrid" 350 and "derivative" 351 financial instruments is an illusion. Nevertheless, this classification into "classic", "hybrid" and "derivative" financial instruments is an established part of the common technical terminology and shall therefore also be used in this study. It is, however, important to keep in mind that the benchmark for drawing analogies from "derivative" and "hybrid" to "classic" financial instruments is not more than an interpretational imagination. Rather, aggregation and disaggregation as a special matter of applying the law is equally relevant for all three classes.

88 The schemes of aggregation and disaggregation are controversial ${ }^{352}$. Apart from practical complications, this is because the specific nature of financial instruments has given rise to fundamental conceptual difficulties ${ }^{353}$ :

(1) Due to their methodological limitations, aggregation and disaggregation are incapable of substituting or even going beyond the interpretation of the tax law in order to alleviate its structural weaknesses ${ }^{354}$. For this reason, they would add no value to the actual problems.

(2) The flexibility and multiplicity of financial instruments allowed the replication and (re-)combination of an infinite or at least non-unique number of not only legal but also economic attributes. This made it impossible to find an equivalent in order to draw an analogy for a given financial instrument. ${ }^{355}$

(3) These economic attributes could even be different for one and the same financial instrument, depending on the context. For instance, the position in a particular financial instrument might be a speculative investment by one taxpayer or point in time but part of a hedge strategy by another ${ }^{356}$. While there are no

\footnotetext{
347 See par. 85 .

348 See par. 73.

349 See par. 85.

${ }^{350}$ In contrast, IFRS 32.28 .

${ }^{351}$ In contrast, IFRS 32.AG15, Appendix A to IFRS 9 and IFRS 9.BA1 - 9.BA5.

${ }^{352}$ For a comprehensive overview see David Weisbach, p. 512 et seqq.

${ }^{353}$ See par. 1 et seqq.

354 Warren, Alvin C. Jr. Financial Contract Innovation and Income Tax Policy, Harvard Law Review 1993, Vol. 107, Issue 2, p. 477; Edward Kleinbard, financial innovations, p. 1355.

355 Brunson, Samuel D., Elective Taxation of Risk-Based Financial Instruments: A Proposal, Houston Business and Tax Law Journal 2007, Vol. 8, Issue 1, p. 11 et seq.; OECD, ST/SG/AC.8/2001/CRP.8, p. 29 et seq., par. 108; Duncan, James A., Tax Treatment of hybrid Financial Instruments in cross-border Transactions - General Report, Series IFA Cahiers 2000, Vol. 85a, p. 30; David Weisbach, p. 512; Kau, Randall Koon Chuck, Carving up Assets and Liabilities - Integration or Bifurcation of Financial Products, Taxes: The Tax Magazine 1990, Vol. 68, Issue 12, p. 1007.

${ }^{356}$ Haufe, IFRS, p. 1653, par. 20.
} 
general tools available to cope with context-specific analyses (aggregation), the available analytical tools (disaggregation) are insensitive to that context. 357

(4) Both schemes created results, which are not economically comparable with the original financial instruments ${ }^{358}$. They ignored the fact that, pursuant to economic organisation theory, the mere existence of the original financial instrument is proof enough that it cannot be replicated more efficiently (synergetic effects) $)^{359}$.

(5) The disaggregation scheme was principally infinite in that there is no limit at which it ought to be stopped. ${ }^{360}$ The same may be true in the opposite way, in that the highest level of aggregation is eventually the taxpayer.

(6) Despite the components or consolidated units in which the financial instruments are to be transformed by the two schemes, in finance theory there were also various methods or techniques taking different assumptions and therefore leading to different results. ${ }^{361}$ In addition, practical considerations with regard to the operational complexity beg the question whether the benefits actually exceed the costs. ${ }^{362}$

\subsubsection{Options as building blocks}

89 As stated above, these issues occur due to the fact that financial instruments can be converted or replicated in multiple ways without changing their economic and potentially also their legal features ${ }^{363}$. Apparently, taxpayers are driven economically, also in tax matters. That is why emphasising that the taxpayer might also be interested in the legal profile of a financial instrument, was an overstatement (which is why, for instance, anti-abuse rules exist). From the taxpayer's view, law is subject and therefore subordinate to economic considerations, in that the legal features are only relevant to the extent that they impact the economic features. Economically, any position is fully and conclusively described by only two parameters: risk and return. ${ }^{364}$ Economic equivalence is therefore typically visualised by a risk-return matrix. Finance theory has shown ${ }^{365}$ that the risk-return profile of any financial instrument (i.e. a data point in that risk-return matrix) can basically be replicated or synthesised by options. In fact, there is nothing more granular than options, as they are the smallest available transactions or units containing all economic attributes to fully describe a risk-return profile. In this sense, they could indeed be called the "quarks" of finance theory ${ }^{366}$. True, on the one hand, options are themselves legal transactions and financial instruments, which can be replicated by other options (put-call parity), so that the problem of aggregation and disaggregation returns to its origin. On the other hand, risks

\footnotetext{
357 Edward Kleinbard, financial innovations, p. 1355 et seqq., noticing on p. 1358 et seq. that also "the substance-over-form doctrine can be applied to financial innovation [only (author's note)] to determine whether each component of a complex financial strategy is real but once the reality of those components has been confirmed, the substance-over-form doctrine has not been invoked to merge these separate and real components into a different synthetic financial instrument."

358 Kuhn / Hachmeister, p. 317 et seq., par. 49; IFRS 7.BC31; Edward Kleinbard, debt, p. 948.

359 Jieyin Tang, substance vs. form, sec. 3.2.1.; Achim Pross, p. 157 et seq.

${ }^{360}$ Achim Pross, p. 147; Kau, Randall Koon Chuck, Carving up Assets and Liabilities - Integration or Bifurcation of Financial Products, Taxes: The Tax Magazine 1990, Vol. 68, Issue 12, p. 1007, accurately noticing that "unlike the natural world, there are no fundamental individual particles such as quarks."

361 Achim Pross, p. 153 et seq. and 158; Jeff Strnad, conceptual framework, p. 574.

362 OECD, ST/SG/AC.8/2001/CRP.8, p. 30, par. 111; Achim Pross, p. 153 and 158.

363 See par. 76.

${ }^{364}$ Finance theory "can convert an infinite-dimensioned erratic examination of limitless factors into a two-dimensional relationship of risk and return." (Anthony Polito, p. 790).

365 Gaspar Lopes Dias, tax arbitrage, p. 3; David Hasen, p. 423; Jeff Strnad, conceptual framework, p. 574 et seq.; Anthony Polito, p. 782 ; all with further citations.

366 See footnote 360 .
} 
rooted in the underlying as the object of the option must naturally follow the economic substance rather than the legal form ${ }^{367}$. In this light, it should be permissible to conclude that the possibility of replicating an option by another option is not of any relevance, as it does not impact the economic substance. That is why options could, in other words, be said to be the building blocks for (re-)assembling or (re-)engineering any economic risk-return profile ${ }^{368}$.

90 The basic economic principle of decomposing and recomposing financial instruments by options is used in finance theory for pricing purposes ${ }^{369}$ and was recovered and discussed by domestic tax academics ${ }^{370}$ in the mid 1990s. In the theoretical context of normative tax policy making it was found that the transition of one tax pattern or box of tax law into another by way of "atomising" them with options can be used for ensuring the consistency and robustness of newly designed ("perfect") tax systems. The idea behind this was to take the total tax on all particular options as a checksum for the total tax on all patterns or boxes, which can be replicated or synthesised with these options ${ }^{371}$. True, the normative context and character of those studies is different from the descriptive and interpretative objective of this study (de lege lata) ${ }^{372}$. And obviously the OECD MTC differs considerably from domestic tax laws in many regards (e.g. purpose, system, interpretation, etc.). However, the following considerations attempt to transfer some of the findings to the OECD MTC. The intention is to draw additional insights or conclusions and to establish a maximum of inherent consistency and systematology in the treatment of financial instruments and transactions with a minimum of assumptions or preconditions.

91 As a starting point, any asset as the source of income may be understood as a continuum of actions. These actions can ultimately be decomposed and economically seen as a cloud or portfolio of multiple binary choices of the identical qualitative structure (i.e. only the quantitative values differ) for either taking or refraining from an action (long option).

Example 11: The acquisition of an asset as a continuum of actions may be decomposed into the two binary choices of (1) buying or not buying the asset and (2) paying or not paying the acquisition price.

Each of these choices has an expected return, which is the net consequence of prospected total proceeds (gain) and costs (option premium). A decision maker takes a choice depending on his subjective assessment of both consequences. The actual costs are typically certain and paid in advance, while the prospected proceeds are typically uncertain and paid in arrear, so that his assessment is influenced by the expected probability of occurrence (risk).

\footnotetext{
367 See par. 78.

368 David Hasen, p. 423.

369 IAS Board, July 2016, 5B, p. 7 et seq., par. 32.

370 See footnote 352 .

371 Achim Pross, p. 171 et seq., accurately illustrating that "disaggregation achieves the target if it becomes dispensible" (translated by the author).

372 See par. 15.
} 
Example 11 (continued): The costs for not paying the acquisition price might be a penalty. Depending on the decision maker's subjective assessment of the circumstances, he is in any case free and might decide to take this penalty (e.g. for some more important reasons). This subjective assessment is not only influenced by the amount of the penalty but also by its probability of occurrence.

In that the other decision makers behave in the same manner (i.e. long option from their perspective), they coincidently shift a higher risk to that single decision maker (i.e. short option from his perspective). This is a necessary consequence from the binary character of the choices in the sense that the one person's chance is the other person's risk. As a result, the environment influences the decision maker's assessment by eliminating and narrowing his reasonable choices (hedging long by short options), whereby the unreasonable choices nevertheless remain existent (incentive compatibility). With this model in mind, the flexibility of financial instruments merely means to arbitrarily pick and extract any particular option (long or short, a single one or a specific set, etc.) from the asset ${ }^{373}$. Not only financial or legal risks might be selected in that way but genuine business risks (e.g. a portfolio might hedge the share of a company with seasonal business with a weather "derivative") as well. The following illustration visualises this understanding:

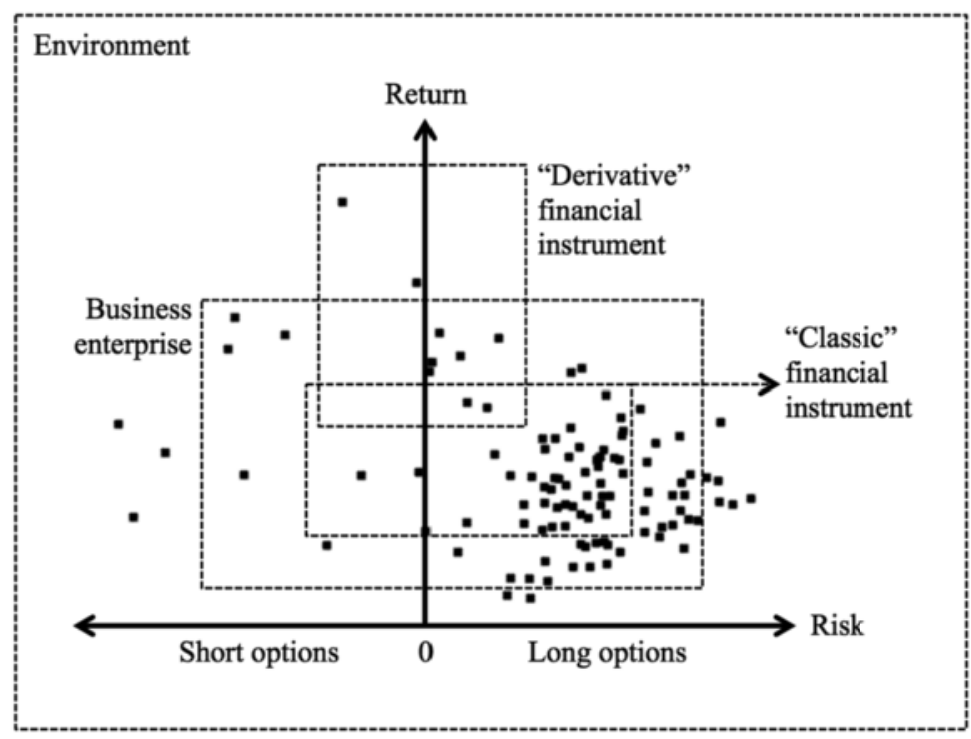

- Choice

Illustration 4: Aggregation and disaggregation in a risk-return matrix

92 The original approach of taking the total tax on all options as a checksum for the total tax on all patterns or boxes in order to ensure consistency in perfect tax systems ${ }^{374}$ drew its binary conclusion (i.e. consistent or not

\footnotetext{
373 Similarly: IFRS 9.B3.2.14; IAS Board, December 2016, 5B, p. 5, par. 16; Shaviro, Daniel, Risk-Based Rules and the Taxation of Capital Income, Tax Law Review 1995, Vol. 50, Issue 4, p. 665.

374 See par. 90 .
} 
consistent) from the quantitative analysis of the options (i.e. total tax equal or not equal). Further, the question may, however, be asked which additional conclusions can be drawn from the qualitative analysis of the options themselves. The idea behind this is the other way around: a principle capable of ensuring consistency in perfect tax systems should also be capable of analysing inconsistencies in imperfect tax systems. Given the assumption (which will be discussed in the following ${ }^{375}$ ) that the OECD MTC is not a consistent tax system, the principle of economic equivalence allows financial instruments to be flexibly converted or replicated into each other by options while maintaining their risk-return profile but with different tax implications. So far the conclusion from the original approach. However, where two financial instruments are not entirely identical (e.g. share and debt-claim), in such an inconsistent tax system their replication or synthesisation into each other by options is necessarily imperfect. It is incomplete in the way that it leaves a residuum of building blocks, i.e. excessive or missing options or both. The total net of such a residuum in terms of risk and return represents a position indicating unique differentiators of the respective financial instrument. The distinction between dividends and interest was said to be a legal rather than an economic question ${ }^{376}$, which finance theory alone cannot answer ${ }^{377}$. However, although such reverse deductions back to some legal differentiators can only be drawn through the coarse and blurry optics of economics (i.e. the two-dimensional risk-return profile of options), the approach might nevertheless allow some general guidelines ${ }^{378}$. The following illustration visualises this understanding:
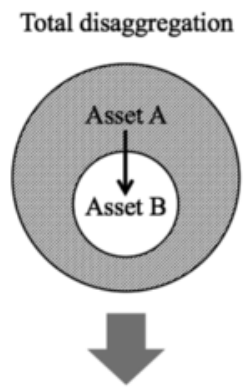

$\mathrm{B}=\mathrm{A}-$

are residual options
Total aggregation

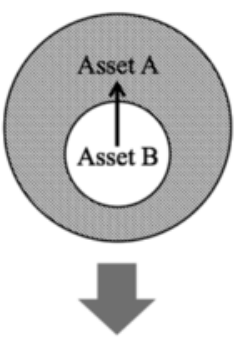

$\mathrm{A}=\mathrm{B}+$

are missing options

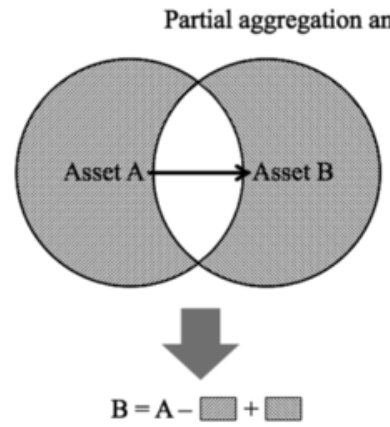

are residual options and are missing options
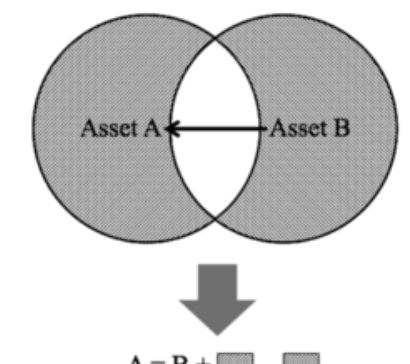

$\mathrm{A}=\mathrm{B}+\square-\square$

are missing options and are residual options

Illustration 5: Residual and / or missing options due to imperfect replication

\subsubsection{Aggregation must be applied restrictively}

93 The baseline for the specific aspect of aggregation and disaggregation is the same as for the general application and interpretation of the OECD MTC ${ }^{379}$ : the legal form ${ }^{380}$. Starting from that point, the two schemes merely

\footnotetext{
375 See par. 95.

376 See par. 56.

377 Equally: Anthony Polito, p. 792.

${ }^{378}$ Equally: Sven-Eric Bärsch, p. 82 et seqq.

379 See par. 72 and $75(3)$.

${ }^{380}$ IFA, $54^{\text {th }}$ IFA Congress, Munich 2000 Summaries of Discussion on Subjects I and II, Bulletin for International Taxation 2001, Vol. 55, No. 2, p. 81 et seq.
} 
head in opposite logical directions (i.e. aggregation as an external financial engineering versus disaggregation as an internal financial engineering). It appears therefore that aggregation and disaggregation are qualitatively identical in that the "weaknesses [...] inherent in one of these methods also will be inherent in the other" ${ }^{381}$. Consequently, the tools available for the analytical analyses of disaggregation would be principally the same and could also be used for the context-specific analysis of aggregation.

Side note: The IAS/IFRS know some techniques for aggregation ${ }^{382}$ such as micro hedging 383 (i.e. one single position), portfolio hedging ${ }^{384}$ (i.e. more than one position with similar risk profiles) and macro hedging ${ }^{385}$ (i.e. more than one position with dissimilar risk profiles) - each for both fair value ${ }^{386}$ (i.e. on asset level) and cash flow ${ }^{387}$ (i.e. on income level). In particular, they provide the concept of economic relationship ${ }^{388}$ as a possible basis for such contextspecific analysis. ${ }^{389}$ In addition, under specific conditions there is an exception from the general prohibition of aggregation ${ }^{390}$ for offsetting financial assets and financial liabilities ${ }^{391}$. The effectiveness of such right to set-off is, however, a legal matter ${ }^{392}$ and would therefore necessarily have to follow the domestic interpretation ${ }^{393}$.

94 However, as a result of the original approach ${ }^{394}$ there is a conditional difference between the two schemes in the sense of a logical one-way dependency. This one-way dependency has implications for the applicability of aggregation only and shall be explained in the following. As a result from that study ${ }^{395}$,

- a tax system was called "universal" where it specifies a tax treatment for every possible transaction (comprehensive scope);

- a tax system was called "consistent" where the total tax on all patterns or boxes is always equal (horizontal view);

- a tax system was called "linear" where the total tax on all particular options is always equal to the total tax on all patterns or boxes, which can be replicated or synthesised with these options (vertical view);

- a tax system was called "continuous" where the total tax on all patterns or boxes similarly composed is similarly high (robustness);

- linearity is the strongest condition, consistency the weakest and continuity is in between: linear tax systems are thus always continuous but non-linear tax systems are not always non-continuous. Continuous tax

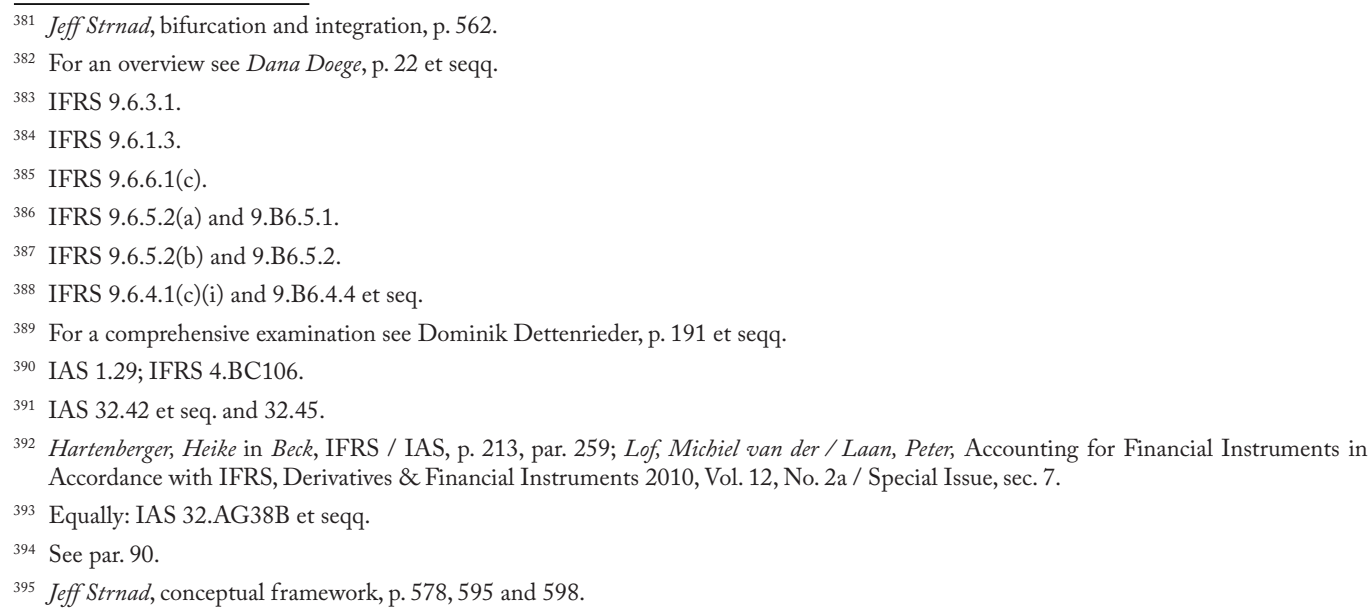


systems are always consistent but non-continuous tax systems are not always non-consistent. Consistent tax systems are not always continuous but non-consistent tax systems are always non-continuous. And continuous tax systems are not always linear but non-continuous tax systems are always non-linear.

- The following illustration visualises this understanding:

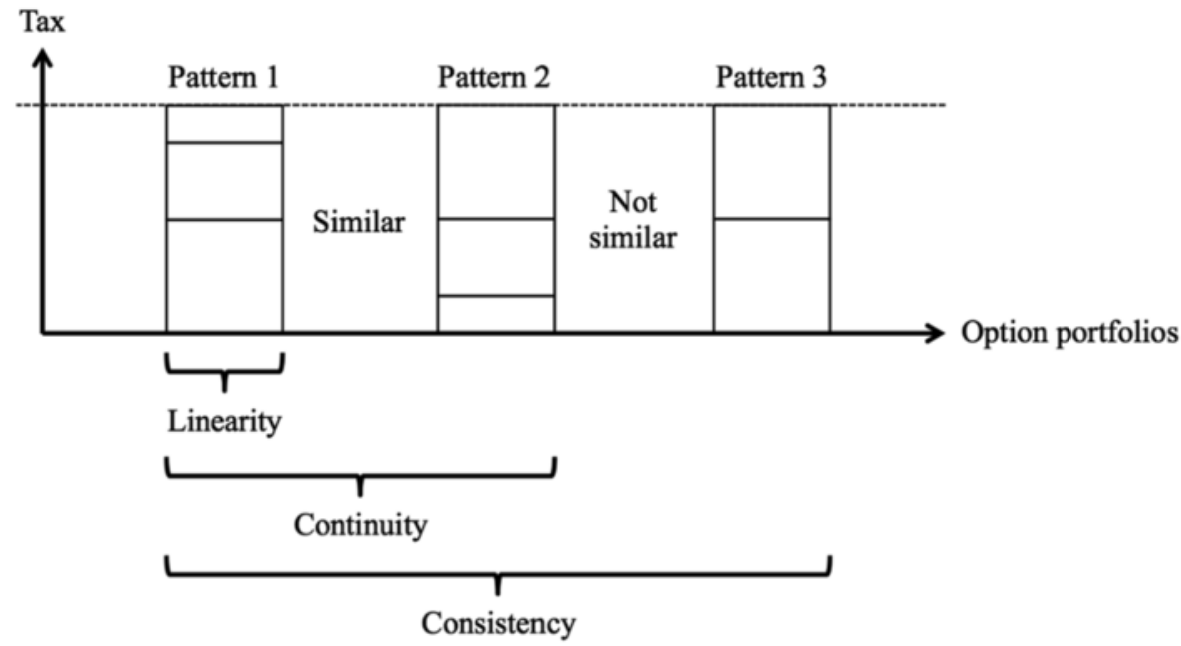

Illustration 6: Linearity, continuity and consistency of tax systems

95 It is apparent that pursuant to these definitions the OECD MTC may be universal but is neither linear (which is why the issue of aggregation and disaggregation even exists) nor consistent (e.g. the different allocation of taxation rights to the source jurisdiction pursuant to the patterns or boxes of the distributive articles). Hence, it cannot be a continuous tax system either. Continuity comes, however, into effect first and foremost in the context of aggregation ${ }^{396}$. Starting from the legal form ${ }^{397}$, only aggregation requires and presumes the contextual or situative information of what shall be in scope or not in scope of the consolidation ${ }^{398}$. In other words: only where the objects or items for such pairing of the original and the target instrument are predetermined can the missing options for replicating or synthesising the original by the target instrument be deduced by reversing the direction (i.e. conversely replicating or synthesising the target by the original instrument). Where this contextual or situative information is missing, however, an axiomatic aggregation ${ }^{399}$ is arbitrary, non-directional or "blind" and its coincidental result highly sensitive to the continuity of the tax system $^{400}$. This is because the treatment of the respective pattern is erratic in that the consolidation of the

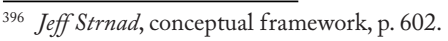

397 See par. 100.

398 See par. 88(3).

399 Pistone, Pasquale / Romano, Carlo, Short report on the proceedings of the 54th IFA Congress, Munich 2000, Bulletin for International Taxation 2001, Vol. 55, No. 1, p. 35, advocating that "integration should instead apply whenever the components of a hybrid are linked in a way that investors would not acquire them separately."

${ }^{400}$ Jeff Strnad, conceptual framework, p. 602.
} 
original financial instrument with one set of options leads to a significantly different treatment than the consolidation of the same original financial instrument with another set of options ${ }^{401}$.

Example 12: For the total aggregation in Illustration $5^{402}$ the information that asset A shall be replicated or synthesised by asset B must be predetermined. Only under this condition is it possible to derive the missing options by way of conversely replicating or synthesising asset B by asset A. In contrast, the partial replication or synthesisation in Illustration $4^{403}$ of the "classic" financial instrument by the "derivative" financial instrument consolidates also some particular options (data points) from the environment. As the aggregation scheme points upward to the taxpayer as the highest level of aggregation ${ }^{404}$, at some point the question arises whether or not income or transactions from different source jurisdictions may or shall be consolidated. The possibility to establish triangular relationships is another example of the discontinuity of treaty law.

As stated above, the conclusion from that study for tax policy making was that continuity requires a highly restrained or cautious invocation of aggregation schemes in imperfect tax systems with special attention to and great care for the risks of exacerbating the distortions from the deeper and therefore inevitable inconsistencies ${ }^{405}$. From the author's point of view, this rationale can also be transferred to the interpretation of the OECD MTC. Since the OECD MTC is an inconsistent and therefore uncontinuous tax system, the possible benefits of aggregation would most likely be outweighed by the negative effects. As a first interim conclusion for the further course of this study, any interpretation towards aggregation is therefore subject to particularly strict requirements, which justifies going beyond the literal or textual interpretation only as an absolute exception. That is why a consolidation of an asset or transaction upwards from its legal form can not be justified by the substance over form principle (e.g. hedges or other composite units).

\subsubsection{What can be learned from the IAS/IFRS}

96 That said, in the following the disaggregation shall be analysed in more detail. In this respect, some commentators take the position that any splitting of financial instruments into components and their separate treatment was generally not compatible with the OECD MTC ${ }^{406}$. However, the problem is quite fundamental in that it is actually inseparable from the substance over form principle ${ }^{407}$. Even an option on one underlying as the most simple unit ${ }^{408}$ can be seen either legally as a bet agreement ${ }^{409}$ or economically as a present disposition

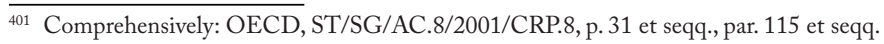

402 See p. 48.

403 See p. 47.

404 See par. 88(5).

405 Jeff Strnad, conceptual framework, p. 603 et seq.

406 Sven-Eric Bärsch, p. 107 et seq., 238 and 323, without justification; Haslehner, Werner in Klaus Vogel Commentaries 2015, p. 927, par. 91, without justification and confusing the applicative aspect of aggregation and disaggregation in the narrow sense with the interpretative aspect of aggregation and disaggregation in the broader sense (see par. 85).

${ }^{407}$ See par. 85.

408 See par. 89.

${ }^{409}$ David Hasen, p. 429. Dolan, Kevin / DuPuy, Carolyn, Equity Derivatives: Principles and Practice, Virginia Tax Review 1995, Vol. 15, Issue 2, p. 207 et seq. See also par. 70 .
} 
of future interests in that underlying, namely its contingent value appreciation ${ }^{410}$. Although the baseline is the legal form ${ }^{411}$, any treatment of the option must nevertheless face the question of whether it stops at the derivative alone (form) or goes beyond towards the underlying (substance). As regards options as the building blocks of financial instruments, this dualism is reflected by the strong interdependencies between the strike price of the option, the probability of success and the gain from the underlying ${ }^{412}$. Even when following the very formal view, the determination alone of whether that option participates in profits pursuant to Art. 10(3) OECD MTC or rather represents a sale pursuant to Art. 13(5) OECD MTC made it necessary to also consider the underlying. Any deviation from the derivative level is, however, actually a disaggregation by way of look-through ${ }^{413}$ to the underlying ${ }^{414}$. And there appears no reason why and according to which criteria "more complex" financial instruments shall be treated differently (e.g. a composite strategy of two options in one legal contract). Like the substance over form principle in general, the author takes the view that it is not a question of whether or not financial instruments are to be disaggregated but only in which scope and to what extent. As will be shown throughout the further course of this study, disaggregation is - consciously or unconsciously - actually also applied in various respects of treaty interpretation and application.

\section{Relevant IAS/IFRS provisions}

97 In this respect, the IAS/IFRS do not take a holistic approach by way of a general principle of interpretation but, rather, a casuistic approach ${ }^{415}$ by way of explicit individual regulations:

(1) In the context of a comprehensive conceptual framework project, the IAS/IFRS tackle the question of disaggregating financial instruments with characteristics of equity $y^{416}$. These are research activities with a special focus on dual-character "derivatives". The value of such instruments is solely dependent on the equity value but their form of settlement causes them to be classified as liabilities. Although these questions deal with the disaggregation of "derivative" financial instruments as well, they nevertheless point to the subjacent interpretational issue of distinguishing equity and debt (i.e. the disaggregation in the broader sense) and are therefore subject of section $2.4^{417}$.

(2) IAS 32.28 provides the separation of non- "derivative" financial instruments as a general principle. This provision takes the issuer's perspective ${ }^{418}$ and must furthermore be seen in the special context of the different purposes, intentions and functions of the IAS/IFRS ${ }^{419}$ as opposed to the OECD MTC. However, conclusions may nevertheless be drawn from its subjacent economic rationale as to the disaggregation of certain "hybrid" financial instruments.

\footnotetext{
$\overline{410}$ IAS 32.AG17 and IAS 32.AG20; Huffman Schenk, Deborah / Cunningham, Noel B., Taxation without Realization: A Revolutionary Approach to Ownership, Tax Law Review 1992, Vol. 47, Issue 4, p. 775 et seq.; David Hasen accurately adding that "the only relevant difference from an ordinary prepaid forward contract is that the option is for a contingent part of the property" (p. 427) and "Appreciation and risk of loss are characteristics of property, not property itself. Viewing an option sale as the sale of 'property' consisting solely of appreciation or liability is mistaken because it treats a feature of property - that it can increase or decline in value - as itself property." (p. 428).

411 See par. 93.

${ }^{412}$ IFRS 7.BC29. See also par. 65.

${ }^{413}$ See par. 72.

${ }^{414}$ IAS 32.AG20.

${ }^{415}$ Dana Doege, p. 39.

416 See par. 47.

417 See par. 86.

${ }^{418}$ IAS 32.AG30. See also par. 46(2).

419 See par. 45.
} 
(3) IFRS 9.4.3 provides the concept of embedded derivatives, which treats the applicative scheme of disaggregation as is understood in the narrow sense here. The provision specifies the conditions and the mode of isolating or separating "derivative" financial components from compound instruments.

(4) IFRS 9.6 deals with the specific aspect of hedge accounting, i.e. the effect of mitigating risks by using financial instruments. Hedging is primarily a concept of aggregation ${ }^{420}$. However, it may nevertheless allow conclusions on the admissibility and structuring (including disaggregation) of hedging instruments and hedging items based on the dependencies between various risks and their influencing factors.

(5) IFRS 4.10 provides the concept of unbundling (i.e. disaggregating) insurance and deposit components from compound contracts. However, the requirement ${ }^{421}$, permission ${ }^{422}$ and prohibition ${ }^{423}$ of such unbundling merely depend on practical considerations with regard to the clear and reliable quantifiability of these components rather than on qualitative ones ${ }^{424}$. Conversely, the aggregation of separated insurance and deposit contracts into one was also discussed within the scope of IFRS 4.10 but not pursued any further ${ }^{425}$. For these reasons, the provision does not provide further insights usable for this study.

\section{Transfer of relevant IAS/IFRS provisions}

98 Because the IAS/IFRS obviously have to face the same conceptual difficulties as the tax law ${ }^{426}$, they provide some general perceptions on the structural rationale. These may also be transferable to the application of the OECD MTC. I shall now attempt to do so. IAS/IFRS terminology:

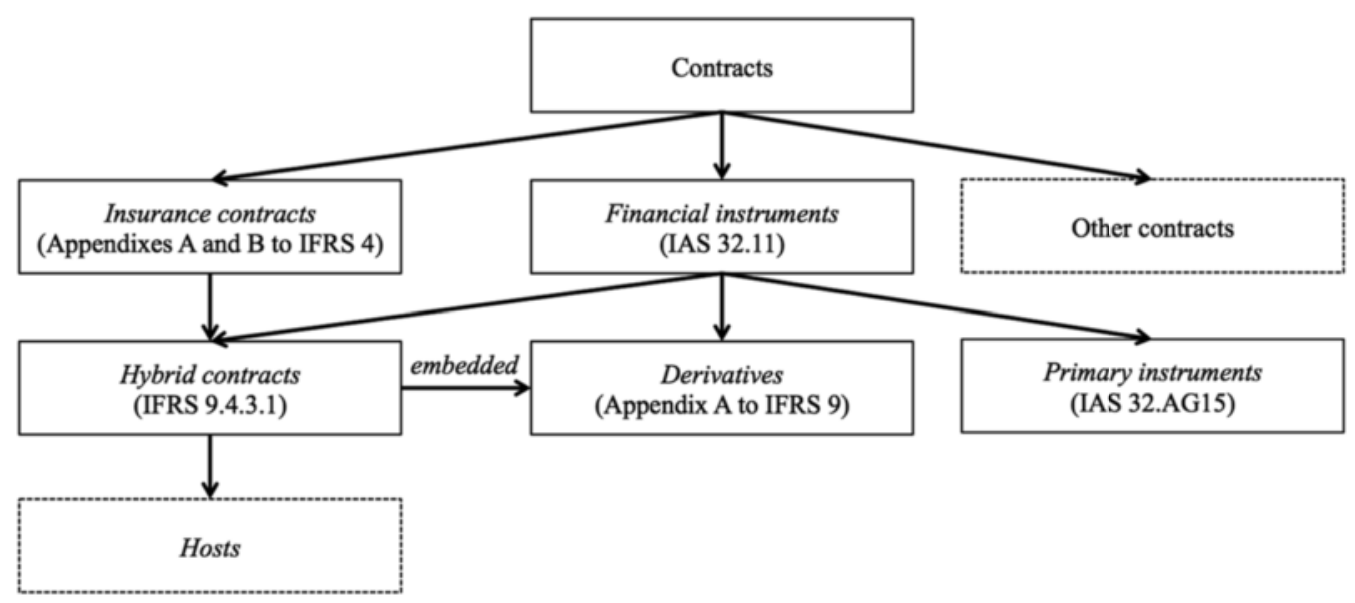

Illustration 7: IAS/IFRS terminology

\footnotetext{
420 See par. 59.

421 IFRS 4.10(a).

${ }^{422}$ IFRS 4.10(b).

${ }^{423}$ IFRS 4.10(c).

${ }^{424}$ IFRS $4 . B C 45$ et seq.

425 IFRS 4.BC54.

${ }^{426}$ See par. 88.
} 
The following list of findings is limited to IAS/IFRS regulations on disaggregation, which potentially allow universal statements by way of transferring their rationale to the OECD MTC. In addition, the IAS/IFRS provide a wide range of further similar requirements and prohibitions with regard to disaggregation. However, these are situative ${ }^{427}$ and/or IAS-/IFRS-specific (such as depending on the measurement regime, e.g. at fair value versus at amortised cost) and therefore do not allow universal statements.

(1) The IAS/IFRS limit the scope of disaggregation to financial instruments ${ }^{428}$. Namely, contracts on nonfinancial items are excluded, even where these are similarly fashioned as financial instruments (e.g. commodity options ${ }^{429}$. The subjacent rationale seems to classify the underlying actually into belonging either to real economy or financial economy ${ }^{430}$. The reason is that the contracting parties are, in effect, trading the non-financial item. Thus, the IAS/IFRS actually distinguish between primary market transactions and secondary market transactions. In the author's view, this criterion and therefore the exclusion of contracts on non-financial items from the disaggregation scheme cannot be transferred to the OECD MTC:

- Though it is true that the contracting parties are economically trading the non-financial item, this conclusion already implies and requires disaggregation (i.e. to that non-financial underlying item ${ }^{431}$.

- This is also the reason why it is inconsistent to say that, on the one hand, an option was a participation in future interests in its underlying (i.e. its contingent value appreciation) ${ }^{432}$ but was, on the other hand, distinct from it ${ }^{433}$. Instead, it is correct to hold that an option is legally distinct from its underlying (form) but economically inseparable from it (substance ${ }^{434}$. This principle is generally valid for all kinds of underlyings and therefore demands application of the disaggregation scheme, irrespective of the nature of the underlying.

- As stated before, it is illusory to draw a dividing line between "financial" and "non-financial" contracts, as it is one of their conceptual features and specific peculiarities to blur these boundaries ${ }^{435}$. That is why their distinction - such as between a gross physical settlement and delivery of the underlying and a non-physical net settlement in cash or substitutes ${ }^{436}$ - is basically ineffective, as it does not touch the fundamental economic character of the transaction.

(2) Among the financial instruments, the disaggregation is further prohibited where the host of a bybrid - taken separately - is a financial instrument itself ${ }^{437}$ (non-qualified host). However, this restriction is mainly rooted in considerations of practical simplification that outweigh the original intention of the disaggregation scheme to prevent abuse ${ }^{438}$. Further, the possibility of reutilising separated embedded derivatives for the purpose of hedge accounting finally did not convince the IAS Board. The IAS-/IFRS-specific reason is that

\footnotetext{
${ }_{427}$ Among others: IFRS 9.B4.3.5 or 9.B4.3.8.

${ }^{428}$ IAS 32.28, IFRS 9.4.3.

${ }^{429}$ Kuhn / Hachmeister, p. 771 et seqq., par. 5 et seqq.; Dana Doege, p. 18.

${ }^{430}$ IAS 32.AG20. Except where they are net settled (IAS 32.AG22).

${ }^{431}$ Circular reasoning. See also par. 96.

${ }^{432}$ IAS 32.AG17 and 32.AG20.

433 IAS 32.AG17.

${ }^{434}$ See par. 91.

435 See par. 87. Equally: IFRS 9.BC6.179.

${ }^{436}$ IAS 32.AG20 et seq.; Anna Verena Matthies, p. 51.

${ }^{437}$ IFRS 9.4.3.2 and 9.BC6.117. This was a change when transitioning from IAS 39, according to which the disaggregation of embedded derivatives was required for all assets (IFRS 9.BC4.83 et seqq.).

${ }^{438}$ IFRS 9.BC4.88 et seqq.
} 
an enhanced accuracy of the risk management reporting was considered an even less important priority of the disaggregation scheme $\mathrm{e}^{439}$. After all, this is even more illusory than drawing a dividing line between "financial" and "non-financial" contracts ${ }^{440}$. For these reasons, the exclusion of bybrids with non-qualified hosts from the disaggregation scheme can, in the author's view, not be transferred to the OECD MTC.

(3) An embedded derivative is subject of a mandatory ${ }^{441}$ separation from its host only if it has, among other conditions, the following cumulative key characteristics:

- It is a component of a financial instrument that also includes a non-"derivative" host, and neither is contractually transferable independently of that instrument nor has a different counterparty. ${ }^{442}$

- In delimitating the "derivative" from insurance contracts ${ }^{433}$, its underlying may not be a variable specific to one of the contracting parties ${ }^{444}$.

- Some of the cash flows of the financial instrument vary in a similar way to a stand-alone derivative.

Example 13: SFAS 133.21(a)(i) admitted by IAS $8.12^{445}$ provides that value changes of the compound position between $9 \%$ and $11 \%$ are considered as similar where the value of the stand-alone position changes by $10 \% .{ }^{446}$

- The embedded derivative earmarks some or all of the cash flows that would otherwise be required by the underlying. ${ }^{447}$

- The economic characteristics and risks of the embedded derivative are not closely related to the economic characteristics and risks of the host. ${ }^{448}$ The reason behind this is the axiomatic assumption that closely related embedded derivatives are unlikely to being employed for abusive purposes. ${ }^{449}$

- A separate financial instrument with the same terms as the embedded derivative would meet the definition of a derivative. ${ }^{450}$

These conditions show, for one thing, that also the IAS/IFRS take the legal form as the baseline for the above question ${ }^{451}$ of where the disaggregation starts ${ }^{452}$. They further emphasise and concretise this finding in that the "derivative" component may not be transferable independently. By doing so, they also give indications on the integrity of financial instruments ${ }^{453}$.

\footnotetext{
${ }^{439}$ IFRS 9.BC6.120 et seq.

${ }^{440}$ See par. 98(1). Argumentum a maiore ad minus.

${ }^{441}$ Hartenberger, Heike in Beck, IFRS / IAS, p. 173, par. 141 and 143; Kuhn / Hachmeister, p. 705, par. 11.

${ }^{442}$ IFRS 9.4.3.1. et seq.

${ }^{443}$ See par. 67.

${ }^{444}$ IFRS 9.4.3.1 and 9.BA.5.

445 IFRS 4.BC18.

446 Equally: Dominik Dettenrieder, p. 137.

447 IFRS 9.4.3.1.

${ }^{448}$ IFRS 9.4.3.3(a).

${ }_{449}$ IFRS 9.BCZ4.92.

${ }^{450}$ IFRS 9.4.3.3(b) and Appendix A of IFRS 9.

451 See par. 93.

${ }^{452}$ Hartenberger, Heike in Beck, IFRS / IAS, p. 172, par. 137; Oldeweme, Daniel Johannes, Die Bilanzierung von Commodity-Hedges nach International Financial Reporting Standards (IFRS), Dissertation No. 3523, University of Sankt Gallen, Sankt Gallen, 2008, p. 137, accurately observing that also IFRS 9.6.2.6 appears to implicitly stipulate a distinction between individually contracted financial instruments incorporating multiple (embedded) “derivatives" (i.e. aggregation) and financial instruments generated by multiply contracted "derivatives" (i.e. disaggregation).

${ }^{453}$ Similarly: Kubn/Hachmeister, p. 62, par. 51. See also par. 85 and 91.
} 
Example 14: A simple termination right or option in a loan agreement is not to be separated (i.e. it is not a financial instrument), whereas complex financial covenants may be.

In addition, the IAS/IFRS are also in line with the above understanding ${ }^{454}$ that legal risks cannot be "resolved" but only transferred, in that derivatives with different contracting counterparties are to be separated, even if otherwise combined. Consequently, the IAS/IFRS further support the view that the existence of financial instruments is predominantly a matter of the legal form ${ }^{455}$.

(4) An aggregate of multiple embedded derivatives may not be further disaggregated to the extent that they relate to the same risk type or factor. ${ }^{456}$ In other words: the risk type or factor represents the limit at which the disaggregation is to be stopped ${ }^{457}$. In addition, non-optional embedded derivatives (e.g. forwards) may generally not be further disaggregated into optional embedded derivatives (i.e. options) ${ }^{458}$, as otherwise a symmetric risk with a value of zero ${ }^{459}$ could be arbitrarily replicated by an asymmetric risk with a positive value ${ }^{460} .{ }^{461}$

(5) Under certain IAS-/IFRS-specific conditions, the currency risk ${ }^{462}$ component (from the reporting currency perspective) may be separated. This possibility is limited to specific non-"derivative" financial instruments. ${ }^{463} \mathrm{~A}$ further disaggregation beyond the currency risk (e.g. into the particular market risk components) is not permitted. This specific restriction reflects the difficulties in reliably and predictably attributing or allocating value changes to such other risks (especially the market risk components). ${ }^{464} \mathrm{It}$ may therefore be assumed in turn that the limitation to non-"derivative" financial instruments is likely to have its reason in the fact that the currency risk component of derivatives is particularly difficult to separate from their other risk components (e.g. where the underlying is traded in a different currency). ${ }^{465}$ Accordingly, a counter-exception are embedded currency derivatives, which obviously bear no other risks than their singular currency risk, and may therefore be separated from their host. This possibility is limited to transactions not denominated in currencies, which are norm or custom pursuant to common market practice (functional currency), as in these cases a close relation to the host $t^{466}$ is assumed.

Side note: A further requirement for a close relation to the host is that the embedded currency "derivative" is non-leveraged and non-optional. ${ }^{467}$ In the author's view, this additional requirement is however owed to and must therefore be seen in the IAS-IFRS-specific context 
of reassessing embedded derivatives ${ }^{468}$, which are not featured to adapt themselves to changes in external circumstances (e.g. market developments) ${ }^{469}$. As a result, this specific context and, consequently, this additional requirement is not transferable to the OECD MTC.

Transferred to the broader understanding of financial instruments in this study as opposed to the narrower understanding by the IAS/IFRS ${ }^{470}$, this condition is however always fulfilled. For securitised financial instruments in particular, their trading currency is per se such custom pursuant to common market practice. But also as regards non-securitised financial instruments in general, in the context of international tax law the functional currency is always the tax currency, the reason being is that the tax payment as the fulfilment of the legal obligation necessarily requires a realised transaction ${ }^{471}$. Consequently, there is no other way than to determine the functional currency pursuant to domestic tax law, which is per se such norm pursuant to common market practice. It may therefore be systematically permissible and technically feasible to separate the currency component from financial instruments on the OECD MTC level by way of disaggregation. However, following the IAS/IFRS rationale it is economically unnecessary. In addition, the only reasonable alternative for classifying a currency component separated from any other income type was capital gains, for which it was equivalent to sales proceeds. Since income is a split-off from capital ${ }^{472}$, it was, however, impossible to determine the corresponding acquisition transaction, as the following example demonstrates:

Example 15: A dividend payment in another currency might be considered an "acquisition" of that currency. However, the dividend as a legal split-off of economical substance from the share is already contained in the economical value of the share at the time of its acquisition. Consequently, it is principally not the dividend payment itself but the acquisition of the share that could represent an "acquisition" of the currency. However, the dividend entitlement is not only unknown or even unexpectable at the time of acquiring the share. In case it exceeds the market expectations it can even be itself a constituting value driver of the share. This makes a viable determination of any acquisition transaction eventually impossible, even retrospectively.

(6) Under certain IAS-/IFRS-specific conditions, the underwriting spot element and the time-based forward element may ${ }^{473}$ be separated from specific options ${ }^{474}$ or aggregates thereof ${ }^{475}$ and from forwards $s^{476}$. Consequently, this equally applies to currency basis spreads ${ }^{477}$, as these bear no other risks than their singular currency risk (i.e. the underwriting element) ${ }^{478}$ and interest rate risk (i.e. the time-based element).

\footnotetext{
${ }^{468}$ IFRS 9.B4.3.11.

${ }^{469}$ IFRS 9.BCZ4.100 et seqq.

470 See par. 98(1).

471 Similarly: Haufe, IFRS, p. 1867, par. 35.

472 See par. 79.

473 Critically: Dominik Dettenrieder, p. 165 et seqq.

${ }^{474}$ IFRS 9.6.2.4(a).

${ }^{475}$ IFRS 9.B6.5.31.

${ }^{476}$ IFRS 9.6.2.4(b).

${ }^{477}$ IFRS 9.6.2.4(b)

${ }^{478}$ See par. 98(5).
} 
Side note: A currency basis spread is the difference between the market interest rates of two currency areas. In contrast to exchange swaps, currency basis spreads also swap the principal amount and therefore contain a time-based element ${ }^{479}$.

However, there is a general exception in analogy to the prohibited disaggregation of non-optional into optional embedded derivatives ${ }^{480}$ : written (short) options or aggregates thereof representing a net short position do not qualify for this separation, unless and to the extent that they are designated as an offset to an individual purchased (long) option or an aggregate thereof representing a net long position ${ }^{481}$. This is because options represent an asymmetric risk ${ }^{482}$. Due to the net short position, such asymmetric risk is, however, to the detriment of the taxpayer in that its potential loss could be significantly greater than its potential gain. Assuming a rational taxpayer, short options are therefore considered as ineffective for hedging purposes ${ }^{483}$. In that regard, there is no economic substance justifying a disaggregation into short options ${ }^{484}$. Conversely, purchased (long) options or aggregates thereof always qualify for this separation: the asymmetric risk from net long positions is advantageous for the taxpayer in that its potential gain could be significantly greater than its potential loss. Again, assuming a rational taxpayer, long options are therefore considered as effective for hedging purposes ${ }^{485}$. There is, therefore, a strong economic substance justifying a disaggregation into long options.

(7) In contrast to the temporal aggregation as a designation of parts of the duration for hedging purposes ${ }^{486}$, the corresponding temporal disaggregation of the time-based element is not permitted (e.g. swaps into a series of forwards $)^{487}$. However, an exception is formed by the time-based elements of long options ${ }^{488}$ as well as of forwards and currency basis spreads ${ }^{489}$ which are to be further separated into transaction related and time-period related components ${ }^{490}$. As regards options, the reason is that economically they represent a protection or insurance ${ }^{491}$ against asymmetric (downside) risks ${ }^{492}$ and still allow the participation in favourable changes. ${ }^{493}$ These one-sided risks can relate to capitalised transactions (i.e. transaction related, e.g. capital gains) or to non-capitalised transactions (i.e. time-period related, e.g. dividends, interest) ${ }^{494}$. As regards forwards and currency basis spreads, the reason is that they are considered economical insurances ${ }^{495}$,

\footnotetext{
$\overline{479}$ Kuhn/Hachmeister, p. 326, par. 86.

${ }^{480}$ See par. 98(4).

${ }^{481}$ IFRS 9.6.2.1, 9.6.2.6 and B6.2.4.

482 See par. 64.

${ }^{483}$ IAS 39.AG94; Haufe, IFRS, p. 1857, par. 12; Dominik Dettenrieder, p. 181 et seq.; Diana Doege, p. 50.

${ }^{484}$ Equally: Kubn/Hachmeister, p. 318, par. 50.

${ }^{485}$ IFRS 9.BC6.195.

${ }^{486}$ Haufe, IFRS, p. 1860, par. 19, and p. 1866, par. 34; Kuhn / Hachmeister, p. 335, par. 140; Dominik Dettenrieder, p. 160 et seq.

${ }^{487}$ IFRS 9.6.2.4(c); Haufe, IFRS, p. 1860, par. 19; Kuhn / Hachmeister, p. 318, par. 52, and p. 367 et seq., par. 315. Critically: Dominik Dettenrieder, p. 131 et seq., generally questioning the transferability of the IAS/IFRS disaggregation scheme to the IAS/IFRS hedging technique due to their different and perhaps incompatible purposes.

${ }^{488}$ IFRS 9.6.5.15(a).

489 IFRS 9.6.5.16.

${ }^{490}$ Critically: Dominik Dettenrieder, p. 173 et seqq., arguing that such distinction was not always clearly and reliably determinable.

491 See par. 70.

492 See par. 64.

${ }^{493}$ IAS Board, portfolio hedging, p. 29, par. 3.5.6.

${ }^{494}$ IFRS 9.B6.5.29 and 9.BC6.391 et seqq.

${ }^{495}$ IFRS 9.BC6.418.
} 
even though they do not represent an asymmetric risk. This is demonstrated by the observation that they are typically used where a risk of depreciation of the hedged item will in any case be protected at a specific value, even by accepting a potential loss in the hedging instrument itself. Consequently, their time-based elements (i.e. their forward components) ${ }^{496}$ can be transaction related and/or time-period related as well ${ }^{497}$. The transaction related component is represented by that part of the option, forward or currency basis spread, which would be attributed to a hypothetical perfect hedge of that transaction ${ }^{498}$. The hypothetical remainder represents the time-period related component ${ }^{499}$. In the author's understanding, this view provides an important redline for the distinction of capital gains from the other income types of financial instruments in that it qualitatively decomposes the time-based element and systematically allocates its components depending on their economic context.

(8) Correspondingly, the interest rate risk may be separated as well ${ }^{500}$ : where the time-based element (interest rate) is clearly and reliably determinable ${ }^{501}$, this must necessarily also apply to potential changes of that time-based element (interest rate risk) ${ }^{502}$.

(9) The restrictive disaggregation scheme under IAS/IFRS, not allowing its voluntary or optional application beyond the permissions and mandatory obligations, is axiomatic and therefore controversial ${ }^{503}$. In the absence of any explicit provision, undoubtedly there are no option rights with regard to disaggregation in the OECD MTC either. The discussion shows, however, that the IAS/IFRS approach would, in principle, be transferable to other circumstances as well.

\subsubsection{What can be learned from finance theory}

99 Having discussed its admissibility, scope and granularity, the disaggregation scheme shall now be examined content-wise. All finance theories cited in the aforementioned tax studies ${ }^{504}$ describe a positive relation between risk and return, in that a higher venture demands a higher compensation and vice versa. On the other hand, risky and riskless positions have in common that the capital or principal is not at the disposal of the investor, for which he will in any case demand a time-dependent compensation (opportunity costs). This relation can most generally be expressed by the following equation ${ }^{505}$ :

Return from risk-based positions = return from time-based positions + risk premium

This means that the return from risk-based positions always includes the return from time-based positions, since underwriting risk implies timing risk ${ }^{506}$. Conversely, however, the return from time-based positions can, except for credit risk ${ }^{507}$, never include the return from risk-based positions, since timing risk does not in turn

\footnotetext{
$\overline{496}$ IFRS 9.BC6.416 and 9.BC6.424.

497 IFRS 9.B6.5.34.

${ }^{498}$ IFRS 9.B6.5.32, 9.B6.5.33(a), 9.B6.5.37, 9.B6.5.38(a) and 9.B6.5.39; IFRS 9.BC6.396.

${ }^{499}$ IFRS 9.B6.5.32, 9.B6.5.33(a), 9.B6.5.37, 9.B6.5.38(a) and 9.B6.5.39; IFRS 9.BC6.397.

500 IFRS 9.5.3.2.

501 See par. 98(6).

${ }^{502}$ Argumentum a minori ad maius.

503 Dominik Dettenrieder, p. 160, 168 et seqq. and 190 et seq.; Oldeweme, Daniel Johannes, Die Bilanzierung von Commodity-Hedges nach International Financial Reporting Standards (IFRS), Dissertation No. 3523, University of Sankt Gallen, Sankt Gallen, 2008 , p. 138 et seq.; Nguyen, Tristan, Bilanzielle Abbildung von Finanzderivaten und Sicherungsgeschäften: Hedge Accounting nach HGB und IAS / IFRS, Munich, 2007, p. 188 et seq. with further citations.

504 See footnote 365 .

505 Equally: Kuhn / Hachmeister, p. 706, par. 17.

506 See par. 69.

${ }^{507}$ IFRS 9.BC6.503.
} 
imply underwriting risk. In other words: while the return from time-based positions compensates timing risk only, the return from risk-based positions compensates both underwriting risk and timing risk.

\section{The role and limitations of finance theory}

100 As stated above ${ }^{508}$, there are, however, no absolutely riskless positions but only relatively riskless ones. That is why finance theory draws its implications exclusively from the levels of risk and does not say anything about the types of risk. Consequently, risk-based and time-based positions are economically fluid and situative categories (e.g. a debtor's credit risk can be higher than an equity's business risk) ${ }^{509}$. Tax law in general and the position-by-position approach of the OECD MTC ${ }^{510}$ in particular call, however, for a clear and universal separation line between the income types of financial instruments ${ }^{511}$. Indeed, any attempt to bring these two heterogeneous dimensions perfectly in line is illusory, which is another reason why finance theory alone cannot distinguish between dividends and interest $t^{512}$. However, the implied suggestion that this was necessary at all was an overrun and may not lead to giving up the entire interpretation and application of law in favour of economy ${ }^{513}$. The mere existence of law in general and tax law in particular is proof enough that there are obviously more and conflicting interests and objectives than just the substance over form principle (e.g. legal certainty, coherence, operational practicability, etc. $)^{514}$. The material object of tax law may not be mixed up with the formal methodology of law making. From this perspective it can be accepted that the formal construct of tax law is materially no more than an approximate model of economic facts ${ }^{515}$. Even turning law into economy would still cause other legal distortions (e.g. a tax bias of financial accounting legally bound to tax classifications). Instead, it remains the interpretational question, which relative importance or priority the substance over form principle shall be given. The key of knowledge lies hidden where finance theory still contributes to legal interpretation and not where legal interpretation already fails at finance theory. In this regard, the glass is half full rather than half empty. On the other hand, any further mismatch and distortion between form and substance beyond having exhausted the general principles of interpretation then has to be accepted in favour of the other conflicting interests of the law.

101 That said, the mere level of risk can never be a priority and even less the sole differentiator between the income types of financial instruments. In order to apply the general guidelines pursuant to the substance over form principle ${ }^{516}$ under the OECD MTC, the level of risk nevertheless appears to be the crucial assessment factor for qualifying the relative importance of the particular fields of legal attributes of financial instruments, since, where this relative importance of legal criteria shall be evaluated in terms of their economic results (i.e. the substance over form principle $)^{517}$, the assessment factor as the measurement reference must necessarily be

\footnotetext{
508 See par. 62.

509 Similarly: Harris, Peter A., Corporate Tax Law: Structure, Policy and Practice, Cambridge University Press, Cambridge, 2013 , p. 192.

510 See par. 59 and 76.

511 Marjaana Helminen, dividend concept, p. 167, accurately calling it an "imaginary line”.

512 See par. 92.

513 OECD, ST/SG/AC.8/2001/CRP.8, p. 30, par. 109; Anthony Polito, p. 762, calling those attempts "fruitless" and "mindless".

514 Similarly: Peter Hongler, p. 270 and 272.

515 "Taxable income is not economic income, it is at best a transaction-based approximation to economic income, which is itself only a proxy for some more fundamental policy goal." (Anthony Polito, p. 765 et seq., and on p. 774 et seq., calling the distinction between equity and debt a legal fiction).

516 See par. 78.

517 See par. 72.
} 
an economic parameter as well. Due to the fact that economics has only two dimensions ${ }^{518}$, risk is, however, the only permissible qualifier for such evaluation. The return as the only other economic qualifier left is no qualitative parameter that allows universal statements, but rather a quantitative one that depends on individual circumstances. The approach for analysing financial instruments must therefore be a multi-stage process of risk identification, risk disaggregation and risk elimination, before such risk evaluation may reveal the relative importance of those particular fields of criteria:

(1) As the first methodological step, any particular risk must be disaggregated and its components classified by type (i.e. by its source or origin) into legal and non-legal risks ${ }^{519}$. However, legal risks were said to be not "resolvable" but only convertible by transfer or re-allocation ${ }^{520}$ and therefore by accepting new legal risks ${ }^{521}$. This entire first step of identifying legal risks must therefore necessarily be subject to form over substance (i.e. by its formal source or origin). In contrast to the infinite-dimensional legal form, the economic substance over form approach would not be able to qualitatively identify and separate different types of risk (such as legal risk ${ }^{522}$ ), since risk as a whole is its sole qualitative dimension ${ }^{523}$. As I have said earlier, in the absence of any explicit provision or implicit principle within the OECD MTC, the aggregation scheme can typically not be justified positively ${ }^{524}$. Consequently, any subsequent step is to be performed regularly based on the disaggregation scheme only. Ergo, disaggregation is de facto a one-way downward. The consequent tax planning possibilities and distortions by discretionarily choosing or structuring the legal (contractual) form of the financial instrument ${ }^{525}$ are the lesser of the two evil alternatives ${ }^{526}$ and therefore acceptable in favour of the other conflicting interests of the law ${ }^{527}$.

(2) Once the legal risk has been identified by way of that form over substance analysis, the substance over form principle can then be applied as a subsequent logical step in order to reveal the relative importance of those particular fields of criteria. However, another interim conclusion can be drawn from the fact that legal risks cannot be "resolved" but only converted by transferring or re-allocating them and therefore accepting new legal risks ${ }^{528}$. Any relative level of risk found as a result of having disaggregated a financial instrument can imperceptibly be of two principal kinds: it could represent either an economic gross risk or a "managed" or "engineered" (hedged) net risk in the sense of being replicated or synthesised.

Example 16: Where a structured product has been disaggregated, a currency risk may stem gross from the trade currency of the underlying straightforward share or net from a hedge strategy synthetically embedded into the structured product itself (e.g. physically-settled compo or quanto equity swaps $\left.{ }^{529}\right)$. Methodologically the underlying straightforward share and the structured product do not differ from the perspective of legally classifying them into

\footnotetext{
518 See par. 89 and 92.

519 IFRS 9.B5.7.14 and 9.BC6.473 as well as analogously for aggregation: IFRS 9.6.4.1(c)(ii) and 9.B6.4.7 et seq. See also par. 78 and 62.

520 Gaspar Lopes Dias, tax arbitrage, p. 14.

521 See par. 78.

${ }^{522}$ Equally: IFRS 9.BC6.470 and 9.BC6.504.

523 Similarly: Anna Verena Matthies, p. 80.

524 See par. 95.

${ }^{525}$ Harris, Peter A., Corporate Tax Law: Structure, Policy and Practice, Cambridge University Press, Cambridge, 2013, p. 205.

526 See par. 95.

527 See par. 100.

528 See par. 101(1).

${ }^{529}$ Juan Ramirez, p. 21 et seq.
} 
the distributive articles of the OECD MTC. As a consequence, the conceptual features and specific peculiarities of financial instruments make it impossible to see to which of those two categories that currency risk belongs ${ }^{530}$.

However, as regards legal risks, any replication or synthesisation would finally lead to the same results (i.e. gross and net legal risks are always equal). Legal risks therefore appear to be of no superior importance for the further distinction between non-legal risks. Where the additional assumption is taken that legal risks do not significantly differ across the different jurisdictions and types of financial instruments, they even become irrelevant. Consequently, the level of legal risks can only be exploited by quantitatively comparing it with the level of non-legal risks rather than qualitatively draw further conclusions from it. As another finding for the further course of this study, legal risks must therefore be eliminated from the successive disaggregation.

(3) In contrast to the legal risks, the gross and net of non-legal risks is not always equal, which is why nonlegal risks merit further disaggregation. The revolving process of risk disaggregation, risk elimination and risk assessment in order to pick out the non-legal risks and put them in relation to each other stops where the relative risk levels of the components from a next iteration's disaggregation would not significantly change any more. This is the point where unrelated risks are close to being "pure" or where related risks fall into the same category. For instance, the sub-risk of a duration extension might increase the default risk and therefore falls into the same category.

(4) The result of such multi-stage process is a selection of non-legal risk types, each represented by a closed and homogeneous portfolio of replicating options ${ }^{531}$. A particular risk type can now be merged into a specified reference portfolio (e.g. a straightforward share or bond) by mixing their replicating options. From the response or behaviour of that consolidated option portfolio it should be possible to draw qualitative reverse deductions towards some general or universal guidelines for its legal classification.

\section{Portfolio theory as a reference model}

102 Without going too deep into finance theory, this approach shall be very briefly introduced in the following, before the conclusions are drawn. The said reference option portfolio must be designed in order to meet two conditions: (1) it must allow objective or universal statements independent of individual circumstances, which (2) are as close as possible to the legal distinction between the income types of financial instruments. Namely, it must be as close as possible to the distinction between dividends pursuant to Art. 10(3) OECD MTC and interest pursuant to Art. 11(3) OECD MTC, as the other income pursuant to Art. 21(1) OECD MTC can then be negatively distinguished as the residual. As modern portfolio theory has shown ${ }^{532}$, such reference portfolio contains one risky (risk-based) and one riskless (time-based) position ${ }^{533}$. The risk-return relation of such a reference portfolio and its complement of two risk-based positions can be visualised as follows:

\footnotetext{
530 See par. 87.

531 See par. 91.

532 Markowitz, Harry Max, Portfolio Selection, The Journal of Finance 1952, Vol. 7, Issue 1, p. 77 et seqq.

533 See par. 96.
} 


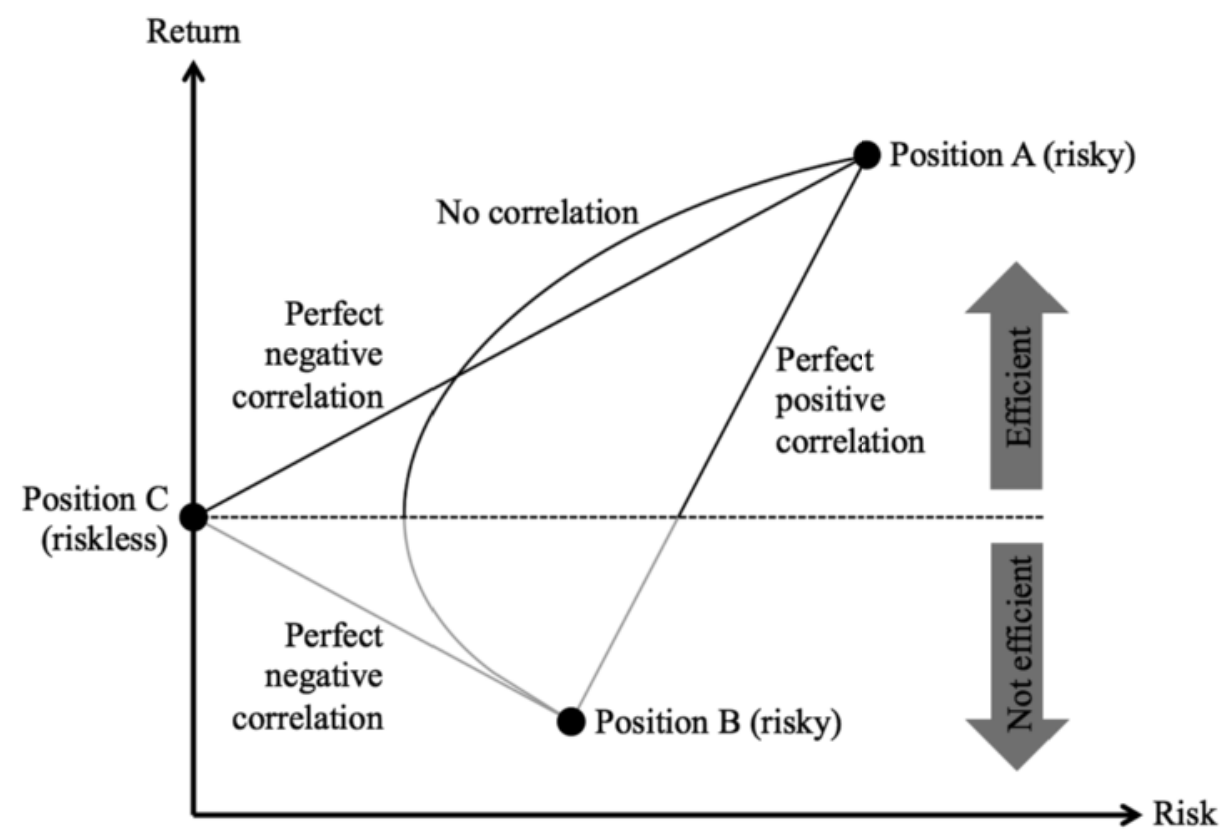

Illustration 8: Option portfolio of non-legal risks (B) and reference portfolio (A, C)

103 Position B represents the particular option portfolio of non-legal risks as the experimental object of the respective sub-analysis. $\mathrm{C}$ represents the riskless position in the above sense of the one with the lowest relative risk $^{534}$. Though not absolutely riskless, position $\mathrm{C}$ as the deemed purely time-based position is nevertheless the theoretical ideal-type of a debt-claim ${ }^{535}$ implying an interest ${ }^{536}$. As such, it does not only meet the second above condition of being as close as possible to its legal intention ${ }^{537}$. It is also easy to distinguish from other income, which must thus necessarily be a risk-based income type. In addition, position $\mathrm{C}$ also meets the first above condition of allowing universal statements independent of individual circumstances, as it can be objectively determined by publicly available information. Unlike position C, position A represents the theoretical idealtype of a share implying a dividend ${ }^{538}$. As such, position A is, however, more difficult to determine, as it must also be distinguished from other income and is not available as publicly available information. Nevertheless, it should be permissible to assume that any company has a minimum of regulatory core equity. Bringing everything together results in three use cases:

(1) The financial instrument to be analysed refers to one single share as its underlying, regardless of how that underlying is further modified (e.g. by adding or subtracting certain effects). In this case, position $A$ is the regulatory core equity of that share.

\footnotetext{
534 See par. 62 and 100.

${ }_{535}$ IFRS 9.4.1.3(b); Christoph Berentzen, p. 82.

${ }_{536}$ See par. 53 et seq.

537 See par. 102.

${ }^{538}$ See par. 53 et seq.
} 
(2) The financial instrument to be analysed refers to more than one share as its underlying, regardless of how these underlyings are further modified. In this case, position A is the weighted regulatory core equity of these shares.

(3) The financial instrument to be analysed refers not to a share. In this case, it can not bear any genuine equity-related risk. Instead, it can only be designed to replicate each and every particular non-legal risk or option portfolio of a certain share synthetically with the same or a similar non-legal risk-return profile. However, not only can such identical risk-return profile not be the only differentiator ${ }^{539}$. More important is that such synthetic replication was possible only at the price of higher legal risks ${ }^{540}$. And this was economically unreasonable, as the mere existence of that share was said to be ceteris paribus proof enough that the underlying business enterprise cannot be replicated more efficiently ${ }^{541}$. This means as another conclusion for the further course of this study that financial instruments not formally referring to a share as their underlying can by themselves not be shares pursuant to Art. 10(3) OECD MTC or profitparticipating debt-claims pursuant to Art. 11(3) OECD MTC (form over substance).

104 Thus, also position A is determinable in that it meets the two above conditions of allowing universal statements independent of individual circumstances and of being as close as possible to its legal intention ${ }^{542}$. We can now come to the analysis of the response or behaviour of that consolidated portfolio between one risk-based and one time-based position by mixing their replicating options with those representing the particular non-legal risk type to be analysed.

\section{Applying the model}

105 The two positions A (share) and C (debt-claim) are mutually exclusive. Therefore, position B as the option portfolio representing the particular non-legal risk can correlate

(1) positively with the option portfolio representing position A (share), which coincidently means a negative correlation with the option portfolio representing position $\mathrm{C}$ (debt-claim). It is the hyperbolic line between $\mathrm{A}$ and $\mathrm{B}$ that morphs into the form of the straight line between $\mathrm{A}$ and $\mathrm{B}$, the more the positive correlation between $\mathrm{A}$ and $\mathrm{B}$ approximates perfection. That a riskless position $(\mathrm{C})$ can positively or negatively correlate with a risky position (B) is no principal contradiction. The reason is that $\mathrm{C}$ is not absolutely riskless but merely represents the position with the lowest relative risk ${ }^{543}$.

(2) negatively with the option portfolio representing position A (share), which coincidently means a positive correlation with the option portfolio representing position $\mathrm{C}$ (debt-claim). It is the hyperbolic line between $\mathrm{A}$ and $\mathrm{B}$ that morphs into the form of the straight line between $\mathrm{A}$ and $\mathrm{C}$, the more the negative correlation between $\mathrm{A}$ and $\mathrm{B}$ approximates perfection. Where the negative correlation between $\mathrm{A}$ and $\mathrm{B}$ is perfect, $\mathrm{C}$ is perfectly replicated synthetically by $\mathrm{A}$ and $\mathrm{B}$.

(3) with neither position A (share) nor position C (debt-claim). It is the hyperbolic line between A and B that does not morph at all.

\footnotetext{
539 See par. 92.

540 Jieyin Tang, bifurcation or integration, sec. 5.1.; Jieyin Tang, substance vs. form, sec. 3.2.1. See also par. 78 .

541 See par. 88(4).

${ }^{542}$ See par. 102.

543 See par. 62 and 100.
} 
106 These use cases demonstrate that any particular non-legal risk type can be clearly classified into either "equity-like" or "debt-like", depending on its relatively higher correlation to the one or the other.

Example 17: The US federal tax law takes the correlation coefficient between a financial instrument and its underlying („delta“) to determine its tax classification (sec. 871m US tax code). In contrast, the correlation approach in this study is, however, not applied to a financial instrument in its entirety, as finance theory alone cannot classify $i t^{544}$. Instead, it is applied to particular risk types in order to draw qualitative reverse deductions towards some general or universal guidelines for its legal classification.

Moreover, the smaller or higher correlation to the one or the other can indicate their relative weight to other risk types. These relative weights can then be used as the said assessment factors for qualifying the relative importance of those particular fields of legal criteria of financial instruments under the OECD $\mathrm{MTC}^{545}$. In this respect, the income types of financial instruments are somewhat successively pulled apart, until their overlap is reduced to a minimum ${ }^{546}$. In a subsequent step, the findings can then be applied to the disaggregation of "more complex" instruments.

\subsubsection{Conclusions}

107 Taking this approach, it should therefore be permissible to draw, for example, the following preliminary conclusions towards the income types of financial instruments, which form the subject of a further detailed examination in the following sections:

(1) One of the most important differentiators between shares pursuant to Art. 10(3) OECD MTC and debt-claims pursuant to Art.11(3) OECD MTC appears to be the effective subordination. The reason for this is that subordinated principal, especially equity, primarily absorbs all risks by participating in losses first and in profits last ${ }^{547}$. In other words: the more subordinated a debt-claim is, the more it approximates, ceteris paribus, to a share in this respect.

(2) The effective duration or maturity of financial instruments in the sense of when the control over the disposal of the capital or principal returns to the investor considerably influences their risk-return profiles. While the short-term volatility typically decreases, the long-term default risks necessarily increase ${ }^{548}$.

(3) For the same reason, there appears to be a significant difference between financial instruments with notional or floating capital or principal and those with actual principal. While the former limits the risks to the return, the latter puts also the capital or principal itself at risk. Since the basic ideal-type of both shares and debt-claims has an actual capital or principal respectively, a notional capital or principal might be an indicator to other income pursuant to Art. 21(1) OECD MTC.

(4) On the other hand, the temporal payment profile does not seem to be a differentiator of major importance. In the sense that any payment profile is economically capitalised or discounted, it is independent of the timing ${ }^{549}$. In other words: it is the underwriting element rather than the time-based element of payments

\footnotetext{
544 See par. 92.

545 See par. 101.

546 See Illustration 5 on p.48.

547 Equally: William Plumb, p. 422; for IAS / IFRS: Anna Verena Matthies, p. 151 et seq.

${ }^{548}$ Equally: IFRS 9.5.5.19 et seq. and 9.B5.5.10 et seq.; William Plumb, p. 416; David Hariton, equity and debt, p. 506; See also par. 69.

549 Equally: Haufe, IFRS, p. 1711, par. 165.
} 
which significantly affects the risk-return profile. Admittedly, just as the effective duration or maturity of the capital or principal affects its own default risk, the effective payment date of the remuneration affects its own default risk ${ }^{550}$.

Example 18: The risk-return profile of a long-term zero bond with notional principal depends exclusively on the remuneration.

However, considering the typical value ratio between the remuneration on the one hand and the capital or principal on the other illustrates that the former is of minor importance compared to the latter ${ }^{551}$. Nevertheless, the significance of the time-based element increases as a consequence of a longer duration or maturity of the financial instrument ${ }^{552}$.

(5) The origin of the capital or principal, i.e. injection from the outside or accumulation from the inside, appears to be a matter of no vital importance as regards the risk-return-profile. Subject of the economic assessment is the asset as a whole, regardless of where its funds originate from, since the risk-returnprofile is basically a concept of pre-tax considerations. Admittedly, reinvested gains are at the same risk as the capital or principal itself ${ }^{553}$. However, considering the typical value ratio between gains on the one hand and the capital or principal on the other illustrates that the former is regularly of minor importance compared to the latter ${ }^{554}$.

(6) Membership rights (e.g. voting, management, etc.) represent legal risks and do therefore not need to be disaggregated. Even in a special particular case, where they, exceptionally, represented non-legal risks, they would typically not have a material impact on the total risk-return profile. For these reasons, membership rights are of subordinate importance compared to proprietary rights ${ }^{555}$.

(7) Risk considerations also support the above conclusions of not separating options from their underlyings but instead treating the two as one logical concept or mechanism ${ }^{556}$. The reason for this is that already upon contracting in the option the underlying's risk burden as one of its most important economic interests changes between the contracting parties. Just like selling the underlying, writing an option on that underlying transfers its impairment risk to the option holder in the way that the owner's (i.e. the option writer's) interest changes from value appreciation into the opposite of value depreciation ${ }^{557}$. This transfer of risks is independent of the option's later execution, by which that risk is merely materialised. In other words: it is the actual signing of the option which transfers the underwriting risk ${ }^{558}$ from the underlying. In contrast, the execution of the option actually represents the redemption of a contingent debt transaction, i.e. of financing the underwriting risk from the underling ${ }^{559}$, and therefore timing risk.

\footnotetext{
550 Equally: David Hariton, equity and debt, p. 507.

${ }^{551}$ Similarly: Kolbrenner, Scott Marc, Derivaties Design and Taxation, Virginia Tax Review 1995, Vol. 15, Issue 2, p. 242 et seq.

552 See par. 107(2).

553 Equally for IAS/IFRS: IAS Board, June 2015, 5A, p. 17, par. 64

${ }^{554}$ Equally for IAS/IFRS: IAS Board, June 2015, 5A, p. 16, par. 59(b).

555 Equally: Sven-Eric Bärsch, p. 238; for IAS / IFRS: IAS Board, June 2015, 5A, p. 16, par. 59(a); Anna Verena Matthies, p. 149.

556 See par. 96 and 98(1).

557 David Hasen, p. 429.

558 See par. 67.

559 David Hasen, p. 429.
} 
108 However, the methodological restrictions and limitations of the approach substantially re-narrow its broad possibilities and therefore must be kept well in mind when drawing such conclusions:

(1) As stated before ${ }^{560}$, the approach should allow objective or universal statements. While the positions A $(\text { share })^{561}$ and B (debt-claim) $)^{562}$ meet this condition, position B (non-legal risk type) strongly depends on the context. Although the approach is independent of the absolute level of risk ${ }^{563}$, it may nevertheless vary between different business enterprises and might therefore cause distortions ${ }^{564}$. For instance, a specific risk type may correlate stronger with equity of one business enterprise, while simultaneously correlating stronger with debt of another. This effect may appear particularly in win-lose situations ${ }^{565}$, which are a typical characteristic of financial transactions ${ }^{566}$ (e.g. where the profit from equity or other income of one party is the debt from a loss of the other).

(2) Another aspect of the requisite objectivity and universality is that the implications must also be independent of domestic law. As stated above, the domestic tax law constitutes a taxable event first, before becoming the subject of treaty law. ${ }^{567}$ The domestic tax law presumes and therefore implies the legal facts from non-tax fields of domestic law ${ }^{568}$. All these legal facts from tax and non-tax fields of domestic laws are in principle infinite ${ }^{569}$, which is why they themselves can't serve as differentiators in the OECD MTC. Instead, they must be grouped or abstracted to some higher-level treaty types of differentiators ${ }^{570}$. In other words: the implications from the approach must begin and end with some "generic" types of legal criteria, which represent the limitations of the legal form and the autonomous interpretation of the OECD MTC ${ }^{571}$.

(3) In addition, due to the fundamental incompatibilities and conflicts ${ }^{572}$ between the economic equivalence of financial instruments ${ }^{573}$ and the schedule-based system of the OECD MTC ${ }^{574}$, the implications gained from the approach can be consistent only to a certain extent. No approach based on legal criteria can overcome the conceptual deficiencies of the OECD MTC. This is also explains why the disaggregation scheme can only be as good as its components ${ }^{575}$.

(4) Disaggregation in practice requires considerably detailed price or value information ${ }^{576}$ (complete market requirement ${ }^{577}$ ), limiting its applicability to marketable and liquid components.

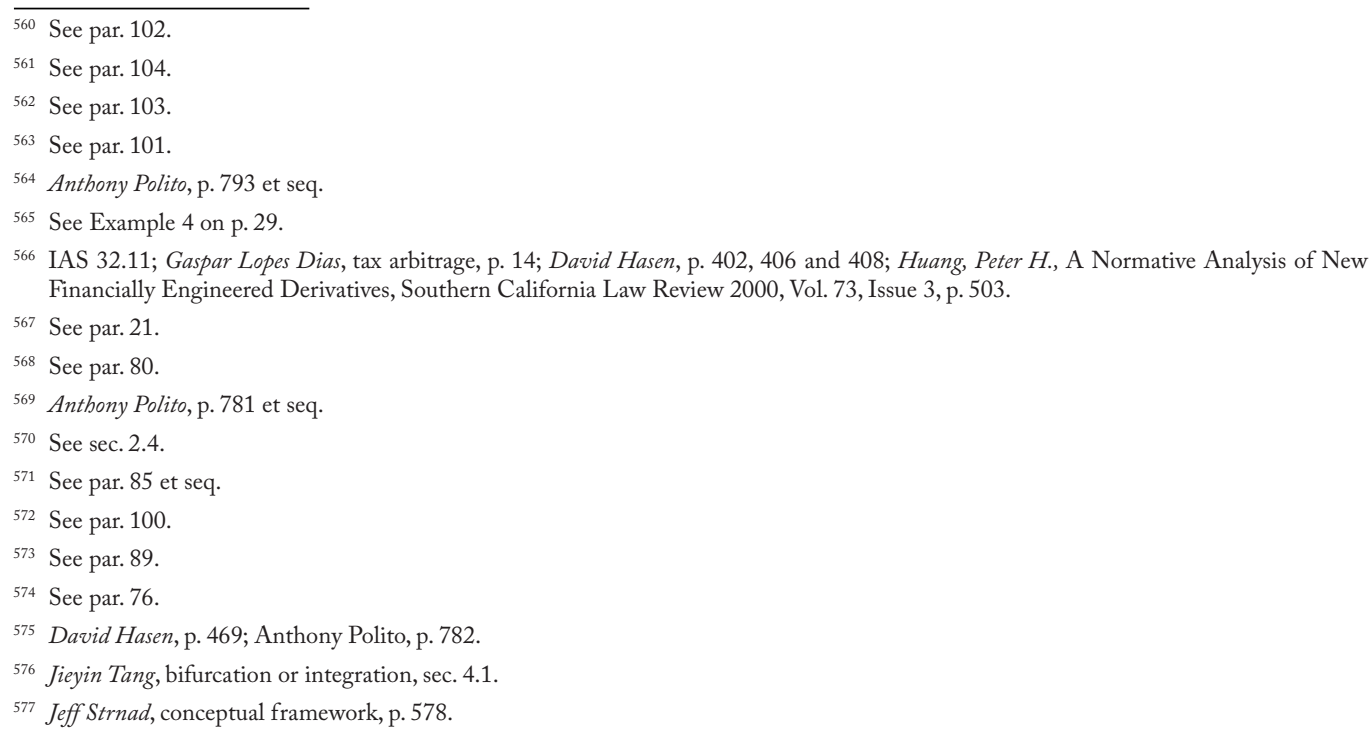


(5) Finally, the implications from the approach back to some "generic" differentiators can only be drawn from the two dimensions of the economic risk-return profile $\mathrm{e}^{578}$.

That is why the approach will not be understood and cannot be used as a best practice or technique for classifying financial instruments on daily case-by-case basis. Rather, it represents an attempt to draw some general guidelines for a classification into the income types of financial instruments ${ }^{579}$. Instead of any direct top-down approach as to what extent the substance over form principle justifies the disaggregation scheme to apply in the OECD MTC, it seems to the author more promising and more robust to indirectly work out these distinction criteria in order to make the inherent and implicit systematic interdependencies between them clearer and more transparent. In other words: a strong and logical system combining a certain degree of disaggregation with some clear and flexible distinction criteria, by simultaneously resting on a minimum of pre-conditions ${ }^{580}$, suggests itself more easily and enjoys more acceptance than any axiom. These would necessarily give rise to significant qualification conflicts and could at worst exclude a significant number of jurisdictions from the scope or application of the OECD MTC ${ }^{581}$.

\subsection{Analysis and discussion of the systematic context}

\subsubsection{Preliminary remarks}

109 The purpose of this section is to outline a clear and distinct understanding of selected systematic aspects of the distributive articles themselves, as far as relevant for this study. Like the analysis and discussion of basic principles before ${ }^{582}$, a first the objective is to present the author's view of these aspects. Another objective is to concretise these aspects in order to set a clear scope and to identify specific key differentiators for classifying the income types of financial instruments. Finally, this section has also the objective to provide a comprehensive discussion, comparison and integration of the different opinions, which have already been expressed elsewhere.

110 In contrast to the preceding analysis and discussion of basic principles, most of the aspects discussed in this section are already concrete enough to be taken from the explicit or at least be derived from the implicit wording of the OECD MTC by way of legal interpretation. However, in order to ensure a maximum of consistency, all this is carried out by carefully embedding the systematic aspects into those general guidelines found in the preceding sections. That is why the way of interpretation in this section is significantly influenced by the above findings. Where it is considered reasonable and appropriate, the following considerations also take the liberty of transferring some structural findings and parallels from other legal sources to the OECD MTC.

\footnotetext{
578 See par. 92.

579 See par. 101.

580 See par. 90.

581 "There was a general consensus that there are insuperable practical or technical obstacles to the adoption of a bifurcation regime" (IFA, $54^{\text {th }}$ IFA Congress, Munich 2000 Summaries of Discussion on Subjects I and II, Bulletin for International Taxation 2001, Vol. 55, No. 2, p. 82 .

582 See sec. 2.2.
} 


\subsubsection{Relations between the distributive articles}

111 As stated earlier ${ }^{583}$, the main function of the distributive Art. 10, 11, 13 and 21 OECD MTC is to restrict or limit the allocation of taxation rights to the source jurisdiction ${ }^{584}$. Just as for all distributive articles in the OECD MTC, this function is served best by covering as much income as possible taxed by domestic tax laws ${ }^{585}$. In fact, it means that the scope of the distributive articles has to be as broad or comprehensive as possible ${ }^{586}$. However, their scope is limited to what the contracting jurisdictions jointly intended to regulate at all ${ }^{587}$. In other words: gaps within, between or around the distributive articles may be considered only where there is certain indication that the contracting jurisdictions did explicitly not intend to regulate that respective point at all.

112 In this intentional context, it is the consensus view ${ }^{588}$ that the entire set of all distributive articles shall completely and comprehensively cover all income considered or treated as taxable by the jurisdictions. In other words: there are no gaps either among Art. 10,11,13(5) and 21(1) OECD MTC or between these and any other distributive provision.

113 Further, there is consensus ${ }^{589}$ on the point that Art. 10,11, 13(5) and 21(1) OECD MTC generally do not overlap, i.e. they are mutually exclusive:

(1) As regards to Art. 10 and 11 OECD MTC, the contrary position ${ }^{590}$ is rejected predominantly as it

- is based on parts of Art. 10(3) OECD MTC which are not only to be interpreted domestically but also subsidiary to other parts being interpreted autonomously ${ }^{591}$;

- also conflicts with the clear wording in (limb 2 of) Art. 10(3) OECD MTC, which explicitly and distinctly negates debt-claims as exclusively employed by Art. 11(3) OECD MTC.

The subsequent question as to whether that mutual exclusivity between Art. 10 and 11 OECD MTC may be a result of either a subordinate relationship ${ }^{592}$ or of their equal position on the same level or rank $k^{593}$

\footnotetext{
583 See par. 19.

${ }^{584}$ Equally: Harris, Peter A. in IBFD Commentaries on Art. 10 OECD MTC, sec. 1.1.2.1.; OECD Commentaries 2014 on Art. 10 OECD MTC, p. C(10)-1 et seq., par. 5; Harun Ogutu, Andrew in Schilcher/Weninger, p. 277; Kragen, Adrian A., Double Income Taxation Treaties: The O.E.C.D. Draft, California Law Review 1964, Vol. 52, No. 2, p. 323.

585 Klaus Vogel Commentaries 1997, p. 358, par. 2.

586 See par. 19 et seqq.

587 Rainer Prokisch, interpretation, p. 56 et seq.

588 Gaspar Lopes Dias, debt-claims, sec. 3.1.; Dürrschmitt, Daniel in Vogel /Lehner, p. 781, par. 2; Cui, Shanshan in Thomas Ecker, p. 638; Fehér, Tamás in Eva Burgstaller, p. 238; Wattel/Marres, fictitious income, p. 69.

${ }^{589}$ Harris, Peter A. in IBFD Commentaries on Art. 10 OECD MTC, sec. 5.1.2.4.1.; Gaspar Lopes Dias, debt-claims, sec. 3.1.; Pöllath, Reinhard / Lohbeck, Allit in Vogel /Lehner, p. 1291, par. 5b; Kopp, Karin E.M. in Wolfgang Schön, equity and debt, p. 850; Santos, Ramon Tomazela, Tax Treaty Qualification of Income Derived from Hybrid Financial Instruments, Bulletin for International Taxation 2013, Vol. 67, No. 10, sec. 4.3.; Peter Hongler, p. 262; Avery Jones Commentaries, sec. 5; Eberhartinger/Six, p. 10; Martin Six, hybrid finance, sec. 3.; Jakob Bundgaard, perpetuals, p. 140; Fehér, Tamás in Eva Burgstaller, p. 238 and 244; Carmine Rotondaro, redemption, p. 266; Michael Lang, hybrids, p. 90, p. 104, 111 and 121; OECD, Report on Thin Capitalization, Issues in International Taxation 1987, No. 2, p. 25, par. 60; OECD, CFA/WP1(73)2, p. 8, par. 13.

590 Tischbirek, Wolfgang / Specker, Gerhard in Vogel / Lehner, p. 1219, par. 201, and Klaus Vogel Commentaries 1997, p. 657, par. 200a, both explicitely giving precedence (lex specialis) only to the extent that the provisions refer to the domestic tax laws; perhaps: Helminen, Marjaana in IBFD Commentaries on Art. 10 OECD MTC, sec. 6.2.2., without taking clear position.

${ }^{591}$ Michael Lang, hybrids, p. 39 et seq. See also par. 268 et seqq.; Federal Court of Australia, judgement ref. [2008] FCA 1570, 2008.

${ }^{592}$ Kaeser, Christian / Wassermeyer, Franz in Wassermeyer Commentaries, p. 1325, par. 136, and p. 1407, par. 10; Hans Pijl, interest, sec. 6.2.; perhaps: Martin Six, hybrid finance, sec. 3.

${ }^{593}$ Peter Hongler, p. 262.
} 
will be addressed later ${ }^{594}$, but is not of vital importance for the further course of this study ${ }^{595}$. As a result of their mutual exclusivity, the consistent and coherent system of Art. 10 and 11 OECD MTC demands that their autonomous parts must basically lead to equivalent results ${ }^{596}$.

(2) As regards Art. 13(5) OECD MTC, the provision is subsidiary to Art. 11 OECD MTC and therefore also to Art. 10 OECD MTC ${ }^{597}$.

As regards Art. 21(1) OECD MTC, the provision is also subsidiary to Art. 10, 11 and 13(5) OECD MTC. This is a result of its character as a residuary clause for all other distributive articles ${ }^{598}$, which may, however, not extend the scope of the OECD MTC as a whole ${ }^{599}$. It means that any gap within or among Art. 10, 11 and 13(5) OECD MTC or between these and any other distributive provision necessarily fall under Art. 21(1) OECD MTC. ${ }^{600}$

\subsubsection{Beneficial ownership}

\subsubsection{Preliminary remarks}

114 Although beneficial ownership is primarily a concept of subjective (re-)attribution rather than of objective income classification, it nevertheless appears to bear a close and strong nexus with a number of subject areas in this study. Accordingly, it is important to have a clear understanding and distinction of beneficial ownership in mind when analysing the tax treatment of financial instruments under the OECD MTC in order to avoid false conclusions. Considering the vital importance of this for the current way of making financial transactions, it proved to be insufficient and possibly misleading to exclude it from the scope of this study ${ }^{601}$. The purpose and objective of this section is therefore to analyse the concept of beneficial ownership in order to provide the author's understanding of its various aspects and implications on the classification of the income types of financial instruments.

\subsubsection{Definition and scope}

115 Financial transactions are often made indirectly by inserting a third party into the legal relationship between the investor and the investment, i.e. a financial intermediary. This intermediary (e.g. bank, broker, agent, issuer, fiduciary, nominee, administrator, etc.) may act on behalf of the investor or on his own behalf. In any case, such intermediation is typically arranged in a way that there is a legal or contractual obligation for the intermediary to pass any proceeds or income from the asset to the investor. As this pass-through normally includes any tax levied on that income, the intermediary as the formal taxpayer and the investor as the effective taxpayer

\footnotetext{
${ }_{594}$ See par. 204 et seq. and 221.

595 Equally: Gaspar Lopes Dias, tax arbitrage, p. 132. See also sec. 1.1.2.

${ }^{596}$ Kaeser, Christian / Wassermeyer, Franz in Wassermeyer Commentaries, p. 1427, par. 71.

${ }^{597}$ Equally: Harris, Peter A. in IBFD Commentaries on Art. 10 OECD MTC, sec. 5.1.2.5.6., and Li, Jinyan / Avella, Francesco on Art. 13 OECD MTC, sec. 6.2.2.; OECD Commentaries 2014 on Art. 10 OECD MTC, p. C(10)-11, par. 28, on Art. 11 OECD MTC, p. C(11)-12, par. 20 et seq. and on Art. 13 OECD MTC, p. C(13)-13, par. 31; Dutch Hoge Raad der Nederlanden, judgement ref. 28.959, 1994.

598 Eduardo Orellana, sec. 1; Alexander Bosman, p. 98 et seq. and 245; Rust, Alexander in Klaus Vogel Commentaries 2015, p. 1541, par. 27, and in Vogel / Lehner, p. 1922, par. 11; Wassermeyer, Franz / Kaeser, Christian in Wassermeyer Commentaries, p. 2053, par. 1; OECD Commentaries 2014 on Art. 21 OECD MTC, p. C(21)-1, par. 1; Kopp, Karin E.M. in Wolfgang Schön, equity and debt, p. 846; Cui, Shanshan in Thomas Ecker, p. 631; Peter Hongler, p. 273; Michael Lang, hybrids, p. 106; Klaus Vogel Commentaries 1997, p. 1071 , par. 7.

${ }_{599}$ Alexander Bosman, p. 79; Rust, Alexander in Klaus Vogel Commentaries 2015,; p. 1541, par. 25; Ismer, Roland in Vogel/Lehner, p. 464 et seq., par. 7; Cui, Shanshan in Thomas Ecker, p. 638; Michael Lang, hybrids, p. 106; Klaus Vogel Commentaries 1997, p. 1072, par. 12.

${ }^{600}$ Wattel/Marres, fictitious income, p. 69; Michael Lang, hybrids, p. 106; Klaus Vogel Commentaries 1997, p. 1072, par. 12.

601 See par. 11 and 16.
} 
become separate. In such cases, the purpose, intention and function of the treaty ${ }^{602}$ can be reached only by making it available to the effective taxpayer. Ergo, there must be some sort of concept beyond the pure legal circumstances in order to include the effective taxpayer to the treaty benefits and simultaneously exclude the formal taxpayer from them. The legal effect of the concept is a deemed (re-)attribution to the beneficial owner instead of to the formal recipient.

116 This original problem of identifying those mismatches between the legal and the economic enjoyment of the income from the asset is addressed by the concept of the beneficial owner as a specific (re-)attribution rule ${ }^{603}$ within the scope of Art. 10(2) and 11(2) OECD MTC under the general substance over form principle ${ }^{604}$. Meanwhile, corresponding to the current secondary objective of the OECD MTC to also prevent double non-taxation ${ }^{605}$, the concept of beneficial ownership has the dual purpose ${ }^{606}$ of being also a specific antiabuse provision ${ }^{607}$ within Art. 10(2) and 11(2) OECD MTC, applicable also to equivalent forms of those mismatches. With respect to the scope of this study ${ }^{608}$, the following analyses primarily focus on the (re-) attributional aspect of the beneficial owner concept. In contrast, the anti-abuse aspect shall only be touched where it serves the better understanding of that (re-)attributional aspect. For instance, from the anti-abuse aspect it may be concluded that there must be at least one beneficial owner. In order to ensure the application of the OECD MTC, it may also be concluded from the word the in Art. 10(2) and 11(2) OECD MTC that there isn't more than one single beneficial owner on the same asset or income (i.e. vertical or serial, e.g. a pass-through). An exception to this basic principle may be where there is a group of persons sharing the same legal and economic situation (i.e. horizontal or parallel, e.g. a partnership). ${ }^{609}$

117 As regards the interpretation of the term beneficial owner, it may legitimately be brought forward that the concept also implies an attribution rule and therefore a certain domestic nexus to a resident person ${ }^{610}$, in that any assignment to someone other than the taxpayer could actually frustrate its purpose, intention and function ${ }^{611}$. However, the mere fact that not all jurisdictions know it in their domestic tax laws ${ }^{612}$ makes plain that the concept of beneficial ownership is necessarily created by, and therefore can only be dealt with, on the treaty level ${ }^{613}$. This becomes especially clear when considering the OECD MTC as a collective law

\footnotetext{
${ }_{602}$ See par. 19.

${ }^{603}$ Robert Danon, sec. 3.3.; Adolfo Martín Jiménez, sec. 3.4., with a detailed justification and sec. 4.; Verdoner, Louan / Offermanns, René / Huibregtse, Steef, A Cross-Country Perspective on Beneficial Ownership, European Taxation 2010, Vol. 50, No. 9 / 10, sec. 2.

${ }^{604}$ Robert Danon, sec. 3.2. See also sec. 2.2.4.

${ }^{605}$ OECD MTC Draft Update, p. 8, par. 15.2, 15.6 and 16 et seq.; OECD Commentaries 2014, introduction, p. I-5, par. 16.

${ }^{606}$ Kemmeren, Eric C.C.M. in Klaus Vogel Commentaries 2015, p. 710, par. 6, and p. 716 et seqq., par. 20 et seqq.; OECD Commentaries 2014, p. C(10)-3, par. 12.1, and p. C(11)-7, par. 9.1; Duff, David G. / Reimer, Ekkehart in Michael Lang, beneficial ownership, p. 16 and 258.; Michael Lang, introduction, p. 101, par. 284; Verdoner, Louan / Offermanns, René / Huibregtse, Steef, A Cross-Country Perspective on Beneficial Ownership, European Taxation 2010, Vol. 50, No. 9 / 10, sec. 2.

${ }^{607}$ See par. 73.

${ }^{608}$ See sec. 1.2.

${ }^{609}$ Reimer, Ekkehart in Michael Lang, beneficial ownership, p. 256; Joanna Wheeler, attribution, p. 482.

${ }^{610}$ See par. 21.

${ }^{611}$ Duff, David G. in Michael Lang, beneficial ownership, p. 16; similarly: Indonesian Pengadilan Pajak, judgement ref. Put-13602/ PP/M.I/13/2008, 2008.

${ }^{612}$ Tischbirek, Wolfgang in Vogel/Lehner, p. 1107, par. 15; Joanna Wheeler, attribution, p. 480.

${ }^{613}$ Oliver, J. David B., Beneficial Ownership and the OECD Model, British Tax Review 2001, No. 1, p. 85 and 68; OECD, Double Taxation Conventions and the Use of Conduit Companies, Paris, 1986, p. R(6)-4, par. 6.
} 
in the sense of a multinational or multi-jurisdictional compromise ${ }^{614}$. True, beneficial ownership was said to be indeed a concept of subjective (re-)attribution ${ }^{615}$. However, it is the further conclusion that this aspect necessarily also bears a domestic nexus. Given this, it appears an impermissible generalisation to transfer such an aspect from a specific DTC between two jurisdictions, which know a beneficial ownership concept in their domestic tax laws, to the OECD MTC in general. Accordingly, the majority of commentators came to the consensus view that the term beneficial owner falls under the exception rule unless the context otherwise requires in Art. 3(2) OECD MTC ${ }^{616}$ and therefore to be interpreted autonomously ${ }^{617}$. In addition, the concept of beneficial ownership for dividends in Art. 10(2) OECD MTC is identical to the one for interest in Art. 11(2) OECD MTC. ${ }^{618}$

118 Obviously, the purpose of beneficial ownership is to go beyond the purely legal relationships. This "quest for the unknown" has led to some uncertainty on the role of the law ${ }^{619}$. Accordingly, the questions raised are, for instance:

- What is meant by "non-legal" relations (e.g. illegal)?

- What is the role of economic or purely factual power structures (e.g. between parent and subsidiary entities)?

- Which are their principles and how can these be operationalised for applying the OECD MTC (e.g. what is an "economic interpretation")?

These ambiguities and questions fall into the two methodological categories of applying the tax $1 \mathrm{law}^{620}$ : (1) the case-by-case assessment or subsumption of concrete facts or attributes from precursory fields of law and (2) the abstract interpretation of the OECD MTC as the tax law itself.

119 As regards the first question of what is meant with "non-legal" relations, it is the author's understanding that this uncertainty is a result from the confusion of two separate aspects. On the one hand, the concept of beneficial ownership can be used to describe a relationship between two persons or subjects (i.e. the recipient and the beneficial owner). According to the purpose of beneficial ownership of going beyond the law, there is no space for this relationship to be anything other than a non-legal one. It is this subject-related aspect,

\footnotetext{
${ }_{614}$ See par. 18.

615 See par. 114 et seq.

${ }^{616}$ See par. 20.

${ }^{617}$ Caroline Poiret, sec. 2.6., and Kemmeren, Eric C.C.M. in Klaus Vogel Commentaries 2015, p. 718 et seq., par. 25, and p. 720 et seq., par. 31 , both with reference to OECD, Beneficial Owner, 2012, p. 3, 18 and 20, deleting the earlier reference to the domestic tax law in OECD, Beneficial Owner, 2011, p. 3 and 5; Tischbirek, Wolfgang in Vogel/Lehner, p. 1107, par. 15; Raber, Hans Georg in Franz Wassermeyer, Festgabe, p. 304, par. 4; Katja Dyppel Weber, sec. 4.1.; OECD Commentaries 2014, p. C(10)-3, par. 12.1, and p. C(11)-7, par. 9.1; OECD, Beneficial Owner, 2012, p. 3, par. 2 et seqq.; UN, Committee of Experts on International Cooperation in Tax Matters - Report on the sixth Session (18 - 22 October 2010), Economic and Social Council, Official Records 2010, Supplement No. 25, UN, New York, 2011, p. 17 et seq., par. 86 et seq.; Robert Danon, sec. 2.1. et seqq. and 6.; Arnold, Brian J. in Michael Lang, beneficial ownership, p. 49; Court of Appeal of England and Wales, judgement ref. A3/2005/2497, 2006; Joanna Wheeler, attribution, p. 481 et seq.; Philip Baker, p. 10-7, par. 10-B13; du Toit, Charl Petrus, royalties, p. 237; Klaus Vogel Commentaries 1997, p. 562, par. 8; unclear: Adolfo Martín Jiménez, in favour in sec. 3.2. but then contrary in sec. 3.4.; perhaps contrary: Kaeser, Christian/Wassermeyer, Franz in Wassermeyer Commentaries, p. 1285, par. 69, referring however to the particular protocol amending the specific German-US DTC, and p. 1413, par. 31a, without justification; OECD, The Granting of Treaty Benefits with Respect to the Income of Collective Investment Vehicles, OECD, Paris, 2010, p. 9, par. 31, remaining vague on whether or not the exception rule unless the context otherwise requires in Art. 3(2) OECD MTC shall actually apply to the specific case of collective investment vehicles (see par. 11).

${ }^{618}$ OECD, Beneficial Owner, 2012, p. 16.

${ }_{619}$ Tischbirek, Wolfgang in Vogel / Lebner, p. 1106, par. 13, and p. 1108 et seq., par. 17 et seqq.; Kemmeren, Eric C.C.M. in Klaus Vogel Commentaries 2015, p. 723, par. 37; OECD Commentaries 2014, p. C(10)-4, par. 12.4, and p. C(11)-8, par. 10.2; Adolfo Martín Jiménez, sec. 3.3., 3.5. and 4; Charl du Toit, evolution, sec. 3.2.5.; Klaus Vogel Commentaries 1997, p. 562 et seq., par. 10.

${ }^{620}$ See par. 72 and 82.
} 
which is typically meant where economic or factual power structures are advocated. On the other hand, the concept of beneficial ownership can be used to describe a relationship between a person or subject and an object (e.g. income, asset). Equally, pursuant to the purpose of beneficial ownership of going beyond the law, there is again no space for this relationship to be anything other than a non-legal one. It is this object-related aspect, which is typically meant where the legal relationship between the two persons or subjects is advocated. Bringing both ways of interpretation together makes it important to keep and address those two aspects clearly separated. A non-legal relationship between a person or subject and an object can nevertheless be the result of a legal relationship between two or more persons or subjects. The following illustration visualises this understanding:
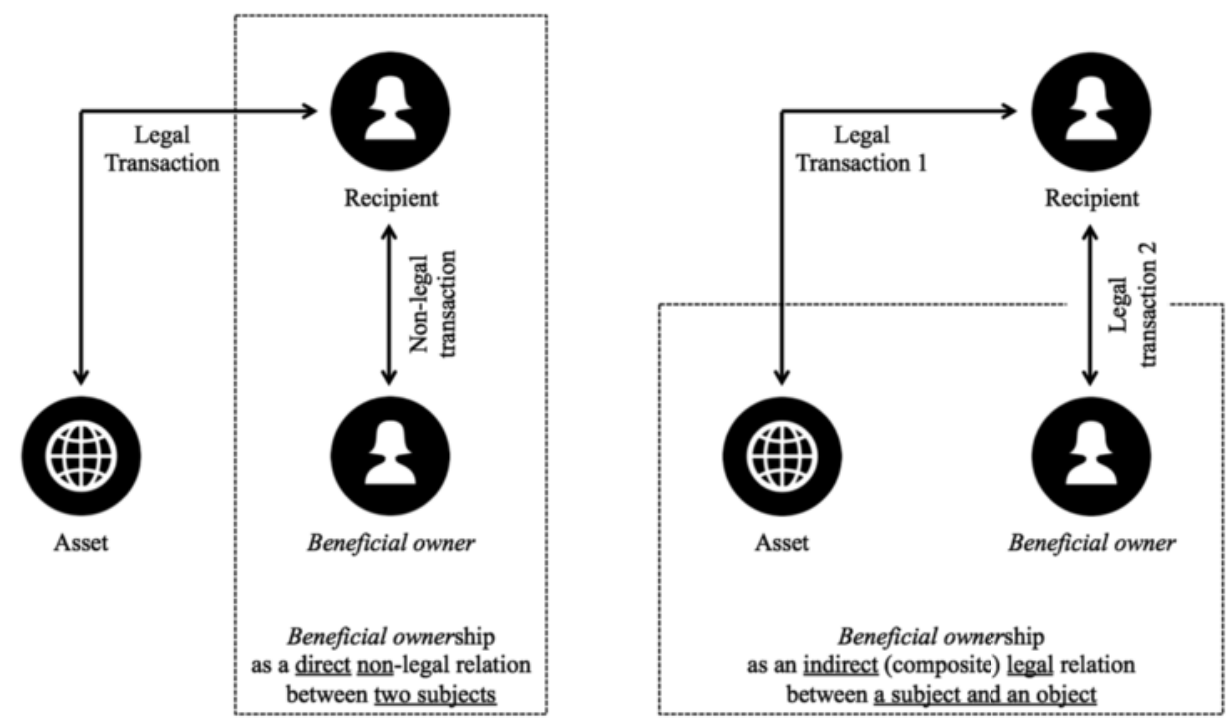

Illustration 9: Subject-related aspect and object-related aspect of beneficial ownership

120 That said, the supposed ambiguity of beneficial ownership seems to be rooted in the application or transfer of the economic or factual power structures from the relation between the two subjects or persons (i.e. the subject-related aspect) to the relation between the subject and the object (i.e. the object-related aspect). Accordingly, the dispute over the relation between the subject (beneficial owner) and the object (asset or income) revolves around an imaginary dualism between its legal or non-legal character and interpretation as a methodological approach. In other words: the misunderstanding appears to be caused by confusing the two methodological steps of applying the tax law ${ }^{621}$. It is a consequence of actually transferring the principles of the case-by-case assessment or subsumption of concrete facts or attributes from precursory fields of law to the abstract interpretation of the OECD MTC as the tax law itself.

${ }_{621}$ See par. 118. 
121 In this respect, it is in line with the above findings ${ }^{622}$ and accurate according to the majority of commentators ${ }^{623}$ to say that, in the end, an "economic interpretation" or an "economic approach" in terms of beneficial ownership do not exist. Ultimately, economic or factual power structures are reducible to legal powers or relations ${ }^{624}$. However, it shall become clear that this view is limited to the object-related aspect of beneficial ownership and to a methodology. In practice, economic or factual power structures between two subjects (i.e. the subjectrelated aspect) as a matter of fact actually exist ("economic compulsion", e.g. incentives to take a certain legal choice $)^{625}$. Nevertheless, with respect to the scope of this study ${ }^{626}$, the focus here shall be limited to the object-related aspect (i.e. the relation between beneficial owner and asset or income). As an interim result for the further course of this study it is held that the beneficial ownership is understood in a narrow sense of requiring composite legal transactions between the beneficial owner and the asset or income. Mere economic or factual relations are not sufficient. In that sense beneficial ownership is a requisite and explicit exception from the finding ${ }^{627}$ that an aggregation of an asset or transaction upwards from its legal form (i.e. composite units of in- and outflow) basically can not be justified by the substance over form principle.

\subsubsection{Asset-and transaction-related aspect}

122 Its position between the general allocation rules in Art. 10(1) and 11(1) OECD MTC respectively and their definitions in Art. 10(3) and 11(3) OECD MTC raises the question whether, and to what extent, the concept of beneficial ownership affects the definitions and interpretations of the terms dividends and interest. On the one hand, Art. 10(2) and 11(2) OECD MTC may be understood as mere (re-)attribution rules, leaving the definitions themselves untouched. This view is not only supported by the fact that both provisions refer back to their general allocation rules in the precedent paragraphs by the word however. In doing so, they require the terms dividends and interest, introduced by Art. 10(1) and 11(1) OECD MTC respectively, as a precondition. In addition, only the specific limitation rules in Art. 10(2) and 11(2) OECD MTC depend on the concept of the beneficial owner but the general allocation rules in Art. 10(1) and 11(1) OECD MTC 628 do not. In other words: the function of beneficial ownership is only to affect the amount of tax allocated to the source jurisdiction but not its subjacent legal grounds. These elements of purposive, intentional and functional interpretation may be complemented by the systematic consideration that the legal consequences of Art. 10(2) and 11(2) OECD MTC cannot at the same time as they depend on Art.10(1) and 11(1) OECD MTC respectively also have any influence back on them ${ }^{629}$.

123 On the other hand, the definitions in Art. 10(3) and 11(3) OECD MTC are located subsequent to the concept of beneficial ownership in the precedent Art. 10(2) and 11(2) OECD MTC. From this textual position, the terms dividends and interest may be understood in that they could be influenced by the concept

\footnotetext{
${ }_{622}$ See par. 80.

${ }^{623}$ Tischbirek, Wolfgang in Vogel/Lehner, p. 1106, par. 13, and p. 1109 et seq., par. 19; Kemmeren, Eric C.C.M. in Klaus Vogel Commentaries 2015, p. 723, par. 37; Gutmann, Daniel in Michael Lang, beneficial ownership, p. 343; Adolfo Martín Jiménez, sec. 3.5. and 4.; Charl du Toit, evolution, sec. 3.2.5.

${ }^{624}$ Equally for IAS / IFRS: Kubn / Hachmeister, p. 604 et seqq., par. 32 et seqq.

${ }^{625}$ Hartenberger, Heike in Beck, IFRS / IAS, p. 163, par. 112; comprehensively: IAS Board, October 2016, 5B.

${ }^{626}$ See sec. 1.2 .

627 See par. 95.

${ }^{628}$ Helminen, Marjaana in IBFD Commentaries on Art. 11 OECD MTC, sec. 3.2.3.3.1.1.; OECD Commentaries 2014, p. C(10)-3, par. 12 , and p. C(11)-7, par. 9 .

${ }^{629}$ Circular reasoning.
} 
of beneficial ownership. This view may also be supported by the systematic argument that the existence of, and the distinction between, shares and debt-claims depend on the attribution and therefore the economic ownership of the underlying capital or principa ${ }^{630}$. Finally, the literal interpretation of the English term beneficial owner is to be understood in a connotation of a static rather than a dynamic reference ${ }^{631}$. In fact, an ownership typically refers to an object or right already in existence (i.e. the asset). In contrast, an alternative reading as ownership in a transaction or an ownership in an income is somehow hard to imagine. The reason is that a transaction requires the consent of the contracting counterparty and an income requires a realisation as a logical pre-step. Since the asset implies the transaction ${ }^{632}$, any influence of the beneficial owner to the asset would - according to that view - necessarily also influence the transaction ${ }^{633}$.

124 In this study, the former position is, however, taken that the beneficial ownership does not affect the genuine legal concepts ${ }^{634}$ and the interpretation of the terms dividends and interest.

- As a literal element of interpretation, its static connotation appears to be a peculiarity of the English version of "beneficial owner". This stands in contrast to the broader and thus more flexible denotation of the term in many other languages, such as - for instance - in Dutch ("uiteindelijk gerechtigde"), French ("bénéficiaire effectif”), German ("Nutzungsberechtigter"), Italian ("beneficiario effettivo"), Portuguese ("beneficiário efectivo") or Spanish ("beneficiario efectivo").

- The first systematic counterargument that Art. 10(3) and 11(3) OECD MTC are textually located subsequent to Art. 10(2) and 11(2) OECD MTC, is not sustainable. Justifying a logical nexus with Art. 10(1) and 11(1) OECD MTC as a precondition would require a stronger emphasis than that provided their mere textual position. In that sense this textual position is unfortunate; the definitions of dividends and interest should rather be moved upward prior to the second paragraphs (e.g. as is in Art. 12 OECD MTC).

- The second systematic counterargument that the existence of and the distinction between shares and debt-claims depend on the attribution and therefore the economic ownership of the underlying capital or principal, represents a circular reasoning. The concept of beneficial ownership is itself the legal consequence of Art. 10 and 11 OECD MTC and therefore cannot simultaneously be a precondition for their application. That is why matters of attribution and ownership of the underlying capital or principal must necessarily be separated from the treaty concept of beneficial ownership.

- The third counterargument that the term beneficial owner appeared closer to a static rather than to a dynamic reference, demands a deeper examination:

125 The OECD MTC uses the term beneficial owner only in conjunction with the income or transaction ${ }^{635}$. However, according to the majority of commentators ${ }^{636}$ there is nevertheless a beneficial ownership in the asset

\footnotetext{
${ }^{630}$ Michael Lang, hybrids, p. 95 et seqq.

631 See par. 55.

${ }^{632}$ See par. 53 et seq.

${ }^{633}$ Argumentum a maiore ad minus.

634 See par. 73.

${ }_{635}$ "However [...] but if the beneficial owner of the dividends is a resident of the other Contracting State, the tax so charged shall not exceed [...]" (Art. 10(2) OECD MTC); "However [...] but if the beneficial owner of the interest is a resident of the other Contracting State, the tax so charged shall not exceed [...]"(Art. 11(2) OECD MTC).

${ }^{636}$ Kemmeren, Eric C.C.M. in Klaus Vogel Commentaries 2015, p. 724, par. 39; Kaeser, Christian / Wassermeyer, Franz in Wassermeyer Commentaries, p. 1282 et seq., par. 68; OECD Commentaries 2014, p. C(10)-4, par. 12.4, p. C(10)-6, par. 12.6, p. C(11)-9 et seq., par. 10.2 and 10.4; Reimer, Ekkehart in Michael Lang, beneficial ownership, p. 257 and 261 et seqq.; OECD, Beneficial Owner, 2012, p. 10;
} 
as well. In other words: the economic aspect of beneficial ownership does not only address the (re-)attribution of the income or transaction but also that of the asset. ${ }^{637}$ The two aspects are independent of each other and can lead to different results ${ }^{638}$.

Example 19: An asset may be legally encumbered in a way that its proceeds are entitled to one beneficiary but its principal or underlying right to another beneficiary. Although both are based on composite legal transactions, the former may be considered the beneficial owner of the income and the latter the beneficial owner of the asset itself.

It may therefore be legitimately questioned where the beneficial ownership in the asset stems from and/or what its purpose and justification is in the context of distributive provisions dealing only with income.

126 The third counterargument, according to which the term beneficial owner appeared closer to a static rather than to a dynamic reference ${ }^{639}$, may suggest that the distinction between the two aspects of beneficial ownership might be seen as a necessary result from the asset-based approach taken by the OECD MTC for dividends and interest ${ }^{640}$. However, as has been shown, these definitions can alternatively be accessed and more precisely be interpreted by means of the transaction-based approach, which leads to the same results ${ }^{641}$. For this same reason, the beneficial ownership in the asset isn't required to distinguish the sources of dividend income from those of interest income either. Ergo, a justification for the view that the concept of beneficial ownership had an influence on the definitions of dividends and interest, must likewise stand against the transactionbased approach. Also the transaction-based approach was said to require the asset in order to identify and tax-systematically classify the source of income ${ }^{642}$. However, this objective classification is independent of the subjective matter of (re-)attribution or (re-)assignment (e.g. both a company and a partnership can each be attributed to a legal owner or to a beneficial owner). Hence, neither the asset-based approach nor the transaction-based approach provide any compelling reason for the conclusion that the concept of beneficial ownership had an influence on the definitions of dividends and interest.

127 According to the author's view, the beneficial ownership in the asset nevertheless follows from other intentional and purposive considerations. As stated above, it is first and foremost the location of the situs of the asset as the source of income, which constitutes a cross-border situation at all and therefore determines the applicability of the OECD MTC as a whole. ${ }^{643}$ From this perspective it is obvious that its purpose of being also a specific anti-abuse provision, for instance to prevent treaty shopping by inserting a legal owner between asset and investor, would fail where the beneficial ownership did not also include that asset. In other words: the

Collier, Richard, Clarity, Opacity and Beneficial Ownership, British Tax Review 2011, No. 6, p. 703; Michael Lang, hybrids, p. 96; Klaus Vogel Commentaries 1997, p. 562, par. 9; OECD, Double Taxation Conventions and the Use of Conduit Companies, Paris, 1986, OECD Commentaries 2014, p. R(6)-7, par. 13; contrary: Robert Danon, sec. 3.2., merely observing that OECD, Beneficial Owner, 2011, does not also refer to beneficial ownership in the asset.

${ }^{637}$ OECD Commentaries 2014, p. C(10)-6, par. 12.6, and p. C(11)-9, par. 10.4.

${ }^{638}$ OECD Commentaries 2014, p. C(10)-4, par. 12.4, p. C(11)-8, par. 10.2.

${ }^{639}$ See par. 123.

${ }^{640}$ See par. 58.

${ }^{641}$ See par. 52 et seqq.

${ }^{642}$ See par. 57 et seq.

${ }^{643}$ See par. 57. 
anti-abuse purpose of beneficial ownership necessarily requires the situs of the asset as the source of income. As an interim result for the further course of this analysis it is held in accordance with the majority's view ${ }^{644}$ that there is not only a beneficial ownership in the income or transaction but also a beneficialownership in the asset.

\subsubsection{Interim conclusions}

128 The dual aspect of the beneficial ownership of referring to the asset and to the income or transaction appears to correspond with its dual purpose and function ${ }^{645}$. While the (re-)attributional purpose relates to the income, the anti-abuse purpose relates to the asset. In other words: the (re-)assignment of assets by way of beneficial ownership serves its anti-abuse function, whereas the (re-)assignment of income by way of beneficial ownership serves its (re-)attributional function. Admittedly, the anti-abuse aspect applies to forms of mismatches between formal and effective taxpayer equivalent to a financial intermediation ${ }^{646}$. It may therefore be legitimately called into question, why the anti-abuse aspect - as opposed to the (re-) attribution aspect - should exclusively refer to the asset rather than to the income as well. In other words: why the asset as the source of income shall not only be a necessary minimum condition (conditio sine qua non) for the anti-abuse purpose ${ }^{647}$ but also its sufficient maximum condition (conditio per quam) or verifier. However, in the treaty context the difference between non-abusive mismatches (e.g. financial intermediation) and abusive mismatches (e.g. conduit companies) can only be the application of the treaty itself (i.e. the misuse of its material benefits). Pursuant to Art. 1 OECD MTC this is possible only by establishing a resident person in the other jurisdiction, i.e. the situs of asset. It is such "creation" of an asset by establishing a resident person between investment and investor at which the anti-abuse aspect of beneficial ownership is targeting. In contrast, the (re-)assignment of income through a financial intermediary - which is a resident person in the other jurisdiction as well - is already covered by the (re-)attributional aspect, even where there was no antiabuse purpose. The observation that beneficial ownership in the asset as a result of the anti-abuse purpose and beneficial ownership in the income or transaction as a result of the (re-)attributional purpose often correlate in practice ${ }^{648}$, may not lead to the conclusion that the two aspects are in any way systemically dependent on each other ${ }^{649}$. This is not to say that it was easy to distinguish abusive and non-abusive mismatches in practice. It only means that, once they have been distinguished, they address different purposes of beneficial ownership with different implications. The reason for this independency is that treaty abuse presupposes additional qualifying elements going beyond a mere financial intermediation. ${ }^{650}$ The asset-based approach implies the classification of the income or transaction ${ }^{651}$ but not its (re-)attribution as a subsequent logical step. In other words: beneficial ownership is not covered by the asset-based approach. Ergo, asset and transaction are - as regards their (re-)attribution - principally independent of each other ${ }^{652}$. Hence, following the consensus that

\footnotetext{
${ }^{644}$ See footnote 636.

${ }^{645}$ See par. 116.

${ }^{646}$ See par. 115 .

${ }^{647}$ See par. 127.

${ }^{648}$ Reimer, Ekkehart in Michael Lang, beneficial ownership, p. 260 et seq., confusing the anti-abuse aspect and the (re-)attributional aspect by making the reservation that an income or transaction attribution different from the asset attribution were subject to a justification under material economic reasons.

${ }^{649}$ Cum hoc ergo propter hoc.

${ }^{650}$ Gutmann, Daniel in Michael Lang, beneficial ownership, p. 342 et seq.

651 See par. 54.

652 See par. 53.
} 
the two purposes are not one and the same ${ }^{653}$, the financial intermediary as a resident person is excluded from the treaty application by way of the (re-)attributional aspect. In contrast, any artificial structure as a resident person (e.g. conduit company) is excluded from the treaty application by way of the anti-abuse aspect. Apparently, there should be no doubt that the (re-)attributional aspect of beneficial ownership relates to the income or transaction ${ }^{654}$. However, the aforementioned considerations confirm the above hypothesis that the anti-abuse aspect of beneficial ownership relates only to the asset. The following illustration visualises this understanding:

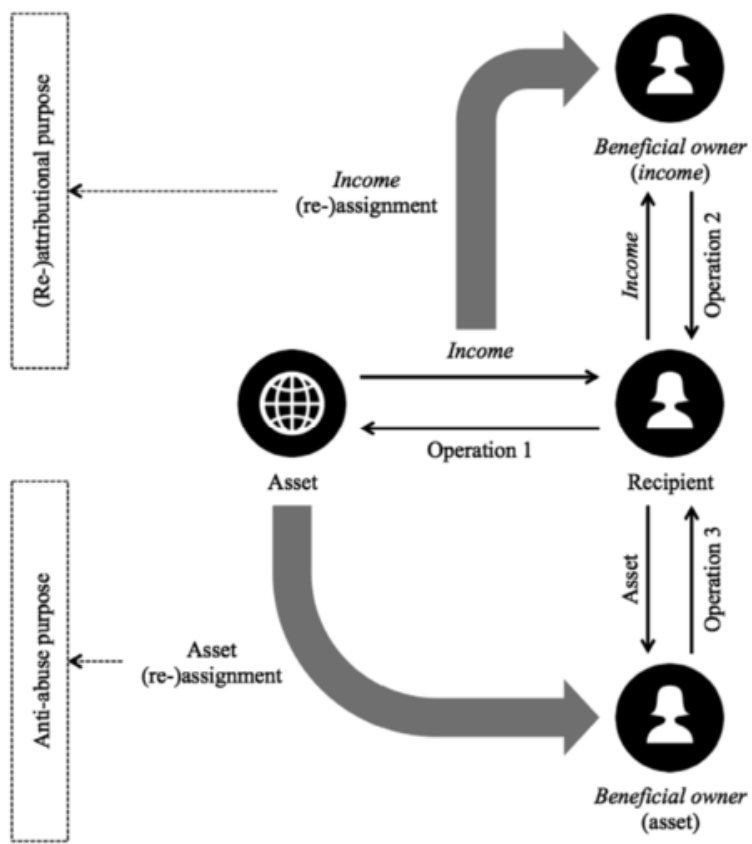

Illustration 10: (Re-)attributional aspect and anti-abuse aspect of beneficial ownership

129 This understanding demonstrates that the third counterargument, according to which the term beneficial owner literally is to be understood in a connotation of a static rather than to a dynamic reference ${ }^{655}$, may indeed be correct. According to the author's understanding, this argument is nevertheless biased to the single aspect of asset (re-)assignment. This asset (re-)assignment, however, does in no way - neither by subject nor by purpose - affect the income ${ }^{656}$. Therefore it does not provide any compelling reason either for the conclusion that the concept of beneficial ownership had any influence on the interpretation of dividends and interest. Summarising this as an interim conclusion, the concept of beneficialownership in Art. 10(2) and 11(2) OECD MTC is independent of, and does not affect, the genuine legal definitions of the terms dividends and interest in Art. 10(3) and 11(3) OECD MTC. As a result, it means in particular that an income from a

\footnotetext{
653 See par. 116.

${ }^{654}$ See par. 125.

655 See par. 123.

${ }^{656}$ Contrary: Reimer, Ekkehart in Michael Lang, beneficial ownership, p. 261 (see footnote 648), consistently endeavouring to approach the beneficial ownership in the income or transaction via the beneficial ownership in the asset.
} 
transaction keeps its genuine nature and is not (re-)classified into something else only because it has been (re-)attributed by way of beneficial ownership. For instance, a dividend income passed-through to a beneficial owner in the form of interest still keeps its nature of a dividend and is not (re-)classified into interest. Or methodologically spoken: the concept of beneficial ownership is not able to substitute the nature of dividends and interest.

130 Beyond this finding, the above understanding also allows additional insights. Where the beneficial ownership in the asset is linked to the source and the beneficial ownership in the transaction is linked to the income from that source ${ }^{657}$, both aspects point in opposite directions of the logical step sequence of a tax event:

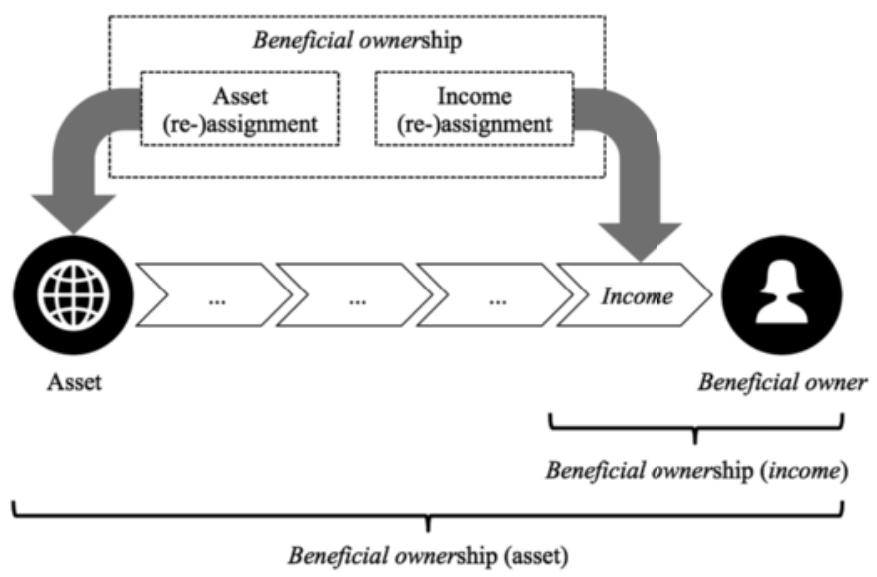

Illustration 11: Different scopes of beneficial ownership in the asset and in the income or transaction

All the logical steps of a tax event such as aggregation versus disaggregation, operation or realisation affect the income but not the asset. Hence, each of them must necessarily bears a nexus with the beneficial ownership in the income or transaction and cannot possibly bear a nexus with the beneficial ownership in the asset. Accordingly, the beneficial ownership in the asset encompasses a person's entire relation with all logical steps including the asset. In contrast, the scope of the beneficial ownership in the transaction is limited to a person's income only. That is not only why the subjective (re-)attribution of the income must be carefully distinguished from all the precedent logical steps, whereas the subjective (re-)attribution of the asset already implies all these logical steps. It is also the systematic reason for the observation that the (re-)attribution of the income or transaction and that of the asset are independent of each other and can lead to different results ${ }^{658}$.

131 Due to the fact that the asset is the source of the income, these two aspects with their different scopes apply very closely to each other and therefore tend to be confused. This may lead to false conclusions when interpreting Art. 10(3) and 11(3) OECD MTC, which shall be demonstrated by the following examples:

\footnotetext{
${ }^{657}$ See par. 128.

${ }^{658}$ See par. 125.
} 
(1) Aggregation versus disaggregation: The beneficial ownership in the asset already includes the information of what the asset structure is (e.g. structured product or underlying). In contrast, the beneficial ownership in the income or transaction does not include or provide information on what the income structure is (e.g. income from the structured product or from its underlying), which is subject to the precedent aggregation versus disaggregation test. Where the beneficial ownership in the asset is extrapolated to the beneficial ownership in the income or transaction from that asset, the structure of the asset may give rise to erroneous conclusions regarding the structure of the income or transaction.

(2) Operation: The beneficial ownership in the asset already includes the information that the asset is subject of finance (e.g. borrowed share). In contrast, the beneficial ownership in the income or transaction does not include or provide the information that the income is derived from that finance (e.g. dividend or compensation), which is subject to the precedent finance operation test. Where the beneficial ownership in the asset is extrapolated to the beneficial ownership in the income or transaction from that asset, the nature of the asset may give rise to erroneous conclusions regarding the nature of the income or transaction. This may not be misunderstood to mean that the beneficial ownership had any influence on the income or transaction. Rather, it means that the nature of the income or transaction may in turn have an influence on its beneficial ownership.

(3) Realisation: The beneficial ownership in the asset already includes the information that the asset "exists tax-wise". In contrast, the beneficial ownership in the income or transaction does not include or provide the information that the income "exists tax-wise", which is subject to the precedent realisation test. Where the beneficialownership in the asset is extrapolated to the beneficialownership in the income or transaction from that asset, the asset (re-)attribution may give rise to erroneous conclusions regarding the income realisation.

132 Having investigated its aspects and consequences as well as its context and scope, it has been found so far that the beneficial ownership in the asset is independent of beneficial ownership in the income or transaction ${ }^{659}$. Therefore, the beneficial ownership in the asset is basically not relevant for the further course of this study. It has also been found that the beneficial ownership in the income or transaction has no influence on the definitions of dividends and interest. ${ }^{660}$ However, the deemed (re-)attribution of income - keeping their genuine legal character - actually means a look-through approach. ${ }^{661}$ In other words: the beneficial owner realises the income in the same legal character as the recipient before him, regardless of the form in which that income is passed through (classification chain). From the beneficial owner's perspective it could therefore be suggested that the concept actually did influence the classification of his dividends and interest. Or in other words: that the income (re-)classification by way of beneficial ownership was a necessary side effect of the income (re-)attribution. However, Art. 10(2) and 11(2) OECD MTC necessarily take the recipient's perspective, as the concept of beneficial ownership is their legal consequence. That is why Art. 10(3) and 11(3) OECD MTC cannot apply to the beneficial owner a priori ${ }^{662}$ but only a posteriori.

Example 20: A beneficial owner resident in the same jurisdiction $\mathrm{A}$ as the recipient is a posteriori set into the treaty A position of the recipient, taking his income classification as a

\footnotetext{
${ }_{659}$ See par. 128.

${ }^{660}$ See par. 129.

${ }^{661}$ Reimer, Ekkehart in Michael Lang, beneficial ownership, p. 261.

${ }^{662}$ Circular reasoning.
} 
legal consequence (classification chain). In contrast, a beneficial owner resident in a different jurisdiction $\mathrm{B}$ than the recipient does not take the income classification as a legal consequence from treaty A. Instead he is a priori recipient himself under treaty B (i.e. no cross-treaty classification chain).

Accordingly, the (re-)classification of the beneficial owner's income is not the primary purpose, intention and function of the concept. Instead, it is rather to include the beneficial owner and simultaneously exclude the recipient from the treaty benefits by entirely replacing the latter by the former. ${ }^{663}$ In other words: beneficial ownership is no (re-)classification of one object into another (i.e. the income) but a replacement of one subject by another (i.e. the recipient by the beneficial owner). This is why there are not two transactions as a result of beneficial ownership (i.e. the genuine income type and a re-classified income type) but only one and the same (i.e. the genuine income type). Again, it is important to emphasise that this replacement is a legal consequence of the beneficial ownership concept and has therefore no influence on the definitions of dividends and interest. This does not only apply to those realised by the recipient but also to those (re-)attributed to the beneficial owner. As stated before ${ }^{664}$, it would nevertheless be insufficient and possibly misleading to exclude the concept of beneficial ownership in the income or transaction as the primary focus ${ }^{665}$, which turns out to be of utmost importance for today's way of making financial transactions.

\subsubsection{Operationalisation}

133 The definition of beneficial ownership in the income or transaction now requires an analysis of the legal relation between the recipient and the beneficial owner. In other words: what material quality this legal relation needs to have in order to constitute beneficial ownership. Although the legal relation as such must be determined individually by reference to the domestic law, the material key question of when their composition turns into a mere formal attribution is a matter to be interpreted autonomously. ${ }^{666}$

134 In this respect, the majority of commentators adopt a control concept consisting of two critical powers ${ }^{667}:(1)$ the power to control whether or not there shall be a distribution, i.e. the power to create or distribute income; and (2) the power to control how this distribution is to be used, i.e. the power to enjoy or apply income. Where a legal position is restrained in a way that one of these two critical control powers is restricted or limited, the recipient is not considered the beneficial owner. The approaches to developing a concrete test for this control concept can be isolated ${ }^{668}$ and categorised as follows:

(1) Risk test: Some commentators ${ }^{669}$ suggest a low dependency to be sufficient by testing the default or market risk remaining with the recipient of the income in the technical sense of a mere correlation between the inand outflows. In other words: to what extent the fulfilment of the legal obligations or commitments by the

\footnotetext{
${ }_{663}$ See par. 115.

${ }^{664}$ See par. 114.

${ }^{665}$ See par. 116.

${ }^{666}$ Tischbirek, Wolfgang in Vogel /Lehner, p. 1107, par. 15; Klaus Vogel Commentaries 1997, p. 562, par. 8. See also par. 72.

${ }^{667}$ Caroline Poiret, sec. 2.5., and Robert Danon, sec. 3.2., particularly stressing the first control power; Collier, Richard, Clarity, Opacity and Beneficial Ownership, British Tax Review 2011, p. 702; Oliver, J. David B., Beneficial Ownership and the OECD Model, British Tax Review 2001, No. 1, p. 57; Klaus Vogel Commentaries 1997, p. 562, par. 9; similarly for IAS / IFRS: Anna Verena Matthies, p. 49 et seq.

${ }_{668}$ Among others: Canadian Federal Court of Appeal, judgement ref. A-252-08, 2009, combining several of these test criteria into one integrated approach.

${ }^{669}$ Joanna Wheeler, attribution, p. 482 et seq. and 488.
} 
recipient towards a creditor (outflows) depends on the fulfilment of the legal obligations or commitments by a debtor (inflows). They argue that such a quantitative approach was a practical compromise between the two extremes of an one-on-one relationship on the one hand and on the other hand the possibility of spotting fragmented or otherwise complex bundles of payments. In addition, it also was the correlation as a strong indicator of risk taken by the recipient which represented the key difference as opposed to financial intermediaries, who are obliged to pay their creditors independently of any other transaction.

(2) Service fee test: Other commentators ${ }^{670}$ suggest a closer dependency between in- and outflows by way of identifying those obligations or commitments to pass-through the inflows by respective service fees. They argue that such a qualitative approach arises from the distinction between the management of own assets on the one hand and on the other hand the management on behalf of someone else.

(3) Intended use test: instead of such objective tests focussing on the mere existence of those obligations or commitments, some commentators ${ }^{671}$ suggest a stronger dependency between in- and outflows by examining their particular nature with the subjective approach of an intended use;

(4) Individual analysis: other commentators ${ }^{672}$ even support a narrow view suggesting that those obligations or commitments to pass-through the inflows must refer to and be verified for each and every payment individually (e.g. pertaining to the currency, settlement or default risk).

135 As discussed before ${ }^{673}$, the IAS/IFRS provide the concept of economic relationship ${ }^{674}$. It describes a general qualifying criterion for putting separate legal items into such context for the purpose of aggregation (hedging). It is qualitatively defined as a causal relation between in- and outflows that must be quantitatively observable by expected negative correlation depending on the same risk in the sense of a typical and systematically similar change in response to that risk. ${ }^{675}$ Such economic relationship must further meet the requirements of hedge effectiveness, which is actually close to the above risk test ${ }^{676}$. This means that credit risk may not dominate $i^{677}$, for instance where in- and outflows are collateralised differently ${ }^{678}$ or where there is a significant time lag between the two ${ }^{679}$. It also means that the in- and outflows must be proportionate in approximately equal amounts or benefits ${ }^{600}$, i.e. a legal relationship providing an outflow that is significantly lower than the respective inflow cannot be considered an effective economic relationship. Admittedly, transferring this approach to the treaty concept of beneficial ownership also requires to take the limited scope of the hedge accounting (i.e. aggregation) rules in general and the economic relationship concept in particular ${ }^{681}$ into account as exceptions

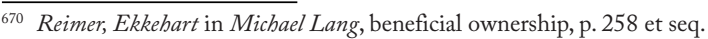

${ }^{671}$ Without providing a methodological justification: Kemmeren, Eric C.C.M. in Klaus Vogel Commentaries 2015, p. 724, par. 38; OECD Commentaries 2014, p. C(10)-4, par. 12.4, p. C(11)-8, par. 10.2; OECD, Beneficial Owner, 2012, p. 6 et seqq., par. 12 et seqq., instead providing a casuistic and non-exhaustive list or catalogue of typical examples empirically encountered in most OECD members.

${ }^{672}$ Without justification: Tischbirek, Wolfgang in Vogel/Lehner, p. 1109 et seq., par. 19; Reimer, Ekkehart in Michael Lang, beneficial ownership, p. 259 et seq.

673 See par. 93.

${ }^{674}$ IFRS 9.6.4.1(c)(i).

${ }^{675}$ IFRS 9.B6.4.4 et seqq.

${ }^{676}$ See par. 134(1), with the difference that credit risk can also be caused by a significant time lag between in- and outflows.

677 IFRS 9.6.4.1(c)(ii).

678 IFRS 9.B6.4.8.

679 IAS 32.48

${ }^{680}$ IFRS 9.6.4.1(c)(iii); Dominik Dettenrieder, p. 205.

${ }^{681}$ Dominik Dettenrieder, p. 194.
} 
from the principal IAS/IFRS prohibition of aggregation ${ }^{682}$. However, not only are these limitations subject of criticism already within the IAS/IFRS ${ }^{683}$; the IAS/IFRS concept of economic relationship also appears to be principally transferable to the OECD MTC concept of beneficial ownership, in that both represent a specific subset of their respective substance over form principles as exceptions from their general primacy of the legal form ${ }^{64}$. Nevertheless, beneficial ownership addresses aspects regarding the payment profile, rights and obligations as well as timing of financial instruments, which all demand a cautious invocation of the substance over form principle ${ }^{685}$. True, it also addresses aspects of risk, which is naturally more associated with the economic substance rather than with the legal form ${ }^{686}$. However, as was found ${ }^{687}$, this particularly does not apply to credit risk as a legal risk ${ }^{68}$. Apart from its limited scope of application, from the author's point of view there are, as a result, no compelling reasons to justify less restrictive requirements than those of the riskbased IAS/IFRS concept of economic relationship, if transferred to the treaty concept of beneficial ownership. Conversely, this result would also systematically correspond to the potential approach found above in regard to the disaggregation scheme ${ }^{689}$. Consequently, beneficial ownership would have to be interpreted narrowly by necessitating particular high demands to the qualitative relation and quantitative correlation between in- and outflows, to their proportionality as well as to the similarity of their causal risks.

136 The IAS/IFRS concept of economic relationship allows the aggregation and contextualisation not only of single but also of multiple transactions ${ }^{690}$. In contrast, from the author's point of view, the treaty concept of beneficial ownership applies to individual transactions only (i.e. one single inflow and its respective outflow). Admittedly, beneficial ownership is a requisite and explicit exception to the finding that an aggregation of a transaction upwards from its legal form can basically not be justified by the substance over form principle ${ }^{691}$. However, there is a difference between the horizontal aggregation of in- and outflows for the purpose of determining their economic relationship and the vertical aggregation of multiple in- or outflows. The reason is that the former is a logical pre-step and necessary pre-condition for the latter ${ }^{692}$. Consequently, the IAS/IFRS provide different concepts for these two independent problems, i.e. economic relationshi ${ }^{693}$ for the horizontal aggregation but bedging instruments ${ }^{694}$ and hedged items ${ }^{695}$ for the vertical aggregation. So does the OECD MTC: subject of the specific rules of beneficial ownership is solely the horizontal aggregation, whereas the vertical aggregation is a result of the substance over form principle ${ }^{696}$ in general. In other words: the specific question of what is to be aggregated (object) is different from the general question of when something is to be aggregated

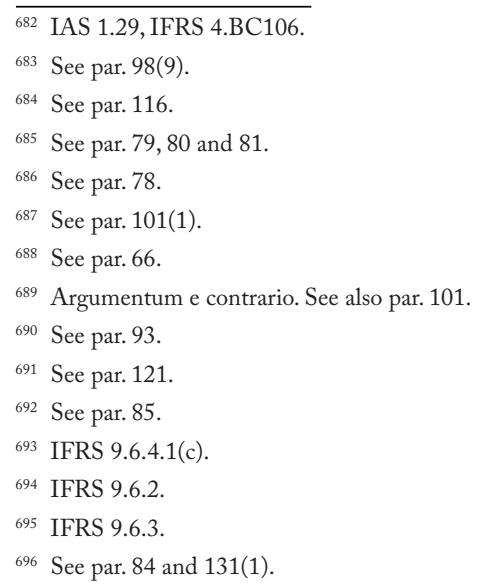


(condition). The exceptional concept of beneficial ownership (horizontal aggregation) is necessarily limited by its logical pre-step (vertical aggregation) to the relation between an individual inflow and its respective outflow, i.e. the inflow cannot be less than the outflow (maximum limit). In other words: a pass-through of multiple inflows by one single outflow of the same total amount cannot be subject of a (re-)attribution by way of beneficial ownership (horizontal aggregation) ${ }^{697}$. This would imply and require their prior consolidation (vertical aggregation) as a logical pre-step, which, however, cannot be justified by the general substance over form principle. Even more restricted for the general principles than the application of the aggregation scheme, are its specific exceptions ${ }^{698}$. The following illustration visualises this understanding:

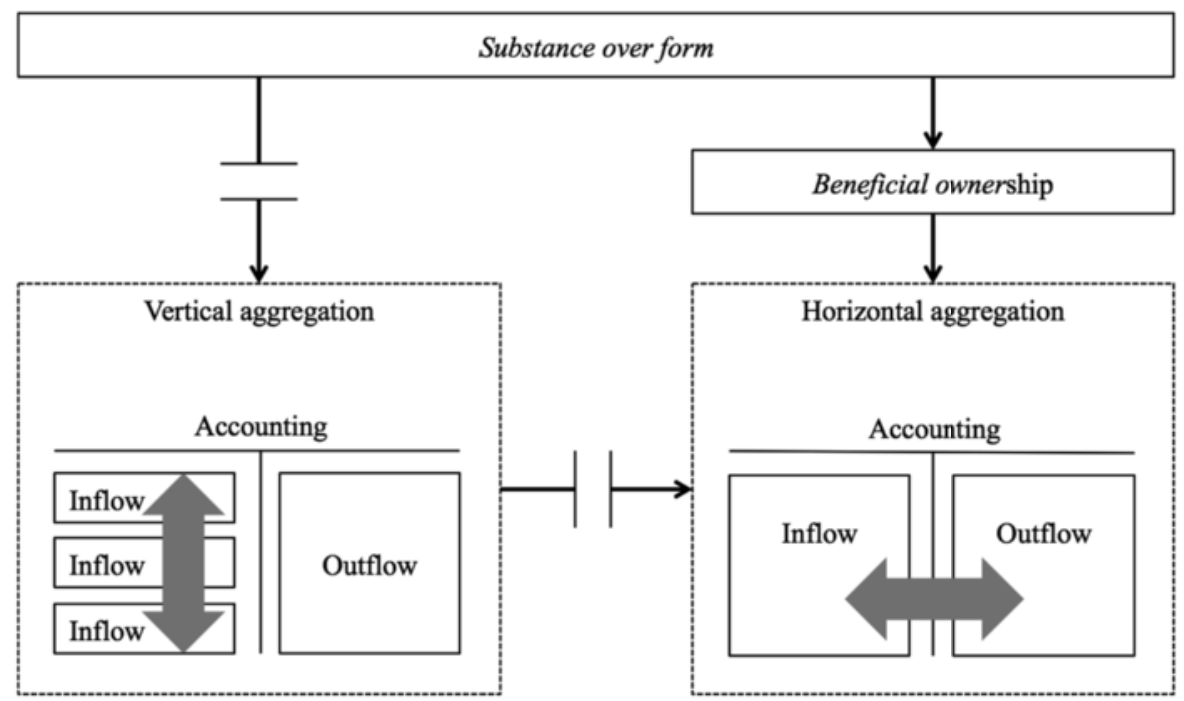

Illustration 12: The horizontal aggregation of beneficial ownership as opposed to the vertical aggregation

137 In contrast to that vertical aggregation, the concept of beneficial ownership is not limited to the same extent by its likewise logical pre-step of vertical disaggregation, which is much less restrictive ${ }^{699}$. In other words: depending on the less restrictive admissibility requirements of the disaggregation scheme, a pass-through of one single inflow by multiple outflows of the same total amount might principally result into (re-)attribution by way of beneficial ownership. However, the additional hedge effectiveness requirement of approximately proportional in- and outflows ${ }^{700}$ necessarily limits it as well, in that the inflow can't be more than the outflow (minimum limit) either. According to its narrow interpretation, this results in the conclusion that beneficial ownership is to be determined on the basis of individual transactions only. The consequent tax planning possibilities and distortions by discretionarily choosing or structuring the legal (contractual) form of the financial instrument as the baseline or starting point were said to be acceptable ${ }^{701}$ also with regard to beneficial ownership.

\footnotetext{
${ }_{697}$ In result equally: Tax Court of Canada, judgement ref. 2012 TCC 57, 2009, par. 43 et seq.

${ }^{698}$ Argumentum a maiore ad minus.

699 See par. 96.

${ }^{700}$ See par. 135.

701 See par. 101(1).
} 
138 The concept of beneficial ownership as a special subset of the general substance over form principle ${ }^{702}$ must necessarily ignore the legal form of the in- and outflows. Obviously, an in- and outflow cannot be excluded from the applicability of beneficial ownership only because of their different income classifications (e.g. an inflow in the form of an interest is passed-through as an outflow in the form of a dividend). That is why the credit risk as an economic parameter induced by the legal form ${ }^{703}$ is of particular importance for indicating a relationship between in- and outflows. While it is not capable of positively verifying a qualitative relation, it is nevertheless capable of negatively falsifying it. Where there is a dominating credit risk because of any kind of gap between in- and outflow for whatever reasons, there cannot possibly be an economic relationship between them ${ }^{704}$. This is why a non-dominating credit risk in turn doesn't necessarily imply such a qualitative relation. Obviously, this qualitative relation cannot be determined on the basis of the relationship's legal terms but must instead depend on its critical economic characteristics (e.g. effective maturity structure, causal risk structure or its sources such as their underlyings or components or substitutes, etc.).

\subsubsection{Limitations}

139 The concept of beneficial ownership as a method of horizontally aggregating in- and outflows necessarily requires and implies that the general principles of the OECD MTC apply to outflows as well. However, this obviousness is neither self-evident nor trivial. The scope of chap. III of the OECD MTC is limited to income from transactions which are subject of a double taxation ${ }^{705}$. The subjacent question is therefore whether or not these outflows must be treated as or are even the same as negative income (e.g. a donation of interest, a passthrough of dividends in the form of transaction costs for capital gains). And, if yes, whether or not negative income can in some sense be subject of double taxation. In the context of financial instruments, the vast majority of the observations in practice may allow the assumption that any form of passed-through income pursuant to the distributive articles of the OECD MTC represents itself any other form of item being subject of the OECD MTC. That is why the question which qualitative criteria or requirements the pass-through must comply with in order to constitute a beneficial ownership, appears to be of no relevance with respect to the scope of this study ${ }^{706}$. Rather, it is sufficient to hold that the concept of beneficial ownership covers as a minimum any pass-through that potentially represents any form of income itself pursuant to the distributive articles of the OECD MTC. This is a direct result of the original purpose, intention and function, according to which first of all income from financial transactions being arranged through intermediaries should be (re-) attributed by way of beneficial ownership ${ }^{707}$. On the one hand, income is regularly interpreted domestically rather than autonomously ${ }^{708}$. On the other hand, this can consequently be only half the truth: the concept of beneficial ownership obviously represents a necessary exception from this general principle ${ }^{709}$. In other words: where the counter-position was taken that any negative amount (i.e. outflow) is considered as either subject of the domestic interpretation or incapable of being subject of double taxation, it was excluded from the applicability of the OECD MTC as a whole. As a consequence, the concept of beneficial ownership

\footnotetext{
702 See par. 116.

703 See par. 76 and 101(1).

704 See par. 135.

705 See par. 19.

706 See sec. 1.2.

707 See par. 115.

708 See par. 21.

709 See par. 117.
} 
would entirely fall short. Accordingly, the position must be taken that the interpretation of income has to be separated into an autonomous and qualitative aspect on the one hand and the domestic and quantitative determination of the tax base on the other ${ }^{710}$. Or in more concrete terms: the disentanglement or separation of the causal or contextual nature of income from its mathematical sign. As a first result of such an approach, the initial question of whether or not negative income can be subject of double taxation would be logically independent of its mathematical sign. Having eliminated its mathematical sign in this way from the entire problem of income classification, it would be methodologically inconsistent to conclude that income was incapable of suffering double taxation only because its amount is negative. As a second result, the requisite double taxation of negative income must instead be determined by also reversing the mathematical sign of the tax itself. These conclusions justify applying the general principles of the OECD MTC to negative income as well ${ }^{711}$ by allowing it to access the concept of beneficial ownership and thus making it yet even clearer and more meaningful.

Example 21: Negative amounts could be classified as negative income or as transaction or acquisition costs. While both have their negative mathematical sign in common, this is nevertheless not their qualitative differentiator but only a quantitative attribute. The qualitative difference between costs and income is actually their different contextual situation caused by different transactions (e.g. income from a financial transactions versus costs for a service transaction). Ergo, drawing reverse deductions from the income's mathematical sign back to its contextual situation is flawed and mixes two different aspects. Once their different contextual situation has been determined pursuant to the autonomous interpretation (income classification), their quantitative tax base can then be determined pursuant to domestic law as a subsequent logical step only by considering their mathematical sign. Where the negative amounts may not be deducted from that domestic tax base in both contracting jurisdictions, be it as negative income or as transaction or acquisition costs, they suffer double taxation and are thus admissible for or accessible to the application of the OECD MTC.

140 Making negative income accessible to the general principles of the OECD MTC via the specific concept of beneficial ownership should, however, not lead to the erroneous reverse deduction that all these general principles must actually apply to the outflows in order to trigger beneficial ownership. The concept of beneficial ownership was said to cover any income as a necessary minimum condition (conditio sine qua non) ${ }^{712}$ but not necessarily also a sufficient maximum condition (conditio per quam). In other words: the requirements to the outflow are weaker than those to the inflow (e.g. the outflow is not required to be realised in the same way or even at the same point in time as the inflow). The reason is that it was not in line at least with the anti-abuse purpose of beneficial ownership ${ }^{713}$, if the outflow was sufficient for being identical with the inflow, which is why the problem of the legal relation between the recipient and the beneficial owner exists ${ }^{714}$ at all. Conversely,

\footnotetext{
710 See par. 56.

711 Equally: Haslehner, Werner in Klaus Vogel Commentaries 2015, p. 924 et seq., par. 86; OECD Commentaries 2014 on Art. 11 OECD MTC, p. C(11)-11 et seq., par. 20; unclear: Pöllath, Reinhard/Lohbeck, Allit in Vogel/Lehner, contrary on p. 473, par. 35 but then in favour on p. 1325 , par. 70 .

712 See par. 139.

${ }^{713}$ See par. 116.

714 See par. 133 et seqq.
} 
it was also methodologically flawed to draw any reverse deduction from these weaker requirements within the specific concept of beneficial ownership to the interpretation of income in general. The particular reason is that the outflow as a genuine concept ${ }^{715}$ is an objective legal precondition of beneficial ownership, whereas the income (re-)attribution as a derivative concept is only its subjective legal consequence that justifies no generalisations.

Example 21 (continued): From the fact that the outflow as a negative income is, within the scope of beneficial ownership, not likewise required to be realised it may not be concluded that income in general was not required to be realised at all.

141 The last topic that should be addressed here is the question whether the concept of beneficial ownership goes beyond Art. 10 and 11 OECD MTC, in particular as regards Art. 13(5) and 21(1) OECD MTC. On the one hand, the concept of beneficial ownership is expressis verbis only employed by Art. 10(2) and 11(2) OECD MTC $^{716}$ and not also by any other distributive provision ${ }^{717}$. Hence, a teleological extension in that it was nevertheless an inherent principle of Art. 13(5) and 21(1) OECD MTC ${ }^{718}$ may be seen as an interpretatio contra legem. Accordingly, there seems to be consensus that the concept of beneficial ownership is at least not a general anti-abuse provision. ${ }^{719}$ But even if it was, there was - by analogy - no reason to assume that the beneficial ownership in the asset was also under Art.13(5) and 21(1) OECD MTC in any way relevant for the beneficial ownership in the income or transaction and therefore for the scope of this study. ${ }^{720}$

142 On the other hand, there is the (re-)attributional purpose of beneficial ownership, making it more difficult to take a clear position, as the initial problem of replacing the formal taxpayer (e.g. a financial intermediary) by the effective taxpayer (i.e. the investor) in order to make the treaty benefits available to him also arises under Art. 13(5) and 21(1) OECD MTC, just as it does under Art. 10 and 11 OECD MTC. True, the additional Art. 29 OECD MTC inserted by the OECD MTC Draft Update ${ }^{721}$ does not enlarge, restrict, alter or otherwise address the specific and genuine (re-)attributional aspect of beneficial ownership ${ }^{722}$. Instead, it is intended to act as a general and derivative limitation in benefits rule. As such it has to be seen solely in the context of the OECD MTC objective, particularly in the background of BEPS, to also limit "opportunities for non-taxation or reduced taxation through tax evasion or avoidance" ${ }^{23}$. This is why the problem is typically solved by way of teleological reduction in that the (re-)attributional aspect of beneficial ownership was generally dispensable ${ }^{724}$. Admittedly, this interpretation may also be seen as an interpretatio contra legem - even more so as the

\footnotetext{
715 See par. 73 and 131(3).

716 And Art. 12(3) OECD MTC, which is however out of scope of this study (see par. 10).

${ }^{717}$ Li, Jinyan / Avella, Francesco in IBFD Commentaries on Art. 13 OECD MTC, sec. 6.4.1.2.

${ }^{718}$ In this sense: Reimer, Ekkehart in Michael Lang, beneficial ownership, p. 265.

${ }^{719}$ Helminen, Marjaana in IBFD Commentaries on Art. 11 OECD MTC, sec. 3.2.3.3.1.2., and Li, Jinyan / Avella, Francesco on Art. 13 OECD MTC, sec. 6.4.1.2.; Caroline Poiret, sec. 4.; Tischbirek, Wolfgang in Vogel / Lehner, p. 1110, par. 19; Adolfo Martín Jiménez, sec. 3.3 with a detailed justification, sec. 3.5 and sec. 4, Collier, Richard, Clarity, Opacity and Beneficial Ownership, British Tax Review 2011, No. 6, p. 702 et seq.; Joanna Wheeler, attribution, p. 478.

${ }^{720}$ See par. 132.

${ }^{721}$ OECD MTC Draft Update, p. 17 et seqq.

722 OECD MTC Draft Update, p. 177, par. 8.

${ }^{723}$ OECD MTC Draft Update, p. 10, par. 4, p. 17, footnote 1, and p. 175, par. 1.

${ }^{724}$ Li, Jinyan / Avella, Francesco in IBFD Commentaries on Art. 13 OECD MTC, sec. 6.4.1.2.; Avery Jones, John F. in Michael Lang, beneficial ownership, p. 333 et seq.
} 
beneficial ownership is a necessary precondition for the specific limitation rules of Art. 10(2) and 11(1) OECD MTC, which would consequently be put into question as a whole. However, according to the view represented here, a teleological extension towards an exceptional rule (i.e. anti-abuse aspect of beneficial ownership under Art. 13 and 21 OECD MTC) demands higher interpretation requirements than a teleological reduction towards the respective basic rule (i.e. no re-attributional aspect of beneficial ownership under Art. 10 and 11 OECD MTC). As a result for the further course of this study, the author therefore comes to the conclusion that the (re-)attributional aspect of beneficial ownership subsists explicitly in Art. 10(2) and 11(2) OECD MTC but implicitly in Art. 13(5) $7^{725}$ and 21(1) OECD MTC. In contrast, the anti-abuse aspect of beneficial ownership subsists in Art. 10(2) and 11(2) OECD MTC only.

143 Thinking this out consequently may suggest that the anti-abuse aspect of beneficial ownership had "squeezed out" its (re-)attributional aspect in that the latter was de facto not part of the concept of beneficial ownership. However, such a final conclusion would not only be still in line with all the material findings aforementioned; it would even reinforce them by accentuating the roles of the two aspects. As a consequence, the divergent application of the beneficial ownership concept within Art. 13(5) and 21(1) OECD MTC to the asset on the one hand and the income or transaction on the other may give rise to systematic distortions in triangular cases. For instance, the financial intermediary as the legal owner may suffer tax withheld by the source jurisdiction pursuant to his DTC with the issuer, which the investor as the beneficial owner might not reclaim pursuant to his DTC with the financial intermediary.

\subsubsection{Realisation}

\subsubsection{Definition and legal basis}

144 Realisation is an event defined by the tax law as a coincidence of factual, spatial and temporal circumstances, which principally triggers a tax consequence (taxable event). As it is typically the link between the subjective and objective criteria of a legal provision, it bears a strong nexus with a number of other legal issues with the effect of multiple and often conflicting aspects. For instance, the term income as used in Art. 10(3), 11(3) and 21(1) OECD MTC - including "other benefits in money or money's worth"726 - as well as the term gain as used in Art. 13(5) OECD MTC are principally not to be interpreted autonomously but domestically ${ }^{727}$. This was said to be a necessary precondition for the purpose of a treaty to "process" the taxable events as constituted by domestic tax law as precursory matters or input information ${ }^{728}$. However, also relevant in this context is the common criterion that this income must have been realised. This requirement is reflected by the words paid in Art. 10(1) OECD MTC for dividends and Art.11(1) OECD MTC for interest, by the word alienation in

\footnotetext{
725 Equally: Indian A.A.R., judgement ref. 2010 TPI 81, 2010, par. 10.

726 OECD Commentaries 2014 on Art. 10 OECD MTC, p. C(10)-11, par. 28; Kaeser, Christian / Wassermeyer, Franz in Wassermeyer Commentaries, p. 1310, par. 114.

${ }^{727}$ Harris, Peter A. in IBFD Commentaries on Art. 10 OECD MTC, sec. 2.1.2.2.2.2., and Li, Jinyan / Avella, Francesco on Art. 13 OECD MTC, sec. 5.1.2.; Alexander Bosman, p. 249; Haslehner, Werner in Klaus Vogel Commentaries 2015, p. 834, par. 89; Tischbirek, Wolfgang / Specker, Gerhard in Vogel / Lehner, p. 1211, par. 186; Wassermeyer, Franz in Wassermeyer Commentaries, p. 1427, par. 72, p. 1611, par. 28, p. 1612, par. 29, p. 1613, par. 31, and p. 1648, par. 137; OECD Commentaries 2014 on Art. 10 OECD MTC, p. C(10)-11, par. 28, and on Art. 13 OECD MTC, p. C(13)-2, par. 6; Michael Lang, introduction, p. 46, par. 77; Peter Hongler, p. 227 et seq.; Philip Baker, p. 13-2, par. 13B.04; Giuliani, Federico Maria, Article 10(3) of the OECD Model and Borderline Cases of Corporate Distributions, Bulletin for International Taxation 2002, Vol. 56, No. 1, p. 11; Klaus Vogel Commentaries 1997, p. 649 et seq., par. 186, p. 657, par. 201, p. 818, par. 24, and p. 1072, par. 11

728 See par. 21.
} 
Art. 13(5) OECD MTC and by the word arising in Art. 21(1) OECD MTC ${ }^{729}$. The terms are considered to be equivalent ${ }^{730}$, which is why they are hereafter collectively referred to as realisation.

145 As regards Art. 11 OECD MTC, the realisation requirement may alternatively also be deduced from the word arising in Art. 11(1) OECD MTC. This does, however, not merit substantive attention and has only the purpose of making clear that the taxation right of the source jurisdiction is limited to its own geographical scope $^{731}$. With regard to Art. 13 OECD MTC, the realisation requirement may alternatively also be deduced from the word derived in Art.13(1) and 13(4) OECD MTC. This may be derived by similar analogy as the word paid has been taken from Art. 10(1) and 11(1) OECD MTC to interpret income from dividends in Art. 10(3) OECD MTC and interest in Art. 11(3) OECD MTC. However, in this case the absence of derived in Art. 13(5) OECD MTC had no substantial meaning ${ }^{732}$. Nevertheless, it is cautiously assumed that Art. 13(5) OECD MTC does not employ the word derive on purpose due to its character of a residuary clause for Art. 13(1) to 13(4) OECD MTC ${ }^{733}$. For these reasons, in the further course of this study the realisation requirement is interpreted from the term alienation.

146 In the context of income classification, to what extent notional or deemed income shall be regarded as being realised - especially as regards to capital gains $^{734}$ - is controversial. The key issue which emerges is the unclear dependency ${ }^{735}$ between the transaction to be interpreted autonomously ${ }^{736}$ versus its income to be interpreted domestically ${ }^{737}$. It is a result from the conflict within the distributive articles between their tax limiting function on the one hand ${ }^{738}$ (i.e. in favour of the autonomous interpretation) and the taxable event as a requisite fact or precursory matter on the other ${ }^{739}$ (i.e. in favour of the domestic interpretation).

147 To clarify this issue, this section starts with an analysis of the terms paid and from in the context of dividends and interest. The findings from this analysis will afterwards be set in a wider context by drawing an outer line around the set of all distributive provisions, i.e. by generally distinguishing income pursuant to chap. III of the OECD MTC from capital pursuant to chap. IV of the OECD MTC). Notably, the conclusions are limited to the relevant Art.10(3), 11(3), 13(5) and 21(1) OECD MTC and make no claim to also applying to other

\footnotetext{
${ }^{729}$ Contrary: Wattel/Marres, fictitious income, p. 72, solely focussing on the term item of income by entirely disregarding the term arising and therefore concluding that "Article 21 does not require that something has been 'paid' or otherwise more or less actually enjoyed or received or benefited from but only that an 'item of income' of a resident be involved that is not covered by any other allocation provision in the treaty."

${ }^{730}$ Alexander Bosman, p. 81 et seq.

731 Helminen, Marjaana in IBFD Commentaries on Art. 11 OECD MTC, sec. 2.1.1. and 2.1.2.3.

732 Alexander Bosman, p. 81; Reimer, Ekkehart in Klaus Vogel Commentaries 2015, p. 1053, par. 23; Wattel/ Marres, fictitious income, p. 69.

${ }^{733}$ Reimer, Ekkehart in Klaus Vogel Commentaries 2015, p. 1077, par. 138, and in Vogel / Lehner, p. 1476, par. 178, and p. 1479, par. 211; OECD Commentaries 2014 on Art. 13 OECD MTC, p. C(13)-12, par. 29; Michael Lang, introduction, p. 109, par. 322 et seq.; Klaus Vogel Commentaries 1997, p. 842, par. 91.

${ }^{734}$ Reimer, Ekkehart in Klaus Vogel Commentaries 2015, p. 1051, par. 10 and 12; Li, Jinyan / Avella, Francesco in IBFD Commentaries on Art. 13 OECD MTC, sec. 5.1.2.; Wassermeyer, Franz in Wassermeyer Commentaries, p. 1609, par. 26, p. 1611, par. 28, p. 1612, par. 29, p. 1613, par. 31, and p. 1648, par. 137; Philip Baker, p. 13-2, par. 13B.04.

735 See par. 144.

${ }^{736}$ Focussing on this aspect: Helminen, Marjaana in IBFD Commentaries on Art. 11 OECD MTC, sec. 5.1.1.2.5.2.; Harris, Peter A. in IBFD Commentaries on Art. 10 OECD MTC, sec. 5.1.2.5.3.; Wassermeyer, Franz in Wassermeyer Commentaries, p. 1270, par. 46, and p. 1415, par. 36.

${ }^{737}$ Focussing on this aspect: Wattel / Marres, fictitious income, p. 69.

738 See par. 19.

739 See par. 21.
} 
distributive articles. The next step then draws another line between capital gains and the other income types within chap. III of the OECD MTC by transferring the implications found in the previous step to capital gains. The final step applies the implications found in the previous steps to deemed income, including deemed capital gains.

\subsubsection{The relevance of the terms 'paid' and 'from'}

148 As a starting point, the majority of commentators tend to the consensus view that the word paid is an auxiliary term that would bear a nexus with the transaction ${ }^{740}$ and therefore had to be interpreted autonomously. The term is to be understood with a broad meaning in the sense that the income must be transferred at the disposal of the recipient or beneficial owner in the manner required by contract or by custom ${ }^{741}$. Accordingly, the OECD MTC grants a certain degree of flexibility in this respect. For instance, it considers not only payments decided by annual general meetings of the shareholders a dividend but also other benefits in money or money's worth ${ }^{742}$. Hence, the term paid goes beyond cash transactions and also includes surrogates ${ }^{743}$.

149 For some commentators it nevertheless appears reasonable to argue in favour of a domestic interpretation of the term paid, in that it would rather bear a nexus with income $e^{744}$. However, from the author's point of view, income must be seen in two contextual aspects:

- On the one side, income has the only purpose and function in the treaty context to serve the assessment of a transaction ${ }^{745}$. In this context, the domestic interpretation of income and therefore its capability to contribute anything to the autonomous meaning of the distributive provisions of the OECD MTC is "reduced to zero". Ergo, on the treaty level the question of whether something has been paid as such is independent of the assessment by the income, i.e. there is no nexus between the two in this respect. ${ }^{746}$

- On the other hand there is the domestic context, in which the jurisdiction - while comprehensively interpreting income pursuant to its domestic tax law - is limited by the treaty in so far ${ }^{747}$ as income must be causally linked to the asset (i.e. share or debt-claim). This limitation is the weaker the more broadly income is interpreted by that jurisdiction. In other words: the elements of share and debt-claim as the sources of that income could almost entirely be marginalised where the domestic interpretation of income is only

\footnotetext{
740 Tischbirek, Wolfgang / Specker, Gerhard in Vogel / Lehner, p. 1156, par. 22; Kaeser, Christian / Wassermeyer, Franz in Wassermeyer Commentaries, p. 1270, par. 45, p. 1414, par. 36, and p. 1305, par. 104; Kemmeren, Eric C.C.M. in Klaus Vogel Commentaries 2015, p. 712, par. 13 .

${ }^{741}$ Kemmeren, Eric C.C.M. in Klaus Vogel Commentaries 2015, p. 712, par. 11; Tischbirek, Wolfgang / Specker, Gerhard / Pöllath, Reinhard / Lohbeck, Allit in Vogel / Lehner, p. 1155, par. 22, p. 1295, par. 14, and p. 1304, par. 34; OECD Commentaries 2014 on Art. 11 OECD MTC, p. C(10)-2, par. 7, and p. C(11)-2, par. 5; Belgian Hof van Beroep, judgement ref. 2010/AR/66, 2011; Brazilian Conselho de Administração de Recursos Fiscais, judgement ref. 106-17.142, 2008; Fuentes Hernandez, Daniel in Thomas Ecker, p. 448; Philip Baker, p. 11-3, par. 11-B06.

${ }^{742}$ Kaeser, Christian/Wassermeyer, Franz in Wassermeyer Commentaries, p. 1271, par. 47; OECD Commentaries 2014 on Art. 10 OECD MTC, p. C(10)-11, par. 28.

743 Tischbirek, Wolfgang/Specker, Gerhard in Vogel/Lehner, p. 1156, par. 22; Kaeser, Christian/Wassermeyer, Franz in Wassermeyer Commentaries, p. 1270, par. 46, p. 1414, par. 36, and p. 1430, par. 76, also making a connection with the beneficial owner, who - as a different person than the recipient - demands a broad meaning of paid; Klaus Vogel Commentaries 1997, p. 587, par. 22, and p. 722, par. 40.

${ }^{744}$ In this sense: Helminen, Marjaana in IBFD Commentaries on Art. 11 OECD MTC, sec. 5.1.1.2.5.2., stating that "if a state deems that interest income exists, it most likely also deems that it is paid.”; Dutch Hoge Raad der Nederlanden, judgement ref. 13/02237, 2014, par. 3.3.3., for capital gains, and Dutch Hoge Raad der Nederlanden, judgement ref. 37651 and 37670, both par. 3.4.1., both 2003, for the term derived in the context of Art. 15 OECD MTC.

745 See par. 56.

746 Similarly: Wattel/Marres, fictitious income, p. 67, stating that "income fictions are, however, not the same thing as a method of calculating advantages that have been actually received."

747 See par. 19.
} 
broad enough. The reason is that the domestic tax law may impose its tax not only based on transactions but also on other trigger events wider than, or even independent of, any transaction. However, in the context of dividends pursuant to Art. 10(3) OECD MTC and interest pursuant to Art. 11(3) OECD MTC the transaction-based approach is not only implied but also required by the asset-based approach ${ }^{748}$.

150 The requisite link between the income and the asset is systematically established by the coincidence of the two words paid in Art. 10(1) and 11(1) OECD MTC and from in Art. 10(3) and 11(3) OECD MTC. The term from determines a causal relation between income and asset ${ }^{749}$. In contrast, the term paid validates this relation as what is considered as realised. ${ }^{750}$ In other words: the two terms act as that said "adapter" between the static reference asset and the dynamic reference transaction $^{751}$. The two terms are interdependent in the sense of bearing an inextricable nexus with each other in a reciprocal relationship, as no validation is possible without a determination and no determination is ascertainable without a validation.

151 As a consequence, both terms, paid and from, form one logical unit or concept that is to be interpreted autonomously. This is a result not only from the aforementioned literal and contextual considerations but also from the systematic structure of Art. 10(3) and 11(3) OECD MTC. The clause income from shares actually represents an indirect paraphrase for the transaction income paid from the provision or contribution of equity and the clause income from debt-claims actually represents an indirect paraphrase for the transaction income paid from the provision or contribution of debt capital. It is obvious that these logical equivalents preserve their meanings only as a whole and may therefore not be divided ${ }^{752}$. More especially this follows also from the tax-limiting function of Art. 10 and 11 OECD MTC 753 as an intentional and purposive argument of interpretation. These financial transactions are the constituting and indispensible elements and their very reasons for existence, which is why they may not be frustrated or marginalised ${ }^{754}$.

152 Admittedly, Art. 3(2) OECD MTC gives prevalence to domestic tax law for the interpretation of terms not defined in the OECD MTC therein ("lex fori") 755 . This is the justification why some commentators do not see any specific treaty law requirement regarding the connection between the income and its trigger event $^{756}$. However, for the aforementioned reasons the systematic structure as well as the purpose, intention and function of Art. 10 and 11 OECD MTC are of particular significance ${ }^{757}$. They justify the autonomous interpretation of the terms paid and from under the exception rule unless the context otherwise requires in Art. 3(2) OECD MTC. This is even more conclusive, as (1) both terms are no termini technici, (2) both limb 2 of Art. 10(3) OECD MTC and Art. 11(3) OECD MTC provide closed and exhaustive definitions and (3) a

\footnotetext{
${ }_{748}$ See par. 53 et seq.

749 Equally: Alexander Bosman, p. 82 and 322; Hans Pijl, hybrid debts, introduction.

750 See par. 144.

751 See par. 55.

${ }^{752}$ See par. 52 et seq.

${ }^{753}$ See par. 112.

${ }^{754}$ Similarly: Dutch Hoge Raad der Nederlanden, judgement ref. 39.385, 2004.

755 See par. 20.

756 Alexander Bosman, p. 81 et seq., p. 93, 252 and 260; Reimer, Ekkehart in Klaus Vogel Commentaries 2015, p. 1052, par. 21, and p. 1053, par. 24, as well as in Vogel/Lehner, p. 1443, par. 28 and 30. All without however providing further justification, particularly in regards to whether or not the exception rule unless the context otherwise requires may apply (see par. 14).

757 Wassermeyer, Franz in Wassermeyer Commentaries, p. 277, par. 78; Klaus Vogel Commentaries 1997, p. 215 et seq., par. 73 and 74(3).
} 
domestic interpretation could make these provisions inapplicable. ${ }^{758}$ In summary, the domestic interpretation of income is limited by the terms from ${ }^{759}$ and paid.

\subsubsection{The relevance of the term 'arising'}

153 While there is more or less consensus on the point that the terms paid and from in the context of dividends and interest are to be interpreted autonomously ${ }^{760}$, the discussion is more controversial with regard to other income pursuant to Art. 21(1) OECD MTC ${ }^{761}$. This is quite remarkable, as the realisation requirements in all distributive provisions are considered equivalent to each other, in that they are not in themselves relevant for the delimitation of the distributive provisions. ${ }^{762}$ The matter of realisation was said to point to subjacent questions on the nature of an income tax. Here, the actual Schanz-Haig-Simons concept calls for common ground between income pursuant to chap. III of the OECD MTC and capital pursuant to chap. IV of the OECD MTC ${ }^{763}$. According to the view represented in this study, this common ground is a legal event (form over substance). This legal event may not be triggered by the domestic tax law but must be triggered by any precursory field of law. In addition, the legal event must - by comparing the states before and after - result in a new right. This limited autonomous interpretation of the realisation principle, which may be called a "principle of autonomous legality", is the result of the following systematic considerations:

154 When it comes to the determination of capital, the law becomes primarily relevant for the subjective aspect of attribution (i.e. who is and who is yet or not yet or no more considered the owner). But it is typically less relevant for the objective aspect of what capital is. As a demonstration, the legal answer to the question of what a given person's capital is, may be something like: "Capital is the total of all his rights" (e.g. assets, entitlements, etc.). This looks like a legal definition of capital but could also be seen as somehow incomplete if looked at more closely as the following example illustrates:

155 The actual share's price is not only affected by (1) the company's substantial assets and rights represented by the share but also (2) by a prospected but uncertain dividend and (3) by the expected but uncertain development of the market interest rates ${ }^{764}$. While the first effect (1) is covered by that legal understanding of capital as the total of all rights, the last two examples (2) and (3) demonstrate that capital is actually more than legal substance: rather, it includes also uncertain future economic expectations. This fact comes into focus against the background that modern and generally accepted methodologies to determine a person's capital are constantly based on a look-forward perspective and on probabilities. In the second example (2), the prospected dividend as the value driver is already forward-looking but still somehow connected with and therefore assignable to the right (i.e. the share). However, in the third example (3), the expected development

\footnotetext{
758 See par. 20.

759 Equally: Harris, Peter A. in IBFD Commentaries on Art. 10 OECD MTC, sec. 5.1.2.5.1.

${ }^{760}$ See par. 148.

${ }^{761}$ See footnote 729

762 See par. 144.

763 See par. 79.

764 Similarly: IFRS 9.3.2.8.
} 
of the market interest rates as the value driver is also forward-looking but caused externally (i.e. it comes from the outer environment) ${ }^{765}$, being completely unrelated and unassignable to the right (i.e. the share $)^{766}$.

156 From the legal perspective, these value drivers are aspects of the assessment of a given right. However, this assessment requires and presumes an assignment of the value drivers to that right. Although this assignment is less a legal but rather an economic discipline, it is the constituting and indispensible core element of capital. While a right assessed at a zero value is not capital, value drivers may in turn be realised in multiple legal ways or even without being attached to any right (e.g. by way of beneficial ownership through factual power structures $^{767}$ ). That is why, from the economic perspective, the legal perspective appears to be limited by being attached to rights. For this reason, the economic answer to the same demonstrative question of what a given person's capital is, may be something like: "Capital is the total of all his value drivers convertible into cash.” This is the economic definition of capital, which is obviously more comprehensive than the above legal understanding ${ }^{768}$. From this economic perspective, the "total of all rights" are mere containers or allocational references for the value drivers.

157 Bringing both together, the legal view that the assignment of value drivers to given rights is an assessment problem is nevertheless as true as the economic view that the assignment of value drivers to rights is an allocation problem. ${ }^{769}$ That is why both the legal and the economic understanding of capital are neither wrong nor incomplete. The legal understanding of capital, such as in Art. 22 OECD MTC, starts with the existence of any right leaving the allocation problem of value drivers (assessment) aside. In contrast, the economic understanding of capital starts with the existence of any value driver leaving the legal rights as allocational references aside. Both aspects form one logical concept or mechanism, being mutually interdependent and bearing an inextricable nexus with each other in a reciprocal relationship. That is why the assessment can solve allocation problems the same way the allocation can solve assessment problems. In economic science, there is even a technical term for this assignment problem: "external effects". It describes value drivers, which are excluded from the pricing mechanism in the sense that uninvolved third parties are affected as well, rather than only the involved legal parties (e.g. pollution). External effects typically result in distorted market prices. However, external effects are actually allocation problems due to the lack of marketable references or units (i.e. rights), by which the involved legal parties and the uninvolved third parties could compensate each other. Nevertheless, even in the absence of those marketable references or units, the value drivers are in fact assigned to rights. However, these are - by way of an "externalisation" - the rights of the uninvolved third parties (i.e. the assessment "solves" the allocation problem). It is rather the undesirable distortion effects of this "assessment solution" which can be mitigated by way of an "internalisation". "Internalisation" does nothing else than create dedicated rights (e.g. pollution certificates) or other negative assets ${ }^{770}$ as marketable references or units in order to involve the third party in the relationship (i.e. the allocation solves the assessment problem). In other words: both views eventually mean the same "coin" and only take their justification from different sides of

\footnotetext{
765 See par. 62.

766 See par. 66.

767 See par. 119 et seq.

${ }^{768}$ See par. 154.

769 Similarly: Kemmeren, Eric C.C.M. in Klaus Vogel Commentaries 2015, p. 719, par. 27.

770 See par. 60.
} 
that "coin". 771 As a first conclusion, capital is here understood as the total of all value drivers, economically allocated to rights as the object, which is legally attributed to a subject ${ }^{772}$.

158 This understanding also demonstrates that the law gains further relevance when it comes to the (de-) composition or structure of the capital in the sense of constituting rights, which are required and presumed for allocating value drivers to them (e.g. assets, entitlements, etc.). Taking the previous example ${ }^{773}$ again, the actual share's price is also affected by the prospected but uncertain dividend. It does not affect the total economic capital as a whole (i.e. share and/or dividend and/or sales proceeds), whether the share is held cum dividend at a higher price (capital) or the income is realised by either selling the share cum dividend at a higher price (capital gain) or by receiving the dividend and holding the share ex dividend at a lower price. Rather, it affects only its decomposition in what is legally considered capital (i.e. the right in the share) and income (i.e. the right in the dividend and/or the sales proceeds). The reason is that income does not arise from "anywhere" outside but from inside the capital itself. This means as another conclusion that capital cannot be distinguished from income economically but only legally. Or in other words: income is part of capital, legally split-off from it ${ }^{774}$. In this respect, one could even go so far as to say that there is no need for legal events (e.g. dividend resolution) for making someone economically richer. Accordingly, a key differentiator within the OECD MTC between income pursuant to chap. III of the OECD MTC and capital pursuant to chap. IV of the OECD MTC is that there must be as a necessary minimum condition (conditio sine qua non) some legal event in the sense of creating a new right. Taxable events not caused by the creation of any new right are not income. To this minimal extent (form over substance ${ }^{775}$ ), the realisation of income must be interpreted autonomously. ${ }^{776}$ The result of that legal event is that the income is legally realised and the capital legally decreases.

\subsubsection{The relevance of the term 'alienation'}

159 Although the realisation requirements in all distributive provisions are considered equivalent, the discussion whether it shall be interpreted autonomously or domestically is the most controversial in respect of capital gains pursuant to Art. 13(5) OECD MTC ${ }^{777}$. Going forward drawing another line between capital gains and the other income types within chap. III of the OECD MTC, the implications found in the previous step shall now be transferred to capital gains.

\footnotetext{
771 Reimer, Ekkehart in Klaus Vogel Commentaries 2015, p. 1050, par. 4, and in Vogel /Lehner, p. 1440, par. 3, falling victim to this ambiguity by saying that "the increase has to follow from the object itself, not from a change in the outer appearance of the object", just as David Hasen, p. 405, by saying that "the fluctuations must result from secondary market effects, rather than from a change either to the property that generates the return, or in the relationship of the holder to the property itself." The increase does actually not only follow from the object itself (i.e. internal value drivers) but inextricably also from a change in its outer appearance (i.e. external value drivers). However, in the absence of other rights as allocational references, the external value drivers will be assigned to the object (see also Example 4 on p. 29). This said externalisation by way of assessment makes those abovementioned statements not wrong but misleading. Likewise ambivalent: Wassermeyer, Franz in Wassermeyer Commentaries, p. 1609, par. 26, p. 1611, par. 28, p. 1612, par. 29, p. 1613, par. 31, and p. 1648 , par. 137.

772 See par. 120 et seqq.

773 See par. 155.

774 Equally: Joanna Wheeler, missing keystone, sec. 3.2.1., accurately stating that "there must be something that is already detached from the source that can be classified as income, and the "paid to' terminology reflects this feature".

775 See par. 79.

776 Equally: IFRS 9.5.7.1A(a); Reimer, Ekkehart in Klaus Vogel Commentaries 2015, p. 1051, par. 11, and p. 1052, par. 15 and 20; Wassermeyer, Franz in Wassermeyer Commentaries, p. 1609, par. 26, by also emphasising that this autonomous interpretation is precedent to Art. 3(2) OECD MTC; Michael Lang, introduction, p. 107, par. 313.

777 See footnote 734 .
} 
160 As stated earlier, capital is economically more than actual legal substance such as real assets and rights ${ }^{778}$. Moreover, even this actual substance is in fact determined by the income that can probably be expected from it (including the proceeds from its possible later re-sale or liquidation). Or in other words: today's capital is tomorrow's income.

Example 22: A strip is a split-off of specifically identified cash flows such as profit entitlements from a financial instrument. It represents income and, at the same time and in the same amount, also capital.

Taking the above example ${ }^{779}$ again, the actual share's price is also affected by the prospected but uncertain dividend. It does not affect the income as a whole, whether the income is realised by either selling the share cum dividend at a higher capital gain or by receiving the dividend and holding the share ex dividend at a lower price. Rather, it only affects its legal classification as a dividend or capital gain. This is not just another reason why capital cannot be distinguished from income economically but only legally. It also means as another conclusion that capital gains cannot be distinguished from the other income types economically ${ }^{780}$ but also only legally. The difference is that the distinction between income pursuant to chap. III of the OECD MTC and capital pursuant to chap. IV of the OECD MTC is the realisation by any legal event at all ${ }^{81}$. In contrast, the distinction within chap. III of the OECD MTC is that the legal event must refer to the asset itself for capital gains (the "tree") and not to the asset for the other income types (the "fruit").

161 Legal events refer to the asset, if they affect the critical ownership rights in the asset ${ }^{782}$. This is the key differentiator of capital gains from the other income types leading to another conclusion: in both categories there must be some legal event that restructures the capital by splitting-off income and creating new rights. Notably, in both categories this legal event does not change the total economic capital as a whole. However, the legal event for capital gains creates a new right (e.g. the sales proceeds) replacing an existing one (e.g. the ownership rights in the asset itself). In contrast, the legal event for the other income types creates a new right (e.g. dividend) set next to that existing one. Since neither category changes the total economic capital, the consequence is a different value allocation for the respective rights. Capital gains leave the value of the existing rights unchanged: their number decreases at the same ratio as their proportional value (vertical split-off of value substance $\left.{ }^{783}\right)^{784}$. On the contrary, the other income types leave the number of the existing rights (i.e. the ownership rights in the asset itself) unchanged. As a consequence, their value must be reallocated to more rights than before by "extracting" or "carving-out" value from the existing rights (horizontal split-off of value substance $\left.{ }^{785}\right)^{786}$. In other words: while capital gains replace one allocational reference by another, the other income types re-allocate the value to more references than before.

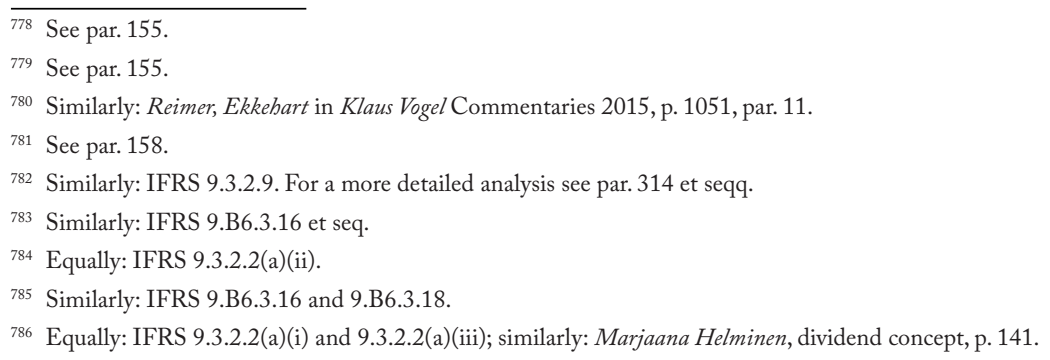


162 On the one side, both capital gains and the other income types give rise to new rights. Hence, this information cannot be taken as a differentiator. On the other side, capital gains decrease the number of the existing rights in a way that they are no longer with the owner once the transaction is completed (i.e. the dual character of alienation $\left.{ }^{787}\right)$. This makes the alienation a legal right that refers to the disposal of the critical ownership rights a dual-purpose differentiator for capital gains in a tie-breaking test. Not only does it distinguish capital gains from capital but at the same time it also distinguishes capital gains from the other income types. As another conclusion for the further course of this study, this means in result: by comparing the states before and after, the legal event must - as a necessary minimum condition (conditio sine qua non) - impair the mathematical number of the critical ownership rights in the asset ${ }^{788}$. Other legal events without such an effect cannot constitute capital gains. Such a differentiator would also comply with the logical, legal and technical requirements to the tie-breaking test aspired to in this study ${ }^{789}$. To this minimal extent, the realisation of capital gains must be interpreted autonomously. An accompanying piece of information that may also be used for an even more precise tie-breaking test, is the criterion if or to what extent the ratio between the number of the critical ownership rights in the asset and their proportional value changes as a result of that legal event (i.e. by comparing the states before and after).

163 Beyond that, these considerations also give indications of an answer to the subsequent question which intensity or qualitative criteria such a legal event must have in order to be independent from the domestic interpretation of the realisation. For instance, a legal event is also a change of the tax status of an asset treated by domestic tax law as a deemed capital gain. In order to constitute any kind of income, from the aforementioned considerations it follows, however, that there are at least two requirements to the quality or intensity of the legal event in the sense of a necessary minimum condition (conditio sine qua non):

(1) It may not be triggered by the domestic tax law but must necessarily be triggered by a precursory field of law. This follows from the fact that the domestic tax law itself builds on precursory fields of law ${ }^{790}$. As was stated, the domestic tax law itself cannot generate the information on the original trigger event as the cause or "input", but can only evaluate it for the purpose of tax classification as the effect or "output"791. This is why the reverse deduction that there was a realisation wherever there is a tax, was an erroneous conclusion from an effect to its cause $\mathrm{e}^{792}$.

(2) The comparison of the states before and after must result in the creation of a new right ${ }^{793}$. This follows from the above conclusion that the determination of income requires a legal event and that the legal events of both capital gains and the other income types create new rights ${ }^{794}$.

\footnotetext{
787 See par. 145 .

788 Similarly: Reimer, Ekkehart in Klaus Vogel Commentaries 2015, p. 1051, par. 12.

789 See par. 5.

790 See Illustration 2 on p.35.

791 See par. 80.

${ }^{792}$ Cum hoc ergo propter hoc.

793 See par. 161 et seq. Similarly: Wattel / Marres, fictitious income, p. 68, stating that 'the terms 'paid' and 'payment' must therefore be interpreted broadly but in any case a fulfilment of an obligation is required, or at least a real shift of assets or value from one taxpayer to another. This is not the case with respect to fictitious income: in fact, it is called 'fictitious' precisely because it is non-existent from a civil law point of view and has not (or has not yet) led to any shift of assets or value."

794 See par. 158 et seqq.
} 


\subsubsection{Deemed income}

164 Coming back to the starting point of this section, the aforementioned considerations provide the background and influence as well as the reason for the considerable significance of the terms paid, arising and from - even though income is unquestionably to be interpreted pursuant to domestic tax law. Said terms actually concretise that requirement and word it into legal language. Applying these considerations to deemed income, the consequence is, on the one hand, that those taxable events creating a new right are clearly considered as realised in line with the above understanding 795 of a limited autonomous interpretation (e.g. the dividend resolution for a dividend in kind or the shareholder resolution for a corporate action).

165 On the other hand, it follows that any other taxable event not triggered by the creation of new rights is not considered as realised in line with that above understanding of a limited autonomous interpretation. In this point the systematic distinction between income and capital coalesces with the meaning and interpretation of the term taxes on income pursuant to Art. 2 OECD MTC. This is of particular importance where a DTC does not contain a provision on the taxation of capital equivalent to Art. 22 OECD MTC. ${ }^{796}$ In those cases the aforementioned conclusions may fail, as they have been systematically deduced from the initial distinction between income and capital. Without such provision equivalent to Art. 22 OECD MTC on the taxation of capital, those DTC apply, however, to taxes on income only. This is why the problem is actually shifted to Art. 2 of that DTC. As stated, this touches on the theory of tax types, which cannot be examined in more detail here ${ }^{797}$. As a side note, some of the following considerations may, however, give indications of the treatment of deemed income and may help to understand the preceding conclusions from this perspective as well.

166 As an example, a source jurisdiction may be assumed to impose a notional income tax based on the absolute value or the value performance of assets held at a particular date (mark-to-market method). This example of an increment value tax shall be analysed in three versions:

(1) the tax covers all income types except capital gains and applies irrespective of the income effectively realised, while capital gains are taxed as effectively realised;

(2) the tax covers all income types including capital gains and applies irrespective of the income and capital gains effectively realised;

(3) the tax regime grants the voluntary option to alternatively declare the income and/or capital gains effectively realised.

167 In all three versions the trigger event for the taxation pursuant to domestic tax law is the mere ownership in the assets held at that particular date. Transformed into the asset-based wording ${ }^{798}$, it would read: "income from the holding of shares/bonds". Obviously, this trigger event is not a legal event in the sense of creating a new right. It shows that an increment value tax serves as a good illustration for the question whether such weak causal link between the asset and that deemed income ${ }^{799}$ shall legitimate the source jurisdiction to impose tax. At the same time it also demonstrates why this problem coalesces with the meaning and interpretation of the term taxes on income pursuant to Art. 2 OECD MTC. While the provisions on the taxation of income require

\footnotetext{
795 See par. 158.

796 Dubut, Thomas in Thomas Ecker, p. 121.

797 See par. 79 and 153.

798 See par. 52.

799 See par. 149.
} 
a transaction as a dynamic reference in order to represent an income tax, the mere bolding of the assets as the trigger event is a static reference ${ }^{800}$. It also demonstrates again that the asset-based approach is not cohesive. Although it is not a transaction but associated with the asset by the domestic tax law, holding is not admissible or accessible to the asset in order to yield income. In other words: the object of an increment value tax is not compatible with the object of an income tax. For this reason the problem cannot be resolved methodologically by reference to the good faith principle in Art. 31(1) VCLT ${ }^{801}$.

168 The third version (3) is a false problem. An assumed rational taxpayer will never declare his income effectively realised where this exceeds the notional or deemed income. Consequently, such contingent notional or deemed income could be assumed to always represent income effectively realised. Taken this separately, the third version (3) is therefore a straightforward income tax in line with the above understanding of a limited autonomous interpretation ${ }^{802}$. Nevertheless, the third version (3) also demonstrates that the interpretation and application of the terms paid, arising and alienation may not depend on the circumstances of an individual case. In particular, they may not depend on the design of an individual tax system. Instead, they must - to a certain extent - necessarily be detached from the domestic tax law.

169 According to the view represented in this study, the first two versions (1) and (2) are examples of taxable events not triggered by a legal event and therefore not realised in line with the above understanding of a limited autonomous interpretation ${ }^{803}$. The second version (2) exposes even more clearly the character of such an increment value tax. "Deemed capital gains" or "accruals" without any legal event are actually the same as capital and consequently a tax on these items is actually a wealth tax ${ }^{804}$ :

(1) As a first argument in favour of a literal or textual interpretation, any other conclusion would contradict the clear and explicit wording of Art. 13(5) OECD MTC. The attempt of some commentators to solve the problem of an increment value tax within the scope of Art. 13(5) OECD MTC ${ }^{805}$ would mean nothing else than actually ignoring the term alienation. Due to its dual character ${ }^{806}$, the term alienation does not only represent the realisation requirement; it also requires a transfer of the asset to another person or subject ${ }^{807}$. Therefore, the attempt of other commentators to "broaden" the interpretation ${ }^{808}$ of the term alienation into its exact opposite of a non-alienation is an interpretatio contra legem. The same would be true for the interpretation of the term paid into its opposite of a non-paid, such as effective interest from an inflation-linked note into nominal "interest" from a non-inflation linked note. Chap. III of the OECD MTC represents a realisation-based rather than an accretion-based tax system in that its application is

\footnotetext{
800 See par. 55.

${ }^{801}$ Alexander Bosman, p. 85, insofar confusing systematic with intentional elements of interpretation.

802 See par. 164.

${ }^{803}$ See par. 165.

804 Equally: David Weisbach, p. 510 et seq.

${ }^{805}$ Without justification: Reimer, Ekkehart/Ismer, Roland/Blank, Alexander in Klaus Vogel Commentaries 2015, p. 160, par. 37, p. 162, par. 48, and p. 1568, par. 8 and 10 et seqq.; Ismer, Roland in Vogel/Lehner, p. 474 et seq., par. 39; Wassermeyer Commentaries, p. 222 , par. 44.

806 See par. 145.

807 See par. 162.

808 Stefano Simontacchi, p. 190 et seq., merely comparing the legal consequences (effect) of Art. 13(5) OECD MTC with those of Art. 7 and $21 \mathrm{OECD}$ MTC. He also seems to draw the impermissible reverse deduction to the legal grounds (cause) that there was an inconsistently different tax regime unless unrealised capital gains were subsumed under Art. 13(5) OECD MTC as well. This argument also prejudices that unrealised income was even subsumable under Art. 7 and 21 OECD MTC.
} 
deferred until a concrete trigger event occurs, i.e. the legal event ${ }^{809}$. This becomes particularly clear where the deemed capital gain, once realised later, is then not taxed. In a consistent tax system this is quite likely, as the capital gain would otherwise be double-taxed, even pursuant to the source jurisdiction's own domestic tax law. Such an interpretatio contra legem would not methodologically justify compensating a "systematic inconsistency" between realised and unrealised capital gains ${ }^{810}$ either. Potential solutions such as mark-to-market, ex-post, risk-based or pattern approaches come into question only in the context of a possible future reform and fundamental change of the entire tax system ${ }^{811}$. A possible need for future action was, however, said to be not the same as the interpretation and application of the existing OECD $\mathrm{MTC}^{812}$. For these reasons any attempt at solving the realisation requirement by way of interpretation at all, in order to make the objects or natures of an increment value tax and an income tax compatible with each other ${ }^{813}$, especially by applying the substance over form principle, is an impermissible interpretatio contra legem.

(2) In addition, the aforementioned arguments make plain that such "systematic inconsistency" between realised and unrealised capital gains actually does not exist. The system of the OECD MTC was said to call, moreover, for a common ground between income and capital gains in order to distinguish the two from capitap ${ }^{14}$ (i.e. the realisation). Furthermore, the realisation represents the necessary link between the asset and the transaction. As such it is independent of the income in the treaty context ${ }^{815}$, so that there is no need either for any domestic interpretation. In addition, the character of a tax determined by its object (i.e. wealth) must be distinguished from its tax base (i.e. increment value or unrealised capital gain). ${ }^{816}$ And finally, the distributive articles cannot go beyond Art. 2 OECD MTC ${ }^{817}$, which is intended to delineate the scope of taxes generally covered by the OECD MTC ${ }^{818}$. These systematic arguments of interpretation are also in line with the consensus that the realisation requirements in all distributive provisions are equivalent ${ }^{819}$. In other words: just as unrealised income is not the same as realised income, unrealised capital gains are not the same as realised capital gains.

(3) As an intentional and purposive argument of interpretation, the financial transactions were said to be the constituting and indispensible elements of the distributive provisions and their very reasons for existence,

\footnotetext{
809 "The capital gains system relies on realization events, or triggers, such as a sale or exchange, before a person's income will be taxed, regardless of any increase in wealth in the meanwhile. This system is known as the 'wait and see' approach because, regardless of appreciation or depreciation of the asset between purchase and sale" (Kolbrenner, Scott Marc, Derivaties Design and Taxation, Virginia Tax Review 1995, Vol. 15, Issue 2, p. 245). In other words: chap. III of the OECD MTC "is able to measure the economically meaningful quantities only as closely as accounting and market-based mechanisms will allow. Taxable income is not economic income, it is at best a transaction-based approximation to economic income, which is itself only a proxy for some more fundamental policy goal." (Anthony Polito, p. 765 et seq.).

810 Stefano Simontacchi, p. 191.

${ }^{811}$ Jieyin Tang, bifurcation or integration, sec. 2; Sven-Eric Bärsch, p. 77; Wood, Richard, Financial Innovation and a Universally Applicable Distinction between Accruals and Realization Taxation, Intertax 2011, Vol. 39, Issue 8 / 9, p. 402 et seq.; Laukkanen, Antti, Taxation of Investment Derivatives, IBFD, Amsterdam, 2007, p. 408 et seq.; David Hasen, p. 399 - 403; Achim Pross, p. 172; Deborah Huffman Schenk, financial instruments, p. 583 et seqq.; David Weisbach, p. 492; Jeff Strnad, conceptual framework, p. 592; Warren, Alvin C. Jr., Financial Contract Innovation and Income Tax Policy, Harvard Law Review 1993, Vol. 107, Issue 2, p. 474.

${ }^{812}$ See par. 76.

${ }^{813}$ See par. 167.

814 See par. 79 and 153.

815 See par. 149 et seqq

816 See footnote 746 .

${ }^{817}$ See par. 113.

${ }^{818} \mathrm{Cui}, \mathrm{Wei}$ in IBFD Commentaries on Art. 2 OECD MTC, sec. 6.2.1.

${ }^{819}$ See par. 144.
} 
which is why they may not be frustrated or marginalised ${ }^{820}$. In addition, pursuant to the laws of logic it should be permissible to make the general assumption that the contracting jurisdictions of a DTC do not intend to regulate something that cannot actually be processed by that DTC.

Metaphorically, DTC are "converters" which receive information from the domestic tax law (i.e. the income classification as the "input"). They act in order to attach an additional piece of information (i.e. the income re-classification as the "conversion") ${ }^{821}$ and then to send it back to the domestic tax law (i.e. the "output"). The input must contain at least two separate pieces of information: (1) the event or matter of fact as the cause and (2) the effect to what extent that event or matter of fact is taxable pursuant to domestic tax law. Where the first piece of information (1) was missing, the input would only read: "We have taxed something" (effect only). Obviously, this information is incomplete and cannot actually be "processed" or converted by the DTC. What was missing was any reference of what that taxation is linked or referring to, namely the complementary input information of "what has happened". In other words: the purpose and function of DTC require and presume an assignment of the tax to an event in the sense that the event must be the object of the tax. While the tax as the effect addresses Art. 2, the event as the cause addresses the distributive articles. The necessity to receive both pieces of information shows once more the nexus between the two aspects ${ }^{822}$. The character of the tax cannot be determined without any reference or object. To a certain extent, this reference must be objectified ${ }^{823}$ in order to separate the information of "what has happened" from "there is a tax", i.e. to separate cause and effect. The mere subjective and unilateral intention of the domestic tax law that the tax (e.g. increment value tax) shall cover certain events (e.g. capital gains) is not sufficient. This holds a fortiori for the eventually axiomatic notice that an increment value tax was an income $\operatorname{tax}^{824}$, because its object was not the total wealth ${ }^{825}$. This is even more crucial since Art. 2(2) OECD MTC also includes "taxes imposed on [...] elements of [...] capital". This expression actually coalesces both in one: rights on certain assets and rights on income from $\operatorname{assets}^{826}$. The arbitrariness is made particularly clear by the demonstrative question, at which point or level the notional tax base shall otherwise "start to turn" from an income into a wealth tax: $5 \%$ of net wealth or $10 \%$ or maybe $15 \%$ ? Obviously, the character of a tax cannot be a question of its level. Instead, that certain extent, to which the event must be objectified, is the interpretation of the terms paid, arising and alienation as the autonomous part of the realisation.

That said, a DTC can "receive" the following states or combinations of information:

- The event and the tax

- The event and no tax

- No event and the tax

- No event and no tax

\footnotetext{
${ }_{820}$ See par. 151.

821 See par. 163.

822 See par. 165 .

${ }^{823}$ See par. 168.

${ }^{824}$ David Weisbach, p. 509.

825 In this sense, however: Dutch Hoge Raad der Nederlanden, judgement ref. 42.211, 2006, and Wattel / Marres, fictitious income, p. 78. They argue that the Dutch increment value tax regime for notional capital income is integrated in the taxation of income from other sources, such as considering some specific deductibles and personal allowances.

${ }^{826}$ See par. 158.
} 
The third case is the only one that cannot be "processed" by the DTC in this respect due to its incompatible objects of taxation (qualification conflicts) ${ }^{827}$. True, the input information represent facts or precursory matters from the treaty perspective ${ }^{828}$, but these facts or precursory matters refer only to tax level of Art. 2 in the sense of "there is a tax" and not to the distributive articles in the sense of "what has happened". This is another reason why at the treaty level the reverse deduction that there was a realisation (cause) wherever there is a tax (effect) ${ }^{829}$, leads to erroneous conclusions.

(4) In this respect, the OECD Commentaries on Art. 13 OECD MTC are not perfectly clear. In the preliminary remarks certain statements can be found suggesting that an increment value tax is considered an income $\operatorname{tax}^{830}$. This would imply that a legal event would not be required at all. Then, some of the general remarks seem to (re-)narrow these statements, without however taking a clear position. ${ }^{831}$ These paragraphs trace back to $1962^{832}$, when Art. 22 OECD MTC already existed.In that sense these statements may enjoy an even greater legitimacy, as the OECD could be said to have acted in its "legislative" role ${ }^{833}$. Therefore the historical interpretation of Art. 13(5) OECD MTC does not give further indication as to whether an increment value tax is considered either an income tax or a wealth tax ${ }^{834}$. The fact that Art. 2(2) OECD MTC also includes taxes on capital appreciation ${ }^{835}$, in itself does not justify a conclusion as to whether or not that capital appreciation is eventually meant as an income tax ${ }^{836}$. The reason is that the OECD MTC does not only apply to taxes on income but also to those on capital ${ }^{\beta 37}$. Art. 13 OECD MTC was introduced later than Art. 22 OECD MTC M $^{838}$ and it might therefore be surmised that the position was chosen merely because the problem came up and is more relevant in the context of Art. 13(5) OECD MTC rather than of Art. 22 OECD MTC. Admittedly, the position of these interpretations in the context of Art. 13(5) OECD MTC in conjunction with the position of Art. 13 in chap. III of the OECD MTC (i.e. "taxation of income") suggests that an increment value tax was at least historically considered an income tax rather than a wealth $\operatorname{tax}^{839}$. However, it seems the OECD Commentaries take a narrow final view $^{840}$ only with respect to accruals on business assets ${ }^{841}$. For those, Art. 13(5) OECD MTC is even more limited, namely to movable business assets not allocated to the source jurisdiction only ${ }^{842}$. This would

\footnotetext{
827 See par. 167.

828 See par. 144.

${ }^{829}$ Cum hoc ergo propter hoc.

830 "It is left to the domestic law of each Contracting State to decide whether capital gains should be taxed and, if they are taxable, how they are to be taxed. [...] The Article [13] does not specify to what kind of tax it applies. It is understood that the Article [13] must apply to all kinds of taxes levied by a Contracting State on capital gains." (OECD Commentaries 2014 on Art. 13 OECD MTC, p. C(13)-1, par. 2 et seqq., explicitly mentioning “increment taxes").

831 "Appreciation in value not associated with the alienation of a capital asset is not taxed, since, as long as the owner still holds the asset in question, the capital gain exists only on paper." (OECD Commentaries 2014 on Art. 13 OECD MTC, p. C(13)-2, par. 7, further merely noticing some observations of special country practices).

832 OECD, FC-WP19(62)1, p. 3.

833 See par. 31.

${ }^{834}$ See also Cui, Wei in IBFD Commentaries on Art. 2 OECD MTC, sec. 3.4.

835 OECD Commentaries 2014 on Art. 2 OECD MTC, p. C(2)-1, par. 3; OECD, FC-WP19(62)2, p. 4, par. 8.

${ }^{836}$ In this sense, however: Ismer, Roland in Vogel/Lehner, p. 474 et seq., par. 39.

837 Equally: Stefano Simontacchi, p. 187.

${ }^{838}$ Li, Jinyan / Avella, Francesco in IBFD Commentaries on Art. 13 OECD MTC, sec. 1.2.1.; Stefano Simontacchi, p. 123).

839 Stefano Simontacchi, p. 139 et seqq.

840 "Where capital appreciation and revaluation of business assets are taxed, the same principle should, as a rule, apply as in the case of the alienation of such assets." (OECD Commentaries 2014 on Art. 13 OECD MTC, p. C(13)-3, par. 9).

${ }^{841}$ Equally: Stefano Simontacchi, p. 191.

${ }^{842}$ Wassermeyer, Franz in Wassermeyer Commentaries, p. 1645, par. 133.
} 
still be in line with the first requirement of the intensity or qualitative requirements of the legal event ${ }^{843}$, according to which it may not be triggered by the domestic tax law but must come from a precursory field of law. As regards business assets, a legal event may be seen in an obligation to recognise, appreciate or revaluate the asset pursuant to the domestic accounting law ${ }^{844}$ but not pursuant to the domestic tax law ${ }^{845}$. This is regardless of the fact that the domestic accounting law itself may adhere more to substantive than to legal concepts ${ }^{846}$. However, it may not be in line with the second requirement ${ }^{847}$, according to which the legal right must eventually give rise to a new right. As regards business assets, the obligation to recognise, appreciate or revaluate the asset pursuant to the domestic accounting law can only be considered as a realisation where there can be simultaneously created a new right. The OECD Commentaries give no indication whether this crucial point was either taken into account or, rather, was simply overlooked.

170 It may be suggested from some comments ${ }^{848}$ that the OECD MTC concept of beneficial ownership necessarily implied deemed income. According to this view, deemed (re-)attribution would actually mean its deemed realisation by the beneficial owner as a third party, especially where the deemed income is "realised" by the recipient only and never actually paid to the beneficial owner. In other words: that there was a deemed realisation wherever there is a deemed taxpayer. Apparently, this view would mix the genuine legal realisation requirement with subsequent matters of (re-)attribution and (re-)classification ${ }^{849}$. As was stated, the law has a dual function ${ }^{850}$ with regard to capital of (1) determining a right in the capital and (2) attributing this right to a person ${ }^{851}$. Even more, the law has that same dual function also with regard to income of (1) determining a right in the income - i.e. the realisation requirement as understood here - and (2) attributing this right to a person. And just as for capital, these two functions must be distinguished carefully $y^{852}$ for the income as well. The objective determination or the initial question whether a transaction is considered as realised ${ }^{853}$ is a different one than the subsequent question to what or whom that income shall subjectively be attributed ${ }^{854}$. The reason is that the former is a logical pre-step and a necessary pre-condition for the latter ${ }^{855}$. That is why the deemed attribution by the concept of beneficial ownership cannot vice versa have any influence back on the deemed realisation. Rather, it can necessarily only have an influence forward on a subsequent and different (re-)classification rule ${ }^{856}$. In other words, there are three instead of two legal issues in this respect logically building on each other: (1) genuine realisation, (2) genuine attribution and (3) derivative reclassifications. While the first two aspects are the general principles, the third is a specific exception rule ${ }^{857}$ not justifying

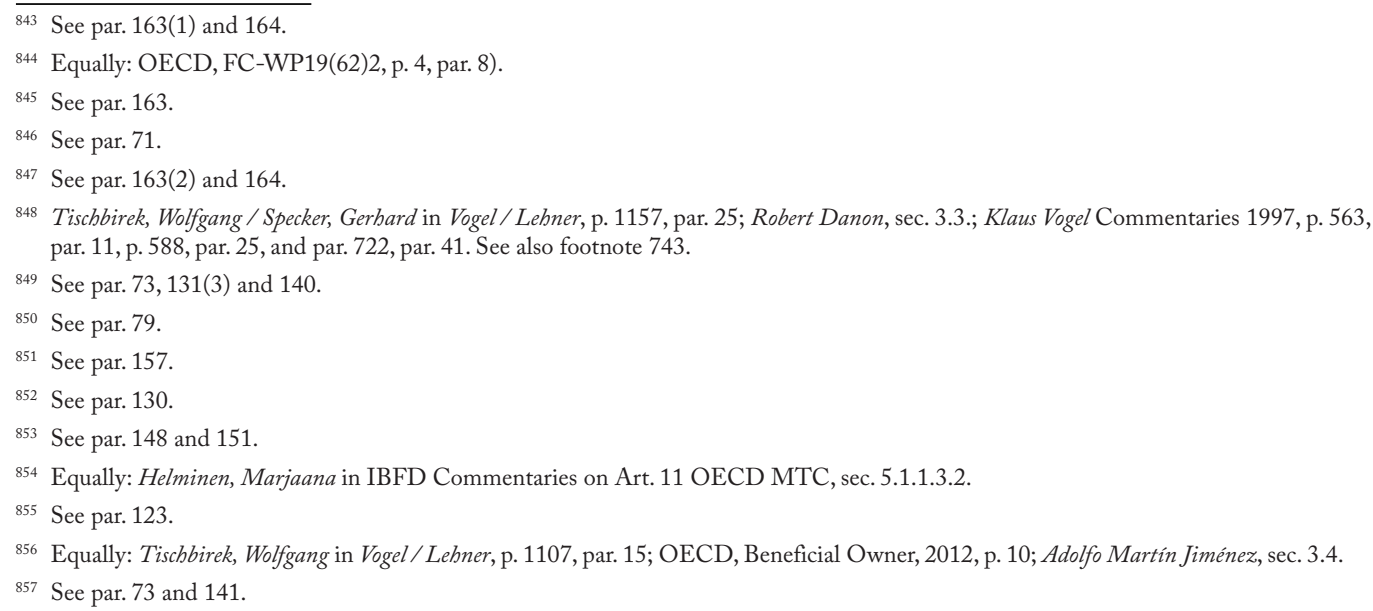


reverse deductions back to the general principles ${ }^{858}$. That is why, in particular, the legal event creating a new right cannot not be suspended by reference to the specific concept of beneficial ownership. This rationale and result remain valid even if the realisation requirement was to be entirely interpreted autonomously. In this case the three legal issues mentioned before would still build on each other in the sense of a one-way dependency, so that the exception rule of beneficial ownership could still reclassify the genuine attribution without also reclassifying the genuine autonomous realisation. Instead of raising a new issue, it would simply leave the initial question of how the two realisation concepts interact (i.e. the one on the treaty level and on the level of the domestic tax law). Further, the aforementioned rationale and result remain also valid even where there was a concept in the domestic tax law equivalent to the OECD MTC concept of beneficial ownership. The reason is that three legal issues would still build on each other in the sense of a one-way dependency, so that the exception rule of beneficial ownership could still reclassify the genuine domestic attribution without also reclassifying the genuine realisation. Instead of raising a new issue, it would simply leave the subsequent question of how the two beneficial ownership concepts interact ${ }^{859}$ (i.e. the one on the treaty level and on the level of the domestic tax law). To sum up, the term from is limited to the objective and general determination of a causal relation between income and asset ${ }^{860}$. It does not also determine the subjective and specific attributional relation between income and taxpayer, which is independent and subject of the subsequent concept of beneficial ownership ${ }^{861}$. That is why it is accurate to say that it was "highly impractical" to replace the concept of beneficial ownership by a formula of the type of income derived by or the like ${ }^{862}$.

171 All these validations show that the above conclusions ${ }^{863}$ of a limited autonomous interpretation of the terms paid, arising and alienation are resilient. According to the view represented here, they should also be transferable to those DTC that do not contain a provision equivalent to Art. 22 OECD MTC on the taxation of capital ${ }^{864}$. They may not be deduced directly from the distinction between income and capita ${ }^{865}$, but they can, however, be deduced indirectly from the distinction between capital gains and the other income types ${ }^{866}$. This latter distinction is that the realisation of income may not, and the realisation of capital gains must decrease the number of critical ownership rights in the asset. However, in both cases the realisation must be triggered by some legal event in the sense of creating a new right, which is required and presumed for allocating the value drivers. In other words: the distinction between income and capital is a necessary and implicit precondition for the distinction between capital gains and the other income types. Where a DTC does not contain a provision equivalent to Art. 22 OECD MTC on the taxation of capital, the systematic reverse deduction of this inherent principle nevertheless suggests itself. Otherwise the requisite distinction between capital gains and the other income types in those DTC would not be possible ${ }^{867}$.

\footnotetext{
${ }^{858}$ See par. 80. Equally: Tischbirek, Wolfgang / Specker, Gerhard in Vogel/Lehner, p. 1156, par. 22.

859 Equally: Avery Jones, beneficial owner, p. 5.

${ }^{860}$ See par. 150.

861 See par. 115 et seqq.

${ }^{862}$ Gutmann, Daniel in Michael Lang, beneficial ownership, p. 342.

${ }^{863}$ See par. 164.

${ }^{864}$ See par. 165.

865 See par. 158.

866 See par. 160 et seqq.

${ }^{867}$ Argumentum a minori ad maius.
} 
172 The term taxes on income in Art. 2 may be interpreted autonomously to the extent that it covers only taxes on income triggered by a legal event in the sense of creating a new right. With respect to the scope of this study ${ }^{868}$, this side note however limited to the sole question whether the aforementioned conclusions are transferable to those DTC. There may be other valid arguments in those cases eventually justifying a different result. In particular, those arguments could come to the conclusion that Art. 2 nevertheless applies for some other good reasons, especially where the increment value tax is listed in Art. 2(3) of the DTC. Otherwise an increment value tax would be generally excluded from the scope and application of those DTC. This would lead to the opposite result, i.e. the source jurisdiction was legitimated to impose such an increment value tax instead of being restricted or limited in its taxation rights.

\subsubsection{Conclusions}

173 The purpose and objective of this section was to analyse the nature, the scope and the influence of the realisation principle. It is reflected by the words paid in Art. 10(1) OECD MTC for dividends and Art.11(1) OECD MTC for interest, by the word alienation in Art. 13(5) OECD MTC and by the word arising in Art. 21(1) OECD MTC. It was found that the realisation principle as the link between the subjective and objective criteria of the distributive articles bears a particularly strong nexus with the asset and transaction on the one hand and the income-related elements on the other. This was identified as the root cause of the conflict and ambiguity between its domestic and its autonomous interpretation. As a result, the author takes the view of a limited autonomous interpretation of the realisation principle. It requires at least a legal event arising from a domestic field of law that is precursory to its tax law. This conclusion draws predominantly upon systematic considerations with in regard to the requisite distinction between income pursuant to chap. III of the OECD MTC and capital pursuant to chap. IV of the OECD MTC. As a secondary result from these considerations, it was further demonstrated that the limited autonomous interpretation of the realisation principle sets the scope for the classification of income types from financial instruments, in so far as deemed or notional income is basically not accessible to the OECD MTC. Finally, it was found as a subsequent conclusion that the characteristics of this legal event may be used as differentiators in a tie-breaking test to distinguish capital gains from other income types.

\subsection{Analysis and discussion of potential differentiators}

\subsubsection{Preliminary remarks}

174 The purpose of this section is to introduce, analyse and discuss possible differentiators with the aim of developing a concrete tie-breaking test that potentially delimitates Art. 10(3), 11(3), 13(5) and 21(1) OECD MTC. In particular, "all debt and equity characterisations can be described as an effort to determine whether (at least in relation to someone else) an investor is participating in the issuer's profits and risks." ${ }^{869}$ As indicated earlier, these differentiators shall as much as possible comply with the logical, legal and technical requirements to the tie-breaking test aspired to in this study ${ }^{870}$. The requirements of autonomy and universality are accorded the highest priority. Like the analysis and discussion of basic principles ${ }^{871}$ and aspects of the systematic

\footnotetext{
${ }_{868}$ See par. 11.

869 David Hariton, equity and debt, p. 515.

870 See par. 5.

${ }^{871}$ See sec. 2.2.
} 
context ${ }^{872}$ before, the objective of this section is further to present the author's view of these differentiators. This attempt to reveal particulars of what many commentators content themselves with terming "general principles" or "typical characteristics" is nothing else than an interpretative concretisation of the legal rule in order to approximate the specific case to decide on ${ }^{873}$. There is indeed a difference between these two techniques. But this difference is merely a matter of precision and therefore methodological heuristics in the law as a deficient rule set rather than a clear distinction line. As the case law method of judiciary in common law jurisdictions demonstrates, the difference between abstraction and casuistry ${ }^{874}$ is fluid. As an illustration, the approach can be compared with the recognition of patterns (e.g. human faces), which are typically all unique (i.e. casuistic) but can still be formalised (e.g. automatised) in a rule-based (i.e. abstract) manner.

175 In the absence of any express wording, most of the differentiators discussed herein cannot, however, be methodologically interpreted literally or textually. Rather, they can be identified only indirectly from inherent and implicit systematic interdependencies within the OECD MTC. Where it is considered reasonable and appropriate, the following considerations therefore take the liberty of transferring some structural findings and parallels from other (inspirational) sources of law to the OECD MTC. Again, all this is carried out while carefully embedding these structural considerations and interpretations into the general guidelines and the systematic aspects found in the preceding sections, by which they are significantly influenced. The methodological justification of such transfer may in certain cases be subject of legitimate debates. However, the author's intention to put them up for discussion is primarily to draw additional insights or conclusions and to establish a maximum of inherent consistency and systematology in the treatment of financial instruments and transactions with a minimum of assumptions or preconditions. The concrete interpretative examination and verification, if and to what extent the differentiators found in this section as potentially appropriate are in line with the particular distributive articles of the OECD MTC, is subject of section 3.

176 Legal criteria were said to necessarily attach to and derive from domestic tax laws ${ }^{875}$. Due to their fundamental incompatibility with the conceptual features and specific peculiarities of financial instruments ${ }^{876}$, they were also said to be infinite. For this reason, they can themselves not serve as differentiators in the OECD MTC ${ }^{877}$. As an example, two comprehensive observative studies ${ }^{878}$ in a domestic tax law have been taken as an empirical basis. Notably, they have identified no less than 27 and 38 criteria respectively. Following the approach of the IAS/IFRS and the US federal tax law, an attempt will be made here to develop some higher-level or generic treaty types of differentiators as independent universal tests. They shall go beyond the formal ways and means of the varying domestic tax laws by evaluating their material or economic substance ${ }^{879}$. Or, as the approach

\footnotetext{
872 See sec. 2.3 .

873 See Illustration 3 on p. 43.

${ }^{874}$ David Hariton, equity and debt, p. 523; Michael Lang, hybrids, p. 131; William Plumb, p. 409.

875 See par. 108(2).

876 See par. 100 and $108(3)$.

877 See however Brown, Patricia, The debt-equity conundrum - General Report, Series IFA Cahiers 2012, Vol. 97B, nonetheless still in this spirit by generally concluding that "perhaps the most elegant description of the debt-equity distinction is found in the branch report from Sri Lanka. It describes debt 'as a resource that does not belong to the company' and equity as 'capital which is part of the own resources of the company'."

878 William Plumb, p. 411 et seq. (concisely summarised, updated and amended by Bowers, William C., Tax Aspects of Debt and Equity, Tulane Tax Institute 1989, Vol. 39); Holzman, Robert S., The Interest-Dividend Guidelines, Taxes: The Tax Magazine 1969, Vol. 47, Issue 1 , p. 4 et seqq.

${ }^{879}$ See par. 37.
} 
and spirit of this section have been well expressed: "If I can find some way to describe [...] five characteristics as 10 characteristics, does the scale tip doubly in my direction? They are all part of the same single truth: [...] The real question, then, is not how many debt characteristics does the instrument possess but rather to what extent does the instrument insulate the investor from the risks and rewards of the issuer's business." 880

177 Equity providers were said to be dual-character investors, in that they can also provide debt capital ${ }^{881}$, even simultaneously. While the former act under company law, the latter do so under contractual law. That is why many potential differentiators discussed in literature actually test to what extent dual-character investors deviate from the behaviour typically required by or observed under contractual law. However, income reclassifications are derivative concepts and as such subsequent to the genuine concept of income classification ${ }^{882}$. In this context, speaking more generally, potential differentiators can principally be of three different kinds: (1) those testing genuine concepts, (2) those testing derivative concepts and (3) those testing both. This section focuses on potential differentiators only of the first type (1) and of the third type (3) with respect to genuine concepts. Differentiators of the second type (2) are generally outside the scope of this section ${ }^{883}$.

178 Tests can be categorised in many ways. For instance, according to the asset-based approach taken by the OECD MTC ${ }^{884}$, most of the differentiators turn out to apply each to the income or transaction on the one hand and analogously to the capital or principal on the other (i.e. the asset). The author has however decided to choose a categorisation which is as close as possible to the legal criteria discussed so far in recent literature. This is to ensure a maximum of mind-set compatibility, a smooth perceptive transition and therefore a better understanding.

\subsubsection{Rights and obligations}

\subsubsection{Preliminary remarks}

179 The legal form and therefore the domestic interpretation are naturally of essential importance for the understanding and relevance of rights and obligations ${ }^{885}$. However, the methodological approach of other collective laws ${ }^{886}$ demonstrates the alternative way. The material key question of which common criteria such domestic rights and obligations must show in order to potentially serve as differentiators can also be answered at the level of the OECD MTC by way of autonomous interpretation. The purpose of this section is therefore to analyse and discuss such common criteria in the field of domestic rights and obligations. It aims at potentially developing such independent universal standards (i.e. a tie-breaking test).

\subsubsection{Reciprocity}

180 Transactions were said to be economically reciprocal arrangements or exchanges of benefits described by an economic operation (i.e. legal obligations) and an economic return (i.e.legal entitlements) ${ }^{887}$. In real economy,

\footnotetext{
${ }_{880}$ David Hariton, equity and debt, p. 522; similarly: Marjaana Helminen, dividend concept, p. 168.

881 See par. 42.

882 See par. 73.

883 See par. 10.

${ }^{884}$ See par. 58.

885 See par. 80.

886 See par. 18.

${ }^{887}$ See par. 52.
} 
a mutual exchange of goods or services without any compensation in cash is actually not observable as a common practice. Instead, the economic operation is typically of a real nature, in that it refers to goods or services. In contrast, the economic return is typically of a monetary nature, in that it refers to cash or cash equivalents. This makes it easy to distinguish and classify the two. However, it is one of the specifics of financial transactions that they exchange their monetary and intangible benefits mutually in both directions. In addition, financial transactions can also exchange negative benefits (such as risk ${ }^{888}$ ). As a consequence, even this flow direction might be opposite to what is observable in real economy. True, just as in real economy it is possible to identify the suppliers more or less precisely, even though this depends typically on the subjective intention of the financial intermediary rather than on the objective facts or circumstances of the operation itself. However, it is much more difficult to identify the financial assets or transactions themselves, because of the particular sensitivity of financial transactions to such contextual or situative determinants ${ }^{889}$. That is why "financial assets", unlike "real assets", imply the (financial) transaction in a particularly weak manner ${ }^{890}$. And this might also be the reason why also the IAS/IFRS do not provide an abstract definition of financial instruments but instead a casuistic list or catalogue of examples ${ }^{891}$.

Example 23: A precious metal dealer can be identified by the precious metal as the tangible object, whereas a financier of that precious metal cannot. Depending on the circumstances, the purchase and resale of the precious metal can be a real transaction (e.g. trade) or a financial transaction (e.g. reverse repurchase agreement). The example also demonstrates that any homogeneous and liquid goods or services can actually serve as a currency equivalent and therefore be subject of a financial transaction, making it particular hard to identify.

181 Transferring the divergent laws and principles of real economy to financial instruments may therefore lead to the temptation to disregard the role of legal entitlements. The reason is that legal entitlements represent economically the return in exchange for legal obligations ${ }^{892}$. In real economy, this economic return is, however, typically of a monetary nature. It is not capable carrying or containing any qualitative element of the subjacent operation. Therefore it merely serves the purpose of quantitatively assessing the return ${ }^{893}$, even more so as it would be subject of the domestic interpretation ${ }^{894}$. It might therefore be concluded that legal entitlements may, if at all, serve merely as indicators to indirectly conclude to the subjacent legal obligations. But they were themselves never of any considerable significance for its autonomous classification. In other words: it was the legal obligations only which determined the autonomous character of a financial transaction. In contrast, however, financial instruments are capable of exchanging their intangible benefits mutually in both directions ${ }^{895}$.

\footnotetext{
888 See par. 60.

889 Similarly for IAS / IFRS: Haufe, IFRS, p. 1654 et seqq., par. 21 et seqq.; Anna Verena Matthies, p. 150. See also par. 59 and 88(3).

890 See par. 53.

${ }^{891}$ IAS 32.11.

892 See par. 180.

893 See par. 56.

${ }^{894}$ See par. 144.

${ }^{895}$ See par. 180.
} 
Example 24: A currency or interest swap can have a unilateral context such as where "sold" from a commercial financial intermediary to a private individual or a bilateral context such as where contracted for hedging purposes between two business enterprises in different currency areas. An option agreement is a one-sided shift of risks (i.e. legal obligations) from the option holder to the option writer. It can be compensated (i.e. legal entitlements), instead of a cash premium, by another converse shift of risk from the option writer to the option holder such as a premium in kind by way of another converse option agreement ${ }^{896}$.

Accordingly, legal entitlements have in principle a dual purpose of representing both the economic return for legal obligations and parts of the economic operation itself. In other words: unlike in the real economy, in the financial economy legal entitlements are more than just the economic return for legal obligations. They can also carry or contain elements or are even themselves an integral part of the economic operation. Methodologically, the legal entitlements must be subject of a precedent analysis in order to determine whether they represent parts of the operation (in which case they are to be interpreted autonomously) or a mere return for legal obligations (in which case they are to be interpreted domestically). It follows from these considerations that the analysis of autonomous criteria may not be limited or narrowed to the legal obligations only. Rather, it must also include the legal entitlements.

182 It can be further concluded from this reciprocity of financial instruments that any legal differentiator must be of equal relative importance, i.e. there cannot be a priority or subordination among them (equivalence of legal criteria). Otherwise classifying a mutual exchange of entitlements in its entirety, while in both directions representing parts of the economic operation, could lead to inconsistent or paradox or otherwise erratic results.

Example 25: Giving priority to one of its components or further down into their particular criteria, a debt-equity swap would be entirely classified into either debt or equity on both sides of the contracting parties.

Also a disaggregation and separate classification of those entitlements does not give rise to the necessity of giving different degrees of priority to the legal differentiators. The disaggregation process was said to stop where the components from the next iteration would not (significantly) change any more ${ }^{897}$. However, at this point any relative weight among the (legal) differentiators is obviously dispensable in that it is not comparatively relevant for their further (isolated) classification.

Example 25 (continued): Disaggregating the debt-equity swap into its debt and equity components or further down into their particular criteria in order to classify them separately makes their relative weights to each other per se unnecessary.

Finally, a priority or subordination of legal differentiators cannot be drawn quantitatively from economic considerations either. Given at arm's length conditions, it must rather be assumed that the legal entitlements (i.e. the economic return) and legal obligations (i.e. the economic operation) of that financial transaction

\footnotetext{
896 See par. 64.

${ }^{897}$ See par. 101(3).
} 
economically proportionate in equal benefits. Legal rights were said to be mere containers or allocational references for the economic value drivers ${ }^{898}$. For instance, a limit or cap of compensation, in that it does legally not participate in the profits, is nothing but an indemnification for the lower relative risk of also legally participating in the losses ${ }^{899}$. This leads to a principal economic equation of:

Legal criteria in favour of the issuer $=$ legal criteria in favour of the holder $\pm \operatorname{cash}^{900}$

In other words: for their final objective of shifting equal benefits the contracting parties employ "whatever" legal instruments there are available. As a consequence, it was not possible to draw any evaluative conclusion from their relations, particularly not that some legal criterion (e.g. a participation in profits) was quantitatively more important or significant than some other (e.g. a participation in losses) ${ }^{901}$. Even if transferred to the weighting of legal criteria, this would only lead to their evaluative equivalence as well. There could never be a quantitative disparity between legal entitlements and legal obligations justifying any further evaluative conclusion on the relative significance of legal criteria. And even if there was, this would be highly situative and therefore erratic, not allowing for any universal statement.

\subsubsection{Control}

183 On the one hand, it was stated that control appeared to be an important concept and constituent element of beneficial ownership ${ }^{902}$. On the other hand, questions of capital attribution and ownership in general cannot be limited to the specific treaty concept of beneficial ownership ${ }^{903}$. Consequently, this inherent concept of capital attribution and ownership can be interpreted autonomously or domestically. In fact, there is no precursory field of international law (e.g. international private or corporate law) that would be able to apply prior to the OECD MTC. Hence, the question to be discussed here is whether or not control is or even can be relevant for such autonomous concept of attribution and ownership. To that end, control is understood in so far congruently with beneficial ownership. Pursuant to the substance over form principle ${ }^{904}$, it is an economic or factual relationship in the material sense (and not in the formal sense such as membership rights) ${ }^{905}$ between a person or subject and an object, which is the result of ${ }^{906}$ composite legal transactions between two or more persons or subjects ${ }^{907}$.

184 Lang $^{908}$ argues that the payer and the beneficial owner, at least pursuant to Art.11(5) and 11(6) OECD MTC, are not necessarily capable of holding legal rights. As a consequence, the term debt-claim in Art. 11 OECD MTC was formed by an economic understanding. Broadly speaking, debt-claims are characterised by the possession of the capital or principal without however holding also its ownership rights. This view implies

\footnotetext{
${ }_{898}$ See par. 156.

899 Similarly: David Hariton, equity and debt, p. 500.

900 See par. 64.

901 Similarly: William Plumb, p. 434 et seq.

${ }_{902}$ See par. 134.

903 See par. $124 \square$.

904 See par. 72.

${ }_{905}$ Equally: William Plumb, p. 447 et seqq. See also par. 107(6).

906 See par. 176.

907 See par. 119 et seq.

908 Michael Lang, hybrids, p. 96.
} 
an economic understanding of the general aspect of attribution of the capital or principal itself ${ }^{909}$ and may thus potentially contribute to the general discussion of the control concept at this point. To the author's understanding, this standpoint nevertheless ignores the fact that Art. 11(5) and 11(6) OECD MTC actually employ fictions. It actually deems the treatment of other subjects, including those not capable of holding legal rights, to be equal with the payer and/or the beneficial owner by explicitly presupposing legal relationships between them. Notably, the payer and the beneficial owner must themselves be legal persons in order to ensure the legal enforceability supported by Lang himself. In that sense, this opinion falls victim to the same ambiguity between those two subject- and object-related aspects as mentioned above. As was stated before, the subject- and object-related aspects conceptually apply not only to the concept of beneficial ownership but also and in every way identically to the general aspect of attribution.

185 The IAS/IFRS apply a broad interpretation of control, which can be classified into the following criteria or uses cases ${ }^{910}$. The legally effective ${ }^{911}$ contractual entitlements of the financial instrument

(1) retain its cash flows ${ }^{912}$ without actually being subject of an economic relationship ${ }^{913}$ ("pass-through arrangement"914)

Side note: The difference between the IAS/IFRS concepts of control and economic relationship ${ }^{915}$ is that the former describes a relationship between a subject and an object, whereas the latter describes a relationship between two objects ${ }^{916}$.

(2) and retain substantially ${ }^{917}$ all its risks and rewards other than the cash flows ${ }^{918}$ without actually transferring them ("risks and rewards approach"1919); or otherwise

(3) retain the ability to actually dispose of it unilaterally and in its entirety to an unrelated third party ${ }^{920}$ ("continuing involvement" 921$)^{922}$. In this context, actually does not just mean legally but effectively (e.g. active and liquid markets) $)^{923}$ and unilaterally means without the consent of any third party ${ }^{924}$.

\footnotetext{
909 Consequently: Michael Lang, hybrids, p. 97.

910 See a summarising scheme in IFRS 9.B3.2.1.

${ }^{911}$ Haufe, IFRS, p. 1672 , par. 67 and 69 er seq. as well as p. 1673, par. 72.

912 IFRS 9.3.2.3(a) and 9.3.2.4(a).

${ }^{913}$ IFRS 9.3.2.3(b), 9.3.2.4(b) and 9.3.2.5.

${ }_{914}$ Haufe, IFRS, p. 1672, par. 69; Weber, Christoph / Tietz-Weber, Susanne in Haisch, Martin L. / Helios, Marcus, Rechtshandbuch Finanzinstrumente, Beck, Munich, 2011, p. 146, par. 144.

915 See par. 135.

916 See Illustration 9 on p. 73.

917 Haufe, IFRS, p. 1676 et seq., par. 79 and 83; Hartenberger, Heike in Beck, IFRS / IAS, p. 161 et seq., par. 107.

${ }_{918}$ IFRS 9.3.2.6(a) and 9.3.2.6(b).

${ }^{19}$ Hartenberger, Heike in Beck, IFRS / IAS, p. 160, par. 104; Weber, Christoph / Tietz-Weber, Susanne in Haisch, Martin L. / Helios, Marcus, Rechtshandbuch Finanzinstrumente, Beck, Munich, 2011, p. 147, par. 147; Christoph Berentzen, p. 183.

${ }_{920}$ IFRS 9.3.2.6(c), 9.3.2.9 and 9.B3.2.7 et seq.

921 IFRS 9.3.2.16.

${ }_{922}$ Haufe, IFRS, p. 1747, par. 254.

${ }_{923}$ IFRS 9.B3.2.8; Haufe, IFRS, p. 1678 et seq., par. 85 et seq.; Christoph Berentzen, p. 188 et seq.

${ }_{924}$ Christoph Berentzen, p. 194 et seq. See also par. 188 et seqq.
} 
(4) or are being substituted or novated by substantially ${ }^{925}$ continuing or upholding the aforementioned retentions ("novation") $)^{926}$.

186 So far, this interpretation is in line with the understanding of substance over form ${ }^{927}$. The broad character of this economic control concept comes from the fact that all these criteria contain a contextual restriction. Being congruent with the aggregation scheme ${ }^{928}$ to this extent, they establish a legal relationship between a criterion within one particular financial instrument and that of the same kind in another financial instrument or legal arrangement respectively ${ }^{929}$. As the result of those composite legal arrangements, they establish a factual relationship between a person or subject and an object ${ }^{930}$. In other words: the affirmation of control is not limited to that one particular object itself (e.g. a sale). It also depends on the context of other legal arrangements in order to avoid a carve-out or skimming of cash flows, risks and rewards as well as the ability to dispose. However, this leads to some basic conflicts:

(1) The subjective determination of whether or not an object is attributed to a subject applies prior to the objective question whether that object is then to be (dis-)aggregated. If that subjective attribution however applies a broad and contextual control concept similar to that of the IAS/IFRS, does that not actually imply, include and pre-empt an aggregation and actually introduce it "through the backdoor" 931 ? In other words: would not any conclusion that an object was not to be attributed to a subject due to its relationship with another object, in fact be an aggregation of these two objects? This question is even more crucial, since the distinction of "classic", "hybrid" or "derivative" financial instruments is illusory ${ }^{932}$. Just as the (dis-)aggregation scheme, in practice any financial instrument is subject of the control concept.

(2) The determination of whether or not an object is attributed to a subject is also prior to the concept of beneficial ownership ${ }^{933}$. So, would a broad and contextual control concept similar to that of the IAS/ IFRS (particularly as regards the "pass-through arrangements"934 and the "continuing involvement" 935 ) not actually imply, include and pre-empt the beneficial ownership ${ }^{936}$ ? Would this relieve the concept of beneficial ownership even from its role of representing an exception to the domestic interpretation of asset and income attribution ${ }^{937}$, making it a subject of autonomous interpretation? This question is even more crucial, since a control concept - unlike beneficial ownership - is not explicitly provided in the Art. 10(3), 11(3), 13(5) and 21(1) OECD MTC.

\footnotetext{
925 Hartenberger, Heike in Beck, IFRS / IAS, p. 161, par. 104, and p. 249, par. 380; IFRS 9.BC6.342.

${ }_{926}$ IFRS 9.BC6.349. See also par. 81.

927 See par. 183.

928 See par. 88(3).

929 Hartenberger, Heike in Beck, IFRS / IAS, p. 238, par. 341.

${ }_{930}$ Haufe, IFRS, p. 1669, par. 61, calling it "a combination of the formal legal and the economic concept" (translated by the author).

931 See par. 95.

932 See par. 87.

${ }_{933}$ See par. 124.

934 See par. 185(1).

935 See par. 185(3).

936 Similarly: Achim Pross, p. 176.

937 See par. 144 and 117.
} 
187 From the author's point of view, these conflicts demonstrate that such an extensive interpretation and application of the substance over form principle would be an overrun ${ }^{938}$. In particular, it would be contrary to the existence of other explicit provisions (e.g. beneficial ownership). And it would be contrary to other implicit principles (such as the domestic interpretation of the asset and income attribution) and findings (such as the restrictive aggregation or the formal interpretation of novations ${ }^{939}$ ). In addition to these literal and systematic considerations there are also methodological arguments. A teleological extension towards exceptional rules demands higher interpretation requirements than a teleological reduction towards the respective basic rules ${ }^{940}$. All this suggest that matters of attribution and ownership must basically follow the legal form (form over substance) and are therefore subject of the domestic interpretation ${ }^{941}$, unless they fall under the treaty concept of beneficial ownership. Or in other words: there is no such thing as "economic ownership" in the Art. 10(3), 11(3), 13(5) and 21(1) OECD MTC other than beneficial ownership. Therefore, matters of attribution and ownership are basically not accessible to the treaty principle of substance over form. Instead, economic control concepts in general such as those suggested by the IAS/IFRS might rather be an inspirer for the interpretation of the OECD MTC concept of beneficial ownership in the asset itself, which is however out of scope of this study ${ }^{942}$. The specific IAS/IFRS concept of control employs and therefore is dependent on that of economic relationship ${ }^{943}$ : economically speaking, today's capital is tomorrow's income ${ }^{944}$. In contrast, in the OECD MTC concept of beneficial ownership the (re-)attribution of the asset is (legally) independent of that of the income ${ }^{945}$.

Side note: This is supposed to be the reason why IFRS 9.3.2.5 and 9.6.4.1(c)(i), despite their different wordings, nevertheless both focus on the credit risk ${ }^{946}$.

\subsubsection{Voluntariness, laterality and self-execution}

188 A similar ${ }^{947}$ but less comprehensive differentiator than contro ${ }^{948}$ might be the criterion to what extent the source is legally ${ }^{949}$ bound or restricted in its genuine powers to decide (1) whether or not there shall be a payment (voluntariness) and (2) how this payment is to be used (enjoyment). It may potentially achieve better acceptance by allowing a partial and more precise focus on the mere disposal and/or the enjoyment of the income or capital, instead of on the entire asset ${ }^{950}$. The starting point of this consideration is that any claim implies some kind of "present obligation of the entity to transfer economic resources in some possible scenario in the future, including at liquidation" ${ }^{\prime 5}$. On the one hand, there is no voluntariness possible where

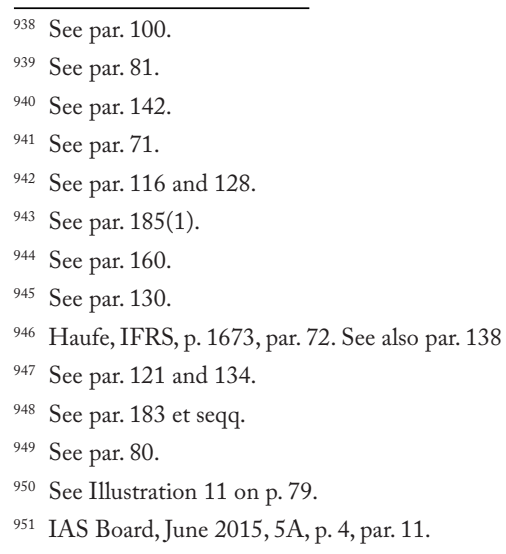


third parties are involved. That is why the aspect of voluntariness also bears a nexus with that of what in this study is called laterality. Laterality means whether the payment legally requires or involves two or more than two contracting parties. A payment is bilateral only if no legal consent is required from any third party other than the two contracting parties ${ }^{952}$. Otherwise it is multilateral ${ }^{953}$.

189 On the other hand, the said restrictions can be arranged in two ways, either being directive in mandatorily taking legal action; or resolutive in providing conditions or reservations. The aspect of voluntariness bears a nexus with that of self-execution. Self-execution means the unconditional payability without any contingent or discretionary action by the issuer ${ }^{954}$. The concept necessarily implies non-voluntariness and therefore bilateralism ${ }^{955}$. Self-execution particularly results in the fact that the payment of the income and/or the principal is determinable ex-ante by a mathematical formula. This ex-ante determinability is independent and must be carefully distinguished from the ex-ante determinability of certain parts or terms or variables of that formula. For instance, an one-to-one relation (e.g. "pay-out = periodic profit") is ex-ante determinable by this mathematical formula as such, although its only term (i.e. "periodic profit") is ex-ante indeterminable. While such term or variable might be uncertain in representing a risk, the formula describes the certain and thus self-executing response to that risk.

190 In other words: laterality describes potential payment conditions due to a third party's subjective decision. Voluntariness describes potential payment conditions due to the source's own subjective decision. As its opposite, self-execution describes the absence of such potential payment conditions due to the source's own subjective decision. And restriction describes potential payment conditions due to any other objective circumstances. The following illustration visualises this understanding:

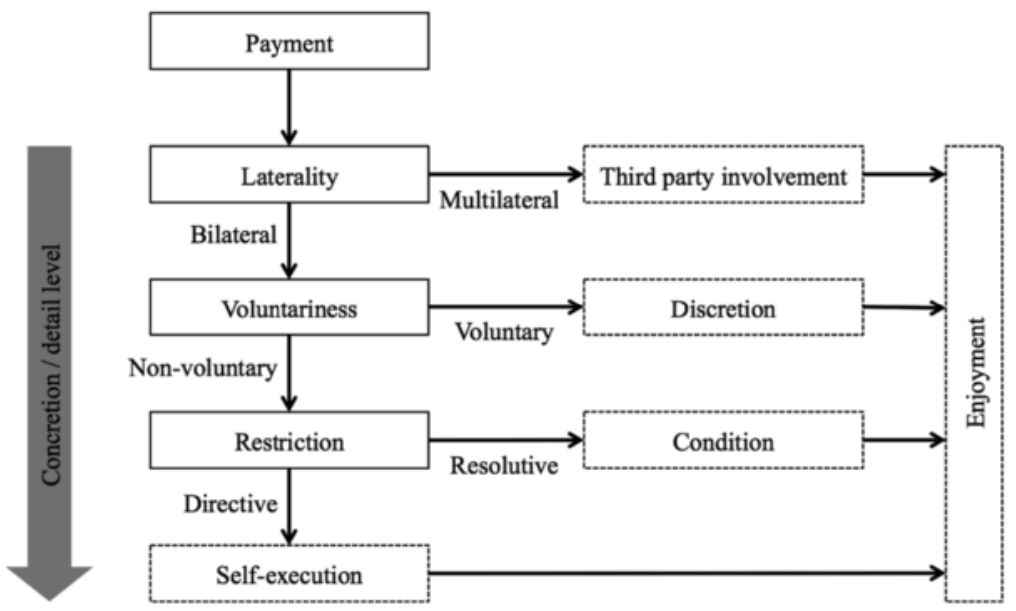

Illustration 13: The nexus between laterality, voluntariness, self-execution and enjoyment

\footnotetext{
952 William Plumb, p. 414 and 452.

953 Anna Verena Matthies, p. 49.

954 Similarly: William Plumb, p. 424.

955 See par. 188.
} 
191 Pursuant to the IAS/IFRS, yield bilateral payment condition basically falsifies equity. This applies in particular where the capital or principal is repaid following a termination by the investor or creditor. ${ }^{956}$ In that, the IAS/ IFRS draw their differentiator from a higher or more abstract concretion or detail level than the proponents of the voluntariness. Notably, the aforementioned nexuses are the link between the two views. From the author's point of view, laterality is too general a concept to serve as an effective differentiator. In particular, it ignores the fact that in turn multilateral payment restrictions, while perhaps being a strong indicator, do, vice versa, neither falsify debts (e.g. factoring) nor verify equity (e.g. equity certificates) ${ }^{957}$. Therefore, such a differentiator based on laterality appeared to (1) be only one-sided or incomplete and (2) serve merely as a negative falsifier rather than as a positive verifier.

Example 26: Collective investment schemes can be constituted in a contractual (i.e. bilateral) or corporative (i.e. multilateral) form.

The reason for this is that laterality is a context-specific concept that is incapable of coping with analytical techniques and is therefore insensitive to more granular circumstances.

192 Instead, the author takes the view that voluntariness is a more effective concept for being a differentiator. First, the power to decide as to whether or not there shall be a payment (voluntariness) is actually the power over the entire economic benefits and therefore the entire value of the proprietary rights ${ }^{958}$. That is why this view is in line with the finding that proprietary rights merit substantive attention ${ }^{959}$, in that, economically, today's capital is tomorrow's income ${ }^{960}$. In addition, the power to decide as to whether or not there shall be a payment (voluntariness) logically applies prior to the subsequent power to decide how the payment is to be used ${ }^{961}$. Even more, the entire aspect to what extent the source is bound or restricted in its payment decision is a "gatekeeper" for the enjoyment. In fact, the power to decide whether or not there shall be a payment at all can exclude yield beneficiary from enjoying it. Consequently, the power or right to decide how the payment is to be used (enjoyment) would, just as the concept of laterality ${ }^{962}$, necessarily be incomplete. Therefore it cannot serve as a reliable differentiator, as well. It is important to note that this does not mean e contrario that voluntariness is to be deemed or treated as if it was one and the same as enjoyment. Instead, the two aspects are generally different from and subsequent to another. The power or right to decide how the payment is to be used (enjoyment) is no precedent aspect of ownership or control but rather a subsequent aspect of attribution ${ }^{963}$. And finally, a differentiator based on voluntariness also complies with the logical, legal and technical requirements to the tie-breaking test aspired to in this study ${ }^{964}$. It describes completely and conclusively the absence of any restriction and may therefore serve as a positive verifier.

\footnotetext{
$\overline{956}$ IAS 32.16A and 32.BC11; Anna Verena Matthies, p. 144.

957 Argumentum e contrario.

958 See par. 156.

959 See par. 107(6).

${ }_{960}$ See par. 160.

${ }_{961}$ See par. 134.

${ }_{962}$ See par. 191.

${ }_{963}$ See Illustration 11 on p. 79 analogously.

964 See sec. 5 .
} 
193 Unlike those in terms of the capital or principa ${ }^{965}$, conditions of any discretionary action by the holder in addition to a contingency in terms of income payability are, however, not relevant as a differentiator. This follows from the consideration that such discretionary actions by the holder can only be of two qualitative kinds: (1) those averting the immediate pay-out and (2) those allowing a choice between diverse payment profiles. The first case (1) represents a use of disposable income in the sense of a transfer at the disposal of the recipient or beneficial owner ${ }^{966}$ (e.g. SCRIP or reinvested dividends). In particular, it does not represent a generation of taxable income and therefore cannot be relevant as its differentiator. Already the entitlement of the holder to suspend, accumulate, convert or defer the pay-out was said to be the legal event representing the realisation ${ }^{967}$ - not the execution of that option right ${ }^{968}$. This view disentangles or separates once again the causal nature of income (i.e. autonomous interpretative element) from its contextual nature (i.e. domestic interpretative element). The second case (2) has two principal sub-cases: (a) the diverse payment profiles are classified into the same income type (e.g. a fixed interest of $\mathrm{X} \%$ or a floating interest based on an index for a certain time period) or (b) the diverse payment profiles are classified into different income types (e.g. a fixed income of $\mathrm{X} \%$ or a profit share for a certain time period). In the first sub-case (a), the respective action by the holder is obviously not relevant as a differentiator for the income classification. In the second sub-case (b), each transaction triggered by the holder's or investor's action is classified individually anyway. This follows from the transaction-based approach ${ }^{969}$ in correspondence to the item-by-item structure of the OECD MTC $^{970}$. In other words: as it is the concrete execution of that option that determines the one particular transaction respectively, i.e. the action taken by the holder itself, its classification is ultimately independent of whether it was actually contingent on that action or not.

194 The conclusion for the further course of this study is that self-execution is the strictest criterion, not only for indicating the internal organisation of the legal relationship between the holder and the issuer, but also for the internal nature of a financial instrument. More particularly, it represents a universal differentiator which allows the distinction between conditional (e.g. options) and unconditional (e.g. forward contracts, debts) financial instruments.

\subsubsection{Time aspects}

\subsubsection{Preliminary remarks}

195 Representing a physical parameter, time is incompatible with the legal interpretation, and is therefore inaccessible as a subject of such interpretation. In addition, it turns out that time can in some cases be converted or approximated by other non-legal parameters. For these reasons, time aspects can themselves not directly serve as differentiators in the OECD MTC. However, time has nevertheless a significant influence on a broad number of legal and economic aspects ${ }^{971}$. The purpose of this section is therefore to analyse and discuss such potential differentiators. Their main driver or key characteristic is the lapse of time and therefore they are

\footnotetext{
965 See par. 191.

966 See par. 148.

${ }_{967}$ See par. 173.

968 See par. 107(7).

969 See par. 58.

970 See par. 59.

971 See par. 81.
} 
mainly associated with and/or discussed as being somehow time-related in recent literature ${ }^{972}$. Aspects of time are somewhat attached to these potential legal differentiators in sharing the same legal fate, including their relative importance and intensity.

\subsubsection{Maturity of principal}

196 Maturity is understood as the expiry of a financial instrument upon a resolutory condition. In a narrow sense, such a condition is typically meant as time-dependent (i.e. a finite duration). However, any condition is actually finite and it rather depends on its probability of occurrence when the duration ends. For instance, the fulfilment of the statutory purposes and objectives of a business enterprise (especially for limited-life entities $^{973}$ ) is actually finite. In fact, this narrow understanding of maturity means a temporary provision or contribution of capital or principal and thus a kind of "reasonably expectable" time periods ${ }^{974}$. This is why it is conceptually weak in the timing of probable conditions (e.g. open-ended weather "derivatives") ${ }^{975}$. For this reason, maturity can be more precisely described in the stochastical sense ${ }^{976}$ : as a more or less certain or uncertain condition.

Example 27: The end of any time period is certain (e.g. bonds, options), whereas the fulfilment of the purposes and objectives of a business enterprise is uncertain. The condition or event of an open-ended weather "derivative" is certain, whereas that of a catastrophe bond is uncertain.

197 This approach does not conflict with the above conclusion that time aspects are basically to be interpreted pursuant to domestic tax law by following the legal form rather than the economic substance ${ }^{977}$. The approach taken here merely transforms and describes the parameter of time into and by the parameter of risk. However, risk obviously requires and presumes the parameter of time as a necessary precondition. In other words: the legal and domestic determination of when a time period ends is a logical pre-step to, and therefore independent of, its autonomous and possibly economic assessment by the OECD MTC, just as it is for other criteria ${ }^{978}$. Nevertheless, the autonomous assessment by way of this risk-based interpretation of maturity is bound by the general principles of interpretation found in this study. Aspects of time have been found to bear a nexus with the aspect of temporal aggregation and disaggregation, just as for other criteria ${ }^{979}$. Hence, any interpretation towards a temporal aggregation is subject to particularly strict requirements, which justify going beyond the literal or textual interpretation only as an absolute exception. As a consequence, the duration of legal time periods can de facto only be reduced by way of economic interpretation, but not extended. As is true for any other aspect, the temporal disaggregation is in fact a one-way downward ${ }^{980}$.

\footnotetext{
972 See par. 178.

${ }^{973}$ Kuhn /Hachmeister, p. 614, par. 60.

974 Similarly: David Hariton, equity and debt, p. 506; William Plumb, p. 415, 504 et seq. and 599; for IAS / IFRS: Anna Verena Matthies, p. 157.

975 See par. 69.

976 See par. 60.

977 See par. 81.

978 See par. 21.

979 See par. 95.

980 See par. 101(1).
} 
Example 28: The duration or maturity of an American-style option might be considered economically shorter than legally contracted. In contrast, the duration or maturity of a demand deposit or perpetual bond may basically not be considered economically longer than legally contracted.

\subsubsection{Maturity of remuneration}

198 This risk-based understanding of maturity ${ }^{981}$ provides a relative and more flexible interpretation and application of time aspects than an absolute number does. However, it still requires a resolutory condition. Consequently, any differentiator based on the maturity of principal must necessarily fail where there is no such resolutory condition. It seems like a contradiction that this is often a feature of financial instruments classified as debt instruments (e.g. perpetual bonds), whose capital provision is even less temporary (i.e. less "reasonably expectable") than those of equity instruments ${ }^{982}$. This is caused by the fact that this understanding ignores the time value of money ${ }^{983}$. Due to the compound interest effect, the economic value of the right on the return of the principal becomes increasingly insignificant compared to the right on the time-based remuneration.

Example 29: The right on the return of the principal mathematically accounts for less than the right on the remuneration after 7 years at $10 \%$ per annum, 10 years at $7 \%$ per annum, 14 years at $5 \%$ per annum and 20 years at $3 \%$ per annum.

In other words: the more long-term a debt instruments is, the less important are its creditor's rights. They might protect from the default of the principal at maturity, but they protect more from the default of the time-based remuneration. Accordingly, at least for financial instruments without resolutory conditions the interpretation of time aspects by the duration or maturity of principal may generally be replaced with that of remuneration. In order to ensure consistency and comparability by avoiding a dualism of methods, this should preferably also apply to those with resolutory conditions. For instance, the value of future remuneration payments tends towards zero, whereas their weighted average duration or maturity approximates to a constant value ${ }^{984}$. This is why it is also known in finance theory as the real duration and the nominal or effective duration ${ }^{985}$. True, the duration of such individual future remuneration payments may be infinite. However, the approach makes is possible to consistently determine in any case a meaningful and effective maturity at least to the relevant point, at which other differentiators are becoming more significant.

199 The approach also corresponds to the fact that the effective duration or maturity correlates with the default risk, i.e. credit risk increasingly resembling or correlating with the business risk ${ }^{986}$. This is because both aspects largely depend on the timing of the payment profile (e.g. deferrals) ${ }^{987}$. Both the remuneration of infinite

\footnotetext{
981 See par. 196.

982 Exemplarily Sven-Eric Bärsch, p. 235; for IAS / IFRS: Kubn / Hachmeister, p. 614, par. 61; Anna Verena Matthies, p. 78 and 156; Fehér, Tamás in Eva Burgstaller, p. 245.

${ }_{983}$ David Hariton, equity and debt, p. 506. See also the detailed analysis in par. 208 et seqq.

984 David Hariton, equity and debt, p. 506.

985 Frank Fabozzi, p. 209 et seqq.

986 See par. 107(2).

987 See par. 107(4).
} 
instruments and their principal are actually exposed to the business risk. However, only the former is also time-based, as infinity can never be time-based. The underlying economic reason is that a rational investor in a time-based investment will not accept an infinite duration or maturity of the remuneration payments where that of the principal is already infinite. This is likely the reason why, for instance, super-maturity and perpetual instruments typically make periodic payments ${ }^{988}$. This peculiarity gives rise to the apparent contradiction $^{989}$ that remuneration payments are time-based and can coincidently also be risk-based. In other words: the duration or maturity of the remuneration replaces that of the principal. Given that the former accounts for more than the latter, it becomes a hybrid concept in being both time-based and risk-based simultaneously. Consequently, the approach reveals an inherent systematic conflict or dualism between the two possible differentiators of time aspects and risk aspects. This dualism becomes particularly apparent by the example of financial instruments without any resolutory condition. Obviously, "the mere fact that most of the value conferred by a long-term debt instrument is in the right to periodic payments is not an equity characteristic, however." ${ }^{\prime 90}$ This means as a conclusion for the further course of this study that time aspects must necessarily take precedence over risk aspects in cases where the two overlay. And further, the absence of a duration or maturity - be it an absolute or relative one - cannot be a differentiator. In result, the time-based understanding of duration or maturity generally cannot be maintained any more. Anything else would be inconsistent, incomparable and not universal by actually establishing a dualism of methods. From the methodological point of view, the interpretation of time aspects in the duration or maturity of principal should therefore be replaced by that of remuneration.

\subsubsection{Payment profile}

\subsubsection{Preliminary remarks}

200 The purpose of this section is to analyse and discuss potential differentiators, which are mainly characterised by the amounts paid or distributed from the financial instruments. On the one hand, this payment profile typically represents the starting point for domestically interpreting the income $e^{991}$ (income-related aspect). On the other hand, at the same time it independently gives far-reaching indications which allow for an autonomous interpretation of the underlying transaction. As a consequence of the transaction-based approach $^{992}$, the payment profile is the most apparent and observable symptom of, and a reflex response to, the economic nature of the subjacent and masked transaction or operation. In that sense, differentiators in the field of the payment profile appear to be very promising for leading to the grounds of the debt-equity distinction (transaction-related aspect).

\subsubsection{Absence of any income}

201 Where a financial instrument does not pay out anything at all (not even deferred), this could be considered as irrelevant for the classification of income types. This is because the scope of the OECD MTC as a whole is basically limited to income from transactions, which are subject of a double taxation ${ }^{993}$. However,

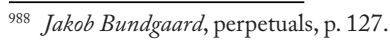

989 See par. 198.

990 David Hariton, equity and debt, p. 506.

991 See par. 144.

${ }_{992}$ See par. 56.

${ }_{993}$ See par. 19.
} 
the OECD MTC necessarily applies to negative income as well ${ }^{994}$. Hence, an absence of any income at all might, for instance, be the surface result from a subjacent net settlement within one and the same financial instrument or across different financial instruments. In the former case, the question whether the absence of any income is relevant for its classification was a result from disaggregation considerations. In the latter case it was important for the question whether the source jurisdiction of both a positive and a negative interest was legitimated to impose tax only on the positive interes ${ }^{995}$. The separation from the income's mathematical sign actually means also its independence from the income's amount altogether ${ }^{996}$. This follows from the view that the interpretative element of autonomous income classification is the causal or contextual nature. Ergo, drawing reverse deductions from the income's amount (e.g. zero) back to its contextual nature (i.e. the asset or transaction) does - just as from its mathematical sign ${ }^{997}$ - not only mix two different aspects but is also a circular reasoning. Pursuant to the explicit wording of the distributive articles ${ }^{998}$, the income classification derives from the asset or transaction ${ }^{999}$. Hence, the asset or transaction classification cannot vice versa derive from the income ${ }^{1000}$. As an introductory conclusion for the further course of this section, the absence of any income at all from a financial instrument does not dispense from the principal necessity and feasibility of classifying that financial instrument into the distributive articles of the OECD MTC.

\subsubsection{Participation in profits and losses}

202 Taking a participation in the profits and/or losses of a business enterprise literally or formally and absolutely would lead to a circular reasoning ${ }^{1001}$. In fact, that participation is vice versa the result of this distinction. For instance, pursuant to the IAS/IFRS profits and losses are "a residual interest in the assets of an entity after deducting all of its liabilities"1002. Ergo, a right participates in profits and/or losses only if it is not previously classified as a deductible liability ${ }^{1003}$. This self-contradiction can be solved by interpreting the participation in profits and losses relatively rather than absolutely, i.e. the participation in profits and/or losses was subordinate to the classification as interest. Alternatively, it can be solved based on an economic profit and loss equivalent, i.e. the participation in profits and/or losses was independent of the formal profit determination procedures of deducting the interest (e.g. by taking the EBIT or EBITDA as a profit and loss equivalent). As regards the latter, however, any compensation or pay-out actually requires and therefore participates in economic "profits" or pay-ins, which is why any compensation eventually also participates in the economic losses.

Example 30: "Excessive interest" actually skims economic profits ${ }^{1004}$, which is the very reason for the anti-abuse provision of Art. 11(6) OECD MTC with regard to shareholder loans ${ }^{1005}$.

\footnotetext{
${ }_{994}$ See par. 139.

995 See footnote 711 .

996 William Plumb, p. 433 et seq., critically citing several (domestic) US court decisions, which fail to see any difference between various free-of-charge capital or principal contributions.

${ }_{997}$ See par. 139.

998 See par. 58.

999 See par. 53.

${ }^{1000}$ See par. 54.

${ }^{1001}$ Equally for IAS / IFRS: Kubn / Hachmeister, p. 601, par. 16.

${ }^{1002}$ IAS 32.11.

${ }^{1003}$ Equally: Peter Hongler, p. 45.

${ }^{1004}$ William Plumb, p. 439 et seq.

${ }^{1005}$ See Example 8 on p. 35.
} 
Conversely, it is objectively impossible for a regular debt to pay out any fixed interest where the debtor has not previously realised some economic profits ${ }^{1006}$.

203 This leads back to, and is in line with, the finding that income cannot be distinguished from capital economically but only legally ${ }^{1007}$. Any determination of a participation in profits and losses based on a profit and loss equivalent rather than on the actual profits and losses was flawed. It would imply a nonlegal and thus artificial imagination of profit and loss as some hypothetical "adjusted" increment, arbitrarily negating certain deductibles ${ }^{1008}$ and therefore negating itself. In other words: it is the legal finding process of formally calculating profits and losses (e.g. by way of accounting law), which represents the first logical step of identifying and determining those parts of the economic capital which are made available for realisation by a legal event. That is why any determination of a participation in profits and losses based on a profit and loss equivalent rather than on the actual profits and losses was also prejudicial. Consequently, an economic interpretation of the participation in profits and losses must be refused. In other words: if the existence of an income or transaction ${ }^{1009}$ and the rights and obligations from financial instruments ${ }^{1010}$ in general already require a cautious invocation of the substance over form principle, its specific right on participating in profits and losses does even more so ${ }^{1011}$.

204 Such cautious invocation of the substance over form principle means e contrario the application of form over substance. However, this may not tempt us to interpret the participation in profits and losses in that strict narrow sense of its formal legal determination, otherwise the requirement of a participation in profits and losses would fall short entirely. The mathematical formula of profit and loss calculation has in fact only one single final result. The only financial instrument participating in profits and losses, as formally determined by way of a final calculation, is a share. Any deviation from that formal result, however small, disqualifies it immediately. That is why it is not possible for two or more different classes of financial instruments to simultaneously participate in this one single final result. Instead, they can only participate either in different relative results (e.g. by sequentially referring to another) or in one single absolute - but then not final - result (e.g. EBIT or EBITDA). Consequently, there is no space for interpreting the participation in profits and losses other than relatively, in the subjective sense that it varies in priority among its beneficiaries. In other words: profit and loss is per se a resultative and therefore binary concept. In that, it requires a multi-static and therefore relative differentiator in order to make it meaningful and significant, whereas any absolute differentiator must necessarily fail. Saying that a financial instrument participating in EBIT was "more equivalent" to profit and loss than another financial instrument participating in EBITDA, was the same as saying that one glass was less empty than another. In fact, both glasses are equally empty, not full. Instead of such absolute references suggesting false accuracy, it appears more promising to focus on the relation between the two: one financial instrument is subordinate to the other, as EBIT applies prior to EBITDA. This understanding is also in line

\footnotetext{
1006 William Plumb, p. 527.

${ }^{1007}$ See par. 158.

${ }^{1008}$ Equally: IAS Board, December 2016, 5B, p. 14, par. 43.

${ }^{1009}$ See par. 79.

${ }^{1010}$ See par. 80.

${ }^{1011}$ Argumentum a maiore ad minus.
} 
with the findings ${ }^{1012}$ and the intuition that a participation in profits and/or losses is a flexible or fluid array of "more or less"1013 rather than of "yes or no", as it can have an unlimited number of possible states or forms.

Example 31: A financial instrument can theoretically be designed to participate in every second profit by $100 \%$ and in every third loss by $150 \%$.

205 The upside of such relative interpretation approach ${ }^{1014}$ is its separation of the two different aspects of profits and losses on the one hand and participation or non-participation on the other. This should not be misunderstood that participation was also possible without having a profit or loss. It merely means that once there is a profit or loss, the subsequent question of whether or not there is also participation is independent. As a result, the aspect of whether or not there is participation is made independent of the arm's length principle which is methodologically unnecessary and potentially unsatisfactory. It is not only limited to marketable and liquid transactions ${ }^{1015}$ but in fact also establishes a "parallel world", meaning that the taxpayer is actually treated according to his environment rather than to his individual circumstances.

Example 32: The income classification of a "guaranteed compensation" actually depends substantially on whether its level is below (then entirely interest) or above (then partly interest and partly dividends) the market interest rates. In contrast, a relative interpretation would separate the "compensation" from the "guarantee" by limiting the arm's length principle only to the initial question as to what extent the level of the "compensation" makes it a dividend or interest. In contrast, the subsequent question as to what extent the "guarantee" represents a participation was dealt with independently.

206 The downside is, however, that the approach is nevertheless limited in allowing objective or universal statements. In fact, the differentiator may vary between different business enterprises and might therefore cause distortions ${ }^{1016}$. One might argue in favour that the participation or non-participation is more a subjective matter of the individual or situative circumstances rather than the objective classification as profit and loss. However, the question of how to operationalise the requirement of participating in profits and losses nevertheless depends on the subjacent conflict between the fundamental legal principles of adequacy versus relevance. This question is far too general and its answer so extensive that a satisfactory answer cannot be given here. With respect to the scope of this study ${ }^{1017}$, it is sufficient to hold that the potential distortions of that relative interpretation are in practice relativised through the interaction with other differentiators, which may therefore deserve a higher significance. As a final remark, all these systematic considerations are equally legitimate or valid within a domestic tax law. Therefore, they are at this point independent of the question as to what extent the participation in profits and losses is to be interpreted autonomously. Nevertheless, profit

\footnotetext{
${ }^{1012}$ See par. 91.

${ }^{1013}$ Equally: David Hariton, equity and debt, p. 501.

${ }^{1014}$ See par. 106.

1015 See par. 108(4).

${ }^{1016}$ See par. 108(1).

${ }^{1017}$ See sec. 1.2.
} 
and loss as income is necessarily to be determined by reference to domestic tax law ${ }^{1018}$. However, the key question of whether or not there is participation in that income also allows an autonomous interpretation.

207 In summary, it is held for the further course of this study that the participation in profits and losses is understood as relatively subordinate to a non-participation in profits and losses. The two form a multi-static (non-binary) array of unlimited forms or states in the sense of a flexible or fluid "more or less" spectrum. Nevertheless, participation in profits and losses represents a non-legal risk-based concept, i.e. loss is a positive risk and profit a negative risk or chance. It can therefore be operationalised as a differentiator by the multi-stage process of risk identification, risk disaggregation and risk elimination ${ }^{1019}$. The ideal-type of a participation in profits and losses is represented by the regulatory core equity. The ideal-type of a non-participation in profits and losses is represented by the market interest rate for time-based positions, i.e. with the relatively lowest available risk. Its weakness of being limited in allowing objective or universal statements deserves, however, a cautious invocation and therefore relatively low significance when interacting with other differentiators.

\subsubsection{Time value of money}

208 Time-based financial instruments are the theoretical ideal-type of a debt-claim ${ }^{1020}$ pursuant to Art. 11(3) OECD MTC. Therefore, they represent the natural complement to the participation in profits and losses ${ }^{1021}$. As a result of the transaction-based approach ${ }^{1022}$, the time value of money forms the starting point for the understanding of interest. On the one hand, the physical parameter of time $\mathrm{e}^{1023}$ is linear, so that any time-based remuneration can be and typically is contracted ex-ante. On the other hand, the interest rates as the "price of (investment) time" are also subject of market fluctuations in response to changes of supply and demand, just like any other prices. Where those changes are reflected in the payment profile rather than in the asset's market value, the time-based remuneration can be contracted by a mathematical formula (e.g. floating rate notes) rather than by an absolute number (e.g. straight bond). In result, the time value of money is typically self-executive ${ }^{1024}$.

209 Going further, the question arises, which and to what extent modifications of the payment profile represent a time-based remuneration. Or in other words: at which point does its purely time-based nature start and end. Particularly debatable are modifications in the $\mathrm{e}^{1025}$ :

(1) periodicity of being regular (e.g. every period) or irregular (e.g. only specific periods);

(2) certainty by being conditional (e.g. hurdles) or unconditional;

(3) amount multiplicatively (e.g. leverage) and/or additively (e.g. premium);

(4) payability by being deferred (e.g. vesting) or not deferred; and

(5) currency.

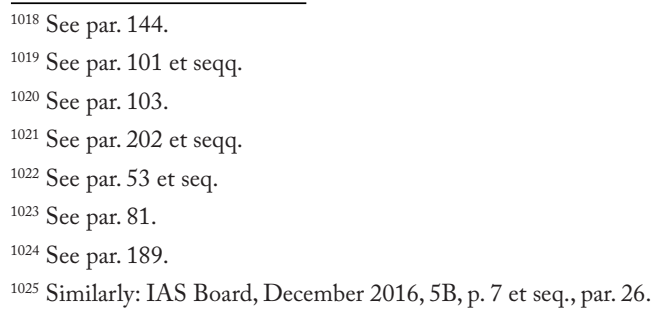


In all cases, it follows from the above equivalence of legal criteria ${ }^{1026}$ that there cannot be any priority or subordination among them.

\section{Periodicity}

210 Analogous to the duration or maturity of the principal ${ }^{1027}$, the first aspect (1) of periodicity of the remuneration payments can be understood as either time-based or risk-based. The difference between the maturity of the remuneration payments and that of the principal is that the former always has a resolutory condition, even where the latter has none. In other words: even where the maturity for repaying the principal is infinite (e.g. by requiring an action, such as a termination) and therefore unknown, that of each individual remuneration payment is ex-ante determined and therefore known (even where also its own duration is infinite ${ }^{1028}$ ). Consequently, there is no compelling need for a risk-based understanding of the remuneration's maturity in order to ensure consistency, comparability and universality ${ }^{1029}$. Therefore, the question remains, which and to what extent risk-based payment profiles represent a time-based remuneration - even more so since underwriting risk can replicate or be converted into timing risk ${ }^{1030}$.

211 This question and the subjacent transformation of time into risk appears quite difficult to tackle. The reason is that the OECD MTC, in contrast to the domestic tax laws, does not have the requisite temporal framework in the sense of tax periods (e.g. tax years) but instead an item-by-item structure ${ }^{1031}$. However, the maturity of the remuneration payments - unlike that of the principal - is always known. Ergo, the congruence of time and risk could be assessed at these points in time (i.e. those of their resolutory conditions). In other words: the transformation of time into risk does not necessarily require an absolute temporal framework of tax periods but merely any relative temporal framework of time marks. As even an infinite duration or maturity of the principal necessarily entails a finite duration or maturity of the remuneration payments ${ }^{1032}$, these time marks are always ex-ante determinable. An exception to these principles, which is also in line with the IAS/ IFRS $^{1033}$, is where the holder has a right to terminate the financial instrument ${ }^{1034}$. In this case both the duration or maturity of the principal and that of the remuneration might be infinite. The right to terminate refers, however, to the primary market only. The financial instrument itself remains infinite and therefore still bears underwriting risk, even if disposed on the secondary market.

Example 33: A tracker certificate might be indirectly linked to a seasonal index instead of directly to the lapse of time. Where such certificate distributes any periodic remuneration, its time-based nature can be assessed at these payment dates. Where such certificate distributes no remuneration and its duration or maturity is finite, its time-based nature can be assessed at this duration or maturity. Where the certificate distributes no remuneration and its duration

\footnotetext{
1026 See par. 182.

${ }^{1027}$ See par. 196.

${ }^{1028}$ See par. 198

${ }^{1029}$ See par. 199

${ }^{1030}$ See par. 69.

${ }^{1031}$ See par. 59.

${ }^{1032}$ See par. 199.

${ }^{1033}$ See par. 191.

${ }^{1034}$ Equally: Peter Hongler, p. 47.
} 
or maturity is infinite but the holder has the right to terminate, its time-based nature can be assessed at this termination date ${ }^{1035}$. Where the certificate distributes no remuneration, its duration or maturity is infinite and the holder has no right to terminate, it cannot be of a time-based nature.

212 For these reasons, periodicity can be used as a two-tier differentiator: its time-based nature is to be assessed by the congruence of the risk-based with the time-based remuneration (time equivalence), but only where the latter does not already exist. Where the risk-based remuneration is congruent to the time-based remuneration, the latter was found necessarily taking precedence over the former ${ }^{1036}$. Where the long-term duration or maturity (especially if infinite) necessitates high interpretation significance and therefore a disaggregation of the time value of money ${ }^{1037}$, this approach should allow for "extraction" from most financial instruments.

Example 34: A straight or finite zero bond is time-based to the extent its value change is congruent with the time value of money (i.e. the entire value change at maturity or the accrued interest when disposed). A tracker certificate on the straight bond is equivalent to the finite zero bond ${ }^{1038}$. An infinite bond with periodic coupons is time-based. An infinite zero bond with termination right is equivalent to the finite zero bond. An infinite zero bond without termination right is not time-based. A tracker certificate on the infinite bond with periodic coupons is equivalent to the zero bond (i.e. time-based with termination right and not time-based without termination right). A share is not time-based, as its maturity is not ex-ante determinable ${ }^{1039}$. In contrast, a tracker certificate on the share may be time-based to the extent that its value change is congruent with the time value of money, given that its (relative ${ }^{1040}$ ) maturity is ex-ante determinable.

\section{Certainty}

213 The second aspect (2) $)^{1041}$ of certainty may naturally only refer to the timing risk of when the remuneration is paid ${ }^{1042}$ but not to the underwriting risk of whether it is paid at all ${ }^{1043}$. However, this obviousness leads to the subjacent question at which point the financial instrument is to be classified ${ }^{1044}$ :

(1) date of issuance or acquisition of the financial instrument (dynamic ex-ante view);

(2) date of income payment in isolation (static view);

(3) date of income payment in consideration of the remaining expectable lifetime of the financial instrument (dynamic forward-looking view); or

(4) at the end of the financial instrument's entire lifetime (dynamic ex-post view).

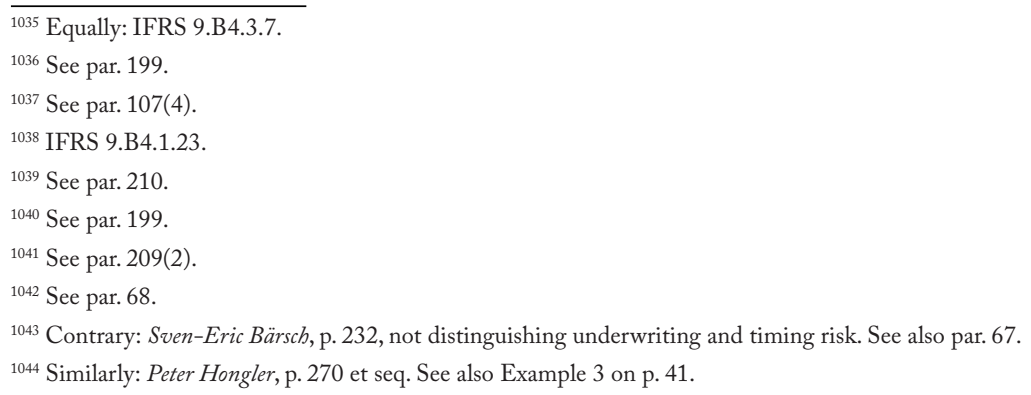


214 In the author's opinion, the income or transaction is basically to be classified according to the dynamic forward-looking view (3) for a number of reasons:

- Any conditional concept in the sense of criteria being subject to a reservation of whether or not an aspect applies at all would entirely fall short where instead only concepts would apply once something has effectively happened.

- Speaking more generally, aspects dealing with the grounds (e.g. conditions) methodologically apply prior to those dealing with the amounts (e.g. payments). Any other approach would mean nothing else than to ignore the cause and only consider the effects.

- In addition, any concept based on time periods would entirely fall short where only concepts would apply which are determined on a particular point in time. ${ }^{1045}$

- Most notably, this does not only include all kinds of risk ${ }^{1046}$ but also the entire asset as the starting point and interpretational baseline of the OECD MTC, which is not substituted but merely enlarged and disentangled by the transaction-based approach ${ }^{1047}$.

- Furthermore, the classification of the income or transaction would be highly erratic. The reason is that its nature would solely depend on its particular context in the respective points in time rather than over the entire lifetime of the financial instrument ${ }^{1048}$. Accordingly, the classification would be subject of more probable changes over time.

Example 35: Where a bond was featured with an increasing interest rate from below to above market interest rate, analysing the individual coupon payments separately might lead to their differing classifications (i.e. time-based and not time-based), compared to if they had been analysed by grouping them together as a coherent whole (i.e. time-based).

- And finally: the approach of basically classifying the income or transaction dynamically was therefore also taken by the IAS/IFRS ${ }^{1049}$.

Consequently, where the remuneration is subject to a condition or reservation of whether or not it is paid at all, this underwriting risk must necessarily apply prior to and therefore falsify time equivalence and consequently the time-based nature of the financial instrument ${ }^{1050}$.

Example 36: A structured product, whose coupon is subject of a netting of its interest component with its capital gain component, is not time-based - even if the coupon taken separately is congruent with the time value of money.

\section{Amount modifications}

215 As regards the third aspect (3) $)^{1051}$, the question is to what extent modified amounts represent the time value of money. Multiplicative modifications are leverage, which can be above $(>1)$ or below $(<1)$ time proportionality

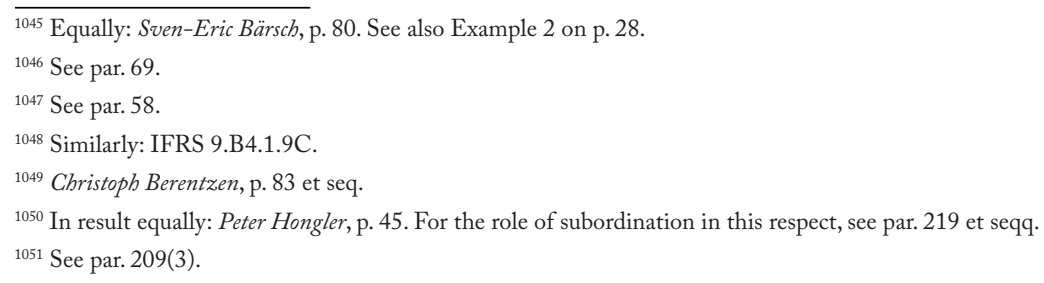


(=1). Additive modifications can be premiums $(>0)$ or discounts $(<0)$. In this respect, the IAS/IFRS correspond with intuitive position that any positive modification (i.e. leverage $>1$ and premiums) is basically not time-equivalent and therefore does not represent the time value of money. The reason is that any excess amount can eventually and economically only be yielded by equity (or perhaps by luck), implying, however, underwriting risk ${ }^{1052}$. This becomes particularly clear where the modification has results in an effect such as an if-at-all condition, i.e. the risk of reducing the amount to zero ${ }^{1053}$. Analogously, any other opportunity costs compensating the lost or prospective time value of money are - unlike in the IAS/IFRS ${ }^{1054}$ - not interest pursuant to Art. 11(3) OECD (e.g. the excess "interest" of inflation-linked bonds or notes). These can only be yielded by equity implying underwriting risk. Admittedly, also the time value of money itself can and must be yielded by implying underwriting risk (e.g. the deposit interest rate at the central bank). Nevertheless, it represents by definition the theoretical ideal-type of a debt-claim pursuant to Art. 11(3) OECD MTC in bearing the lowest relative underwriting risk ${ }^{1055}$. One exception to this general principle is however where the long-term duration or maturity, especially if infinite, necessitates high interpretation significance and therefore a disaggregation of the time value of money ${ }^{1056}$. Another exception is where the excess amounts, analysed by grouping them together as a coherent whole ${ }^{1057}$, are exactly and certainly compensated by lower amounts elsewhere and therefore actually represent the time value of money. Such grouping of the remuneration payments from one and the same financial instrument for the purpose of dynamically ${ }^{1058}$ classifying it represents a requisite exception from the finding that an aggregation of transactions upwards from their individual singularities is not justifiable ${ }^{1059}$. However, where such lower compensating amounts are uncertain, this necessarily implies underwriting risk and therefore does not represent the time value of money. From this rationale follows e contrario that negative amount modifications (i.e. leverage $<1$ and discounts) are time-equivalent. Therefore, they represent the time value of money where lower amounts, analysed by grouping them together as a coherent whole, are exactly and certainly compensated by excess amounts elsewhere, or where the long-term duration or maturity (especially if infinite) necessitates high interpretation significance and therefore a disaggregation of the time value of money.

Example 37: A finite structured product pays a periodic remuneration and, at maturity, a capital gain from its underlying. Where the remuneration is positively or negatively modified and the correspondingly lower or higher capital gain is certain (i.e. a forward component), the structured product is time-based (i.e. the forward component is in fact a positive or negative interest). Where the remuneration is positively or negatively modified and the correspondingly lower or higher capital gain is uncertain (e.g. an option component), the structured product is not time-based (i.e. the option component is in fact a positive or negative risk premium).

\footnotetext{
${ }^{1052}$ Christoph Berentzen, p. 82.

${ }^{1053}$ See par. 213 et seq.

${ }^{1054}$ Haufe, IFRS, p. 1712, par. 166.

${ }^{1055}$ See par. 103.

${ }^{1056}$ See par. 212.

${ }^{1057}$ See Example 35 on p. 125.

${ }^{1058}$ See par. 214.

${ }^{1059}$ See par. 95.
} 


\section{Payability}

216 The fourth aspect (4) ${ }^{1060}$ of payability is basically analogous to the third aspect (3) of amount modifications ${ }^{1061}$. The difference is that the relevant period for assessing the time equivalence starts with the maturity of the remuneration. Accordingly, deferrals represent a negative amount modification and therefore not the time value of money, except where they bear interest as well (i.e. are subject of compound interest). ${ }^{1062}$

\section{Currency}

217 As regards the last aspect (5) ${ }^{1063}$, time equivalence must necessarily be determined in the currency, in which the principal nominates ${ }^{1064}$ - even where the remuneration itself is paid in a different currency. This means in particular that any currency conversion is a subsequent logical step to the capital provision. Thus, currency risk has no influence on the assessment of the time equivalence.

\subsubsection{Risks and opportunities}

\subsubsection{Preliminary remarks}

218 The purpose of this section is to analyse and discuss potential differentiators which are mainly characterised by positive and negative risks arising from financial instruments ${ }^{1065}$. On the one hand, risk as a mathematical and therefore quantitative parameter is an economic category ${ }^{1066}$. Except for legal risk and timing risk, such quantitative parameters do not allow qualitative conclusions on the types of risk ${ }^{1067}$. On the other hand, it was nevertheless found capable of indicating some general guidelines for the various fields of those potential differentiators. In addition, it was also found capable of being an interpretative and/or applicative assessment factor for methodologically evaluating the relative importance of these fields of criteria ${ }^{1068}$. Especially for the systematic approach taken in this study ${ }^{1069}$, risk turns out the be a crucial qualitative criterion. Its absolute and binary existence of "yes or no" and its relative and multi-static occurrence of "more or less" suffice in many aspects for revealing far-reaching indications. These allow for the interpretation of the nature of the underlying transaction autonomously and may therefore potentially lead to the grounds of the debt-equity distinction. Like the payment profile ${ }^{1070}$, with which risk bears a natural nexus ${ }^{1071}$, the apparent and observable behavioural adaptations of the contracting counterparties of financial instrument to their particular risk exposures are symptoms of or reflex responses to the economic nature of the subjacent and masked transaction or operation. Differentiators in the field of risks and opportunities appear likewise to be very promising for contributing value added to this study.

\footnotetext{
${ }^{1060}$ See par. 209(4).

${ }^{1061}$ See par. 215.

${ }^{1062}$ IFRS 9.B4.1.14, example/instrument H.

${ }^{1063}$ See par. 209(5).

${ }^{1064}$ IFRS 9.B4.1.8.

${ }^{1065}$ See par. 60.

${ }^{1066}$ See par. 65.

${ }^{1067}$ See par. 101.

${ }^{1068}$ See par. 107.

${ }^{1069}$ See par. 13.

${ }^{1070}$ See par. 200.

${ }^{1071}$ See par. 89.
} 


\subsubsection{Subordination}

219 At first glance, subordination appears to be closely related to with the participation in profits and/or losses ${ }^{1072}$. Admittedly, a limit or cap of compensation, in that it does legally not participate in the profits, was said to be nothing but an indemnification for the subordinate and therefore lower relative risk of also legally participating in the losses ${ }^{1073}$. As a consequence, there is typically a positive correlation between a participation in profits (and maybe losses) and subordination. For instance, any principal repayment actually requires and therefore participates in economic capital contributions or pay-ins, analogous to any compensation or payout $^{1074}$. For this reason, any capital or principal eventually also participates in the economic business risk ${ }^{1075}$. However, this turns out to be an imprecise view, if looked at more closely. The positive correlation may not lead to the erroneous reverse deduction that there was, in turn, subordination wherever there is a participation in profits ${ }^{1076}$ (and maybe losses). For instance, "hybrid" debts may participate in profits (and maybe losses) without however being subordinated. The primary reason is that subordination refers to and primarily means the principal (i.e. the asset), and does not necessarily also include the compensation (i.e. the income or transaction).

Example 38: Shares are subordinated in both principal and compensation, whereas ("hybrid") debts are typically subordinated in principal only. A fortiori, in order to attract investors it is often a typical feature of such "hybrids" to grant priority or seniority for the income as an additional compensation for the subordination of the principal.

This follows from the fact that subordination is logically determined prior to and therefore in no way linked with the legal process of formally determining or calculating equity and liabilities ${ }^{1077}$.

Side note: Just like the OECD MTC ${ }^{1078}$, the IAS/IFRS apply an asset-based approach by defining equity as residual "assets of an entity after deducting all of its liabilities"1079. “[...] distributions to holders of equity instruments are recognised directly in equity. Interest, dividends and other returns relating to financial instruments classified as financial liabilities are expenses [...]." ${ }^{1080}$ In contrast, corporate law is typically more flexible, in that subordination in principal does not necessarily imply subordination also in the compensation.

Unlike the formally determined profits and/or losses ${ }^{1081}$, subordination is consequently not resultative or binary, and therefore not an absolute but rather a relative concept per $\mathrm{se}^{1082}$. While the formally determined profit and loss is an absolute figure of "yes or no", subordination describes a relative relationship between

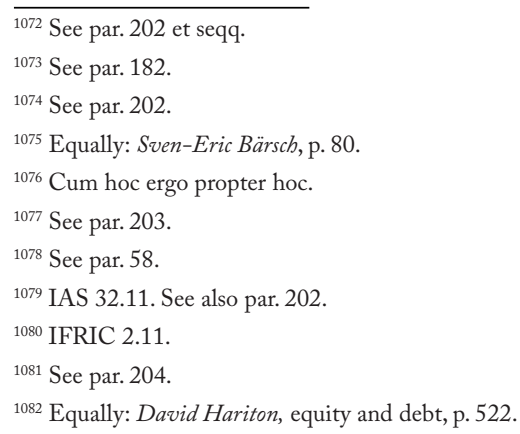


two figures in terms of a "more or less". As a result, subordination can not only be interpreted relatively or economically but also absolutely and formally and therefore domestically.

Example 38 (continued): Interpreted relatively, the principal of equity was subordinate to the classification as a liability. Since "excessive debt" actually skims economic equity ${ }^{1083}$, thin capitalisation rules often provide a debt-equity ratio instead of an interest-profit ratio. Interpreted economically, the principal of equity was independent of the formal equity determination procedures of deducting the liability.

220 Also, subordination represents a non-legal risk-based concept ${ }^{1084}$. However, in contrast to the participation in profits and/or losses ${ }^{1085}$, subordination cannot be operationalised as a differentiator by the multi-stage process of risk identification, risk disaggregation and risk elimination ${ }^{1086}$. Unlike the relatively highest subordination represented by the regulatory core equity ${ }^{1087}$, the ideal-type of the relatively lowest subordination (i.e. with the relatively lowest available risk) and therefore a requisite reference and the starting point for applying the model, is not determinable. Subordination in the principal is completely independent and therefore not deducible from that in the compensation ${ }^{1088}$. Apart from that, subordination is - in contrast to profits and/ or losses ${ }^{1089}$ - already by its wording (“sub...”) a relative concept per se and as such determinable only on an individual or situative basis. Profits and losses as such are absolute figures, whereas the separate and subsequent question of whether or not there is also participation ${ }^{1090}$ must be answered relatively. Therefore, profits and losses represent the reference and starting point for giving this answer. In contrast, subordination as such is a relative figure and therefore strongly depends on the context. As a consequence, subordination represents an erratic and inhomogeneous and therefore non-marketable and non-transferable risk ${ }^{1091}$. In the absence of any possibility for such standardisation there is no objectified reference for risks from subordination. In this light, the accurate notice that any subordination makes a financial instrument not necessarily a debt-claim ${ }^{1092}$ appears however meaningless. The undisputedly important criterion of subordination simply negated. Consequently, it is not even theoretically possible to draw any objective or universal statement at all, as a differentiator on such basis would be highly erratic and eventually arbitrary.

Example 39: One and the same financial instrument A can be subordinate to another financial instrument $\mathrm{B}$ in one context but simultaneously vice versa in another context. ${ }^{1093}$ Financial

\footnotetext{
$\overline{{ }^{1083} \text { See Example } 30 \text { on p. } 119 .}$

${ }^{1084}$ See par. 107.

${ }^{1085}$ See par. 207.

${ }^{1086}$ See par. 101 et seqq.

${ }^{1087}$ IAS 33.5, ordinary share.

${ }^{1088}$ See par. 219.

${ }^{1089}$ See par. 204.

${ }^{1090}$ See par. 205 et seq.

${ }^{1091}$ See par. 60.

${ }^{1092}$ Among others: Anna Verena Matthies, p. 153 et seqq

${ }^{1093}$ Similarly: David Hariton, equity and debt, p. 523, illustrating that "asking 'how much' without fitting the answer into an understanding of the issuer's capital structure is like playing blind man and the elephant"; William Plumb, p. 605 et seq., noticing that "subordination to one or a limited number of creditors does not ordinarily have the same significance as subordination to all creditors".
} 
instrument $\mathrm{A}$ might be classified as debt in the one context but simultaneously as equity in the other. ${ }^{1094}$

221 In other words: this conceptual weakness may still be acceptable or justifiable for the participation in profits and/or losses ${ }^{1095}$ due to the existence of an objectified directional reference. But it can, in the absence of the same, not be maintained any more for subordination. A legal criterion that cannot possibly be relevant, however, cannot possibly be purposeful either. That is why even considering its paramount importance ${ }^{1096}$, an autonomous interpretation of subordination must be excluded. This outcome is also in line with and supported by the finding that the default risk of not paying back the capital or principal itself must necessarily be a legal risk (i.e. the credit risk) ${ }^{1097}$ and thus be interpreted domestically. For these reasons, it can be concluded e contrario that subordination must be interpreted formally and therefore necessarily pursuant to the domestic law. Unlike the participation in profits and/or losses ${ }^{1098}$, any domestic law must necessarily apply a relative interpretation of subordination. However, the concurrence with its domestic interpretation as such while coincidently being of significant importance may nevertheless frustrate the distinction of the OECD MTC income types of financial instruments, which would otherwise give rise to qualification conflicts. As a final remark, this domestic interpretation is also the reason why subordination is not capable of giving any indication as to whether the mutual exclusivity between Art. 10 and 11 OECD MTC - in contrast to the IAS/IFRS $^{1099}$ - is a result of either their subordinate relationship or of an equal position on the same level or $\operatorname{rank}^{1100}$.

\subsubsection{Coverage and collateral}

222 At first glance, both coverage and collateral appear to be protective measures against credit risk. Consequently, there is a substitutive effect and therefore typically a negative correlation between the two. However, this turns out to be an imprecise view if looked at more closely, in that coverage actually reduces the probability of the credit default event and collateral the value of the credit default event ${ }^{1101}$. Credit default is a legal event due to the specific legal characteristics of debts given by law, which is why credit risk is a legal risk. ${ }^{1102}$ As such it emerges as a result of the legal relationship, i.e. at the edge of the formal interface between the contracting parties: it represents the "residual" counterparty risk after having already included and netted all risk minimising effects within the financial instrument itself (e.g. coverage). In addition, credit risk ceases to exist as a hazard once the credit default event occurs, turning from uncertainty into certainty. From this perspective, coverage is understood here as any feature or protection within a financial instrument that minimises the probability of its credit risk. In contrast, collateral is understood as any compensation of a financial instrument for the adverse effects of its credit default event itself. On the one hand, neither of the two concepts is part of the credit risk itself. Also collateral does not reduce the credit risk itself but in fact

\footnotetext{
${ }^{1094}$ Equally: William Plumb, p. 475.

${ }^{1095}$ See par. 206.

1096 See par. 107.

${ }^{1097}$ See par. 66.

1098 See par. 205 et seq.

${ }^{1099}$ See par. 219.

${ }^{1100}$ See par. 113.

${ }^{1101}$ See par. 60.

${ }^{1102}$ See par. 66.
} 
reduces the credit amount economically. Where collateral is perfect, there is economically no credit or debt. The reason is that the provision or contribution of the capital or principal is perfectly compensated by the provision or contribution of the collateral, which becomes particularly clear from the example of a credit or debt in kind. Even where the provision or contribution of cash capital or principal was considered a formal credit or debt by legal convention, a collateralisation will typically not be a requirement by such convention but rather a response to it. In other words: collateralisation might be an indicator for credit risk, but cannot be a credit risk itself. On the other hand, the two concepts differ in the way that coverage is in fact part of the underwriting risk, being in effect just prior to the occurrence of the legal credit default event. In contrast, only collateral is complementarily related to the credit risk, coming into effect just after the occurrence of the legal credit default event. Considering coverage as equivalent with collateral was a circular reasoning, as it would imply a non-legal and thus artificial imagination of credit risk as some hypothetical "uncovered" state that actually negates coverage itself. Accordingly, there is a positive correlation between credit risk and collateral but a negative one between credit risk and coverage. Where coverage is perfect, there is no credit risk; but collateral is only necessary where there is credit risk. The following illustration visualises this understanding:

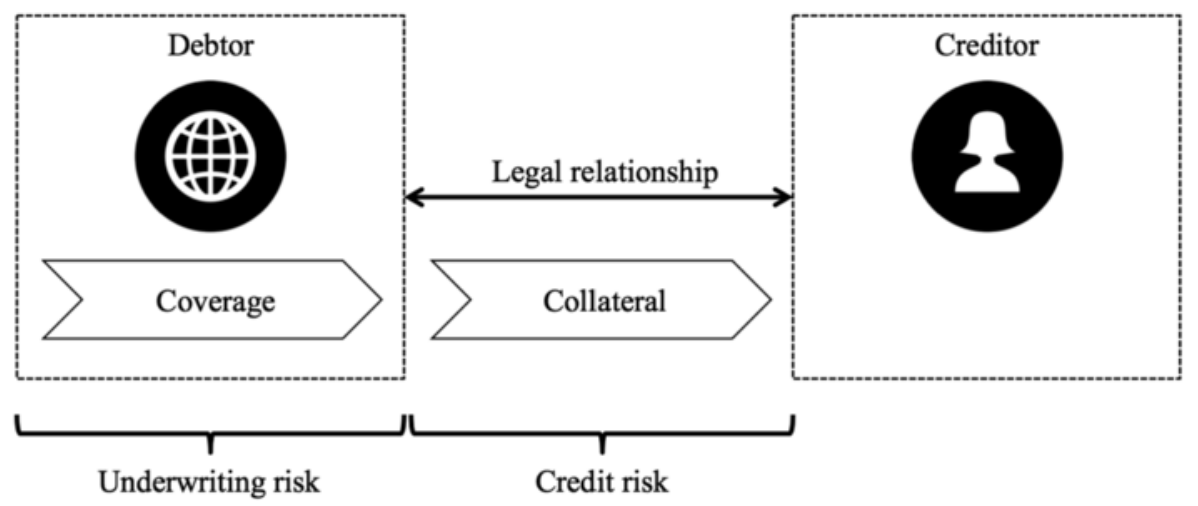

Illustration 14: Coverage as part of underwriting risk versus collateral as related to credit risk

223 After these considerations it might be naturally suggested that any conclusion in order to indicate credit risk and therefore debt-claims may be potentially drawn from collateral only but never from coverage. However, the question arises why it should be necessary at all to draw such conclusions from an effect that is obviously rooted in a debt classification already. The answer is that the positive correlation between credit risk and collateral ${ }^{1103}$ should not lead to the conclusion that there is in turn a credit risk wherever there is a collateral ${ }^{1104}$ (e.g. where the collateral is the coverage, such as commodity-backed payment-in-kind bonds). The substitutive economic effect between coverage and collateral ${ }^{1105}$ allows "squeezing" or carving out the material effects of collateral (i.e. minimising the adverse effects of the credit default event) by those of coverage (i.e. minimising the probability of the credit default event). As a consequence, credit risk can be "squeezed" or carved out by underwriting risk. That is why collateral is not capable of positively verifying credit risk in a reliable manner.

\footnotetext{
${ }^{1103}$ See par. 222.

${ }^{1104}$ Cum hoc ergo propter hoc.

1105 See par. 222.
} 
224 On the other hand, it is not possible to vice versa "squeeze" or carve out the material effects of coverage by those of collateral, as the former logically applies prior to the latter, so that underwriting risk can in turn not be "squeezed" or carved out by credit risk. That is why coverage is capable of negatively falsifying credit risk reliably. In other words: the economic substitutability between coverage and collateral can be transformed into an economic approach that might open up new possibilities for differentiating the income types from financial instruments by identifying counterparty risk indirectly but more reliably in its form of underwriting risk (i.e. via coverage) rather than in its form of credit risk (i.e. via collateral). This is also why the approach does not violate the finding that credit risk is a legal risk, being accessible only by form over substance ${ }^{1106}$. The idea behind the approach is that uncovered debts bear the risk in the debtor's ability to recover the capital or principal (i.e. credit risk). In contrast, covered debts merely bear the risk of ownership in the capital or principal itself (i.e. underwriting risk), which the creditor also had to take without having left it to the debtor. ${ }^{1107}$ As the sum of the two effects is always the same in value due to their economic substitutability, the existence or non-existence of coverage as a part of underwriting risk can indicate whether or not there is any space left for effective credit risk, making it a possible differentiator for debt-claims. This approach is even more promising as credit risk has a limited analytical value due to the fact that it cannot be "resolved" but only converted by transferring or re-allocating it and therefore accepting new legal risks ${ }^{1108}$.

225 Admittedly, it might be objected that this approach poses a number of systematically difficult problems, such as $^{1109}$ :

(1) The look through the debt down to its coverage extends the economic character of the approach also to the understanding of capital or principal. In fact, it is split economically into the two logical aspects of lending cash (i.e. finance) and binding that cash in an utilisation (i.e. investment ${ }^{1110}$. In doing so, the approach goes beyond the mere provision or contribution of capital or principal between debtor and creditor (i.e. finance) by actually also involving its utilisation by the debtor (i.e. investment). Where coverage is perfect, a cash credit cannot be invested or capitalised in the sense of sourcing potential income. For example, a cash credit perfectly covered and therefore bound by a real asset cannot generate any income. Instead, cash can only generate income by being utilised other than by perfect coverage. That is why the economic understanding of capital and capitalisation necessitates the relinquishment of control over the cash for the purpose of income generation (i.e. investment). In other words: capital investment implies and requires counterparty risk as a necessary condition. Hence, the classification of the financial instrument and therefore the treatment of the creditor depend on the way in which the debtor effectively uses the borrowed capital or principal (inter-subjective classification chain).

(2) Beyond that, the further question arises which nature and what intensity the coverage must have in order to qualify as such a differentiator. Thinking it through to the end would mean that not only physical (e.g. by real assets) but also synthetic coverage (e.g. by other financial instruments) should be capable of qualifying. This appears to be a result from the economic character of the approach, according to which

\footnotetext{
${ }_{1106}$ See par. 101(1).

${ }^{1107}$ Weissbrodt, Jan, Die sonstige Kapitalforderung im Sinne von § 20 Absatz 1 No. 7 EStG, Deutsches Steuerrecht 2012, Vol. 31 , p. 1535.

${ }^{1108}$ See par. 101(2).

${ }^{1109}$ Weissbrodt, Jan, Die sonstige Kapitalforderung im Sinne von $§ 20$ Absatz 1 No. 7 EStG, Deutsches Steuerrecht 2012, Vol. 31, p. 1535 et seq.

${ }^{1110}$ Zantow, Roger / Dinauer, Josef, Finanzwirtschaft des Unternehmens: Die Grundlagen des modernen Finanzmanagements, Series wi wirtschaft, $4^{\text {th }}$ edition, Pearson, Hallbergmoos, 2016, p. 24.
} 
coverage is part of the underwriting risk, making no difference in any way between identical risk profiles of different kinds of assets.

(3) Where the debt is not perfectly covered, it is either a question of whether to disaggregate the covered and the uncovered components, or a matter of degree, how much coverage is critical to turn the financial instrument entirely from being classified as covered into being classified as uncovered (or vice versa).

226 As regards the first objection (1), the dependency of the creditor's tax treatment on the debtor's behaviour might indeed be impermissible or inappropriate within the context of a domestic tax law. DTC have to integrate themselves as coherent elements by respecting and being bound to the instruments and principles granted by their domestic tax law systems, particularly the superior domestic (e.g. constitutional) laws ${ }^{1111}$. However, the purpose and function of DTC - even in jurisdictions applying the monistic system - are considerably different from or even opposite to those of their domestic tax laws ${ }^{1112}$. In fact, they focus on limiting the taxation of the source ${ }^{1113}$ rather than on generating tax revenues. In this light, focussing likewise on the debtor as the source of income from debt-claims not only appears to be free of conflicts with the domestic tax law but also seems in line with the purpose and function of the OECD MTC and therefore necessary.

227 As regards the second objection (2), synthetic replication is possible only at the price of higher legal risks ${ }^{1114}$. This would, however, run contrary to the initial idea of the approach to identify counterparty risk indirectly in its form of non-legal (i.e. underwriting) risk rather than in its form of legal (i.e. credit) risk ${ }^{1115}$. Consequently, only physical and not synthetic coverage is capable of qualifying as a differentiator, whereby physical means that those assets do not bear any credit risk themselves. As the subprime mortgage crisis has shown, any discretionary level of insignificance for some minor credit risk allows for diluting the intensity of the coverage as a differentiator by way of disaggregating and re-aggregating credit risk.

228 As regards the third objection (3), this is also the reason why the disaggregation appears to be more purposeful and resilient than a discretionary level of insignificance for some minor credit risk. The process of successively disaggregating the underwriting risk stops where the counterparty risk can be distinctly attributed to the (non-)coverage ${ }^{1116}$. In this point, the counterparty risk can be clearly distinguished and separated from other underwriting risks. This is why the absence of any coverage - just as the absence of any collateral - is still not an indicator and even less a verifier for a participation in underwriting risk, justifying a negation of debt ${ }^{1117}$. This is also demonstrated by the fact that the credit rating typically does not change where collateral is transmutated into coverage or vice versa.

229 In conclusion, the economic substitutability between coverage and collateral allows for the use of coverage as a differentiator for identifying counterparty risk in a potentially more reliable manner than collateral, in

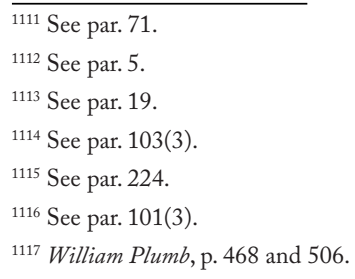


that it is capable of negatively falsifying credit risk. Such an approach is in line with the purpose and function of the OECD MTC and conflicts neither with previous systematic findings nor with the objectives and principles of the domestic tax laws. In particular, it does not violate the finding ${ }^{1118}$ that credit risk as a legal risk cannot be interpreted economically but must necessarily be subject of form over substance, since coverage (i.e. underwriting risk) applies prior to and therefore independent of collateral (i.e. credit risk) ${ }^{1119}$.

230 However, a special question that deserves particular attention is where the coverage or even the collateral is provided or represented by own equities (e.g. shares) of the issuer himself, or, speaking more generally, by physical assets bearing underwriting risk that significantly correlates with the issuer's own business risk. In these cases, the coverage meets all the requirements found here before ${ }^{1120}$. But the credit risk is merely converted into, and thus inextricably coalesced with, the business risk ${ }^{1121}$ and therefore cannot be distinctly attributed to the (non-)coverage by way of successively disaggregating the underwriting risk ${ }^{1122}$. The specific "hybrid" nature of such debts becomes particularly clear, when considering that in cases of default the equity appreciates in direct response to the debt's corresponding depreciation (circular effect). As a consequence, the creditor genuinely participates in the business risk for the benefit of the debtor (risk sharing) ${ }^{1123}$. Nevertheless, financial instruments providing the coverage or even the collateral by own equities merely represent a particular use case in a more general class of financial instruments, whose "amount of economic resources required to settle the claim is not independent of the entity's economic resources." ${ }^{1124}$ Such financial instruments touch a number of aspects which are subject in this study. This is why they are predominantly analysed in the following sub-section in the context of capital or principal repayment at maturity. ${ }^{1125}$

\subsubsection{Termination risk}

\section{Definition}

231 Time-based financial instruments were said to represent the theoretical ideal-type of a debt-claim pursuant to Art. 11(3) OECD MTC, in that they bear the lowest relative risk ${ }^{1126}$. Excluding credit risk ${ }^{1127}$ as a legal risk ${ }^{1128}$ and timing risk as an admissible non-legal risk ${ }^{1129}$, this means residually the lowest relative underwriting risk. This characteristic and requirement does not only apply to the income or transaction ${ }^{1130}$ but analogously also to the capital or principal ${ }^{1131}$. Accordingly, the pure form of a debt-claim and the starting point for the understanding of interest basically implies and requires a perfect recovery of the invested capital (i.e. the

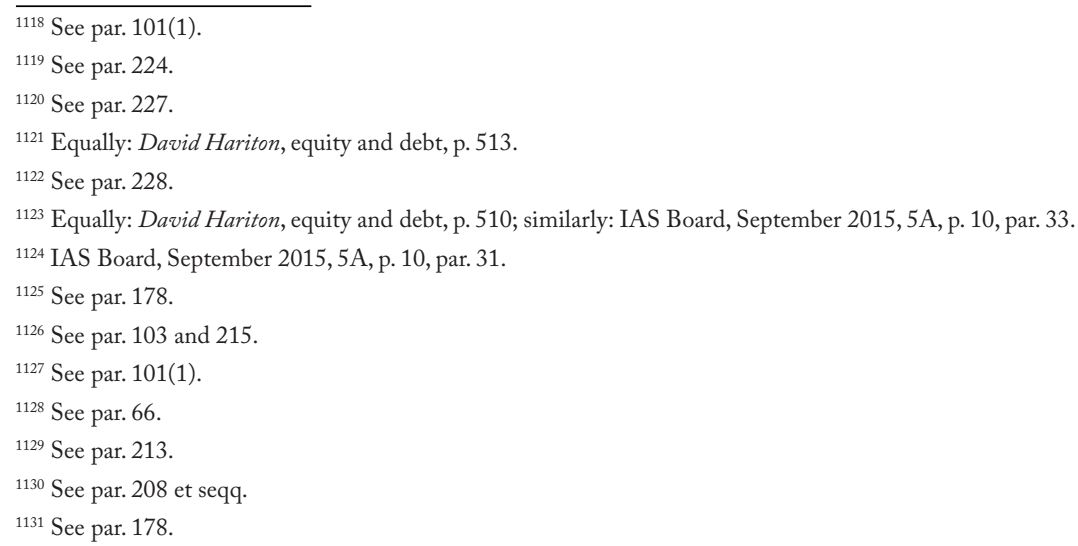


principal $)^{1132}$. Analogously to the time value of money (i.e. the income or transaction) ${ }^{1133}$, this capital recovery refers first of all to the primary market only. The reason is that any disposal of the financial instrument on the secondary market naturally happens before its maturity. As, economically, today's capital is tomorrow's income ${ }^{1134}$, the value of a financial instrument, however, depends also on the environmental influences ${ }^{1135}$ of potential alternative possibilities or opportunities to invest the capital for its remaining duration (opportunity costs $)^{1136}$. In other words: these value fluctuations are merely reflex responses to the fixed-interest period of the financial instrument ${ }^{1137}$. The more the lapse of time approximates the end of the respective fixed-interest period, the fewer alternative possibilities or opportunities are available on the market, so that the value of the financial instrument correspondingly approximates the principal amount. As those value fluctuations are thus merely temporary, they represent in fact timing risk ${ }^{1138}$ and are therefore irrelevant with regard to the principal's underwriting risk.

\section{Step 1: redemptions in kind}

232 For these reasons, termination risk means any non-legal underwriting risk towards a non-perfect recovery of the capital or principal at maturity. In contrast to the multi-statically modifiable time value of money ${ }^{1139}$, (non-)perfection is a binary concept and therefore much more clearly and reliably determinable. This is why only the one use case shall be analysed in more detail here, in which the capital or principal is in result redeemed in kind instead of in the currency nominated. This understanding is broad and also includes, for instance, novations, substitutions or redemption in different currencies (e.g. physically-settled compo or quanto equity swaps ${ }^{1140}$, etc.).

Example 40: Payment-in-kind bonds are redeemed in their underlyings. Structured products in general can optionally be redeemed in their underlyings; convertible bonds in particular can optionally be redeemed in shares. Bonds can be perpetual where they are redeemed in an identical bond ${ }^{1141}$.

The specific systematic question in this case is, what constitutes a potential difference between the capital or principal provided and that redeemed. The reason is the dual purpose of legal entitlements (i.e. the capital or principal) in potentially representing both the economic return for legal obligations and parts of the economic operation itself. This is why they must methodologically be subject of a precedent autonomous analysis in order to determine whether they represent parts of the operation, before being subject of a subsequent domestic analysis in order to determine whether they represent parts of the mere return for legal obligations ${ }^{1142}$. For instance, where another financial instrument is both provided and redeemed as capital (e.g. covered securities

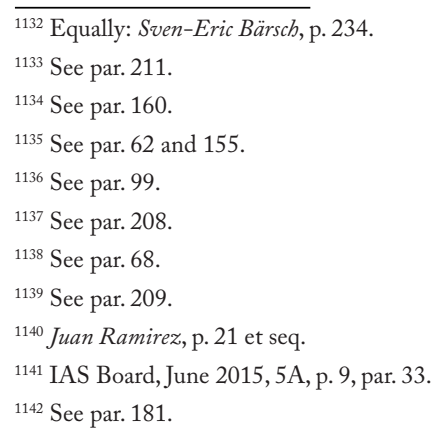


lending), there is actually no qualitative difference between the former and the latter. In other words: wherever the creditor bears the same underwriting risks with regard to the capital or principal as if he had not provided it to the creditor ${ }^{1143}$, the redemption he gets back is in fact the same as what he had once provided ${ }^{1144}$. Beforehand, the answer to that question can obviously not depend on what has been contractually agreed upon as the object of the capital provision and/or redemption, as this would likewise be true also for any object bearing underwriting risk. Consequently, non-perfection cannot depend on whether or not the creditor's subjective confidence in a perfect recovery (i.e. his risk expectation) is potentially or actually frustrated either.

Example 41: A finite delta-one payment-in-kind certificate on one share is a contractual agreement to be redeemed at maturity in the one share. Although the creditor's subjective expectation can necessarily be only be that he eventually gets back the one share, he obviously takes the underwriting risk of a non-perfect capital recovery (i.e. the price risk of that share).

233 It appears therefore that redemptions in kind not only demonstrate the particular overlay and the subsequent dependence of underwriting risk and timing risk ${ }^{1145}$. Moreover, they generally coalesce both the time-based (e.g. finance) and simultaneously also the risk-based aspect (e.g. speculation) in themselves ${ }^{1146}$. While there is actually no difference whatsoever between the time-based provision of cash and that of cash-equivalents, there is a considerable difference between the risk-based values of cash representing nominal goods and cash-equivalents representing real goods. In fact, the units of the latter are assessed in units of the former, but not vice versa ${ }^{1147}$. This is the reason why redemptions in cash are typically perfect, whereas redemptions in kind are typically non-perfect. Corresponding to the income or transaction (i.e. the time value of money), the inherent systematic conflict or dualism between the two possible differentiators of time aspects on the one hand and risk aspects on the other ${ }^{1148}$ appears to arise also in the context of the capital or principal. This becomes particularly apparent by the example of financial instruments with redemption in kind. Consequently, the conclusion that time aspects must necessarily take precedence over risk aspects in cases where the two overlay, must be the same. This means as an interim conclusion that termination risk as such can not be the sole or exclusive differentiator between time-based and risk-based financial instruments, in that it falls short of redemptions in kind. In such cases, the risk-based aspect, which potentially leads to a non-perfect redemption and therefore represents a falsifier for time equivalence and consequently for time-based financial instruments, is inextricably coalesced with the time-based aspect that leads to a perfect redemption and therefore represents a verifier for time-based financial instruments. Redemptions in kind are not per se a falsifier for time equivalence and consequently for time-based financial instruments, which can principally be established by way of providing cash-equivalents. Or, in other words: a debt is in the first instance a debt, regardless of what its object is ${ }^{1149}$.

\footnotetext{
${ }^{1143}$ See par. 224.

${ }^{1144}$ See par. 70.

${ }^{1145}$ See par. 69.

${ }^{1146}$ See par. 99.

${ }^{1147}$ See Example 23 on p. 107.

${ }^{1148}$ See par. 199.

${ }^{1149}$ Equally: IAS 32.16(a)(i) e contrario; IAS 32.BC7 and 32.BC11; IAS Board, September 2015, 5A, p. 7, par. 18; IAS Board, June 2015, 5A, p. 8, par. 29.
} 


\section{Step 2: redemptions in own equities}

234 Instead, the answer to that initial question of what constitutes a potential difference between the capital or principal provided and that redeemed ${ }^{1150}$, must be underneath. The approach to this subjacent criterion shall be to directly analyse the most ambiguous case of redemptions in own equities. While any potential differentiator able to tackle this case should allow universal statements analogously ${ }^{151}$, any potential differentiator on a higher level would in turn necessarily be flawed or incomplete. However, just like financial instruments with coverage or collateral by own equities ${ }^{1152}$, those with redemptions in own equities represent in fact one and the same class of financial instruments, whose "amount of economic resources required to settle the claim is not independent of the entity's economic resources." 1153 . Indeed, this special class of structurally "hybrid” financial instruments seems to lead to the grounds of the debt-equity distinction. It shows features of both during their entire lifetimes, which are coalesced so inextricably that they cannot be separated or disaggregated ${ }^{1154}$.

\section{Step 3: what can be learned from the IAS/IFRS}

235 Correspondingly, the IAS/IFRS have identified this special class of financial instruments with own equities as underlying and dedicated a fundamental research project in the context of the IFRS framework ${ }^{1155}$ to them. Pursuant to their present legal status ${ }^{1156}$, the IAS/IFRS currently treat such financial instruments in this regard as equity where the following criteria are met $^{1157}$ :

(1) it includes no contractual obligation for the issuer or creditor to deliver cash or another financial asset ${ }^{1158}$ or an unconditional right to refuse $i^{1159}$; and it is

- either a non-derivative with a variable number of own equity instruments as underlying ${ }^{1160}$; or

- a derivative with a fixed number of own equity instruments as underlying, gross physically settled only by the issuer or creditor against a fixed amount of cash or another financial instrument (fixed-for-fixed condition) ${ }^{1161}$; or

(2) the financial instrument

- includes a contractual obligation for the issuer or creditor to redeem or repurchase the capital or principal for cash or another financial asset on exercise of the put by the holder or debtor (puttable instrument $)^{1162}$; and

- includes an entitlement to a pro rata part of the issuer's or debtor's net assets in the event of his liquidation. Net assets are those that remain after deducting all other claims on the gross assets. A pro

\footnotetext{
${ }^{1150}$ See par. 232.

${ }^{1151}$ Argumentum a minori ad maius.

${ }^{1152}$ See par. 230.

${ }^{1153}$ IAS Board, September 2015, 5A, p. 10, par. 31.

${ }^{1154}$ Peter Hongler, p. 9.

${ }^{1155}$ See par. 47.

${ }^{1156}$ See par. 46.

${ }^{1157}$ See a summarising scheme at Clemens, Ralf in Bohl, Werner/Beiersdorf, Kati, Beck'sches IFRS-Handbuch: Kommentierung der IFRS / IAS, $4^{\text {th }}$ edition, C. H. Beck, Munich, 2013, p. 561, par. 10.

${ }^{1158}$ IAS 32.16(a)(i). See also par. 98(1).

${ }^{1159}$ IFRIC 2.7. IFRIC 2.8, applying these principles analogously to (unconditional) statutory or otherwise public redemption prohibitions, was de facto declared by the IAS / IFRS research project as being not applicable anymore (IAS Board, February 2017, 5B, p. 5, par. 19).

${ }^{1160}$ IAS 32.16(b)(i).

${ }^{1161}$ IAS 32.16(b)(ii) and 32.22.

${ }^{1162}$ IAS 32.16A; IFRIC 2.6.
} 
rata part is determined by the net assets on liquidation, divided into units of equal amount and then multiplied by the number of the units of the financial instrument held ${ }^{1163}$; and

- is unconditionally (e.g. non-convertible) subordinate to other claims to the assets of the entity on liquidation ${ }^{1164}$; and

- has total prospected cash flows over its lifetime which are based substantially on the profits or losses or on the change in the inventory or value of the net assets, excluding any effect of the financial instrument itself ${ }^{1165}$; and

- where it grants a choice to one of the contracting parties how it is settled (e.g. gross, net, cash, physically, etc.), all of the settlement alternatives would result into classifying it as an equity instrument ${ }^{1166}$.

236 The parts (1) and (2) take the issuer's or creditor's finance perspective ${ }^{1167}$ (put). The first part (1) represents a type of financial instruments on own equities featured with a net entitlement in his favour (long put). In contrast, the second part (2) represents that featured with a net obligation to his detriment (short put). Although both types bear termination risk in the broader sense (i.e. the first part a negative and the second part a positive one $)^{1168}$, only a positive termination risk actually deserves the term obligation. It is the very nature of an obligation to uphold a commitment even though its conditions or effects are potentially unfavourable ${ }^{1169}$. This also includes contingencies ${ }^{1170}$ but no termination rights of the issuer or debtor ${ }^{1171}$. On the contrary, it may include termination rights of the holder or creditor ${ }^{1172}$, as the transfer or redemption is actually left to his discretion ${ }^{1173}$. Consequently, it is the second part (2) that covers redemptions in own equities due to its obligatory character and therefore has the potential to reveal the critical differentiator for the debt-equity distinction ${ }^{1174}$. In that, it also promises to resolve the inherent conflict between the possible differentiators of voluntariness ${ }^{1175}$ on the one hand and participation in profits and losses on the other ${ }^{1176}$. Consequently, the IAS/IFRS research project particularly focuses on this specific type of obligatory financial instruments on own equities. It successively analyses their various sub-types from the simplest to the most difficult ones. These most difficult ones are equity derivatives, which particularly demonstrate the dual purpose of legal entitlements by multiple leg modes, representing actually both the return for an obligation and the operation itself $^{1177}$. The following illustration visualises this methodological cascade:

\footnotetext{
${ }^{1163}$ IAS $32.16 \mathrm{~A}(\mathrm{a})$.

${ }^{1164}$ IAS $32.16 \mathrm{~A}(\mathrm{~b})$ and $32.16 \mathrm{~A}(\mathrm{c})$.

${ }^{1165}$ IAS 32.16 A(e).

${ }^{1166}$ See IAS 32.26.

${ }^{1167}$ See par. $46(2)$.

${ }^{1168}$ See par. 60.

${ }^{1169}$ IAS 32.17 .

${ }^{1170}$ Kuhn / Hachmeister, p. 13, par. 64.

${ }^{1171}$ See par. 188.

${ }^{1172}$ See par. 211 and 191.

${ }^{1173}$ Clemens, Ralf in Bohl, Werner / Beiersdorf, Kati, Beck'sches IFRS-Handbuch: Kommentierung der IFRS / IAS, $4^{\text {th }}$ edition, C. H. Beck, Munich, 2013, p. 559, par. 6; equally: William Plumb, p. 418.

${ }^{1174}$ See par. 234.

${ }^{1175}$ See par. 188.

${ }^{1176}$ See par. 202 et seqq.

${ }^{1177}$ See par. 181.
} 

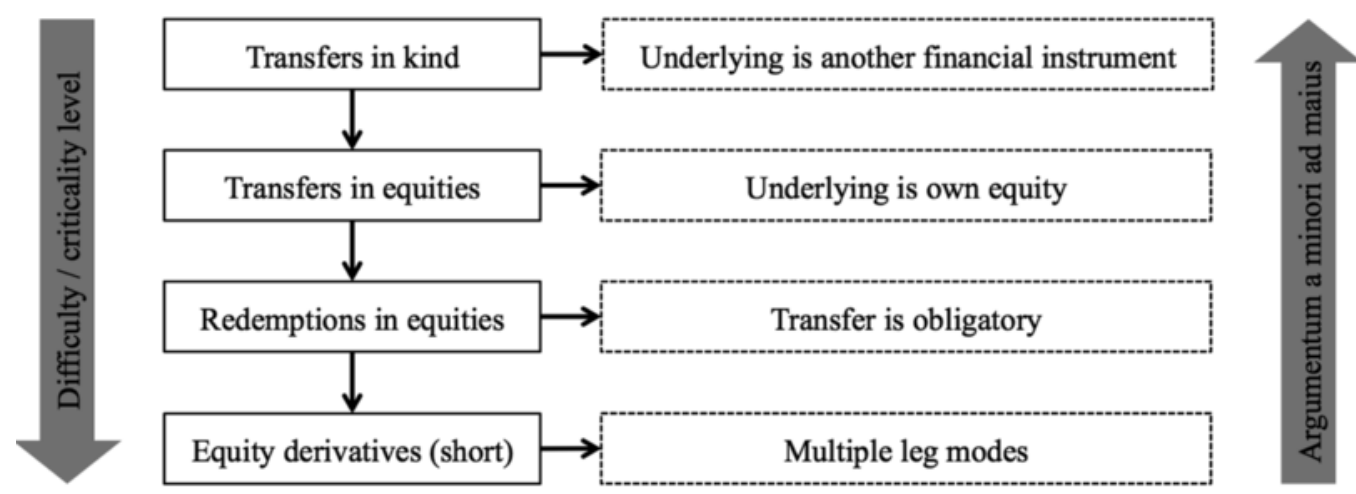

Illustration 15: Methodological cascade for debt-equity distinction

237 Pursuant to its current status ${ }^{1178}$, the IAS/IFRS research project has reached consensus that financial instrument shall be classified as

(1) debt where all of the following criteria are met:

- the financial instrument includes a contractual obligation for the issuer or creditor to redeem or repurchase the capital or principal (redemption obligation) ${ }^{1179}$; and

- subject of such transfer is either any economic resource of the issuer or debtor prior to his liquidation including an equivalent (i.e. fix) number of equity instruments in exchange for a variable amount (variable-for-fixed leg mode $\left.{ }^{1180}\right)^{1181}$, or a cash amount including an equivalent (i.e. variable) number of equity instruments in exchange for a fixed amount (fixed-for-variable leg mode ${ }^{1182}$ ) ${ }^{1183}$ that is independent of his economic resources (gamma approach) ${ }^{1184}$; and

- such transfer is net-settled in cash ${ }^{1185}$ or another financial instrument (net share settlement) ${ }^{1186}$; and

- the issuer or debtor has no unconditional right either to avoid such transfer ${ }^{1187}$ nor to settle it at an amount that is not independent of his economic resources ${ }^{1188}$;

(2) equity where all of the following criteria are met:

- subject of its repayment transfer are - mandatorily ${ }^{1189}$ or optionally ${ }^{1190}$ - economic resources of the issuer or debtor only at his liquidation, from which their amount is not independent; and

\footnotetext{
$\overline{1178}$ As per 15 September 2017.

${ }^{1179}$ IAS Board, July 2016, 5D, p. 14, par. 57(a); IAS 32.23.

${ }^{1180}$ IAS Board, July 2016, 5D, p. 6, par. 23.

${ }^{1181}$ IAS Board, July 2016, 5D, p. 19, par. 75(b).

${ }^{1182}$ IAS Board, July 2016, 5C, p. 8, par. 34(b).

${ }^{1183}$ IAS Board, July 2016, 5C, p. 6 et seq., par. 24(b).

${ }^{1184}$ IAS Board, September 2015, 5A, p. 20 et seq., par. 80.

${ }^{1185}$ IAS Board, July 2016, 5C, p. 6 et seq., par. 24(a).

${ }^{1186}$ IAS Board, July 2016, 5C, p. 7, par. 28.

${ }^{1187}$ IAS 32.19; IAS Board, September 2015, 5A, p. 20, par. 80(a).

${ }^{1188}$ IAS Board, February 2016, 5C, p. 15 et seq., par. 51.

${ }^{1189}$ IAS Board, September 2015, 5A, p. 21, par. 81.

${ }^{1190}$ IAS Board, February 2016, 5C, p. 16, par. 52.
} 
- such transfer is settled in other financial instruments only, either gross physically ${ }^{1191}$ or net fixed-forfixed $^{1192}$.

The following illustration visualises the core of this (IAS/IFRS) understanding ${ }^{1193}$ :

\begin{tabular}{cccc}
\hline $\begin{array}{c}\text { Leg mode } \rightarrow \\
\text { Settlement } \downarrow\end{array}$ & Fixed cash for fixed equities & $\begin{array}{c}\text { Variable cash for fixed } \\
\text { equities }\end{array}$ & $\begin{array}{c}\text { Fixed cash for variable } \\
\text { equities }\end{array}$ \\
\hline Gross physical & Equity & Liability* & Liability \\
Net share & Equity* $^{*}$ Liability & Liability \\
Net cash & Liability & Liability & Liability \\
\hline
\end{tabular}

*) Proposed change of IAS 32

Illustration 16: Current IAS/IFRS debt-equity classification and proposed changes

238 These definitions and their changes are the result of the following key considerations:

(1) Equity derivatives shall not be disaggregated but rather classified in their entirety ${ }^{1194}$. Apart from practical considerations ${ }^{1195}$, this is because the approach of disaggregating derivatives into other derivatives does not solve the principal classification problem ${ }^{1196}$. In addition, the IAS/IFRS also avoid the requirement of disaggregation particularly by limiting the equity classification to the fixed-for-fixed condition. ${ }^{1197}$

(2) Equity derivatives involve a receive leg and a pay leg, which each can be fixed or variable and transfer equities or non-equities. Only their net effect determines whether or not the equity derivative depends in its entirety on the issuer's or debtor's economic resources. ${ }^{1198}$ Consequently, the classification of the equity derivative into equity depends on whether the pay leg transfers equity instruments equivalent to a cash amount that is dependent on the issuer's or debtor's economic resources. ${ }^{1199}$ This condition was found being fulfilled under the combination of a settlement in other financial instruments, either gross physically or net ${ }^{1200}$, and the

- fixed-for-fixed condition always ${ }^{1201}$;

- fixed-for-variable condition never ${ }^{1202}$;

- variable-for-fixed condition to a certain extent ${ }^{1203}$.

In contrast to the current application of the IAS/IFRS ${ }^{1204}$, the variable-for-fixed leg mode must be classified into debt and not into equity, since equity derivatives shall not be disaggregated but rather classified in

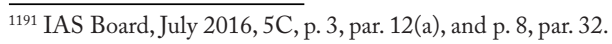

${ }^{1192}$ IAS Board, July 2016, 5C, p. 6, par. 21, and p. 13, par. 51.

${ }^{1193}$ IAS Board, March 2017, 5A, Appendix B, p. 22 et seqq.; IAS Board, July 2016, 5C, Appendix A.

${ }^{1194}$ IAS Board, July 2016, 5B, p. 10 et seq., par. 42(a) and 43.

${ }^{1195}$ IAS Board, July 2016, 5B, p. 8, par. 33(a).

${ }^{1196}$ IAS Board, July 2016, 5B, p. 8, par. 33(b).

${ }^{1197}$ IAS Board, July 2016, 5B, p. 7, par. 29(a).

${ }^{1198}$ IAS Board, December 2016, 5B, p. 5, par. 17.

${ }^{1199}$ IAS Board, December 2016, 5B, p. 5 et seq., par. 18.

${ }^{1200}$ IAS Board, December 2016, 5B, p. 2 et seq., par. 6 et seqq.

${ }^{1201}$ IAS Board, July 2016, 5C, p. 6, par. 21, and p. 8, par. 34(a).

${ }^{1202}$ IAS Board, July 2016, 5C, p. 8, par. 34(b).

${ }^{1203}$ IAS Board, July 2016, 5C, p. 8, par. 34.

${ }^{1204}$ See par. 237(1).
} 
their entirety ${ }^{1205}$. Thus, the fixed-for-fixed condition was strengthened for the equity classification as a consequence of non-disaggregating equity derivatives ${ }^{1206}$.

(3) The current application of the IAS/IFRS ${ }^{1207}$ falls victim to the finding in this study ${ }^{1208}$ that it obviously seeks to solve the circular reasoning of the participation in profits and losses ${ }^{1209}$ by actually defining an equity equivalent in the sense of its non-formal and thus artificial imagination as some hypothetical "adjusted" increment. By doing so, it actually negates its own formal IAS/IFRS accounting process and eventually itself ${ }^{1210}$, since such financial instruments shall in result be classified into equity as a residual instead of debt. This problem was identified by the IAS/IFRS project, which tried to resolve it by replacing the equity equivalent definition with the new term of economic resources ${ }^{1211}$. The concept of economic resources takes a reverse approach ${ }^{1212}$. It starts with identifying those obligatory financial instruments which are independent of the residual amount (i.e. the profit and loss), and then attributes the respective economic resources required to satisfy them. As a subsequent step, the remaining economic resources will be attributed to the remaining obligatory financial instruments, which are thus not independent of the residual amount. Where there are no economic resources left after satisfying all claims that are independent of the residual amount, there are actually no obligatory financial instruments capable of transferring any economic resource (i.e. equity). In other words: instead of distinguishing debt and equity by directly referring to the formal concept of the residual amount, the approach uses it merely indirectly as an attribution ratio for the material concept of the economic resources. On this basis, the IAS/IFRS research project analysed a number of variables for determining the value of obligatory financial instruments not independent of the residual amount. It found the following dependencies:

- The time value of money is not necessarily independent of the residual amount and therefore no verifier for debt. The reason is that the risk-based aspect also implies the time-based aspect. ${ }^{1213}$

- Where the currency is not identical to the reporting currency, it is necessarily independent of the residual amount and therefore a verifier for debt. ${ }^{1214}$ Where the currency is conversely identical to the reporting currency, it is necessarily dependent on the residual amount and therefore a verifier for equity.

- Anti-dilution provisions ${ }^{1215}$ and missed-dividends compensations ${ }^{1216}$ are basically dependent on the residual amount and are therefore verifiers for equity. An exception is where they ensure an absolute amount or an equivalent number of equity instruments rather than a relative proportion in the underlying equity instruments.

\footnotetext{
${ }_{1205}$ See par. 238(1).

${ }^{1206}$ IAS Board, July 2016, 5C, p. 13, par. 51.

${ }^{1207}$ See par. 235(2).

${ }^{1208}$ See par. 202.

${ }^{1209}$ IAS Board, September 2015, 5A, p. 9, par. 28(a).

${ }^{1210}$ See par. 203.

${ }^{1211}$ IAS Board, December 2016, 5B, p. 4, par. 11.

${ }^{1212}$ IAS Board, December 2016, 5B, p. 4 et seq., par. 14.

${ }^{1213}$ IAS Board, December 2016, 5B, p. 8, par. 28.

${ }^{1214}$ IAS Board, December 2016, 5B, p. 9, par. 30.

${ }^{1215}$ IAS Board, December 2016, 5B, p. 11, par. 33.

${ }^{1216}$ IAS Board, December 2016, 5B, p. 12, par. 38 et seq.
} 
- Any component of the residual amount (e.g. EBITDA) ${ }^{1217}$ as well as non-controlling interests ${ }^{1218}$ (i.e. minority participation) are necessarily dependent on the residual amount and therefore a verifier for equity. The reason is that the economic resources will always be sufficient for satisfying such claims.

(4) On the one hand, the redemption obligation bears a nexus with the criterion of whether the transfer of the capital or principal is timed to either prior to or at the issuer's liquidation. Where the issuer has the right to postpone or delay the transfer until liquidation, the timing of settlement of the claim does not affect the prospected future cash flows as they are independent of the issuer's economic resources. ${ }^{1219}$ Consequently, the legal (formal) criterion of the redemption obligation is integrated into and therefore substituted by the (material) concept of economic resources. On the other hand, the redemption obligation also bears a nexus with the criterion of a contractual obligation for the issuer to redeem or repurchase the capital or principal for cash or another financial asset on exercise of the put by the holder (puttable instrument). The reason is that, pursuant to the current application of the IAS/IFRS ${ }^{1220}$, those puttable instruments are the only exception from the general redemption obligation requirement. Notably, the necessity to uphold the puttable instruments exception was not yet ${ }^{1221}$ discussed within the IAS/IFRS research project ${ }^{1222}$. Thinking it through may, however, suggest that it will no longer be required, as the puttable instruments exception has in fact two aspects of formally constituting an obligation, which materially depends of the residual amount (i.e. participates in profits and losses). While the former is integrated into and therefore substituted by the likewise formal redemption obligation requirement, the latter is integrated into and therefore substituted by the material concept of economic resources. Thus, the redemption obligation requirement would be strengthened and the IAS/IFRS debt-equity classification scheme simplified from three dependent criteria (i.e. transfer prior to liquidation, redemption obligation requirement and puttable instruments exception) into just two independent ones (i.e. redemption obligation requirement and transfer of economic resources) ${ }^{1223}$.

\section{Step 4: transfer of the IAS/IFRS methodology to the OECD MTC}

239 From the author's point of view, the first consideration (1) might be principally transferable to the OECD MTC. Admittedly, the theoretical ${ }^{1224}$ and practical ${ }^{1225}$ considerations of applying the disaggregation scheme have also been identified in the context of the OECD MTC. In addition, the fixed-for-fixed condition applied to the OECD MTC analogously would obviate the requirement for any disaggregation. However, the argument is fairly weak, even within the IAS/IFRS themselves. On the one hand, the second consideration (2) demonstrates that strengthening the fixed-for-fixed condition was in fact the consequence of nondisaggregating equity "derivatives" and therefore cannot simultaneously be its justification ${ }^{1226}$. Even more, the fixed-for-fixed condition was found by the IAS/IFRS research project itself as a kind of fall-back or

\footnotetext{
${ }^{1217}$ IAS Board, December 2016, 5B, p. 13 et seq., par. 42.

${ }^{1218}$ IAS Board, December 2016, 5B, p. 15, par. 45.

${ }^{1219}$ IAS Board, June 2015, 5A, p. 10, par. 39.

${ }^{1220}$ See par. 235(2).

${ }^{1221}$ As per 15 September 2017.

${ }^{1222}$ IAS Board, July 2016, 5D, p. 4, par. 14.

${ }^{1223}$ Equally: IFRIC 2.6 et seq.; IAS Board, February 2017, 5B, p. 11, par. 49(b).

${ }^{1224}$ See par. $88(1)$.

1225 See par. 88(6).

${ }^{1226}$ Circular reasoning.
} 
second-best solution for the problems caused just by the non-disaggregation ${ }^{1227}$. Instead, the decision was actually to accept the problems either from the non-disaggregation or from the variable-for-fixed leg mode. On the other hand, the IAS/IFRS themselves are well aware of those theoretical and practical difficulties but nevertheless provide the disaggregation scheme elsewhere ${ }^{1228}$. Consequently, there appears to be no reason why a certain class of financial instruments should be treated differently ${ }^{1229}$. This is even more crucial, as the IAS/IFRS research project itself held in another context that "ring-fencing' the fixed-for-fixed condition $[\ldots]$ is inconsistent" ${ }^{1230}$. And secondly, such ring-fencing gives rise to another level of the very same problem, i.e. distinguishing equity "derivatives" from non-equity "derivatives". In addition, the research project already came to the abstract-theoretical grounds of the IAS/IFRS debt-equity distinction, which do not seem to encounter any particular application problem for variable-for-fixed equity "derivatives". Insofar, these principles also represent a concretisation of that current IAS/IFRS criterion, according to which all of the possible settlement alternatives must result into classifying the financial instrument as equity. In the author's view, separating the pay leg from the receive leg by way of disaggregating the equity "derivative" makes it possible to determine relatively easily whether (then equity) or not (then debt) the former fulfils the critical condition of transferring either any economic resource of the issuer or debtor or an equivalent number of equity instruments. For these reasons, it is held as a conclusion for the further course of this study: where the IAS/IFRS rationale of distinguishing debt and equity by that critical condition is transferred to the OECD MTC, this must - contrary to the research project's recommendations ${ }^{1231}$ - also apply to variable-for-fixed equity "derivatives" by way of disaggregating them into their pay leg and receive leg.

240 As regards the third consideration (3), the attempt to replace the formal equity equivalent definition with the material concept of economic resources appears as a consequent step from the IAS/IFRS perspective. However, in practice such an approach requires very detailed information about the internal flow of economic resources. In addition, these might not be available for a number of issuers or debtors (e.g. private individuals). Admittedly, the approach is applied by the IAS/IFRS from the issuer's or creditor's perspective ${ }^{1232}$, which is in line with the treaty purpose and function of primarily addressing the source jurisdiction ${ }^{1233}$. However, transferring such an approach to the OECD MTC would eventually mean nothing else than giving the determination of the debt-equity distinction more or less exclusively into the hands of the source jurisdiction's domestic law. Being aware of its systematical and methodological limitations and weaknesses ${ }^{1234}$, it still appears to the author more purposeful and practicable to operationalise the dependency of the residual amount (i.e. the participation in profits and losses) by way of heuristic correlation ${ }^{1235}$. In this point, however, the IAS/IFRS concept seems to embark upon the same path as this study. At least, it seems to support the methodological approach of identifying and analysing the particular legal (formal) attributes or features of a disaggregated financial instrument towards its (material) dependency of the issuer's business risk. However, those concrete findings

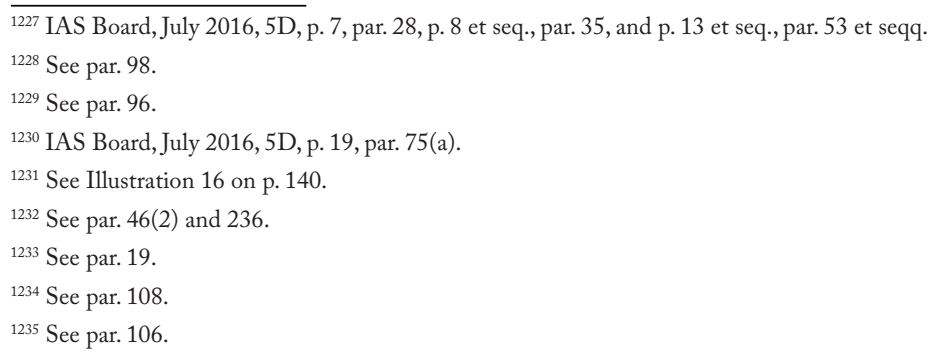


by the IAS/IFRS project are only examples and therefore not intended to comprehensively and exhaustively describe the debt-equity distinction. They are also significantly influenced by the fixed-for-fixed condition as a consequence of the IAS/IFRS non-disaggregation of equity "derivatives"1236. For these reasons, reference is instead made to the corresponding analysis and its findings in this study ${ }^{1237}$.

241 As regards the fourth consideration (4), the author must consequently disagree with the substitution of the redemption obligation requirement by the concept of economic resources, as the latter was already rejected for being purposively transferable to the OECD MTC ${ }^{1238}$. Insofar, the redemption obligation requirement turns out to be indispensible. However, this is not only in line with the IAS/IFRS result but, advantageously, also substitutes the puttable instruments exception. Finally, the strengthening and purity of the redemption obligation requirement also correspond better with the narrow understanding of an obligation's involuntary character ${ }^{1239}$. Nevertheless, financial instruments actually transferring equity in any case bear termination risk in the form of genuine business risk ${ }^{1240}$ (i.e. irrespective of which leg mode the redemption obligation applies to $)^{1241}$. In this respect, the subsidiarity of business risk in the form of termination risk as a sub-type of underwriting risk to the formal redemption obligation requirement applies in fact form over substance ${ }^{1242}$. However, this is not only a consequent step from the IAS/IFRS perspective ${ }^{1243}$ but also from the position taken in this study ${ }^{1244}$, in that the existence of financial instruments must predominantly be a matter of the legal form.

\subsubsection{Conclusions}

242 Completing the circle, the following conclusions can be summarised as a result from this analysis:

(1) Termination risk can be determined without applying different classification schemes on redemptions in cash and those in kind (ring-fencing). As a consequence of this independence, the partial adoption of the IAS/IFRS approach not only allows for the classification of equity "derivatives" of whatever leg modes, but also exchanges in kind (e.g. share-for-share "derivatives") or exchanges of currencies (e.g. currency "derivatives"1245).

(2) The initial question what constitutes a potential difference between the capital or principal provided and that redeemed ${ }^{1246}$ can be answered as follows: termination risk arises where the pay leg of the financial instrument, separated by way of disaggregation, transfers a cash amount that is not solely dependent on the time value of money ${ }^{1247}$ or an equivalent number of financial instruments ${ }^{1248}$. Consequently, the concept of termination risk is understood as a falsifier for time equivalence and thus for the time value 
of money. In contrast, the corresponding IAS/IFRS concept of "termination risk" is a verifier for equity, which is, however, the result of not separating it from the dependency on the residual amount (i.e. the participation in profits and losses) as a consequence of not disaggregating equity "derivatives".

(3) The material criterion of termination risk principally implies and therefore potentially substitutes the legal redemption obligation requirement. The redemption obligation is understood in the narrow formal sense of involuntarily and therefore irrevocably upholding a commitment despite its possibly unfavourable conditions or effects ${ }^{1249}$. Unlike the termination risk, the redemption obligation requirement implies, however, a time-based aspect ${ }^{1250}$, in that it actually means only redemptions prior to the issuer's liquidation ${ }^{1251}$. Hence, where the redemption obligation requirement ought to be substituted by the criterion of termination risk, this would simultaneously mean a high interpretation significance of that of the relative maturity ${ }^{1252}$. As the duration or maturity was, however, found incapable of being a differentiator ${ }^{1253}$, a substitution of the redemption obligation requirement by the termination risk would necessarily lead to an incomplete set of differentiation criteria ${ }^{1254}$ and therefore to remaining ambiguities. This is even more important as time aspects were found to necessarily take precedence over risk aspects in cases where the two overlay ${ }^{1255}$. Consequently, the redemption obligation requirement remains indispensible as a differentiator ${ }^{1256}$.

\subsubsection{Origin of funds}

\subsubsection{Preliminary remarks}

243 The repayment of funds focuses on the question of which conclusions can be drawn primarily from their origin by considering the entire lifetime of the financial instrument. In general, there are three possible sources of funds available for repaying capital or principal provisions or contributions: liquidation of assets, business profits and (re-)financing.

\subsubsection{Liquidation of assets}

244 As regards the first one, any kind of assets can be assumed to represent a necessary minimum condition (conditio sine qua non) for doing business. This means, in turn, that they are necessarily exposed to business risk. However, this may not elicit the false reverse deduction that all these assets do necessarily also have influences on the business risk. That is why it could be conceivable to apply an approach of "core assets", without which the business could hypothetically not be operated as it actually is ${ }^{1257}$. The approach is similar to the substance requirement of functional adequacy in international tax law. It is founded on the idea that the liquidation of "core assets" represents a partial liquidation of the business enterprise itself, and that, due to its ultimate subordination, its pay-out cannot be anything other than equity. On the contrary, the pay-out of

\footnotetext{
${ }^{1249}$ See par. 236.

${ }^{1250}$ See par. 196.

${ }^{1251}$ Equally: William Plumb, p. 414. See also par. 238(4).

${ }^{1252}$ See par. 198.

${ }^{1253}$ See par. 199.

${ }^{1254}$ See par. 5.

1255 See par. 199.

${ }^{1256}$ See par. 241.

${ }^{1257}$ William Plumb, p. 520 et seq.
} 
proceeds from the liquidation of non-“core assets" was debt ${ }^{1258}$. This rationale of actually matching assets and capital according to their liquidability also corresponds with that behind the basic structure and taxonomy of the IAS/IFRS statement of financial positions ${ }^{1259}$. Nevertheless, the approach was discarded quite early. The reason was predominantly the understanding that the assets' and capital's liquidability are not necessarily interlinked with their functional relevance ${ }^{1260}$.

Example 42: Real property may be a "core asset" for a landlord but not for a property dealer. The example demonstrates that the functional relevance and the duration or maturity of an asset depend both on the context rather than on each other.

245 In other words: duration or maturity and functional relevance may often correlate, but they are nevertheless independent of each other ${ }^{1261}$. However, it appears that the two aspects at least coincide in the point where "the uncertainties of successful operation are such that the only reasonably assured source of funds for repayment, at maturity or within a reasonable time, is the liquidation of the enterprise" 1262 . At one end of the scale, an asset's duration or maturity as an indicator of its liquidability is not capable of positively verifying the functional relevance of its corresponding capital. At the other end of the scale, it may nevertheless be capable of negatively falsifying it.

Example 43: A dividend distribution itself requires cash, which is the most liquid asset per se.

Conversely, the basic working capital might be financed by long-term debt capital.

In other words: the less liquidable an asset, the stronger it indicates equity (but not vice versa). This approach would also be in line with the finding that the systematics within the OECD MTC basically do not conflict with the approach of classifying a recipient's income or transactions (i.e. finance) by also considering the capital's or principal's utilisation by the source (i.e. investment) ${ }^{1263}$. However, such approach would result into eventually locking-in the equity by introducing a deemed distribution order, which was in no way indicated and justifiable by the wording and system of the OECD MTC. In addition, and even worse, it was potentially liable to infringe financing neutrality. A classifier deduced from such a binary and unidirectional approach was also considerably weak, in that it would not provide significant new information beyond what could already be derived otherwise. Financial institutions have the business purpose and regulatory requirement to transform, match and balance maturities between their assets and capitals ${ }^{1264}$. In contrast, most non-financial industries will typically show an incongruent and highly diverse duration or maturity structure between their assets and capitals. This is the reason why there are no qualitative, universal and resilient conclusions possible beyond confirming the natural intuition that the most illiquid or non-current class of assets of a business enterprise

\footnotetext{
1258 "Furthermore, the Tax Court seems clearly correct in pointing out that an arm's-length creditor would almost never lend to a business until the equity owners had at least provided the basic assets." (Goldstein, William M., Corporate Indebtedness to Shareholders: Thin Capitalizatin and Related Problems, Tax Law Review 1960, Vol. 16, Issue 1, p. 32).

${ }^{1259}$ IAS 1.64 et seq.

${ }^{1260}$ William Plumb, p. 522 et seq.

${ }^{1261}$ Cum hoc ergo propter hoc.

${ }^{1262}$ William Plumb, p. 526.

${ }^{1263}$ See par. 226.

${ }^{1264}$ IAS 1.63 .
} 
typically - but not necessarily - yield income on equity (i.e. dividends). But even this would probably be very rarely shown to be true in view of the large diversity of non-financial industries.

\subsubsection{Business profits \\ Context and problem}

246 As regards the second possible source of funds, there should be no doubt that business profits are the prototypical and most common use case of income on equity (i.e. dividends). Income in general is necessarily to be determined by reference to domestic tax $l_{a w^{1265}}$ and so is basically also the specific determination of whether or not a pay-out is the result from the domestic law of tax accounting. On the other hand, the asset-based approach taken by the OECD MTC ${ }^{1266}$ requires the autonomous distinction of income between that from an asset as the compensation for the capital or principal contribution (i.e. dividends and interest) and that with an asset as the capital or principal itself (i.e. capital gains). ${ }^{1267}$ In this respect, the allocation of taxation rights to the source jurisdictions must be limited by new rights created through legal events from precursory fields of non-tax law. These new rights are to be distinguished by either referring or not referring to the asset in the sense of impairing the number of its critical ownership rights ${ }^{1268}$. Where capital or principal provisions or contributions are, however, being repaid only in part, that number of ownership rights in the asset may not be impaired, although such pay-outs do not originate from business profits. It appears therefore that there is a nexus between business profits as the second possible source of funds and partial repayments of capital or principal provisions or contributions as the third possible source of funds. In particular, the question arises whether or not there is a further differentiator for the autonomous distinction within the OECD MTC between dividends and interest on the one hand and capital gains on the other. Such differentiator had to limit the domestic tax law also in treating partial repayments of capital or principal provisions or contributions as income. Similar to the terms paid in Art. 10(1) and 11(1) OECD MTC and from in Art. 10(3) and 11(3) OECD MTC ${ }^{1269}$, this requisite systematic distinction within the OECD MTC between dividends and interest on the one hand and capital gains on the other could almost entirely be marginalised where the domestic interpretation of income is broad enough. For instance, where the domestic interpretation of income would encompass the partial repayment as a whole, the source jurisdiction had set itself in the position to skim the entire partial capital gain to the detriment of the jurisdiction of residence.

\section{The difference between repayments and disposals}

247 This question can be approached by setting it in the wider context of whether a repayment in general is actually the same as a disposal. If this question is to be answered in the affirmative, then partial repayments would be necessarily the same as partial disposals ${ }^{1270}$. As a consequence, they had to be exclusively attributed to the income with the asset (i.e. capital gains) $)^{1271}$ and there was no nexus with business profits. In that case, a further analysis of (re-)financing sources as possible differentiators for the income types of financial instruments was actually dispensable. If, however, the question is to be answered in the negative, then there is no further

\footnotetext{
1265 See par. 144 .

1266 See par. 58.

1267 See par. 53.

${ }^{1268}$ See par. 160 et seqq.

1269 See par. 149.

${ }^{1270}$ Argumentum e contrario.

${ }^{1271}$ Argumentum a maiore ad minus.
} 
distinction between business profits and partial repayments on the treaty level. As a consequence, their nexus would make (re-)financing sources impossible as differentiators due to the influence of the domestic income interpretation.

248 Contributions and repayments of equity are often compared with those of debts. The analysis shall therefore start with the initial illustrative example of a straightforward debt-claim or credit. At first glance, its repayment appears not to be the same as its disposal: it is the capital's or principal's mere possession that returns back into the hands of its owner without creating any new right. However, this turns out to be an incomplete view when looked at more closely. Such repayment simultaneously impairs the number of ownership rights in the straightforward debt-claim or credit itself - i.e. the ownership rights in the straightforward debt-claim or credit cease, so that its resumption requires a new contractual agreement. The difference and interaction between the two legal levels is made clear by the next illustrative example of a contingent debt-claim or credit such as an undrawn commitment (e.g. master credits, guarantees, demand deposits, etc.). Here, its repayment is obviously not the same as its disposal. True, it is likewise the capital's or principal's mere possession that returns into the hands of its owner without creating any new right. But this is notably not a right in the contingent debt-claim or credit itself - i.e. the ownership rights in the undrawn commitment do not cease, so that its resumption requires no new contractual agreement. For determining capital gains, it is necessary to focus on the ownership rights of the financial instrument as the asset itself rather than on those of its underlying capital or principal. However, taking both legal levels into account nevertheless builds the bridge for understanding the difference between repayments of debt capital and those of equity, and thus between business profits and repayments of capital or principal provisions or contributions in general. Unlike debt-claims or credits, repayments of equity represent a transfer of ownership rights in the underlying capital or principal from the payer to the payee, just as the original equity contribution was a transfer of ownership rights from the shareholder to the company. Unlike contingent debt-claims or credits, repayments of equity consequently create new rights. And unlike the repayment of straightforward debt-claims or credits, these rights cannot impair the number of ownership rights in the financial instrument (i.e. the share) itself, the reason being that the transfer of the ownership rights in the equity cannot simultaneously also be a transfer of the ownership rights in the share itself. In other words: the legal event creating that right cannot refer to the asset and simultaneously not to the asset. True, one and the same transaction can transfer both the capital or principal itself and the financial instrument as its legal veil at the same time (e.g. a capital decrease or liquidation by way of a total distribution with an immediate cancellation of the shares). However, the two objects are nevertheless sequenced in a logical oneway order. The following illustration visualises this understanding:

\begin{tabular}{llll}
\hline \multicolumn{2}{c}{ Abstract } & \multicolumn{2}{c}{ Examples } \\
\hline Trigger & OECD MTC & Debt & Equity \\
\hline $\begin{array}{l}\text { - Legal event creating a } \\
\text { new right }\end{array}$ & Chap. III & & \\
- Refers on the assest & Art. 13(5) & Repayment of regular credit & $\mathrm{n} / \mathrm{a}$ \\
- Refers not on the assest & Art. 10(3) or Art. 11(3) & $\mathrm{n} / \mathrm{a}$ & Repayment of equity contribution \\
- No legal event creating a & $\mathrm{n} / \mathrm{a} /$ chap. IV & Repayment of regular credit & $\mathrm{n} / \mathrm{a}$ \\
new right & & & \\
\hline
\end{tabular}

Illustration 17: The difference between repayments of debt and equity 
249 In fact, there appears to be a one-way dependency between the impairment of ownership rights in the financial instrument itself and that in its underlying capital or principal. The former is possible only where the latter is excluded, but not vice versa. Apparently, transferring the financial instrument is impossible where the capital or principal is transferred instead. Conversely, transferring the financial instrument is not requisite where the capital or principal is not transferred. This lays the ground for the key difference between repayments of equity and those of debt. Any pay-out from equity necessarily impair the ownership rights in the capital or principal itself. As a consequence, repayments of equity can e contrario never impair the ownership rights in the financial instrument itself. In contrast, any pay-out from debts can never impair the ownership rights in the capital or principal itself. Since the dependency is one-way, it does, however, not mean that they necessarily also impair the ownership rights in the financial instrument itself. Rather, this would require that they have also been triggered by a legal event. Accordingly, it is this legal event that is an inherent element of equity repayments, but not necessarily of debt repayments. As an interim conclusion, any comparison of equity repayments with those of debt capital or any analogy between them is insufficient for distinguishing them from business profits.

\section{Developing a differentiator}

250 The next level down in the analysis is to identify any autonomous differentiator from business profits within the equity contributions themselves. However, it turns out that this attempt is hopeless, in that equity repayments can normally not be distinguished objectively from business profits ${ }^{1272}$. Both are triggered by a legal event that does not impair the ownership rights in the share itself. Especially in a dynamic view over more than one period, the company typically has the possibility to accumulate the business profits. This includes the possibility to subjectively choose in later periods between taking pay-outs from those accumulated business profits or from equity contributions. The accumulated business profits are the result from the domestic law of tax accounting and thus necessarily determined by reference to domestic tax law ${ }^{1273}$. Hence, the separation of other equity components (particularly equity contributions) becomes significantly dependent on the peculiarities of the source jurisdiction's tax system. The relevance of this aspect had already been identified by the OECD in the context of business profits ${ }^{1274}$, and becomes even more relevant in interaction with other equity components as possible differentiators between dividends and capital gains (e.g. in the context of liquidation proceeds). Thus, there is in fact an inter-temporal nexus between equity contributions and business profits ${ }^{1275}$. This nexus leads to an inextricable mix or "infection" of the former by the latter, making any attempt to disentangle the two in order to reach an autonomous interpretation of equity contributions impossible and illusory. The following illustration visualises this understanding:

\footnotetext{
${ }^{1272}$ In result perhaps contrary without however going into this crucial practical question of how that theoretical distinction between business profits and equity repayments shall actually be made: OECD Commentaries 2014 on Art. 10 OECD MTC, p. C(10)-11, par. 28 and on Art. 13 OECD MTC, p. C(13)-13, par. 31; Marjaana Helminen, dividend concept, p. 141, 144 and 238.

${ }^{1273}$ See par. 246.

${ }^{1274}$ OECD (Working Party No. 1 of the Fiscal Committee, Working Group No. 23), Report on the Double Taxation of Dividends received by an Individual, ref. FA/WP1(71)6, Paris, 1971, comprehensively analysing the effects of various special tax systems.

${ }^{1275}$ See par. 247.
} 


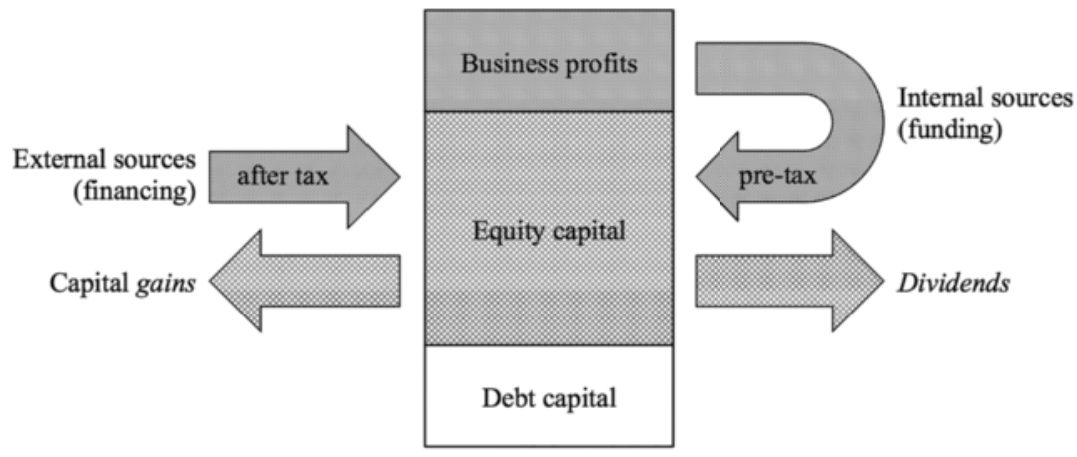

\section{Potentially subject to autonomous interpretation}

Subject to domestic interpretation

Potential result of a mix between autonomous and domestic interpretation

Illustration 18: Systematic inseparability of equity contributions and business profits

\section{Interim conclusions}

251 As a conclusion for the further course of this study it is therefore necessary to hold that the sources of funds for repaying capital or principal provisions or contributions are not capable of serving as an autonomous differentiator. This is predominantly rooted in purposive and systematic considerations and the peculiarities of equity: any limited application or autonomous interpretation of those sources was either non-universal or a circular reasoning. In addition, the results from such an interpretation dualism would conflict with the general principle that the consistent and coherent system of Art. 10(3) and 11(3) OECD MTC demands that their autonomous parts must lead to equivalent results ${ }^{1276}$. Instead, the determination of these sources turns out to bear a comprehensive and inextricable nexus with that of the income, being entirely subject of the domestic interpretation.

252 These considerations, however, bring forth that repayments of capital or principal provisions or contributions can be basically one of three kinds: (1) income from the asset, (2) income with the asset and (3) no income at all. Repayments of equity capital are necessarily always covered by the term dividends pursuant to Art. 10(3) OECD MTC, being in that sense subject of the domestic interpretation. Repayments of debt capital can not be covered by the term interest pursuant to Art. 11(3) OECD MTC. Instead, they can only be covered by the term capital gains pursuant to Art. 13(5) OECD MTC or they are potentially out of scope of the OECD MTC altogether. This divergence reflects the fact that the difference between dividends and interest is a legal rather than an economic one ${ }^{1277}$. Consequently, repayments of equity and debt capital can only be treated equally and in accordance with their economic nature (i.e. as a reduction of acquisition costs for the purpose of capital gains) under very specific conditions. An example could be, where the source jurisdiction's domestic tax law grants both a tax exemption of equity repayments ${ }^{1278}$ and a deduction of equity and debt repayments from a later capital gain. As a result from these heterogeneous and complex requirements to the source jurisdiction,

\footnotetext{
${ }^{1276}$ See par. 113(1).

${ }^{1277}$ See par. 56.

1278 Similary: William Plumb, p. 553.
} 
functional and inter-temporal qualification conflicts and/or a potential frustration or marginalisation of the residence jurisdiction's taxation rights must be considered possible and likely to occur in the context of partial capital or principal repayments.

253 Another conclusion can be drawn from these considerations with regard to the nominal value of debt instruments. This nominal value actually represents the encashment value and therefore basically describes the critical ownership rights in the debt instruments by type, quantity and unit. Where a partial repayment of debt contributions

- is equal to a simultaneous reduction of the nominal value, the ownership rights in the debt instrument are impaired (i.e. capital gain);

- does not reduce the nominal value, the ownership rights in the debt instrument are not impaired (i.e. no capital gain) but instead those in the debt capital or principal itself ${ }^{1279}$ (i.e. no income);

- reduces the nominal value disproportionally, the ownership rights in the debt instrument are impaired only to this extent (i.e. capital gain) ${ }^{1280}$. In contrast, the excess amount reduces the ownership rights in the debt capital or principal itself (i.e. no income) $)^{1281}$.

It appears therefore that the effective nominal value of debt instruments may potentially serve as a verifier for capital gains.

\footnotetext{
${ }^{1279}$ See par. 249.

${ }^{1280}$ See par. 162.

${ }^{1281}$ Quantitative disaggregation (see par. 84).
} 



\section{Chapter 3}

\section{Analysis and discussion of the relevant distributive articles}

\subsection{Preliminary remarks}

254 The purpose and objective of this section is to comprehensively analyse, compare and discuss the different interpretations of the relevant distributive articles of the OECD MTC. These are Art. 10(3) OECD MTC on dividends ${ }^{1282}$, Art. 11(3) OECD MTC on interest ${ }^{1283}$, Art. 13(5) OECD on capital gains ${ }^{1284}$ and Art. 21(1) OECD MTC on other income ${ }^{1285}$. The intention is also to confront them with and integrate them into those systematic aspects found in the preceding sections. Where it is considered reasonable and appropriate, the author also endeavours to contribute his view to the current fields of discussion. These contributions are, however, limited to questions and topics on which there is a need to take position or where the author wishes to add some remarks relevant for the further course of this study. Another objective of this section is to identify specific key differentiators for the purpose of classifying the income types of financial instruments.

255 In contrast to the preceding analyses and discussions of basic principles ${ }^{1286}$ and aspects of the systematic context ${ }^{1287}$, this section takes its conclusions more from the legal wording than from systematic considerations. Unlike in the aforementioned analyses and discussions of possible differentiators ${ }^{1288}$, this section concretely examines and verifies if and to what extent the differentiators found as potentially appropriate are in line with the scientific discourse on the particular distributive articles of the OECD MTC. Again, all this is carried out by carefully embedding the way of interpretation into those general guidelines and systematic aspects found in the preceding sections in order to ensure a maximum of consistency.

\footnotetext{
1282 See sec. 3.2.

${ }^{1283}$ See sec. 3.3.

${ }^{1284}$ See sec. 3.4 .

${ }^{1285}$ See sec. 3.5 .

${ }^{1286}$ See sec. 2.2 .

${ }^{1287}$ See sec. 2.3.

${ }^{1288}$ See sec. 2.4.
} 


\subsection{Dividends}

\subsubsection{Structure of the provision}

256 Art. 10(3) OECD MTC represents an incomplete "means" definition and so its subject matter must be positively found ${ }^{1289}$. The current structure of the provision appears to have its origin in the endeavours of the OEEC Working Parties No. 12 and 14. Their aim was to cover all legal and organisational forms of structures in civil and common law jurisdictions, each considering either its incorporation or its place of management, as well as all typified tax treatments including as many domestic specifics as possible ${ }^{1290}$. As a starting point, the majority of commentators ${ }^{1291}$ read Art. 10(3) OECD MTC in the sense of a 3-limb interpretation that is also taken as the baseline for the further course of this study (the enumeration has been added by the author accordingly):

"The term 'dividends' as used in this Article means income from

- shares, 'jouissance' shares or 'jouissance' rights, mining shares, founders' shares [limb 1]

- or other rights, not being debt-claims, participating in profits, [limb 2]

- as well as income from other corporate rights which is subjected to the same taxation treatment as income from shares by the laws of the State of which the company making the distribution is a resident. [limb 3]"

257 In fact, most of these commentators seem to understand the provision as more or less one conjoined or integrated definition. As a result from the word other, it appears there is a general consensus that the structure of the provision reads in such a way that the three limbs open up from the most special use cases in limb 1 to the most general sub-type in limb 3 by each referring to its precedent one. ${ }^{1292}$ In other words: $\operatorname{limb} 2$ is a subsidiary clause to limb 1 and limb 3 a subsidiary clause to limb 2, including limb 1 . However, that word other has an ambiguous meaning. It can be understood either in the sense of further or in the sense of different ${ }^{1293}$. It is therefore controversial and gives rise to discussions as to what extent and in which direction (up- or downwards) each limb takes which attributes from its precedent ones ${ }^{1294}$. Depending on the position taken, this question also determines in what regard and to what extent the provision is to be interpreted domestically or autonomously ${ }^{1295}$. It appears, however, that there is a general consensus that limb 2 provides a general and

\footnotetext{
$\overline{1289}$ Harris, Peter A. in IBFD Commentaries on Art. 10 OECD MTC, sec. 5.1.1.

${ }^{1290}$ For an overview on the provision's history see Avery Jones Commentaries.

${ }^{1291}$ Harris, Peter A. in IBFD Commentaries on Art. 10 OECD MTC, sec. 5.1.2.1.; Haslehner, Werner in Klaus Vogel Commentaries 2015, p. 834, par. 85; Tischbirek, Wolfgang/Specker, Gerhard in Vogel/Lehner, p. 1211, par. 185; Kaeser, Christian/Wassermeyer, Franz in Wassermeyer Commentaries, p. 1253, par. 4; Gaspar Lopes Dias, debt-claims, sec. 1.2.; Santos, Ramon Tomazela, Tax Treaty Qualification of Income Derived from Hybrid Financial Instruments, Bulletin for International Taxation 2013, Vol. 67, No. 10, sec. 4.1.; Kopp, Karin E.M. in Wolfgang Schön, equity and debt, p. 844; May, Nicolás in Thomas Ecker, p. 415; Marjaana Helminen, dividend concept, p. 63; Marjaana Helminen, classification, p. 58; Avery Jones Commentaries, sec. 1; Giuliani, Federico Maria, Article 10(3) of the OECD Model and Borderline Cases of Corporate Distributions, Bulletin for International Taxation 2002, Vol. 56, No. 1, p. 11; Klaus Vogel Commentaries 1997, p. 649, par. 185; Hans Pijl, hybrid debts, sec. 4.4., suspecting a 2-limb interpretation due to the different conjunctions or suggesting a choice and as well as suggesting an enumeration.

${ }^{1292}$ Haslehner, Werner in Klaus Vogel Commentaries 2015, p. 835, par. 90; Sven-Eric Bärsch, p. 99; Hans Pijl, hybrid debts, sec. 4.2., calling it "projection theory"; May, Nicolás in Thomas Ecker, p. 433; Marjaana Helminen, dividend concept, p. 96; Klaus Vogel Commentaries 1997, p. 649, par. 185 , and p. 650, par. 188.

${ }^{1293}$ Hans Pijl, hybrid debts, sec. 4.4 .

${ }^{1294}$ As will be elaborated in the following (see par. 265 and 271).

${ }^{1295}$ As will be elaborated in the following (see par. 269 et seq.).
} 
therefore closed and exhaustive formula for assets not listed in limb $1^{1296}$, and that it is in its entirety to be interpreted autonomously ${ }^{1297}$. In contrast, both limbs 1 and 3 contain at least some parts which are more or less interpreted domestically.

258 In other words: it is limb 2 only, which undisputedly provides a short but positive and general definition of dividends, while also being exhaustively subject of a closed and autonomous interpretation. That is why limb 2 represents the key provision when it comes to the autonomous definition and delimitation of dividends. Interestingly, it is limb 3 that nevertheless enjoys much more attention. The reason is probably its appearance as a kind of ultimate residuary clause promising the ultimate definition of dividend. However, it should be kept in mind that the impact of limb 3 for the autonomous definition and delimitation of the term dividends is naturally limited due to its undisputed subsidiarity to limb 2 and its immanent and strong dependency of the domestic interpretation ${ }^{1298}$. Indeed, the list of the most common and frequent examples in limb 1 is likely to solve the large majority of use cases in the treaty practice. Intermediate cases, however, are primarily to be solved by limb 2 rather than limb 3, which has been intended to be the ultima ratio ever since ${ }^{1299}$. From this perspective, it is remarkable that the scientific discourse seems to deal predominantly with aspects of limb 3's formal relation to $\operatorname{limb} 1$, negatively defining the limitations of the domestic interpretation. In contrast, the material substance of what a dividend in the treaty context actually is, enjoys comparably little attention. For these reasons, this study takes the alternative approach of putting the main focus on limb 2.

259 At the same time, some of the questions and findings from those legitimate discourses with regard to limbs 1 and 3 are also relevant for the interpretation of limb 2. This is why they shall, as far as relevant for this study, be analysed in the following. However, it deserves initial mentioning that most of these findings are negative criteria in the sense of what was not required for a right to qualify as a dividend. In contrast, as far as can be seen, the attempts to make a positive definition of minimum criteria are fairly limited ${ }^{1300}$ and probably not deep or granular enough to provide sufficient clarity. Due to the complex structure of the provision allowing different ways of understanding an interpretation, the following illustration shall summarise and visualise the various discussion fields in order to compare the divergent positions in a clear and consistent manner:

\footnotetext{
${ }^{1296}$ Haslehner, Werner in Klaus Vogel Commentaries 2015, p. 840, par. 101; OECD Commentaries 2014 on Art. 10 OECD MTC, p. C(10)-9, par. 23.

${ }^{1297}$ Jakob Bundgaard, hybrids, p. 140; Tischbirek, Wolfgang / Specker, Gerhard in Vogel / Lehner, p. 1211, par. 186, and p. 1217, par. 198; Kaeser, Christian / Wassermeyer, Franz in Wassermeyer Commentaries, p. 1306, par. 108, p. 1325, par. 136, p. 1326, par. 139, and p. 1427, par. 71; Hans Pijl, hybrid debts, sec. 4.3.; Eberhartinger / Six, p. 8; Martin Six, hybrid finance, sec. 2.; Michael Lang, hybrids, p. 90; Klaus Vogel Commentaries 1997, p. 649, par. 186, and p. 655, par. 198; unclear: Haslehner, Werner in Klaus Vogel Commentaries 2015, in favour on p. 834, par. 86 , and p. 840 , par. 101 but in par. 89 on p. 834 supporting the opinion that rights shall be interpreted pursuant to domestic tax law of the treaty-applying jurisdiction leaving open what this means for limb 2 (why this opinion cannot be explained in more detail). See also par. 19 et seqq.

${ }^{1298}$ Equally: Fehér, Tamás in Eva Burgstaller, p. 240.

${ }^{1299}$ Avery Jones Commentaries, sec. 3.1.

${ }^{1300}$ OECD Commentaries 2014 on Art. 10 OECD MTC, p. C(10)-10, par. 25. See also par. 282.
} 


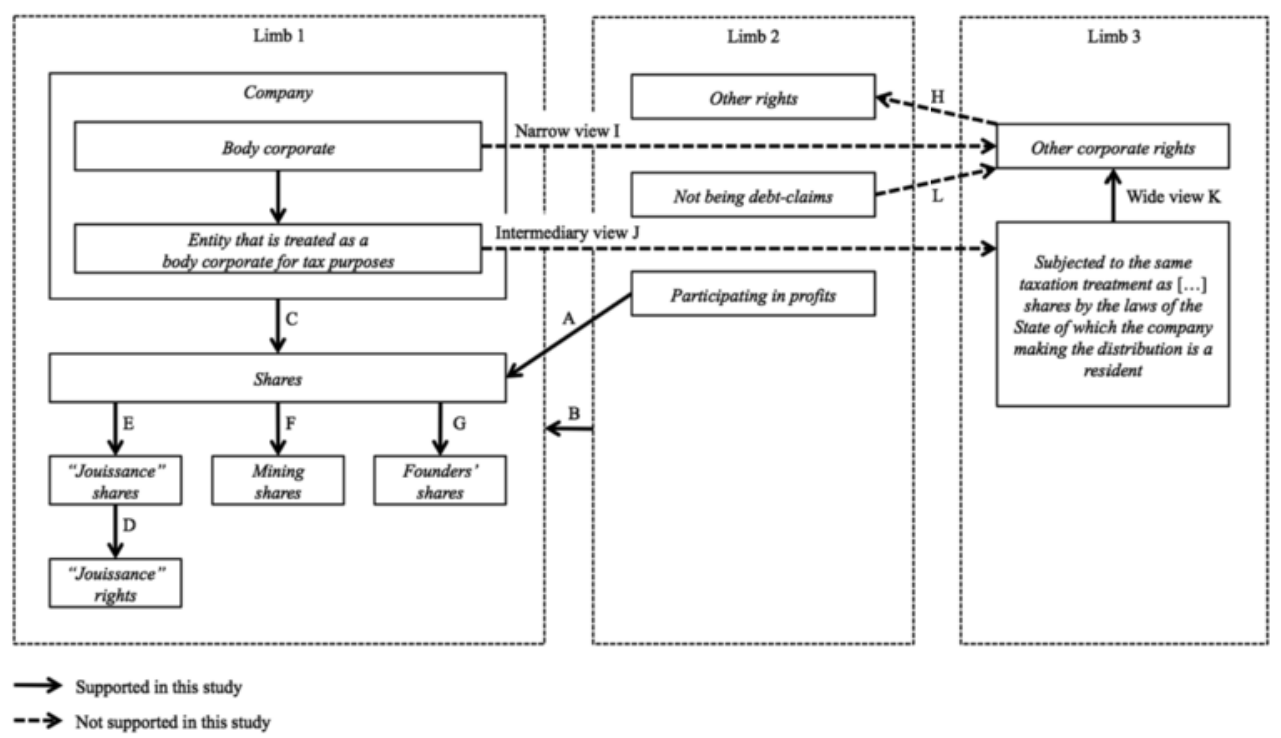

Illustration 19: The interpretational structure of Art. 10(3) OECD MTC

\subsubsection{Shares and the like}

260 The majority of commentators ${ }^{1301}$ came to the consensus view that limb 1 requires a participating in profits taken from limb $2\left(\mathrm{~A}^{1302}\right)$. This is a result from the fact that limb 1 provides no abstract definition but contains a casuistic and non-exhaustive list or catalogue of typical examples empirically encountered in most OECD member states. In the sense of the lowest common denominator ${ }^{1303}$, these examples were grouped by not entailing significant differences in them ${ }^{1304}$. The function of limb 1 becomes particularly clear when set at the end of Art. 10(3) OECD MTC, such as by wording it "dividends include in particular income from shares, 'jouissance' shares or 'jouissance' rights, mining shares and founders' shares”. In contrast, limb 2 provides such an abstract definition to those examples ${ }^{1305}$ and therefore acts as a general clause to limb 1 . Since a general clause represents an intersection with its special clauses, limb 1 is its subset and can take attributes upwards from limb $2\left(\mathrm{~B}^{1306}\right)$. This applies even though limb 2 is in its entirety to be interpreted autonomously and limb 1 is not ${ }^{1307}$. The benefit of such an approach is to serve as a convenience for the practitioner when applying the law. Similarly, this approach has also been taken by the IAS/IFRS in providing a general or generic definition based on what has legally happened in result, without however recurring to the domestic laws ${ }^{1308}$.

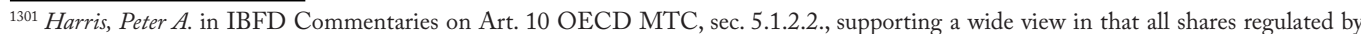
corporate law qualify as participating in profits; Michael Lang, introduction, p. 100, par. 279; Hans Pijl, hybrid debts, sec. 4.8.; Klaus Vogel Commentaries 1997 , p. 649, par. 185, and p. 655, par. 198, supporting a narrow view in that shares qualify as participating in profits only if they participate at the business opportunities equivalent to those of a shareholder including the liquidation proceeds or hidden reserves. All insofar applying the "2-limb-interpretation" (see footnote 1291).

${ }^{1302}$ See Illustration 19 on p. 156.

${ }^{1303}$ See footnote 1489 analogously.

${ }^{1304}$ OECD Commentaries 2014 on Art. 10 OECD MTC, p. C(10)-9, par. 23.

${ }_{1305}$ See par. 258.

${ }^{1306}$ See Illustration 19 on p. 156.

${ }^{1307}$ See par. 257 et seq.

${ }^{1308}$ As an example, see IAS 32.13, giving a generic definition of contract.
} 
Only subsequently, the IAS/IFRS also list the most common use cases in order to improve the Standard's usability $^{1309}$. Consequently, the word other in limb 2 is to be understood in the sense of further ${ }^{1310}$.

261 Shares are securitised holdings in public ${ }^{1311}$ companies pursuant to Art. 3(1)(b) OECD MTC $\left(\mathrm{C}^{1312}\right)^{1313}$ that was specifically inserted for this purpose ${ }^{1314}$ and reads as follows ${ }^{1315}$ :

"For the purposes of this Convention, unless the context otherwise requires, the term 'company' means

- any body corporate

- or any entity that is treated as a body corporate for tax purposes."

Unlike Art. 3(2) OECD MTC ${ }^{1316}$, the insertion unless the context otherwise requires in Art. 3(1)(b) OECD MTC is an interpretation aid originating from the Anglo-Saxon methodology and does not merit substantive attention $^{1317}$.

262 The qualifying element for such holdings is the proprietary right. Proprietary rights, however, do not require full membership or ownership but include limited or preferential membership rights. ${ }^{1318}$ Company is a subtype of person pursuant to Art. 3(1)(a) OECD MTC. As such, it takes all of a person's attributes covering only those structures, which the domestic tax law grants the same rights as persons. ${ }^{1319}$ This means in particular that a structure is considered a body corporate only where it is subject to tax itself and independently ${ }^{1320}$. This is the constituent or qualifying element of limb 1 and allows in so far an autonomous interpretation ${ }^{1321}$ despite the implicit reference to domestic tax $\operatorname{law}^{1322}$. A residency as separately defined in Art. 4 OECD MTC is

\footnotetext{
${ }^{1309}$ See par. 45.

${ }^{1310}$ See par. 257.

${ }^{1311}$ Haslehner, Werner in Klaus Vogel Commentaries 2015, p. 839, par. 97; OECD Commentaries 2014 on Art. 10 OECD MTC, p. C(10)-10, par. 24; unclear: Kaeser, Christian / Wassermeyer, Franz in Wassermeyer Commentaries, p. 1318, par. 123, leaving open if he refers to the term body corporate or to that of entity.

${ }^{1312}$ See Illustration 19 on p. 156.

${ }^{1313}$ Harris, Peter A. in IBFD Commentaries on Art. 10 OECD MTC, sec. 5.1.1. and 5.1.2.2.; Tischbirek, Wolfgang / Specker, Gerhard in Vogel /Lehner, p. 1212, par. 188; OECD Commentaries 2014 on Art. 10 OECD MTC, p. C(10)-10, par. 24; Klaus Vogel Commentaries 1997, p. 651, par. 190.

${ }^{1314}$ OECD Commentaries 2014 on Art. 3 OECD MTC, p. C(3)-1, par. 3.

${ }^{1315}$ The enumeration has been added by the author according to Avery Jones Commentaries, sec. 2.1. and Harris, Peter A. in IBFD Commentaries on Art. 10 OECD MTC, sec. 6.3.1.

${ }^{1316}$ See par. 20.

${ }^{1317}$ Klaus Vogel Commentaries 1997, p. 169, par. 4.

${ }^{1318}$ Jakob Bundgaard, hybrids, p. 141 and 149; Gaspar Lopes Dias, tax arbitrage, p. 121; Haslehner, Werner in Klaus Vogel Commentaries 2015, p. 839, par. 97; Wassermeyer, Franz in Wassermeyer Commentaries, p. 1326, par. 139; Hans Pijl, hybrid debts, sec. 4.7. and 6.; Martin Six, hybrid finance, No. 1, sec. 2.; Jakob Bundgaard, perpetuals, p. 139; Marjaana Helminen, classification, p. 59; Carmine Rotondaro, redemption, p. 266; Klaus Vogel Commentaries 1997, p. 650 et seq., par. 189, and p. 653, par. 192.

${ }^{1319}$ Dürrschmitt, Daniel in Vogel / Lehner, p. 504 et seq., par. 10 and 13; Marjaana Helminen, dividend concept, p. 77 et seqq.; Klaus Vogel Commentaries 1997, p. 171 et seq., par. 15.

${ }^{1320}$ Tischbirek, Wolfgang / Specker, Gerhard in Vogel/Lehner, p. 1213 et seq., par. 190; Wassermeyer, Franz in Wassermeyer Commentaries, p. 251, par. 18; OECD Commentaries 2014 on Art. 10 OECD MTC, p. C(10)-1, par. 1 - 3; Marjaana Helminen, dividend concept, p. 80 et seqq.; Michael Lang, hybrids, p. 117; Klaus Vogel Commentaries 1997, p. 651, par. 190; OECD, CFA/WP1(73)2, p. 6, par. 11.

${ }^{1321}$ Harris, Peter A. in IBFD Commentaries on Art. 10 OECD MTC, sec. 6.3.1.2.; Haslehner, Werner in Klaus Vogel Commentaries 2015, p. 834, par. 86, and p. 835, p. 91; Klaus Vogel Commentaries 1997, p. 649, par. 186; Kaeser, Christian / Wassermeyer, Franz in Wassermeyer Commentaries, p. 1306, par. 108.

${ }^{1322}$ OECD, CFA/WP1(73)2, p. 7, par. 11, p. 8, par. 14, and p. 9, par. 18.
} 
not required ${ }^{1323}$, nor is a special or effective taxation of the income $e^{1324}$. Conversely, the income from a resident body corporate can in any case be nothing else than a dividend. This is why the reference to the domestic tax law has in this case a mere declaratory effect ${ }^{1325}$. Not essential for a company either are any restrictions or limitations of membership rights ${ }^{1326}$ or the unit of the nominal value (e.g. par/non-par value shares) $)^{1327}$. The provision applies the incorporation system, meaning that the place or jurisdiction in which the company has been founded or incorporated is not of importance ${ }^{1328}$. Finally, the legal form is not relevant either, so that rights of ownership or membership are generally not required. For instance, this allows non-corporate entities such as foundations or trusts ${ }^{1329}$ as well as partnerships ${ }^{1330}$ or other structures ${ }^{1331}$ with partial legal capacity ${ }^{1332}$ to qualify as company.

263 "Jouissance" rights grant ownership rights equal or similar to those of a shareholder but exclude certain or all membership rights $\left(\mathrm{D}^{1333}\right)^{1334}$. "Jouissance" shares are securitised "jouissance" rights $\left(\mathrm{E}^{1335}\right)^{1336}$. Mining shares are holdings in mining unions $\left(\mathrm{F}^{1337}\right)^{1338}$. Founders' shares are exclusively reserved for and issued to the originators of a company, and normally carry certain priority or subordination rights $\left(\mathrm{G}^{1339}\right)^{1340}$. As limb 1 takes the

\footnotetext{
${ }^{1323}$ Harris, Peter A. in IBFD Commentaries on Art. 10 OECD MTC, sec. 6.3.1.2.; Wassermeyer, Franz in Wassermeyer Commentaries, p. 251, par. 18;

${ }^{1324}$ Wassermeyer, Franz in Wassermeyer Commentaries, p. 250, par. 18; Klaus Vogel Commentaries 1997, p. 172 et seq., par. 16 et seq.

${ }^{1325}$ Klaus Vogel Commentaries 1997, p. 652, par. 191.

${ }^{1326}$ Gaspar Lopes Dias, tax arbitrage, p. 121; Tischbirek, Wolfgang / Specker, Gerhard in Vogel / Lehner, p. 1212, par. 189, and p. 1214, par. 192; Kaeser, Christian / Wassermeyer, Franz in Wassermeyer Commentaries, p. 1317, par. 122 et seq.; Hans Pijl, hybrid debts, sec. 4.7. and 6.; Martin Six, hybrid finance, sec. 2.; Marjaana Helminen, classification, p. 59; Marjaana Helminen, dividend concept, p. 178; Carmine Rotondaro, redemption, p. 266; Klaus Vogel Commentaries 1997, p. 652 et seq., par. 192.

${ }^{1327}$ Harris, Peter A. in IBFD Commentaries on Art. 10 OECD MTC, sec. 5.1.2.2.; Tischbirek, Wolfgang / Specker, Gerhard in Vogel/Lehner, p. 1214, par. 192; Kaeser, Christian / Wassermeyer, Franz in Wassermeyer Commentaries, p. 1317, par. 122 et seq.; Kopp, Karin E.M. in Wolfgang
} Schön, equity and debt, p. 855; Klaus Vogel Commentaries 1997, p. 653, par. 192.

${ }^{1328}$ Dürrschmitt, Daniel in Vogel/Lehner, p. 505, par. 13; Wassermeyer, Franz in Wassermeyer Commentaries, p. 252, par. 18a, and p. 1317, par. 122; Klaus Vogel Commentaries 1997, p. 171 et seq., par. 15, and p. 652, par. 191.

${ }^{1329}$ Dürrschmitt, Daniel in Vogel / Lehner, p. 508, par. 16a; Wassermeyer, Franz in Wassermeyer Commentaries, p. 253, par. 19; Klaus Vogel Commentaries 1997, p. 172, par. 16.

${ }^{1330}$ Klaus Vogel Commentaries 1997, p. 173, par. 17.

${ }^{1331}$ Klaus Vogel Commentaries 1997, p. 172 et seq., par. 16a.

${ }^{1332}$ Dürrschmitt, Daniel in Vogel / Lehner, p. 508 et seq., par. 18; Haslehner, Werner in Klaus Vogel Commentaries 2015, p. 835, par. 91; Wassermeyer, Franz in Wassermeyer Commentaries, p. 251, par. 18; May, Nicolás in Thomas Ecker, p. 157; Klaus Vogel Commentaries 1997, p. 172, par. 15; OECD, CFA/WP1(73)2, p. 7, par. 12(b).

${ }^{1333}$ See Illustration 19 on p. 156.

${ }^{1334}$ Jakob Bundgaard, hybrids, p. 141; Harris, Peter A. in IBFD Commentaries on Art. 10 OECD MTC, sec. 5.1.2.2.; Haslehner, Werner in Klaus Vogel Commentaries 2015, p. 839, par. 98; Tischbirek, Wolfgang/Specker, Gerhard in Vogel/Lehner, p. 1215, par. 193; Kaeser, Christian /Wassermeyer, Franz in Wassermeyer Commentaries, p. 1318, par. 124, and p. 1435, par. 87; Klaus Vogel Commentaries 1997, p. 653, par. 193; Michael Lang, hybrids, p. 141; OECD, CFA/WP1(73)2, p. 10, par. 20(a).

1335 See Illustration 19 on p. 156.

${ }^{1336}$ Kaeser, Christian /Wassermeyer, Franz in Wassermeyer Commentaries, p. 1318, par. 125; Klaus Vogel Commentaries 1997, p. 654, par. 194.

${ }^{1337}$ See Illustration 19 on p. 156.

${ }^{1338}$ Haslehner, Werner in Klaus Vogel Commentaries 2015, p. 840, par. 101; Tischbirek, Wolfgang / Specker, Gerhard in Vogel/Lebner, p. 1216, par. 196; Kaeser, Christian / Wassermeyer, Franz in Wassermeyer Commentaries, p. 1320, par. 127; Klaus Vogel Commentaries 1997, p. 654, par. 196.

${ }^{1339}$ See Illustration 19 on p. 156.

${ }^{1340}$ Avery Jones Commentaries, sec. 2.2.3.; Tischbirek, Wolfgang/Specker, Gerhard in Vogel/Lehner, p. 1217, par. 197; OECD, CFA/WP1(73)2, p. 10 , par. 20(b). 
attribute participating in profits from limb $2^{1341}$, the provision is limited to equity-like "jouissance" shares and "jouissance" rights ${ }^{1342}$. This should analogously apply to mining shares and founders' shares.

264 The extent to which limb 1 is interpreted autonomously is fairly limited ${ }^{1343}$, whereas its coordinating character or function by directly or indirectly referring to domestic tax law is much stronger. As a result, the main discussion within limb 1 deals with questions to what extent the domestic interpretation shall be bound ${ }^{1344}$. These legitimate questions are indeed considerably complex and important for the interpretation of limb 1 but are, however, not relevant for the scope this study ${ }^{1345}$. That also explains why the question of whether Art. 10(3) OECD MTC is to be interpreted by two or three limbs is not of major importance for this study. It actually leads merely to the particular issue whether or not the domestic interpretation of limb 1 shall be bound by the attribute not being debt-claims taken from limb $2^{1346}$.

\subsubsection{Corporate rights}

\section{The corporate rights test}

265 Due to the ambiguous meaning of the terms as well as ${ }^{1347}$ and other ${ }^{1348}$ in limb 3, it is controversial whether the term other rights in limb 2 requires corporate rights taken from limb $3\left(\mathrm{H}^{1349}\right)$. The proponents of such "corporate-rights test" 1350 understand the word other in limb 3 in the sense of further and consequently the term as well as in limb 3 in the sense of an enumeration. In contrast, the opponents to this view understand the word other in limb 3 in the sense of different and consequently the term as well as in limb 3 in the sense of a separation. As such, it was able only to extend but not to limit the scope of limb $2^{1351}$. They further argue that the term rights in limb 2 must obviously include debt-claims to make their exclusion reasonable ${ }^{1352}$. And lastly, even if limb 2 did require corporate rights taken from limb 3, some commentators ${ }^{1353}$ emphasise that the attribute corporate rights would still be subsidiary to the attribute not being debt-claims. As such, it would consequently be the precedent criterion for defining and delimiting limb 2.

\footnotetext{
${ }_{1341}$ See par. 260.

${ }^{1342}$ Hans Pijl, hybrid debts, sec. 4.8.; Tischbirek, Wolfgang / Specker, Gerhard in Vogel / Lehner, p. 1216, par. 194 et seq.; Kaeser, Christian / Wassermeyer, Franz in Wassermeyer Commentaries, p. 1320, par. 126; Marjaana Helminen, dividend concept, p. 189; Klaus Vogel Commentaries 1997, p. 654, par. 194.

${ }^{1343}$ See par. 259.

${ }^{1344}$ See par. 258.

${ }^{1345}$ See par. 9 and 14.

${ }^{1346}$ Kaeser, Christian / Wassermeyer, Franz in Wassermeyer Commentaries, p. 1325, par. 136; Haslebner, Werner in Klaus Vogel Commentaries 2015, p. 840, par. 101; Hans Pijl, hybrid debts, sec. 2.3.1.

${ }^{1347}$ See footnote 1291.

${ }^{1348}$ See par. 257.

${ }^{1349}$ See Illustration 19 on p. 156.

${ }^{1350}$ Jakob Bundgaard, hybrids, p. 140 et seq.; Gaspar Lopes Dias, tax arbitrage, p. 115 and 127; Tischbirek, Wolfgang / Specker, Gerhard in Vogel /Lehner, p. 1211, par. 185, and p. 1212, par. 188; Santos, Ramon Tomazela, Tax Treaty Qualification of Income Derived from Hybrid Financial Instruments, Bulletin for International Taxation 2013, Vol. 67, No. 10, sec. 4.1.; Marjaana Helminen, dividend concept, p. 175; Eberhartinger / Six, p. 9; Martin Six, hybrid finance, sec. 2. and 4; Marjaana Helminen, classification, p. 58 et seq.; Klaus Vogel Commentaries 1997, p. 573, par. 185.

${ }^{1351}$ Fehér, Tamás in Eva Burgstaller, 2007, p. 240.

${ }^{1352}$ Hans Pijl, hybrid debts, sec. 4.7.

${ }^{1353}$ Gaspar Lopes Dias, tax arbitrage, p. 129, 131 and 133; Fehér, Tamás in Eva Burgstaller, p. 245 et seq.; according to Harris, Peter A. in IBFD Commentaries on Art. 10 OECD MTC, sec. 5.1.3.1., this would be a rather "formalistic approach" but in line with OECD, CFA/ WP1(73)2, p. 8, par. 13.
} 
266 These two opposing positions principally aim to differentiate dividends from interest by identifying a shared reference. Nevertheless, the definition of the term other rights in limb 2 by way of positively deriving it from the term corporate rights in limb 3 or by way of negatively delimitating it from Art. 11(3) OECD MTC by the term not being debt-claims in limb 2 must eventually lead to the same result. The proponents see this reference in the term corporate rights indirectly via limb 3, considering it the material opposite of debt-claims. Contrariwise, the opponents directly focus on the formal state of not being debt-claims within limb 2 that does not require corporate rights as an additional reference. However, due to the consensus view that limb 2 is entirely to be interpreted autonomously ${ }^{1354}$, both corporate rights and debt-claims would also from the proponents' view be interpreted autonomously in this context according to the same material attributes. In other words: both views eventually mean the same "coin" and only take their justification from different sides of that "coin"1355.

\section{The relevance of the corporate rights test}

267 Notwithstanding this resultative equivalence ${ }^{1356}$, the author agrees with the opponents' view that the term other rights in limb 2 does not require the indirect reference to the attribute corporate rights taken from limb 3. On the one hand, this follows e contrario from the clear and explicit wording not being debt-claims in limb 2. In the absence of any reference to domestic tax law and even from the proponents' view, the term not being debt-claims is in any case to be interpreted autonomously ${ }^{1357}$. On the other hand, any reference from limb 2 to limb 3 would represent a circular reasoning, as the latter itself is in fact subsidiary to the former ${ }^{1358}$ and therefore cannot at the same time have any influence back on it. The said uncertainty as to whether limb 2 takes attributes from limb 3 (upwards) or vice versa (downwards), appears to be caused by the ambiguity of limb 3 in being either a general or a special clause. While the former includes the latter in the sense of a superset and therefore shares its attributes, the latter excludes the former in the sense of a carve-out or would otherwise make it redundant. Pursuant to the laws of logic, these two aspects are mutually exclusive. As it is undisputed that limb 2 is in any case to be interpreted autonomously in its entirety ${ }^{1359}, \operatorname{limb} 3$ cannot possibly be its general but only its special clause. While an autonomous provision can represent a general clause for a partly domestic provision (e.g. limb 2 for limb 1) ${ }^{1360}$, a partly domestic provision cannot, vice versa, represent a general clause for an autonomous provision (i.e. limb 3 for limb 2). Consequently, any overlap between limb 2 and limb 3 must be rejected.

\section{The limitations of the corporate rights test}

268 But even if there was such reference, the term other rights in limb 2 itself is in any case to be interpreted autonomously. Admittedly, due to the particular uncertainty within limb 3 of whether other corporate rights is precedent or subsidiary to the reference to domestic tax law ${ }^{1361}$, it is controversial how far this reference is to be understood. Namely, whether other corporate rights in limb 3 shall be limited to rights in a corporate body

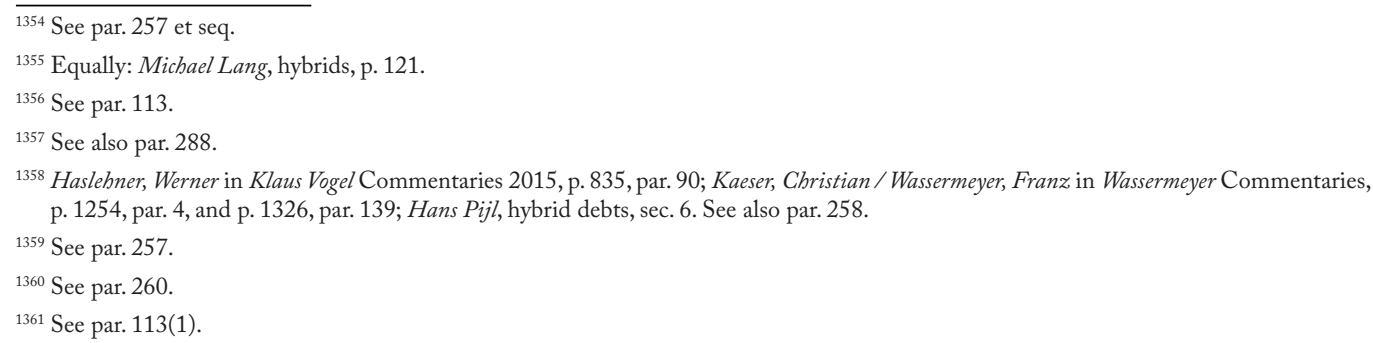


pursuant to limb 1 (narrow view $\mathrm{I}^{1362}$ ) or shall also include rights in an entity that is treated as a body corporate for tax purposes pursuant to limb 1 (intermediary view $\mathrm{J}^{1363}$ ) or shall also include other rights subjected to the same taxation treatment as shares pursuant to $\operatorname{limb} 3$ (wide view $\mathrm{K}^{1364}$ ):

(1) The representatives of a narrow view $(\mathrm{I})^{1365}$ primarily argue:

- As a result from the word other, limb 3 referred to shares in limb 1 and therefore to Art. 3(1)(b) OECD MTC. This view was supported by the clause company making the distribution. In that, limb 3 represented a closed and exhaustive definition, not being inaccessible to Art. 3(2) OECD MTC ${ }^{1366}$.

- Only shares could grant shareholder rights as required by Art. 10(3) OECD MTC in order to yield dividends.

(2) In contrast, the representatives of an intermediary view $(\mathrm{J})^{1367}$ primarily argue:

- The phrase company making the distribution suggested not only shares. The reason for this argument was that the English term company had, for Art.3(1)(b) OECD-MTC as well, a wider meaning than the term corporation. This view was also supported by the fact that all other language versions use their wider terms as well.

- The term other corporate rights already existed in the OEEC drafts before the reference to the domestic tax law of the source jurisdiction was included. This fact suggests the intention of a different (i.e. wider) understanding.

- The purpose and function of limb 3 was to ensure that Art. 10(3) OECD MTC covers income from an entity falling under the definition of company.

(3) The representatives of a wide view $(K)^{1368}$ primarily argue:

- Limb 3 would entirely fall short, violating its purpose, intention and function.

269 Other commentators ${ }^{1369}$ seem to read the provision in a way that supports a modified narrow view that the term other corporate rights in limb 3 shall also include the attribute debt-claims participating in profits in limb 3 and Art. 11(3) OECD MTC. The entire discussion, however, focuses on the key question of whether (intermediary view J) or not (narrow view I) limb 3, if not even genuinely subject of the domestic interpretation (wide view $\mathrm{K}$ ), shall take the reference to the domestic tax law from limb 1. In other words: it is controversial whether the attribute other corporate rights in limb 3 is either to be interpreted autonomously (narrow view I) or domestically (intermediary view $\mathrm{J}$ and wide view $\mathrm{K}$ ). To the author's understanding, the narrow view (B) is inconsistent with the 3 -limb interpretation, which is supported mainly by the same representatives ${ }^{1370}$. Any direct reference from limb 3 to limb 1 would not only conflict with the consensus view that limb 2 is first of all

\footnotetext{
$\overline{1362 \text { See Illustration } 19 \text { on p. } 156 .}$

${ }^{1363}$ See Illustration 19 on p. 156.

${ }^{1364}$ See Illustration 19 on p. 156.

${ }_{1365}$ Tischbirek, Wolfgang/Specker, Gerbard in Vogel/Lehner, p. 1212 et seq., par. 189, and p. 1215, par. 192; Kaeser, Christian/Wassermeyer, Franz in Wassermeyer Commentaries, p. 1305, par. 107, p. 1317, par. 122, and p. 1327, par. 140; May, Nicolás in Thomas Ecker, p. 443; Fehér, Tamás in Eva Burgstaller, p. 243 and 246; Klaus Vogel Commentaries 1997, p. 650, par. 188 and 651, par. 190; perhaps Michael Lang, hybrids, p. 90 and 132; unclear: Haslehner, Werner in Klaus Vogel Commentaries 2015, in favour on p. 840, par. 102 but in par. 89 on p. 834 supporting the view that rights shall be interpreted pursuant to domestic tax law of the treaty-applying jurisdiction.

${ }^{1366}$ See par. 20.

${ }^{1367}$ Harris, Peter A. in IBFD Commentaries on Art. 10 OECD MTC, sec. 5.1.2.4.2. and 5.1.3.1.; Avery Jones Commentaries, sec. 3.2. et seq.

${ }^{1368}$ OECD, Report on Thin Capitalization, Issues in International Taxation 1987, No. 2, p. 24, par. 57 et seqq., and p. 33, par. 85(a); Hans Pijl, hybrid debts, sec. 4.2, 4.7., 5.8. and 6.

${ }^{1369}$ Gaspar Lopes Dias, tax arbitrage, p. 115 et seq.; Eberhartinger / Six, p. 9; Martin Six, hybrid finance, sec. 2.; Marjaana Helminen, classification, p. 59.

${ }^{1370}$ See footnotes 1291 and 1365 .
} 
a general clause for limb 1 (B) ${ }^{1371}$ but also with the finding that limb 3 is a special clause, which does not share its attributes at all ${ }^{1372}$. Such direct reference from limb 3 would actually establish a formal bridge or bracket to $\operatorname{limb} 1$. It would ignore both the undisputed priority ${ }^{1373}$ and the character of limb 2 that would at worst fall short entirely. In other words: it follows from its position between limbs 1 and 3 that the purpose and function of limb 2 may not be frustrated or marginalised by limb 3, which provides a domestic and special definition.

\section{Own alternative view on the corporate rights test}

270 Instead, limb 3 must in its entirety be interpreted domestically (i.e. wide view K) as a coherent whole. Unlike in limb $2^{1374}$, the word other in limb 3 must consequently be understood in the sense of different ${ }^{1375}$. This conclusion is in line with the asset-based approach implying and requiring the income or transaction ${ }^{1376}$. It would not be reasonable and give rise to considerable systematic distortions to interpret the term income in limb 3 pursuant to domestic law, but the term corporate rights in limb 3 as the asset and source of that income autonomously ${ }^{1377}$. Even if there was a reference from limb 2 to limb $3^{1378}$, the autonomous term other rights in limb 2 had necessarily a different meaning than the domestic term other corporate rights in limb $3^{1379}$. Consequently, the conclusion that other rights in limb 2 actually means equity rights (corporate rights test) must be drawn directly from the reference phrase not being debt-claims in conjunction with the attribute participating in profits. Namely, it cannot be drawn indirectly from the term corporate rights in limb 3.

271 On the other hand, there is a parallel discussion on the converse question whether limb 3 shall also take the attribute not being debt-claims from limb $2\left(\mathrm{~L}^{1380}\right)$. This discussion is not of particular relevance for limb 2 as the focus of this study ${ }^{1381}$ and, even if it had been, it would have had to be rejected ${ }^{1382}$. However, the opponents of this view ${ }^{1383}$ use the argument that pursuant to par. 15(d) of the OECD Commentaries 2014 on Art. 10 OECD MTC, Art. 10(2)(a) OECD MTC also covered certain debt-claims. This argument might potentially give rise to doubts within limb 2 as to whether it is the special function of its insertion not being debt-claims to actually differentiate and mutually exclude limb 2 from non-equity rights ${ }^{1384}$. This argument does nevertheless not apply to limb 2, since pursuant to its tax-limiting function and correspondently its broad scope $\mathrm{e}^{1385}$, Art. 10(2)(a) OECD MTC must necessarily include limbs 1 and 3 as well. Accordingly, par. 15(d) of the OECD

\footnotetext{
${ }^{1371}$ See par. 260.

${ }^{1372}$ See par. 267.

${ }^{1373}$ See par. 258.

${ }^{1374}$ See par. 260.

${ }^{1375}$ See par. 265.

${ }^{1376}$ See par. 54.

${ }^{1377}$ Marjaana Helminen, dividend concept, p. 145.

${ }^{1378}$ See par. 268.

${ }^{1379}$ Equally: Jakob Bundgaard, hybrids, p. 148.

${ }^{1380}$ See Illustration 19 on p. 156.

${ }^{1381}$ See par. 258.

${ }^{1382}$ See par. 267.

${ }^{1383}$ See footnote 1368.

${ }^{1384}$ See par. 113(1).

${ }^{1385}$ See par. 112.
} 
Commentaries 2014 on Art. 10 OECD MTC explicitly refers to the "internal law or practice" and therefore not to $\operatorname{limb} 2^{1386}$.

\section{Interim conclusions}

272 From these systematic considerations follows as an interim conclusion for the further course of this study that $\operatorname{limb} 3$ represents a special clause to $\operatorname{limb} 2$. As such, limb 3 actually excludes limb 2 and therefore shares none of its own attributes. In contrast, limb 2 represents as a general clause an intersection with limb 1 . As such, limb 2 includes limb 1 and therefore shares its own attributes. Or to put it the other way round: limb 1 takes attributes from limb 2, while limb 2 takes no attributes from limb 3. In particular, the attribute other corporate rights in limb 3 is not relevant for the interpretation of limb 2. This the reason why the subsequent question of whether that attribute is to be interpreted autonomously or domestically is not relevant for this study. This disentanglement of limb 2 from the formal requirement of a corporate right in limb 3 also corresponds to the examples of "jouissance" shares or "jouissance" rights in limb 1, which do apparently not meet this condition. That is why the term other rights in limb 2 is to be interpreted autonomously and actually means equity rights as opposed to debt-claims. Consequently, the word other in limb 3 is, unlike in limb 2, to be understood in the sense of different.

\subsubsection{Participating in profits}

\section{The relevance of the profit participation}

273 At first glance, the attribute participating in profits appears to be dispensable, in that it is mentioned in both Art. 10(3) and 11(3) OECD MTC. In other words: "the term 'dividends' as used in this Article [i.e. Art. 10(3) OECD MTC] means income from [...] other rights, [...] participating in profits" and thus seems to also fully include "income from debt-claims of every kind, [...] whether or not carrying a right to participate in the debtor's profits" in the sense of Art. 11(3) OECD MTC. However, the syntax of the two provisions differs in that the attribute participating in profits is an integral part of the independent clause and therefore a constituent element of the positive definition in Art. 10(3) OECD MTC. Contrariwise, it is part of a dependent clause in Art.11(3) OECD MTC and therefore an extension of the definition there. In other words: Art. 10(3) OECD MTC actually reads as "other rights, which are participating in profits", whereas Art. 11(3) OECD MTC actually reads as "debt-claims, even though participating in profits". This is the interpretational justification that the profit participation is a genuine and integral element and therefore a necessary minimum condition (conditio sine qua non) for dividends, but not for debt-claims. This conclusion is even more evident when set into a relationship with the phrase not being debt-claims in Art. 10(3) OECD MTC. This negating insertion appears, at first glance, as merely declaratory or even redundant. In fact, however, it supports the view that debt-claims, which are as such excluded from other rights, bear themselves no right to participate in profits. In other words: the significance of this interpretative detail arises as a consequence of the different logical levels, on which the two provisions interact by the word debt-claims. In that, it also supports the view that the term other rights in limb 2 must include debt-claims to make their exclusion reasonable ${ }^{1387}$. The following illustration visualises this understanding:

\footnotetext{
${ }^{1386}$ Similarly: Harris, Peter $A$. in IBFD Commentaries on Art. 10 OECD MTC, sec. 5.1.2.4.2.; OECD, BEPS Action No. 6 - Preventing the Granting of Treaty Benefits in Inappropriate Circumstances (Final Report), 5 October 2015, OECD, Paris, 2015, p. 70, par. 33.

${ }^{1387}$ See par. 265 .
} 


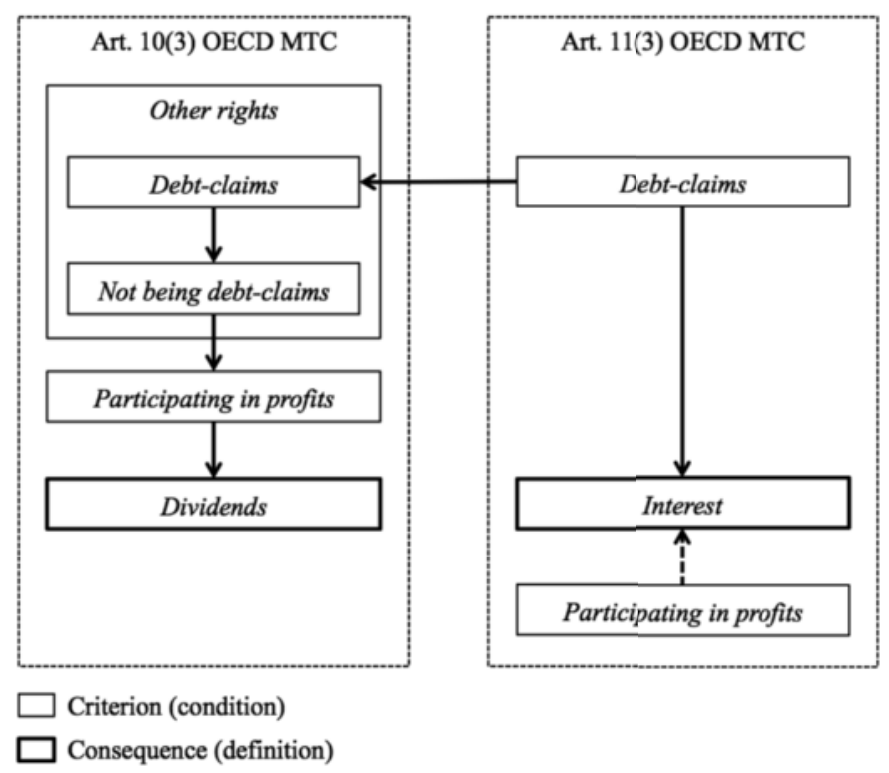

Illustration 20: The interaction of Art. 10(3) and 11(3) OECD MTC and the participation in profits

\section{Modifications of the payment profile}

274 Just as for the systematic considerations as regards the time value of money ${ }^{1388}$, with regard to the interpretation of Art. 10(3) OECD MTC the question also arises, which and to what extent modifications of the payment profile represent a participating in profits ${ }^{1389}$. Or in other words: at which point its risk-based nature starts and ends. Since dividends are per se risky in terms of periodicity ${ }^{1390}$, certainty ${ }^{1391}$, payability ${ }^{1392}$ and currency ${ }^{1393}$, debatable are particularly modifications in the

(1) amount multiplicatively (e.g. leverage) and/or additively (e.g. premium) ${ }^{1394}$; and

(2) symmetry (i.e. in its profits and maybe losses in equal or unequal proportions).

Again, it follows from the equivalence of legal criteria ${ }^{1395}$ that there cannot be any priority or subordination among them, in that one feature was more important or significant than any other.

275 As regards the first aspect (1), amount modifications are analogous to the time value of money ${ }^{1396}$. They can have the multiplicative form of a leverage, which can be above $(>1)$ or below $(<1)$ profit-loss proportionality $(=1)$, or the additive form of premiums $(>0)$ or discounts $(<0)$. In this respect, the author takes the view that positive modifications can still represent a participation in profits (i.e. leverage $>1$ and premiums, e.g.

\footnotetext{
1388 See par. 209

${ }^{1389}$ See par. 204.

${ }^{1390}$ See par. 209(1).

${ }^{1391}$ See par. 209(2).

${ }^{1392}$ See par. 209(4).

${ }^{1393}$ See par. 209(5).

${ }^{1394}$ See par. 209(3).

${ }^{1395}$ See par. 182.

${ }^{1396}$ See par. 215.
} 
dividend step-ups). This follows e contrario from the systematic considerations with regard to the time value of money, according to which any excess amount can eventually and economically only be yielded by equity implying underwriting risk. Conversely, a rational investor will not accept negative modifications (i.e. leverage $<1$ and discounts) while fully participating in underwriting risk. In other words: just like the theoretical ideal-type of debt-claims are time-based financial instruments not bearing any underwriting risk ${ }^{1397}$,its natural complement and the theoretical ideal-type of equity rights are risk-based (i.e. underwriting risk) financial instruments ${ }^{1398}$. While the return from the former is basically the time value of money, the return from the latter necessarily includes a risk premium ${ }^{1399}$.

276 However, the fact that a rational investor will not accept negative modifications of the payment profile while fully participating in underwriting risk, may not lead to the erroneous conclusion that they actually do not exist in practice. Rather, it only means that they must be compensated otherwise, namely on the risk level, by limiting the investor's risk exposure. Notably, such negative modifications result in opposite risk-wise consequences for risk-based and time-based payment profiles: a negatively modified time-based payment profile implies a participation in risk, turning it into risk-based. In contrast, a negatively modified risk-based payment profile implies a limitation of risk, keeping it basically risk-based (except if it is time-equivalent ${ }^{1400}$ ). In other words: in both cases the negative modification implies time-inequivalence ${ }^{1401}$ and therefore underwriting risk. However, for this reason the former turns into risk-based due to embedding the risk premium, whereas the latter remains risk-based even though embedding the risk premium. True, underwriting risk (superset) is not necessarily business risk (subset) ${ }^{1402}$, just as a risk premium (superset) is not necessarily a participation in profits (subset). However, as a risk premium (superset) compensates underwriting risk (superset), a participation in profits (subset) must necessarily compensate business risk (subset) ${ }^{1403}$. From the author's view, this systematic rationale can be transferred to the OECD MTC by analogy. As a conclusion for the further course of this study, positive and - as opposed to the time value of money - also negative modifications of the payment profile participating in profits represent business risk.

277 These considerations also support the natural and widely accepted intuition that participation in profits is first of all a compensation for a participation in losses (i.e. business risk) ${ }^{1404}$. In other words: participation in profits implies business risk, which represents the material link to the participation in losses ${ }^{1405}$. Where the participation in profits and that in losses are asymmetric ${ }^{1406}$, the financial instrument necessarily contains an optional component ${ }^{1407}$. Such asymmetry ${ }^{1408}$ is basically independent of possible amount modifications ${ }^{1409}$,

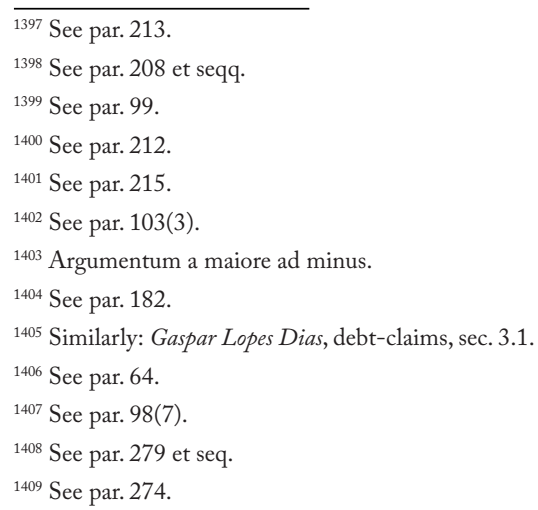


since leverage can also be symmetric. Where such asymmetry ${ }^{1410}$ is, however, in favour of the participation in profits, there cannot possibly be a full participation in the business risk (economic insurance). A partial but positive participation due to a slight asymmetry may still represent business risk ${ }^{1411}$. However, the asymmetry can be so strong that it seems to eventually eliminate business risk entirely and thus eliminate one of the constituting elements of other equity rights pursuant to Art. 10(3) OECD MTC ${ }^{1412}$. The price to pay for such risk "elimination" is actually the premium of the embedded optional component, which represents itself a risk-based element. While the risk from the underlying is asymmetric, the optional component itself remains nevertheless risk-based. In other words: the elimination of business risk from the level of the underlying by embedding an optional component may not be confused with the business risk coincidently transferred onto the level of the optional component itself. Even a strong asymmetry of the payment profile is thus not capable of actually "eliminating" the business risk (i.e. from the underlying) but can merely replace it by another risk (i.e. from the optional component), keeping the financial instrument as a whole risk-based. As a consequence, negative modifications of a risk-based payment profile participating in profits represent in any case business risk unless not being time-equivalent.

278 In addition, business risk is the link between a participation in profits and that in losses and as such bears a nexus with the timing ${ }^{1413}$. As a consequence, a participation in losses is inextricably coalesced with the loss of the capital or principal itself, just as a participation in profits is inextricably coalesced with the liquidation proceeds or hidden reserves. In fact, both are merely deferred ${ }^{1414}$. This structural mechanism, interpretatively deducible from the attribute participating in profits, is also the systematic reason why the participation in profits necessarily implies termination risk in the form of business risk. Another consequence and conclusion for the further course of this study is that the word profits in Art.10(3) OECD MTC includes negative profits (i.e. losses), despite the fact that its narrow literal understanding might suggest a limitation to positive results only. On the one hand, the words profits and income are independent of each other, as the former is to be understood autonomously and in the sense of potential, whereas the latter is to be understood domestically ${ }^{1415}$ and in the sense of actual ${ }^{416}$. On the other hand, the two terms were said to include also losses, which makes them eventually independent from the amount. As a consequence, the two terms have in common that even the absence of any profit at all (i.e. no potential income, e.g. zero-interest bond) does not negate the principal necessity and feasibility of classifying the respective financial instrument into the distributive articles of the OECD MTC ${ }^{1417}$.

\footnotetext{
${ }^{1410}$ See par. 279 et seq.

${ }^{1411}$ See par. 276.

${ }^{1412}$ As will be elaborated in the following (see par. 282).

1413 See par. 69 and 250.

${ }^{1414}$ Equally: Michael Lang, hybrids, p. 130; contrary: Gaspar Lopes Dias, debt-claims, sec. 3.1., ignoring this interdependent mechanism by formalising that "the predicament here resides in that the risk of not obtaining profits is not the same as the risk of losing the invested capital, as it is perfectly possible to hold a right to profits in a company and yet not have a share in the liquidation proceeds; one thing does not result from the other. Moreover, if the access to profits were necessarily a consideration for the total risk assumed, then it would be antithetical to accept that payments could be characterised as interest for treaty purposes if they were profit sharing. Therefore, the author fails to see a legally binding link that allows such requirement (to share in the liquidation proceeds indicating a business risk of total loss) to be attained based on the wording of article 10."; Jakob Bundgaard, perpetuals, p. 140, merely observing that "the wording of Art. 10 of the OECD Model, however, does not explicitly list these criteria, nor does it go into detail on how these two criteria must be formulated in order for a specific hybrid instrument to be classified as a dividend-generating instrument (equity)." See also par. 219.

1415 See par. 144.

${ }^{1416}$ See par. 158.

${ }^{1417}$ See par. 201.
} 


\section{Symmetry of the payment profile}

279 The second aspect (2) $)^{1418}$ of symmetry leads to the question which characteristics constitute a participation in profits (and losses).

Example 44: An optional convertible bond does not legally participate in profits and losses before having been converted into the share. However, the option to convert economically represents nevertheless a participation in the future value appreciation of that share (i.e. in the profits and losses). ${ }^{1419}$ The dependency becomes even more evident by the example of a mandatory convertible bond, whose market value is almost entirely determined by that of the share $^{1420}$.

On the one hand, the classification of an individual remuneration payment into the distributive articles of the OECD MTC depends on all other remuneration payments, including those paid at maturity ${ }^{1421}$. As a consequence, they were found to be analysed by grouping them together as a coherent whole ${ }^{1422}$. On the other hand, the payment profile as a whole interacts with the termination risk ${ }^{1423}$. As a consequence, business risk as a sub-type of underwriting risk ${ }^{1424}$ can necessarily be contained within the participation in profits and losses (e.g. "jouissance" share) or the capital or principal (e.g. equity-linked note) or both (e.g. share) ${ }^{1425}$, the reason being that today's capital is economically tomorrow's income ${ }^{1426}$, so that the requisite legal event does not only split-off income ${ }^{1427}$ but also underwriting risk from capital. In fact, a dividend distribution reduces also the investor's total investment risk over the share's entire lifetime. This means in turn that underwriting risk remains left for capital gains unless being shifted at some point to the other income types by such legal event. In other words: the participation in losses implies business risk on both profits (i.e. opportunity costs) and the capital or principal itself (i.e. actual costs). Hence, the former represents in fact a remuneration risk (also referred to as "coupon at risk") and the latter a termination risk (also referred to as "principal at risk"). The aspect of symmetry of the payment profile therefore points to two interpretational questions: (1) whether or not the remuneration risk must be seen as one logical unit or concept with the termination risk and (2) what the sources of interpretation for it are.

280 As regards the first question (1), to the author's understanding the two aspects must be considered separately ${ }^{1428}$. Notably, this applies irrespective of their nexus as both representing business risk. Both participating in profits and, due to the extended definition in Art. 11(3) OECD MTC ${ }^{1429}$, also debt-claims imply business risk and cannot serve as a differentiator. Only termination risk is capable of falsifying time equivalence and consequently

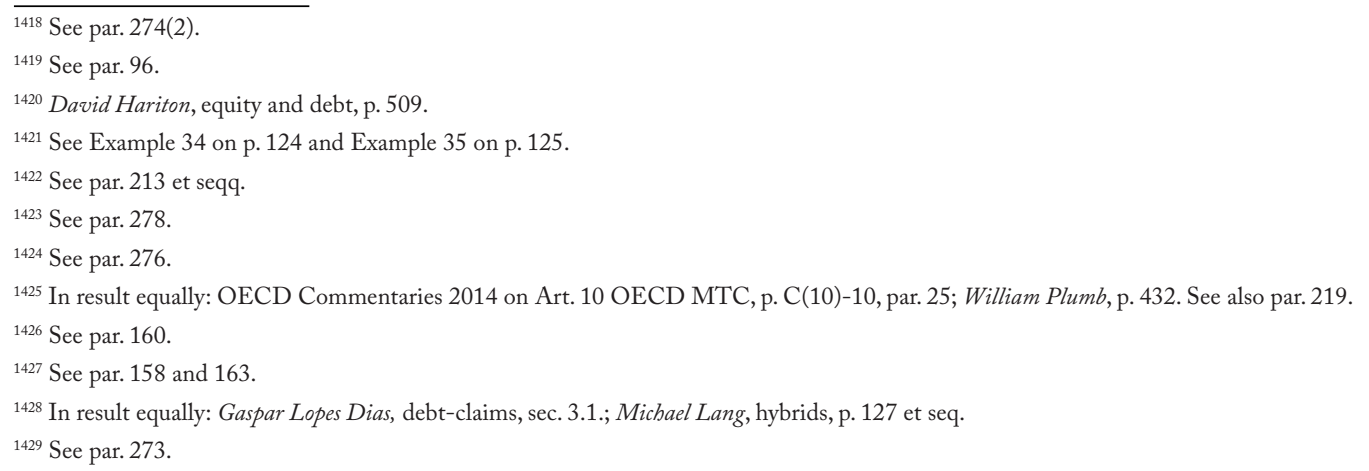


the time value of money ${ }^{1430}$. In other words: business risk can be contained within both the participation in profits and losses (i.e. remuneration risk) and the capital or principal (i.e. termination risk) ${ }^{1431}$. However, only the former is covered by the extended definition of debt-claims in Art. 11(3) OECD MTC, as the latter is a falsifier for debt-claims as such ${ }^{1432}$. Any other conclusion would mean letting Art. 11(3) OECD MTC fall short entirely. Not only by ignoring the term debt-claim but also by the self-contradiction that the termination risk in the attribute participating in profits would negate its previous term debt-claims ${ }^{1433}$. As a consequence, the attribute participating in profits not only has a different legal quality but also a different legal consequence within Art. 10(3) OECD MTC as compared to Art.11(3) OECD MTC. In the former it means any form of business risk, whereas in the latter it means only business risk in the form of remuneration risk. The consequent tax planning possibilities and distortions by discretionarily structuring the business risk into the capital or principal ${ }^{1434}$ have to be accepted ${ }^{1435}$. Accordingly, the answer to the second question (2) is that the source of interpretation for the termination risk is not the attribute participating in profits but rather the composite phrase other rights, not being debt-claims. That is why the interpretative embedding of the termination risk into Art. 10(3) OECD MTC is discussed in the following separately ${ }^{1436}$. As a conclusion for the further course of this study it is held that the attribute participating in profits cannot serve as a differentiator for the distinction between Art. 10(3) and 11(3) OECD MTC ${ }^{1437}$. This result also corresponds to the systematic considerations and finding that this criterion has relatively low interpretation significance ${ }^{1438}$.

\subsubsection{Other rights}

\section{The corporate rights test by analogy}

281 From the author's view, the requirement found in previous discussions ${ }^{1439}$ that a structure must be abstractly and independently subject to tax itself in order to qualify for originating shares pursuant to limb 1 applies also to the term other rights in limb 2. This cannot be the result of any reference from limb 2 to limb 1 , which would represent a circular reasoning, as the former shares its own attributes with the latter as its subset ${ }^{1440}$ and not vice versa. However, limb 2 represents as its general clause an intersection with limb 1 . This is why it is methodologically permissible to interpret limb 2 by drawing implicit reverse conclusions from the list or catalogue of particular examples in limb 1, which is the stronger provision (e.g. common characteristics), to the abstract definition in limb 2 , which is the weaker provision ${ }^{1441}$. Notably, this may not be understood as creating a reference from limb 1 but rather as a methodology of interpretation within limb 2. Admittedly, this tends to make limb 1 redundant. However, this is the logical necessity of any intersection and therefore the very nature of any general clause as opposed to a residuary clause. This result as interpreted by such analogy is that a structure must be abstractly and independently subject to tax itself in order to qualify for other

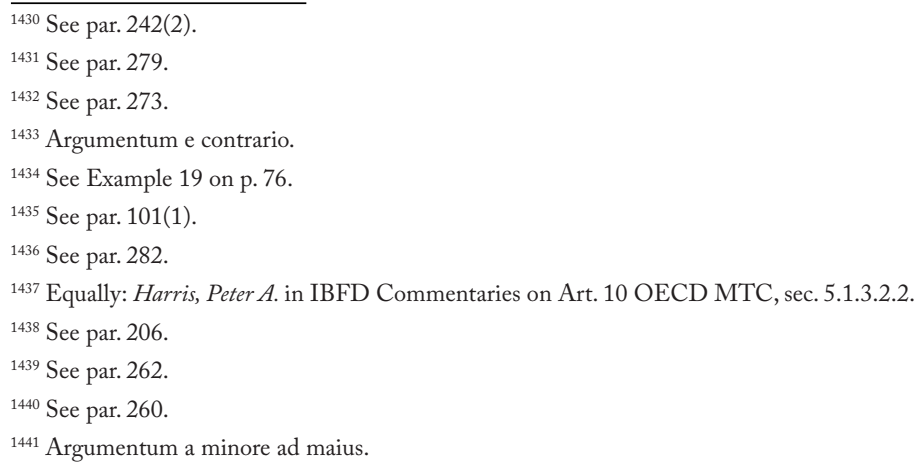


rights pursuant to limb 2 . It is also systematically in line with limb 1 , as both are interpreted autonomously and clearly separated from debt-claims ${ }^{1442}$. According to the author's view, this tax subjectivity is concretely governed by the domestic tax law also for limb 2 . This view is systematically in line with limb $1^{1443}$ and limb $3^{1444}$, as all three are interpreted domestically.

\section{The relevance of business risk}

282 There appears to be a certain consensus that the term other rights in limb 2 requires at least

(1) an actual provision of capital ${ }^{1445}$,

(2) which participates in the business risk equivalent to that of a shareholder, including the risk of loss of the capital or principal itself ${ }^{1446}$; and

(3) in the business opportunities equivalent to those of a shareholder, including the liquidation proceeds or hidden reserves ${ }^{1447}$.

However, this turns out to be an imprecise view, when looked at more closely, in that the term other rights was actually found to include debt-claims ${ }^{1448}$. As was further concluded, the difference between other equity rights and debt-claims by way of business risk and opportunities cannot be taken from the attribute participating in profits ${ }^{1449}$ either. Consequently, the difference between other equity rights and debt-claims by way of business risk and opportunities can only be deduced from the negating insertion not being debt-claims as the only remaining part of limb 2 justifying such interpretation. Debt-claims themselves bear no genuine right to participate in profits. This means in turn that they do not bear genuine business risk in either way ${ }^{1450}$, even less where there is no participation in losses. This permissible reverse deduction is a result of the above systematic considerations ${ }^{1451}$ that such amounts exceeding the time value of money necessarily bear business risk. In that, the negating insertion not being debt-claims carves out the time value of money from limb 2 of Art. 10(3) OECD MTC, leaving the crucial aspect of business risk as a residuum within the term other rights. On the other hand, the attribute participating in profits in limb 2 of Art. 10(3) OECD MTC already accounts for the business risk to the extent that it is contained within the remuneration (i.e. the remuneration risk). However, it can simultaneously also be contained within the capital or principal itself (i.e. the termination risk) ${ }^{1452}$. At first glance, the negating insertion not being debt-claims appears a mere complementary exclusion. In fact,

\footnotetext{
${ }^{1442}$ See par. 267.

${ }^{1443}$ See par. 262.

${ }^{1444}$ See par. 270.

${ }^{1445}$ See par. 106(3) and 113(1).

${ }^{1446}$ See footnote 1365. Also supported by Jakob Bundgaard, hybrids, p. 147; Santos, Ramon Tomazela, Tax Treaty Qualification of Income derived from Hybrid Financial Instruments, Bulletin for International Taxation 2013, Vol. 67, No. 10, sec. 4.1.; Eberhartinger / Six, p. 9; Martin Six, hybrid finance, sec. 2.; Jakob Bundgaard, perpetuals, p. 139; Marjaana Helminen, classification, p. 59; Marjaana Helminen, dividend concept, p. 178; Giuliani, Federico Maria, Article 10(3) of the OECD Model and Borderline Cases of Corporate Distributions, Bulletin for International Taxation 2002, Vol. 56, No. 1, p. 14; Michael Lang, hybrids, p. 112 and 127.

${ }^{1447}$ See footnote 1365. Also supported by Jakob Bundgaard, hybrids, p. 149; Michael Lang, introduction, p. 100, par. 280; Eberhartinger / Six, p. 9; Martin Six, hybrid finance, sec. 2.; Marjaana Helminen, classification, p. 58; Marjaana Helminen, dividend concept, p. 176; Giuliani, Federico Maria, Article 10(3) of the OECD Model and Borderline Cases of Corporate Distributions, Bulletin for International Taxation 2002, Vol. 56, No. 1, p. 14; Michael Lang, hybrids, p. 127; contrary: Gaspar Lopes Dias, debt-claims, sec. 3.1. and Jakob Bundgaard, perpetuals, p. 140 (both see footnote 1414).

${ }^{1448}$ See par. 273.

${ }^{1449}$ See par. 280.

${ }^{1450}$ Argumentum e contrario.

${ }^{1451}$ See par. 215 and 275.

${ }^{1452}$ See par. 279.
} 
however, it consequently provides in conjunction with the attribute participating in profits ${ }^{1453}$ the necessary clarification and specification to the debt-equity distinction. It leaves the business risk only in the form of termination risk as a residuum within the term other rights and therefore limb 2 of Art. 10(3) OECD MTC. This conclusion is in line with the finding ${ }^{1454}$ that the material underwriting risk in general and therefore also its specific subset of business risk is basically subsidiary to the formal redemption obligation requirement (form over substance).

283 These conclusions are also independent of the finding ${ }^{1455}$ that subordination and therefore business risk do not necessarily occur, wherever there is a participation in profits and losses. Subordination is merely one of multiple possible sources of business risk ${ }^{1456}$. Admittedly, these considerations appear to apply to the theoretical ideal-types of equity rights and debt-claims only, while there are countless variations in between ${ }^{1457}$. However, the methodological step of abstractly and textually interpreting Art. 10(3) OECD MTC has to be distinguished from that of concretely applying the provision (i.e. the case-by-case assessment of which variations are to be subsumed under the attribute participating in profits $)^{1458}$.

\section{The relevance of securitisation}

284 In order to ensure that limb 3 does not fall short, many commentators ${ }^{1459}$ take the position that limb 2 applies to securitised rights only ${ }^{1460}$. This requirement can however not be interpreted from the wording of limb 3 and also limb 1 was said to merely contain a non-exhaustive list of examples ${ }^{1461}$. Even more, Lang $^{1462}$ and Hongler ${ }^{1463}$ accurately refer to the rather general meaning of the term rights, being basically independent of domestic laws. In addition, systematic considerations do not necessitate such restriction ${ }^{1464}$ either. And finally, the OECD Commentaries ${ }^{1465}$ only refer "in the first instance" to stock-listed companies and therefore do not give an undisputable answer ${ }^{1466}$. That is why the securitisation requirement is typically justified by way of historic interpretation, in that it originated from Germany's pre-World-War-II DTC in order to be in line with its domestic taxation at that time ${ }^{1467}$. However, not only did this specific never find its way

\footnotetext{
${ }_{1453}$ See par. 270 .

${ }^{1454}$ See par. 241.

1455 See par. 219.

${ }^{1456}$ Cum hoc ergo propter hoc.

${ }^{1457}$ See par. 91 and Illustration 8 on p. 63.

${ }^{1458}$ See par. 72.

${ }^{1459}$ Haslehner, Werner in Klaus Vogel Commentaries 2015, p. 840, par. 101; Tischbirek, Wolfgang / Specker, Gerhard in Vogel/Lebner, p. 1217, par. 198; Kaeser, Christian / Wassermeyer, Franz in Wassermeyer Commentaries, p. 1319, par. 125, and p. 1326, par. 139, without justification; Klaus Vogel Commentaries 1997, p. 655, par. 198, merely referring to the OECD Commentaries; critically: Harris, Peter A. in IBFD Commentaries on Art. 10 OECD MTC, sec. 5.1.2.3., calling such restriction as "an unnecessary and superfluous limitation into the definition".

${ }^{1460}$ As will be explained and discussed in the following.

${ }^{1461}$ Equally: Hans Pijl, hybrid debts, sec. 4.9. and 6.; Michael Lang, hybrids, p. 122 et seq.

${ }^{1462}$ Michael Lang, hybrids, p. 122 et seq.

${ }^{1463}$ Peter Hongler, p. 244.

${ }^{1464}$ See par. $98(5)$.

${ }^{1465}$ OECD Commentaries 2014 on Art. 10 OECD MTC, p. C(10)-10, par. 24.

${ }^{1466}$ Equally: Hans Pijl, hybrid debts, sec. 4.9. and 6.

${ }^{1467}$ Haslehner, Werner in Klaus Vogel Commentaries 2015, p. 840, par. 101; Tischbirek, Wolfgang/Specker, Gerhard in Vogel/Lehner, p. 1217, par. 198; Avery Jones Commentaries, sec. 2.2.1. and 3.1.
} 
into even the earliest OECD MTC $1963^{1468}$, withdrawing this occurrence its historic significance ${ }^{1469}$; in any case the dynamic interpretation of Art. 10(3) OECD MTC ${ }^{1470}$ places more weight on the substance over form principle ${ }^{1471}$. As a consequence, it demands that the formal aspect of securitisation does not impact the material substance or nature of a dividend ${ }^{1472}$, just as the question of whether the company is publicly or privately held ${ }^{1473}$. And even if it did, the purpose, intention and function of Art. 10(3) OECD MTC deserved more importance than its historical interpretation, and eventually did not justify such a conclusion.

\subsubsection{Not being debt-claims}

285 The negating insertion not being debt-claims was found leaving the aspect of business risk in the form of termination risk as a residuum within the term other rights and therefore limb 2 of Art. 10(3) OECD MTC ${ }^{1474}$. In the absence of a logical equivalent within limb 2 of Art. 10(3) OECD MTC ${ }^{1475}$, the term debt-claims represents the natural complement to the term dividends. On the one hand, the word debt etymologically originates from the Latin word débitum ("thing owed"). This term stems from the root word débere ("to owe") as a contraction of debibere ("to have from" or "to keep away from"), which combines the particles de ("from" or "away") and haberre ("to have") ${ }^{1476}$. The word claim originates from the Latin word clämäre ("to call") $)^{1477}$. Effectively it descends from its French version, which had been concretised into the meaning of a "thing demanded" ${ }^{1478}$. The original meanings of these terms were thus already associated with a specifically dissociating and involuntary denotation. This is even more evident in the term interest, as implied by the term debt-claim due to the transaction-based approach ${ }^{1479}$. The word interest originates from the identical Latin word and actually combines the particles inter ("between") and est ("it is") ${ }^{1480}$. However, this word does not descend directly from Latin either but indirectly from its French version. It had been concretised from its original denotation of "it is of importance" or "it makes a difference" into the meaning of "damage", "loss" or "harm" and was already used at that time in the financial sense of "money paid for the use of money lent" or "compensation due from a defaulting debtor". ${ }^{1481}$ In contrast, the word dividend originates from the Latin word dividère ("spread apart" or "cleave" or "distribute") $)^{1482}$ and combines the particles dis ("asunder" or "apart" or "in two") and viedere ("to separate") ${ }^{1483}$. This etymology conversely demonstrates that the term dividend is associated with a specifically participating and voluntary denotation. In that sense, the negating insertion not being debt-claims represents the source of literal or textual interpretation and therefore the justification for

\footnotetext{
$\overline{1468}$ OECD, Draft Convention for the Avoidance of Double Taxation with respect to Taxes in Income and Capital, Paris, 30 July 1963.

${ }^{1469}$ Tischbirek, Wolfgang / Specker, Gerhard in Vogel/Lehner, p. 1217, par. 198; Klaus Vogel Commentaries 1997, p. 655, par. 198.

${ }^{1470}$ See par. 35 .

1471 See sec. 2.2.4.

${ }^{1472}$ Kopp, Karin E.M. in Wolfgang Schön, equity and debt, p. 868; Martin Six, jouissance rights, p. 111.

${ }^{1473}$ Haslehner, Werner in Klaus Vogel Commentaries 2015, p. 840, par. 101.

${ }^{1474}$ See par. 282.

${ }^{1475}$ See par. 273.

${ }^{1476} \mathrm{https}: / /$ en.wiktionary.org/wiki/debt and www.etymonline.com/index.php?term=debt (last retrieved on 15 September 2017).

1477 https://en.wiktionary.org/wiki/claim (last retrieved on 15 September 2017).

${ }^{1478}$ www.etymonline.com/index.php?term=claim (last retrieved on 15 September 2017).

${ }^{1479}$ See par. 53.

${ }^{1480}$ https://en.wiktionary.org/wiki/interest (last retrieved on 15 September 2017).

${ }^{1481}$ www.etymonline.com/index.php?term=interest (last retrieved on 15 September 2017).

${ }^{1482}$ https://en.wiktionary.org/wiki/dividend (last retrieved on 15 September 2017).

${ }^{1483}$ www.etymonline.com/index.php?term=dividend (last retrieved on 15 September 2017).
} 
the criterion of voluntariness ${ }^{1484}$. It excludes its logical complement of involuntariness ${ }^{1485}$ from Art. 10(3) OECD MTC, elevating voluntariness to the status of a verifier for dividends ${ }^{1486}$. In other words: voluntariness represents a sufficient maximum condition (conditio per quam) for constituting dividends, without however being necessarily the only one of that kind (no exclusivity).

\subsection{Interest}

\subsubsection{Structure of the provision}

"The term 'interest' as used in this Article means income from debt-claims of every kind, whether or not secured by mortgage and whether or not carrying a right to participate in the debtor's profits, and in particular, income from government securities and income from bonds or debentures, including premiums and prizes attaching to such securities, bonds or debentures. Penalty charges for late payment shall not be regarded as interest for the purpose of this Article."

287 Like Art. 10(3) OECD MTC ${ }^{1487}$, Art. 11(3) OECD MTC represents a "means" definition ${ }^{1488}$ as well, and contains a casuistic list or catalogue of typical examples empirically encountered in most OECD member states $^{1489}$. Unlike limb 1 of Art. 10(3) OECD MTC ${ }^{1490}$, the majority of commentators consider it nevertheless as exhaustive ${ }^{1491}$. Admittedly, the OECD originally considered that "in any case, the Article does not give a complete and exhaustive list of the various kinds of interest", as "such a list might not be fully in harmony with the various States' laws, which may differ among themselves in their interpretation of the concept of interest"1492. However, the only consequence drawn was that "it therefore seems preferable to include in a general formula $[\ldots]]^{1493}$, which was obviously put in practice to the provision's present shape.

\footnotetext{
${ }^{1484}$ See par. 188.

${ }^{1485}$ See par. 289.

${ }^{1486}$ In result equally: Wolfgang Schön, comparative analysis, p. 199 et seq.; Sven-Eric Bärsch, p. 76; Peter Hongler, p. 45; Marjaana Helminen, dividend concept, p. 166.

${ }^{1487}$ See par. 256.

${ }^{1488}$ Hans Pijl, hybrid debts, sec. 3.2., according to whom "only the necessary is said"; Martin Six, hybrid finance, sec. 3.; Klaus Vogel Commentaries 1997, p. 731, par. 56.

${ }^{1489}$ Jakob Bundgaard, hybrids, p. 144; Haslehner, Werner in Klaus Vogel Commentaries 2015, p. 925, par. 87; Pöllath, Reinhard / Lohbeck, Allit in Vogel / Lehner, p. 1320, par. 60; Wassermeyer, Franz in Wassermeyer Commentaries, p. 1430, par. 79; Hans Pijl, interest, sec. 6.1.; Eberhartinger/Six, p. 9; Martin Six, hybrid finance, sec. 3.; Hans Pijl, hybrid debts, sec. 3.2., according to whom the current structure of the provision appears to have its origin in being "more or less a common denominator of the existing interest definitions in tax treaties of the 1950s”; Jakob Bundgaard, perpetuals, p. 91.; Achim Pross, p. 174.

${ }^{1490}$ See par. 260.

${ }^{1491}$ Jakob Bundgaard, hybrids, p. 144; Helminen, Marjaana in IBFD Commentaries on Art. 11 OECD MTC, sec. 5.1.1.1.3.; Gaspar Lopes Dias, debt-claims, sec. 1.3.; Gaspar Lopes Dias, tax arbitrage, p. 117; Haslehner, Werner in Klaus Vogel Commentaries 2015, p. 923, par. 83; Pöllath, Reinhard/Lobbeck, Allit in Vogel/Lehner, p. 1318, par. 56, and p. 1320, par. 59a; ; Wassermeyer, Franz in Wassermeyer Commentaries, p. 1427, par. 71; OECD Commentaries 2014 on Art. 11 OECD MTC, p. C(11)-12, par. 21; Peter Hongler, p. 254; Hans Pijl, hybrid debts, sec. 2.2.2.; Eberhartinger/Six, p. 9; Martin Six, hybrid finance, sec. 3.; Achim Pross, p. 174; OECD, Taxation of new Financial Instruments, OECD, Paris, 1994, p. 33, par. 142; Klaus Vogel Commentaries 1997, p. 732, par. 59.

${ }^{1492}$ OEEC (Working Party No. 11 of the Fiscal Committee), Fourth Report on the Taxation of Interest, ref. FC-WP11(61)1, Paris, 1961, p. 9 et seq.

${ }^{1493}$ OEEC (Working Party No. 11 of the Fiscal Committee), Fourth Report on the Taxation of Interest, ref. FC-WP11(61)1, Paris, 1961, p. 10
} 
288 The majority of commentators ${ }^{1494}$ further take the position that the provision including the term debt-claim ${ }^{1495}$ is to be interpreted autonomously. This is also supported by the fact that the original extending reference to the domestic tax law was removed in $1977^{149}$. Notably, this reference in the OECD MTC $1963^{1497}$ was not the result from the conclusion that an exhaustive list or definition of interest was not possible ${ }^{1498}$. Rather, it was owed to political considerations by the OEEC Fiscal Committee overruling Working Party No. 11, which had been aiming for an autonomous definition ever since ${ }^{1499}$. Thus, it might even be suggested that the current remainder of the definition in Art. 11(3) OECD MTC has not been closed by the removal of that reference but was always closed from its very first introduction. In result, today's Art. 11(3) OECD MTC presents itself as a short but positive and general definition equivalent to limb 2 of Art. 10(3) OECD MTC ${ }^{1500}$. It is subject of a closed and autonomous interpretation in its entirety, followed by a list or catalogue of typical examples equivalent to limb 1 of Art. 10(3) OECD MTC ${ }^{1501}$.

\subsubsection{Debt-claims}

\section{The relevance of self-execution}

289 A dissociating and involuntary denotation of both terms debt-claims and interest ${ }^{1502}$ was found to be suggested by their very etymology, justifying the criterion of involuntariness as the logical complement of voluntariness by way of literal or textual interpretation. The criterion of involuntariness elevates in turn to the status of a necessary minimum condition (conditio sine qua non) for debt-claims and consequently also for interest ${ }^{1503}$. This criterion is represented by the redemption obligation ${ }^{1504}$ (debt-claim test) in the sense of an absolute and unconditional ${ }^{1505}$ legal right to be repaid. According to the view represented in this study, the material test for such formal feature is the criterion of self-execution ${ }^{1506}$. The subsequent formal questions whether ${ }^{1507}$

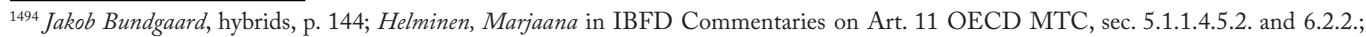
Gaspar Lopes Dias, debt-claims, sec. 1.3. and 2.3.; Gaspar Lopes Dias, tax arbitrage, p. 117 and 122; Haslehner, Werner in Klaus Vogel Commentaries 2015, p. 923, par. 83; Wassermeyer, Franz in Wassermeyer Commentaries, p. 1427, par. 71; OECD Commentaries 2014 on Art. 11 OECD MTC, p. C(11)-35, par. 21; Avery Jones Commentaries, sec. 4; Eberhartinger / Six, p. 9; Martin Six, hybrid finance, sec. 3.; Jakob Bundgaard, perpetuals, p. 139; German Bundesfinanzhof, judgement ref. I B 47/05, 2006; Michael Lang, hybrids, p. 109 and 120; OECD, Consolidated List of outstanding Points concerning the OECD Draft Convention on Income and Capital, ref. TFD/FC/218, Paris, 1967, p. 33, sec. A; contrary: Achim Pross, p. 175 et seqq.; Canadian Federal Court of Appeal, judgement ref. A-147-80, 1981, par. 16., in fact referring to Art. 3(2) OECD MTC without, however, providing further justification, particularly with regard to whether or not the exception rule unless the context otherwise requires may apply (see par. 14).

${ }^{1495}$ Peter Hongler, p. 57; Fehér, Tamás in Eva Burgstaller, p. 247; contrary: Michael Lang, hybrids, p. 97 (see par. 184).

${ }^{1496}$ OECD Commentaries 2014 on Art. 11 OECD MTC, p. C(11)-35, par. 21; OEEC Fiscal Committee, Minutes of the 22 $2^{\text {nd }}$ session held at the Château de la Muette, Paris, on Tuesday $17^{\text {th }}$, Wednesday $18^{\text {th }}$, Thursday $19^{\text {th }}$ and Friday $20^{\text {th }}$ January 1961 , ref. FC-M(61)1, Paris, 1961, p. 12; OEEC (Working Party No. 11 of the Fiscal Committee), Third Report on the Taxation of Interest, ref. FC-WP11(60)2, Paris, 1960, p. 3.

${ }^{1497}$ OECD, Draft Convention for the Avoidance of Double Taxation with respect to Taxes in Income and Capital, Paris, 30 July 1963.

${ }^{1498}$ Hans Pijl, hybrid debts, sec. 2.2.1. et seq. and 3.3.

${ }^{1499}$ Fuentes Hernandez, Daniel in Thomas Ecker, p. 462.

${ }^{1500}$ See par. 257 et seq.

${ }^{1501}$ See par. 260.

${ }^{1502}$ See par. 285.

${ }^{1503}$ Argumentum e contrario.

${ }^{1504}$ Jakob Bundgaard, hybrids, p. 144 et seq.; Sven-Eric Bärsch, p. 76; Peter Hongler, p. 45 et seqq.; Marjaana Helminen, dividend concept, p. 166; See also par. 241.

${ }^{1505}$ Haslehner, Werner in Klaus Vogel Commentaries 2015, p. 924, par. 84; Sven-Eric Bärsch, p. 106; Carmine Rotondaro, redemption, p. 264 et seqq.; contrary: Gaspar Lopes Dias, tax arbitrage, p. 130, mixing legal and business risk by saying that "there is no such thing as an 'absolute and unconditional' right to repayment that admits the possibility of total loss" (see par. 231). See also par. 235(1) and 237(1).

${ }^{1506}$ Similarly: William Plumb, p. 431.

${ }^{1507}$ Jakob Bundgaard, hybrids, p. 144; Gaspar Lopes Dias, debt-claims, sec. 2.3. and 3.3.; Gaspar Lopes Dias, tax arbitrage, p. 117, 122 and 130; Haslehner, Werner in Klaus Vogel Commentaries 2015, p. 923, par. 84; Kubn / Hachmeister, p. 12, par. 61; Kopp, Karin E.M. in Wolfgang
} 
or not ${ }^{1508}$ a legal enforceability is required to constitute a redemption obligation and whether such legal enforceability had to be determined pursuant to domestic tax $l a w^{1509}$, are therefore not relevant for the further course of this analysis.

290 In contrast to the context of Art. 10(3) OECD MTC ${ }^{1510}$, in the context of Art. 11(3) OECD MTC selfexecution includes also the participation in profits. In other words: income from debt-claims can only be interest where also a participation in profits is self-executing. On the one hand, profit and loss is basically a resultative and therefore binary concept ${ }^{1511}$, being formally determined by domestic law ${ }^{1512}$. Its aspect of quantitative proximity and characteristics must be (re-)interpreted as a multi-static array of unlimited forms or states in the sense of a flexible or fluid "more or less" spectrum to make it meaningful and significant for treaty purposes ${ }^{1513}$. On the contrary, its qualitative aspect of obtaining the genuine power to decide whether or not there shall be distribution (voluntariness) must necessarily remain an absolute and binary criterion of "yes or no" 1514 . In other words: any profit and loss equivalent ${ }^{1515}$ above the "total profits line" cannot possibly be featured with genuine corporate voluntariness. In contrast, any true participation in the genuine profits and losses below the "total profits line" is entitled to the legal shareholders only. Any further transfer of these formally determined profits and losses is necessarily a different legal relationship between these shareholders and third parties (e.g. sub-participation). As such, it is outside the company's or entity's sphere and consequently out of scope for potential ("hybrid") financial instruments. On the other hand, any other conclusion would again mean letting Art. 11(3) OECD MTC fall short entirely. In fact, such result would not only ignore the term interest. It would also lead to the self-contradiction that the voluntariness in the attribute participating in profits would actually negate its previous term debt-claims instead of extending it. In result, the attribute participating in profits not only has a different legal quality ${ }^{1516}$ and a different legal consequence ${ }^{1517}$; it also has a different legal the meaning within Art. 11(3) OECD MTC in the sense of self-executive, as compared to Art. 10(3) OECD MTC in the sense of voluntary.

291 Nevertheless, this aspect appears to be of minor practical relevance. A rational investor in a financial instrument with redemption obligation ${ }^{1518}$ will not accept an arrangement that puts the remuneration at the discretion of the debtor. The reason is that the redemption obligation is an expression of a subjacent conflict of interests between the two contracting parties ${ }^{1519}$, which does not only refer to the capital or principal but naturally also to the remuneration. In other words: as much as interest and its principal are payments to "someone else" and

Schön, equity and debt, p. 870; Fehér, Tamás in Eva Burgstaller, p. 245; David Hariton, equity and debt, p. 523; Michael Lang, hybrids, p. 96.

${ }^{1508}$ Kemmeren, Eric C.C.M. in Klaus Vogel Commentaries 2015, p. 712, par. 11.

${ }^{1509}$ Gaspar Lopes Dias, debt-claims, sec. 2.3. and 3.3.; Jakob Bundgaard, perpetuals, p. 140.

${ }^{1510}$ See par. 285.

${ }^{1511}$ See par. 204.

${ }^{1512}$ See par. 246.

${ }^{1513}$ See par. 207.

${ }^{1514}$ See par. 219.

1515 See par. 202 et seq.

${ }^{1516}$ See par. 273.

${ }^{1517}$ See par. 280.

${ }^{1518}$ See par. 289.

${ }^{1519}$ See par. 192. 
therefore involuntary, dividends and their equity are payments to "oneself" and therefore voluntary. ${ }^{1520}$ Whether or not an involuntary remuneration depends on further objective circumstances or resolutive conditions ${ }^{1521}$ is merely a subsequent question towards the time value of money ${ }^{1522}$, but not backwards to a classification as a dividend pursuant to Art. 10(3) OECD MTC. That is why voluntariness represents a verifier for dividends ${ }^{1523}$, whereas involuntariness is not in turn a verifier for interest.

\section{The limitations of debt-claims}

292 Pursuant to the IAS/IFRS understanding and rationale, the obligatory character does not only include certain redemptions ${ }^{1524}$ but also repurchase obligations ${ }^{1525}$ (substance over form). On the one hand, this view conflicts with the finding ${ }^{1526}$ that disaggregation as a material aspect of substance is necessarily subsidiary to the formal redemption obligation requirement (form over substance). This was a consequence from the position that the existence of financial instruments must predominantly be a matter of the legal form ${ }^{1527}$. On the other hand, it also conflicts with the finding ${ }^{1528}$ that aggregation is subject to particularly strict requirements, justifying to go beyond the literal or textual interpretation only as an absolute exception. Any consolidation of an asset or transaction upwards from its legal form was said not to be justifiable by the substance over form principle. In other words: the literal and textual interpretation of the term debt-claim does not allow disaggregation in the broader sense $\mathrm{e}^{1529}$. Accordingly, the law application by way of aggregation in the narrow sense does not allow the consolidation of the resale and the repurchase either. Hence, the term debt-claim does not cover repurchase obligations ${ }^{1530}$ (e.g. „wash sales “1531 ${ }^{\text {, Islamic finance }}{ }^{1532}$, etc.). This view is supported by the fact that the UN Commentaries on Art. 11(3) UN MTC refer to the OECD Commentaries on Art. 11(3) OECD MTC only as a basic principle ${ }^{1533}$. As an exception, they provide, however, the explicit addition of "certain non-traditional financial arrangements [...] assimilated to debt relations under domestic tax law [...]"1534, "[...] for instance, to Islamic financial instruments where the economic reality of the contract underlying the instrument is a loan" ${ }^{1535}$. In that, the term interest employed by Art. 11(3) UN MTC is actually broader Joseph, Anton, Islamic Finance, Derivatives \& Financial Instruments 2010, Vol. 12, No. 1, sec. 2 et seq.; UN Committee of Experts on International Cooperation in Tax Matters, Treatment of Islamic financial instruments under the United Nations Model Double Taxation Convention between Developed and Developing Countries - Note by the Working Group on Treatment of Islamic Financial Instruments (third Session in Geneva from 29 October - 2 November 2007), ref. E/C.18/2007/9, UN Economic and Social Council, Geneva, 2007. 
by incorporating domestic concepts as well. In contrast, Art. 11(3) OECD MTC employs an integrated and cohesive term which is exclusively to be interpreted autonomously ${ }^{1536}$.

\section{The relevance of risk}

293 There is broad consensus that income from debt-claims bearing business risk is not interest ${ }^{1537}$ and that remuneration risk alone is not considered business risk ${ }^{1538}$. Business risk is basically understood in a broader sense here, being also represented by and contained within the participation in profits and losses ${ }^{1539}$. However, the consensus view is supported by the above conclusions that the participation in profits and losses including the business risk contained therein - can itself not serve as a differentiator for the distinction between Art. 10(3) and 11(3) OECD MTC ${ }^{1540}$. In other words: where the remuneration cannot contribute to the debt-equity distinction, this must also be true for the remuneration risk. Instead, business risk was found to be the key differentiator only in its form of termination risk ${ }^{1541}$. Correspondingly, the red line in the sense of a falsifier for debt-claims pursuant to Art. 11(3) OECD MTC is where the creditor starts to participate in the business opportunities by way of liquidation proceeds (i.e. goodwill) or hidden reserves ${ }^{1542}$. This view is supported by the fact that Art. 11(3) OECD MTC, although applying the asset-based approach ${ }^{1543}$, only mentions the participation in profits. This can in turn be interpreted in the sense that a participation in risks and chances (i.e. termination risk) is not part of the extended definition of the term debt-claims ${ }^{1544}$. However, the economic participation in business risk by means of credit risk alone ${ }^{1545}$ is considered not to be sufficient for bearing business risk ${ }^{1546}$. This is in line with the understanding that credit risk as a legal risk must necessarily be subject of form over substance ${ }^{1547}$. Or, as it has been accurately formulated: "Nevertheless, while the distinction between risk capital and a risky loan is an 'elusive categorization,' it is one which the law requires to be made." 1548

\section{The relevance of a remuneration}

294 In order to qualify as interest, the literature suggests

(1) a remuneration ${ }^{1549}$

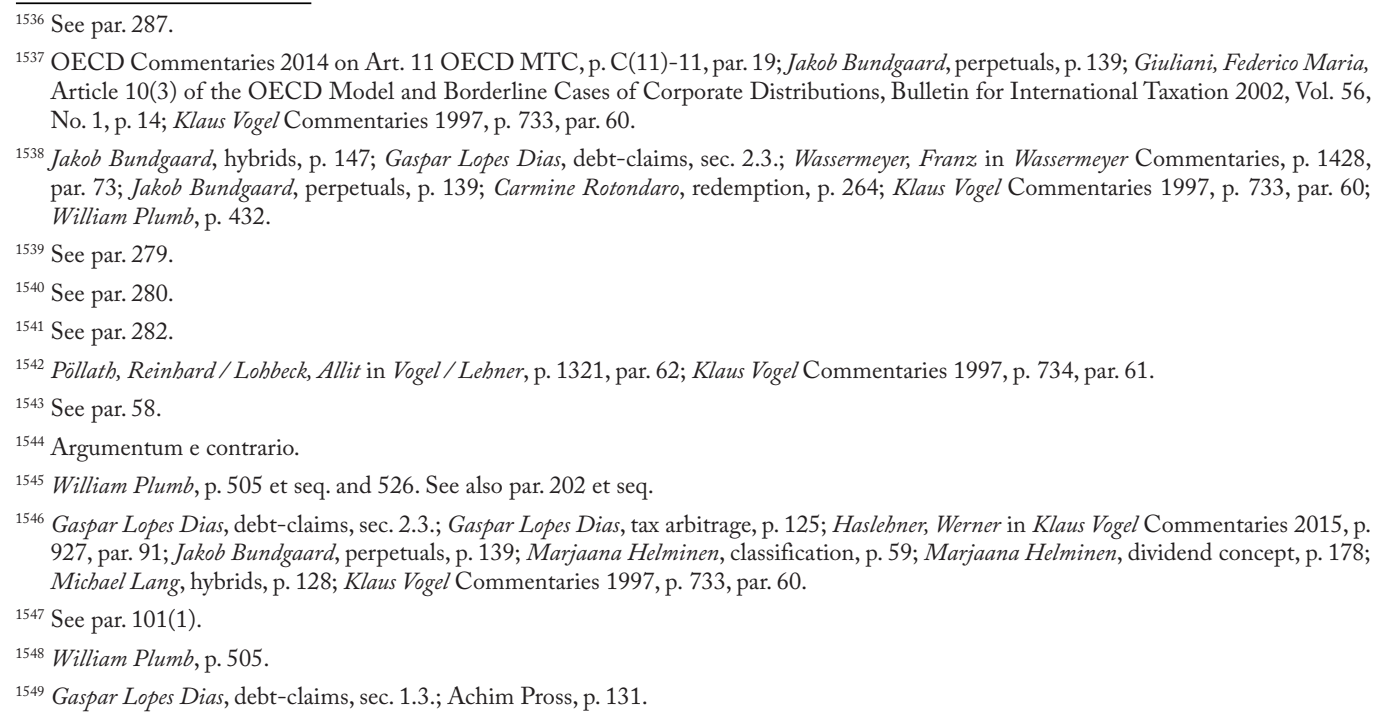


(2) for the temporary ${ }^{1550}$ provision of capital as principal ${ }^{1551}$ in the sense of an economical ${ }^{1552}$ transfer of such capital at the disposal of the debtor,

(3) based on a nominal value $\mathrm{e}^{1553}$.

295 From the author's point of view, the first aspect (1) is redundant. On the one hand, the attribute is already covered by that of the income. This income is also the trigger for activating Art. 11(3) OECD MTC at all, so that there appears to be no need for another synonymous criterion. On the other hand, anything else would not be reasonable and would give rise to considerable systematic distortions. In case the remuneration were to be interpreted domestically, this would conflict with the autonomous interpretation of Art. 10(3) OECD MTC. In case the remuneration were to be interpreted autonomously, this would conflict with the domestic interpretation of the term income $e^{1554}$. But even if the remuneration was meant in the sense of mere potential income, the principal necessity and feasibility of classifying financial instruments into the distributive articles of the OECD MTC is independent of the amounts actually paid and consequently from any income at all ${ }^{1555}$. In other words: a time value of money in the amount of zero makes a capital provision not less a debt-claim (e.g. zero-interest bond) ${ }^{1556}$. Consequently, the classification as a debt-claim is independent of whether its remuneration is fixed or floating ${ }^{1557}$. In addition, variable ${ }^{1558}$ and/or irregular ${ }^{1559}$ payment profiles were not necessarily found to be in conflict with the time value of money either. And lastly, the extended definition of debt-claims in Art. 11(3) OECD MTC by the attribute whether or not carrying a right to participate in the debtor's profits must cover all amount modifications admissible for shares pursuant to Art. 10(3) OECD MTC ${ }^{1560}$ in order to ensure systematically equivalent results ${ }^{1561}$. Importantly, this should, however, not be understood to mean that the remuneration was generally irrelevant for the classification of financial instruments. It only means that it is already covered by the existing income criterion. Consequently, it is in fact this actual income once having been paid which is eventually subject of such classification. The expectable income ${ }^{1562}$ during the financial instrument's remaining lifetime serves merely as an ancillary consideration ${ }^{1563}$.

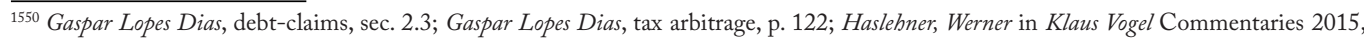
p. 924, par. 85; Pöllath, Reinhard / Lobbeck, Allit in Vogel / Lehner, p. 1318, par. 56; Wassermeyer, Franz in Wassermeyer Commentaries, p. 1431, par. 79; Kopp, Karin E.M. in Wolfgang Schön, equity and debt, p. 846; Carmine Rotondaro, redemption, p. 265; Achim Pross, p. 131.

${ }^{1551}$ Jakob Bundgaard, hybrids, p. 145; Gaspar Lopes Dias, debt-claims, sec. 1.3.; Pöllath, Reinhard/Lohbeck, Allit in Vogel/Lehner, p. 1291, par. 56; Wassermeyer, Franz in Wassermeyer Commentaries, p. 1431, par. 79; Achim Pross, p. 130; Arnold, Brian J., Deductibility of Interest and other financing Charges in computing Income - General Report, Series IFA Cahiers 1994, Vol. 79a, International Fiscal Association, Rotterdam, 1994, p. 497.

${ }^{1552}$ Michael Lang, hybrids, p. 96 et seq.

${ }^{1553}$ Gaspar Lopes Dias, debt-claims, sec. 1.3.; Gaspar Lopes Dias, tax arbitrage, p. 123; Michael Lang, hybrids, p. 129.

${ }^{1554}$ See par. 144.

${ }^{1555}$ See par. 201.

${ }^{1556}$ See par. 103 and 215.

${ }^{1557}$ Helminen, Marjaana in IBFD Commentaries on Art. 11 OECD MTC, sec. 5.1.1.3.1.; Gaspar Lopes Dias, tax arbitrage, p. 124; Hans Pijl, interest, sec. 6.1.; Hans Pijl, hybrid debts, sec. 3.2; Fehér, Tamás in Eva Burgstaller, p. 245.

${ }^{1558}$ See par. 208 and Example 33 on p. 123.

${ }^{1559}$ See par. 211 et seq.

${ }^{1560}$ See par. 274 et seqq.

${ }^{1561}$ See par. 113(1).

${ }^{1562}$ See par. 278.

${ }^{1563}$ See par. 214.
} 


\section{The relevance of a temporary provision of capital}

296 As regards the second aspect $(2)^{1564}$, the author basically shares the principal view that financial instruments can be considered debt-claims only if they represent ex ante a temporarily limited provision of capital. This is an expression of the redemption obligation requirement ${ }^{1565}$ and the concept of time value of money ${ }^{1566}$ under the dynamic forward-looking view ${ }^{1567}$, meaning only redemptions prior to the issuer's liquidation ${ }^{1568}$. However, this may not lead to the conclusion that there was any absolute temporal concept such as a fixed deadline. The absence of a duration or maturity was principally found incapable of being a differentiator ${ }^{1569}$. In addition, the duration of legal time periods can only be reduced by way of economic interpretation but not extended ${ }^{1570}$. Instead, the specific temporal concept of duration or maturity of the principal should rather be understood relatively by that of remuneration. Following the systematic interpretation of time aspects in general, it means the point in time in which the right on the return of the principal mathematically starts to account for less than the right on the remuneration.

Example 45: A zero-interest bond never amortises and therefore must basically be considered long-term. Where such economically interpreted duration or maturity (i.e. $\infty$ ) is, however, longer than its legal one (e.g. 1 year), it cannot be extended. The final interpretation result in this example is therefore 1 year.

A high-yield bond (e.g. 10\% per annum) amortises quickly and therefore must basically be considered short-term. Where such economically interpreted duration or maturity (i.e. 7 years ${ }^{1571}$ ) is, however, shorter than its legal one (e.g. 10 years), it is reduced. The final interpretation result in this example is therefore 7 years.

297 The transfer of the capital as principal at the disposal of the debtor ${ }^{1572}$ may not be a mere economic one but must necessarily be a legal one in order to trigger Art. 11(3) OECD MTC ${ }^{1573}$. On the one hand, matters of attribution and ownership other than beneficial ownership were found inaccessible to the treaty principle of substance over form but must rather follow the legal form (i.e. form over substance). ${ }^{1574}$ This was a result from the systematic considerations that there cannot possibly be such a thing as "economic ownership" in Art. 11(3) OECD MTC. Accordingly, the capital or principal cannot be transferred from its mere beneficial owner to the debtor in order to trigger Art. 11(3) OECD MTC either, since beneficial ownership is the legal consequence of the provision and therefore cannot simultaneously be its precondition ${ }^{1575}$. On the other hand, the asset (i.e. the debt-claim) is basically the result of the transaction (i.e. the transfer of the capital as principal) and not

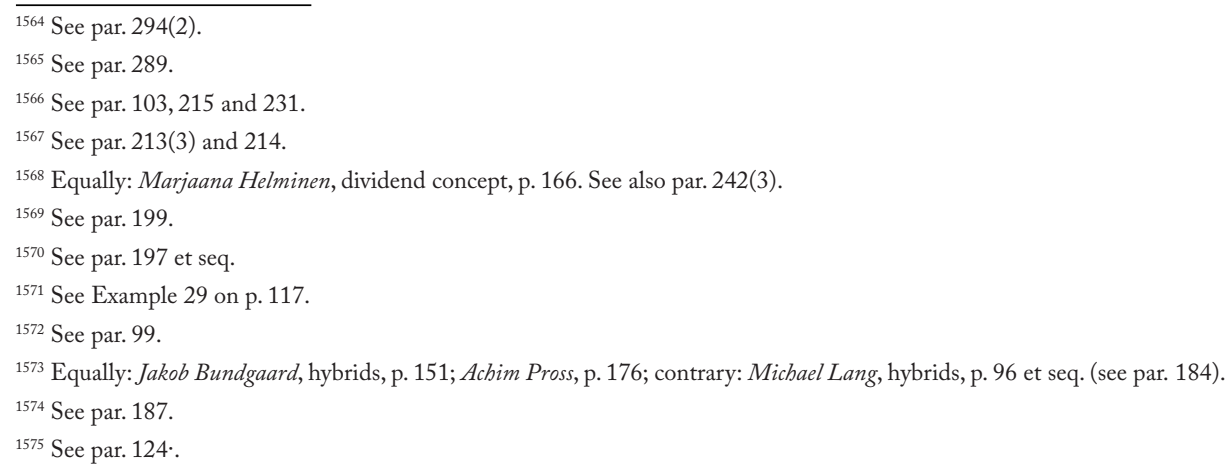


vice versa ${ }^{1576}$. The consequent domestic interpretation of both the transfer of the capital or principal as such and its subsequent attribution gives rise to potential qualification conflicts ${ }^{1577}$. This result applies regardless of the admissible forms of transferable capital or principal (e.g. where capital or principal is a debt-claim itself, i.e. securities lending) $)^{1578}$. This is because Art. 11(3) OECD MTC is not interpreted iteratively by referring back to its own legal consequences ${ }^{1579}$. Instead, it must necessarily assess its legal requirements and conditions autonomously and independently from the same starting point, regardless of whether or not some attributes are themselves subject of a treaty. Otherwise such a classification chain could establish triangular relationships.

\section{The relevance of a nominal value}

298 As regards the third aspect $(3)^{1580}$, the nominal value is the legal value formally represented by a financial instrument. Financial instruments are typically, but not necessarily, featured with an ex-ante determinable, nominal value in order to make them self-executive ${ }^{1581}$. For debts, the nominal value usually, but not necessarily, represents their principal or redemption value. This redemption value can however be understood in a narrow sense of a fixed absolute face amount with a currency unit, or alternatively in a broad sense of any specified capital transferred for lending. The distinction between these two is fluid, as the examples of pool factor bonds, percentage- or yield-traded bonds or bonds in non-deliverable currencies demonstrate. On the one hand, the criterion of a nominal value appears to be merely a formal one, especially since the redemption value can principally differ from the nominal value ${ }^{1582}$. On the other hand, the concept of nominal value even in its broadest understanding represents a kind of logical link between the receive leg of what the creditor transfers to the debtor for lending and the pay leg of what the debtor owes in return to the creditor as the repayment. In contrast, where there is no such link (e.g. a tracker certificate ${ }^{1583}$ ) there can by definition not possibly be any provision of capital ${ }^{1584}$. This view is supported by the fact that penalty charges, which do not compensate capital provisions, are consequently not regarded as interest pursuant to Art. 11(3) OECD ${ }^{1585}$.

299 This understanding of the nominal value requirement further supports the finding ${ }^{1586}$ that a mere notional or floating principal is a falsifier for debt-claims ${ }^{1587}$ but might rather be one indicator or even verifier for other income. In other words: the criterion of a nominal value abstractly implies and demonstrates a certain determination and fixation of the redemption value. In the most ambiguous class of equity "derivatives"1588, this fixation leads in fact to the leg modes. True, the fixed-for-fixed and the fixed-for-variable conditions

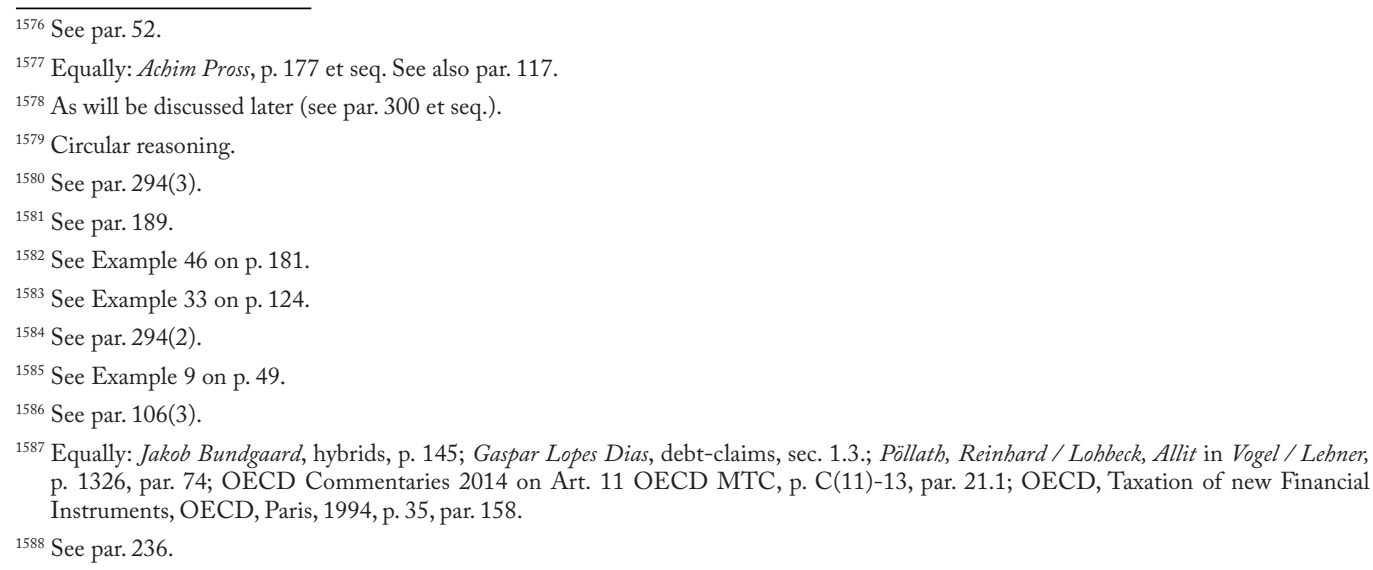


are contrary in terms of transferring the issuer's or debtor's economic resources ${ }^{1589}$ and thus business risk. However, both conditions always have a nominal value. Under the fixed-for-fixed condition, the repayment value the debtor owes to the creditor (pay leg) is fixed and therefore directly linked to what the creditor had previously transferred to the debtor for lending (receive leg). Under the fixed-for-variable condition the pay leg is variable, but nevertheless equal to the same value and therefore is indirectly linked to the receive leg. In contrast, under the variable-for-fixed condition the receive leg and the pay leg are typically self-executive by way of a mathematical formula ${ }^{1590}$, but neither directly nor indirectly linked to each other. That this relation is actually floating is the very reason why such financial instruments bear termination risk ${ }^{1591}$. For these reasons, the author agrees to the formal criterion of a nominal value. As a conclusion for the further course of this study, this nominal value is, however, understood in the broad sense of any capital specified for repayment, which is either directly linked or at least equal to the same value and therefore is indirectly linked to what the creditor transfers to the debtor for lending. From the systematical point of view, the formal criterion of a legal nominal value is nevertheless included or covered and therefore should preferably be replaced by the material differentiator of termination risk.

\subsubsection{Of every kind}

\section{Non-cash obligations}

300 Pursuant to the OECD Commentaries, interest "is generally taken to mean remuneration on money lent"1592 in that "the term 'debt-claims of every kind' obviously embraces cash deposits and security in the form of money"1593. Most commentators refer to these phrases, leaving however open whether the meaning of the word debt-claim is actually limited to cash obligations only ${ }^{1594}$ or also includes non-cash obligations. At first glance, the scope of application and therefore the relevance of that question appears to be limited.In fact, many similar legal transactions fall under other distributive articles of the OECD MTC ${ }^{1595}$ (e.g. rentals, royalties, instalment payments, leases, guarantees, etc.). Nevertheless, the issue gains in importance considering that many classes of financial instruments (e.g. convertibles, payment-in-kind bonds, securities lending, swaps, etc.) are effectively featured with alternative redemption or termination rights (e.g. physically, conversion, etc.). This raises at least the question as to whether Art. 11(3) OECD MTC requires a cash obligation or a cash redemption or even both. According to the author's point of view, the meaning of the word debtclaim is not limited to cash but also includes non-cash obligations ${ }^{1596}$. This is the result from the following considerations:

301 On the one hand, the express wording of Art.11(3) OECD MTC demands a broad interpretation of the term debt-claims ${ }^{1597}$, comprehensively encompassing those of every kind. Also the clear and explicit wording of those

\footnotetext{
1589 See par. 238(2).

${ }^{1590}$ Marjaana Helminen, dividend concept, p. 166.

${ }^{1591}$ See par. 242(2) and 293.

${ }^{1592}$ OECD Commentaries 2014 on Art. 11 OECD MTC, p. C(11)-1, par. 1.

${ }^{1593}$ OECD Commentaries 2014 on Art. 11 OECD MTC, p. C(11)-11, par. 18.

${ }^{1594}$ Pöllath, Reinhard / Lobbeck, Allit in Vogel/Lehner, p. 1318, par. 56.

${ }^{1595}$ Klaus Vogel Commentaries 1997, p. 738, par. 67, and p. 739, par. 68.

${ }^{1596}$ Contrary: Wassermeyer, Franz in Wassermeyer Commentaries, p. 1440, par. 91, without justification.

${ }^{1597}$ Jakob Bundgaard, hybrids, p. 144; Helminen, Marjaana in IBFD Commentaries on Art. 11 OECD MTC, sec. 5.1.1.3.1.; Haslehner, Werner in Klaus Vogel Commentaries 2015, p. 923, par. 84; Wassermeyer, Franz in Wassermeyer Commentaries, p. 1430, par. 79; Kopp, Karin
} 
aforementioned phrases in the OECD Commentaries ${ }^{1598}$ does not justify a more restrictive understanding. They are rooted in OEEC Working Party No. 11, according to which "in general meaning of the term 'interest' it is proper to include remuneration on money lent ${ }^{\text {“1599 }}$, making its non-exclusive denotation even more evident. On the other hand, any limitation to cash obligations would actually require a distinction between cash and non-cash capital. This would, however, lead to the circular reasoning that debt-claims as the most proximate equivalent to cash (e.g. demand deposits, short-term call money, debit or credit cards, complementary currencies, etc.) are themselves the legal consequence of Art. 11(3) OECD MTC.Therefore, they cannot simultaneously be a precondition for their application. The reason for this natural similarity of cash and debt is that any currency is itself a claim against its issuing central bank. As was stated, Art. 11(3) OECD MTC is not interpreted iteratively by referring back to its own legal consequences ${ }^{1600}$. In addition, any ringfencing of financial instruments, except where expressly or systematically required, is unpurposeful ${ }^{1601}$ and methodologically flawed ${ }^{1602}$. This becomes even more evident when considering that such ring-fencing is dispensable for the systematical and interpretational definition and delimitation of the term debt-claims ${ }^{1603}$ and that financial instruments transfers are per se homogeneous and liquid forms of capital and therefore cash-equivalents ${ }^{1604}$. That is why neither the literal or textual interpretation of the term debt-claims ${ }^{1605}$ nor its key characteristics of risk $^{1606}$ and redemption obligation ${ }^{1607}$ are qualitatively affected by the mere formal question of what its form of transferable capital is. Notably, this aspect (A) is independent and therefore must be carefully distinguished from the close and likewise formal but quantitative aspects of whether or not the financial instrument indexes any debt-claim as its underlying (B) and is covered and/or collateralised by its underlying ${ }^{1608}(\mathrm{C})$. This is made clear by the fact that both cash and non-cash obligations (A) can each index or not index a debt-claim as their underlying (B) but can be covered/collateralised by something different (C).

Example 46: A certificate might index the price of gold (B) but be redeemed by the physical delivery of an equivalent amount of silver (A), while being partially covered/collateralised by platinum (C).

Instead, non-cash obligations were found not to be per se a falsifier for debt-claims, which can principally be established also by way of transferring cash-equivalents ${ }^{1609}$.

\footnotetext{
E.M. in Wolfgang Schön, equity and debt, p. 858; Jakob Bundgaard, perpetuals, p. 140.; OECD, Report on Thin Capitalization, Issues in International Taxation 1987, No. 2, p. 24, par. 57 et seq.

${ }^{1598}$ See par. 300 .

${ }^{1599}$ OEEC (Working Party No. 11 of the Fiscal Committee), Report on the Taxation of Interest, ref. FC-WP11(59)1, Paris, 1959 , p. 1.

${ }^{1600}$ See par. 297.

${ }^{1601}$ See par. 98(1).

${ }^{1602}$ See par. 87.

${ }^{1603}$ See par. 242(1).

${ }^{1604}$ See Example 23 on p. 107.

${ }^{1605}$ See par. 285.

${ }^{1606}$ See par. 293.

${ }^{1607}$ See par. 289.

${ }^{1608}$ See par. 223, 225(1) and 226.

${ }^{1609}$ See par. 233.
} 


\section{The relevance of the origin of funds}

302 Not essential for the classification as a debt-claim are the capital's or principal's origins or sources ${ }^{1610}$. This is a consequence from the systematic finding that the determination of these sources bears a comprehensive and inextricable nexus with that of the income, being entirely subject of the domestic interpretation ${ }^{1611}$. Admittedly, repayments of debt capital were basically found incapable of being interest pursuant to Art. 11(3) OECD MTC $^{1612}$. This is owed to the fact that debt capital is basically not funded by business profits ${ }^{1613}$. However, this basic principal is explicitly repealed by the extended definition of debt-claims in Art.11(3) OECD MTC by the attribute whether or not carrying a right to participate in the debtor's profits. In other words: just like equity capital, debt capital may participate in profits. In that sense it shares its fate of likewise bearing an inter-temporal nexus and therefore being inextricably "infected" with the business profits. In fact, debt capital is the formal result of the domestic law of tax accounting and as such of the peculiarities of the source jurisdiction's domestic tax law system. This is even more apparent, where the financial instrument is also featured with a self-executive profit accumulation, putting it in the same dynamic context of more than one period (e.g. tracker certificate without periodic coupons).

\section{The relevance of coverage and collateral}

303 It has further been suggested that the question whether financial instruments are collateralised was irrelevant for their classification as a debt-claim pursuant to Art. 11(3) OECD MTC ${ }^{1614}$. On the one hand, this view is in line with the findings that collateral is typically not required to legally constitute a debt-claim ${ }^{1615}$ but rather a response to it, and that, even if it was, it is not reliably capable of positively verifying credit risk ${ }^{1616}$. On the other hand, due to the economic substitutability between coverage and collateral, the latter was found capable of negatively falsifying credit risk ${ }^{1617}$. The predominant reason was that only uncovered debts bear the credit risk in the debtor's real and true ability to recover the capital or principal. In contrast, covered debts rather bear the underwriting risk of ownership in the capital or principal itself, which the creditor had also to take without having left it to the debtor ${ }^{1618}$.

Example 47: A depository receipt (also referred to as "certificate of deposit") is a certificate representing ownership rights of an underlying number of shares. A fully covered delta-one payment-in-kind certificate on one share is a contractual agreement to be redeemed in the one share ${ }^{1619}$. A fully covered (e.g. commodity-backed) payment-in-kind bond on precious metal is a contractual agreement to be redeemed in that precious metal ${ }^{1620}$.

\footnotetext{
${ }^{1610}$ Helminen, Marjaana in IBFD Commentaries on Art. 11 OECD MTC, sec. 5.1.1.3.1.; Pöllath, Reinhard/Lobbeck, Allit in Vogel/Lehner, p. 1320, par. 59b; Haslehner, Werner in Klaus Vogel Commentaries 2015, p. 923, par. 84.

${ }^{1611}$ See par. 251.

${ }^{1612}$ See par. 252.

${ }^{1613}$ See par. 250.

${ }^{1614}$ Gaspar Lopes Dias, debt-claims, sec. 2.3.; Gaspar Lopes Dias, tax arbitrage, p. 124; Haslehner, Werner in Klaus Vogel Commentaries 2015, p. 923, par. 84; Pöllath, Reinhard/Lohbeck, Allit in Vogel/Lehner, p. 1318, par. 56; OECD Commentaries 2014 on Art. 11 OECD MTC, p. C(11)-11, par. 18; Kopp, Karin E.M. in Wolfgang Schön, equity and debt, p. 858; Fehér, Tamás in Eva Burgstaller, p. 245.

${ }^{1615}$ See par. 222, 292 and 297.

${ }^{1616}$ See par. 223.

${ }^{1617}$ See par. 229.

${ }^{1618}$ See par. 224.

${ }^{1619}$ See Example 41 on p. 136.

${ }^{1620}$ See Example 46 on p. 181.
} 
It is therefore important to hold that the classification of financial instruments as a debt-claim pursuant to Art. 11(3) OECD MTC, while indeed being independent of collateralisation, may however depend on coverage. This is a conclusion from the approach of indirectly identifying counterparty risk by way of coverage (i.e. underwriting risk) rather than by collateral (i.e. credit risk). Nevertheless, it should in result not impact the concurring understanding and technique of treaty interpretation and application. The mere absence of credit risk as a constituent element of debt-claims ${ }^{1621}$ does not necessarily mean that there was no counterparty risk at all ${ }^{1622}$. Rather, it may actually represent a "managed" or "engineered" zero risk ${ }^{1623}$. In other words: not the absence of credit risk alone but only full coverage is capable of effectively falsifying counterparty risk ${ }^{1624}$. Its determination is merely shifted from the first methodological step of eliminating the legal credit risk to the subsequent methodological steps of successively disaggregating the underwriting risk ${ }^{1625}$. As a conclusion for the further course of this study, fully covered obligatory financial instruments are not considered debt-claims but must instead be classified according to their underlying's quality.

\section{The relevance of other aspects}

304 Lastly the purpose of a debt-claim and whether or not it is securitised ${ }^{1626}$ or subordinated $^{1627}$ is not relevant for its classification as a debt-claim. As regards the securitisation, this view is analogous to limb 2 of Art. 10(3) OECD MTC ${ }^{1628}$. Otherwise the system of Art.10(3) and 11(3) OECD MTC was not consistent and coherent, in that their autonomous parts led to systematically equivalent results ${ }^{1629}$. As regards the subordination, this position is a result from the finding that it is systematically not capable of being an autonomous differentiator. Instead, it was found to be interpreted formally and therefore pursuant to the domestic tax law ${ }^{1630}$.

305 Also not relevant for the classification as interest is the aspect whether or not the amounts paid are admissible for being deducted from the debtor's tax base, or have effectively been so deducted. "Interest does not suffer economic double taxation, i.e. it is not taxed both in the hands of the debtor and in the hands of the creditor" 1631 . However, this is exclusively governed by domestic tax law and therefore incapable of contributing anything to its autonomous interpretation and meaning ${ }^{1632}$. In addition, it would principally lead to the circular reasoning of being vice versa the result of such classification ${ }^{1633}$. This becomes even more evident when considering the

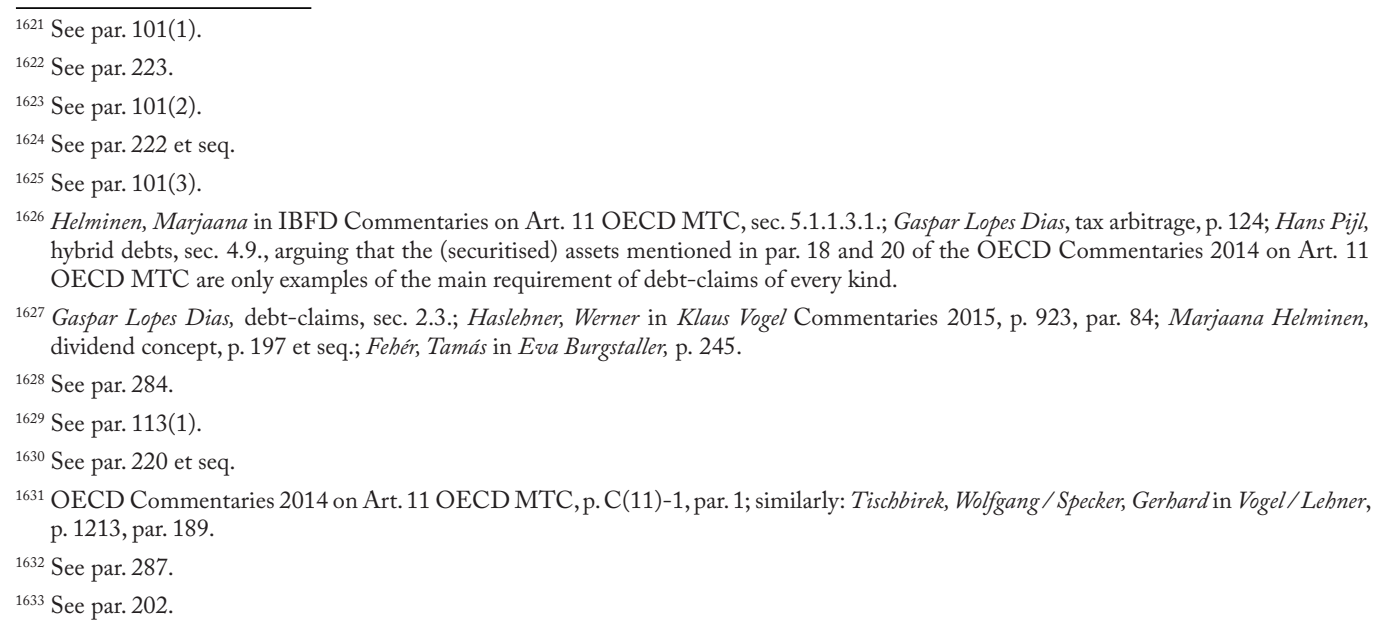


definition of debt-claims in Art. 11(3) OECD MTC extended by the attribute whether or not carrying a right to participate in the debtor's profits ${ }^{1634}$.

\subsubsection{Accrued interest}

\section{Accrued interest is imputed interest}

306 Going further, there seems to be consensus that accrued interest shall be considered paid ${ }^{1635}$, whereas imputed interest shall not ${ }^{1636}$. Accrued interest is the interest entitlement accumulated over time but not yet paid out. Imputed interest is the time value of money that is calculated into the price of goods or services. At first glance, this position appears to be a contradiction. Accrued interest is in fact imputed interest with the only peculiarity that its financial instrument can possibly be quoted on some organised markets "ex-coupon" at the so-called "clean price" (i.e. the coupon is quoted separately from the nominal or face value). Nor can it be argued that accrued interest is, unlike other forms of imputed interest, a cyclical or periodical value fluctuation. This fluctuation is rather a natural characteristic and consequence of any time-dependent accrual. The key difference is, however, that those other forms of imputed interest are typically not a remuneration for the main or principal service: financing the purchase price of an asset is a service ancillary to the provision of that asset. This difference is rooted in the necessity to eventually disaggregate any remuneration in order to analyse the tax-wise nature of its corresponding operation for the purpose of treaty application ${ }^{1637}$. In other words: irrespective of the substance over form principle, all factual analyses for applying a DTC necessarily include some form of disaggregation (in the narrow sense) as a preparatory methodological step in order to determine and classify the respective transaction. Unlike other forms of imputed interest, only accrued interest represents always and necessarily the remuneration for a finance transaction as the main or principal service.

\section{Accrued interest is not realised}

307 Having ascertained this distinction, a different question is whether or not accrued interest can be considered paid. On the one hand, it can be objected that accrued interest actually represents parts of capital rather than income. This is because it has not yet been realised by a legal event creating a new right ${ }^{1638}$. Even if the alienation of the debt-claim itself was considered such a legal event, this would basically refer to the debt-claim and therefore perhaps also to the coupon right. However, this would potentially make it a capital gain rather than interest ${ }^{1639}$. Any other conclusion would mean mixing the legal trigger of Art. 13 OECD MTC with the legal consequence of Art. 11 OECD MTC. It might further be argued that Art. 11 OECD MTC must lead to the same consistent results irrespective of any distinction between primary and secondary market ${ }^{1640}$.

\footnotetext{
1634 See par. 295 and 302.

${ }^{1635}$ Li, Jinyan / Avella, Francesco in IBFD Commentaries on Art. 13 OECD MTC, sec. 6.3.2.; Wassermeyer, Franz in Wassermeyer Commentaries, p. 1435, par. 86; OECD Commentaries 2014 on Art. 11 OECD MTC, p. C(11)-12, par. 20.1.; US Tax Court, judgement ref. 740-92, 1994.

${ }^{1636}$ Jakob Bundgaard, hybrids, p. 145; Gaspar Lopes Dias, debt-claims, sec. 1.3. and 2.3.; Gaspar Lopes Dias, tax arbitrage, p. 124; Pöllath, Reinhard / Lohbeck, Allit in Vogel / Lehner, p. 1319, par. 57; Wassermeyer, Franz in Wassermeyer Commentaries, p. 1431, par. 79, and p. 1440, par. 93; Klaus Vogel Commentaries 1997, p. 731 et seq., par. 57; equally for IAS/IFRS: IAS 32.AG11; unclear: Haslehner, Werner in Klaus Vogel Commentaries 2015, in favour on p. 927, par. 90 but then contrary on p. 924, par. 85, as the term paid was to be understood in an economic sense.

${ }^{1637}$ See Illustration 3 on p. 43.

${ }^{1638}$ Pöllath, Reinhard / Lobbeck, Allit in Vogel/Lebner, p. 1326, par. 72. See also par. 158.

${ }^{1639}$ See par. 160 et seq.

${ }^{1640}$ See par. $98(1)$
} 
This distinction, which has been proved to be of principal relevance ${ }^{1641}$, is, however, the very purpose and function of Art. 13 OECD MTC ${ }^{1642}$. In other words: it is the very nature of Art. 13 OECD MTC to establish the secondary recovery of the debt capital by disposing it as an alternative way of realisation in addition to splitting it off as interest ${ }^{1643}$. Notably, this additional and alternative way of realisation pursuant to Art. 13(5) OECD MTC is - unlike pursuant to Art. 11(3) OECD MTC - explicitly and completely independent of the tax-wise nature of its respective financial instrument ${ }^{1644}$. The reason is that the OECD MTC has taken the transaction-based approach for capital gains but the asset-based approach for interest ${ }^{1645}$. In addition, Art. 13(5) OECD MTC is the residuary clause for the asset-related Art. 13(1) to 13(4) OECD MTC $^{1646}$.

308 Considering the beneficial ownership concept governed in Art. 11(2) OECD MTC, it may also be suggested that the definition of the term debt-claim within the scope of Art. 11(3) OECD MTC was principally independent of who the payer pursuant to Art. 11(5) OECD MTC is. As a consequence, the alienation of the debt-claim itself could be considered a realisation of accrued interest from the buyer of the debt-claim. However, this would not be reasonable and give rise to considerable systematic distortions by establishing triangular interpretative and applicative relationships. Such deemed interest was actually subject of the DTC with the issuer's jurisdiction ${ }^{1647}$, while the capital gain itself was simultaneously subject of the DTC with the buyer's jurisdiction. Consequently, it cannot be argued either that accrued interest paid to the seller of a debtclaim represents negative interest ${ }^{1648}$. The underlying argument could be that such pass-through by way of beneficial ownership is not necessarily required to comply with all general principles of the OECD MTC ${ }^{1649}$, particularly not the realisation requirement ${ }^{1650}$. However, the concept of beneficial ownership explicitly takes the approach of constituting the replacement of one subject by another ${ }^{1651}$ exclusively at the receiver end. Hence, any additional equivalent at the payer end within the scope of Art. 13(5) OECD MTC is dispensable, even more as Art. 13(5) OECD MTC is subsidiary to Art. 11(2) OECD MTC ${ }^{1652}$.

309 It might be suggested by reference to the substance over form principle that the repurchase of a debt-claim by its issuer itself was to be considered an interest realisation. This might also be supported by the argument that, without such fiction, the distinction between primary and secondary market would make Art. 13(5) OECD MTC actually dependent to the situative aspect of who the contracting counterparty (i.e. the issuer versus another person). However, such fiction would not solve the problem but rather exacerbate it. In fact, it would establish the same dependency within Art. 11(3) OECD MTC. Repurchases of debt-claims by their issuers would then have to be treated differently (i.e. as interest) compared to those by other persons

\footnotetext{
1641 See par. 211 and 231.

1642 See par. 313.

1643 See par. 145.

1644 See par. 313

1645 See par. 58.

1646 See par. 145.

1647 See par. 143.

1648 See par. 139.

1649 See par. 140.

1650 See Example 21 on p. 87.

1651 See par. 338.

1652 See par. 113(2).
} 
(i.e. as capital gains). In addition, the term debt-claims generally does not cover repurchase obligations due to the restrictive application of the aggregation scheme ${ }^{1653}$. This ensures and enhances the systematic coherence and consistence between Art. 11(3) and 13(5) OECD MTC. And lastly, even if the aggregation scheme was applied less restrictively, its result could not possibly be anything other than the alienation of the interest coupon pursuant to Art. 13(5) OECD MTC. As such, it was however not realised as interest pursuant to Art. 11(3) OECD MTC.

310 It might be argued that such a legal event was already represented, at the time the debt-claim was issued, by the one-time legal commitment to pay a periodic coupon in future periods. However, this would actually separate the realisation trigger from the realisation date, thus raising the additional issue of how the latter should then be determined. Instead, such unforfeitable entitlements or vested claims based on resolutive conditions are typically considered not realised. The reason for this is that, until then, the accrued interest has not yet been paid in the sense of being actually transferred at the disposal of the recipient or beneficial owner ${ }^{1654}$. This is also reasonable in the light of the economic fact that the coupon is, until actually transferred, typically exposed to credit risk $^{1655}$ and therefore - if at all - a debt-claim itself ${ }^{1656}$.

311 For these systematic reasons it is the author's impression that the consensus view that accrued interest was paid ${ }^{1657}$ actually appears to be a common or best practice rather than a justifiable legal principle ${ }^{1658}$. In particular, any quotation requirement is not only a merely formal criterion but also and above all a very situative one (e.g. depending on the local market practices). This would create highly erratic or arbitrary and in any case coincidental results. Even understanding it in a broader sense of a merely calculatory or calculable interest does not alter the fact that accrued interest can only be realised as a capital gain pursuant to Art.13(5) OECD MTC.

\subsection{Capital gains}

\subsubsection{Structure of the provision}

312 Art. 13(5) OECD MTC reads as follows ${ }^{1659}$ :

"Gains from the alienation of any property, other than that referred to in paragraphs 1 [i.e. immovable property], 2 [i.e. movable property attributed to a permanent establishment], 3 [i.e. ships or aircraft operated in international traffic] and 4 [i.e. shareholdings of more than 50\%], shall be taxable only in the Contracting State of which the alienator is a resident."

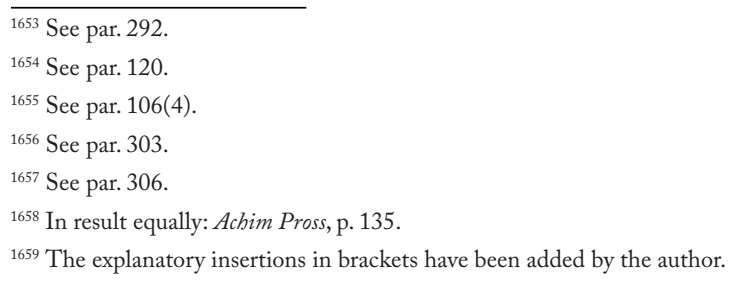


313 Art. 13(5) OECD MTC is a residuary clause for Art. 13(1) to 13(4) OECD MTC ${ }^{1660}$. Therefore, it applies to any other asset and in particular makes no difference between shares, debt-claims and positions yielding other income. In fact, capital gains are financial transactions as well, the only difference being that they are contracted on the secondary market. This deserves careful consideration when delimiting capital gains from other income types $^{1661}$. From the absence of any reference to a situs of assets in Art. 13(5) OECD MTC, as opposed to Art. 13(1) to 13(4) OECD MTC, most commentators conclude that the provision also covers assets sited in third party jurisdictions ${ }^{1662}$. For this study, the interpretational issues within Art. 13(5) OECD MTC are therefore limited to the terms gains and alienation.

\subsubsection{Alienation}

314 According to the majority's view, the term alienation has a broad meaning ${ }^{1663}$ and is to be interpreted autonomously ${ }^{1664}$. It requires at least an asset transaction ${ }^{1665}$ in the sense of an unrestricted transfer to another person or subject ${ }^{1666}$ including the issuer itself ${ }^{1667}$. This transfer is not necessarily required to be a legal one but may also an economic one in the sense of a "change in economic ownership" (substance over form) ${ }^{1668}$. It shall contain two critical aspects of (1) the power to control whether or not there shall be a disposal of the asset and (2) the capacity to bear the risks of the asset ${ }^{1669}$. This position shall now be analysed in more detail, as the term alienation actually coalesces the following different aspects discussed so far, which must however be distinguished carefully ${ }^{1670}$ :

(1) a change of asset attribution;

(2) a transfer transaction as a result from that change ${ }^{1671}$;

1660 Reimer, Ekkehart in Klaus Vogel Commentaries 2015, p. 1077, par. 138, and in Vogel/Lehner, p. 1476, par. 178, and p. 1479, par. 211; OECD Commentaries 2014 on Art. 13 OECD MTC, p. C(13)-12, par. 29; Michael Lang, introduction, p. 109, par. 322 et seq.; Klaus Vogel Commentaries 1997, p. 842, par. 91.

${ }^{1661}$ As already noted while drafting the OECD Commentaries 1963 (Li, Jinyan / Avella, Francesco in IBFD Commentaries on Art. 13 OECD MTC, sec. 1.2.2.2.).

${ }^{1662}$ Reimer, Ekkehart in Klaus Vogel Commentaries 2015, p. 1079, par. 149, and in Vogel / Lehner, p. 1480, par. 220; Wassermeyer, Franz in Wassermeyer Commentaries, p. 1645, par. 134, and p. 1649, par. 147; Klaus Vogel Commentaries 1997, p. 842, par. 94.

${ }^{1663}$ Stefano Simontacchi, p. 183; Philip Baker, p. 13-2, par. 13B.04.

${ }^{1664}$ Reimer, Ekkehart in Klaus VogelCommentaries 2015,p.1051,par.11; Reimer, Ekkehart in Vogel/Lehner, p.1441, par.11; Wassermeyer, Franzin Wassermeyer Commentaries, p. 1609, par. 27; Dutch Hoge Raad der Nederlanden, judgement ref. 25308, 1991; deviating: Reimer, Ekkehart in Klaus Vogel Commentaries 2015, p. 1052, par. 15, and in Vogel/Lehner, p. 1442, par. 20, stating that "all around this core meaning, the semantic span of the term 'alienation' under treaty law is defined by domestic law" as well as (similarly) Stefano Simontacchi, p. 184 and 196, both briefly referring to Art. 3(2) OECD MTC and to the purpose of Art. 13 OECD MTC without however providing further justification, particularly with regard to whether or not the exception rule unless the context otherwise requires may apply (see par. 14).

${ }^{1665}$ Wassermeyer, Franz in Wassermeyer Commentaries, p. 1618, par. 37.

${ }^{1666}$ Reimer, Ekkehart in Klaus Vogel Commentaries 2015, p. 1051, par. 12; Reimer, Ekkehart in Vogel / Lehner, p. 1441, par. 15; Stefano Simontacchi, p. 176; Michael Lang, hybrids, p. 104.

${ }^{1667}$ Reimer, Ekkehart in Klaus Vogel Commentaries 2015, p. 1078, par. 145; Dutch Hoge Raad der Nederlanden, judgement ref. 38.461, 2003; Rainer Prokisch, share buy-backs, p. 402 et seq. The additional exception of a 365 day period inserted into Art. 10(2)(a) OECD MTC by the OECD MTC Draft Update, p. 14, par. 14, would not alter this result either and is thus not relevant for the scope of this study (see par. 10), as it does not affect but rather presupposes the genuine definition (see par. 73) of the term dividends pursuant to Art. 10(3) OECD MTC. Originally contrary: Dutch Hoge Raad der Nederlanden, judgement ref. 28.959, 1994, par. 9.3. et seq., first interpretating accurately that its wording and intention do not suggest Art. 13(5) OECD MTC being an exception rule (lex specialis) of Art. 10 OECD MTC but then going too far in concluding that there was an overlap between the two provisions, in which the latter would conversely take precedence. See also par. 113(2) and 309.

${ }^{1668}$ See footnote 1664.

${ }^{1669}$ Reimer, Ekkehart in Michael Lang, beneficial ownership, p. 263; Oliver, J. David B., Beneficial Ownership and the OECD Model, British Tax Review 2001, No. 1, p. 55 et seq.

${ }^{1670}$ Similarly: Stefano Simontacchi, p. 132

${ }^{1671}$ See par. 58. 
(3) the realisation of this transaction ${ }^{1672}$; and

(4) the attribution of (the capital gain from) this realised transaction ${ }^{1673}$.

\section{The change of asset attribution}

315 To the author's understanding, the first aspect (1) is the starting point. In other words: it is not the change in the asset attribution, which is a logical result from the transfer transaction, but it is, conversely, the transfer transaction, which is a logical result from the change in the asset attribution. On the one hand, this does not conflict with the general principle that the asset is the result of the transaction (and not vice versa) ${ }^{1674}$ : Art. 13 OECD MTC takes the transaction-based approach per $\mathrm{se}^{1675}$, which is completely independent of the asse ${ }^{1676}$. On the other hand, anything else would mean actually leaving the question open of what then should constitute alienation. In contrast to the other distributive articles, the disposal of assets is the very nature and purpose of the alienation and therefore its constitutive characteristic. Accordingly, the change of asset attribution to the disposal of the acquirer may not be a merely economic one but must necessarily be a legal one in order to trigger Art. 13(5) OECD MTC. Matters of attribution and ownership other than beneficial ownership were found inaccessible to the treaty principle of substance over form but must rather follow the legal form (i.e. form over substance). ${ }^{1677}$ This was a result from the above systematic considerations that there cannot possibly be such a thing as "economic ownership" in Art. 13(5) OECD MTC. This view is in line with the same question whether a change in the attribution of the capital or principal must be a legal or an economic one in order to constitute debt-claims ${ }^{1678}$. It leads to equivalent results in so far as the possession of legal ownership rights in the capital or principal during the investment period is governed by Art. 11 OECD MTC, whereas their termination at the end of the investment period is governed by Art. 13 OECD MTC. Unlike Art. 13 OECD MTC, Art. 11 OECD MTC also contains an explicit provision for attributional aspects within the substance over form principle ${ }^{1679}$. Accordingly, the asset cannot be transferred from its beneficial owner to the debtor in order to trigger Art. 13(5) OECD MTC either, since the beneficial ownership is its legal consequence and therefore cannot simultaneously be its precondition ${ }^{1680}$. As an interim conclusion for the further course of this study it is therefore held that the particular aspect of changing the asset attribution to the disposal of the acquirer must be interpreted formally or legally and not economically. Therefore it is subject of Art. 3(2) OECD MTC and thus of the domestic tax law ${ }^{1681}$.

Example 48: Merely writing a put option (i.e. long put) can economically be seen as a present disposition of future interests in the underlying (i.e. its contingent value appreciation). However, it will not be considered a change of the underlying's attribution where the option contract is treated formally as a separate agreement (e.g. a bet) ${ }^{1682}$ by the domestic tax law.

\footnotetext{
${ }^{1672}$ See par. 145.

${ }^{1673}$ See par. 142.

${ }^{1674}$ See par. 52.

${ }^{1675}$ See par. 58.

${ }^{1676}$ See par. 307.

${ }^{1677}$ See par. 187.

${ }^{1678}$ See par. 297.

${ }^{1679}$ Argumentum a minore ad maius.

${ }^{1680}$ See par. 142.

${ }^{1681}$ Equally: Federal Court of Australia, judgement ref. NG 225 of 1997, 1997.

${ }^{1682}$ See par. 96.
} 
316 That is why it cannot be said at this first level of asset attribution that the treaty term alienation would exclude, for instance, non-physical or net settlements or hedges, where these change the asset attribution pursuant to domestic tax law. This might be the case where the domestic tax law itself would adhere more to substantive than to formal concepts. Also, the question of whether the substitution of one asset by another (e.g. corporate actions) represents a transfer for Art. 13(5) OECD MTC ${ }^{1683}$ or rather a surrogate ${ }^{1684}$ is subject of the domestic tax law. This becomes even more evident as a replacement by a surrogate is typically tax-exempt and therefore does not trigger but rather suspends double taxation, being typically out of scope of the OECD MTC at all. Even a temporal double taxation due to grandfathering effects was, however, not a matter of income classification but rather of income determination. This view is also in line with the finding that the subjacent aspect of novation must be interpreted formally and therefore pursuant to domestic tax law ${ }^{1685}$. Actually, these consequences from the domestic interpretation of both the asset transfer and its subsequent attribution give rise to potential qualification conflicts ${ }^{1686}$. However, they correspond to the finding that economic or factual power structures are ultimately reducible to legal powers or relations ${ }^{1687}$. It is rather the transfer transaction as the result than the change in the asset attribution as such ${ }^{1688}$, which may be subject of the substance over form principle and shall therefore be analysed now.

\section{The transfer transaction}

317 As regards this second aspect (2), the transfer transaction can be economically evaluated independent of the first aspect (1) of a change in the asset attribution ${ }^{1689}$. The two aspects may, but not necessarily do, lead to the same results (i.e. "economic ownership" in the asset). However, they must nevertheless be analysed separately. Just as the legal change of the asset attribution does not necessarily imply a legal transaction (A), the legal change of the asset attribution does not necessarily imply an "economic transaction" (B) either.

Example 49: There may be assumed to be an asset (e.g. capital or principal), a legal transaction on this asset between a creditor and a debtor (e.g. debt) and another legal transaction on the debt between the creditor and a third party (e.g. credit "derivative"). The credit "derivative" is a legal transaction in relation to the debt, but may be seen as an "economic transaction" in relation to the asset. A straight debt as a legal transaction typically does not provide a change in the legal ownership of the asset to the debtor (A). The credit "derivative" as an "economic transaction" does not necessarily provide a change in the legal ownership of the asset to the third party (B).

In other words, "economic ownership" in an asset (e.g. precious metal) can principally be transferred in two ways: either by a change in the economic attribution of the asset itself (e.g. "derivative" on that precious metal) ${ }^{1690}$ or in the legal attribution of another composite legal transaction with that asset (e.g. securities

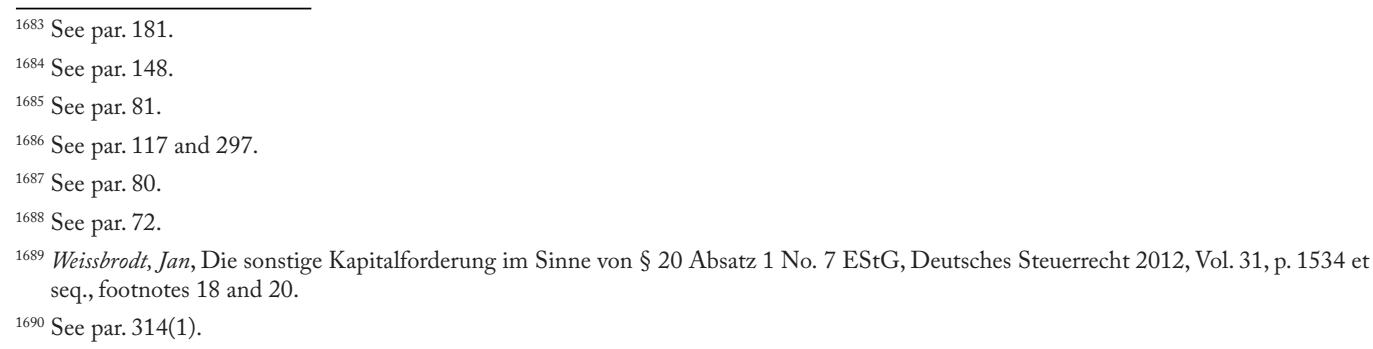


lending with that "derivative" ${ }^{1691}$. Both aspects are matters of attribution and ownership. As such, they must necessarily follow the legal form (i.e. form over substance) ${ }^{1692}$. However, as the former was rejected ${ }^{1693}$, only the latter remains left for potentially justifying a change of "economic ownership" in an asset within the scope of Art. 13(5) OECD MTC.

318 The issue discussed here appears to bear a striking resemblance to the object-related aspect of "beneficial ownership"1694. This is owed to the fact that it tackles the same conceptual problem. It might therefore be reasonably suggested that the second aspect (2) of economically evaluating changes in an asset's legal attribution as the result of composite legal transactions resembles the transaction-related or (re)attributional aspect of beneficial ownership ${ }^{1695}$. This would not only support the finding that the first aspect (1) of changes in the economic attribution of the asset itself must be rejected ${ }^{1696}$. The reason is that, conversely, it appears to resemble the asset-related (anti-abuse) aspect of beneficial ownership, which does not implicitly subsist in Art. 13(5) OECD MTC ${ }^{1697}$. It would also lead to the conclusion that Art. 13(5) OECD MTC, unlike Art. 10 and 11 OECD MTC, would eventually imply a certain form of "economic ownership" in the asset other than beneficial ownership ${ }^{1698}$, since the transaction-related or (re-)attributional aspect of beneficial ownership subsists implicitly in Art. 13(5) OECD MTC.

319 However, this turns out to be an imprecise view, when looked at more closely. In contrast to the other distributive articles, it is the particular nature of Art. 13 OECD MTC that it deals with the disposal of assets. This is the very reason why the OECD MTC had to take the transaction-based approach for capital gains ${ }^{1699}$. The transaction-based approach, however, necessarily contains an asset-related aspect ${ }^{1700}$ and therefore gives rise to the temptation of confusing ${ }^{1701}$ the change of asset attribution ${ }^{1702}$ and the transfer transaction as a result from that change ${ }^{1703}$. In other words: the term alienation coalesces both a static element (i.e. the asset as such) and a dynamic element (i.e. its disposal) in itself. Therefore, it is methodologically flawed to reestablish the static and asset-related aspect, which has already been rejected for systematic considerations by way of the dynamic and transaction-related aspect ${ }^{1704}$. This is the very source of that confusion. It becomes particularly evident by recognising the circular reasoning that such a form of "economic ownership" in the asset would again depend on the composite legal transaction, whereas it was found to actually represent the starting point ${ }^{1705}$. In addition, the concept of beneficial ownership may be limited in scope to its transaction-related

\footnotetext{
1691 See par. 314(2).

1692 See par. 187.

1693 See par. 315.

${ }^{1694}$ See Illustration 9 on p. 73.

1695 See par. 128.

1696 See par. 315.

${ }^{1697}$ See par. 142.

1698 See par. 187 and 297.

1699 See par. 58.

${ }^{1700}$ See par. 53.

1701 See par. 131.

1702 See par. 314(1).

${ }^{1703}$ See par. 314(2).

${ }^{1704}$ Circular reasoning.

1705 See par. 315.
} 
or (re-)attributional aspect, but it is nevertheless implied in Art. 13(5) OECD MTC as a coherent whole. In other words: it was systematically and methodologically flawed to conclude that the integral concept of beneficial ownership had any other role or relevance in Art. 13(5) OECD MTC as compared to Art. 10 and 11 OECD MTC. Consequently, the transaction-related or (re)attributional aspect of beneficial ownership cannot, within the scope of Art. 13(5) OECD MTC, possibly be more than merely its legal consequence and simultaneously its precondition ${ }^{1706}$. As an interim conclusion for the further course of this study it is therefore held that the particular aspect within the term alienation of a transfer transaction as a result from the change of the asset attribution must be interpreted formally or legally rather than economically, and therefore pursuant to domestic tax law.

\section{The realisation of the transfer transaction}

320 As regards the third aspect $(3)^{1707}$, the realisation requirement reflected by the term alienation was found to be subject of a limited autonomous interpretation applying form over substance. It requires at least a legal event arising from a domestic field of law that is precursory to its tax law and refers to the asset, in that it impairs the mathematical number of the critical ownership rights in the asset ${ }^{1708}$. This limited autonomous interpretation of the term alienation includes partial disposals ${ }^{1709}$, being in line with the finding that these must also be determined pursuant to domestic law (particularly their distinction from partial redemptions) ${ }^{1710}$. Only at this third level of the realisation requirement are the varieties of domestic asset attribution ${ }^{1711}$ and transfer transactions ${ }^{1712}$ restricted by the tax-limiting function of Art. 13(5) OECD MTC ${ }^{1713}$ and therefore by the autonomous interpretation ${ }^{1714}$.

\section{The attribution of the gain from the transfer transaction}

321 As regards the fourth aspect $(4)^{1715}$, the attribution of the capital gain from the realised transaction was found to be subject of the substance over form principle in the form of the beneficial ownership concept ${ }^{1716}$. Its transaction-related or (re-)attributional aspect was found to subsist implicitly also in Art. 13(5) OECD MTC $^{1717}$.

\section{The relevance of the change in economic ownership is limited}

322 It is important to note that the aforementioned considerations demonstrate that the substance over form principle takes effect only upon the last aspect of the subjective attribution of the capital gain. In other

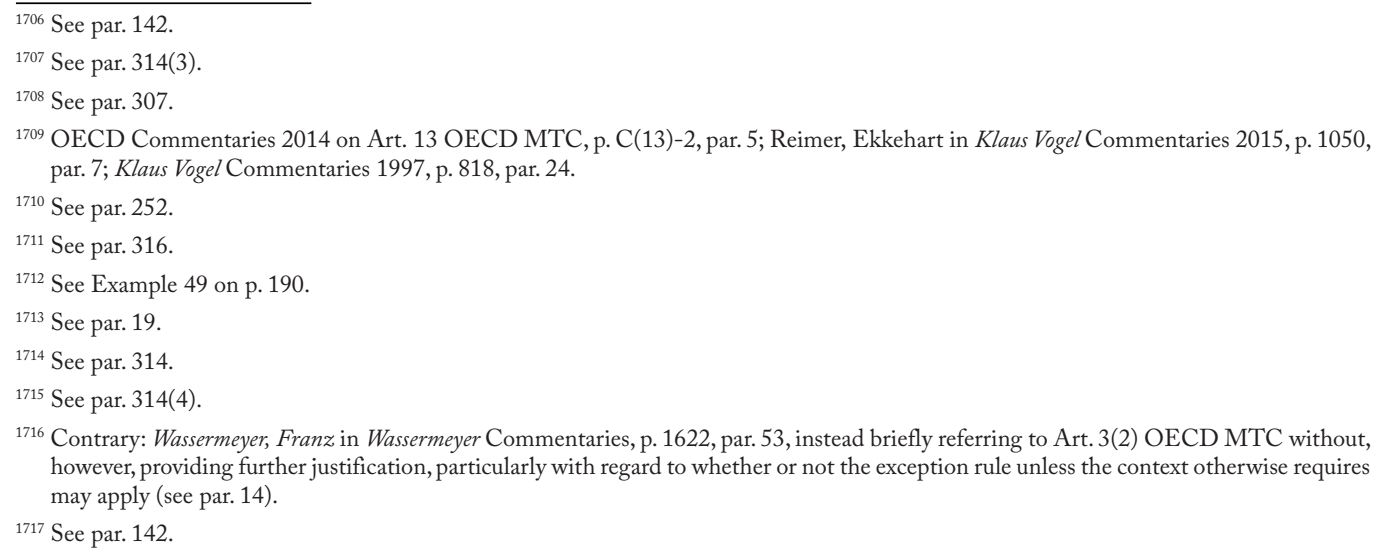


words: it is the pass-through of the realised income rather than the ownership rights in the asset itself, which are interpretatively influenced by the economic perspective. The following illustration visualises this understanding:
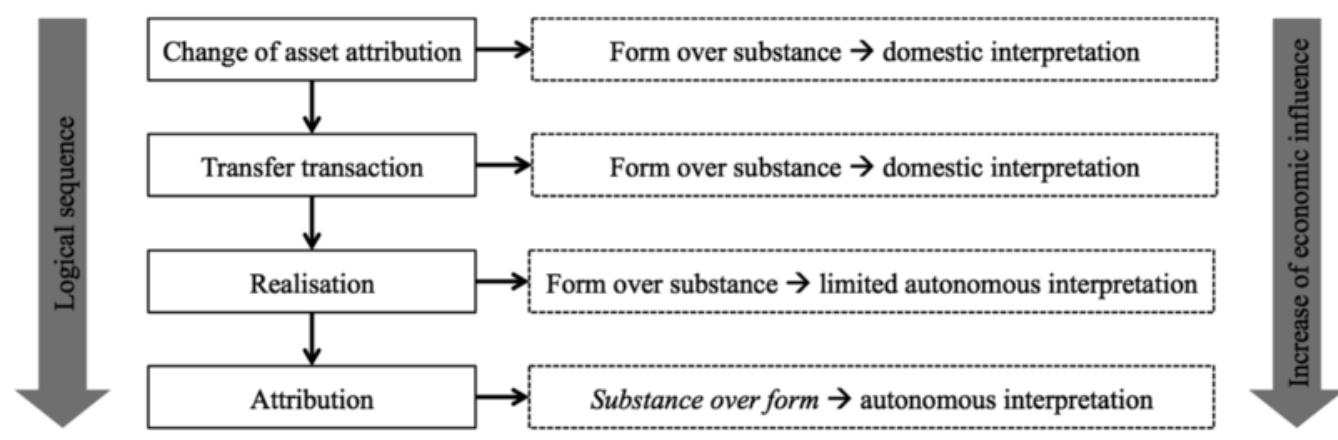

Illustration 21: The different aspects of the term alienation in Art. 13(5) OECD MTC

323 While this conclusion makes a big difference from the systematical point of view, its impact on the treaty interpretation nevertheless appears to be limited. Again, the reason is the said specific nature of Art. 13 OECD MTC that deals with the disposal of assets per se ${ }^{1718}$. True, an asset can principally be transferred, if not legally, either directly by changing the economic asset attribution or indirectly by changing the legal composite transaction attribution ${ }^{1719}$. However, this concurrency can lead to different results only in terms of who is considered the attributee of the asset ${ }^{1720}$. Nevertheless, once someone is determined as this attributee of the asset in either way, any deviation from the attributee of the capital gains can necessarily only be rooted in the transaction-related or (re)attributional aspect of beneficial ownership. In contrast to dividends or interest, it can particularly not be rooted in any form of "economic ownership" in the asset itself. The reason shall be explained based on the following illustration:

\footnotetext{
${ }_{1718}$ See par. 319.

${ }^{1719}$ See par. 317.

${ }^{1720}$ See Example 49 on p. 190.
} 


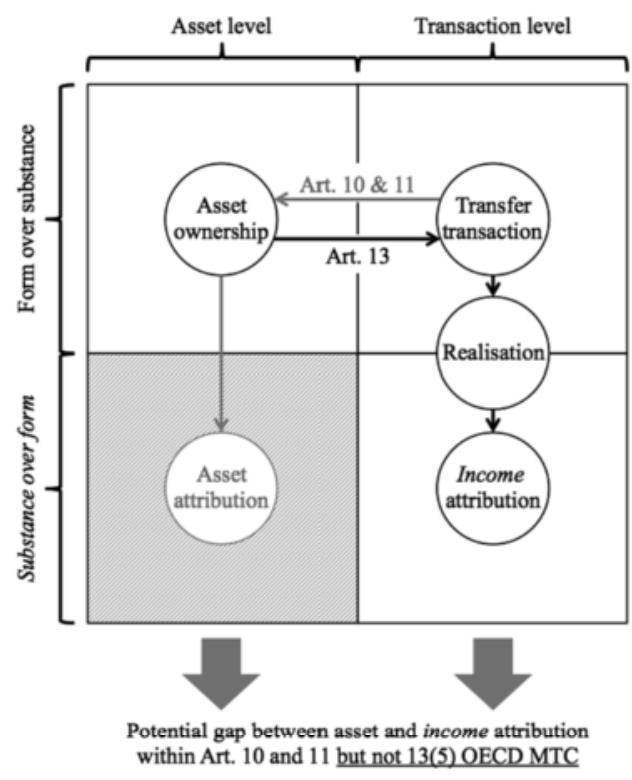

Does not apply to Art. 13(5) OECD MTC

Illustration 22: The genuine attributee of capital gains is always identical to the attributee of the asset

In contrast to Art. 10(3) and 11(3) OECD MTC, the starting point within Art. 13(5) OECD MTC is the change in the asset attribution. ${ }^{1721}$ This change follows form over substance (i.e. legal asset ownership): matters of attribution and ownership other than beneficial ownership are inaccessible to the treaty principle of substance over form, and the asset-related aspect of beneficial ownership does not apply to Art. 13(5) OECD ${ }^{1722}$. At the same time, this legal singularity of the asset attribution leads to the systematic and methodological consequence that the transaction as the subsequent logical step is not capable of transferring "economic ownership" in the asset ${ }^{1723}$ either. Thus, the attributee of the asset cannot differ from its legal owner, who is identical with the attributee of the capital gains (i.e. the recipient), unless passed-through to the beneficial owner.

Example 50: Dividends and interest ${ }^{1724}$ are independent rights, whereas a capital gain is a dependent increment. In contrast to dividends and interest, an asset can therefore not be legally encumbered in a way that its capital gain is entitled to one beneficiary while its principal or underlying right is entitled to another beneficiary. Both are inextricably coalesced by one and the same right, i.e. the ownership right in the asset itself. That is why the capital gain can merely be passed-through in amount to the beneficial owner, without, however, altering that legal indivisibility.

\footnotetext{
${ }^{1721}$ See par. 315 .

${ }^{1722}$ See par. 318.

${ }^{1723}$ See par. 319.

${ }^{1724}$ See Example 19 on p. 76.
} 


\section{Conclusions}

324 Hence, the influence of the substance over form principle is limited to the (re)attributional aspect of beneficial ownership. As a result, the genuine attributee of income in the form of capital gains (i.e. the recipient) is, unlike that of dividends or interest, always identical to the attributee of the asset itself (i.e. its legal owner). In other words: the beneficiaries of capital gains and those of the asset itself are in a way the same, as the former is an integral and inseparable part of the latter. Consequently, the conclusion that the substance over form principle takes effect only upon the income attribution of Art. 13(5) OECD MTC and not upon the asset itself ${ }^{1725}$ appears to be of limited relevance for the theory of treaty interpretation ${ }^{1726}$ (but is perhaps relevant for the practice of treaty application ${ }^{1727}$ ). This becomes even more evident when remembering that the subject of the distributive articles is actually the tax treatment of income and not of assets. Coming back to the initial question ${ }^{1728}$, the author agrees therefore only with the reservations explained in this section to the majority's view and condensed statement that the term alienation could in result be said to require an asset transaction in the sense of a "change in economic ownership".

325 These reservations are also the reason why this economic view does not conflict with the finding that the realisation of capital gains requires and presumes a legal event as a necessary minimum condition (form over substance $)^{1729}$. The reason is that beneficial ownership is a specific exception from the general principles of attribution (form over substance). As such, it is a rule subsequent to the definition of the term capital gain and a derivative concept to the genuine concept of alienation, which in no way justifies generalisations ${ }^{1730}$. In other words: even less permissible than the reverse deduction from the realisation to the transaction ${ }^{1731}$ is the reverse deduction from the realisation to the asset attribution ${ }^{1732}$. The reason is that, within the scope of Art. 13(5) OECD MTC, the transaction is a logical pre-step of the asset attribution ${ }^{1733}$. In summary, the term gains from the alienation requires (1) a legal event that (2) changes the "economic ownership".

326 Going further, the provision takes the alienator's perspective ${ }^{1734}$, which stipulates an asset outflow ${ }^{1735}$ and focuses on the mere disposal. In this respect, the duration or maturity of the pending transaction in cases of deferrals between obligation and execution is not relevant, so that forwards or options can principally be disposals as well. ${ }^{1736}$ However, alienation requires at least some asset inflow, i.e. an acquisition or receipt ${ }^{1737}$. Otherwise it would not truly represent a "transfer" to another person or subject ${ }^{1738}$. Consequently, cases

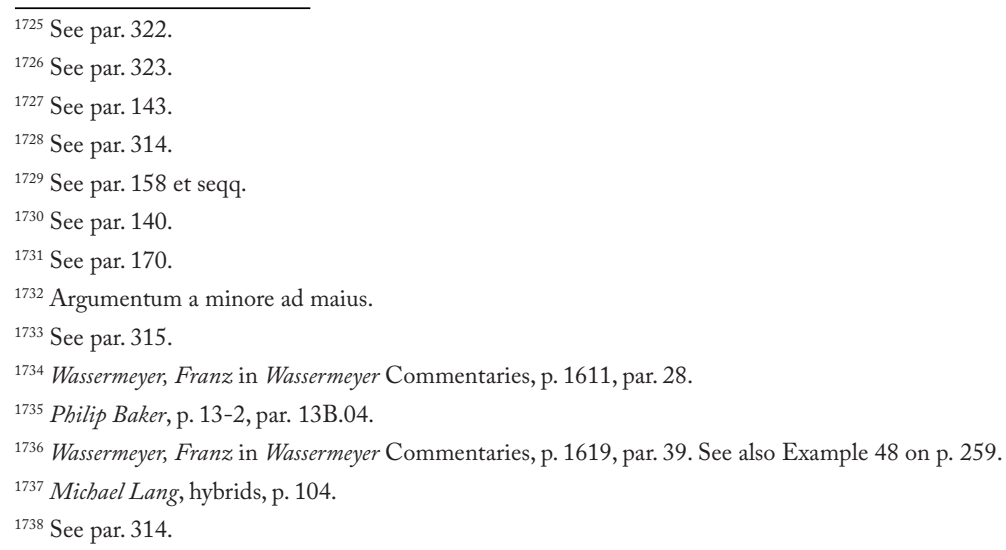


of unilateral termination are not covered by the term alienation (e.g. renunciation, liquidation ${ }^{1739}$, expiry, destruction ${ }^{1740}$, etc. $)^{1741}$. This corresponds with the natural understanding of a capital gain that would otherwise not actually be computable. As a further consequence of the alienator's perspective, the return from the disposal is not relevant either. Therefore, the term alienation also includes non-cash exchange transactions (e.g. transfers to a company in exchange for stock) ${ }^{1742}$ and transactions without any return at all ${ }^{1743}$ (e.g. gifts $^{1744}$ or inheritances). That is why the information to what extent the ratio between the number of the critical ownership rights in the asset and their proportional value may change as a result of the transaction ${ }^{1745}$ cannot be used as an universal differentiator for Art. 13(5) OECD MTC. In addition, the origin ${ }^{1746}$ of the asset or the motivation ${ }^{1747}$ for the transfer (e.g. expropriation ${ }^{1748}$ ) aren't relevant for the classification as a capital gain. An important exception is, of course, where the disposal of the asset represents the fulfilment of a legal redemption obligation ${ }^{1749}$. For the practice of treaty application, this reservation appears to be of limited relevance, as the legal redemption obligation typically excludes the concurrent legal ownership rights in the capital or principal ${ }^{1750}$ and/or is unilaterally terminated. For the theory of treaty interpretation, the reservation is relevant, however. The conclusion that the redemption obligation is a necessary minimum condition (conditio sine qua non) for Art. 11(3) OECD MTC ${ }^{1751}$ and the consensus view that the distributive articles are mutually exclusive ${ }^{1752}$ lead to the systematic result that Art. 13(5) OECD MTC must necessarily be subsidiary to Art. 11(3) OECD MTC.

\subsection{Other income}

\subsubsection{Structure of the provision}

327 Art. 21(1) OECD MTC reads as follows:

"Items of income of a resident of a Contracting State, wherever arising, not dealt with in the foregoing Articles of this Convention shall be taxable only in that State."

\footnotetext{
${ }^{1739}$ Contrary: Marjaana Helminen, dividend concept, p. 235, and Dutch Hoge Raad der Nederlanden, judgement ref. 41376, 2006, both applying however the domestic tax law by actually referring to limb 3 of Art. 10(3) OECD MTC (see par. 270).

1740 Wassermeyer, Franz in Wassermeyer Commentaries, p. 1614, par. 32.

${ }^{1741}$ See par. 81.

${ }^{1742}$ OECD Commentaries 2014 on Art. 13 OECD MTC, p. C(13)-2, par. 5; Klaus Vogel Commentaries 1997, p. 818, par. 24; League of Nations, Annex to London and Mexico Model Tax Conventions Commentary and Text, Geneva, November 1946, available online at http://adc.library.usyd.edu.au (last retrieved on 15 September 2017), p. 67.

${ }^{1743}$ Reimer, Ekkehart in Klaus Vogel Commentaries 2015, p. 1050, par. 5.

${ }^{1744}$ Tax Court of Canada, judgement “William C. Krafve vs. M.N.R.”, 1983.

${ }^{1745}$ See par. 162 and 253.

${ }^{1746}$ OECD Commentaries 2014 on Art. 13 OECD MTC, p. C(13)-3, par. 11.

${ }^{1747}$ Wassermeyer, Franz in Wassermeyer Commentaries, p. 1611, par. 28.

${ }^{1748}$ OECD Commentaries 2014 on Art. 13 OECD MTC, p. C(13)-2, par. 5; Klaus Vogel Commentaries 1997, p. 818, par. 24.

${ }^{1749}$ See par. 300 et seq.

${ }^{1750}$ See par. 315 .

${ }^{1751}$ See par. 289.

${ }^{1752}$ See par. 113.
} 
328 The provision is a residuary clause for all other distributive articles of the OECD MTC 1753 , which is why this brief section serves the sole purpose of completeness.

329 The provision also covers assets sited in third party jurisdictions. This follows from its character as a residuary clause, from the phrase wherever arising and from the absence of any reference to a situs of assets. ${ }^{1754}$ According to the majority of commentators, the term items is to be interpreted autonomously. ${ }^{1755}$ This is a logical reverse deduction ${ }^{1756}$ from the residuary character of Art. 21(1) OECD MTC for all other distributive articles, which are to be interpreted autonomously ${ }^{1757}$. On the one hand, these interpretations and the provision's systematic context of being basically as broad or comprehensive as possible ${ }^{1758}$ suggest a wide meaning of the term items. On the other hand, the scope of application is substantially re-narrowed due to the fact that the purpose and function of Art. 21(1) OECD MTC is not to resolve interpretation problems in other articles ${ }^{1759}$. That is why, for instance, it does not include deemed income of other distributive articles, which is a matter of realisation ${ }^{1760}$ rather than of a specific income type ${ }^{1761}$.

\subsubsection{Gamble}

330 At first glance, the most relevant use case and distinction of Art. 21(1) OECD MTC from the other distributive articles appears to be the gamble (e.g. lotteries, bets, etc.). A gamble is typically considered as any claim on benefits which is more or less contingent on the random principle. As such, it was said to be in fact a negative insurance in the sense of taking a negative underwriting risk (i.e. granting a chance ${ }^{1762}$. Therefore, income from gambling obviously does not represent the time value of money ${ }^{1763}$. Art. 13(5) OECD MTC is not intended to apply to prizes in a lottery or to premiums and prizes attaching to bonds or debentures either. ${ }^{1764}$ To the author's understanding, this should also apply to equivalent or similar forms of gambles. Consequently, the delimitation seems to put the focus on the particular question of whether (then dividends or interest) or not (then other income) gambling can represent a participation in profits.

\footnotetext{
1753 See par. 113 .

${ }^{1754}$ Alexander Bosman, p. 79 et seq. and 87 et seqq.; Rust, Alexander in Klaus Vogel Commentaries 2015, p. 1547, par. 33, and in Vogel/Lehner, p. 1920, par. 3; Wassermeyer, Franz / Kaeser, Christian in Wassermeyer Commentaries, p. 2053, par. 1; OECD Commentaries 2014 on Art. 21 OECD MTC, p. C(21)-1, par. 1; Cui, Shanshan in Thomas Ecker, p. 639; Michael Lang, hybrids, p. 107; Klaus Vogel Commentaries 1997, p. 1071, par. 7 .

${ }^{1755}$ Rust, Alexander in Klaus Vogel Commentaries 2015, p. 1541, par. 25, and in Vogel / Lehner, p. 1922, par. 10; Wassermeyer, Franz / Kaeser, Christian in Wassermeyer Commentaries, p. 2057, par. 16; Klaus Vogel Commentaries 1997, p. 1072, par. 11; perhaps contrary: Cui, Shanshan in Thomas Ecker, p. 638, generally referring to Art.3(2) OECD MTC but leaving open whether or not the exception rule unless the context otherwise requires may actually apply.

${ }^{1756}$ Argumentum e contrario.

${ }^{1757}$ See par. 257, 287, 314 and 320 .

${ }^{1758}$ See par. 111 et seq.

${ }^{1759}$ Alexander Bosman, p. 79; Rust, Alexander in Klaus Vogel Commentaries 2015, p. 1542, par. 27 and 29, and in Vogel/Lehner, p. 1923, par. 12; Michael Lang, hybrids, p. 106; Klaus Vogel Commentaries 1997, p. 915, par. 12.

${ }^{1760}$ Accurate: Rust, Alexander in Klaus Vogel Commentaries 2015, p. 1544, par. 30; Swedish Högsta Förvaltningsdomstolen, judgement ref. 6687-11, 2012. Unclear: Alexander Bosman, in favour on p. 81 et seq. but contrary on p. 322.

${ }^{1761}$ In this sense, however: Dutch Gerechtshof Amsterdam, judgement ref. 03/03165, 2005; Wattel/Marres, fictitious income, p. 69. See also par. 144 et seqq.

${ }^{1762}$ See par. 70.

${ }^{1763}$ See par. 213.

${ }^{1764}$ Wassermeyer, Franz in Wassermeyer Commentaries, p. 1618, par. 38; OECD Commentaries 2014 on Art. 13 OECD MTC, p. C(13)-6, par. 19.
} 
331 However, as an overall result from the findings and conclusions in this study, the issue is of fairly small significance for the practice of treaty application. The scope of Art. 21(1) OECD MTC was said to be limited, in that the resolution of interpretation problems from other distributive articles is not its purpose and function ${ }^{1765}$. In addition, the issue turns out to be of limited relevance also for the theory of treaty interpretation. True, while the attribute participating in profits cannot serve as a differentiator for the distinction between Art. 10(3) and 11(3) OECD MTC ${ }^{1766}$, it might nevertheless be considered a classifier for Art. 21(1) OECD MTC. However, the criterion of profit participation emerges explicitly in Art. 10(3) and 11(3) OECD MTC. Therefore, it ought to have a reasonable role within Art. 21(1) OECD MTC only as a falsifier, i.e. a nonparticipation in profits would negate other income. Nevertheless, its specific character as a residuary clause generally excludes such falsifiers by itself, since any residuum is the result of such negation (double negation). Or in other words: "the rest" cannot be defined positively ${ }^{1767}$. As a result for its further course, the definition and delimitation of gambles is not capable of contributing any value to this study.

\footnotetext{
${ }_{1765}$ See par. 329.

${ }^{1766}$ See par. 280.

${ }^{1767}$ Similarly: Achim Pross, p. 177.
} 



\section{Chapter 4}

\section{Summary of conclusions}

332 This section is an abstract of the most important conclusions found so far, briefly summarising the storyline of this study.

333 The OECD MTC is a collective law in the sense of a multi-jurisdictional compromise. It aggregates the heterogeneous peculiarities of individual (domestic) or cultural (regional) tax laws and tax systems into a generic and autonomous taxonomy. ${ }^{1768}$ In this respect, the OECD MTC shares the same nature with other collective tax laws. This justifies them to be consulted as inspirational legal sources for the systematic interpretation of the OECD MTC, particularly as regards aspects and concepts under the substance over form principle. ${ }^{1769}$ The approach can help interpreting and applying the OECD MTC more consistently by consulting other legal sources, which have similar problems to solve or are even closer to a solution of these problems.

334 This study takes the transaction-based approach as a basis of its analyses. It derives the income classification directly from the effective operation rather than indirectly from its source or origin ${ }^{1770}$, like the asset-based approach taken by the OECD MTC does ${ }^{1771}$. In that the transaction-based approach decomposes the object of law into the asset-related and the transaction-related bit of information, the asset-based approach implies and requires the transaction-based approach ${ }^{1772}$. Consequently, the transaction-based approach is no substitute for the asset-based approach but rather an enlargement and breakdown of it. The benefit of this approach is that it provides a better understanding of multiple aspects in the interpretation and application of the OECD MTC. These include, for instance, fundamental concepts such as beneficial ownership, the realisation principle or the role of the payment profile. But they also help to solve practical problems such as the delimitation of income and capital gains, the qualification of accrued interest and the classification of ambiguous financial instruments.

\footnotetext{
${ }_{1768}$ See par. 18.

${ }^{1769}$ See par. 45.

${ }^{1770}$ See par. 52.

${ }^{1771}$ See par. 58.

${ }^{1772}$ See par. 54.
} 
335 Risk is a mathematical and economic ${ }^{1773}$ parameter, and therefore a more quantitative one $\mathrm{e}^{1774}$. It is principally limited in allowing conclusions on the qualitative aspects and concepts of law ${ }^{1775}$. In that, risk is however not only an important interpretative and/or applicative assessment factor for methodologically evaluating the relative importance of potential differentiators or criteria for the classification of income from financial instruments. The most relevant risk types for this study are symmetric versus asymmetric risk ${ }^{1776}$, formal versus material risk ${ }^{1777}$, legal versus non-legal risk ${ }^{1778}$ and underwriting versus timing risk ${ }^{1779}$. Although risk is principally masked, it can often be spotted by behavioural adaptations of the contracting counterparties of financial instrument to their risk exposures. The systematic approach of this study, the mere existence of certain types of risk therefore makes is possible in many aspects to reveal qualitative indications and conclusions towards the nature of the underlying transaction or operation. In that, it particularly helps to limit, structure and allocate the relevant and significant attributes for the interpretation and application of the OECD MTC.

336 This study focuses on genuine legal concepts of income classification, whereas derivative legal concepts are out of scope ${ }^{1780}$. While these typically trigger the same legal consequences, the difference between them is that the latter implies and requires the former as a necessary precondition ${ }^{1781}$. Whether a legal provision or term in the OECD MTC belongs to the one or the other concept can often be concluded neither from their wording nor from their purpose, intention or function ${ }^{1782}$. Therefore, this study primarily concentrates on the systematic element of interpretation. From this systematic element of interpretation the most important conclusions can be drawn:

- The mere existence of financial instruments as the asset ${ }^{1783}$ and consequently also the income or transaction ${ }^{1784}$ require a cautious invocation of the substance over form principle.

- Risk must be separated into legal and non-legal risks ${ }^{1785}$.

- "Non-legal rights and obligations" are not relevant for the classification of income types from financial instruments into the distributive articles of the OECD MTC ${ }^{1786}$.

- Time represents a physical parameter and therefore is principally incompatible with and inaccessible to legal interpretation ${ }^{1787}$. However, time aspects interact and therefore bear a nexus with a broad number of

\footnotetext{
1773 See par. 65.

${ }^{1774}$ See par. 60.

${ }^{1775}$ See par. 218.

${ }^{1776}$ See par. 64.

1777 See par. 65.

${ }^{1778}$ See par. 66.

${ }^{1779}$ See par. 67 et seqq.

${ }^{1780}$ See par. 75.

${ }^{1781}$ See par. 73.

${ }^{1782}$ See par. 74.

${ }^{1783}$ See par. 77.

${ }^{1784}$ See par. 79.

${ }^{1785}$ See par. 78.

${ }^{1786}$ See par. 80 .

${ }^{1787}$ See par. 81.
} 
legal and economic aspects by interacting with them. That is why they are attached to them and basically share their same legal fate ${ }^{1788}$.

On the one hand, the separation of genuine and derivative concept helps to focus on the actual root causes of challenges to the OECD MTC. On the other hand, the key insight of focussing on the systematic interpretation is: which attributes of financial instruments and the OECD MTC are generally accessible to an autonomous or an domestic interpretation respectively. With regard to the autonomous interpretation, they also set the scope of aspects for which the interpretation and/or application of the OECD MTC might be inspired by other comparable legal sources. In combination, the approach fosters the primary law and thus strengthens the legal certainty and the role of the OECD MTC as the world's leading and most influential standard template for the negotiation of DTC.

337 Aggregation and disaggregation are applicative techniques for preparing the legal case as a pre-step for the subsequent abstract interpretation of the law. ${ }^{1789}$ While the application actually refers to the object of the legal issue, the interpretation refers to the target of the legal issue. The approach transferred from finance theory and domestic tax policy making of "atomising" and replicating the economic risk-return profile of financial instruments by options as their ultimate building blocks ${ }^{1790}$ principally allows us to draw conclusions towards legal differentiators. In imperfect tax systems such as the OECD MTC it leaves a theoretical residuum of building blocks with specific risk characteristics ${ }^{1791}$. Combined with the systematic considerations by the IAS/ IFRS and the techniques of finance theory, this approach led to the following conclusions:

- Aggregation cannot be justified by the substance over form principle ${ }^{1792}$. It would create highly erratic or arbitrary and eventually coincidental results, which would not be in line with the purpose, intention and function of the OECD MTC's distributive articles.

- The necessity of disaggregating financial instruments for the application of the OECD MTC cannot be generally rejected. ${ }^{1793}$

- Legal risks in general ${ }^{1794}$ and membership rights in particular ${ }^{1795}$ must be excluded from disaggregation.

- Financial instruments not formally referring to a share as their underlying are not shares pursuant to Art. 10(3) OECD MTC and are not profit-participating debt-claims pursuant to Art. 11(3) OECD MTC $^{1796}$.

- Subordination has a major influence on the investor's exposure to business risk, in that it represents the primary absorber for business losses ${ }^{1797}$.

- The maturity of financial instruments considerably affects their risk-return profiles, in that the default risks increase the longer the durations are ${ }^{1798}$.

\footnotetext{
1788 See par. 195.

${ }^{1789}$ See par. 85 et seq.

${ }^{1790}$ See par. 89.

${ }^{1791}$ See par. 92.

${ }^{1792}$ See par. 95.

${ }^{1793}$ See par. 96.

${ }^{1794}$ See par. 101(2).

1795 See par. 106(6).

${ }^{1796}$ See par. 103(3).

${ }^{1797}$ See par. 107.

${ }^{1798}$ See par. 107(2).
} 
- Financial instruments with a mere notional or floating principal cannot be shares pursuant to Art. 10(3) OECD MTC or debt-claims pursuant to Art. 11(3) OECD MTC. However, they are an indicator for other income pursuant to Art. 21(1) OECD MTC ${ }^{1799}$.

- The temporal payment profile ${ }^{1800}$ and the origin of the capital or principal ${ }^{1801}$ basically have little interpretation significance. This is why the time-based and risk-based components are not to be separated by way of disaggregation.

- Option rights and optional components are not to be separated from their underlyings but instead represent an integral part of them ${ }^{1802}$.

The key insight of these conclusions is to set the scope and an important limitation for the substance over form principle. By providing a clear rule against a consolidated view of separate legal instruments, it accentuates the legal form of financial instruments as the general baseline. It actually determines the upper limitation and the largest logical unit for the interpretation and application of the OECD MTC. On the other hand, the approach gives important guidelines for certain fields of potential differentiators, in that it further limits their number and indicates their significance.

338 Beneficial ownership is an indirect relation between a subject (i.e. a person) and an object (i.e. the asset or transaction) by way of composite legal transactions ${ }^{1803}$. The concept must be separated into beneficial ownership in the income or transaction and beneficial ownership in the asset ${ }^{1804}$. While the former serves the (re-)attributional purpose, the latter serves the anti-abuse purpose ${ }^{1805}$. The (re)attributional aspect subsists explicitly in Art. 10(2) and 11(2) OECD MTC but implicitly in Art. 13(5) and 21(1) OECD MTC. In contrast, the anti-abuse aspect subsists in Art. 10(2) and 11(2) OECD MTC only ${ }^{1806}$. The concept does not affect the genuine legal concepts and the interpretation of the terms dividends and interest ${ }^{1807}$. It replaces one subject by another instead of (re-)classifying one object into another ${ }^{1808}$. Consequently, it leaves the general principles and requirements to the inflow untouched (i.e. the income) but applies them to the outflow (i.e. the re-attribution) in a comparably less stringent manner ${ }^{1809}$. The concept of beneficial ownership might principally be operationalised by a narrow risk test similar to the IAS/IFRS concept of economic relationship. ${ }^{1810}$ In systematic correspondence to the converse approach for the disaggregation scheme, this risk test is founded on a causal relation between the in- and outflows of individual transactions ${ }^{1811}$. This causal relation must be quantitatively observable by an expected negative correlation depending on the same risk, and the in- and outflows must proportionate in approximately equal amounts or benefits. Where there is a dominating credit risk because of a time gap between the in- and outflow of an individual transaction, there cannot possibly

\footnotetext{
${ }^{1799}$ See par. 107(3).

1800 See par. 107(4).

${ }^{1801}$ See par. 107(5).

1802 See par. 107(7).

1803 See par. 119 et seqq.

${ }^{1804}$ See par. 127.

1805 See par. 128.

1806 See par. 142.

${ }^{1807}$ See par. 124 and 129.

1808 See par. 132.

${ }^{1809}$ See par. 140.

${ }^{1810}$ See par. 135.

1811 See par. 137.
} 
be an economic relationship between them. As a consequence, a non-dominating credit risk is not capable positively verifying beneficial ownership, whereas a dominating credit risk is capable negatively falsifying it ${ }^{1812}$. The key outcome of this section for the application of the OECD MTC to financial instruments is to introduce the concept of beneficial ownership as an important link between the various differentiators. It helps to better understand the treatment of basic terms such as income, accrued interest or capital gains. In that, it also contributes to avoid narrowing the view and thus constricting some crucial attributes towards meaninglessness.

339 The concept of beneficial ownership leads to the systematic conclusion that the term income has to be separated into an autonomous and qualitative aspect of its causal or contextual nature on the one hand and the domestic and quantitative determination of the tax base on the other ${ }^{1813}$. This makes negative income accessible to the general principles of the OECD MTC. The actual separation of the income's causal or contextual nature from its mathematical sign also means its independence from the income's amount ${ }^{1814}$. As a consequence, the absence of any income from a financial instrument at all does not remove the necessity and feasibility of classifying it into the distributive articles of the OECD MTC.

340 The terms paid in Art. 10(1) and 11(1) OECD MTC and from in Art. 10(3) and 11(3) OECD MTC form one logical unit or concept to be interpreted autonomously ${ }^{1815}$. They further limit the domestic interpretation of income ${ }^{1816}$.

341 Capital pursuant to chap. IV of the OECD MTC cannot be distinguished from income pursuant to chap. III of the OECD MTC economically but only legally. ${ }^{1817}$ Consequently, any income including capital gains must be realised at least by way of a legal event that creates a new right arising from a domestic field of law that is precursory to its tax law. ${ }^{1818}$ Thus, the OECD MTC represents a realisation-based tax system rather than an accretion-based tax system, being subject of a limited autonomous interpretation. Such a realisation principle sets the scope for the classification of income types from financial instruments in so far as deemed or notional income is basically not accessible to the OECD MTC. ${ }^{1819}$ The differentiator of capital gains pursuant to Art. 13(5) OECD MTC as opposed to the other income types of financial instruments is that the legal event must refer to the asset, in that it impairs the mathematical number of the critical ownership rights in the asset. ${ }^{1820}$

342 The key benefit of these sections for the interpretation and application of the OECD MTC is to demonstrate and disentangle the ambiguous meaning of the term income as an important link between the treaty law and the domestic tax law. As such, it particularly contributes to the understanding and role of the realisation

\footnotetext{
1812 See par. 138.

${ }^{1813}$ See par. 139.

${ }^{1814}$ See par. 201.

${ }^{1815}$ See par. 151.

${ }^{1816}$ See par. 152.

${ }^{1817}$ See par. 158.

${ }^{1818}$ See par. 163(1).

${ }^{1819}$ See par. 173.

${ }^{1820}$ See par. 160 et seqq
} 
principle in the distinction between income pursuant to chap. III of the OECD MTC, capital gains pursuant to Art. 13(5) OECD MTC and capital pursuant to chap. IV of the OECD MTC.

343 Financial instruments are particularly sensitive to contextual or situative determinants. ${ }^{1821}$ This is why legal entitlements have a dual purpose of potentially representing both the economic return for legal obligations and parts of the economic operation itself. ${ }^{1822}$ Therefore, the legal entitlements must be subject of a precedent analysis in order to determine whether they represent the former (then to be interpreted domestically) or the latter (then in so far to be interpreted autonomously). Apart from this, the various legal criteria are principally equivalent. ${ }^{1823}$ The main outcome of this section is to call attention to some peculiarities of financial instruments and to recommend a respective orientation for the perspective in which the OECD MTC should be applied in this respect.

344 Within the scope of this study ${ }^{1824}$, matters of attribution and ownership are not accessible to the treaty principle of substance over form other than the concept of beneficial ownership ${ }^{1825}$. In particular, there is no inherent systematic principle like an "economic ownership" in the Art. 10(3), 11(3), 13(5) and 21(1) OECD MTC. In order to constitute a debt-claim pursuant to Art. 11(3) OECD MTC ${ }^{1826}$ or capital gains pursuant to Art. 13(5) OECD MTC ${ }^{1827}$, the transfer of the capital as principal may consequently not be a mere economic one but must necessarily be a legal one. The result of this section for the interpretation and application of the OECD MTC is to strengthen the role and purity of the beneficial ownership concept. In that, it provides clarity in regards to alternative concepts of attribution and ownership and thus helps to further focus on the relevant aspects when dealing with financial instruments.

345 The voluntariness test describes potential payment conditions due to the source's subjective decision on whether or not there shall be a payment or distribution. ${ }^{1828}$ Voluntariness represents a sufficient maximum condition for constituting other equity rights and consequently also for dividends pursuant to Art. 10(3) OECD MTC. ${ }^{1829}$ In the sense of a non-exclusive verifier, it can also be interpreted from the term's etymological origin. Multilateralism in the sense of an involvement of more than two contracting parties can be an indicator for voluntariness, but neither be its verifier nor a falsifier for its complement of involuntariness. ${ }^{1830}$

346 Involuntariness is represented by the redemption obligation in the sense of an absolute and unconditional legal right to be repaid ${ }^{1831}$ and can likewise be interpreted from the term's etymological origin ${ }^{1832}$. However, it has merely the status of a necessary minimum condition (i.e. not of a verifier) for constituting time value of

\footnotetext{
${ }^{1821}$ See par. 180 .

${ }^{1822}$ See par. 181.

${ }^{1823}$ See par. 182.

${ }^{1824}$ See sec. 1.2.

${ }^{1825}$ See par. 187.

${ }^{1826}$ See par. 297.

${ }^{1827}$ See par. 359 and seq.

${ }^{1828}$ See par. 188.

${ }^{1829}$ See par. 285.

${ }^{1830}$ See par. 191.

${ }^{1831}$ See par. 289.

${ }^{1832}$ See par. 285.
} 
money ${ }^{1833}$ and consequently also for genuine debt-claims and interest pursuant to Art. 11(3) OECD MTC ${ }^{1834}$. The material test for the formal criterion of involuntariness is self-execution. ${ }^{1835}$ It describes the absence of any payment condition at all. ${ }^{1836}$ The redemption obligation and therefore Art. 11(3) OECD MTC do not apply to repurchase obligations. ${ }^{1837}$

347 The concept of duration or maturity, which is reflected by the redemption obligation ${ }^{1838}$, can be more precisely described in the stochastical sense as a more or less certain or uncertain condition ${ }^{1839}$. It is most meaningful when being replaced with the stochastical concept of remuneration. ${ }^{1840}$ In that, it becomes a hybrid concept, which is, at the same time, both time-based and risk-based. The subjacent conflict or dualism between aspects of time and those of risk must be solved in favour of the former where the two overlay. ${ }^{1841}$ This leads to the conclusion that the absence of a duration or maturity cannot be a differentiator for the income types of financial instruments. Where a duration of legal time periods actually exists, it can only be reduced by way of economic interpretation, and not extended. ${ }^{1842}$

348 Participation in profits and losses is a relative concept and subordinate to a non-participation in profits and losses $^{1843}$. The two form a multi-static array of unlimited forms or states in the sense of a flexible or fluid "more or less" spectrum. As a consequence, it is systematically divided into the two different aspects of profits and losses on the one hand and participation or non-participation on the other ${ }^{1844}$ While actual profits and losses as income are to be determined by reference to domestic tax law, the question whether there is participation in that income also allows an autonomous interpretation. However, the purposive weakness of this approach in not allowing objective or universal statements, potentially deserves a cautious invocation and therefore relatively little interpretation significance of the participation in profits and losses criterion. ${ }^{1845}$ The criterion is legally reflected by the attribute participating in profits in both Art. 10(3) and 11(3) OECD MTC. It represents a constituent element of the term other rights but an extending modification of the term debtclaims. ${ }^{1846}$ Set into a relationship with the negating insertion not being debt-claims in Art. 10(3) OECD MTC, this interaction of the two provisions on different logical levels is the interpretational justification that the term debt-claims bears itself no genuine right to participate in profits. Beyond that, the attribute participating in profits is, however, not capable of serving as a differentiator for distinguishing equity and debt. ${ }^{1847}$

\footnotetext{
1833 See par. 242(3).

${ }^{1834}$ See par. 291.

1835 See par. 289.

${ }^{1836}$ See par. 189.

${ }^{1837}$ See par. 292.

${ }^{1838}$ See par. 296.

${ }^{1839}$ See par. 196.

${ }^{1840}$ See par. 198.

${ }^{1841}$ See par. 199.

${ }^{1842}$ See par. 197.

${ }^{1843}$ See par. 204.

${ }^{1844}$ See par. 205.

${ }^{1845}$ See par. 206.

${ }^{1846}$ See par. 273.

${ }^{1847}$ See par. 280 and 295.
} 
349 Modifications of the payment profile represent a time-based remuneration:

- independent of its periodicity, if the remuneration is either time-based or risk-based but time-equivalent ${ }^{1848}$;

- if an uncertainty refers only to the timing risk of when the remuneration is paid, but not to the underwriting risk of whether or not it is paid at all ${ }^{1849}$;

- where modified amounts from remuneration payments, analysed by grouping them together as a coherent whole, are exactly and certainly compensated by other remuneration payments from the same financial instrument ${ }^{1850}$;

- if deferred payments bear compound interest ${ }^{1851}$; and

- independent of currency risk ${ }^{1852}$.

The income or transaction is basically to be classified according to the dynamic forward-looking view ${ }^{1853}$. This is at the date of income payment, but in consideration of the remaining expectable lifetime of the financial instrument.

350 Unless they are time-equivalent ${ }^{1854}$, positive modifications of the payment profile still represent a participation in profits and - in contrast to the time value of money ${ }^{1855}$-negative ones as well. The word profits in Art. 10(3) OECD MTC also includes losses. As a consequence, business risk is necessarily contained in and inextricably coalesced with both the participation in profits and losses (remuneration risk) and the capital or principal itself (termination risk). ${ }^{1856}$ Nevertheless, the two aspects must be kept separated because the term debt-claims in Art. 11(3) OECD MTC, which bears itself no termination risk, is extended only by the remuneration risk $^{1857}$. This conceptual deficiency within the OECD MTC is due to the necessity that the underwriting risk in general and thus also the business risk in particular must be subsidiary to the redemption obligation requirement in order to constitute debt-claims as a legal construct (form over substance). ${ }^{1858}$ Thus, the negating insertion not being debt-claims in conjunction with the attribute participating in profits turns out as to be the interpretational key element for the debt-equity distinction ${ }^{1859}$. It leaves the crucial aspect of business risk only in the form of termination risk as a residuum within the term other rights and therefore Art. 10(3) OECD MTC.

351 Termination risk is the non-legal underwriting risk towards a non-perfect recovery of the capital or principal at maturity ${ }^{1860}$ It is capable of falsifying time equivalence and consequently the time value of money. ${ }^{1861}$ Termination risk arises where the pay leg of a financial instrument, separated by way of disaggregation,

\footnotetext{
${ }_{1848}$ See par. 211 et seq.

${ }^{1849}$ See par. 213.

${ }^{1850}$ See par. 215.

${ }^{1851}$ See par. 216.

${ }^{1852}$ See par. 217.

${ }^{1853}$ See par. 214.

${ }^{1854}$ See par. 276 et seq.

${ }^{1855}$ See par. 349.

${ }^{1856}$ See par. 279.

${ }^{1857}$ See par. 280.

${ }^{1858}$ See par. 346 et seq.

${ }^{1859}$ See par. 282 and 293.

${ }^{1860}$ See par. 232.

${ }^{1861}$ See par. 242(2).
} 
transfers a cash amount that is not solely dependent on the time value of money or an equivalent number of financial instruments. ${ }^{1862}$ In that, termination risk can principally be determined without applying different classification schemes for various classes of financial instruments (ring-fencing). The material termination risk test includes the formal criterion of a nominal value. ${ }^{1863}$ The nominal value represents the redemption value and therefore a logical link between and fixation of what the creditor transfers to the debtor for lending (receive leg) and what the debtor owes in return to the creditor as the repayment (pay leg). ${ }^{1864}$ This fixation is the legal justification for the transferrable finding from the IAS/IFRS that the pay leg and the receive leg correspond to each other under the fixed-for-fixed condition in a direct way and under the fixed-for-variable condition in an indirect way, whereas under the variable-for-fixed they correspond in neither way. Consequently, where there is no such link there cannot be any provision of capital. As a result, a mere notional or floating principal is a falsifier for dividends pursuant to Art. 10(3) OECD MTC ${ }^{1865}$ and for debt-claims pursuant to Art. 11(3) OECD MTC ${ }^{1866}$ and therefore a verifier for other income pursuant to Art. 21(1) OECD MTC ${ }^{1867}$.

352 Subordination cannot be operationalised in a purposeful way as an autonomous differentiator, as it is determinable only on an individual or situative basis not allowing objective or universal statements. ${ }^{1868}$ Instead, subordination must be interpreted formally and therefore pursuant to the domestic law, giving rise to potential qualification conflicts.

353 Coverage and collateral are economically substitutable. This allows the use of coverage as a differentiator for identifying counterparty risk in a potentially more reliable manner than collateral, in that it is capable of negatively falsifying credit risk. ${ }^{1869}$ Fully covered obligatory financial instruments are not considered debtclaims pursuant to Art. 11(3) OECD MTC, but must rather be classified according to their underlying's nature. ${ }^{1870}$

354 Sources of funds for repaying capital or principal provisions or contributions are not capable of serving as an autonomous differentiator for distinguishing equity and debt ${ }^{1871}$. The reasons are:

- Proceeds from the liquidation of assets are individual or situative, not allowing objective or universal and significant new statements. ${ }^{1872}$

- Business profits are to be determined by reference to domestic tax law. ${ }^{1873}$

- (Re-)financing sources bear a nexus with business profits, making any attempt to disentangle the two in order to reach an autonomous interpretation impossible. ${ }^{1874}$

\footnotetext{
${ }_{1862}$ See par. 348.

${ }^{1863}$ See par. 299.

${ }^{1864}$ See par. 298.

${ }^{1865}$ See par. 282.

${ }^{1866}$ See par. 299.

${ }^{1867}$ See par. 337.

${ }^{1868}$ See par. 220 et seq.

${ }^{1869}$ See par. 229.

${ }^{1870}$ See par. 303.

${ }^{1871}$ See par. 251.

${ }^{1872}$ See par. 244 et seq.

${ }^{1873}$ See par. 246.

${ }^{1874}$ See par. 250.
} 
Instead, the determination of these sources bears a comprehensive and inextricable nexus with that of the income. They actually represent an inseparable mix or "infection" of the former by the latter. In that, they are entirely subject of the domestic interpretation ${ }^{1875}$ and therefore give rise to potential qualification conflicts ${ }^{1876}$. Due to the phrase whether or not carrying a right to participate in the debtor's profits, this also applies to debtclaims pursuant to Art. 11(3) OECD MTC. ${ }^{1877}$

355 Limb 2 of Art. 10(3) OECD MTC acts as a general clause for limb 1 in the sense of an intersection ${ }^{1878}$, whereas limb 3 acts as a special clause for limb 2 in the sense of a carve-out ${ }^{1879}$. As a consequence, limb 2 can share its attributes with limb 1 (upwards) but not take any attribute from limb 3 (downwards). In particular, the attribute other corporate rights as such is not relevant for the interpretation of the term other rights. ${ }^{1880}$ Instead, it is to be interpreted autonomously and actually means equity rights as opposed to debt-claims. Consequently, the word other in limb 2 is to be understood in a different sense than the word other in limb 3. ${ }^{1881}$

356 The meaning of the word debt-claim is not limited to cash but also includes non-cash obligations. ${ }^{1882}$ The purpose of the debt-claim and whether or not it is securitised or subordinated ${ }^{1883}$ is not relevant for its classification pursuant to Art. 11(3) OECD MTC, nor is the deduction from the debtor's tax base $\mathrm{e}^{1884}$.

357 The difference between accrued interest and other forms of imputed interest is that the latter is no remuneration for the main or principal service of financing. ${ }^{1885}$ However, to the author's understanding, the consensus view that accrued interest shall be considered paid is not a justifiable legal principle but rather appears to be a common or best practice ${ }^{1886}$.

358 The following illustration visualises and summarises the understanding of debt-equity delimitation as represented in this study:

\footnotetext{
1875 See par. 251.

${ }^{1876}$ See par. 252.

1877 See par. 302.

${ }^{1878}$ See par. 260 and 272.

${ }^{1879}$ See par. 267 and 272.

${ }^{1880}$ See par. 272.

${ }^{1881}$ See par. 270 and 272.

${ }^{1882}$ See par. 300 et seq.

${ }^{1883}$ See par. 304.

${ }^{1884}$ See par. 305 .

1885 See par. 306.

${ }^{1886}$ See par. 307 et seqq.
} 


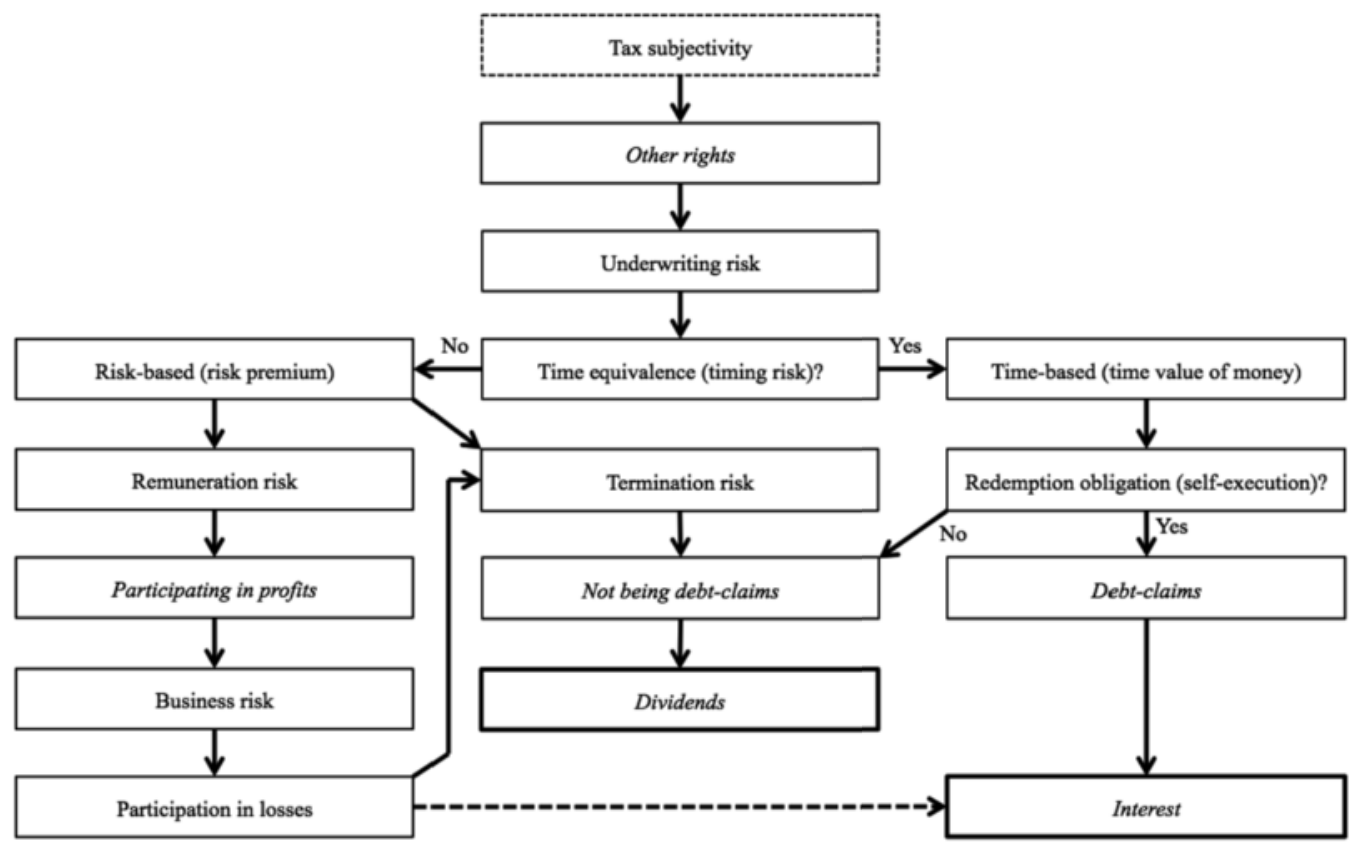

Criterion (condition) entirely subject of domestic interpretation

$\square$ Criterion (condition) subject entirely or partially of autonomous interpretation

$\square$ Consequence (definition)

Illustration 23: Logical debt-equity delimitation scheme (high-level)

359 The main outcome of these sections is not only to introduce, analyse and distinguish some inherent concepts in what is discussed in the jurisprudential research and discourse as potential differentiators between debt and equity. In particular, these concepts are embedded and discussed in a thorough legal interpretation of Art.10(3) and 11(3) OECD MTC. Beyond that, those concepts are also operationalised into concrete tie-breaking tests. In addition, the sections further analyse the relations between these classifiers and their relative significance. In that, they are re-evaluated against each other and reduced to a compact set of clear and meaningful differentiators for the interpretation and application of the OECD MTC to financial instruments. As the key objective, the study thus recommends a system of classifiers, which are coherent, consistent, universal, complete, mutually exclusive, justifiable, autonomous, objective, resilient and operationalizable ${ }^{1887}$.

360 As regards capital gains pursuant to Art. 13(5) OECD MTC, the term alienation must be subject of a differentiated interpretation. The reason is that it actually coalesces the following different aspects: ${ }^{1888}$

\footnotetext{
1887 See sec. 1.1.2.

${ }^{1888}$ See par. 314.
} 
- A change in the asset attribution, which must be interpreted formally or legally and therefore under the terms of domestic tax law pursuant to Art. 3(2) OECD MTC. ${ }^{1889}$

- A transfer transaction as a result from that change, which must likewise be interpreted formally or legally and therefore under the terms of domestic tax law. ${ }^{1890}$

- The realisation of this transaction, which includes partial disposals and is subject of a limited autonomous interpretation applying form over substance. ${ }^{1891}$ It requires at least a legal event arising from a domestic field of law that is precursory to its tax law and refers to the asset, in that it impairs the mathematical number of the critical ownership rights in the asset pursuant to domestic law.

- The attribution of the capital gain from this realised transaction, which is subject of the substance over form principle in the form of the beneficial ownership concept. ${ }^{1892}$

361 Hence, the substance over form principle theoretically takes effect only upon the subjective attribution of the capital gains, i.e. the pass-through of the realised income rather than the ownership rights in the asset itself. ${ }^{1893}$ This view is however not of major relevance for the theory of interpreting Art. 13(5) OECD MTC (but may be relevant for the practice of its application). The reason is that the genuine attributee of capital gains is always identical with the attributee of the asset itself. ${ }^{1894}$ Only with this reservation and to this extent does the author agree with the majority view that the term alienation could in result be said to require a "change in economic ownership". ${ }^{1895}$

362 Cases of unilateral termination without a transfer to another person or subject are not included in the term alienation pursuant to Art.13(5) OECD MTC. ${ }^{1896}$ Among the bilateral transfers to another person or subject, the return for the disposal is not relevant either. As a consequence, the term alienation also includes non-cash exchange transactions and transactions without any return at all. That is why the information to what extent the ratio between the number of the critical ownership rights in the asset and their proportional value changes as a result of the transaction ${ }^{1897}$ cannot be used as a differentiator for capital gains ${ }^{1898}$.

363 The key benefit of these sections is to complement the recommended debt-equity delimitation by a corresponding analysis and presentation of capital gains. In that, the study not only contributes to the better understanding and application of numerous DTC to financial instruments; altogether, it also reveals and demonstrates the limitations, deficiencies and areas for potential improvements of the OECD MTC when tackling the specific challenges of modern financial instruments.

\footnotetext{
${ }^{1889}$ See par. 315 .

${ }^{1890}$ See par. 317 et seqq.

${ }^{1891}$ See par. 320 .

${ }^{1892}$ See par. 321.

${ }^{1893}$ See par. 322.

${ }^{1894}$ See par. 323.

1895 See par. 324.

${ }^{1896}$ See par. 326.

${ }^{1897}$ See par. 162 and 253.

${ }^{1898}$ See par. 326.
} 
364 While Art. 21(1) OECD MT is a residuary clause for all other distributive articles of the OECD MTC ${ }^{1899}$, the definition and delimitation of gambles is in result not relevant for this study ${ }^{1900}$.

1899 See par. 328.

${ }^{1900}$ See par. 330 et seq. 



\section{Chapter 5}

\section{Classification of selected types of financial instruments}

\subsection{Preliminary remarks}

365 The purpose and objective of this practice section is to concretely subsume a variety of financial instruments under the relevant distributive articles of Art. 10(3), 11(3), 13(5) or 21(1) OECD MTC. The classification is made on the level of types or classes described by one or more specific features. As a consequence, the analysis remains on a certain abstraction level. Furthermore, the range of financial instruments chosen for such application represents an open selection without making any claim to be complete or exhaustive. Facing a vast diversity of new innovations and modifications as well as an almost infinite number of financial instruments throughout the world ${ }^{1901}$, it picks those types or classes which the author encountered during this study and which seem conceptually the most ambiguous and controversial ones. The selection starts with forward transactions, including options and swaps as the building blocks ${ }^{1902}$ of many financial instruments ${ }^{1903}$, particularly convertibles ${ }^{1904}$. It then proceeds to so-called linkers ${ }^{1905}$ as a kind of "integrated convertibles" and eventually to preference shares ${ }^{1906}$, which in some respect may be seen as the conceptual opposite of such linkers. The section ends with a side note on strips ${ }^{1907}$ because of their specific ambiguity between income (transaction) and capital (asset) and a side note on the cross-sectional class of non-cash based financial instruments ${ }^{1908}$, which exhibits some very specific features which give rise to additional systematic issues.

\footnotetext{
${ }^{1901}$ See par. 8.

1902 See par. 89.

${ }^{1903}$ See sec. 5.2.

${ }^{1904}$ See sec. 5.3.

${ }^{1905}$ See sec. 5.4.

${ }^{1906}$ See sec. 5.5.

${ }^{1907}$ See sec. 5.6.

${ }^{1908}$ See sec. 5.7.
} 


\subsection{Forward transactions and swaps}

\subsubsection{Structure}

366 Forward transactions in the broader sense are financial instruments featured with a deferral between obligation and execution. The minimum length of this deferral period in order to separate spot and forward transactions is typically set by convention ${ }^{1909}$ and depends to a large extent on the respective market practice (e.g. currency forwards between institutional counterparties can be intra-day). The underlyings of forward transactions in the broader sense can be assets (e.g. securities, currencies) but also future cash flows (e.g. interest ${ }^{1910}$, mortgages ${ }^{1911}$, etc.) or risks (e.g. credit default swap ${ }^{1912}$, variance or volatility swaps ${ }^{1913}$, compound or split-fee options). Swaps are recurring or repetitive forward transactions, which actually means that the execution of the entire financial instrument is spread over more than one single time.

367 As a general issue applying to all kinds of such forward transactions in the broader sense, the question arises whether the deferral as such has any relevance for the income classification. To the author's understanding, the answer must be in the negative. The reason is that it is not the mere entering into an obligation or commitment which is a transfer at the disposal of the counterparty ${ }^{1914}$ and thus a realised tax event ${ }^{1915}$, but rather its later execution. This becomes even more evident by considering that the amount of the future income pursuant to chap. III of the OECD MTC is not even known at this early point in time. Although it can admittedly be argued that an option premium is such realised income, this is, however, not a consequence of the deferral as such but rather of the financial instrument's optional nature ${ }^{1916}$. The reason is that the option premium is realised solely and exclusively because the option holder has to compensate the option writer definitively for taking the definitive risk of maybe not executing the option in future. This becomes particularly clear when considering that, if the financial instrument was not optional and thus that risk not definitive, any premium would be merely a provisional pre-payment (e.g. margin payments) on the total income (i.e. the actual capital gain) and could therefore not yet be realised. While the purpose and value of the optional component depends on the deferral (i.e. the longer the maturity the higher usually the option premium), the deferral does, in turn, not depend on the optional component. The natural reason is that the deferral is a constituent feature of all kinds of forward transactions, whereas the optional component is a constituent feature only of a specific class of forward transactions (hereinafter referred to as "options"). For these reasons, it can be held as an interim conclusion for the further course of this study that a deferral between the obligation and execution of financial instruments has itself no relevance for their classification. Therefore, forward transactions are - in this temporal respect - nothing but the respective spot transactions and therefore basically share their underlyings' fate. For instance, a forward purchase - just as a spot purchase - is not a realised tax event, whereas a forward sale is basically nothing other than a spot sale and therefore principally capable of realising a capital gain ${ }^{1917}$.

\footnotetext{
${ }^{1909}$ See Example 10 on p. 41.

${ }^{1910}$ For a comprehensive overview of common products observable on the market see Frank Fabozzi, p. 756 et seqq.

${ }^{1911}$ Frank Fabozzi, p. 775 et seqq.

${ }^{1912}$ Frank Fabozzi, p. 790 et seq.

${ }^{1913}$ Juan Ramirez, p. 58 et seqq.

${ }^{1914}$ See par. 148,169 and 320.

${ }^{1915}$ As will be shown in the following (see par. 370).

1916 See par. 369 et seq.

${ }^{1917}$ See par. 326
} 
368 Going further, the relevant legal features of forward transactions in that broader sense are:

(1) optionality, i.e. whether or not the execution is at the discretion of one contracting party;

(2) seriality, i.e. whether or not the execution is spread over more than one single time;

(3) the tax-wise nature of the underlying pursuant to the distributive articles of the OECD MTC; and

(4) the way or method of settlement, i.e. gross physically or net cash or net share.

\subsubsection{Optionality}

369 As regards the first aspect (1), options are different from non-optional forward transactions (i.e. in the narrow sense, hereinafter referred to as "forwards"). The difference is that the deferred execution is subject to the holder's subjective decision or discretion. In fact, such unilateral participation in value appreciation without also participating in value depreciation represents a separation of the underlying's risks and chances. It is followed by a shift of solely the underlying's risks from the option holder to the option writer (i.e. an asymmetric net risk ${ }^{1918}$ ), which is typically compensated by the risk premium ${ }^{1919}$ as the price of the option agreement (economic insurance). This option price is the expectable (risk-adjusted) return or income of the option holder from the underlying (e.g. the expected capital gain), which is correspondingly the expectable loss of the option writer from that underlying. Unlike the actual capital gain of forwards, this return or income is typically, but not necessarily ${ }^{1920}$, paid in advance. In fact, this merely means that it is debt-financed by the option writer ${ }^{1921}$ and therefore reduced (discounted) by the respective debit interest (time-adjusted) ${ }^{1922}$. However, this advance financing is not the constituent or qualifying feature of options ${ }^{1923}$. And even if it was, such financing of the expected return or income was ancillary to the main or principal service of the underlying operation itself (e.g. transferring the underlying asset) and therefore gave rise to imputed interest only ${ }^{1924}$. In addition, the typical short-term duration or maturity of options does not necessitate a high application significance and therefore a disaggregation of that interest component ${ }^{1925}$. In result, the only question remaining is therefore whether options and consequently realised option premiums are ceteris paribus to be classified separated from their underlyings.

\section{Options are to be classified at their maturity}

370 In this respect, it was stated that risk considerations principally support the view of not separating options from their underlyings but instead of treating the two as one logical concept or mechanism. The reason was that already upon entering into the option obligation or commitment the underlying's risk burden as one of its most important economic interests, just as selling the underlying spot, changes from the option holder to the option writer ${ }^{1926}$. However, this autonomous view basically conflicts with the semi-autonomous

\footnotetext{
${ }^{1918}$ See par. 64.

${ }^{1919}$ See Example 24 on p. 108.

${ }^{1920}$ IAS Board, December 2016, 5B, p. 8 et seq., par. 29(a).

${ }^{1921}$ See par. 106(7).

${ }^{1922}$ Black, Fischer / Scholes, Myron, The Pricing of Options and Corporate Liabilities, The Journal of Political Economy 1973, Vol. 81, No. 3 , p. 644.

${ }^{1923}$ See par. 89 and 91

${ }^{1924}$ See par. 306.

${ }^{1925}$ Perhaps contrary: Achim Pross, p. 167 et seq., discussing the principal separability of the interest component of swaps only in the general context of financial engineering without, however, taking a clear position on whether or not it is actually suggested in the particular context of the OECD MTC. See also par. 106(4) and 212.

${ }^{1926}$ See par. 106(7).
} 
interpretation of the realisation requirement, particularly where the option is not executed ${ }^{1927}$. In this case, the genuine income is not yet transferred at the disposal of the recipient or beneficial owner in the manner required by contract or by custom ${ }^{1928}$ (e.g. interest exchanged with an optional forward rate agreement). Where the underlying is an asset, it also conflicts with the domestically interpreted change of the asset attribution $^{1929}$ as a necessary minimum condition (conditio sine qua non) for constituting capital gains pursuant to Art. 13(5) OECD MTC ${ }^{1930}$. In this case, the formally interpreted legal event could not refer to the asset, as the mathematical number of its critical ownership rights is not impaired. These conflicts are actually caused by the optional nature of perhaps not being executed and therefore not transferring the underlying. And, secondly, they are rooted in the deferral between the realisation of the option premium and the realisation of the underlying. In fact, the optional character was found to be independent of the realisation itself and therefore irrelevant for the income classification ${ }^{1931}$, even more as the mere advance payment as such is no constituent or qualifying feature of options ${ }^{1932}$. In other words: the payment date cannot possibly alter the genuine nature and therefore the classification of the income. In fact, the option premium represents a participation in the positive economic interests without necessarily transferring also the underlying itself, which are however both required by Art. 10(3), 11(3) and 13(5) OECD MTC. As the temporal element is irrelevant, the distributive articles are consequently triggered as soon as the last legal condition or requirement is fulfilled, just as for any other structured transfer (e.g. pre-payments, initial public offerings). In other words: the distributive articles require an actual transfer at the disposal of the counterparty. Consequently, the nature and therefore the classification of an option premium - even though being realised itself ${ }^{1933}$ - can eventually not be determined before the option is due. This also reflects the key difference between the nature of options and any form of capital provision (i.e. debt or equity), in that a capital provision actually represents a total of two closed transfers (i.e. the provision and repayment of the underlying), each out of one opening (i.e. the obligation) and one closing event (i.e. the execution). In contrast, an option actually represents a total of just one transfer (i.e. of the underlying) out of one opening and one closing event (pending transaction). In addition, this understanding is also in line with the dynamic forward-looking view of income classification, which must consider the remaining expectable lifetime of the option ${ }^{1934}$. Ergo, once the option is executed and settled gross physically, the option premium fulfils all information requirements to be classified into the distributive articles of the OECD MTC.

Example 51: The option premium of a "deep-in-the-money option"1935 (short call or long put) should regularly be subsumable under Art. 13(5) OECD MTC if gross-physically settled.

\footnotetext{
1927 See par. 320 et seqq.

${ }^{1928}$ See par. 148.

${ }^{1929}$ See par. 315 .

${ }^{1930}$ See par. 314.

${ }^{1931}$ See par. 367.

${ }^{1932}$ See par. 369.

1933 See par. 367.

${ }^{1934}$ See par. 214.

${ }^{1935}$ See Example 5 on p. 30.
} 
Obviously, these principals of such late classification only at closing ("wait and see” approach ${ }^{1936}$ ) are even more evident for forwards ${ }^{1937}$, which bear symmetric risks and therefore do not pay out any risk premium at all. As regards the option right itself, its execution represents a unilateral termination without a transfer to another person or subject and therefore no alienation pursuant to Art. 13(5) OECD MTC ${ }^{1938}$.

\section{Premiums of expired options are other income pursuant to Art. 21(1) OECD MTC}

371 Hence, where the option expires, the option premium does not fulfil the requirements to a capital gain pursuant to Art. 13(5) OECD MTC. However, the subsequent question arises whether its participation in the positive economic interests of the underlying may makes the option premium itself a dividend pursuant to Art. 10(3) OECD MTC or perhaps a profit-participating debt-claim pursuant to Art. 11(3) OECD MTC. Beforehand, this could only be the case if the option formally refers to a share as its underlying. ${ }^{1939}$ Otherwise the option premium must necessarily be subsumed under Art. 21(1) OECD MTC. Given this formal reference, such mere partial participation in only the positive economic interests of the underlying can still represent a participation in profits. The reason is that the word profits in Art. 10(3) OECD MTC can, but not necessarily must, include losses. ${ }^{1940} \mathrm{In}$ addition, the business risk from the level of the underlying is merely replaced by the business risk coincidently transferred into the level of the option itself. ${ }^{1941}$ Due to the concept of time equivalence ${ }^{1942}$, it also does not principally conflict with the time value of money as a constituting element ${ }^{1943}$ of genuine debt-claims, even more as any option always has a time-based duration or maturity. However, the premium of an expired option obviously does not represent a requisite capital provision to constitute a genuine share or debt-claim. In fact, there is no capital provision with a total of two closed transfers ${ }^{1944}$ of a provision and a repayment of capital or principal. As a consequence, the extending modification in Art. 11(3) OECD MTC cannot come into effect either.

372 Lastly, the option premium of an expired option cannot represent a derivative dividend or interest by way of beneficial ownership either. The reason here is not that an option is not a capital provision ${ }^{1945}$, as the concept of beneficial ownership was found to be separated into the asset-related and transaction-related aspect ${ }^{1946}$. Instead, the reason is that beneficial ownership is not a (re-)classification of the option premium into a dividend or interest but rather a replacement of its recipient by the beneficial owner. ${ }^{1947}$ Therefore it still requires a genuine dividend or interest as a necessary minimum condition (conditio sine qua non) to apply. For the following reasons, this can never be true:

\footnotetext{
${ }^{1936}$ See footnote 809 .

${ }^{1937}$ Argumentum a minori ad maius.

${ }^{1938}$ See par. 326.

${ }^{1939}$ See par. 103(3).

${ }^{1940}$ See par. 350.

${ }^{1941}$ See par. 277.

${ }^{1942}$ See par. 212.

${ }^{1943}$ See par. 296.

${ }^{1944}$ See par. 370.

${ }^{1945}$ See par. 371.

${ }^{1946}$ See par. 122 et seqq.

${ }^{1947}$ See par. 132.
} 
(1) Where the expired option aims at the change of the asset attribution, the option premium as the riskand time-adjusted capital gain $^{1948}$ depends solely on its unrealised value appreciation. Therefore it is independent of any legal event creating a new right. ${ }^{1949}$

(2) Where the underlying is neither a share nor a dividend or interest cash flow there is no requisite formal reference.

(3) From the long perspective of the expired option, the option premium is paid out and not received.

(4) Where the short option is a call, the option writer as the receiver of the option premium had to pay out the dividend or interest cash flow to the option holder (i.e. in the opposite direction of the option premium), so that the former cannot possibly replace the latter.

(5) Where the expired short option is a put on an interest cash flow, the actual interest cash flow is obviously higher than agreed, as the option would otherwise have been executed by the option holder. Consequently, the option premium would represent - if at all - a negatively modified "interest". This was however found incompatible with the concept of time value of money ${ }^{1950}$ as one of the constituting elements ${ }^{1951}$ of genuine debt-claims pursuant to Art. 11(3) OECD MTC. This result remains valid irrespective of the extending modification towards a profit participation, which can thus not come into effect, even more as the financial instrument obviously contains an optional component ${ }^{1952}$.

(6) Where the expired short option is a put on a dividend cash flow, the actual dividend cash flow is obviously higher than agreed, as the option would otherwise have been executed by the option holder. Admittedly, the option premium could analogously represent a negatively modified "dividend", which was found not to be in conflict with business risk ${ }^{1953}$ as one of the constituting elements of other (equity) rights pursuant to Art. 10(3) OECD MTC ${ }^{1954}$. In addition, the transfer of such dividend cash flow should also comply with the requirement of beneficial ownership of a causal relation between the in- and outflows of individual transactions, quantitatively observable by an (expected negative) correlation depending on the same risk ${ }^{1955}$. In the author's view, the transfer of such dividend cash flow does not, however, comply with the requirement of beneficial ownership that the in- and outflows must also proportionate in approximately equal amounts or benefits, which was found to be interpreted in a particularly restrictive sense ${ }^{1956}$. In other words: negatively modified cash flows on the one hand and passed-through ones on the other may - each taken separately - represent dividends pursuant to Art. 10(3) OECD MTC. But the particularly high demands of the beneficial ownership concept on the proportionality of the in- and outflows make it eventually impossible to also subsume the combination of both under Art. 10(3) OECD MTC (i.e. negatively modified cash flows passed-through).

\footnotetext{
${ }^{1948}$ See par. 369.

${ }^{1949}$ See par. 158.

${ }^{1950}$ See par. 215.

${ }^{1951}$ See par. 296.

${ }^{1952}$ See par. 213.

${ }^{1953}$ See par. 276 et seq.

${ }^{1954}$ See par. 282.

1955 See par. 338.

${ }^{1956}$ See par. 135.
} 
For these reasons, the option premium must necessarily be subsumed under Art. 21(1) OECD MTC, where the option expires. As regards the option itself, its expiry represents a unilateral termination without a transfer to another person or subject and therefore not an alienation pursuant to Art. 13(5) OECD MTC 1957 .

\subsubsection{Seriality}

373 As regards the second aspect (2) of seriality ${ }^{1958}$, the execution of forward transactions can be spread over more than one single time (swaps) ${ }^{1959}$. In this respect, it might initially be suggested that swaps are to be disaggregated into a series of forward transactions. In fact, such disaggregation turns out to be unnecessary. The reason is that those partial executions are nothing other than partial transfers of the underlying. Where the underlying is an asset, partial disposals were found to be included in the term alienation pursuant to Art. 13(5) OECD MTC ${ }^{1960}$. Where the underlying is a cash-flow, however, (e.g. total return swap), the question arises what the difference is between a realised partial transfer and a provisional and therefore not yet realised pre-payment on the total income ${ }^{1961}$ from the swap - even more as swaps can themselves be optional (swaption). To the author's understanding, the difference is that partial transfers are themselves closed and cohesive transactions. They refer to different legal events (e.g. time periods, obligations, etc.) and are therefore independent from each other. In contrast, provisional pre-payments are related transactions as they refer to one and the same legal event and are therefore interdependent on each other. Correspondingly, the IAS/IFRS do not recognise payments as assets which compensate future benefits instead of past or actual ones ${ }^{1962}$ either. Consequently, there are principally three types of payments to be distinguished:

- Income, i.e. partial (e.g. swap) or total (e.g. forward) transfers being realised and classifiable on their payment date;

- Option premiums, i.e. partial (e.g. swaption) or total (e.g. option) transfers being actually realised but classifiable only on the option's maturity date; and

- Provisional prepayments, i.e. partial transfers (e.g. margin payments) not being realised, as the requisite legal event of the realisation requirement is in the future.

In other words: the periodic transfers of swaps and swaptions with a cash flow or any other non-asset as their underlying are ultimately transferred at the disposal of the recipient or beneficial owner in the manner required by contract or by custom. ${ }^{1963}$ In that, they represent realised partial transfers analogous and equivalent to partial disposals pursuant to Art. 13(5) OECD MTC. Consequently, swaps and swaptions are already somewhat disaggregated, making any disaggregation dispensable as a separate preparatory step ${ }^{1964}$. This also means that each particular swap or swaption period is in result subject of an individual analysis.

\footnotetext{
${ }^{1957}$ See par. 326.

${ }^{1958}$ See par. 368(2).

${ }^{1959}$ See par. 366.

${ }^{1960}$ See par. 320.

${ }^{1961}$ See par. 367.

${ }^{1962}$ IAS 32.AG11.

${ }^{1963}$ See par. 148.

${ }^{1964}$ See par. 86.
} 


\subsubsection{Underlying}

The underlying's classification as the general principle

374 Concerning the third aspect (3) ${ }^{1965}$, gross-physically settled forward transactions were found to share their underlyings' tax-wise nature ${ }^{1966}$. Regardless of whether optional or non-optional, they are thus to be classified into the same distributive articles of the OECD MTC as their underlyings. In that, they also reflect and integrate themselves into the systematic structure and taxonomy of the OECD MTC. Hence, where the underlying is an asset, its gross-physically settled disposal by way of a forward transaction constitutes a capital gain pursuant to Art. 13(5) OECD MTC ${ }^{1967}$, where a legal event from the domestic law changes the asset attribution by impairing the mathematical number of the asset's critical ownership rights. Accordingly, where the underlying is a cash flow (e.g. forward rate agreement) or any other non-asset (e.g. total return swap), its gross-physically settled transfer at the recipient's or beneficial owner's ${ }^{1968}$ disposal by way of a forward transaction may principally constitute a dividend or interest ${ }^{1969}$, depending on the underlying's classification. In contrast, premiums from expired options and swaptions generally constitute other income pursuant to Art. 21(1) OECD MTC. ${ }^{1970}$

\section{The relevance of beneficial ownership in general}

375 However, like expired options ${ }^{1971}$, gross-physically settled forward transactions with a cash flow or any other non-asset as their underlying must be analysed methodologically as by applying a two-tier approach. The reason is that they might either represent genuine dividends or interest or, if not, passed-through income by way of the derivative concept of beneficial ownership. While this two-tier approach principally also applies to Art. 13(5) OECD MTC, disposals by way of forward transactions represent, however, genuine capital gains. This is due to the fact that the genuine attributee of capital gains is always identical to the attributee of the asset itself. ${ }^{1972}$ In contrast, gross-physically settled forward transactions with a cash flow or any other non-asset as their underlying can not represent genuine dividends or interest. The reason is that those financial instruments can be featured in such a way that the transfer either includes or excludes the asset itself. In the former case, the financial instrument does not transfer the mere cash flow but actually the asset itself and therefore falls as a capital gain under Art. 13(5) OECD MTC. In the latter case, the financial instrument has - even if seen as a capital provision with a total of two closed transfers ${ }^{1973}$ - a mere notional capital or

\footnotetext{
1965 See par. 368(3).

${ }^{1966}$ See par. 367.

${ }^{1967}$ Perhaps contrary: Federal Court of Canada, judgement ref. T-3194-78, 1979, par. 21, leaving however open whether the exercise of the option was considered not a genuine alienation of the underlying capital asset(s) at all or, instead, was actually considered such genuine alienation but constituted and thus to be classified in the derivative context of employment income (see par. 10 and 74) as the subject of this case.

${ }^{1968}$ Swiss Bundesgericht, judgement ref. 2C_364/2012 and 2C_895/2012, 2015.

${ }^{1969}$ Perhaps Contrary: Pöllath, Reinhard / Lohbeck, Allit in Vogel/Lehner, p. 1327, par. 75, without justification.

${ }^{1970}$ See par. 372.

${ }^{1971}$ See par. 371 et seq.

${ }^{1972}$ See par. 323.

${ }^{1973}$ See par. 370 .
} 
principal ${ }^{1974}$. Therefore it cannot be a genuine share ${ }^{1975}$ or debt-claim ${ }^{1976}$ but, in the absence of any finance transaction, basically only other income.

\section{The relevance of beneficial ownership where the underlying is not an asset}

376 However, Art. 21(1) OECD MTC is not only subsidiary to Art. 10(3) and 11(3) OECD MTC but also to Art. 10(2) and 11(2) OECD MTC and thus to the beneficial ownership. The concept of beneficial ownership was found to be separated into the asset-related and transaction-related aspects ${ }^{1977}$. As a derivative concept, it is not necessarily required to comply with all the general principles of the OECD MTC applicable to genuine concepts. ${ }^{1978}$ In other words: where the underlying is classified as a share or debt-claim (i.e. a cash flow or risk with no mere notional capital or principal), the question of whether its gross-physical settlement represents beneficial ownership pursuant to Art. 10(2) or 11(2) OECD MTC (i.e. the underlying level) methodologically applies prior to the subsequent potential classification of the forward transaction itself as other income pursuant to Art. 21(1) OECD MTC (i.e. the "derivative" level). In the author's view, the transfer of cash flows from such forward transactions basically complies with the requirement of a causal relation between the in- and outflows of individual transactions quantitatively observable by an expected negative correlation depending on the same risk, whereby the in- and outflows proportionate in approximately equal amounts or benefits ${ }^{1979}$.

\section{The special case of put options}

377 In the absence of a respective inflow, these conclusions do not apply to uncovered long puts on a dividend or interest cash flow (i.e. forward short sales). These represent actually a net-cash settlement, which will be analysed separately ${ }^{1980}$. Apart from this exception, it applies, however, to gross-physically settled short puts on dividend ${ }^{1981}$ and interest ${ }^{1982}$ cash flows. Admittedly, the actual cash flow is obviously lower than agreed and therefore could be seen as a positively modified "interest". This was found to be incompatible with the concept of time value of money ${ }^{1983}$ as one of the constituting elements ${ }^{1984}$ of genuine debt-claims pursuant to Art. 11(3) OECD MTC. And it also does not comply with the restrictive requirement to beneficial ownership that the in- and outflows must also proportionate in approximately equal amounts or benefits, as the option would otherwise not have been executed by the option holder. In contrast to expired options, the gross-physically settlement produces, however, an additional payment that exactly amounts to the actual cash flow and eventually complements or replaces the option premium received (i.e. pass-through). As a consequence, short put options represent beneficial ownership where the underlying is subsumed under Art. 10(3) and 11(3) OECD MTC respectively.

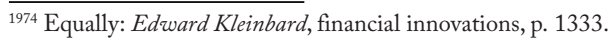

${ }^{1975}$ See par. 282.

${ }^{1976}$ Equally: Gaspar Lopes Dias, debt-claims, sec. 1.3.; OECD, Taxation of new Financial Instruments, OECD, Paris, 1994, p. 13, par. 36, and p. 32, par. 141. See also par. 299.

${ }^{1977}$ See par. 122 et seqq.

${ }^{1978}$ See par. 140.

${ }^{1979}$ See par. 338.

${ }^{1980}$ See par. 380.

${ }^{1981}$ See par. 372(6).

1982 See par. 372(5).

${ }^{1983}$ See par. 215.

${ }^{1984}$ See par. 296.
} 


\subsubsection{Settlement}

378 Regarding the fourth aspect (4) ${ }^{1985}$, to the author's understanding, any form of net settlement principally implies an additional realisation transaction.

Example 52: A net-settled forward sale, long put or short call constitutes not only a disposal of the underlying at the forward price. In addition, it also constitutes the immediate reacquisition of the underlying at the spot price. A net-settled forward purchase, long call or short put constitutes not only an acquisition of the underlying at the forward price. In addition, it also constitutes its immediate resale at the spot price.

While this should be obvious with net cash settlements, it also applies to net share settlements. The reason is that the gross receive leg actually represents a surrogate for the return. ${ }^{1986}$ As such, it is covered by the term paid in Art.10(1) and 11(1) OECD MTC and analogously also by the term alienation ${ }^{1987}$ in Art. 13(5) OECD MTC $^{1988}$. However, where the underlying is an asset, the application of Art. 13(5) OECD MTC fails at least in the absence of its actual transfer in the sense of formally and legally changing its attribution ${ }^{1989}$. In contrast, Art. 10(3) and 11(3) OECD MTC naturally do not provide such a restrictive formal requirement of an asset transfer ${ }^{1990}$. Consequently, only where the underlying is a cash flow from a financial instrument classified as shares or debt-claims, the question remains whether or not the settlement method gains in significance for the classification of financial instruments. Admittedly, financial instruments with a mere notional principal which always coincides with net-settlements were thus found to be unclassifiable as a share or debt-claim. ${ }^{1991}$ Instead, they should be treated as other income. However, such residual classification was said to be subsidiary to the concept of beneficial ownership. Ergo, the question arises whether a net-settled cash flow from financial instrument classified as shares or debt-claims can still represent a passed-though dividend or interest, just as gross-physically settled cash flows from shares or debt-claims do.

379 From the author's point of view, the answer must be in the negative ${ }^{1992}$. On the one hand, the disaggregation of net-settled options into their hypothetic forward and spot components or legs was found incapable of contributing any value added ${ }^{1993}$. The reason was that options represent the building blocks of financial instruments, and are replicable only by other options (put-call parity) without however impacting the economic substance. In result, this applies also to forwards, although in this sense they represent "more complex" financial instruments. The reason is that their multi-stage processing of risk identification, risk disaggregation and risk elimination ${ }^{1994}$ could bring forth only one single non-legal risk type: the underwriting risk from the underlying itself. Obviously, it is this underwriting risk from the underlying itself to which

\footnotetext{
1985 See par. 368(4).

${ }^{1986}$ See par. 181.

${ }^{1987}$ See par. 145.

${ }^{1988}$ See par. 316.

${ }^{1989}$ Equally: Wassermeyer, Franz in Wassermeyer Commentaries, p. 1618, par. 37. See also par. 315.

${ }^{1990}$ See par. 162.

${ }^{1991}$ See par. 375 et seq.

${ }^{1992}$ In result perhaps equally: Carmine Rotondaro, credit derivatives, p. 89 et seqq.

${ }^{1993}$ See par. 89.

${ }^{1994}$ See par. 101 et seqq.
} 
both hypothetic components or legs necessarily refer ${ }^{1995}$. This applies, for instance, also to debt-equity swaps. Their receive leg is merely the return for the underlying operation represented by the pay leg ${ }^{1996}$ and is thus as the income out of scope for any disaggregation. In other words: any disaggregation of forwards still could not resolve the problem of allocating the net-settlement amounts to the hypothetic forward and spot components or legs respectively. In contrast, net-settled options strategies can also represent "more complex" financial instruments if incorporated into one legal contract (e.g. spreads, straddles, strangles, cliquets, etc.) and may, depending on the individual circumstances, be subject of disaggregation.

380 Considering the net-settlement of forward transactions thus as one coherent whole, net-settled cash flows from shares or debt-claims as their underlying would represent a modified payment profile. While the hypothetic "interest" or debt leg as the basis would be negatively modified by the profit or "dividend", the hypothetic "dividend" or equity leg as the basis would in turn be negatively modified by the time value of money or "interest". In the former case, negatively modified "interest" was found incompatible with the concept of time value of money ${ }^{1997}$ as one of the constituting elements ${ }^{1998}$ of genuine debt-claims pursuant to Art. 11(3) OECD MTC. Again, this applies irrespective of the extending modification towards a profit participation, which can thus not come into effect, and even more where the financial instrument contains an optional component ${ }^{1999}$. In the latter case, negatively modified "dividends" were, however, found to be basically compatible with the attribute participating in profits ${ }^{2000}$. This applies even more as any optional component would necessarily have to refer to and thus derive from one and the same underlying (i.e. the share). As a consequence, even disaggregating the financial instrument's risk profile could reveal nothing other than that the risk from the underlying (i.e. the share) is replaced by the literally identical risk from the optional component ${ }^{2001}$. In result, it is therefore held as a conclusion for the further course of this study that income from net-settled forward transactions must basically be classified as other income pursuant to Art. 21(1) OECD MTC. An important exception is the income from the equity leg, which must - given the requisite formal reference to a share $e^{2002}$ as its underlying - be classified as genuine dividends pursuant to Art. 10(3) OECD MTC. rights and thus referring either to membership rights (see par. 262) or to limb 3 of Art. 10(3) OECD MTC to be interpreted domestically (see par. 270), both however not being relevant. See also par. 276 et seq. 


\subsubsection{Conclusions}

381 The following illustration visualises and summarises the overall subsumption of forward transactions as understood and represented in this study:

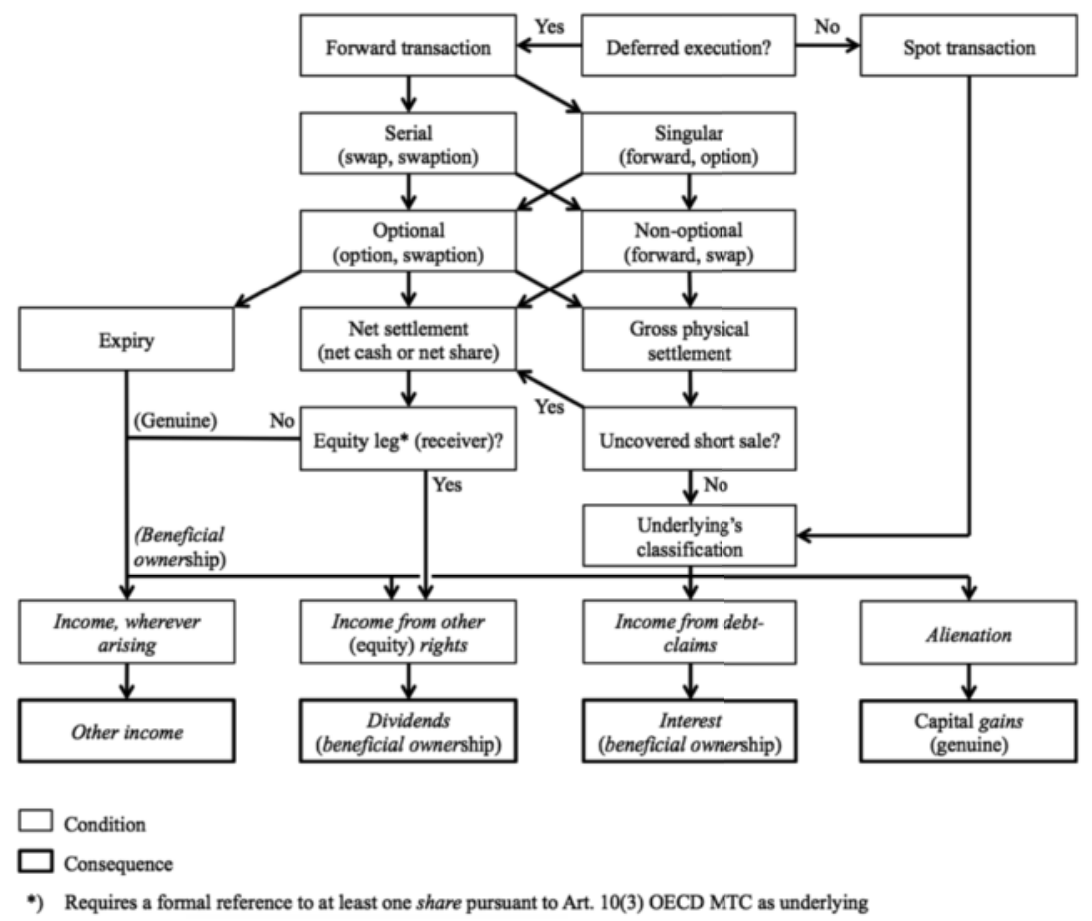

Illustration 24: Classification/subsumption scheme of forward transactions

\subsection{Convertibles}

\subsubsection{Structure}

Debt-into-equity convertibles are more common

382 Generally speaking, a convertible is a financial instrument that can be converted into another financial instrument (e.g. exchangeable preferred stock). In the real-life "more or less" spectrum between pure debt and pure equity ${ }^{2003}$, however, the conversion into financial instruments of the same issuer is typically one-directional "towards equity" (e.g. bond into shares or preferred stock into ordinary shares but not vice versa). The reason is probably that a rational investor will not accept the other way around. On the one hand, such conversion from "more equity" into "more debt" would basically reduce the investor's entire risk-return position. On the other hand, "more equity" usually confers more discretion upon the issuer as regards distributing or retaining the return. In fact, this goes along with a higher discretion with regard to

${ }^{2003}$ See par. 103. 
temporarily ${ }^{2004}$ compensating the investor for his provision of risk capital (voluntariness) ${ }^{2005}$. In other words: the possibility of having certainly participated in more risk in the past but not certainly also participating in more return in the future gives rise to an asymmetry. Notably, this asymmetry has a temporal nature, in that the risk depends on the investor's actual holding period until the financial instrument is converted. Unlike "more debt", "more equity" is typically organised multilaterally ${ }^{2006}$. This is why such temporal asymmetry can typically not be compensated between issuer and investor on an individual basis but only by way of "one size fits all”. This would necessarily give rise to systemic distortions between the investors (e.g. arbitrage). In contrast to similar occurrences (e.g. accrued interest), the distorting effects of such singular events are also often too complex for their compensation between the investors to be operationalised on organised markets. This leaves the what the critical quality of a conversion is in order to either classify or re-classify a financial instrument from a debt-claim pursuant to Art. 11(3) OECD MTC into an other equity right pursuant to Art. 10(3) OECD MTC. For these reasons, the following analysis primarily puts the focus on debt-intoequity convertibles.

\section{Conversion is a feature and not a transaction}

383 At first glance, it might be suggested that the conversion was a result of classifying the financial instruments before and after the conversion. In other words: if the two financial instruments before and after the conversion were classified into different distributive articles of the OECD MTC, the conversion would be a transaction itself rather than a feature of the financial instrument. In fact, conversions principally appear to have a dual character: they are actually both a feature of financial instruments (i.e. convertibility) and possibly also an actual transaction (i.e. the conversion itself). However, focussing only on the conversion transaction by disregarding the convertibility feature ${ }^{2007}$ would imply a static ${ }^{2008}$ or perhaps ex-post ${ }^{2009}$ view of income classification. It would take a potentially uncertain conversion for certain. In that, it would actually ignore the important temporal mechanism ${ }^{2010}$ that the investor, even without an actual conversion, is long since exposed to and thus also compensated for qualitatively different risks (i.e. timing versus underwriting risk) ${ }^{2011}$. In addition, such transaction could only be a capital gain (i.e. an exchange transaction ${ }^{2012}$ ), which, conversely, was found to stipulate the existence of the financial instrument ${ }^{2013}$. Admittedly, the conceptual difference between the convertibility as a feature and/or the conversion as a transaction appears to be of limited relevance for the practice of treaty application: the vast majority of convertibles are unilaterally terminated by the conversion anyway (expiry) and therefore eventually cannot represent a capital gain transaction at all ${ }^{2014}$.

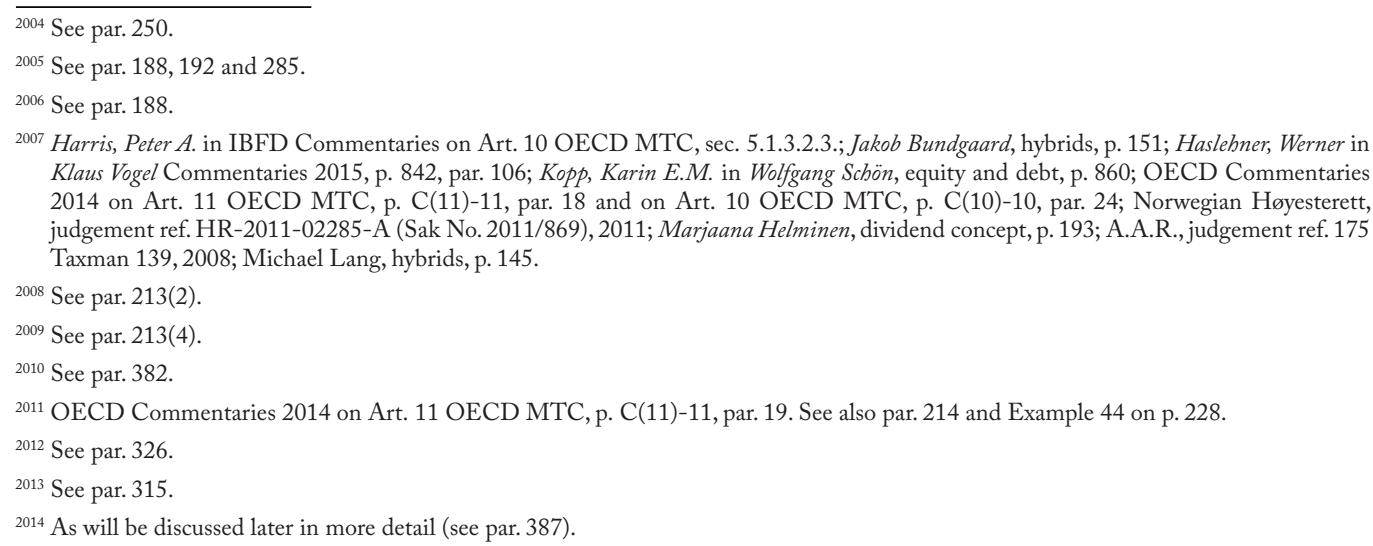


For these reasons, conversions are understood and regarded as relevant primarily by their aspect of being features rather than transactions themselves.

\section{The key questions to be answered}

384 All kinds of financial instruments can be equipped with a separate conversion feature (warrant) attached to the provision of the capital or principal (packaged convertibles, also referred to as "bond cum warrant"). However, only those with a redemption obligation ${ }^{2015}$ can also be equipped with a conjoined or integrated conversion feature embedded into to the provision of the principal itself. The borderline between these two types is, however, fluid. The reason is that a separately attached formal conversion feature can also, in a material way, be entangled with the provision of the principal. Examples of this effect are variable conversion ratios (ratchet convertible ${ }^{2016}$ ) or providing an acquisition of the new equity-like financial instrument at preferential conditions in return for non-preferential conditions of the original debt-like instrument. In addition, the conversion feature can be timed or not timed and optional or non-optional (mandatory convertibles). Such option can be in favour of either the investor (i.e. long call from the investor's perspective) or the issuer (i.e. short put from the investor's perspective, reverse convertible ${ }^{2017}$ ) and non-optional convertibles can be contingent (e.g. contingent convertible bonds) or non-contingent ${ }^{2018}$. It should be permissible to take the general assumption that all these variations basically bear underwriting risk, which need not necessarily be time-inequivalen $\mathrm{t}^{2019}$. As a consequence, the analysis of classifying this variety of convertibles into the distributive articles of the OECD MTC must address the key questions ${ }^{2020}$ of whether or not the

(1) convertible has to be disaggregated into its components ${ }^{2021}$;

(2) convertible provides a self-executive redemption obligation ${ }^{2022}$;

(3) investor is exposed to business risk in the form of termination risk ${ }^{2023}$;

(4) remuneration can principally represent the time value of money in order to constitute a genuine debt-claim pursuant to Art. 11(3) OECD MTC ${ }^{2024}$; and

(5) remuneration - if any - is self-executive ${ }^{2025}$.

\subsubsection{Disaggregation}

385 Convertibility appears to bear a nexus in an ambiguous way with the following aspects already discussed:

- The existence of the financial instruments as such ${ }^{2026}$ : whether or not the financial instrument before the conversion ceases to exist (i.e. is expired or renunciated) or continues to exist (i.e. is substituted by the financial instrument after the conversion as its surrogate);

\footnotetext{
2015 See par. 242(3).

${ }^{2016}$ IAS Board, February 2016, 5C, p. 6, par. 18(d).

${ }^{2017}$ IAS Board, February 2016, 5C, p. 14, par. 47(a).

${ }^{2018}$ For a comprehensive overview see and Jakob Bundgaard, hybrids, p. 303 et seqq. and Jakob Bundgaard, convertibles, sec. 2.

${ }^{2019}$ See par. 211.

${ }^{2020}$ See par. 358.

${ }^{2021}$ See par. 86.

${ }^{2022}$ See par. 289.

${ }^{2023}$ See par. 282.

${ }^{2024}$ See par. 296.

${ }^{2025}$ See par. 290

${ }^{2026}$ See par. 77.
} 
- The redemption obligation ${ }^{2027}$ : whether the capital or principal is redeemed or rather the entire financial instrument as its legal veil is exchanged;

- The income $e^{2028}$ : whether or not the conversion as such represents a realisation event; and

- The termination risk ${ }^{2029}$ : whether or not the conversion exposes the holder to the risk of a non-perfect recovery or redemption of the capital or principal provided.

The first three of these aspects were found to adhere to form over substance and thus cannot be overruled by the substance over form principle. Instead, the substance over form principle takes effect primarily in the context of the subsequent fourth aspect (4) of termination risk ${ }^{2030}$. Consequently, also for the classification or subsumption of convertibles, the above first question (1) of disaggregation as a specific sub-type of the substance over form principle applies only subsidiary to the second one (2) of the redemption obligation. In contrast to most discussions of convertibles, the redemption obligation therefore represents the starting point of the following analysis. In other words: any financial instrument is likewise object of the same legal subsumption $^{2031}$ (i.e. no ring-fencing ${ }^{2032}$ ). Therefore, it was prejudicial and methodologically flawed to run a disaggregative risk analysis towards the underlying's tax-wise nature before having actually verified whether the financial instrument as a whole can even come potentially into question for being a debt-claim by fulfilling its most necessary minimum condition ${ }^{2033}$.

Example 53: A zero bond might be legally equipped with a formal "conversion" feature of two partial hedging options. These can be combined in a way that their net cash settlement perfectly replicates or synthesises the interest (synthetic zero coupon convertible) 2034 . The question is whether or not such feature can be considered a "conversion".

\subsubsection{Redemption obligation}

386 The conversion feature is actually nothing other than a forward transaction ${ }^{2035}$ with another asset as its underlying. As regards the second question (2) as the starting point, convertibles must thus be separated into those still upholding a self-executive redemption obligation and those which do not. The redemption obligation is a necessary minimum condition (conditio sine qua non) for Art. 11(3) OECD MTC. ${ }^{2036}$ It was said to be principally independent of any time-based duration or maturity ${ }^{2037}$ but to require an absolute and unconditional legal right to be repaid ${ }^{2038}$ prior to the issuer's liquidation ${ }^{2039}$. This condition should be fulfilled for all packaged convertibles ${ }^{2040}$, for all mandatory convertibles as well as for all optional convertibles

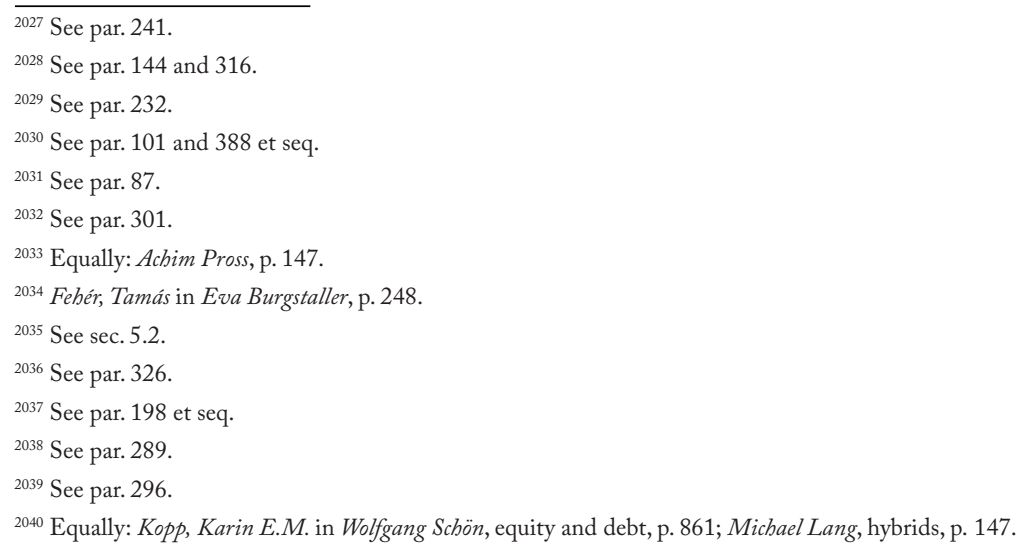


in favour of the holder (i.e. long call from the investor's perspective) or in favour of the issuer (i.e. short put from the investor's perspective), unless the latter does not leave it to the discretion of the issuer whether or not he redeems the capital or principal at all ${ }^{2041}$. Importantly, the redemption obligation itself is independent of the third subsumption step (3) of termination risk ${ }^{2042}$. In particular, the type and value of what the issuer repays to the investor (e.g. the underlying) is not relevant for the existence of a redemption obligation as such $^{2043}$. In other words: an alternative settlement right is nevertheless still a settlement obligation. This can be demonstrated by the example of mandatory convertibles or by the example of reverse convertibles. Although putting only the conversion as such and therefore its mere quantitative effect at the discretion of the issuer, they do not suspend him from fulfilling the qualitative redemption obligation. In other words: termination risk can falsify time equivalence and therefore the time-based nature of the financial instrument (material level) ${ }^{2044}$, but not its legal redemption obligation as such (formal level). The reason is the equivalence of legal criteria ${ }^{2045}$, according to which it was flawed and impermissible to suggest that the expected total benefits represented in all legal rights in favour of the holder (i.e. the redemption and remuneration value) was lower than his expected total costs (i.e. the capital or principal provided to the issuer). In fact, this assumption would actually mix the ex post view (quantitative risk) and the ex ante view (qualitative redemption obligation). Therefore, these considerations lead e contrario to the result that all other convertibles cannot possibly be classified as debt-claims pursuant to Art. 11(3) OECD MTC. Such contingent convertibles and optional convertibles, which leave to discretion of the issuer whether or not he redeems the capital or principal at all, include for example:

- Contingent convertible bonds $(\mathrm{CoCo})^{2046}$ : they put the repayment optionally at the discretion of the issuer and typically also to the consent of the regulator. ${ }^{2047}$

- Other structured notes tied to binary events such as certain insurance-linked securities (ILS, e.g. catastrophe bonds): they redeem the capital or principal depending on whether or not a predefined trigger event occurs.

- Convertible preferred equity certificates (CPEC): they are often non-terminable until the issuer is liquidated. ${ }^{2048}$

387 This also leads to the further conclusion that these financial instruments before and after the conversion must be classified separately ${ }^{2049}$, at least where there is a redemption obligation. Importantly, this no consequence of any form of disaggregation but rather of the fact that the financial instrument before the conversion is redeemed and thus does actually cease to exist (i.e. is expired or renunciated) ${ }^{2050}$. Accordingly, such conversions fulfilling a redemption obligation cannot possibly constitute capital gains pursuant to Art. 13(5) OECD MTC. ${ }^{2051}$

\footnotetext{
${ }^{2041}$ See par. 236.

${ }^{2042}$ See par. 388 et seq.

${ }^{2043}$ Perhaps contrary: Fehér, Tamás in Eva Burgstaller, p. 248, mixing the two aspects by saying that "if a drop in the share price were lead to a drop in the redeemable amount of the contribution, then we could hardly speak of a genuine claim in respect of the principal".

${ }^{2044}$ See par. 242(2).

${ }^{2045}$ See par. 182.

${ }^{2046}$ Juan Ramirez, p. 127 et seq.

${ }^{2047}$ Equally: IBFD, Introduction to the Comparative Survey, Derivatives \& Financial Instruments 2011, Vol. 13, No. 3.

${ }^{2048}$ Equally: Jakob Bundgaard, convertibles, sec. 2.3., footnote 37.

${ }^{2049}$ Equally: Marjaana Helminen, dividend concept, p. 191 et seq.

${ }^{2050}$ Equally: Fehér, Tamás in Eva Burgstaller, p. 247.

${ }^{2051}$ See par. 314 et seqq.
} 
They do not represent a transfer transaction at all but rather a unilateral termination that was found not to be covered by the term alienation ${ }^{2052}$. Notably, this may, however, not lead to the erroneous reverse deduction that conversions not fulfilling a redemption obligation would necessarily constitute capital gains pursuant to Art. 13(5) OECD MTC. The reason is that a conversion alone gives no indications on whether the convertible itself ceases or continues to exist, which is subject to the alienation test on the convertible level ${ }^{2053}$. In market practice, the large majority of debt-into-equity conversions, even if not fulfilling a redemption obligation, should, however, unilaterally terminate (e.g. CoCo) or otherwise not dispose (e.g. packaged convertibles) of their convertibles. In result, capital gains pursuant to Art. 13(5) OECD MTC triggered by conversions appear to be fairly rare ${ }^{2054}$.

\subsubsection{Termination risk}

388 Having thus verified the redemption obligation as the first step, the classification or subsumption of convertibles must now proceed with the above third question (3) of whether (then potentially dividends or interest) or not (then potentially other income or interest) the financial instrument bears business risk. And, if yes, whether (then dividend) or not (then dividends or interest, depending on the redemption obligation ${ }^{2055}$ ) this business risk is limited to the specific form of termination risk. These two sub-questions apparently require a (qualitative) disaggregation of the financial instrument, which is indispensible but subsequently takes effect only now. Beforehand, business risk requires a formal reference to a share as its underlying ${ }^{2056}$. Given this formal reference, the above multi-stage process of risk identification, risk disaggregation and risk elimination ${ }^{2057}$ reveals whether or not the underlying's underwriting risk qualitatively resembles business risk $^{2058}$. One result of such risk disaggregation will be that the time-based element (i.e. timing risk) of packaged convertibles is basically independent of their risk-based element (i.e. underwriting risk). This is the systematic reason why packaged convertibles can also quantitatively be separated into their debt and option components ${ }^{2059}$. Even where the underwriting risk contained in the conversion feature (warrant) is inextricably entangled with the timing risk contained in the provision of the principal (e.g. ratchet convertibles ${ }^{2060}$, the risk disaggregation scheme is principally capable of determining whether or not the compound financial instrument qualitatively approximates equity. Apart from this special case, the underlying's underwriting risk should actually resemble business risk for all convertibles with one or more shares as their underlyings. In any case, the option feature itself isn't part of the time-based element in the sense of an interest in kind ${ }^{2061}$. The reason is that it is actually not granted as a "free bonus" but only in return for a correspondingly lower remuneration from the convertible's debt component.

\footnotetext{
${ }^{2052}$ See par. 326.

${ }^{2053}$ Equally: Michael Lang, hybrids, p. 146.

${ }^{2054}$ See par. 326.

${ }^{2055}$ See par. 386.

${ }^{2056}$ See par. 103(3).

${ }^{2057}$ See par. 101 et seqq.

${ }^{2058}$ IFRS 9.B4.3.5 and 9.B4.3.8; comprehensively: Kubn/Hachmeister, p. 715 et seqq.

${ }^{2059}$ Jakob Bundgaard, hybrids, p. 341; Jakob Bundgaard, convertibles, sec. 8.4.; Wassermeyer, Franz in Wassermeyer Commentaries, p. 1434, par. 85a; Michael Lang, hybrids, p. 147.

${ }^{2060}$ See par. 384.

${ }^{2061}$ Achim Pross, p. 155.
} 
389 The conversion event naturally occurs at the end of the financial instrument's duration or maturity, i.e.is a form of termination. Therefore, the underwriting (business) risk will typically also have the form of the termination risk. In fact, there appear to be only very few cases where the business risk is limited to mere remuneration risk. This is also the reason why even a high interpretation significance and therefore a disaggregation of the time value of money due to the convertible's long-term duration or maturity eventually does not alter its classification ${ }^{2062}$. Due to the interdependency between termination risk and remuneration risk ${ }^{2063}$, this is principally conceivable only where the pay and receive legs of convertibles proportionate in equal values ${ }^{2064}$ (i.e. the financial instruments before and after the conversion). This was found to be always true only under the fixed-for-variable condition, but never under the fixed-for-fixed and the variable-for-fixed conditions. Consequently, convertibles with one or more shares as their underlyings must, at least under the fixed-forfixed and the variable-for-fixed conditions, necessarily be classified as shares pursuant to Art. 10(3) OECD MTC $^{2065}$. These include for example:

- Mandatory convertibles ${ }^{2066}$ : these apply either a fixed conversion ratio (i.e. fixed-for-fixed condition) or a variable conversion ratio that typically does not convert into a variable number of shares equivalent to the fixed redemption amount and therefore not does not fulfil the fixed-for-variable condition.

- Contingent convertibles: these put the repayment not just optionally at the discretion of the issuer but typically also to the consent of the regulator ${ }^{2067}$; thus, the repayment is supposed to predominantly depend on the business risk.

- Reverse convertibles ${ }^{2068}$ : these put the conversion option in favour of the issuer (i.e. puttable in favour of the issuer), effectively allowing him to redeem a value lower than what the holder provided to him and therefore not to fulfil the fixed-for-variable condition.

- Some types of convertible preferred stock, such as preferred equity redemption cumulative stock $(\mathrm{PERCS})^{2069}$ or dividend enhanced convertible securities (DECS, also referred to as "dividend enhanced convertible stock" or "debt exchangeable for common stock" $)^{2070}$ : these typically apply a variable conversion ratio that is not equivalent to the fixed redemption amount and therefore does not fulfil the fixed-forvariable condition. The reason is that this conversion ratio depends on the strike price of the embedded put option (i.e. puttable in favour of the issuer).

- Depository receipts ${ }^{2071}$ and delta-one-certificates: even where granting a conversion right to the holder (i.e. callable in favour of the investor), these typically apply a fixed conversion ratio (i.e. fixed-for-fixed condition).

\footnotetext{
${ }^{2062}$ As will be shown hereinafter (see par. 390 et seq.).

${ }^{2063}$ See par. 278.

${ }^{2064}$ See par. 299 and 351.

${ }^{2065}$ Equally: Dutch Hoge Raad der Nederlanden, judgement ref. 43.643, 2007.

${ }^{2066}$ Equally: Fehér, Tamás in Eva Burgstaller, p. 248.

${ }^{2067}$ See footnote 2047.

${ }^{2068}$ Equally: Carmine Rotondaro, redemption, p. 265 et seqq. and 271.

${ }^{2069}$ Equally: IAS Board, March 2017, 5A, Appendix B, p. 21.

${ }^{2070}$ Juan Ramirez, p. 118 et seqq.; Frank Fabozzi, p. 295.

${ }^{2071}$ Frank Fabozzi, p. 166.
} 


\subsubsection{Remuneration}

390 As regards the fourth question (4) ${ }^{2072}$, termination risk was found capable of falsifying the time value of money $y^{2073}$ as one of the constituting elements ${ }^{2074}$ of genuine debt-claims pursuant to Art. 11(3) OECD MTC. Conversely, the remuneration from a convertible can thus potentially represent the time value of money only where there is a redemption obligation and no termination risk ${ }^{2075}$. Admittedly, it is the economic purpose of convertibles and their peculiarity to combine their periodic remuneration before the financial instrument is converted with their termination proceeds from the conversion itself. As a consequence, the time value of money could basically be determined only by considering the total return ${ }^{2076}$. In other words: as the remuneration risk forms one logical unit or concept with the termination risk ${ }^{2077}$, the remuneration itself forms one logical unit or concept with the termination proceeds. Thus, the conversion of convertibles typically contains not only a redemption component but also a remuneration component.

Example 54: Cumulative rate reset preferred shares can be featured in a way that retained remunerations are accumulated and distributed at the deferred reset date ${ }^{2078}$. Where such financial instruments are also callable in favour of the issuer or puttable in favour of the holder, their periodic remuneration is inextricably entangled with their conversion proceeds.

391 However, the termination proceeds and thus the total return are typically unknown or even unexpectable at the time the remuneration is paid. In addition, the legal interpretation brought forth compelling systematic reasons why the two aspects of remuneration and termination must nevertheless be kept separated ${ }^{2079}$. While this requisite separation was a finding in the context of risk in Art. 10(3) OECD MTC, it must apply to the remuneration in Art. 11(3) OECD MTC ${ }^{2080}$, too. The reasons are that

- the time value of money is the natural complement of the risk-based remuneration ${ }^{2081}$;

- the remuneration is a reflex response to risk $^{2082}$; and

- the consistent and coherent system of Art. 10(3) and 11(3) OECD MTC principally demands that their autonomous parts must lead to equivalent results ${ }^{2083}$.

This means as an interim conclusion that the time value of money is a test that is not per se falsified by the convertibility feature. In as much as these two aspects are actually independent from each other, the periodic remuneration of convertibles can principally represent the time value of money in order to constitute, ceteris paribus, a genuine debt-claim pursuant to Art.11(3) OECD MTC.

\footnotetext{
2072 See par. 384(4).

${ }^{2073}$ See par. 242(2).

${ }^{2074}$ See par. 296.

2075 Argumentum e contrario.

${ }^{2076}$ See Example 34 on p. 124 and Example 35 on p. 125.

${ }^{2077}$ See par. 279.

${ }^{2078}$ IAS Board, February 2016, 5C, p. 7, par. 21.

${ }^{2079}$ See par. 280.

${ }^{2080}$ Argumentum e contrario.

${ }^{2081}$ See par. 208 et seqq. and 275.

${ }^{2082}$ See par. 200.

${ }^{2083}$ See par. 113(1).
} 
392 However, in the practice of applying the OECD MTC to convertibles this is just half of the truth. In fact, the independence of remuneration and termination is a mere necessary minimum condition (conditio sine qua non) but not a sufficient maximum condition (conditio per quam) or verifier for the time value of money. This can be demonstrated by the example of callable convertibles (i.e. in favour of the holder). Callable convertibles actually may participate in general business risk, but not in its specific form of termination risk as one of the constituting elements of other equity rights pursuant to Art. 10(3) OECD MTC ${ }^{2084}$. Instead, they leave the termination risk entirely to the issuer ${ }^{2085}$ and thus only participate in the termination chances ${ }^{2086}$. In that, their net-settled payment profile inextricably coalesces the time-based remuneration received (interest component) and the risk-based remuneration (option component) paid out. Again considering the two as one coherent whole ${ }^{2087}$, such negatively modified payment profile cannot possibly constitute interest pursuant to Art. 11(3) OECD MTC 2088 either. This becomes even more evident against the background of the call option itself, which is risk-based ${ }^{2089}$ and may expire ${ }^{2090}$. This means as a conclusion for the further course of this study that the remuneration from callable convertibles basically represents neither interest pursuant to Art. 11(3) OECD MTC nor dividends pursuant to Art. 10(3) OECD MTC. Instead, it is to be classified as other income pursuant to Art. 21(1) OECD MTC. Exceptions to this general principle might appear where a long-term duration or maturity necessitates high interpretation significance and therefore a disaggregation of the time value of money (e.g. infinite or open-ended convertibles) ${ }^{2091}$.

\subsubsection{Self-execution}

393 The last question (5) 2092 with regard to the debt-equity distinction of convertibles is whether or not the remuneration is self-executive. On the one hand, this question is less difficult to answer for the periodic remuneration before the financial instrument is converted ${ }^{2093}$. On the other hand, in the context of selfexecution the question arises how relevant the peculiarity of convertibles is that the periodic remuneration actually forms one logical unit or concept with the termination proceeds. For instance, it could be legitimately concluded that the total remuneration cannot possibly be self-executive where there is no redemption obligation, which is always self-executive ${ }^{2094}$. Adding to the aforementioned arguments ${ }^{2095}$, such conclusion was however incomplete as well. Convertibility does not necessarily imply or include a redemption obligation (e.g. $\mathrm{CoCo}$ ). Just as the qualitative redemption obligation as such must be separated from the quantitative termination risk ${ }^{2096}$, it must be even more separated from the quantitative termination proceeds and therefore from its self-execution ${ }^{2097}$. In other words: the remuneration contained in the conversion can logically be

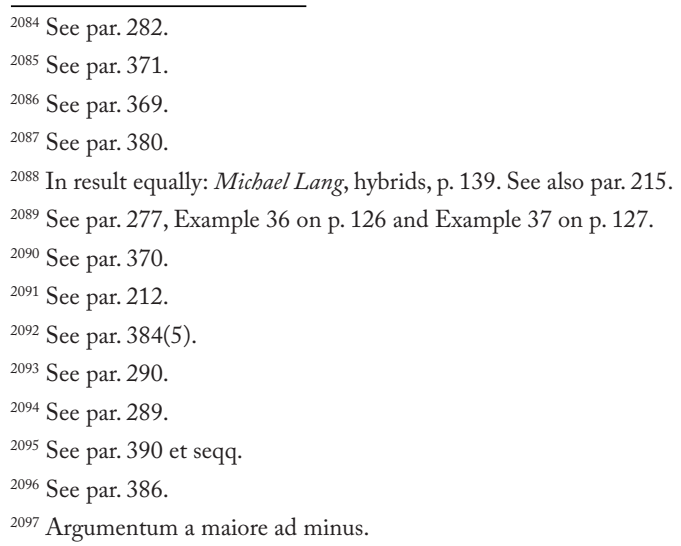


self-executive as such, even though there is no redemption obligation at all. Consequently, the remuneration's self-execution as such for convertibles is independent of the redemption obligation.

394 As another argument, it might be suggested that in the practice of treaty application the remuneration's self-execution was only subsequently relevant for classification purposes where there is no termination risk at all ${ }^{2098}$. Otherwise the financial instrument was unclassifiable as a debt-claim pursuant to Art. 11(3) OECD MTC anyway. It might also be suggested that where there is remuneration risk, there could not possibly be self-execution. However, this approach was methodologically flawed as it implied that there was necessarily remuneration risk wherever there is no termination risk. However, convertibles are conceivable which bear neither remuneration risk nor termination risk (e.g. convertibles under the fixed-for-variable condition and with a fixed coupon). In addition, remuneration is just a reflex response to risk ${ }^{2099}$, which is why their temporal distribution is principally independent of each other ${ }^{2100}$. As a consequence, termination risk could principally be - and typically is - fully compensated by the periodic and self-executive remuneration until the financial instrument is converted ${ }^{2101}$. Lastly, the only types of convertibles complying with both necessary minimum conditions of the redemption obligation and the absence of termination risk are packaged and callable convertibles (i.e. in favour of the holder). However, packaged convertibles were found to be disaggregated into their time-based and risk-based components ${ }^{2102}$, and thus to be independent of each other anyway. In addition, the risk premium for callable convertibles is paid out instead of received and therefore cannot possibly be relevant for the self-execution test. Consequently, the remuneration's self-execution remains principally independent of the termination risk.

395 As a consequence, the remuneration's self-execution is an independent test for convertibles as well. Notably, it appears that this test can be performed in perfect analogy with non-convertible financial instruments. The reason is that, since the remuneration risk and the termination risk must be considered separately ${ }^{2103}$, the periodic remuneration itself and the termination proceeds must also be considered separately ${ }^{2104}$. In other words: with regard to the self-execution test of the remuneration, convertibles do not differ in any way from other financial instruments. While the remuneration from packaged convertibles is to be quantitatively disaggregated into its time-based component (i.e. interest if self-executive ${ }^{2105}$ ) and risk-based component (i.e. basically a capital gain $^{2106}$ ), the qualitative risk disaggregation of the remuneration from non-packaged convertibles is principally capable of determining whether such compound remuneration approximates more closely to equity or to debt $^{2107}$. The remaining tax planning possibilities and distortions by discretionarily structuring the risk premium into or out of the periodic remuneration have to be accepted ${ }^{2108}$. In the market

\footnotetext{
${ }^{2098}$ See par. 389.

${ }^{2099}$ See par. 200.

${ }^{2100}$ See par. 369.

${ }^{2101}$ See par. 382 et seq.

${ }^{2102}$ See par. 388.

${ }^{2103}$ See par. 280.

${ }^{2104}$ See par. 391 et seqq.

${ }^{2105}$ See par. 290.

${ }^{2106}$ See par. 367.

${ }^{2107}$ See par. 388.

${ }^{2108}$ See par. 101(1).
} 
practice, most debt-into-equity convertibles can be assumed to typically distribute their periodic remuneration self-executively.

\subsubsection{Conclusions}

396 Combining all these necessary minimum conditions of a redemption obligation, the absence of termination risk, the time value of money and the self-execution of the remuneration describes the fairly limited scope for convertibles being debt-claims pursuant to Art. 11(3) OECD MTC. For example, it includes packaged convertibles with self-executive remuneration, whose qualitative disaggregation will typically give rise to a straight bond and an option, so that its quantitative disaggregation will typically constitute interest. The following illustration visualises and summarises the overall subsumption of convertibles as understood and represented in this study:

\begin{tabular}{|c|c|c|c|c|c|}
\hline Convertible type & $\begin{array}{c}\text { Redemption } \\
\text { obligation }\end{array}$ & $\begin{array}{l}\text { Business risk }{ }^{1} \\
\text { in the form of } \\
\text { termination risk }\end{array}$ & $\begin{array}{c}\text { Time } \\
\text { value of } \\
\text { money }\end{array}$ & $\begin{array}{l}\text { Self-executive } \\
\text { remuneration }{ }^{2}\end{array}$ & $\begin{array}{c}\text { Classification } \\
\text { (Art. OECD MTC) }\end{array}$ \\
\hline Packaged & У & 唯 & ஏ & У & 11 (interest) \\
\hline Mandatory & ஏ & च & 目 & 口 & 10 (dividend) \\
\hline Contingent & 冈 & У & 目 & 目 & 10 (dividend $)$ \\
\hline Callable $^{3}$ & 口 & 目 & 目 & 口 & 21 (other income) ${ }^{4}$ \\
\hline Puttable $^{5}$ (reverse) & 口 & 口 & 目 & च & 10 (dividend) \\
\hline Fixed conversion ratio ${ }^{6}$ & 口 & У & 目 & प9 & 10 (dividend $)$ \\
\hline Variable conversion ratio & 口 & 口7 & 目 & 包 & $10(\text { dividend })^{7}$ \\
\hline Variable nominal value $^{8}$ & 目 & $\square$ & 目 & च9 & 10 (dividend $)$ \\
\hline
\end{tabular}

1) Requires a formal reference to at least one share pursuant to Art. 10(3) OECD MTC as underlying

2) As typically - but not necessarily - observable in practice

3) From the holder's or investor's perspective

4) Unless long-term

5) From the issuer's perspective

6) Fixed-for-fixed condition

7) Unless the financial instruments before and after the conversion proportionate in equal values (i.e. fixed-for-variable condition)

8) Variable-for-fixed condition

9) Unless contingent

冈曰 Decisive criterion (condition)

四 Non-decisive criterion (condition)

Illustration 25: Classification table of convertibles

397 As a side note, the question arises of how to subsume financial instruments, which are featured in a way that eventually allows them to change their own classification. While this is a general problem of all financial instruments, it is nevertheless typical for convertibles due to their difficult debt-equity-delimitation and their corresponding variety. 
Example 55: A puttable financial instrument (i.e. in favour of the issuer) might be featured in the way that, if the put option expires, its redemption amount successively increases at a certain rate over time. ${ }^{2109}$ In that, it actually changes from dividend classification (i.e. reverse convertible) to interest classification (i.e. zero bond).

According to the dynamic forward-looking view, each income or transaction from such financial instruments must be classified individually at the date of payment but in consideration of the remaining expectable lifetime of the financial instrument ${ }^{2110}$. This is a compromise in the conflict between the dynamic criterion of risk on the one hand and the static position-by-position or item-by-item approach of the OECD MTC on the other ${ }^{2111}$. Consequently, the risk-based income from such financial instruments before being converted differs qualitatively from the time-based income after having been converted, in that it also accounts for the future convertibility ${ }^{2112}$. In other words: while the future underwriting risk impacts the classification of the income before being converted (i.e. contains a risk premium), the elapsed underwriting risk does not impact the classification of the income after being converted (i.e. contains no risk premium). Art. 10(3) and 11(3) OECD MTC on the one hand are independent of Art. 13(5) OECD MTC on the other ${ }^{2113}$. This is why the classification of income from the financial instrument (i.e. the transaction) is also independent of the classification of capital gains with the financial instrument itself (i.e. the asset). Hence, a change in the income's classification is possible even though the convertible itself has not been alienated ${ }^{2114}$.

\subsection{Other debt-based financial instruments}

\subsubsection{Structure}

398 As a starting point, other non-convertible "hybrids" likewise raise issues regarding the classification or subsumption into the distributive articles of the OECD MTC but have not yet been discussed elsewhere in this study. They can roughly be grouped according to their determinants, i.e. rights on the provision of capital, time value of money and redemption obligation ${ }^{2115}$. In summary, they encompass financial instruments, which (1) yield income that exceeds the time value of money;

(2) bear risks, which however are typical or even constitutive for debt-claims; and/or

(3) replicate or synthesise the risk-return profile of debt-based financial instruments.

In addition, this section presents a side note on negative interest.

\subsubsection{Linkers}

399 As regards the first group (1), in market practice there is a broad variety of financial instruments yielding income in excess of the time value of money. Such excessive payment profile is typically, but not necessarily, structured by linking the remuneration and/or the capital or principal to an underlying (linkers, e.g. index-

\footnotetext{
${ }^{2109}$ IAS Board, February 2016, 5C, p. 4 et seq., par. 15(a).

${ }^{2110}$ See par. 214.

${ }^{2111}$ See par. 59.

${ }^{2112}$ See par. 383.

${ }^{2113}$ See par. 113 and 315.

${ }^{2114}$ Equally: IAS 32.AG32.

2115 See par. 358.
} 
linked, equity-linked, inflation-linked ${ }^{2116}$, etc.). Here, we have already reached the crucial point for subsuming or not subsuming such financial instruments under the distributive articles of the OECD MTC. On the one hand, positive modifications of the payment profile beyond the mere time value of money can be compatible with the extending attribute whether or not carrying a right to participate in the debtor's profits ${ }^{2117}$ in Art. 11(3) OECD MTC. In contrast, they are, however, incompatible with, and falsify, the constituent element of genuine debt-claims ${ }^{2118}$. In other words: on the level of the income, the remuneration amount basically forms one logical unit or concept with the remuneration risk and thus shares its irrelevance for the debt-equity distinction. On the level of the capital or principal, the redemption amount basically forms one logical unit or concept with the termination risk and thus shares its relevance for the debt-equity distinction. On the other hand, the extending attribute of the profit participation is limited to business risk and thus incompatible with any other risk. Combining both aspects means in turn that, where either the remuneration bears any nonbusiness risk or the redemption bears any risk (particularly business risk), linkers cannot possibly be classified as a debt-claim ${ }^{2119}$. Just as for convertibles in particular ${ }^{2120}$, Art. 11(3) OECD MTC generally demands a careful analysis and distinction of whether (then potentially dividend) or not (then interest or other income) the amount in excess of the time value of money is paid as an integral part of the redemption amount or, if not, whether (then potentially interest) or not (then other income) it represents a business profit. This is particularly difficult when we remember that business risk can be contained in both the remuneration risk and the termination risk ${ }^{2121}$, so that profit participation is also contained in both the remuneration amount and the redemption amount ${ }^{2122}$.

400 In this respect, the OECD Commentaries are not clear:

- In favour of dividends: "[...] the interest on such bonds [i.e. convertibles] should be considered as a dividend if the loan effectively shares the risks run by the debtor company" ${ }^{2123}$. In the author's view, this must apply analogously to comparable non-convertible financial instruments. In fact, any income that exceeds the time value of money is basically not time-equivalent and therefore cannot possibly constitute a genuine debt-claim ${ }^{2124}$.

- Contra interest. "[...] premiums or prizes attaching thereto [i.e. government securities, bonds and debentures] constitute interest" 2125 . In the author's view, this must apply analogously to comparable financial instruments. Apparently, excessive redemption amounts above par are typically in no way "attached" but rather its integral part.

- In favour of interest: "Generally speaking, what constitutes interest yielded by a loan security [...] is all that the institution issuing the loan pays over and above the amount paid by the subscriber, that is to say,

\footnotetext{
${ }^{2116}$ See par. 215 .

${ }^{2117}$ See par. 280.

${ }^{2118}$ See par. 275 and 293.

${ }^{2119}$ Argumentum e contrario.

${ }^{2120}$ See par. 390 .

${ }^{2121}$ See par. 279.

${ }^{2122}$ Achim Pross, p. 160 et seq. See also par. 278.

${ }^{2123}$ OECD Commentaries 2014 on Art. 11 OECD MTC, p. C(11)-11, par. 19. The explanatory insertion in brackets has been added by the author.

${ }^{2124}$ See par. 215.

${ }^{2125}$ OECD Commentaries 2014 on Art. 11 OECD MTC, p. C(11)-11, par. 20. The explanatory insertion in brackets has been added by the author.
} 
the interest accruing plus any premium paid at redemption or at issue." ${ }^{2126}$ While this may be undisputed, it is, however, not a sufficient maximum condition (conditio per quam) or verifier for Art. 11(3) OECD MTC.

- Contra interest: "On the other hand, the definition of interest does not cover any profit or loss that cannot be attributed to a difference between what the issuer received and paid (e.g. a profit or loss, not representing accrued interest or original issue discount or premium, which a holder of a security such as a bond or debenture realises by the sale thereof to another person or by the repayment of the principal of a security that he has acquired from a previous holder for an amount that is different from the amount received by the issuer of the security)." ${ }^{2127}$ The reference for that difference is the nominal value, which was found to represent such fixation only for the fixed-for-fixed and the fixed-for-variable conditions but not for the variable-for-fixed condition ${ }^{2128}$, which is, however, typical for linkers.

- In favour of interest. "The same interpretation may apply if bonds or debentures are redeemed by the debtor at a price which is higher than the par value or the value at which the bonds or debentures have been issued; in such a case, the difference may represent interest [...]"2129. While this is obviously a subjunctive wording, it reads as corresponding to the previous statements as regards accrued interest and premiums.

401 To the author's understanding, it was therefore an imprecise misinterpretation and overrun to understand these specific statements in the general sense that any positive difference between what the creditor transfers to the debtor for lending and what the debtor owes in return to the creditor as the repayment was interest ${ }^{2130}$. It was also methodologically flawed, prejudicial and unpurposeful. In fact, it would actually ignore the role of the payment profile for the income classification as an inextricable reflex response to its risk exposure. Further, it would confuse the extending character of the profit participation with the genuine term of debt-claims. And lastly, it would entirely level any distinguishability between Art. 10(3) and 11(3) OECD MTC ${ }^{2131}$. Instead, these statements within the OECD Commentaries accurately and consistently integrate themselves into the systematic understanding of this study, if considered in the context of remunerations paid concurrently with, but detached from, the redemption. This is always the case for any amount separately paid at maturity (e.g. coupons, agios or premiums paid in arrear) and, according to the majority view ${ }^{2132}$, also to accrued interest. In other words: in order to apply these statements of the OECD Commentaries in a consistent and meaningful way to linkers, it is actually required and essential to draw a certain line in respect of whether or not the amount in excess of the time value of money is paid as an integral part of the redemption amount and, subsequently, whether or not it represents business profits.

\footnotetext{
$\overline{{ }^{2126} \text { OECD Commentaries } 2014}$ on Art. 11 OECD MTC, p. C(11)-11, par. 20.

${ }^{2127}$ OECD Commentaries 2014 on Art. 11 OECD MTC, p. C(11)-12, par. 20.

${ }^{2128}$ See par. 299.

${ }^{2129}$ OECD Commentaries 2014 on Art. 11 OECD MTC, p. C(13)-13, par. 31.

${ }^{2130}$ Equally: Wassermeyer, Franz in Wassermeyer Commentaries, p. 1429 et seq., par. 75.

${ }^{2131}$ Equally: Achim Pross, p. 160.

${ }^{2132}$ See par. 306.
} 
402 Drawing this line from the author's point of view, linkers are structured identically to non-packaged ${ }^{2133}$ net-settled ${ }^{2134}$ convertibles. As such, they are typically - but not necessarily - cash-settled and therefore typically - but not necessarily - have a variable nominal value ${ }^{2135}$. Consequently, they have to be classified accordingly. Making thus reference to the subsumption of convertibles ${ }^{2136}$, the only question left is whether or not the net settlement of the embedded forward component as the only differentiator between linkers and convertibles alters those aforementioned conclusions. This becomes particularly clear, when remembering that non-packaged convertibles can also yield genuine dividends pursuant to Art. 10(3) OECD MTC, whereas net-settled forward transactions can also yield genuine other income pursuant to Art. 21(1) OECD MTC 2137 . According to the view represented here, this question is to be answered in the negative by drawing an analogy to convertibles again ${ }^{2138}$. Given the requisite formal reference to a share as the underlying ${ }^{2139}$, the qualitative disaggregation process of risk identification, risk disaggregation and risk elimination ${ }^{2140}$ would reveal whether the linker's underwriting risk is more distinctly determined by the embedded forward transaction (then potentially other income) or by the underlying itself (then dividend). However, the forward transaction is actually derived from the linker's underlying itself ${ }^{2141}$. As a consequence, their risks are literally identical ${ }^{2142}$. True, in the absence of a secondary market transfer ${ }^{2143}$ of the asset, a net settlement of forward transactions cannot yield capital gains pursuant to Art. 13(5) OECD MTC. Nevertheless, this aspect is obviously independent of the fact that it can bear business risk. In that linkers actually combine primary market transactions (i.e. the capital provision) and secondary market transactions (i.e. the capital's realisation by way of net-settlement), they also coalesce the respective income types in themselves. However, these different income types have no impact on the results from the underwriting risk disaggregation. In result, this peculiarity of linkers is therefore a false problem for their classification. For these reasons, it is held as a conclusion for the further course of this study that linkers cannot possibly represent genuine debt-claims pursuant to Art. 11(3) OECD MTC, irrespective of the extending modification towards a profit participation that can thus not come into effect.

\subsubsection{Linkers on debt-specific risks}

403 As regards the second group (2) $)^{2144}$, the question arises whether it alters the aforementioned conclusion that linkers cannot be subsumed under Art. 11(3) OECD MTC where their underlying bears risks (i.e. the linker is risk-based), which are typical or even constitutive for debt-claims (e.g. credit risk, currency risk, interest rate risk, etc.). Typical examples are credit-linked notes $(\mathrm{CLN})^{2145}$, inverse floating rate notes or targeted accrual 
redemption notes (TARN), dual- or multi-currency notes or collateralised debt obligations (CDO) ${ }^{2146}$. Like linkers with a formal reference to a share as their underlying ${ }^{2147}$, classifying such financial instruments by way of disaggregating their risk profile reveals only that it is more distinctly determined by debt-specific elements. The question therefore arises whether the risk-based nature of the financial instrument as such is subsidiary to the fact that it is a debt-specific risk profile (then interest) or vice versa (then other income).

404 However, it was stated that the entire methodological step of risk disaggregation as a specific sub-type of the material substance over form principle cannot overrule and must instead apply only subsidiarily to the formal redemption obligation. Therefore, the redemption obligation represents the starting point of the subsumption ${ }^{2148}$, which must also apply to linkers ${ }^{2149}$ with debt-specific underlyings. They are to be classified in analogy to non-packaged net-settled convertibles and thus are likewise object of the same legal subsumption (i.e. no ring-fencing). Again, it was prejudicial and methodologically flawed to run a disaggregative risk analysis towards their underlying's tax-wise nature before having verified whether the linker as such can even come potentially into question for being a debt-claim by fulfilling its most necessary minimum condition. On the one hand, linkers will often - but not necessarily - have a formal redemption obligation, which is also independent of the material termination risk $^{2150}$. On the other hand, their termination risk of any type whatsoever (i.e. even if debt-specific) nevertheless falsifies the time value of money ${ }^{2151}$ and therefore genuine debt-claims, so that linkers are basically risk-based financial instruments ${ }^{2152}$.

405 The reason is that underwriting risk is broader than underlying risk, so that the former is not necessarily rooted in the latter. Namely, the total underwriting risk contains the risk arising from the underlying (e.g. currency risk) and that arising from the financial instrument as such (e.g. legal risk). However, termination risk is always underlying risk ${ }^{2153}$ and not underwriting risk, as the concept of underwriting risk would otherwise be self-referential ${ }^{2154}$. In this case, for instance, cascading financial instruments would be positively "infected" in the sense of: debt-claim once and forever. In that, the underwriting risk arising from one financial instrument as such (e.g. legal risk of a bond) is actually converted into the underlying risk of a different financial instrument (e.g. CDO). Or in other words: the legal veil turns into an underlying itself. As a consequence from this consideration, the qualitative classification of the risk type as being typical or even constitutive for debt-claims is not of any relevance for the preceding quantitative determination of whether there is any termination risk at all ${ }^{2155}$. To the author's understanding, debt-specific underlyings therefore do not alter the aforementioned conclusion that linkers cannot be subsumed under Art. 11(3) OECD MTC ${ }^{2156}$. Instead, these must be classified pursuant to the general rules applicable for non-packaged net-settled convertibles.

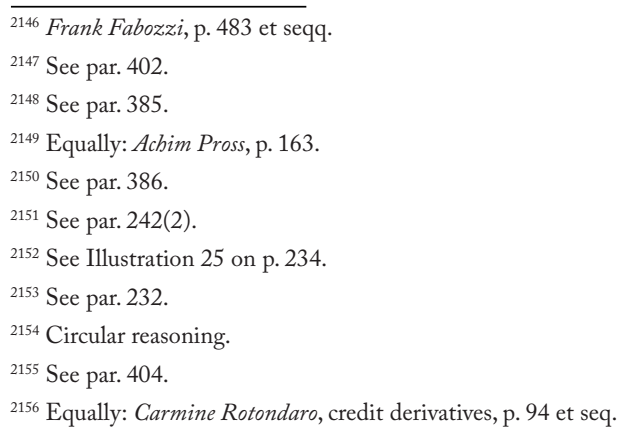




\subsubsection{Replicated debts}

406 As regards the third group (3) $)^{2157}$, the risk-return profile of debt-based financial instruments can be replicated or synthesised in countless varieties ${ }^{2158}$. True, the restrictive application of the aggregation scheme excludes most of them from being classified as debt-claims pursuant to Art.11(3) OECD MTC (e.g. the consolidated treatment of composite strategies with two or more forward transactions $\left.{ }^{2159}\right)^{2160}$. However, underwriting risk can generally replicate timing risk ${ }^{2161}$, so that risk-based debt-like financial instruments can be structured in such a way that they replicate time-based financial instruments (e.g. synthetic zero bonds ${ }^{2162}$ such as repurchase obligations ${ }^{2163}$ incorporated into one legal contract). The question raised by this particularly ambiguous group of financial instruments is therefore whether the risk-based nature of the underlying itself is subsidiary to its hedge by the embedded forward transactions (then interest) or vice versa (then dividends or other income, depending on the formal reference to any underlying classified as a share).

407 Approaching this question, the methodological interim step or starting point of subsumption must again be the redemption obligation ${ }^{2164}$. However, it should be permissible to assume that all such interest-replicating linkers always and necessarily have a redemption obligation. On the one hand, any replication of a time-based risk-return profile implies and requires two or more counteractive positions, whose risk components (e.g. variables, optionalities, contingencies, etc.) refer to one and the same trigger event or occurrence in order to constitute a perfect hedge. At least one of these positions, the pay leg, must however contain an obligatory element. While even options ${ }^{2165}$ as the smallest available building blocks of financial instruments ${ }^{2166}$ may not represent a redemption obligation themselves in the sense of a capital provision with a total of two closed transfers ${ }^{2167}$, they nevertheless have an obligatory character ${ }^{2168}$. In addition, the debt-based financial instruments transfer an actual and not a mere notional capital or principal ${ }^{169}$ or would otherwise have to be classified as other income. Combining the two aspects means as a consequence that the transfer of the capital or principal by interest-replicating linkers is subject of an absolute and unconditional formal right to actually be repaid (redemption obligation) ${ }^{2170}$. The formal credit risk from this right is also independent of the material termination risk ${ }^{2171}$.

\footnotetext{
${ }^{2157}$ See par. 398(3).

${ }^{2158}$ See par. 61.

${ }^{2159}$ See par. 292.

${ }^{2160}$ See par. 95.

${ }^{2161}$ See par. 69.

${ }^{2162}$ See Example 53 on p. 227.

${ }^{2163}$ Frank Fabozzi, p. 173 et seqq. See also par. 292.

${ }^{2164}$ See par. 385.

${ }^{2165}$ See par. 236.

${ }^{2166}$ See par. 89.

${ }^{2167}$ See par. 371.

${ }^{2168}$ Argumentum a minori ad maius. Contrary: Achim Pross, p. 142 et seq., ignoring this obligatory element of options when concluding from the disaggregation of synthetic zero bonds that there may be a creditor but there was no debtor.

${ }^{2169}$ Contrary: Achim Pross, p. 142 et seq., ignoring this actual transfer of the capital or principal of synthetic zero bonds in contrast to options (i.e. the second closed transaction, see par. 370) when suggesting to disaggregate the former into the latter. See also par. 406.

${ }^{2170}$ See par. 289.

${ }^{2171}$ See par. 386.
} 
408 Again, any financial instrument is likewise object of the same legal subsumption ${ }^{2172}$ (i.e. no ring-fencing ${ }^{2173}$ ), so that it was prejudicial and methodologically flawed to run a disaggregative risk analysis towards its underlying's tax-wise nature before having verified whether the financial instrument as a whole can even potentially come into question for being a debt-claim by fulfilling its most necessary minimum condition. Beyond the redemption obligation, which has been verified now, this also includes the time value of money ${ }^{2174}$. Continuing the analysis, interest-replicating linkers do not bear any termination risk but merely timing risk. The reason is that its risk components refer to exactly the same trigger event or occurrence (e.g. the same underlying) in order to constitute a perfect hedge ${ }^{2175}$. As a consequence, their counteractive risks are literally identical ${ }^{2176}$ and the process of risk determination thus is not capable of eventually validating more than just the "managed" or "engineered" (i.e. hedged) net risk ${ }^{2177}$, which amounts in fact only to timing risk. In other words: the evaluative process of risk assessment cannot do more than verify time equivalence ${ }^{2178}$. Notably, this is not a consequence of any form of disaggregation as a qualitative risk classification but rather of the prior methodological step of a quantitative underwriting risk determination. Coming back to the initial question $^{2179}$, it is therefore held as an interim conclusion that the risk-based nature of the underlying itself is subsidiary to its hedge by the embedded forward transactions.

409 The time value of money is a quantitative concept in the sense that any risk type can amount to time equivalence, as time is a physical and thus a universal parameter ${ }^{2180}$. In contrast, business risk is not only a qualitative concept in the sense that it is one specific risk type out of many but it is eventually also situative to the individual business enterprise. Consequently, genuine business risk was found not to be qualitatively or universally replicable or synthesisable, but instead to require a formal reference to any underlying classified as a share pursuant to Art. 10(3) OECD MTC ${ }^{2181}$. In contrast, the time value of money is quantitatively and universally replicable ${ }^{2182}$, so that genuine debt-claims as such do not in turn require a formal reference to any underlying classified as a debt-claim. However, due to the extending modification in Art. 11(3) OECD MTC, profit-participating debt-claims likewise require a formal reference to any underlying classified as a share pursuant to Art. 10(3) OECD MTC. It is therefore held as a conclusion that a time-equivalent remuneration replicated by linkers is to be classified as interest pursuant to Art. 11(3) OECD MTC, even without referring to an underlying classified as a debt-claim and even when referring to an underlying classified as a share. In contrast, a time-inequivalent remuneration replicated by linkers can principally be classified as profitparticipating interest pursuant to Art. 11(3) OECD MTC or as dividend pursuant to Art. 10(3) OECD MTC, if they formally refer to any underlying classified as a share pursuant to Art. 10(3) OECD MTC. Otherwise they are to be classified as other income pursuant to Art.21(1) OECD MTC.

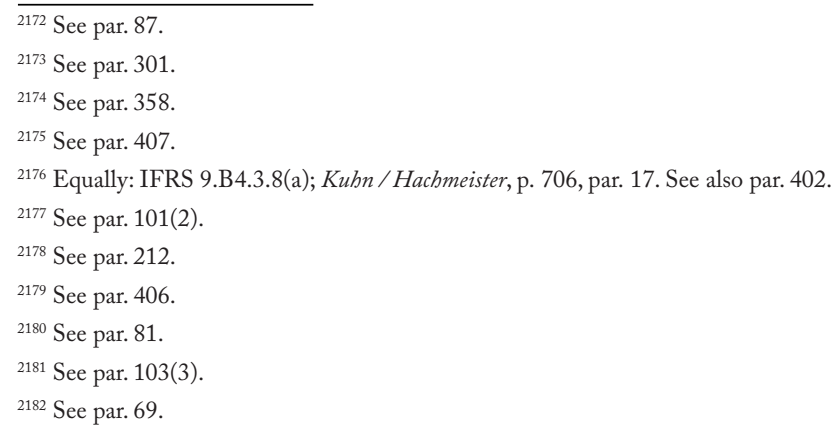




\subsubsection{Negative interest}

410 The last topic that should be discussed here in the form of a short side note is the nature of negative interest. On the one hand, the phenomenon of negative interest is nothing new. For instance, Switzerland introduced a "commission" of $2 \%$ on the value appreciation of foreign cash deposits as early as $1972{ }^{2183}$. The majority of commentators ${ }^{2184}$ came to the consensus view that negative interest can and must eventually be subsumed under Art. 11(3) OECD MTC. On the other hand, it appears that no systematic justification for this conclusion has been discussed yet. The key issue in this context is the question whether (then no income at all but maybe costs) or not (then income) the underlying transaction changes its economic nature if its price drops from positive into negative.

411 In this respect, it might initially be suggested that the qualitative classification or subsumption of income may not depend on its quantitative assessment or calculation. The latter deals with the grounds (cause) and therefore methodologically applies prior to the former that deals with the amounts (effects). On the other hand, mathematically speaking, the particular disparity between positive and negative amounts may be seen as more than just in the quantitative sense of being an absolute difference between two figures. Rather, it may also be seen in the qualitative sense of representing two entirely diverse numerical ranges. In other words: their opposite mathematical signs constitute a qualitative disparity beyond their mere quantitative difference in pivoting to diametrical directions. Or, shorter: "positive and negative" is more than just "more or less". This qualitative element can be set in the context of the fact that the payment profile is an apparent and observable symptom of or reflex response to subjacent and masked qualifiers for the economic nature of the transaction or operation ${ }^{2185}$. In this context, it might be assumed that changes in the direction of cash flows actually indicate changes in the subjacent nature of the transaction or operation, particularly from a positive into a negative asset ${ }^{2186}$. This approach of drawing qualitative reverse deductions from quantitative facts and figures is a common and accepted legal methodology. It becomes evident when we consider that the mere direction of paying a positive or negative risk premium determines whether a legal relationship is, for instance, a bet or an insurance ${ }^{2187}$.

412 To the author's understanding, a negative price of the time value of money as the market "price of investment time" 2188 does not impact the operation's economic nature as a finance transaction ${ }^{2189}$. Without going too deep into economic theory, the systematic reason can, however, not be understood without some very briefly explained basics. In economic theory, negative assets in the broader sense are characterised by negative utility, i.e. the negative net residual of gross costs and gross benefit. In the narrow sense, negative assets are characterised by negative gross benefit. Obviously, where the gross benefit is already negative, this must be even more true for the net utility ${ }^{2190}$ (but due to the cost impact not necessarily also vice versa). The difference

\footnotetext{
${ }^{2183}$ Art. 5(1) of the Swiss Verordnung über die Verzinsung ausländischer Gelder from 5 Juli 1972, Sammlung der eidgenössischen Gesetze: Amtliche Sammlung der Bundesgesetze und Verordnungen, supplement of Bundesblatt der Schweizerischen Eidgenossenschaft, Stämpfli, Berne, 1973, p. 1522.

${ }^{2184}$ See footnote 711 .

${ }^{2185}$ See par. 200.

${ }^{2186}$ See par. 60.

${ }^{2187}$ See par. 70.

${ }^{2188}$ See par. 208.

${ }^{2189}$ See par. 295.

${ }^{2190}$ Argumentum a minori ad maius.
} 
between negative utility and negative benefit is the "social dimension" 2191 : The former takes the individual or subjective perspective and thus is situative or relative in having a positive individual benefit merely exceeded by individual costs. In contrast, the latter takes the social or objective perspective and thus is global or absolute in having no positive benefit at all (i.e. for nobody).

Example 56: Drugs, crime or recyclable waste (e.g. second-hand goods) may be negative assets in the broader sense by having positive individual benefit exceeded by individual costs. Pollution, risk ${ }^{2192}$, physical harm (e.g. diseases, death) or non-recyclable (e.g. radioactive) waste may be negative assets in the narrow sense by having a negative benefit (i.e. for everybody).

413 Due to the quantitative interdependency of the social benefit as the sum of all individual benefits, the borderline between the two concepts is fluid. The more individuals derive negative benefit from an asset (e.g. due to scientific findings), the more it turns first from a positive into a negative one (e.g. smoking) and eventually from a negative one in the broader sense into a negative one in the narrow sense (e.g. carcinogenic construction materials). One important determining factor of such successive revaluation is glut in the market in the sense that most assets naturally turn from positive into negative as soon as they pass saturation (e.g. carbon dioxide). This is made even more evident by considering that market prices are determined by marginal utility (i.e. of the asset's last additional unit) rather than by absolute utility (i.e. of the asset's total units). In respect of capital supply, glutted markets are, however, always and necessarily temporarily and even also locally limited. The reason is that capital is a requisite production factor and as such can never be a negative asset in the narrow sense. In other words: no matter how much a particular market is glutted, there is always and necessarily sooner or later a minimum demand for capital. For instance, central banks raise negative interest only on the respective currency deposits of financial institutions, which actually represent the secondary market for capital, in order to increase their individual capital costs. By doing so, it is their very intention to meet the existing positive capital demand directly on the primary market. Consequently, a temporarily and locally negative "price of investment time" alone may not lead to the false reverse deductions that debt capital as such had a negative benefit. For these reasons the debt capital does not change its subjacent nature of being a finance transaction or operation, for instance, into a mere custody service ${ }^{2193}$. In other words: a bad deal is nevertheless still a deal.

414 Thinking this argumentation to its end, it may legitimately be suggested by analogy that any negative price paid for disposing of negative assets in the broader sense could potentially represent negative sales proceeds pursuant to Art. 13(5) OECD MTC (e.g. an insurance premium as the sales price of the risk). Indeed, this is a logical consequence of the above disentanglement or separation of the causal or contextual nature of income from its mathematical sign ${ }^{2194}$. In fact, no one will seriously doubt that, for instance, negative electricity prices in any way alter the fact that the underlying transaction or operation remains the disposal of electricity. In other words: in that the scope of its distributive articles must be basically as broad or comprehensive as

\footnotetext{
${ }^{2191}$ Fuchs, Hans Gerd/Klose, Alfred / Kramer, Rolf, Güter und Ungüter: Eine Freundesgabe für Gerhard Merk zum 60. Geburtstag, Duncker \& Humblot, Berlin, 1991, p. 4 et seq. 
possible ${ }^{2195}$, the OECD MTC is principally open and accessible for all kinds of positive (e.g. capital gains) and negative income (e.g. capital losses) from both positive (e.g. bets) and negative assets (e.g. insurances), irrespective of what their price is. However, for the practice of treaty application, the issue is presumably of fairly low significance. The reason is that the terms income and capital gains are to be interpreted pursuant to the domestic tax $\operatorname{law}^{2196}$. This typically adheres non-treaty purposes (e.g. to generate tax revenue ${ }^{2197}$ ) and thus applies additional principles (e.g. an intention of making profits) ${ }^{2198}$ re-narrowing this comprehensive autonomous understanding of income.

\subsection{Other equity-based financial instruments}

\subsubsection{Structure}

415 The most important class of other non-convertible and non-"derivative" equity-based "hybrids" are preference shares (also referred to as "preferred stock"). Preference shares actually form a class of financial instruments that is so diverse that a comprehensive and detailed analysis cannot be given here satisfactorily. Instead, their most typical and relevant features may be roughly grouped into:

(1) redeemability;

(2) preference in the remuneration;

(3) preference in the event of liquidation; and

(4) preference in membership rights.

\subsubsection{Redeemability}

416 As a starting point, it should be permissible to assume that preference shares generally bear business risk. Hence, the crucial question and critical differentiator for classifying them is whether or not this business risk is limited to the specific form of termination risk. Approaching this question, the methodological interim step or starting point of subsumption must again be the redemption obligation. In this first respect (1), preference shares can be featured in a way that formally provides the repayment of their capital or principal (e.g. redeemable preferred stock), which is also independent of the material termination risk. To the extent that such redeemability substantiates into an absolute and unconditional legal right to be repaid ${ }^{2199}$, preference shares ceteris paribus have a structure identical to that of linkers with own "ordinary" shares of the issuer ${ }^{2200}$ itself as their underlying. Consequently, they have to be classified accordingly ${ }^{2201}$. However, a substantial difference emerges in cases where such qualitative redemption obligation also includes a perfect quantitative recovery of the invested capital ${ }^{2202}$, i.e. where there is no termination risk at all (e.g. guaranteed redeemable preferred stock). Those specific kinds of guaranteed redeemable preference shares might in fact be seen as representing rather the conceptual opposite of linkers. In fact, their business risk is exclusively limited to

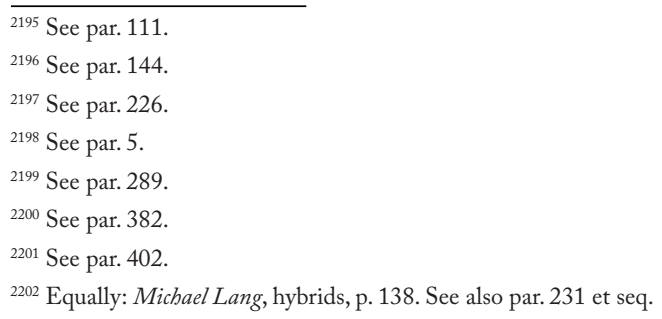


remuneration risk, whereas that of typical linkers is exclusively limited to termination risk ${ }^{2203}$. It is probably this dichotomy that gives rise to the association of linkers with debt instruments and that of preference shares with equity instruments. Nevertheless, the exclusion of termination risk actually limits the investor's business risk exposure and thus impacts the payment profile 2204 as compared to ordinary shares (i.e. a lower remuneration), which is the very economic purpose of preference shares. Hence, the question arises whether or not such specific combination of redemption obligation and business risk in the form of remuneration risk as the only key differentiator between preference shares and linkers alters the prior conclusions. This becomes particularly clear when considering the apparent contradiction that linkers, although associated as "debt-like", primarily yield genuine dividends pursuant to Art. 10(3) OECD MTC ${ }^{2205}$. In contrast, guaranteed redeemable preference shares, although associated as "equity-like", seem to fulfil all legal requirements for a classification as profit-participating debt-claims pursuant to Art. 11(3) OECD MTC. The answer to this question is to be found in the remuneration, which will be analysed in the following.

\subsubsection{Preference in the remuneration}

417 As regards the second group (2) 2206 , the remuneration from preference shares can be featured in a way that its risks in respect of (a) periodicity, (b) certainty, (c) payability, (d) currency and/or its (e) payment profile ${ }^{2207}$ approximate to the time value of money ${ }^{2208}$. In terms of periodicity (a), preference shares might distribute their remuneration at maturity instead of periodically (e.g. zero-dividend preferred stock). However, it was found that it is the very nature of time equivalence to be independent of any temporal framework ${ }^{2209}$. In other words: the periodicity of remuneration payments is not a differentiator for subsuming preference shares under Art. 10(3) or 11(3) OECD MTC. As a consequence, the question of whether or not the remuneration is paid in regular periods is irrelevant.

418 In terms of certainty (b), the remuneration from preference shares can also be featured in a way that the remuneration risk is reduced compared to ordinary shares. For instance, it may grant priority distribution (e.g. preferred dividend stock) or even guarantee a remuneration (e.g. fixed dividend preferred stock). The critical element is, however, self-execution in the sense of an ex-ante determinability at least by a mathematical formula ${ }^{2210}$. While not being a verifier for interest pursuant to Art. 11(3) OECD MTC ${ }^{2211}$, self-execution is nevertheless a falsifier for dividends pursuant to Art. 10(3) OECD MTC ${ }^{2212}$. In other words: no matter how much the remuneration risk is quantitatively reduced, it takes effect on the income classification only if qualitatively eliminated. However, as there is no absolutely riskless state in practice ${ }^{2213}$, the determination of what can still be associated with the lowest relative risk must probably be set by convention (e.g. where the distribution is subject to a very likely condition). Where preference shares guarantee a remuneration that is

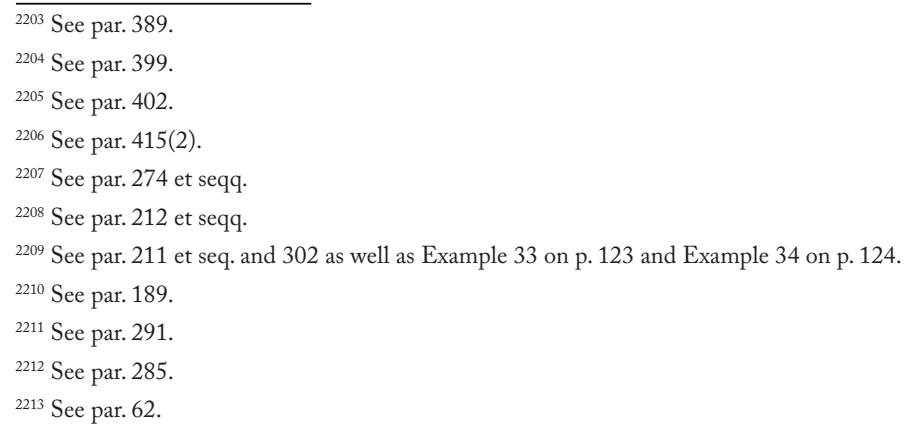


considered the lowest relative risk (i.e. no remuneration risk), they can - in the absence of voluntariness not possibly be subsumed under Art. 10(3) OECD MTC. Instead, they must ceteris paribus rather be classified under Art. 11(3) OECD MTC214.

419 In terms of payability (c) $)^{2215}$, the remuneration from preference shares can also be featured in a way that the distribution is deferred. The most typical use case is where the remuneration is not actually distributed but accumulated for future payment (e.g. cumulative preferred stock $^{2216}$ ). As was found ${ }^{2217}$, deferrals basically represent a negative amount modification of the payment profile (e). Therefore, they represent the time value of money only in case they bear interest themselves (i.e. are subject of compound interest), which may be assumed to be highly uncommon in practice. In that, the payability feature actually coincides with the payment profile (e), which is analysed separately in the following.

420 Currency effects (d) ${ }^{2218}$ are likewise no differentiator for subsuming preference shares (e.g. dual- or multicurrency preferred stock) under Art. 10(3) or 11(3) OECD MTC. In result, the question in which currency the principal nominates or the remuneration is distributed is principally irrelevant ${ }^{2219}$. As regards the former, time equivalence was said to have been determined in the currency in which the principal nominates. That is why any currency conversions are subsequent logical steps to the capital provision, so that currency risk has no (negating) impact on the time equivalence. As regards the latter, currency effects coincide with the payment profile (e), which is analysed separately in the following.

421 In terms of the payment profile $(e)^{2220}$, the remuneration distributions from preference shares can also be featured in a way that their amounts - if analysed by grouping them together as a coherent whole approximate to the time value of money ${ }^{2221}$. This is typical for guaranteed redeemable preference shares, in that it is the consequent economic response to their aforementioned limitation of the investor's business risk exposure to its form of remuneration risk ${ }^{2222}$. Admittedly, due to the extending modification towards a profit participation in Art. 11(3) OECD MTC, the quantitative remuneration amounts cannot serve as a differentiator for classifying preference shares ${ }^{2223}$. However, the remuneration distribution is typically subject of qualitative voluntariness ${ }^{2224}$ (e.g. participating preferred stock), whereas the redemption obligation remains self-executive ${ }^{2225}$. In other words: it is this specific combination of self-executive redemption obligation (i.e. no termination risk) but voluntary remuneration distribution (i.e. remuneration risk) as the distinctive feature of guaranteed redeemable preference shares, which makes them a particularly ambiguous group of financial

\footnotetext{
${ }^{2214}$ See par. 290.

${ }^{2215}$ See par. 417.

${ }^{2216}$ See Example 54 on p. 231.

${ }^{2217}$ See par. 216.

${ }^{2218}$ See par. 417.

${ }^{2219}$ See par. 217.

${ }^{2220}$ See par. 417.

${ }^{2221}$ See par. 215.

${ }^{2222}$ See par. 416.

${ }^{2223}$ See par. 280.

${ }^{2224}$ See par. 285.

${ }^{2225}$ See par. 289.
} 
instruments in respect of whether they actually represent a profit-participating debt-claim (then interest) or rather a negatively modified risk-based payment profile (then dividend) ${ }^{2226}$.

422 However, it was found that the extending attribute of profit participation in Art. 11(3) OECD MTC also requires self-execution in order to constitute debt-claims ${ }^{2227}$. In addition, the principle of reciprocity ${ }^{2228}$ demands that a rational investor will basically not accept negative modifications or even voluntariness ${ }^{2229}$ with regard to the payment profile (lower risk premium) unless compensated on the risk level (no termination risk) ${ }^{2230}$. This principle was found to result in opposite classification consequences for risk-based remunerations (preference shares) and time-based remunerations (linkers ${ }^{2231}$ ). Negative modifications of a time-based remuneration or even voluntariness demand a participation in negative risk (chances) turning it into risk-based (termination risk). Contrariwise, negative modifications of a risk-based remuneration demand a limitation of positive risk keeping it basically risk-based. Combining those two findings means that the additional requirement whether or not the remuneration is self-executive is the reference point for the question whether a financial instrument represents a profit-participating debt-claim (then interest) or rather a negatively modified risk-based payment profile (then dividend). In other words: while both profit-participating debt-claims and guaranteed redeemable preference shares participate in remuneration risk but not in termination risk, the former is subject of selfexecution and is thus a profit-participating debt-claim (interest). In contrast, the latter is subject of voluntariness and is thus a negatively modified risk-based payment profile (dividend). In that, the superficial aspect of payment profile actually reveals that subjacent qualitative difference between linkers, profit-participating debt-claims and those specific kinds of guaranteed redeemable preference shares. It also resolves the apparent contradiction that the one as a "debt-like" instrument primarily yields genuine dividends ${ }^{2232}$, whereas the other as an "equity-like" instrument seems to call for a classification as profit-participating debt-claim. Linkers are risk-based due to embedding a risk premium ${ }^{2233}$ for their termination risk. Preference shares remain risk-based even though embedding a risk premium for their voluntary remuneration. And profit-participating debt-claims embed none of such risk premiums at all. This view is also in line with the aforementioned analogy of preference shares with linkers and thus with non-packaged net-settled convertibles ${ }^{2234}$. Such embedded risk premiums actually turn the holder into the equity leg receiver. Accordingly, linkers represent genuine shares pursuant to Art. 10(3) OECD MTC due to their termination risk. Preference shares represent a negatively modified risk-based payment profile and therefore genuine shares as well due to their voluntary remuneration. On the contrary, profit-participating debt-claims are to be subsumed under Art. 11(3) OECD MTC due to their self-execution. The following illustration visualises this understanding:

\footnotetext{
2226 See par. 277.

${ }^{2227}$ See par. 290.

${ }^{2228}$ See par. 180.

${ }^{2229}$ See par. 291.

${ }^{2230}$ See par. 276.

${ }^{2231}$ See par. 391 and 402.

${ }^{2232}$ See par. 402.

${ }^{2233}$ See par. 392 and 402.

${ }^{2234}$ See par. 416.
} 


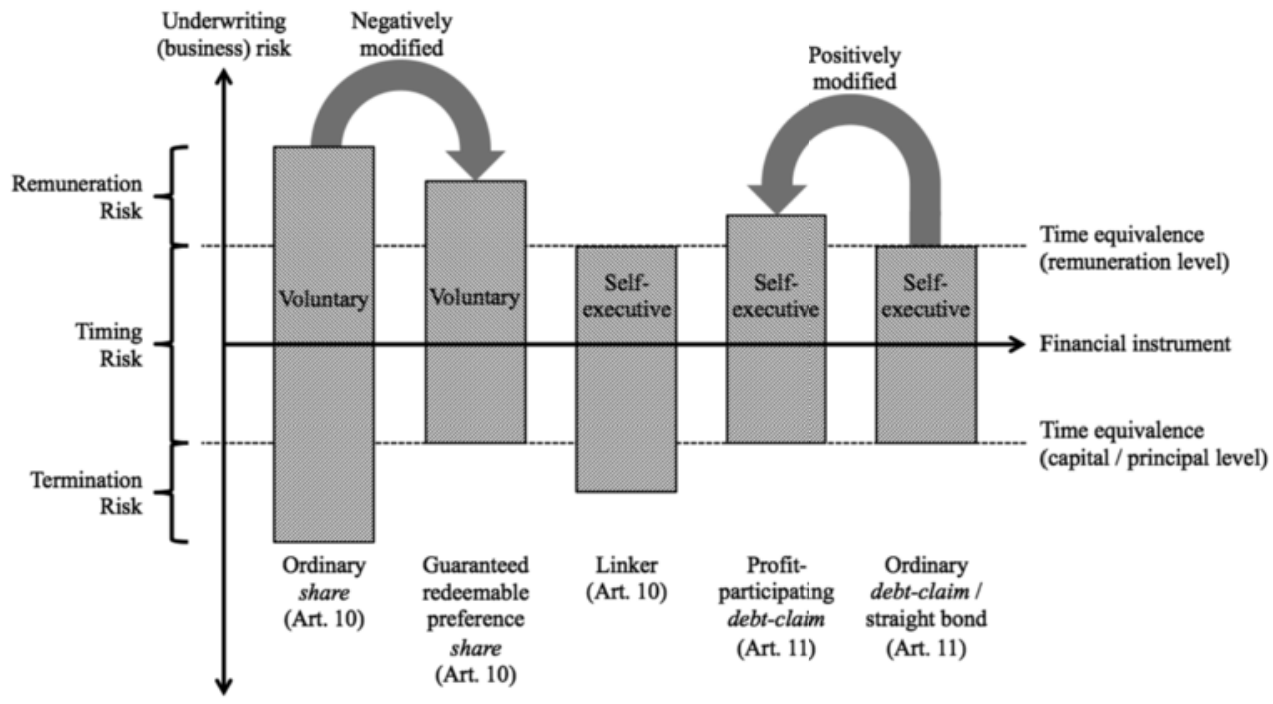

$\square$ Capital / principal

Remuneration

Illustration 26: The delimitation of preference shares, profit-participating debt-claims and linkers

\subsubsection{Preference in the event of liquidation}

423 As regards the third group (3 $)^{2235}$, preference shares can also be featured in a way that they participate in the liquidation proceeds, which are senior to those of ordinary shares. Such participation was found to be a necessary minimum condition (conditio sine qua non) in order to constitute shares pursuant to Art. 10(3) OECD MTC $^{2236}$. The reason is that it represents a part of negative termination risk by participating in the business opportunities equivalent to those of a shareholder. Accordingly, seniority actually represents a form of negative subordination, which was found incapable of being a differentiator ${ }^{2237}$. In other words: while the participation in the liquidation proceeds supports the subsumption of preference shares under Art. 10(3) OECD MTC ${ }^{2238}$, its seniority cannot possibly falsify this classification ${ }^{2239}$. In contrast, preference shares that do not participate in the liquidation proceeds (e.g. debt-like "jouissance" shares or "jouissance" rights) are - even if redeemable at liquidation - not to be classified as shares pursuant to Art. 10(3) OECD MTC.

\footnotetext{
2235 See par. 415(3).

${ }^{2236}$ See par. 278 and 282.

${ }^{2237}$ See par. 220 et seq.

${ }^{2238}$ Equally: Jakob Bundgaard, hybrids, p. 384; Haslehner, Werner in Klaus Vogel Commentaries 2015, p. 842, par. 106; Jakob Bundgaard, debtflavored equities, p. 425; Marjaana Helminen, dividend concept, p. 203.

${ }^{2239}$ Perhaps Contrary: Marjaana Helminen, dividend concept, p. 203, by holding that "the only situation where a preferred share may not qualify as a corporate right is when it contains [...] and a provision that grants liquidation preference".
} 


\subsubsection{Preference in membership rights}

424 As regards the fourth group (4) ${ }^{2240}$, preference shares can also be featured in a way that gives preference in membership rights. On the one hand, membership rights were basically found incapable of being a differentiator ${ }^{2241}$. On the other hand, membership rights can be so preferential that - even though being merely formal or legal - they actually impact the proprietary rights and thus might eventually have influence on the material differentiators discussed in this study (e.g. super-voting preferred stock, class A shares). For instance, class A shares distort the concordance between benefit as a proprietary right and control as a membership right by actually exposing the former to the latter. In that, they seem to erode the differentiator of voluntariness, which is, however, relevant for classifying the class B shares. Such influence is a natural consequence of the fact that the peculiarities of financial instruments and thus the delimitation of their various types are in large part the result and effect of legal relationships ${ }^{2242}$. Consequently, the subjacent question arises whether or not those interdependencies merit substantive attention. Or in more general terms: which conflicts between those potential differentiators are relevant or not relevant for the income classification.

425 This question is so general and its answer so extensive that it cannot be given here satisfactorily. With respect to the particular use case of super-voting preference shares, it is sufficient to hold that the exposure of the underrepresented owner of the proprietary rights to the control of the overrepresented owner of the membership rights isn't materially relevant for the income classification ${ }^{2243}$ either. The reason for this is that voluntariness as the source's own decision presumes bilateralism in the sense that there is no external consent required from any third party other than the two contracting parties. These two are only the particular investor in the financial instrument and the source as such, regardless of any of the source's other investor ${ }^{2244}$. In other words: where the source's decision is merely bound by other owners of proprietary rights, this is actually no involuntariness but rather indicates the internal organisation within the source itself (i.e. between the investors). The voluntariness at the source level cannot be infringed by the investor level, as anything else would mean to actually confuse the source's legal position with that of its investors, which would give rise to considerable systematic distortions. In particular, this approach would create a relative classification concept similar to subordination ${ }^{2245}$. As such, it would not allow any universal statement but rather be highly sensitive to the contextual or situative determinants among the various investors and therefore lead to inconsistent, paradoxical or otherwise erratic results. This becomes particularly clear when considering the contradiction that the underrepresented owner of the proprietary rights might - and typically will - own some membership rights as well. Hence, although being underrepresented, he actually binds the source's decision qualitatively. As a consequence, even his own influence would impact the material differentiator of voluntariness ${ }^{2246}$ or otherwise would have had to be quantitatively assessed against the overrepresented owner of the membership rights. This means as a conclusion for the further course of this study that it does not alter the prior conclusion that membership rights are incapable of being a differentiator. This remains valid even where they are so

\footnotetext{
${ }^{2240}$ See par. 415(4).

${ }^{2241}$ See par. 262.

${ }^{2242}$ See par. 56 and 77.

${ }^{2243}$ In result equally: Jakob Bundgaard, hybrids, p. 384 et seq.; Haslebner, Werner in Klaus Vogel Commentaries 2015, p. 842, par. 106; Jakob

Bundgaard, debt-flavored equities, p. 425; Marjaana Helminen, dividend concept, p. 202 et seq.; Michael Lang, hybrids, p. 137.

${ }^{2244}$ See par. 188.

${ }^{2245}$ See par. 220.

${ }^{2246}$ Circular reasoning.
} 
preferential that they might impact the proprietary rights and even where they are detached from the proprietary rights or otherwise delegated from the original owner to any third party.

Example 57: A company has just one single share, from which its one single voting right was split-off (stripped), traded separately and also delegated from its new owner to a bank. The owner of the remaining proprietary rights in that share himself had no influence on the decision whether a dividend is distributed. However, voluntariness takes the company's (i.e. the source's) disposal perspective rather than the shareholder's enjoyment perspective ${ }^{2247}$. Therefore, it is in no way limited or restricted as compared to ordinary unstripped free-float shares (i.e. of minority shareholders). Ergo, the internal organisation between the owner of the proprietary right and the owner of the membership right does not impact the company's (i.e. the source's) decision as to whether or not a dividend shall be distributed.

\subsubsection{Conclusions}

426 The following illustration visualises and summarises the overall classification of preference shares as understood and represented in this study:
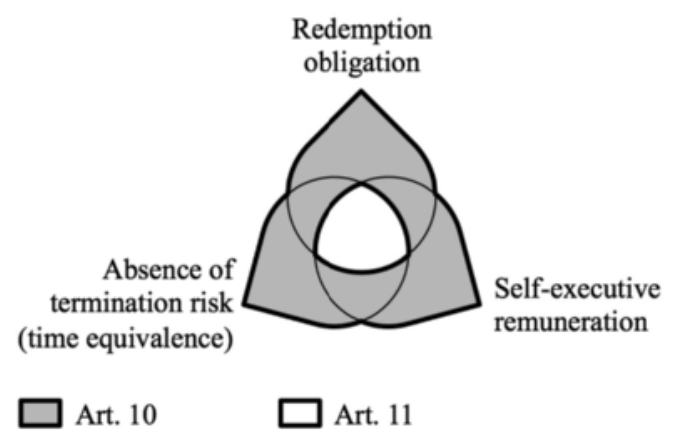

Illustration 27: Classifiers/differentiators for preference shares

\subsection{Strips}

\subsubsection{Structure}

427 Strips originally stands for "separate trading of registered interest and principal securities". In the narrow sense, they are the earnings coupons (e.g. interest or dividend coupons) detached from the capital or principal of their respective securities (e.g. bonds or shares) and traded independently (e.g. strip bond and zero coupon bond, also referred to as "z-bonds"). In more general terms, strips are the claims on only the income stream as a partial proprietary right ${ }^{2248}$ from a capital provision, isolated into a separate financial instrument. The reason

\footnotetext{
${ }^{2247}$ See par. 192.

${ }^{2248}$ See Example 57 on p. 250 for the analogous strip of a membership right.
} 
for devoting this separate section to them is their specific ambiguity in appearing as income (transaction) and capital (asset) simultaneously ${ }^{2249}$, which gives rise to the following systematic key issues:

(1) the role or relevance of the separate capital or principal;

(2) the conflict between termination and remuneration risk; and

(3) the conflict between dividends or interest on the one hand and capital gains on the other.

\subsubsection{The relevance of the separate capital}

428 The first issue (1) sets the general course for the subsumption of strips, in that it actually determines whether they are to be classified independently or by considering the capital or principal securitised into a separate financial instrument. The subjacent question is whether (then other income) or not (then potentially dividends or interest) a coupon stripping turns a capital provision as a finance transaction into something different. On the one hand, it seems reasonable to suggest that considering also the separate capital or principal would actually represent a form of aggregating the two financial instruments which is subject to particularly strict requirements ${ }^{2250}$. On the other hand, the concept of beneficial ownership was found to be a requisite and explicit exception to that aggregation scheme ${ }^{2251}$. However, beneficial ownership is the replacement of the recipient by the beneficial owner and therefore requires an inflow and an outflow ${ }^{2252}$. In contrast, strips have neither two subjects (i.e. the recipient and the beneficial owner) nor two objects (i.e. the genuine dividend or interest as the inflow and a pass-through outflow) but instead only one of each. It is this peculiarity of strips which makes the difference to similar financial instruments such as gross-physically settled forward transactions with a cash flow as their underlying 2253 or securities lending transactions. Countering this, it may be argued that beneficial ownership actually required neither those two subjects nor those two objects. This is demonstrated by the example of an ordinary dividend that apparently has also at least one beneficial owner 2254 . However, pursuant to its purpose, intention and function, the concept of beneficial ownership is obviously necessary and meaningful only in cases where the recipient and the beneficial owner differ from each other. As a consequence, the example of an ordinary dividend represents in so far its counterexception rather than its general rule. Therefore, it would be methodologically flawed to draw any reverse deduction from such exception to a general rule. This is even more true as anything else would unintentionally frustrate the restrictions to the aggregation scheme and eventually let them fall short entirely. For these reasons, it can initially be held that it is impermissible to put strips in a context of the separate capital or principal by way of beneficial ownership 2255 .

429 Instead, associating this context of strips with the separate capital or principal by way of the aggregation scheme at all appears to be a false problem. In fact, the determination whether or not a payment represents a remuneration for a capital provision as a qualified finance transaction is an essential and indispensible material element and the starting point of the subsumption of any financial instrument. As such, it is subject of the

${ }^{2255}$ Contrary: Dutch Hoge Raad der Nederlanden, judgement ref. 28638, 1994, merely holding that "the interested party has, by purchasing the dividend coupons, become their owner. This Court may further assume that the interested party had, after their purchase, the free disposal of the dividend coupons and, after cashing them, of the distributions received and that, when cashing the dividend coupons, it did not act as an agent or nominee. Under these circumstances, the interested party may be considered to be the beneficial owner of the dividends." (translation from Hans Pijl, beneficial owner, p. 258).
} 
substance over form principle per $\mathrm{se}^{2256}$. Suggesting that the capital provision as a finance transaction was also another differentiator between Art. 10 and 11 OECD MTC on the one hand and Art. 21 OECD MTC on the other would actually elevate the concept of aggregation to the status of a general principle within chap. III or even the entire OECD MTC. This argument is far too fundamental and extensive to discuss here satisfactorily. It shall therefore be sufficient to hold that the concept of aggregation and disaggregation is by all means a result of the specific flexibility of financial instruments to synthesise any legal and economic effect $^{2257}$. As such, they are however replicable only into each other and never into "real assets"2258. As a consequence, the concept of aggregation and disaggregation appears to be dispensable for the identification of financial instruments subject of Art. 10 or 11 OECD MTC as opposed to other assets such as those subject of Art. 13 or 21 OECD MTC. Instead, it seems to apply within the group of what has priorly been identified as financial instruments and therefore to point predominantly at the delimitation of the respective Art. 10 and 11 OECD MTC.

430 Accordingly, strips represent an overlay of the substance over form principle in general and that in its specific form of the aggregation scheme, whereby the former methodologically applies prior to the latter. In other words: before the aggregation scheme can potentially affect the classification of a financial instrument, it must priorly be determined whether or not there is a qualified finance transaction at all. That is why setting strips in the context of the separate capital or principal for determining whether or not they represent a financial instrument at all is, at this stage, no exception from the restrictions to the aggregation scheme. The reason is that the aggregation scheme does not yet come into effect on this first subsumption level. It appears that the specific ambiguity of strips is rooted in the subjacent conflict between these two aspects or layers of the substance over form principle in actually taking different perspectives: on the one hand, splitting a composite finance operation sufficiently into partial transactions leads to the point where the individual component taken separately - cannot be considered a finance operation anymore 2259 . This is even more evident where its key element of the capital provision is attributable to another person. On the other hand, this view in favour of the aggregation aspect actually takes the holder's or investor's perspective. In contrast, from the issuer's perspective strips obviously represent the genuine remuneration for a qualified finance operation. Considering that the classification of strips cannot possibly depend on the situative context of whether (then potentially dividends or interest) or not (then potentially other income) their owner also holds or held the separate capital or principal ${ }^{2260}$ makes evident, however, that the general aspect of the substance over form principle must - in the sense of "one fits all" - principally take precedence over its specific aggregation aspect.

431 This result for strips is in natural contrast to the classification of forward sales that depends on whether or not their underlying is actually available for sale and thus the forward transaction gross-physically settleable ${ }^{2261}$. The existence of both capital gains and beneficial ownership requires two composite transactions (i.e. acquisition and sale as well as inflow and outflow) as a necessary minimum condition (conditio sine qua

\footnotetext{
2256 See par. 56.

${ }^{2257}$ See par. 76.

${ }^{2258}$ See par. 1 and 180.

${ }^{2259}$ See par. 306.

${ }^{2260}$ In this sense, however: Tischbirek, Wolfgang / Specker, Gerhard in Vogel / Lehner, p. 1215, par. 192; Wassermeyer, Franz in Wassermeyer Commentaries, p. 1616, par. 35; Marjaana Helminen, dividend concept, p. 102.

${ }^{2261}$ See par. 376.
} 
non). In contrast, genuine dividends or interest, as demonstrated by strips, are singular events. As a conclusion for the further course of this study, strips cannot per se be excluded from representing a genuine material return for a qualified finance transaction pursuant to Art. 10(3) or 11(3) OECD MTC respectively. This is regardless of the subsequent fact that this return is formally or legally isolated into a separate financial instrument. Or to answer the initial question ${ }^{2262}$ in other words: a coupon stripping as such does not turn a capital provision as a finance transaction into something different. It is this peculiarity of strips, which makes the difference to similar financial instruments, such as those with a mere notional capital or principal ${ }^{2263}$, uncovered long puts with a cash flow as their underlying ${ }^{2264}$ or repurchase obligations ${ }^{2265}$.

\subsubsection{The conflict between termination and remuneration risk}

432 As regards the second issue $(2)^{2266}$, the general relevance of the capital or principal for the determination whether or not the strip represents a qualified finance operation ${ }^{2267}$ may not lead to the conclusion that it was automatically also relevant for the subsequent subsumption level, i.e. the determination of the strip's particular classification characteristics. The reason is that this aspect, which distributive article applies within the group of priorly identified finance transactions (i.e. Art. 10 or 11 OECD MTC), is governed by the substance over form principle in its specific form of the aggregation scheme, which comes only now into effect on this subsequent subsumption level. At first glance, strips seem to not differ in any way from other financial instruments carving-out or skimming-off cash flows (e.g. replicating financial instruments) in merely "picking and extracting" 2268 the quantitative earnings or income cash flow. Hence, there appear to be no compelling reasons to refrain from those particular aggregation restrictions. However, in contrast to any of those other financial instruments carving-out or skimming-off cash flows, strips represent also a qualitative proprietary right $^{2269}$ in their respective finance transaction itself. The first subsumption step of determining whether or not the strip represents a qualified finance operation at all is an economic problem ${ }^{2270}$. On the contrary, the second subsumption step of determining the existence of the strip as a financial instrument was said to be predominantly a matter of the legal form ${ }^{2271}$. Just as the former, the latter must take the issuer's perspective as well in order to be coherent and consistent. Anything else would give rise to inconsistent or paradoxical or otherwise considerable systematic distortions.

Example 58: Where an issuer's entire equity was stripped, he would - from the holder's or investor's perspective - not have any share pursuant to Art.10(3) OECD MTC and thus would have no shareholders at all. If, in addition, also his entire debt capital was stripped, there would be - from the holder's or investor's perspective - no debt-claims pursuant to Art. 11(3) OECD MTC either. Thus, there would be no finance transaction at all, even though a company

\footnotetext{
2262 See par. 428.

${ }^{2263}$ See par. 282 and 299.

${ }^{2264}$ See par. 377.

2265 See par. 292.

${ }^{2266}$ See par. 427(2).

${ }^{2267}$ See par. 429 et seqq.

${ }^{2268}$ See par. 91.

${ }^{2269}$ See par. 427.

${ }^{2270}$ See par. 430.

${ }^{2271}$ See par. 77.
} 
pursuant to Art. 3(1)(b) OECD MTC can be financed only by equity and/or debt. As a consequence, the legal and the economic view on the same aspect (i.e. the determination of whether or not a strip represents a finance transaction at all) would fall apart in such a severe way that such a view cannot be considered in line with the purpose, intention and function of Art. 10(3) and 11(3) OECD MTC.

433 In other words: only the issuer's perspective is capable of giving an overall picture for the determination whether or not a reciprocal relationship represents an economic finance transaction in general. Any debtequity distinction in particular must stand against the company pursuant to Art. 3(1)(b) OECD MTC as an issuer capable of operating debt and equity simultaneously. As a consequence, the systematic approach must necessarily correlate for both the economic and the legal aspect in order to avoid a dualism of methods. Insofar, strips - in having just one subject (i.e. the recipient and beneficial owner ${ }^{2272}$ ) and one object (i.e. the income $)^{2273}$ - coalesce both an economic return for a finance operation ${ }^{2274}$ and simultaneously also a legal proprietary right in this finance operation itself. It is this peculiarity of strips which makes the difference to similar financial instruments carving-out or skimming-off cash flows (e.g. replicating financial instruments). As such, it provides not only a criterion for consistently and resiliently distinguishing them in this respect for the purpose of treaty application. It is also the systematic justification for the fact that setting strips in the context with their separate capital or principal ${ }^{2275}$ represents a legitimate exception from the restrictions to the aggregation scheme.

434 The issuer's perspective ${ }^{2276}$ is in line with the IAS/IFRS classification scheme ${ }^{2277}$ and with the tax-limiting purpose, intention and function of the distributive articles, in that it primarily addresses the source jurisdiction ${ }^{2278}$. Considering the separate capital or principal for the classification of strips is therefore not arbitrary either by implying any prejudicial and artificial imagination of an "original" financial instrument (ring-fencing ${ }^{2279}$ ). Even considering that any financial instrument is actually the object of the same legal subsumption ${ }^{2280}$, the strip's legal participation as a proprietary right in the finance operation itself actually makes it part of the genuine capital provision. In addition, this view does not conflict either with the fact that the formal or legal interpretation necessarily adheres to the domestic tax law. The reason is that the domestic tax law is limited to the strip's mere existence as such ${ }^{2281}$ and does not necessarily also include its context. As a conclusion for the further course of this study, the strip's context to the separate capital or principal is not

\footnotetext{
${ }^{2272}$ Equally: Marjaana Helminen, dividend concept, p. 102.

${ }^{2273}$ See par. 428.

${ }^{2274}$ David Hasen, p. 419, even suggesting that a strip economically represents rather an individual but entire bond or share itself due to the economic inseparability of capital and income (see also par. 158).

${ }^{2275}$ In result equally: Harris, Peter A. in IBFD Commentaries on Art. 10 OECD MTC, sec. 5.1.2.4.2.; Reimer, Ekkehart in Klaus Vogel Commentaries 2015, p. 1078, par. 147.

${ }^{2276}$ See par. 430.

${ }^{2277}$ See par. 236

${ }^{2278}$ See par. 19.

${ }^{2279}$ See par. 301.

${ }^{2280}$ See par. 87.

${ }^{2281}$ See par. 81.
} 
limited to its economic determination as a finance transaction. Instead, it also includes its legal determination as being subsumed under either Art. 10(3) or 11(3) OECD MTC respectively ${ }^{2282}$.

435 As a consequence of such aggregation, the redemption obligation and therefore the timing or termination risk of strips is not to be determined separately and individually but by also considering the characteristics of their capital or principal. Following the general principles of the debt-equity delimitation ${ }^{2283}$, strips may thus be either risk-based or time-based. And, in the former case, they may bear either business risk or non-business risk, depending on their formal reference to a share $e^{2284}$.

436 The following illustration visualises this understanding:

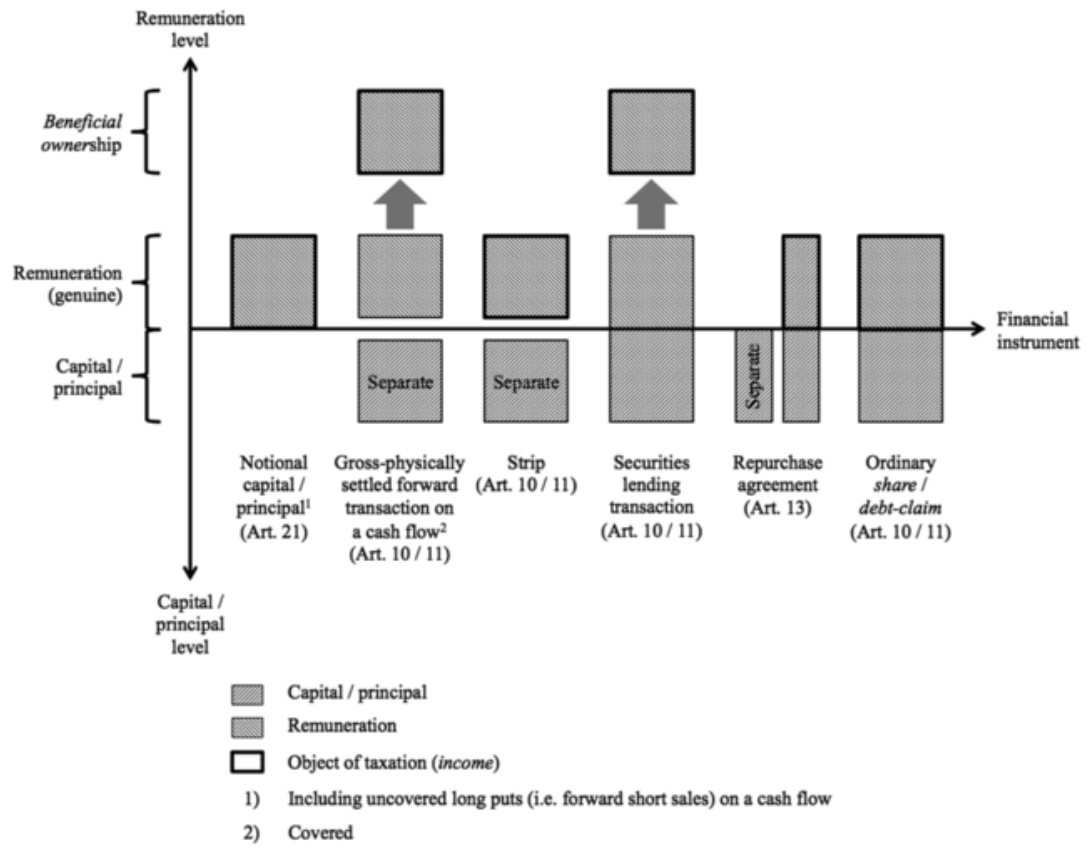

Illustration 28: Delimitation of strips and similar financial instruments

437 Having ascertained the general relevance of the capital or principal, the subsequent question arises who is to be considered the attributee of the income (i.e. the strip holder or the shareholder). Obviously, the attributee of the income is the strip holder, even though he is not also the holder of the capital or principal and thus does typically not provide the capital himself. This is even more evident by considering that both Art. 10(3) ${ }^{2285}$

\footnotetext{
${ }^{2282}$ In result equally: Harris, Peter A. in IBFD Commentaries on Art. 10 OECD MTC, sec. 5.1.2.4.2.; Reimer, Ekkehart in Klaus Vogel Commentaries 2015, p. 1078, par. 147; unclear: Wassermeyer, Franz in Wassermeyer Commentaries, contrary on p. 1430, par. 75 but then in favour on p. 1435 , p. 86.

${ }^{2283}$ See par. 358.

${ }^{2284}$ See par. 103(3).

${ }^{2285}$ Equally: Marjaana Helminen, dividend concept, p. 97 and 102.
} 
and 11(3) 2286 OECD MTC do not provide any income attribution rule. That the provision of the capital as the operation and the remuneration as the return actually fall apart in such a way, is the consequence of the issuer's perspective to be taken for the determination whether or not the strip represents a finance operation at all ${ }^{2287}$. However, such determination was said to be not so much a legal as an economic problem. From this economic perspective the strip holder does nothing else than to compensate and credit the shareholder for his lost profits, so that he actually participates indirectly in the genuine capital provision as well.

\subsubsection{Dividends or interest versus capital gains}

438 With respect to the third issue (3) ${ }^{2288}$, it cannot be argued either that the compensation of the shareholder for his lost profits by the strip holder actually represents a pass-through of the genuine income by the latter back to the former. Admittedly, such transfer may comply with the requirement to beneficial ownership of a causal relation between the in- and outflows of individual transactions, quantitatively observable by expected negative correlation depending on the same risk ${ }^{2289}$. And, of course, an inflow in the form of income (dividends or interest) can also be passed-through as an outflow in the form of sales proceeds (capital gains) ${ }^{2290}$. However, in the author's view such transfer does not comply with the requirement for beneficial ownership that the in- and outflows must also proportionate in approximately equal amounts or benefits, which was found to be interpreted in a particular restrictive sense ${ }^{2291}$. The reason is that the compensation as the outflow can only account for expected amounts (ex ante). On the contrary, the genuine income naturally accounts for the actual amounts (ex post). This means as a conclusion that the strip holder is not only the recipient but also remains the beneficial owner of the respective income. And where the (re-)attributional purpose of the specific and explicit beneficial ownership concept is not sufficient to substitute the nature of an income ${ }^{2292}$, this must be even more true for the general and implicit substance over form principle 2293 .

439 Going further, the realisation of the income from the strip by the strip holder is no capital gain pursuant to Art. 13(5) OECD MTC. Even where its total value was distributed, it might quantitatively have a zero value but nevertheless qualitatively continues to exist as a right (at least on future distributions) ${ }^{2294}$. Consequently, such distribution represents a legal event that does not refer to the strip in the sense of impairing the mathematical number of the critical ownership rights in the strip ${ }^{2295}$. This means as a conclusion that the income from the strip also keeps its original nature, i.e. its realisation does not turn it into something different (particularly not into capital gain ${ }^{2296}$.

\footnotetext{
${ }^{2286}$ Helminen, Marjaana in IBFD Commentaries on Art. 11 OECD MTC, sec. 5.1.1.3.2.

${ }^{2287}$ See par. 429 et seqq.

${ }^{2288}$ See par. 427(3).

${ }^{2289}$ See par. 338.

${ }^{2290}$ See par. 138.

${ }^{2291}$ See par. 135.

${ }^{2292}$ See par. 129.

${ }^{2293}$ Argumentum a minori ad maius.

${ }^{2294}$ See Example 61 on p. 263.

${ }^{2295}$ See par. 160 et seqq.

${ }^{2296}$ Equally: Reimer, Ekkehart in Klaus Vogel Commentaries 2015, p. 1078, par. 147; perhaps contrary: OECD, CFA/WP1(73)2, p. 11, par. 21, but probably referring to limb 3 of Art. 10(3) OECD MTC in saying that "the definition has been widened to that the term dividends also covers income arising from the alienation of dividend coupons or other similar rights where the capital relating thereto has not been transferred at the same time".
} 


\subsection{Non-cash based financial instruments}

\subsubsection{Structure}

440 Non-cash based transactions represent a horizontal cross type rather than a vertical class of financial instruments. Non-cash elements can principally be attached to a number of different features and classifiers (e.g. financial operation in general, capital or principal in particular, remuneration, underlying, etc.). The reason for devoting this separate section to them is that non-cash based financial instruments or transactions give rise to specific ambiguities, which may be roughly grouped into the following issues:

(1) As was found, non-cash assets may represent parts of both the operation or obligation (i.e. the pay leg) to be interpreted autonomously and/or of the return or redemption (i.e. the receive leg) to be interpreted domestically ${ }^{2297}$, each on both the capital or principal level and/or the remuneration level. This directional aspect as a consequence of reciprocity has a significant impact on the financial instrument's classification, which is solely determined by the operation ${ }^{2298}$.

(2) Any asset other than the tax currency itself bears underwriting risk, in that its assessment depends on the currency exchange rates to the tax currency. These risk-driven aspects of assessment necessitate a careful distinction and consideration of risk types which are relevant for the income classification and those which are not.

(3) Where non-cash assets are mutually exchanged, they can interact with each other in a way that the net result of the two is not equal to the sum of their individual cash-equivalents. Such synergetic effects challenge even more the aspects of assessment. This applies in particular to financial instruments, which can or may not be disaggregated ${ }^{2299}$ or are subject of the fixed-for-fixed condition ${ }^{2300}$.

(4) All financial instruments allow for the replication or synthesisation of any variety of economic features by way of embedding other financial instruments. However, non-cash based financial instruments allow for these features to becoming effective also legally in that they materialise from a mere variable into a noncash asset (e.g. the underlying) by - so to say - "piercing the legal veil". This peculiarity raises additional issues, such as on which level (e.g. the underlying or the financial instrument itself) and thus at which point in time such features take effect on the income classification.

In addition, this section presents a side note on securities lending transactions.

\subsubsection{Determination of the operation}

The remuneration as the starting point

441 As regards the first issue (1), the question of whether a non-cash asset represents parts of the operation or obligation (i.e. the pay leg) or rather of its return (i.e. the receive leg) is particularly difficult to answer where negative assets are subject of the financial transaction. At first glance, this problem appears to arise only from the operation or obligation side and not from the return or redemption side. The reason is that this return or redemption side is typically positive and should therefore be easy to identify as anything received by the contracting parties (i.e. the receive leg).

\footnotetext{
${ }^{2297}$ See par. 180 et seq.

${ }^{2298}$ See par. 56.

${ }^{2299}$ OECD, ST/SG/AC.8/2001/CRP.8, p. 30, par. 110.

${ }^{2300}$ See par. 299.
} 
Example 59: Taking an option risk (i.e. a negative asset) in exchange for shares (i.e. a positive asset), these shares could be considered as income for taking the option risk ${ }^{2301}$ (i.e. as option premium in kind). Alternatively, the shares could also be considered as alienated themselves realising a capital gain. In fact, they are both simultaneously: one contracting party receives the shares as income (i.e. the receive leg) in exchange for taking the option risk as the transaction or operation (i.e. the pay leg); the other contracting party receives the option as income (i.e. the receive leg) for disposing of the shares as the transaction or operation (i.e. the pay leg).

Bearing this in mind, it might be suggested to take the receive leg as the starting point for resolving this directional problem. The reason is that it is admissible to assume that the direction of cash flows and equivalents actually indicates the subjacent nature of the underlying operation ${ }^{2302}$. However, in fact a remuneration can also be negative, so that focussing merely on the receive leg as the starting point is incomplete.

Example 59 (continued): Taking the same option risk (i.e. a negative asset) in exchange for paying negative interest ${ }^{2303}$ (i.e. a negative asset), this negative interest could analogously be considered as income for taking the option risk (i.e. as option premium). Alternatively, the negative interest could be considered as interest itself. Obviously, it cannot possibly be both simultaneously, as there is just one contracting party receiving both the option and the negative interest.

This is a natural consequence of the fact that financial instruments are cash equivalents and as such particularly sensitive to contextual or situative determinants. That is why legal entitlements were found to have a dual purpose of potentially representing both the economic return for legal obligations and parts of the economic operation itself $\mathrm{f}^{2304}$.

Example 60: Depending on the context, taking obligations (i.e. a negative asset) can be considered a kind of operation (e.g. factoring) or a kind of payment (e.g. debt assumption).

442 In consideration of this inescapable dual purpose, there is still no other way than to either stick to the receive leg as the indirect starting point for the income classification or to go for the pay leg directly (i.e. the operation or obligation). From the author's point of view, the receive leg appears as more expedient for theoretical and practical considerations. On the one hand, such approach is the same as for a positive remuneration ${ }^{2305}$, avoiding a dualism of methods. On the other hand, there are at least three kinds of negative assets on the operation level which are relevant for the income classification (i.e. redemption obligation, termination risk and business risk). On the contrary, only one kind of negative income can be seen on the remuneration level (i.e. negative interest). Financial instruments mutually exchange negative non-cash values by combining them into new negative non-cash assets within one legal contract (e.g. swaps, composite option strategies). In contrast, negative remunerations for such assets appear to be fairly rare. The delimitation between the two

\footnotetext{
$\overline{{ }^{2301} \text { See Illustration } 24 \text { on p. } 224 .}$

${ }^{2302}$ See par. 411.

${ }^{2303}$ See par. 410 et seqq.

${ }^{2304}$ See par. 343.

${ }^{2305}$ See par. 358.
} 
levels of operation (receive leg) and remuneration (pay leg) is the legal form in the sense that the former would require qualitative disaggregation and the latter quantitative disaggregation. However, both are subsequent methodological steps to the legal form of the financial instrument as such ${ }^{2306}$. In other words: the holder of the financial instrument may be obliged to economically compensate more than what the contract explicitly dedicates to the remuneration (e.g. by also taking certain non-cash obligations). But the pay leg is understood here only in the sense of what that contract explicitly dedicates to the remuneration (form over substance). The reason is that any additional remuneration component would eventually require and imply disaggregation (i.e. substance over form). This approach is also in line with the working assumption that the subjective intention of the parties involved basically coincides with the objective observables ${ }^{2307}$.

443 In this light, the particular issue of determining the relevant operation for classifying non-cash based financial transactions swapping negative values seems to be limited to negative interest. It might be suggested that there would be no particular problem with identifying negative interest. However, non-cash based financial instruments are object of the same legal subsumption (no ring-fencing) as well. It was therefore prejudicial and methodologically flawed to pre-classify one of the two legs as interest, which represents the final result rather than the starting point of the treaty interpretation and application process. This becomes even more evident when remembering that negative interest can also be replicated or synthesised ${ }^{2308}$. Notably, these considerations may not be misunderstood in such a way that the transaction would be classified by the remuneration rather than by the operation ${ }^{2309}$. As an interim conclusion for the further course of this study, it means only that the remuneration represents the mere starting point for resolving the directional issue of identifying the operation where both are non-cash values.

\section{The more homogeneous and/or liquid asset represents the remuneration (receive leg)}

444 Having set the formal remuneration as that starting point, the next step in the analysis is its concrete identification. To the author's understanding, the key to resolving this issue appears to be rooted again in the difference between negative assets in the broader or relative sense (negative for someone) and those in the narrow or absolute sense (negative for anyone) ${ }^{2310}$. Although the term income pursuant to chap. III of the OECD MTC principally includes negative income as well ${ }^{2311}$, it nevertheless focuses primarily on positive income as the very purpose, intention and function of the OECD MTC of limiting the allocation of taxation rights to the source jurisdiction ${ }^{2312}$. In fact, negative assets in the narrow or absolute sense can themselves not represent income $e^{2313}$. Simply put: the OECD MTC associates the term income with "something positive", while nevertheless being accessible to a "certain grey area" (i.e. negative income in the broader or relative sense $)^{2314}$, unless not obviously being "something negative" per se (i.e. negative income in the narrow or absolute sense). The natural reason is the collective character of the OECD MTC in the sense of a multinational or

\footnotetext{
2306 See par. 93.

2307 See par. 10.

${ }^{2308}$ See par. 408 et seq.

${ }^{2309}$ See par. 56.

${ }^{2310}$ See par. 412 et seq.

2311 See par. 139.

2312 See par. 19.

${ }^{2313}$ Argumentum e contrario.

${ }^{2314}$ See par. 414.
} 
multi-jurisdictional compromise across multiple domestic tax laws. It reflects their homogeneous purpose of generating tax revenue ${ }^{2315}$ on the one hand and their heterogeneous recognition and treatment of certain types of negative income on the other. As a consequence, income in the widest sense is not only the appreciation of potentially or subjectively positive assets but also the depreciation of absolutely or objectively negative assets. In that, income coessentially shares the same nature with cash, which is a positive asset by convention. This remains true even though the technical requirements to an economic currency function of merely being homogeneous and liquid ${ }^{2316}$ could principally also be fulfilled by a negative asset ${ }^{2317}$. In the context of financial instruments, any risk or obligation is obviously an absolutely or objectively negative assets, as it cannot be resolved but only transferred or re-allocated ${ }^{2318}$. In contrast, negative interest is a relatively or subjectively negative asset and as such - although negative - closer to a cash equivalent. This is the systematic justification, why a transfer of any risk or obligation must always and necessarily represent the operation (pay leg). On the contrary, negative interest represents the remuneration ("receive" leg). These considerations regarding the example of non-cash based financial transactions swapping negative values again demonstrate the requisite precedent analysis in order to determine whether the legal entitlements represent parts of the operation or the remuneration ${ }^{2319}$. As a general conclusion for non-cash based financial instruments, the remuneration (pay leg) is always represented by the non-cash asset that is closer to a cash equivalent (i.e. more homogeneous and/ or liquid). Notably, such analysis may be much more difficult where only absolutely or objectively negative assets are exchanged, which may however be assumed as highly uncommon in practice ${ }^{2320}$.

\subsubsection{Relevant risk types}

445 As regards the second issue (2) ${ }^{2321}$, spot transactions in kind can be assumed to bear no significant risks (e.g. stock swap). The reason is that the pay and receive legs must necessarily equal the same values and are typically also settled within a short period of time. Due to the natural nexus between risk and timing ${ }^{2322}$, the dependency of the income classification on risk-related aspects rather takes effect on forward transactions or financial instruments with embedded forward components. In this respect, forward elements are meant here in the general economic sense of any future fixation of uncertain income determinators, and not in the specific legal sense of one transaction out of one opening and one closing event (pending transaction) ${ }^{2323}$. For such forward transactions in kind, any legal risk was found to be generally irrelevant for the classification ${ }^{2324}$. The elimination of legal risks should also be easy to identify and to apply, since risks in general can as such not possibly be transferred in kind but only through a legal medium (e.g. cash or stock). Timing risk and consequently also interest rate risk can be ignored for the following reasons:

\footnotetext{
${ }^{2315}$ See par. 18.

${ }^{2316}$ See Example 23 on p. 107.

${ }^{2317}$ See Example 60 on p. 258.

${ }^{2318}$ See par. 59.

${ }^{2319}$ See par. 181.

${ }^{2320}$ See par. 442.

${ }^{2321}$ See par. 440(2).

${ }^{2322}$ See par. 69.

${ }^{2323}$ See par. 370.

${ }^{2324}$ See par. 231.
} 
- Although the time value of money is a constituting element ${ }^{2325}$ of genuine debt-claims, it is an immanent part of all forward elements anyway ${ }^{2326}$.

- In regards to a potential remuneration, the extending modification in Art. 11(3) OECD MTC covers all attributes of shares pursuant to Art. 10(3) OECD MTC anyway ${ }^{2327}$. This particularly includes general time-inequivalence in its specific forms of both remuneration risk and business risk.

- Termination risk falsifies the time value of money ${ }^{2328}$ and therefore represents its natural complement ${ }^{2329}$. As a consequence, there is no need for two differentiators with eventually the same logical meaning.

Lastly, currency risk is no differentiator either. In terms of termination risk, currency risk was found to be subsequent to the capital provision. In terms of remuneration risk, currency risk was found to coincide with the payment profile, sharing all attributes of shares due to the extending modification in Art. 11(3) OECD $\mathrm{MTC}^{2330}$.

\subsubsection{Synergetic effects}

446 As regards the third issue (3) ${ }^{2331}$, the most typical use case of financial instruments exchanging non-cash assets which interact in such a way that their consolidated net result is not equal to the sum of their individual cash-equivalents (synergetic effects), is a swap. In fact, a swap is an exchange of partially hedged risks 2332 . As risks can themselves not be transferred in kind but only through a medium (e.g. cash or stock) ${ }^{2333}$, such swaps are typically net-settled. Since the payment profile is a reflex response to risk ${ }^{2334}$, the issue leads back to the finding ${ }^{2335}$ that synergetic effects - considered analogously as one coherent whole - give rise to an independently classifiable risk-return profile. In that, the example of such swaps as financial instruments mutually shifting risks coalesces the systematic link between the findings made on the level of the payment profile (e.g. net-settlements ${ }^{2336}$ ) with those made on the level of the risk profile (e.g. interest replication or synthesisation ${ }^{2337}$ ). Consequently, their risk consolidation (hedge), which is typically lower than the sum of the individual risk components, actually represents a "managed" or "engineered" net risk ${ }^{2338}$.

447 Where this net risk is lower than the timing risk, it should be permissible to conclude that the corresponding net remuneration does not compensate the time value of money ${ }^{2339}$. As a consequence, it cannot possibly constitute genuine debt-claims pursuant to Art. 11(3) OECD MTC but must rather give rise to other income

\footnotetext{
2325 See par. 296.

${ }^{2326}$ See par. 367.

${ }^{2327}$ See par. 295.

${ }^{2328}$ See par. 242(2).

${ }^{2329}$ See par. 208 et seqq. and 275.

${ }^{2330}$ See par. 420.

${ }^{2331}$ See par. 440(3).

${ }^{2332}$ See Example 24 on p. 108.

${ }^{2333}$ See par. 445.

${ }^{2334}$ See par. 200.

${ }^{2335}$ See par. 379.

${ }^{2336}$ See par. 380.

${ }^{2337}$ See par. 406 et seqq.

${ }^{2338}$ See par. 101(2).

${ }^{2339}$ See par. 215.
} 
pursuant to Art. 21(1) OECD MTC. On the one hand, this finding is in line with finance theory ${ }^{2340}$, according to which such synergetic effects necessarily imply and require the respective risks to be diverse in their nature (risk diversification). This is why they cannot possibly comply with the fixed-for-fixed condition. On the other hand, swaps as forward transactions do not comply with the fixed-for-variable condition either. The reason is that the exchanged amounts are typically not ex-ante determinable and typically do not ex-post equal the same values $^{2341}$. Such swaps do therefore not fulfil the necessary minimum conditions (conditio sine qua non) for a nominal value and are thus to be subsumed under Art. 21(1) OECD MTC ${ }^{2342}$. Conversely, where the net risk is higher than the timing risk, it should be permissible to conclude that the corresponding net remuneration compensates also underwriting risk. Depending on the requisite formal reference to a share ${ }^{2343}$ (equity leg ${ }^{2344}$ ) and on whether or not such remuneration is self-executive ${ }^{2345}$, it thus represents either dividends pursuant to Art. 10(3) OECD MTC or interest pursuant to Art. 11(3) OECD MTC. As a result, the analysis of asset swaps comes to the same interpretative and applicative implications via the risk level as well. As the systematic link between the payment profile and risk, it demonstrates that the previous analyses have led to consistent and resilient results.

\subsubsection{The relevant level}

448 As regards the last issue $(4)^{2346}$, it is the distinctive nature of non-cash based financial instruments that their remuneration basically takes the specific peculiarities of the respective non-cash asset. In other words: financial transactions generally exchange monetary benefits ${ }^{2347}$ in the economic sense of the two-dimensional riskreturn profile $\mathrm{e}^{2348}$. But non-cash assets are nevertheless inhomogeneous in representing a multi-dimensional bundle of principally unlimited attributes (e.g. risks, payment profile, obligatory elements, etc.). On the contrary, cash is - apart from the currency - a homogeneous asset in representing a merely binary concept of "yes or no". Insofar, non-cash based financial instruments are characterised by coalescing not only the features of their underlyings but also those of the respective non-cash asset as a cash equivalent in the sense of an "inhomogeneous currency" 2349 . Notably, this view is based on the legal form as the baseline of treaty interpretation and application ${ }^{2350}$. Consequently, once the domestic tax law treats the non-cash based financial instrument as separate from the non-cash asset instead of as one coherent whole ${ }^{2351}$, the two must be kept separated also at the treaty level. In particular, they may not be fused with the argument that the non-cash based financial instrument was influenced by the non-cash asset. The reason is that the return or remuneration (i.e. the income), regardless of whether in cash or kind, represents just a small part of a financial instrument's overall attributes relevant for its classification. In other words: given their separate treatment by the domestic tax law, the existence of the non-cash based financial instrument as such is in any case independent of the

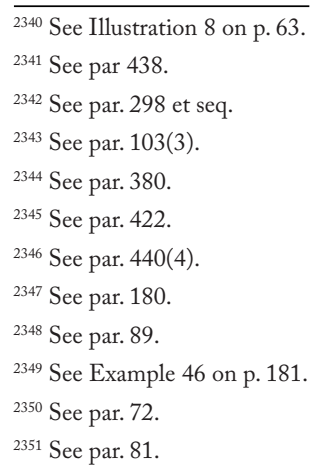


existence of the non-cash asset as such. In contrast, the non-cash asset affects the non-cash based financial instrument only subsequently at the level of particular attributes. This important systematic distinction sets the ground particularly for those configurations in which the non-cash assets has influence on the non-cash based financial instrument's classification (e.g. risks, payment profile, etc.) and those, in which it does not (e.g. asset attribution ${ }^{2352}$, transfer transactions ${ }^{2353}$, redemption obligation ${ }^{2354}$, etc.).

449 Applied to the abstract findings in the previous sections on cash-based financial instruments, this view supports the following implications:

(1) The non-cash based financial instrument continues to exist irrespective of whether the non-cash asset itself ceases to exist.

Example 61: Where the share goes into default (e.g. the company's bankruptcy), the convertible might (quantitatively) have a zero value but nevertheless (qualitatively) continues to exist. Where an underlying debt-claim ceases to exist by fusing debtor and creditor, the structured product on this debt-claim nevertheless continues to exist. Where the receive leg of a stock swap (share A) ceases to exist by being merged into another share (B), the pay leg nevertheless represents an alienation (share $\mathrm{C}$ ).

(2) Corresponding to how the non-cash based financial instrument comes into existence independent of the non-cash asset ${ }^{2355}$, the latter, conversely, also comes into existence independent of the former. In particular, the non-cash asset is neither (re-)attributed nor transferred by the non-cash based financial instrument's opening but - if at all - only by its settlement.

Example 61 (continued): The share is (re-)attributed and transferred only by redeeming the convertible. The debt-claim is (re-)attributed and transferred only by redeeming the structured product on this debt-claim. The underlying is (re)attributed and transferred only by grossphysically settling the forward transaction ${ }^{2356}$.

(3) The question of whether the non-cash based financial instrument constitutes or repeals beneficial ownership in the non-cash asset (i.e. its asset-related aspect), is basically not of major importance for this study ${ }^{2357}$. True, there are some non-cash based transactions which constitute beneficial ownership in the non-cash asset and simultaneously give rise to the constitution of beneficial ownership also in the income from that non-cash asset ${ }^{2358}$. Notably, this is, however, not a result due to but rather despite the non-cash character of that asset. As a consequence, any reverse deduction from this circumstance to beneficial ownership - particularly that in the income - was a false conclusion ${ }^{2359}$. Nevertheless, the same question

\footnotetext{
2352 See par. 315.

${ }^{2353}$ See par. 317 et seqq.

${ }^{2354}$ See par. 384.

2355 See par. 449(1).

${ }^{2356}$ See par. 374.

${ }^{2357}$ See par. 116.

${ }^{2358}$ As will be elaborated in the following (see par. 450).

${ }^{2359}$ Cum hoc ergo propter hoc. See also par. 129.
} 
also arises when it comes to a remuneration in kind. However, within the concept of beneficial ownership, such remuneration in kind actually represents the inflow (i.e. the income), whose general principles and requirements (e.g. realisation) were found to be left untouched. The reason was that it merely replaces one subject (i.e. the recipient) by another (i.e. the beneficial owner) ${ }^{2360}$. Hence, corresponding to how non-cash based financial instruments come into existence ${ }^{2361}$ and cease to exist ${ }^{2362}$ independently of the non-cash asset, the latter is - also when receipted as a remuneration in kind - not realised by the non-cash based financial instrument's opening. Instead, it is realised only when actually being transferred at the disposal of the recipient or beneficial owner in the manner required by contract or by custom ${ }^{2363}$.

Example 62: New shares distributed by way of a stock dividend (A) from original shares (B) are realised as dividend pursuant to Art. 10(3) OECD MTC and thus acquired pursuant to Art. 13(5) OECD MTC only by actually being transferred at the payment date. Consequently, those new shares (A) cannot possibly be subject of any prior beneficial ownership, particularly not through the original shares (B).

(4) In contrast, the non-cash asset indeed impacts the non-cash based financial instrument's attributional aspects, particularly its risk profile.

Example 61 (continued): The share's risk profile makes the convertible typically a risk-based asset itself and thus a share pursuant to Art. 10(3) OECD MTC ${ }^{2364}$. Typically, the debt-claim's risk profile keeps the structured product a time-based asset and thus a debt-claim itself. The reason is that any qualitative disaggregation process of risk identification, risk disaggregation and risk elimination could reveal nothing else than that the debt-claim's risks are literally identical to those of the structured product itself ${ }^{2365}$.

Example 62 (continued): The new shares (A) represent income from the original shares (B). The risk profile of the new shares (A) makes that dividend risk-based pursuant to Art. 10(3) OECD MTC and consequently also the original shares (B) themselves.

(5) Lastly, with respect to a net share settlement, the non-cash asset may have influence on the non-cash based financial instrument's classification. It often simplifies the identification of whether or not the non-cash based financial instrument provides the requisite formal reference to a share ${ }^{2366}$ (equity leg) in order to constitute dividends pursuant to Art. 10(3) OECD MTC ${ }^{2367}$.

\footnotetext{
${ }^{2360}$ See par. 132.

${ }^{2361}$ See par. 449(1).

${ }^{2362}$ See par. 449(2).

${ }^{2363}$ See par. 148.

${ }^{2364}$ See Illustration 25 on p. 234.

${ }^{2365}$ See par. 402 et seqq.

${ }^{2366}$ See par. 103(3).

${ }^{2367}$ See par. 447.
} 
Example 63: Shares received from the net share settlement of a total return swap obviously represent the receiver's equity $\operatorname{leg}^{2368}$. Unlike a corresponding total return swaption, this equity leg is also self-executive. Therefore it represents a negatively modified risk-based remuneration that is ceteris paribus to be subsumed under Art. 10(3) OECD MTC 2369.

\subsubsection{Securities lending transactions}

450 The last topic that should be discussed here in the form of a short side note, are securities lending transactions (also referred to as "share loan agreements") ${ }^{2370}$. On the one hand, such non-cash obligations were found to be basically covered by Art. 11(3) OECD MTC ${ }^{2371}$. The reason was that their genuine remuneration (i.e. the lending fee) was ceteris paribus considered as genuine interest $t^{2372}$, even more as they typically fulfil the fixed-for-fixed condition ${ }^{2373}$. On the other hand, the further question arises how to classify their additional compensation payments, i.e. the passed-through income from the borrowed asset. In contrast to the majority view $^{2374}$ it is the author's understanding that such payments basically share the non-cash asset's fate by actually representing beneficial ownership. The one-to-one transfer of such cash flows obviously complies with all its requirements of a causal relation between the in- and outflows ${ }^{2375}$, quantitatively observable by expected negative correlation depending on the same risk. These in- and outflows proportionate also in approximately equal amounts or benefits ${ }^{2376}$ and are typically not dominated by credit risk in the sense of a time gap between them $^{2377}$. This is a result of the finding that the concept of beneficial ownership replaces one subject (i.e. the recipient) by another (i.e. the beneficial owner) instead of (re-)classifying one object (e.g. the genuine dividend from the borrowed share) into another (e.g. an interest from the securities lending transaction) ${ }^{2378}$. In particular, mixing the classification of the genuine remuneration (i.e. the lending fee) from the securities lending transaction as an interest with the independent classification of the additional compensation payment (i.e. the passed-through income from the borrowed asset) was found to be methodologically flawed ${ }^{2379}$. In other words: securities lending transactions turn out to be the ideal-typical example, demonstrating the specific capability of financial instruments to represent both transactions giving rise to genuine income and simultaneously also beneficial ownership giving rise to derivative income from another asset. 



\section{Chapter 6}

\section{General discussion}

451 In contrast to the above summary of conclusions in section 4, the purpose and objective of this final section is to give a brief outline of the key finding from each topic, embedding them into the high-level storyline of this study. It forms a contentual framework by taking up the introductory remarks in section 1 and sets the aspirations and conclusions of this study into the higher evaluative context of a perspective outlook.

452 Like most other commercial activities, financial instruments and transactions transfer economic attributes by using legal contracts. It is, however, their peculiar capability to extract these economic attributes from basically all kinds of real assets, transform these into freely substitutable cash-equivalents and transfer them under considerably low frictions. This economic purity enjoys a multi-faceted universality independent of the normal physical constraints (i.e. ratione temporis, ratione loci and ratione materiae). It causes an exceptional detachment from their legal grounds, giving rise to the motivation for this study and the problems discussed therein ${ }^{2380}$. At the same time, it is also the primary reason why the treatment of financial instruments and transactions under the OECD MTC calls for putting a comparably strong emphasis on the systematic element of interpretation ${ }^{2381}$. To a certain extent, this systematic element of interpretation necessarily includes the abstract-theoretical grounds and mechanisms of financial instruments as well as their basic principles in terms of economic and financial theory. This is in order to understand their inherent rationales and structural links to the corresponding legal concepts within the OECD MTC. The interaction within and between these conceptual economic and legal levels turned out to be a strongly interdependent matter. It therefore had to be disentangled as the methodological starting point in this study.

453 The basic principles ${ }^{2382}$ encompass first of all the conceptual perspectives and their mutual interactions of the asset as explicitly mentioned in Art. 10(3), 11(3) and 13(5) OECD MTC and the transaction. As a dynamic reference, the transaction is closer to the nature and object of an income tax and therefore has been identified as the relevant basis of the further analysis ${ }^{2383}$. In the following, the key concept of risk was introduced and

\footnotetext{
2380 See sec. 1.1.1.

${ }^{2381}$ See sec. 1.3.

${ }^{2382}$ See sec. 2.2.

${ }^{2383}$ See sec. 2.2.2.
} 
structured in all its relevant forms ${ }^{2384}$, notably applied only within and not beyond the scope of that legal transaction. Risk can be understood in a material and formal sense and it allows reverse deduction to the material nature of the underlying economic operation. These considerations led to the principal discussion of potential measures and/or guidelines indicating the general applicability and scope of the substance over form principle in all its relevant aspects ${ }^{2385}$. The analysis concluded with the discussion of potential measures and/ or guidelines indicating if and to what extent financial instruments and transactions are to be aggregated or disaggregated ${ }^{2386}$. Combining and condensing all the previous outcomes into this question, the examination came to the major conclusion that there are good reasons to restrict aggregation and to permit disaggregation, even if only selectively and on a rule base.

454 This first step of the basic principles represents the first building block for the elaboration of differentiators in order to develop a tie-breaking test as the primary objective of this study 2387 . The examination has illustrated the implicitness of fundamental concepts, which can be interpreted only indirectly from inherent interdependencies within the OECD MTC. In this respect, it has shown on the one hand that the normative research area of tax policy making is able to contribute valuable insights into those conceptual interrelationships. On the other hand, it also demonstrated that other collective legal frameworks may well be unbinding, but are still compatible in so far as they deal with similar economic situations and may perhaps have reached a more advanced evolutionary stage (e.g. US federal tax law ${ }^{2388}$, IAS/IFRS ${ }^{2389}$ ). In that, they are able to give inspiration to structure those interlinkages, notably where their subjacent structural rationales are appropriately comparable and transferable to those of the OECD MTC ${ }^{2390}$. As the key insight from this section, this transfer demonstrates that the OECD MTC - like other comparable legal frameworks are already - might perhaps be more open for inter-disciplinary concepts (e.g. economic theories, behavioural science, policy making, mathematic modelling, etc.). Accumulating more and more diverse information might promise to make it even more universal and compatible, more flexible and resilient and thus eventually more durable and competitive with other international legal frameworks.

455 Having set this baseline of conceptual mechanisms, the study went on by shedding light on the systematic legal context of, and the relations between, those relevant distributive articles ${ }^{2391}$ by carefully embedding the argumentation into the previous findings. The analysis held their completeness and comprehensiveness in generally covering all income as well as their mutual exclusivity in being generally not overlapped. ${ }^{2392} \mathrm{It}$ continued by putting the focus particularly on the concept of beneficial ownership ${ }^{2393}$ and the realisation principle ${ }^{2394}$. Beneficial ownership was found not to affect the genuine legal concepts of dividends and interest, but its (re-)attributional aspect was concluded to subsist not only in Art. 10(2) and 11(2) OECD MTC but

\footnotetext{
${ }^{2384}$ See sec. 2.2.3.

2385 See sec. 2.2.4.

${ }^{2386}$ See sec. 2.2.5.

${ }^{2387}$ See sec. 1.1.2.

${ }^{2388}$ See sec. 1.4.4.

${ }^{2389}$ See sec. 1.4.6.

2390 See sec. 1.4.

${ }^{2391}$ See sec. 2.3.

${ }^{2392}$ See sec. 2.3.2.

${ }^{2393}$ See sec. 2.3.3.

${ }^{2394}$ See sec. 2.3.4.
} 
also in Art. 13(5) and 21(1) OECD MTC. While independent of the income classification, the concept was found to be of major importance for applying the OECD MTC accurately to a number of ambiguous and controversial financial instruments and transactions. The realisation principle was found to have an autonomous core element, which particularly allows and requires to delimit income pursuant to chap. III from capital pursuant to chap. IV of the OECD MTC.

456 This second step of the systematic context of the distributive articles represents the second building block for the elaboration of differentiators in order to develop a tie-breaking test as the primary objective of this study ${ }^{2395}$. The topic has illustrated the interpretational relevance of the legal interdependencies within the OECD MTC for the subject of this study. It has also demonstrated that considering the various relevant aspects between the pure and isolated concepts of dividends, interest, capital gains and other income mitigates the risks of constricting the individual attributes towards meaninglessness and/or distorting their classification into inconsistency ${ }^{2396}$. As the main outcome, the section has illustrated the conceptual limitations of the OECD MTC to deal with "organic topics" such as financial instruments, which can hardly be described by individually picking out certain isolated aspects. Complementing the OECD MTC with additional legal techniques and applicative methodologies such as, for instance, tests or the rigorous separation of genuine and derivative concepts might reduce ambiguities and increase its clarity and usability.

457 Having thus prepared the building blocks, the study continued with combining and condensing all those outcomes into an analysis and discussion of potential differentiators. ${ }^{2397}$ The formal aspect of legal rights and obligations was found to play a particularly important role for the distinction between dividends and interest on the one hand and of capital gains on the other. ${ }^{2398}$ In contrast, time turned out to be a hybrid and multicharacter auxiliary concept that coalesces interconvertible temporal and risk-related aspects in itself, whereby the former takes precedence and may be understood substantially to a certain extent. ${ }^{2399}$ The payment profile of financial instruments was proved to likewise have an autonomous core element. ${ }^{2400}$ Although conceptually and legally limited, it was nevertheless found to be of superior relevance for the distinction between dividends and interest. In terms of risks and obligations, the concept of risk was separated and classified into a matrix of termination risk versus remuneration risk on the one hand and business risk versus other risks on the other. ${ }^{2401}$. The concept of risk was likewise found to be of major importance for the distinction between dividends and interest. Coverage was distinguished from collateral and found to qualitatively and quantitatively indicate risk. In contrast, subordination and the origin of funds have both been discarded as differentiators. ${ }^{2402}$

458 The discussion has illustrated the strong systematic interdependencies within and between the economic and the legal layer. It has proven that the "funnel approach" of making a methodological compromise by

\footnotetext{
2395 See sec. 1.1.2.

${ }^{2396}$ See sec. 1.2 .

${ }^{2397}$ See sec. 2.4 .

2398 See sec. 2.4.2.

${ }^{2399}$ See sec. 2.4.3.

${ }^{2400}$ See sec. 2.4.4.

${ }^{2401}$ See sec. 2.4.5.

${ }^{2402}$ See sec. 2.4.6.
} 
combining a holistic or synthetic with the reductive or analytical view as imperative and expedient. ${ }^{2403}$ The analysis made also clear that appropriate differentiators on the level of the OECD MTC as a collective tax law system cannot purposively be found among the infinite and incompatible formal features of domestic tax laws. Instead, the section reduced or compressed them to their substantial "key messages" in order to then transform these into truly autonomous test criteria ${ }^{2404}$. In addition, the aspect of such strong interweavement resulted in a segregation of main and auxiliary attributes, and the approach of such substantive compression grouped them into entire attribute classes, which made it possible to reduce the potential differentiators to a fairly modest number. The main outcome of this section was thus not only to introduce, analyse and distinguish some inherent concepts in what is discussed in the jurisprudential research and discourse as potential differentiators between debt and equity. Beyond that, these concepts were also operationalised into concrete tie-breaking tests. As the key objective of this study, they were also re-evaluated against each other and reduced to a compact set of clear and meaningful classifiers which are coherent, consistent, universal, complete, mutually exclusive, justifiable, autonomous, objective, resilient and operationalizable.

459 As the next methodological step, the study proceeded to test these concrete but still potential differentiators interpretatively against the legal texts within the relevant distributive articles of Art. 10(3), 11(3), 13(5) and 21(1) OECD MTC. ${ }^{2405}$ The analysis of Art. 10(3) OECD MTC produced a way of interpretation that does not only allow us to isolate its relevant parts entirely from any domestic influence and to seamlessly deduce the key differentiators of payment profile and business risk from the provision ${ }^{2406}$. The interpretation found is also capable of separating the concept of dividends distinctly from the concept of interest. ${ }^{2407}$ In this respect, the examination further verified the crucial importance of business risk in the form of termination risk as a falsifier for the time value of money and the relevance of the self-execution test. The concept of capital gains was found to coalesce multiple closely related aspects in itself. ${ }^{2408}$ It depends to a large extent on the formalities of the domestic laws, in that the substance over form principle comes into effect only in the context of realisation and income attribution. While other income was hold as being a residuary schedule, gambles were proven not to be relevant for this study. ${ }^{2409}$

460 This step of analysing and discussing the relevant distributive articles built in large parts on all the previous outcomes. It took up those structural findings and embedded them conclusively into a technical interpretation of the concrete legal texts. It has proven that most of the priorly acquired potential differentiators are reflected by the respective sources of law in a recognisable and justifiable manner. The examination further demonstrated that the condensation to a compact set of clear and meaningful attributes makes these stronger and thus provides a higher degree of consistency and resilience. Not least, the analysis also integrated a wide range of dissenting opinions into the discourse. It set them into the context of the insights gained in this study and thus contributed to the clarification of current disputes. As an important result, the section has illustrated that the respective phrases in the OECD MTC might offer opportunities for improvements in order to adapt

\footnotetext{
${ }^{2403}$ See sec. 1.3 .

${ }^{2404}$ See sec. 1.1.2.

2405 See sec. 3.

${ }^{2406}$ See sec. 3.2.

${ }^{2407}$ See sec. 3.3.

${ }^{2408}$ See sec. 3.4.

${ }^{2409}$ See sec. 3.5.
} 
to the challenges of modern financial instruments. While their wording may have been be re-considered in all major updates of the OECD MTC and the treatment of financial instruments is actually a hot topic in the current OECD initiatives, these phrases nevertheless remain almost unchanged since they were introduced.

461 Closing the theoretical parts at this point, the study then proceeded with practically applying all the abstract findings to a selection of concrete financial instruments and transactions. ${ }^{2410}$ The classification of forward transactions and swaps revolves around the interplay between the level of the underlying versus that of the forward transaction itself. It was found to be predominantly dependent on how the forward transaction is terminated and apart from that on highly technical details. ${ }^{2411}$ Building on these conclusions, the income from debt-into-equity convertibles was shown to have been classified as dividends pursuant to Art. 10(3) OECD MTC in most configurations. ${ }^{2412}$ Other debt-based financial instruments, such as particularly socalled linkers, were systematically deduced from non-packaged net-settled convertibles. As such, they share their fate ${ }^{2413}$, whereas negative interest was argued to be classifiable as genuine interest pursuant to Art. 11(3) OECD MTC. Other equity-based financial instruments, such as particularly so-called preference shares, appear to be the conceptual opposite of linkers. Nevertheless, they were also classified as dividends pursuant to Art. 10(3) OECD MTC in most configurations. ${ }^{2414}$ Strips were proved to represent genuine income from their capital or principal, sharing likewise their fates as being subsumable under Art. 10(3) or 11(3) OECD MTC respectively. ${ }^{2415}$ Finally, the cross-sectional topic of non-cash based financial instruments has revealed specific systematic insights such as regarding the identification of operation versus income, aspects of risk, synergetic effects or the relevant classification level. ${ }^{2416}$ These conclusions may be transferrable to a number of various configurations or classes of transactions featured with non-cash elements.

462 Facing the historic origins and context of the OECD MTC and considering the consequent interpretation difficulties $^{2417}$, this section has demonstrated that the tie-breaking test developed as the primary objective of this study ${ }^{2418}$ is actually practicable. While their relation to each other might be subject of the legitimate discussions, the test meets the required logical, legal and technical criteria to the maximum possible extent. In particular, it is capable of solving the conceptually most ambiguous and controversial use cases discussed to date in research and practice. The fairly few remaining inconsistencies and distortions have to be accepted as a "sacrifice" to the rule of law and the legality principle as the admissible limit of legal interpretation.

463 Accordingly, these remaining inconsistencies and distortions can be overcome only by undertaking a reform of the OECD MTC. On the one hand, such reform would perhaps have to take only quite selective and focussed measures. On the other hand, these measures would certainly have to touch some of the most fundamental principles of the OECD MTC with a correspondingly high risk of side effects. Considering its purpose,

\footnotetext{
${ }^{2410}$ See sec. 5 .

${ }^{2411}$ See sec. 5.2.

${ }^{2412}$ See sec. 5.3.

${ }^{2413}$ See sec. 5.4.

${ }^{2414}$ See sec. 5.5.

${ }^{2415}$ See sec. 5.6.

${ }^{2416}$ See sec. 5.7.

2417 See sec. 1.1.3.

2418 See sec. 1.1.2.
} 
intention and function of being a compromise of making a large number of diverse tax law systems compatible with each other, such fundamental reform appears as a fairly long and drawn out process. As a consequence, it remains to be seen how the inevitable drift and tensions between the diverse domestic tax law systems, which operate on different levels and at different paces of development, will affect the OECD MTC. This will be even more interesting against the background of the acute situation nowadays and the corresponding momentum in the international developments concerning the taxation of financial instruments. 


\section{Bibliography}

Andriessen, Floris, Accounting for Derivatives under IFRS, Derivatives \& Financial Instruments 2006, Vol. 8, No. 6, IBFD, Amsterdam, 2006

Angermann, Frank, Die Bilanzierung von Alternativen Risikotransferinstrumenten nach HGB und IFRS, Series Schriften zum Controlling, Finanz- und Risikomanagement, Vol. 8, PL Academic Research, Frankfurt am Main, 2015, quoted: "Frank Angermann"

Arnold, Brian J., Deductibility of Interest and other financing Charges in computing Income - General Report, Series IFA Cahiers 1994, Vol. 79a, International Fiscal Association, Rotterdam, 1994

Ault, Hugh J., The Role of the OECD Commentaries in the Interpretation of Tax Treaties, Intertax 1994, Vol. 22, No. 4, Kluwer Law International, The Hague, 1994

Avery Jones, John F. et al., The Definitions of Dividends and Interest in the OECD Model: Something Lost in Translation?, in: Word Tax Journal 2009, Vol. 1, No. 1, IBFD, Amsterdam, 2009, quoted: "Avery Jones Commentaries"

Avery Jones, John F. / Vann, Richard / Wheeler, Joanna, OECD Discussion Draft "Clarification of the Meaning of 'Beneficial Owner' in the OECD Model Tax Convention" - Response by John Avery Jones, Richard Vann and Joanna Wheeler, OECD, Paris, 2011, available online at www.oecd.org/tax/treaties/48420432.pdf (last retrieved on 15 September 2017), quoted: "Avery Jones, beneficial owner"

Baker, Philip, Double Taxation Conventions: A Manual on the OECD Model Taxation Convention on Income and on Capital, loose-leaf, Thomson / Sweet \& Maxwell, London, 2003 - 2005, quoted: "Philip Baker"

Baer, Robert, Understanding Derivatives and Financial Instruments, Taxes: The Tax Magazine 1994, Vol. 72, Issue 12, CCH Incorporated, Chicago, 1994

Bärsch, Sven-Eric, Taxation of hybrid Financial Instruments and the Remuneration derived therefrom in an international and cross-border Context: Issues and Options for reform, Springer, Berlin / New York, 2012, quoted: "Sven-Eric Bärsch"

Bell, Susan, Cross-border Repatriation of Dividends: tax neutral in the European Union?, Derivatives \& Financial Instruments 2005, Vol. 7, No. 1, IBFD, Amsterdam, 2005

Berentzen, Christoph, Die Bilanzierung von finanziellen Vermögenswerten im IFRS-Abschluss nach IAS 39 und nach IFRS 9: Eine vergleichende Untersuchung der Entscheidungsnützlichkeit unter besonderer Berücksichtigung des Komplexitätsgrads, Series Rechnungslegung und Wirtschaftsprüfung, Vol. 23, Josef Eul, Lohmar, 2010, quoted: "Christoph Berentzen"

Black, Fischer/Scholes, Myron, The Pricing of Options and Corporate Liabilities, The Journal of Political Economy 1973, Vol. 81, No. 3, The University of Chicago Press, Chicago, 1973, available online at www.cs.princeton. edu/courses/archive/ fall09/cos323/papers/black_scholes73.pdf (last retrieved on 15 September 2017)

Bloom, David H., Interpretation of Double Taxation Conventions - Country Report Australia, Series IFA Cahiers 1993, Vol. 78a, International Fiscal Association, Rotterdam, 1993

Bohl, Werner / Beiersdorf, Kati, Beck'sches IFRS-Handbuch: Kommentierung der IFRS / IAS, 4th edition, C. H. Beck, Munich, 2013

Bosman, Alexander, Other Income under Tax Treaties: An Analysis of Article 21 of the OECD Model Convention, Series on International Taxation, Issue 55, Wolters Kluwer, Alphen aan den Rijn, 2015, quoted: "Alexander Bosman"

Bowers, William C., Tax Aspects of Debt and Equity, Tulane Tax Institute 1989, Vol. 39, Tulane University Law School, New Orleans, 1989 
Brooks, John R. II, Taxation, Risk, and Portfolio Choice: The Treatment of Returns to Risk under a Normative Income Tax, Tax Law Review 2013, Vol. 66, Issue 3, New York University School of Law, New York, 2013

Brown, Patricia, The Debt-Equity Conundrum - General Report, Series IFA Cahiers 2012, Vol. 97B, International Fiscal Association, Rotterdam, 2012

Brunson, Samuel D., Elective Taxation of Risk-Based Financial Instruments: A Proposal, Houston Business and Tax Law Journal 2007, Vol. 8, Issue 1, University of Houston Law Center, Houston, 2007

Bundgaard, Jakob, Classification and Treatment of Hybrid Financial Instruments and Income derived therefrom under EU Corporate Tax Directives, European Taxation 2010, Vol. 50, No. 10 / 11, IBFD, Amsterdam, 2010, quoted: "Jakob Bundgaard, EU Tax Directives"

Bundgaard, Jakob, Convertible Debt Instruments in International Tax Law, European Taxation 2017, Vol. 57, No. 4 and 5, IBFD, Amsterdam, 2017, quoted: "Jakob Bundgaard, convertibles"

Bundgaard, Jakob, Debt-flavored equity instruments in international tax law, Intertax 2014, Vol. 42, Issue 6 / 7 , Kluwer Law International, The Hague, 2014, quoted: "Jakob Bundgaard, debt-flavored equities"

Bundgaard, Jakob, Hybrid Financial Instruments in International Tax Law, Wolters Kluwer, Alphen aan den Rijn, 2017, quoted: "Jakob Bundgaard, hybrids"

Bundgaard, Jakob, Perpetual and Super-Maturity Debt Instruments in International Tax Law, Derivatives and Financial Instruments 2008, Vol. 10, No. 4, IBFD, Amsterdam, 2008, quoted: "Jakob Bundgaard, perpetuals"

Burgstaller, Eva, Conflicts of qualification in Tax Treaty Law, Schriftenreihe zum Internationalen Steuerrecht No. 52, Linde, Vienna, 2007, quoted: "Eva Burgstaller"

Castelijn, Bas / van der Veen, Ivo, Securities Lending: A Market Perspective on the Changing Securities Lending Landscape, Derivatives \& Financial Instruments 2015, Vol. 17, No. 2, IBFD, Amsterdam, 2015

Ceryak, David V., Using Risk Analysis to Classify Junk Bonds as Equity for Federal Income Tax Purposes, Indiana Law Journal 1990, Vol. 66, Issue 1, Indiana University Maurer School of Law, Bloomington, 1990

Collier, Richard, Clarity, Opacity and Beneficial Ownership, British Tax Review 2011, No. 6, Sweet \& Maxwell, London, 2011

Danon, Robert J., Clarification of the Meaning of "Beneficial Owner" in the OECD Model Tax Convention Comment on the April 2011 Discussion Draft, Bulletin for International Taxation 2011, Vol. 65, No. 8, IBFD, Amsterdam, 2011, quoted: "Robert Danon"

de Gunst, Erik/Rompen, Joost W., Supreme Court Ruling on Taxation of Convertibles and Application of Participation Exemption: A Discussion of the Case and its broader Meaning, Derivatives \& Financial Instruments 2008, Vol. 10, No. 1, IBFD, Amsterdam, 2008, quoted: "de Gunst/Rompen"

de Hosson, Fred C., The Parent-Subsidiary Directive, Intertax 1990, Vol. 18, Issue 10, Kluwer Law International, The Hague, 1990

Dettenrieder, Dominik, Hedge Accounting in Industrieunternehmen nach IFRS 9, Series Rechnungslegung und Wirtschaftsprüfung, Vol. 48, Josef Eul, Lohmar, 2014, quoted: "Dominik Dettenrieder"

Doege, Dana, Hedge Accounting nach IAS / IFRS: Bilanzielle Abbildung ökonomischer Sicherungsbeziehungen, Series Hallesche Schriften zur Betriebswirtschaft, Band 29, Springer Gabler, Wiesbaden, 2013, quoted: "Dana Doege"

Dolan, Kevin /DuPuy, Carolyn, Equity Derivatives: Principles and Practice, Virginia Tax Review 1995, Vol. 15, Issue 2, University of Virginia School of Law, Charlottesville, 1995

Douma, Sjoerd / Engelen, Frank, The legal Status of the OECD Commentaries, Conflict of Norms in International Tax Law Series, Vol. 1, IBFD, Amsterdam, 2008, quoted: "Frank Engelen" 
Driesch, Dirk et al., Beck'sches IFRS-Handbuch: Kommentierung der IFRS / IAS, 5th edition, C. H. Beck, Munich, 2016, quoted: "Beck, IFRS / IAS"

Duncan, James A., Tax Treatment of hybrid Financial Instruments in cross-border Transactions - General Report, Series IFA Cahiers 2000, Vol. 85a, International Fiscal Association, Munich, 2000

$d u$ Toit, Charl Petrus, Beneficial Ownership of Royalties in Bilateral Tax Treaties, IBFD, Amsterdam, 1999, quoted: "Charl du Toit, royalties"

du Toit, Charl Petrus, The Evolution of the Term "Beneficial Ownership" in Relation to International Taxation over the Past 45 Years, Bulletin for International Taxation 2010, Vol. 64, No. 10, IBFD, Amsterdam, 2010, quoted: "Charl du Toit, evolution"

Dyppel Weber, Katja, Tax Treaty Treatment of Dividend Related Payments under Share Loan Agreements, World Tax Journal 2014, Vol. 6, No. 2, IBFD, Amsterdam, 2014, quoted: “Katja Dyppel Weber"

Eberhartinger, Eva/Six, Martin, Taxation of Cross-Border Hybrid Finance: A Legal Analysis, Intertax 2009, Vol. 37, No. 1, Kluwer Law International, The Hague, 2009, quoted: "Eberhartinger/Six"

Ecker, Thomas, The Relevance of the OECD Documents for the Interpretation of Tax Treaties, History of Tax Treaties, Linde, Vienna, 2011, quoted: "Thomas Ecker"

Ellis, Maarten J., The Influence of the OECD Commentaries on Treaty Interpretation - Response to Prof. Dr. Klaus Vogel, Bulletin for International Taxation 2000, Vol. 54, No. 12, IBFD, Amsterdam, 2000

Emmerich, Adam O., Hybrid Instruments and the Debt-Equity Distinction in Corporate Taxation, University of Chicago Law Review 1985, Vol. 52, Issue 1, University of Chicago, Chicago, 1985

Erasmus-Koen, Monica / Douma, Sjoerd, Legal Status of the OECD Commentaries - in Search of the Holy Grail of International Tax Law, Bulletin for International Taxation 2007, Vol. 61, No. 8, IBFD, Amsterdam, 2007

Fabozzi, Frank J., The Handbook of Financial Instruments, The Frank J. Fabozzi Series, Wiley, Hoboken (New Jersey), 2002, quoted: "Frank Fabozzi”

Ferguson, Bradford L., The Rationales for the Rules: How to think about Derivatives in the Tax World, Taxes: The Tax Magazine 1994, Vol. 72, Issue 12, CCH Incorporated, Chicago, 1994

Fernandes, Sandra Martinho et al., A comprehensive Analysis of Proposals to amend the Interest and Royalties Directive, European Taxation 2011, Vol. 51, No. 9 / 10 / 11, IBFD, Amsterdam, 2011

Fucbs, Florian, Close-out Netting, Collateral und systemisches Risiko: Rechtsansätze zur Minderung der Systemgefahr im außerbörslichen Derivatehandel, Schriften zum Unternehmens- und Kapitalmarktrecht No. 6, Mohr Siebeck, Tübingen, 2013

Fuchs, Hans Gerd / Klose, Alfred / Kramer, Rolf, Güter und Ungüter: Eine Freundesgabe für Gerhard Merk zum 60. Geburtstag, Duncker \& Humblot, Berlin, 1991

Giuliani, Federico Maria, Article 10(3) of the OECD Model and Borderline Cases of Corporate Distributions, Bulletin for International Fiscal Documentation 2002, Vol. 56, No. 1, IBFD, Amsterdam, 2002

Goldstein, William M., Corporate Indebtedness to Shareholders: Thin Capitalizatin and Related Problems, Tax Law Review 1960, Vol. 16, Issue 1, New York University School of Law, New York, 1960

Haig, Robert Murray, The Federal Income Tax, Columbia University Press, New York, 1921, available online at https://archive.org/details/cu31924020062935 (last retrieved on 15 September 2017)

Haisch, Martin L. / Helios, Marcus, Rechtshandbuch Finanzinstrumente, Beck, Munich, 2011

Hariton, David P., Distinguishing between Equity and Debt in the New Financial Environment, Tax Law Review 1994, Vol. 49, Issue 3, New York University School of Law, New York, 1994, quoted: “David Hariton, equity and debt" 
Hariton, David P., When and how should the Economic Substance Doctrine be applied, Tax Law Review 2006, Vol. 60, Issue 1, New York University School of Law, New York, 2006, quoted: "David Hariton, substance"

Harris, Peter A., Corporate Tax Law: Structure, Policy and Practice, Cambridge University Press, Cambridge, 2013

Hasen, David M., A Realization-Based Approach to the Taxation of Financial Instruments, Tax Law Review 2004, Vol. 57, Issue 3, New York University School of Law, New York, 2004, quoted: "David Hasen"

Helminen, Marjaana, Dividend equivalent Benefits and the Concept of Profit Distribution of the EC ParentSubsidiary Directive, EC Tax Review 2000, Vol. 9, Issue 3, Wolters Kluwer (Law \& Business), Alphen aan den Rijn, 2000, quoted: "Marjaana Helminen, Parent-Subsidiary Directive"

Helminen, Marjaana, The international Tax Law Concept of Dividend, Series of International Taxation, Vol. 36, Wolters Kluwer (Law \& Business), Alphen aan den Rijn, 2010, quoted: "Marjaana Helminen, dividend concept"

Helminen, Marjaana, Classification of cross-border Payments on hybrid Instruments, Bulletin for International Fiscal Documentation 2004, Vol. 58, No. 2, IBFD, Amsterdam, 2004, quoted "Marjaana Helminen, classification"

Hongler, Peter, Hybride Finanzierungsinstrumente im nationalen und internationalen Steuerrecht der Schweiz, Schulthess Juristische Medien, Zurich, 2011, quoted: "Peter Hongler"

Holzman, Robert S., The Interest-Dividend Guidelines, Taxes: The Tax Magazine 1969, Vol. 47, Issue 1, CCH Incorporated, Chicago, 1969

Huang, Peter H., A Normative Analysis of New Financially Engineered Derivatives, Southern California Law Review 2000, Vol. 73, Issue 3, University of Southern California Gould School of Law, Los Angeles, 2000

Huffman Schenk, Deborah, Colloquium on Financial Instruments: Foreword, Tax Law Review 1995, Vol. 50, Issue 4, New York University School of Law, New York, 1995, quoted: "Deborah Huffman Schenk, financial instruments"

Huffman Schenk, Deborah, Taxation of Equity Derivatives: A Partial Integration Proposal, Tax Law Review 1995, Vol. 50, Issue 4, New York University School of Law, New York, 1995, quoted: "Deborah Huffman Schenk, equity derivatives"

Huffman Schenk, Deborah / Cunningham, Noel B., Taxation without Realization: A Revolutionary Approach to Ownership, Tax Law Review 1992, Vol. 47, Issue 4, New York University School of Law, New York, 1992

IBFD, Global Tax Treaty Commentaries, Online Commentary, IBFD, Amsterdam, 2015 - 2017, available online at www.ibfd.org (last retrieved on 15 September 2017), quoted: "IBFD Commentaries"

IBFD, Introduction to the Comparative Survey, Derivatives \& Financial Instruments 2011, Vol. 13, No. 3, IBFD, Amsterdam, 2011

Joseph, Anton, Islamic Finance, Derivatives \& Financial Instruments 2010, Vol. 12, No. 1, IBFD, Amsterdam, 2010

Kau, Randall Koon Chuck, Carving up Assets and Liabilities - Integration or Bifurcation of Financial Products, Taxes: The Tax Magazine 1990, Vol. 68, Issue 12, CCH Incorporated, Chicago 1990

Kemmeren, Eric C. C. M., Double Tax Conventions on Income and Capital and the EU: Past, Present and Future, EC Tax Review 2012, Vol. 21, Issue 3, Wolters Kluwer (Law \& Business), Alphen aan den Rijn, 2004

Kleinbard, Edward D., Beyond Good and Evil Debt (and Debt Hedges): A Cost of Capital Allowance System, Taxes: The Tax Magazine 1989, Vol. 67, Issue 12, CCH Incorporated, Chicago, 1989, quoted: "Edward Kleinbard, debt"

Kleinbard, Edward D., Equity Derivative Products: Financial Innovation's Newest Challenge to the Tax System, Texas Law Review 1991, Vol. 69, Issue 6, University of Texas School of Law, Austin, 1991, quoted: "Edward Kleinbard, financial innovations" 
Kolbrenner, Scott Marc, Derivaties Design and Taxation, Virginia Tax Review 1995, Vol. 15, Issue 2, University of Virginia School of Law, Charlottesville, 1995

KPMG Deutsche Treuhand-Gesellschaft Aktiengesellschaft Wirtschaftsprüfungsgesellschaft, Offenlegung von Finanzinstrumenten und Risikoberichterstattung nach IFRS 7: Analyse der Offenlegungsvorschriften für Finanzinstrumente nach IFRS 7 sowie zum Kapital nach IAS 1, Schäffer-Poeschel, Stuttgart, 2007

Kragen, Adrian A., Double Income Taxation Treaties: The O.E.C.D. Draft, California Law Review 1964, Vol. 52, No. 2, University of California (School of Law), Berkeley, 1964, available online at http://scholarship.law. berkeley.edu (last retrieved on 15 September 2017)

Krüger, Paul et al., Bonner Festgabe für Ernst Zitelmann zum fünfzigjährigen Doktorjubiläum, Zur Dogmatik des Begriffs "Steuerumgehung", Duncker \& Humblot, Munich 1923, quoted: "Paul Krüger"

Kuhn, Steffen / Hachmeister, Dirk, Rechnungslegung und Prüfung von Finanzinstrumenten: Handbuch nach IFRS, HGB und EMIR, Schäffer-Poeschel, Stuttgart, 2015, quoted: "Kuhn / Hachmeister"

Lang, Michael, Art. 3 Abs. 2 OECD-MA und die Auslegung von Doppelbesteuerungsabkommen, IWB 2011, No. 8, NWB Verlag, Bochum, 2011, quoted: "Michael Lang, interpretation"

Lang, Michael, Beneficial Ownership: Recent Trends, IBFD, Amsterdam, 2013, quoted: “Michael Lang, beneficial ownership"

Lang, Michael, Hybride Finanzierungen im internationalen Steuerrecht: Rechtsgrundlagen der Doppelbesteuerungsabkommen zur Beurteilung von Mischformen zwischen Eigen- und Fremdkapital, Orac, Vienna, 1991, quoted: "Michael Lang, hybrids"

Lang, Michael, Introduction to the Law of Double Taxation Conventions, 2nd edition, Linde, Vienna, 2013, quoted: "Michael Lang, introduction"

Lang, Michael, Later Commentaries of the OECD Committee on Fiscal Affairs, Not to affect the Interpretation of previously concluded Tax Treaties, Intertax 1997, Vol. 25, No. 1, Kluwer Law International, The Hague, 1997, quoted: "Michael Lang, later commentaries"

Laukkanen, Antti, Taxation of Investment Derivatives, IBFD, Amsterdam, 2007

Lof, Michiel van der / Laan, Peter, Accounting for Financial Instruments in Accordance with IFRS, Derivatives \& Financial Instruments 2010, Vol. 12, No. 2a / Special Issue, IBFD, Amsterdam, 2010

Lopes Dias V.S., Gaspar, Tax Arbitrage through cross-border Financial Engineering, Wolters Kluwer (Law \& Business), Alphen aan den Rijn, 2015, quoted: "Gaspar Lopes Dias, tax arbitrage"

Lopes Dias V.S., Gaspar, The Concept of Debt-Claim as the Key Distinguishing Factor between Dividend and Interest Income in the OECD Model, Derivatives \& Financial Instruments 2015, Vol. 17, No. 2, IBFD, Amsterdam, 2015, quoted: "Gaspar Lopes Dias, debt-claims"

Lüdenbach, Norbert et al., Haufe IFRS-Kommentar, 14th edition, Haufe, Freiburg, 2016, quoted: "Haufe, IFRS"

Maisto, Guglielmo, The 2003 Amendments to the EC Parent-Subsidiary Directive: What's next?, EC Tax Review 2004, Vol. 13, Issue 4, Wolters Kluwer (Law \& Business), Alphen aan den Rijn, 2004, quoted: “Guglielmo Maisto, Parent-Subsidiary Directive"

Maisto, Guglielmo, The Observations on the OECD Commentaries in the Interpretation of Tax Treaties, Bulletin for International Fiscal Documentation 2005, Vol. 59, No. 1, IBFD, Amsterdam, 2005, quoted: "Guglielmo Maisto, observations"

Markowitz, Harry Max, Portfolio Selection, The Journal of Finance 1952, Vol. 7, Issue 1, The American Finance Association, Philadelphia, 1952, available online at www.math.ust.hk/ maykwok/courses/ma362/07F/ markowitz_JF.pdf (last retrieved on 15 September 2017) 
Martín Jiménez, Adolfo, Beneficial Ownership: Current Trends, Word Tax Journal 2010, Vol. 2, No. 1, IBFD, Amsterdam, 2010, quoted: “Adolfo Martín Jiménez"

Matthies, Anna Verena, Die Abgrenzung von Eigen- und Fremdkapital entsprechend der Rechnungslegung nach deutschem Handelsrecht und IAS / IFRS, Europäische Hochschulschriften, Series 2, Rechtswissenschaft, Vol. 4703, Lang, Frankfurt am Main, 2008, quoted: “Anna Verena Matthies”

Miller, David S., Distinguishing Risk: The Disparate Tax Treatment of Insurance and Financial Contracts in a Converging Marketplace, Tax Lawyer 2002, Vol. 55, Issue 2, American Bar Association, Chicago, 2002, quoted: "David Miller"

Nethercott, Craig R. / Eisenberg, David M., Islamic Finance: Law and Practice, Oxford University Press, Oxford, 2012

Nguyen, Tristan, Bilanzielle Abbildung von Finanzderivaten und Sicherungsgeschäften: Hedge Accounting nach HGB und IAS / IFRS, Series Hochschulschriften zur Betriebswirtschaftslehre, Vol. 149, Herbert Utz Verlag, Munich, 2007

Offermanns, René H. M. J., Restrictions on Treaty Override Resulting from EU Law, European Taxation 2013 , Vol. 53, No. 9 / Special Issue, IBFD, Amsterdam, 2013

Oldeweme, Daniel Johannes, Die Bilanzierung von Commodity-Hedges nach International Financial Reporting Standards (IFRS), Dissertation No. 3523, University of Sankt Gallen, Sankt Gallen, 2008

Oliver, J. David B., Beneficial Ownership and the OECD Model, British Tax Review 2001, No. 1, Sweet \& Maxwell, London, 2001

Orellana Polo, Eduardo, The "Other Income" Article in Tax Treaties as interpreted by the Courts: A Case Law Analysis, Bulletin for International Taxation 2017, Vol. 71, No. 3 / 4, IBFD, Amsterdam, 2017, quoted: "Eduardo Orellana"

Peters, M. J., IFRS, Tax Accounting and Derivatives, Derivatives \& Financial Instruments 2010, Vol. 12, No. 2a / Special Issue, IBFD, Amsterdam, 2010

Pijl, Hans, Interest from Hybrid Debts in Tax Treaties, Bulletin for International Taxation 2011, Vol. 65, No. 9, IBFD, Amsterdam, 2011, quoted: "Hans Pijl, hybrid debts"

Pijl, Hans, Tax Treatment of Interest for Corporations, online book, IBFD, Amsterdam, 2012, quoted: “Hans Pijl, interest"

Pijl, Hans, The Definition of “Beneficial Owner” under Dutch Law, Bulletin for International Taxation 2000 , Vol. 54, No. 6, IBFD, Amsterdam, 2000, quoted: "Hans Pijl, beneficial owner"

Pistone, Pasquale / Romano, Carlo, Short Report on the Proceedings of the 54th IFA Congress, Munich 2000, Bulletin for International Taxation 2001, Vol. 55, No. 1, IBFD, Amsterdam, 2001

Plambeck, Charles T. / Rosenbloom, H. David / Ring, Diane M., Tax Aspects of derivative Financial Instruments General Report, Series IFA Cahiers 1995, Vol. 80b, IFA, Rotterdam, 1995

Plumb, William T.Jr., The Federal Income Tax Significance of Corporate Debt: A Critical Analysis and a Proposal, Tax Law Review 1971, Vol. 26, Issue 3, New York University School of Law, New York, 1971, quoted: "William Plumb"

Poiret, Caroline, Beneficial Ownership: Concept, History and Perspective, European Taxation 2016, Vol. 56, No. 7, IBFD, Amsterdam, 2016, quoted: "Caroline Poiret"

Polito, Anthony P., Useful Fictions: Debt and Equity Classification in Corporate Tax Law, Arizona State Law Journal 1998, Vol. 30, Issue 3, Arizona State University, Tempe, 1998, quoted: "Anthony Polito"

Prokisch, Rainer, Fragen der Auslegung von Doppelbesteuerungsabkommen, Steuer \& Wirtschaft International, Linde, Vienna, 1994, quoted: “Rainer Prokisch, interpretation” 
Prokisch, Rainer, Share Buy-backs by listed Companies from individual Minority Shareholders, European Taxation 1998, Vol. 38, No. 11 / 12, IBFD, Amsterdam, 1998, quoted: "Rainer Prokisch, share buy-backs"

Prokisch, Rainer, The Status of the OECD Commentaries in OECD Member Countries (2nd revised draft), ref. DAFFE/CFA/WP1/WD(95)15, OECD, Paris, 1995, quoted: "Rainer Prokisch, OECD Commentaries"

Pross, Achim C., Swap, Zins und Derivat: Finanzinnovationen im nationalen und internationalen Steuerrecht unter besonderer Berücksichtigung des Zinsbegriffes, Münchener Schriften zum internationalen Steuerrecht, Vol. 22, n/a, C. H. Beck, Munich, 1998, quoted: "Achim Pross"

Ramirez, Juan, Handbook of Corporate Equity Derivatives and Equity Capital Markets, The Wiley Finance Series, Wiley, Hoboken (New Jersey / USA), 2011, quoted: "Juan Ramirez"

Rotondaro, Carmine, Tax Treaty Characterization Issues of Credit Derivatives, Derivatives \& Financial Instruments 2000, Vol. 2, No. 2, IBFD, Amsterdam, 2000, quoted: “Carmine Rotondaro, credit derivatives"

Rotondaro, Carmine, The Right to Redemption as a Key Characterization Factor in the OECD Model Convention Passive Income Taxation System - The Case of Reverse Convertibles, Derivatives \& Financial Instruments 2000, Vol. 2, No. 5, IBFD, Amsterdam, 2000, quoted: “Carmine Rotondaro, redemption"

Santos, Ramon Tomazela, Tax Treaty Qualification of Income derived from Hybrid Financial Instruments, Bulletin for International Taxation 2013, Vol. 67, No. 10, IBFD, Amsterdam, 2013

Schilcher, Michael / Weninger, Patrick, Fundamental Issues and Practical Problems in Tax Treaty Interpretation, Schriftenreihe zum Internationalen Steuerrecht No. 54, Linde, Vienna, 2008, quoted: "Schilcher/Weninger"

Schön, Wolfgang, Eigenkapital und Fremdkapital, MPI Studies in Tax Law and Public Finance, Vol. 3, Springer, Berlin, 2013, quoted: "Wolfgang Schön, equity and debt"

Scbön, Wolfgang et al., Debt and Equity in Domestic and International Tax Law - A Comparative Policy Analysis, British Tax Review 2014, No. 2, Sweet \& Maxwell, London, 2014, quoted: “Wolfgang Schön, comparative analysis"

Shaviro, Daniel, Risk-Based Rules and the Taxation of Capital Income, Tax Law Review 1995, Vol. 50, Issue 4, New York University School of Law, New York, 1995

Simontacchi, Stefano, Taxation of Capital Gains under the OECD Model Convention (with special Regard to Immovable Property), Series on International Taxation, Issue 29, Wolters Kluwer, Alphen aan den Rijn, 2007, quoted: "Stefano Simontacchi"

Six, Martin, Hybrid Finance and Double Taxation Treaties, Bulletin for International Fiscal Documentation 2009, Vol. 63, No. 1, IBFD, Amsterdam, 2009, quoted: "Martin Six, hybrid finance"

Six, Martin, Hybride Finanzierung im Internationalen Steuerrecht am Beispiel von Genussrechten, Linde, Vienna, 2007, quoted: "Martin Six, jouissance rights"

Steinberg, Lewis R., Colloquium on Financial Instruments: Commentary, Tax Law Review 1995, Vol. 50, Issue 4, New York University School of Law, New York, 1995

Strnad, Jeff, Taxing New Financial Products: A Conceptual Framework, Stanford Law Review 1994, Vol. 46, Issue 3, Stanford Law School, Stanford, 1994, quoted: "Jeff Strnad, conceptual framework"

Strnad, Jeff, Taxing New Financial Products in a Second-Best World: Bifurcation and Integration, Tax Law Review 1995, Vol. 50, Issue 4, New York University School of Law, New York, 1995, quoted: "Jeff Strnad, bifurcation and integration"

Tang, Jieyin, Bifurcation or Integration: The Choice of Method To Tax Compound Financial Instruments, Derivatives \& Financial Instruments 2016, Vol. 18, No. 6, IBFD, Amsterdam, 2017, quoted: "Jieyin Tang, bifurcation or integration" 
Tang, Jieyin, Economic Substance vs. Legal Form: Financial Transactions as Taxable Events, Derivatives \& Financial Instruments 2014, Vol. 16, No. 2, IBFD, Amsterdam, 2014, quoted: "Jieyin Tang, substance vs. form"

Terra, Ben J. M. / Wattel, Peter Jacob, European Tax Law, 6th edition, Wolters Kluwer (Law \& Business), Alphen aan den Rijn, 2012

van Arendonk, Henk/Engelen, Frank et al., A Tax Globalist: Essays in Honour of Maarten J. Ellis, IBFD, Amsterdam, 2005

van den Hurk, Hans, Proposed Amended Parent-Subsidiary Directive reveals the European Commission's Lack of Vision, Bulletin for International Taxation 2014, Vol. 68, No. 9, IBFD, Amsterdam, 2014

Verdoner, Louan / Offermanns, René / Huibregtse, Steef, A Cross-Country Perspective on Beneficial Ownership, European Taxation 2010, Vol. 50, No. 9 / 10, IBFD, Amsterdam, 2010

Vogel, Klaus, The Influence of the OECD Commentaries on Treaty Interpretation, Bulletin for International Fiscal Documentation 2000, Vol. 54, No. 12, IBFD, Amsterdam, 2000, quoted: "Klaus Vogel, interpretation"

Vogel, Klaus, Klaus Vogel on Double Taxation Conventions: A Commentary to the OECD, UN and US Model Conventions for the Avoidance of Double Taxation of Income and Capital, 3rd edition, Kluwer Law International, The Hague, 1997, quoted: "Klaus Vogel Commentaries 1997"

Vogel, Klaus / Lehner, Moris / Dürrschmidt, Daniel, Doppelbesteuerungsabkommen der Bundesrepublik Deutschland auf dem Gebiet der Steuern vom Einkommen und Vermögen: Kommentar auf der Grundlage der Musterabkommen, 6th edition, C. H. Beck, Munich, 2015, quoted: "Vogel/Lehner"

Vogel, Klaus / Prokisch, Rainer, Interpretation of Double Taxation Conventions - General Report, Series IFA Cahiers 1993, Vol. 78a, International Fiscal Association, Rotterdam, 1993

Vogel, Klaus / Reimer, Ekkehart/Becker, Johannes, Klaus Vogel on Double Taxation Conventions, 4th edition, Wolters Kluwer (Law \& Business), Alphen aan den Rijn, 2015, quoted: "Klaus Vogel Commentaries 2015”

Ward, David A., The Interpretation of Income Tax Treaties with particular Reference to the Commentaries on the OECD Model, IFA, Kingston (Ontario / Kanada), 2005, quoted: "David Ward, interpretation"

Ward, David A., The Role of the Commentaries on the OECD Model in the Tax Treaty Interpretation Process, in: Bulletin for International Fiscal Documentation 2006, Vol. 60, No. 3, IBFD, Amsterdam, 2006, quoted: "David Ward, commentaries"

Warren, Alvin C. Jr., Financial Contract Innovation and Income Tax Policy, Harvard Law Review 1993, Vol. 107, Issue 2, Harvard Law School, Cambridge, 1993

Wassermeyer, Franz, Doppelbesteuerung: Festgabe zum 75. Geburtstag von Prof. Dr. Dr. h.c. Franz Wassermeyer: 75 Beiträge zum Recht der DBA, C. H. Beck, Munich, 2015, quoted: "Franz Wassermeyer, Festgabe"

Wassermeyer, Franz / Eilers, Stephan, Doppelbesteuerung - OECD-Musterabkommen, 3rd edition, Linde, Vienna, 2015, quoted: "Wassermeyer Commentaries"

Wattel, Peter Jacob / Marres, Otto, Characterization of fictitious Income under OECD-patterned Tax Treaties, European Taxation 2003, Vol. 43, No. 3, IBFD, Amsterdam, 2003, quoted: "Wattel / Marres, fictitious income"

Wattel, Peter Jacob / Marres, Otto, The Legal Status of the OECD Commentary and Static or Ambulatory Interpretation of Tax Treaties, European Taxation 2003, Vol. 43, No. 7, IBFD, Amsterdam, 2003, quoted: "Wattel/Marres, interpretation"

Weisbach, David A., Tax Responses to Financial Contract Innovation, Tax Law Review 1995, Vol. 50, Issue 4, New York University School of Law, New York, 1995, quoted: "David Weisbach"

Weissbrodt, Jan, Die sonstige Kapitalforderung im Sinne von § 20 Absatz 1 No. 7 EStG, Deutsches Steuerrecht 2012, Vol. 31, C. H. Beck, Munich, 2012 
Wheeler, Joanna C., The Attribution of Income to a Person for Tax Treaty Purposes, Bulletin for International Taxation 2005, Vol. 59, No. 11, IBFD, Amsterdam, 2005, quoted: "Joanna Wheeler, attribution"

Wheeler, Joanna C., The Missing Keystone of Income Tax Treaties, World Tax Journal 2011, Vol. 3, No. 2, IBFD, Amsterdam, 2011, quoted: "Joanna Wheeler, missing keystone"

Wheatcroft, George Shorrock Ashcombe, The Interpretation of Tax Laws with special Reference to Form and Substance - General Report, Series IFA Cahiers 1965, Vol. 50a, IFA, London, 1965

Wood, Richard, Financial Innovation and a Universally Applicable Distinction between Accruals and Realization Taxation, Intertax 2011, Vol. 39, Issue 8 / 9, Kluwer Law International, The Hague, 2011

Zantow, Roger / Dinauer, Josef, Finanzwirtschaft des Unternehmens: Die Grundlagen des modernen Finanzmanagements, Series wi wirtschaft, 4th edition, Pearson, Hallbergmoos, 2016

Zimmer, Frederik, Form and Substance in Tax Law - General Report, Series IFA Cahiers 2002, Vol. 87a, IFA, Rotterdam, 2002 



\section{Materials}

A.A.R., judgement ref. 175 Taxman 139 (“LMN India Ltd.”), A.A.R. No. 769 of 2007, 10 October 2008, New Delhi, 2007, summarised online at www.ibfd.org (last retrieved on 15 September 2017)

A.A.R., judgement ref. 2010 TPI 81 (“E*Trade Mauritius Ltd."), A.A.R. No. 826 of 2009, 22 March 2010, New Delhi, 2010, summarised online at www.ibfd.org (last retrieved on 15 September 2017)

Auswärtiges Amt der Bundesrepublik Deutschland, Länderverzeichnis für den amtlichen Gebrauch in der Bundesrepublik Deutschland, 23 February 2017, Auswärtiges Amt der Bundesrepublik Deutschland, Berlin, 2017, available online at www.auswaertiges-amt.de (last retrieved on 15 September 2017)

Bundesfinanzhof, judgement ref. I B 47/05, BStB1 II 2009, p. 766 et seqq., Munich, 20 December 2006, summarised online at www.ibfd.org (last retrieved on 15 September 2017)

Bundesgericht, judgement ref. 2C_364/2012 and 2C_895/2012, Lausanne, 5 May 2015, summarised online at www.ibfd.org (last retrieved on 15 September 2017)

Conseil d'État, judgement ref. 215124 (“Golay Buchel France”), Paris, 27 July 2001, summarised online at www. ibfd.org (last retrieved on 15 September 2017)

Conselho de Administração de Recursos Fiscais, judgement ref. 106-17.142, Brasília, 5 November 2008, summarised in IBFD Commentaries on Art. 11 OECD MTC, sec. 5.1.1.2.5.1.

Court of Appeal of England and Wales, judgement ref. A3/2005/2497 ("Indofood International Finance Limited vs. JPMorgan Chase Bank NA"), London, 2 March 2006, summarised online at www.ibfd.org (last retrieved on 15 September 2017)

ECJ, judgement ref. C-101/05 ("Skatteverket vs. A"), Luxemburg, 18 December 2007, European Court Reports 2007 I-11531, available online at http://eur-lex.europa.eu (last retrieved on 15 September 2017)

ECJ, judgement ref. C-282/04 and C-283/04 ("Commission of the European Communities vs. Kingdom of the Netherlands"), Luxemburg, 28 September 2006, European Court Reports 2006 I-09141, available online at http://eur-lex.europa.eu (last retrieved on 15 September 2017)

ECJ, judgement ref. C-336/96 (“Gilly vs. Directeur des services fiscaux du Bas-Rhin”), Luxemburg, 12 May 1998, European Court Reports 1998 I-02793, available online at http://eur-lex.europa.eu (last retrieved on 15 September 2017)

ECJ, judgement ref.C-446/04 ("Test Claimants in the FII Group Litigation vs. Commissioners of Inland Revenue"), Luxemburg, 12 December 2006, European Court Reports 2006 I-11753, available online at http://eur-lex. europa.eu (last retrieved on 15 September 2017)

ECJ, judgement ref. C-492/04 ("Lasertec Gesellschaft für Stanzformen mbH vs. Finanzamt Emmendingen"), Luxemburg, 10 May 2007, European Court Reports 2007 I-03775, available online at http://eur-lex. europa.eu (last retrieved on 15 September 2017)

EU, Council Directive 90/435/EEC of 23 July 1990 on the common System of Taxation applicable in the Case of Parent Companies and Subsidiaries of different Member States, Official Journal L 225, 20 August 1990, p. 6 et seqq., EU, Brussels, 1990, available online at http://eur-lex.europa.eu (last retrieved on 15 September 2017), quoted: "Directive 90/435/EEC"

EU, Council Directive 2003/48/EC of 3 June 2003 on Taxation of Savings Income in the Form of Interest Payments, Official Journal L 157, 26 June 2003, p. 38 et seqq., EU, Luxemburg, 2003, available online at http://eur-lex. europa.eu (last retrieved on 15 September 2017), quoted: "Directive 2003/48/EC" 
EU, Council Directive 2003/49/EC of 3 June 2003 on a common System of Taxation applicable to Interest and Royalty Payments made between associated Companies of different Member States, Official Journal L 157, 26 June 2003, p. 49 et seqq., EU, Luxemburg, 2003, available online at http://eur-lex.europa.eu (last retrieved on 15 September 2017), quoted: "Directive 2003/49/EC"

EU, Council Directive 2011/96/EU of 30 November 2011 on the Common System of Taxation applicable in the Case of Parent Companies and Subsidiaries of different Member States (Recast), Official Journal L 345, 29 December 2011, p. 8 et seqq., EU, Brussels, 2011, available online at http://eur-lex.europa.eu (last retrieved on 15 September 2017), quoted: "Directive 2011/96/EU"

EU, Council Directive 2014/107/EU of 9 December 2014 amending Directive 2011/16/EU as regards mandatory Automatic Exchange of Information in the Field of Taxation, Official Journal L 359, 16 December 2014, p. 1 et seqq., EU, Brussels, 2014, available online at http://eur-lex.europa.eu (last retrieved on 15 September 2017), quoted: "Directive 2014/107/EU"

EU, Council Directive 2015/121 of 27 January 2015 amending Directive 2011/96/EU on the Common System of Taxation applicable in the Case of Parent Companies and Subsidiaries of different Member States, Official Journal L 21, 28 January 2015, p. 1 et seqq., EU, Brussels, 2015, available online at http://eur-lex.europa.eu (last retrieved on 15 September 2017), quoted: "Directive 2015/121/EU"

EU, Council Directive 2016/1164/EU of 12 July 2016 laying down Rules against Tax Avoidance Practices that directly affect the Functioning of the internal Market, Official Journal L 193, 19 July 2016, p. 1 et seqq., EU, Brussels, 2016, available online at http://eur-lex.europa.eu (last retrieved on 15 September 2017), quoted: "Directive 2016/1164/EU"

EU, Explanatory Memorandum to the Proposal for a Council Directive on a common System of Taxation applicable to Interest and Royalty Payments made between associated Companies of different Member States, ref. COM(1998)67 final, EU, Brussels, 4 March 1998, available online at http://eur-lex.europa.eu (last retrieved on 15 September 2017), quoted: "Explanatory Memorandum COM(1998)67"

EU, Explanatory Memorandum to the Proposal for a Council Directive on a common System of Taxation applicable to Interest and Royalty Payments made between associated Companies of different Member States (Recast), ref. COM(2011)714 final, EU, Brussels, 11 November 2011, available online at http://eurlex.europa.eu (last retrieved on 15 September 2017), quoted: "Explanatory Memorandum COM(2011)714"

EU, Proposal for a Council Directive on a common System of Taxation applicable to Interest and Royalty Payments made between associated Companies of different Member States (Recast), ref. 2011/0314(CNS), EU, Brussels, 11 November 2011, available online at http://eur-lex.europa.eu (last retrieved on 15 September 2017), quoted: "Directive Proposal 2011/0314(CNS)"

EU, Proposal for a Council Directive amending Directive 2016/1164/EU as regards hybrid Mismatches with third Countries, ref. 2016/0339(CNS), EU, Strasbourg, 25 October 2016, available online at http://eur-lex. europa.eu (last retrieved on 15 September 2017), quoted: "Directive Proposal 2016/0339 (CNS)"

EU, Report from the Commission to the Council in Accordance with Article 8 of Council Directive 2003/49/EC on a common System of Taxation applicable to Interest and Royalty Payments made between associated Companies of different Member States, ref. COM/2009/0179 final, EU, Brussels, 17 April 2009, http:// eur-lex.europa.eu (last retrieved on 15 September 2017), quoted: "Report COM/2009/0179"

Federal Court of Appeal, judgement ref. A-147-80 ("Melford Developments Inc. vs. Her Majesty the Queen"), Ottawa, 15 January 1981, summarised online at www.ibfd.org (last retrieved on 15 September 2017)

Federal Court of Appeal, judgement ref. A-252-08 ("Prévost Car Inc. vs. Her Majesty the Queen"), [2009] 3 CTC 160, Ottawa, 26 February 2009, summarised online at www.ibfd.org (last retrieved on 25 September 2017)

Federal Court of Australia, judgement ref. [2008] FCA 1570 ("Deutsche Asia Pacific Finance Inc. Federal Commissioner of Taxation"), Melbourne, 22 October 2008, summarised online at www.ibfd.org (last retrieved on 15 September 2017) 
Federal Court of Australia, judgement ref. NG 225 of 1997 ("Lamesa Holdings BV vs. Commissioner of Taxation"), Melbourne, 20 August 1997, summarised online at www.ibfd.org (last retrieved on 15 September 2017)

Federal Court of Canada, judgement ref. T-3194-78 (“Vincent N. Hurd vs. Her Majesty the Queen”), Ottawa, 18 October 1979, summarised online at www.ibfd.org (last retrieved on 15 September 2017)

Gerechtshof Amsterdam, judgement ref. 03/03165, Amsterdam, 14 March 2005, summarised online at www.ibfd. org (last retrieved on 15 September 2017)

High Court of Australia, judgement ref. [1990] HCA 37 ("Thiel vs. Commissioner of Taxation"), Parkes (Australia), 22 August 1990, summarised in Bloom, David H., Interpretation of Double Taxation Conventions - Country Report Australia, Series IFA Cahiers 1993, Vol. 78a, International Fiscal Association, Rotterdam, 1993, p. 181 et seqq.

Hof van Beroep, judgement ref. 2010/AR/66, Antwerpen, 14 June 2011, summarised online at www.ibfd.org (last retrieved on 15 September 2017)

Hoge Raad der Nederlanden, judgement ref. 13/02237, BNB 2014 / 170, The Hague, 23 May 2014, summarised online at www.ibfd.org (last retrieved on 15 September 2017)

Hoge Raad der Nederlanden, judgement ref. 25308, BNB 1991 / 248, The Hague, 3 July 1991, summarised in Michael Lang, introduction, p. 107, par. 314, and by van Weeghel, Stef, in van Arendonk, Henk / Engelen, Frank et al., A Tax Globalist: Essays in Honour of Maarten J. Ellis, IBFD, Amsterdam, 2005, p. 172

Hoge Raad der Nederlanden, judgement ref. 28638, BNB 1994 / 217, The Hague, 6 April 1994, summarised in Hans Pijl, beneficial owner, p. 257 et seq.

Hoge Raad der Nederlanden, judgement ref. 28.959, BNB 1994 / 219c, The Hague, 25 May 1994, summarised online at www.ibfd.org (last retrieved on 15 September 2017)

Hoge Raad der Nederlanden, judgement ref. 33267, BNB 2000 / 16, The Hague, 29 September 1999, summarised in Alexander Bosman, p. 249 and 317

Hoge Raad der Nederlanden, judgement ref. 37651, BNB 2003 / 379, The Hague, 5 September 2003, summarised in Alexander Bosman, p. 252

Hoge Raad der Nederlanden, judgement ref. 37670, BNB 2003 / 381, The Hague, 5 September 2003, summarised in Alexander Bosman, p. 252

Hoge Raad der Nederlanden, judgement ref. 38.461, BNB 2004 / 123, The Hague, 12 December 2003, summarised online at www.ibfd.org (last retrieved on 15 September 2017)

Hoge Raad der Nederlanden, judgement ref. 39.385, BNB 2004 / 314, The Hague, 18 June 2004, summarised online at www.ibfd.org (last retrieved on 15 September 2017)

Hoge Raad der Nederlanden, judgement ref. 41376, BNB 2007 / 41, The Hague, 9 June 2006, summarised in Alexander Bosman, p. 276 and 393 et seqq.

Hoge Raad der Nederlanden, judgement ref. 42.211, BNB 2007 / 68, The Hague, 1 December 2006, summarised online at www.ibfd.org (last retrieved on 15 September 2017)

Hoge Raad der Nederlanden, judgement ref. 43.643, BNB 2008 / 6, The Hague, 12 October 2007, summarised in de Gunst / Rompen, p. 5 et seqq.

Högsta Förvaltningsdomstolen, judgement ref. 6687-11, Stockholm, 25 October 2012, summarised in IBFD Commentaries on Art. 13 OECD MTC, sec. 5.1.2.1.4.

IAS Board, Accounting for dynamic Risk Management: A Portfolio Revaluation Approach to Macro Hedging, Series Discussion Paper / IAS Board 2014 / 1, IAS Board, London, 2014, quoted: "IAS Board, portfolio hedging" 
IAS Board, Financial Instruments with Characteristics of Equity - Discussion Paper, IAS Board, London, 2008, available online at http://archive.ifrs.org (last retrieved on 15 September 2017)

IAS Board, IFRS 9 Financial Instruments, Vol. 2: Basis for Conclusions, IAS Board, London, 2014, quoted: "IFRS 9.BC"

IAS Board, Financial Instruments with Characteristics of Equity - Alternative Settlement Outcomes within the Control of the Entity, IFRS Staff Paper ref. 5B to the IAS Board Meeting October 2016, London, 18 - 19 October 2016, available online at http://archive.ifrs.org (last retrieved on 15 September 2017), quoted: "IAS Board, October 2016, 5B"

IAS Board, Financial Instruments with Characteristics of Equity - Application of the Gamma Approach to Derivatives on 'own Equity', IFRS Staff Paper ref. 5B to the IAS Board Meeting December 2016, London, 13 - 14 December 2016, available online at http://archive.ifrs.org (last retrieved on 15 September 2017), quoted: "IAS Board, December 2016, 5B"

IAS Board, Financial Instruments with Characteristics of Equity - Applying Gamma to Asset / Equity Exchange Derivatives, IFRS Staff Paper ref. 5C to the IAS Board Meeting July 2016, London, 18 - 19 July 2016, available online at http://archive.ifrs.org (last retrieved on 15 September 2017), quoted: "IAS Board, July 2016, 5C"

IAS Board, Financial Instruments with Characteristics of Equity - Applying Gamma to Asset / Equity Exchange Derivatives, IFRS Staff Paper ref. 5D to the IAS Board Meeting July 2016, London, 18 - 19 July 2016, available online at http://archive.ifrs.org (last retrieved on 15 September 2017), quoted: "IAS Board, July 2016, 5D"

IAS Board, Financial Instruments with Characteristics of Equity - Claims with conditional alternative Settlement Outcomes, IFRS Staff Paper ref. 5C to the IAS Board Meeting February 2016, London, 16 - 17 February 2016, available online at http://archive.ifrs.org (last retrieved on 15 September 2017), quoted: "IAS Board, February 2016, 5C"

IAS Board, Financial Instruments with Characteristics of Equity - Derivatives on 'own Equity', IFRS Staff Paper ref. 5B to the IAS Board Meeting July 2016, London, 18 - 19 July 2016, available online at http://archive. ifrs.org (last retrieved on 15 September 2017), quoted: "IAS Board, July 2016, 5B"

IAS Board, Financial Instruments with Characteristics of Equity Research Project - Analysis of IAS 32 and Outline of potential Approaches, IFRS Staff Paper ref. 5A to the IAS Board Meeting September 2015, London, 21 - 24 September 2015, available online at http://archive.ifrs.org (last retrieved on 15 September 2017), quoted: "IAS Board, September 2015, 5A"

IAS Board, Financial Instruments with Characteristics of Equity Research Project - Contractual Terms, IFRS Staff Paper ref. 5B to the IAS Board Meeting February 2017, London, 22 - 23 February 2017, available online at http://archive.ifrs.org (last retrieved on 15 September 2017), quoted: "IAS Board, February 2017, 5B"

IAS Board, Financial Instruments with Characteristics of Equity Research Project - Features of Claims, IFRS Staff Paper ref. 5A to the IAS Board Meeting June 2015, London, 22 - 25 June 2015, available online at http:// archive.ifrs.org (last retrieved on 15 September 2017), quoted: "IAS Board, June 2015, 5A"

IAS Board, Financial Instruments with Characteristics of Equity - Summary of Discussion to date, IFRS Staff Paper ref. 5A to the IAS Board Meeting March 2017, London, 21 - 22 March 2017, available online at http://archive.ifrs.org (last retrieved on 15 September 2017), quoted: "IAS Board, March 2017, 5A"

IAS Committee Foundation, Financial instruments: A User's Guide through the official Text of IAS 32, IAS 39 and IFRS 7, Basis for Conclusions, IAS Committee Foundation, London, 2009, quoted: "IAS 32.BC" / "IAS 39.BC" / "IFRS 7.BC"

IAS Committee Foundation, IFRS 4 Insurance Contracts, Vol. 2: Basis for Conclusions (including Dissenting Opinions), IAS Committee Foundation, London, 2004, quoted: "IFRS 4.BC" 
ICJ, Case concerning Delimitation of the Maritime Boundary in the Gulf of Maine Area (Canada vs. United States of America), The Hague, 12 October 1984, available online at www.icj-cij.org (last retrieved on 14 November 2016), quoted: "Gulf of Maine"

ICJ, Case concerning Land, Island and Maritime Frontier Dispute (E1 Salvador vs. Honduras), The Hague, 11 September 1992, available online at www.icj-cij.org (last retrieved on 14 November 2016), quoted: "Maritime Frontier Dispute"

ICJ, Case concerning Maritime Delimitation and Territorial Questions between Qatar and Bahrain (Qatar vs. Bahrain), The Hague, 1 July 1994, available online at www.icj-cij.org (last retrieved on 14 November 2016), quoted: "Qatar vs. Bahrain"

ICJ, Case concerning the North Sea Continental Shelf (Federal Republic of Germany vs. Netherlands), The Hague, 20 February 1969, available online at www.icj-cij.org (last retrieved on 14 November 2016), quoted: "North Sea Continental Shelf"

ICJ, Case concerning the Temple of Preah Vihear (Cambodia vs. Thailand), The Hague, 15 June 1962, available online at www.icj-cij.org (last retrieved on 14 November 2016), quoted: "Temple of Preah Vihear"

ICJ, Fisheries Case (United Kingdom vs. Norway), The Hague, 18 December 1951, available online at www.icj-cij. org (last retrieved on 14 November 2016), quoted: "Fisheries case"

IFA, 54th IFA Congress, Munich 2000 Summaries of Discussion on Subjects I and II, Bulletin for International Taxation 2001, Vol. 55, No. 2, IBFD, Amsterdam, 2001

International Monetary Fund, World Economic Outlook Database (Gross Domestic Product) 2016, International Monetary Fund, Washington D.C., 2016, available online at www.imf.org (last retrieved on 15 September 2017)

Korkein Hallinto-oikeus, judgement ref. KHO:2002:71, Helsinki, 6 November 2002, summarised online at www. ibfd.org (last retrieved on 15 September 2017)

League of Nations, Document C.216.M.85, ref. C.216.M.85, London, 12 April 1927, available online at http://adc. library.usyd.edu.au (last retrieved on 15 September 2017)

League of Nations (Economic and Financial Commission), Report on Double Taxation submitted to the Financial Committee - Economic and Financial Commission Report by the Experts on Double Taxation, ref. E.F.S.73. F.19, Vol. 4, sec. 1, Geneva, 5 April 1923, available online at http://adc.library.usyd.edu.au (last retrieved on 15 September 2017)

League of Nations, Report presented by the General Meeting of Government Experts on Double Taxation and Tax Evasion, ref. C.562.M.178.1928.II., Geneva, 31 October 1928, available online at http://adc.library.usyd. edu.au (last retrieved on 15 September 2017)

Nejvyšší Správní Soud, judgement ref. 2Afs 108/2004-106 ("AAA vs. Financial Directoratej”), Brno-střed (Czech Republic), 10 February 2005, summarised online at www.ibfd.org (last retrieved on 15 September 2017)

Norges Høyesterett, judgement ref. HR-2011-02285-A (Sak No. 2011/869) ("Industriinvesteringer AS and Hafslund Venture AS”), Oslo, 8 December 2011, summarised in Jakob Bundgaard, convertibles, sec. 3.1.

OECD, BEPS Action No. 2 - Neutralising the Effects of Hybrid Mismatch Arrangements (Final Report), 5 October 2015, OECD, Paris, 2015

OECD, BEPS Action No. 6 - Preventing the Granting of Treaty Benefits in Inappropriate Circumstances (Final Report), 5 October 2015, OECD, Paris, 2015

OECD, Clarification of the Meaning of "Beneficial Owner" in the OECD Model Tax Convention (Discussion Draft), Paris, 29 April 2011 to 15 July 2011, quoted: "OECD, Beneficial Owner, 2011" 
OECD, Consolidated List of outstanding Points concerning the OECD Draft Convention on Income and Capital, ref. TFD/FC/218, Paris, 21 July 1967, available online at www.taxtreatieshistory.org (last retrieved on 15 September 2017)

OECD, Developing a Multilateral Instrument to Modify Bilateral Tax Treaties, Action 15 - 2015 Final Report, Paris, 5 October 2015, available online at www.oecd.org (last retrieved on 15 September 2017)

OECD, Double Taxation Conventions and the Use of Conduit Companies, Paris, 1986, available as Appendix R(6) to the OECD Commentaries 2014

OECD, Draft Contents of the 2017 Update to the OECD Model Tax Convention, Paris, 11 July 2017, available online at www.oecd.org (last retrieved on 15 September 2017), quoted: "OECD MTC Draft Update"

OECD, Innovative Financial Transactions: Tax Policy Implications (A Report by the Special Sessions on Innovative Financial Transactions of the OECD on $10-14$ September 2001), ref. ST/SG/AC.8/2001/CRP.8, Geneva, 19 July 2001, available online at www.un.org (last retrieved on 15 September 2017), quoted: "OECD, ST/ SG/AC.8/2001/CRP.8"

OECD, Neutralising the Effects of Hybrid Mismatch Arrangements, Action 2 - 2015 Final Report, Paris, 5 October 2015, available online at www.oecd.org (last retrieved on 25 September 2017)

OECD, Peer Review - An OECD Tool for Co-operation and Change, Paris, 22 January 2003, available online at www.oecd.org (last retrieved on 15 September 2017)

OECD, Recommendation of the OECD Council concerning the MTC, ref. C(97)195, Paris, 13 October 1997, available online at www.taxtreatieshistory.org (last retrieved on 15 September 2017), quoted: "Recommendations 1997"

OECD, Report on Thin Capitalization, Issues in International Taxation 1987, No. 2, Paris, 26 November 1986

OECD, OECD Model Tax Convention: Revised Proposals concerning the Meaning of "Beneficial Owner" in Articles 10, 11 and 12, Paris, 19 October 2012 to 15 December 2012, available online at www.oecd.org (last retrieved on 25 September 2017), quoted: "OECD, Beneficial Owner, 2012"

OECD, Taxation of new Financial Instruments, OECD, Paris, 1994

OECD, The Granting of Treaty Benefits with Respect to the Income of Collective Investment Vehicles, OECD, Paris, 2010, available online at www.oecd.org/tax/treaties/45359261.pdf (last retrieved on 15 September 2017)

OECD (Working Party No. 1 of the Fiscal Committee, Working Group No. 23), Report on the Double Taxation of Dividends received by an Individual, ref. FA/WP1(71)6, Paris, 30 December 1971, available online at www. taxtreatieshistory.org (last retrieved on 15 September 2017)

OECD (Working Party No. 1 of the Fiscal Committee, Working Group No. 23), Revision of Art. 10 of the 1963 Model Convention and the Commentary thereon, ref. CFA/WP1(73)2, Paris, 31 January 1973, available online at www.taxtreatieshistory.org (last retrieved on 15 September 2017), quoted: "OECD, CFA/ WP1(73)2"

OECD (Working Party No. 19 of the Fiscal Committee), Taxation of Capital Gains, ref. FC-WP19(62)1, Paris, 15 June 1962, available online at www.taxtreatieshistory.org (last retrieved on 15 September 2017), quoted: "OECD, FC-WP19(62)1"

OECD (Working Party No. 19 of the Fiscal Committee), Taxation of Capital Gains, ref. FC-WP19(62)2, Paris, 15 September 1962, available online at www.taxtreatieshistory.org (last retrieved on 15 September 2017), quoted: "OECD, FC-WP19(62)2"

OECD, The Taxation of Net Wealth, Capital Transfers and Capital Gains of Individuals: Report of the OECD Committe on Fiscal Affairs, Paris, 1979

OEEC Council, Fourth Report of the Fiscal Committee, ref. C(61)97, Paris, 19 June 1961, available online at www. taxtreatieshistory.org (last retrieved on 15 September 2017) 
OEEC Fiscal Committee, Minutes of the 22nd session held at the Château de la Muette, Paris, on Tuesday 17th, Wednesday 18th, Thursday 19th and Friday 20th January 1961, ref. FC-M(61)1, Paris, 17 February 1961, available online at www.taxtreatieshistory.org (last retrieved on 15 September 2017)

OEEC (Working Party No. 11 of the Fiscal Committee), Third Report on the Taxation of Interest, ref. FCWP11(60)2, Paris, 20 October 1960, available online at www.taxtreatieshistory.org (last retrieved on 15 September 2017)

OEEC (Working Party No. 11 of the Fiscal Committee), Fourth Report on the Taxation of Interest, ref. FCWP11(61)1, Paris, 1 November 1961, available online at www.taxtreatieshistory.org (last retrieved on 15 September 2017)

OEEC (Working Party No. 11 of the Fiscal Committee), Report on the Taxation of Interest, ref. FC-WP11(59)1, Paris, 15 January 1959, available online at www.taxtreatieshistory.org (last retrieved on 15 September 2017)

OEEC (Working Party No. 12 of the Fiscal Committee), Report on the Taxation of Dividends, ref. FCWP12(58)1part1, Paris, 23 November 1958, available online at www.taxtreatieshistory.org (last retrieved on 15 September 2017)

OEEC (Working Party No. 12 of the Fiscal Committee), Second Report on the Taxation of Dividends, ref. FC/ WP12(60)4, Paris, 24 September 1960, available online at www.taxtreatieshistory.org (last retrieved on 15 September 2017)

Pengadilan Pajak,judgement ref.Put-13602/PP/M.I/13/2008 ("PT.Transportasi Gas Indonesia vs. Direktur Jenderal Paiak"), Jakarta, 14 March 2008, summarised online at www.ibfd.org (last retrieved on 15 September 2017)

Supreme Court of Canada, judgement ref. 23940 ("Crown Forest Industries Ltd. vs. Her Majesty the Queen"), [1995] 2 C.T.C. 64, Ottawa, 22 June 1995, summarised online at www.ibfd.org (last retrieved on 15 September 2017)

Tax Court of Canada, judgement ref. 2012 TCC 57 ("Velcro Canada vs. Her Majesty The Queen"), [2012] 4 CTC 2029, Ottawa, 26 February 2009, summarised online at www.ibfd.org (last retrieved on 25 September 2017)

Tax Court of Canada, judgement “William C. Krafve vs. M.N.R.”, 84 C.T.C. 2021, Ottawa, 21 November 1983, summarised in Stefano Simontacchi, p. 180 et seq.

UN, Committee of Experts on International Cooperation in Tax Matters - Report on the sixth Session (18 - 22 October 2010), Economic and Social Council, Official Records 2010, Supplement No. 25, UN, New York, 2011, available online atwww.un.org, (last retrieved on 15 September 2017)

UN Committee of Experts on International Cooperation in Tax Matters, Treatment of Islamic financial instruments under the United Nations Model Double Taxation Convention between Developed and Developing Countries - Note by the Working Group on Treatment of Islamic Financial Instruments (third Session in Geneva from 29 October - 2 November 2007), ref. E/C.18/2007/9, 21 August 2007, UN Economic and Social Council, Geneva, 2007, available online at www.un.org (last retrieved on 15 September 2017)

US Tax Court, judgement ref. 740-92 ("Tate \& Lyle Inc. and Subsidiaries vs. Commissioner of Internal Revenue"), Washington D.C., 15 November 1994, summarised online at www.ibfd.org (last retrieved on 15 September 2017)

World Bank, World Bank national Accounts Data and OECD National Accounts Data Files (Gross Domestic Product) 2016, World Bank, Washington D.C., 2016, available online at http://data.worldbank.org (last retrieved on 15 September 2017) 



\section{Illustrations}

Illustration 1: Asset-based approach versus transaction-based approach $\quad 24$

Illustration 2: Genuine and derivative legal concepts under the substance over form principle 35

Illustration 3: Aggregation and disaggregation in the narrow versus in the broader sense 43

Illustration 4: Aggregation and disaggregation in a risk-return matrix $\quad 47$

Illustration 5: Residual and / or missing options due to imperfect replication 48

Illustration 6: Linearity, continuity and consistency of tax systems $\quad 50$

Illustration 7: IAS/IFRS terminology

Illustration 8: Option portfolio of non-legal risks (B) and reference portfolio (A, C) 63

Illustration 9: Subject-related aspect and object-related aspect of beneficial ownership 73

Illustration 10: (Re-)attributional aspect and anti-abuse aspect of beneficial ownership 78

Illustration 11: Different scopes of beneficial ownership in the asset and in the income or

transaction $\quad 79$

Illustration 12: The horizontal aggregation of beneficial ownership as opposed to the vertical aggregation $\quad 84$

Illustration 13: The nexus between laterality, voluntariness, self-execution and enjoyment 113

Illustration 14: Coverage as part of underwriting risk versus collateral as related to credit risk $\quad 131$

Illustration 15: Methodological cascade for debt-equity distinction $\quad 139$

Illustration 16: Current IAS/IFRS debt-equity classification and proposed changes $\quad 140$

Illustration 17: The difference between repayments of debt and equity $\quad 148$

Illustration 18: Systematic inseparability of equity contributions and business profits $\quad 150$

Illustration 19: The interpretational structure of Art. 10(3) OECD MTC 156

Illustration 20: The interaction of Art. 10(3) and 11(3) OECD MTC and the participation in profits $\quad 164$

Illustration 21: The different aspects of the term alienation in Art. 13(5) OECD MTC 192

Illustration 22: The genuine attributee of capital gains is always identical to the attributee of

the asset $\quad 193$

Illustration 23: Logical debt-equity delimitation scheme (high-level) 209

Illustration 24: Classification/subsumption scheme of forward transactions $\quad 224$

Illustration 25: Classification table of convertibles $\quad 234$

Illustration 26: The delimitation of preference shares, profit-participating debt-claims and linkers 248

Illustration 27: Classifiers/differentiators for preference shares $\quad 250$

Illustration 28: Delimitation of strips and similar financial instruments 255 



\section{Valorisation Addendum}

\section{Relevance}

For the scientific and practical relevance of this doctoral thesis reference is made to section 1.1.3.

\section{Target groups}

This dissertation contains an abstract theoretical part with fundamentals in section 2, an abstract methodological part with interpretations in section 3 and a practical application part with subsumptions in section 5. With these main contents, this thesis is aimed to reach the broadest possible audience of interested readers.

The abstract theoretical part with fundamentals addresses primarily law-making and related function holders such as tax policy makers, politicians in the field of regulatory governance or interdisciplinary scholars, as well as jurisprudence and other interested conceptualists. These could include, for instance, national ministries, other public authorities and expert committees in the field of tax affairs, supra-national organizations, think tanks and sectoral working groups, (law) faculties of universities, courts or conceptual specialists in such institutions.

The abstract methodological part with interpretations addresses primarily legal practitioners entrusted with the interpretation of the law, but also jurisprudence. In addition to the previously mentioned target groups, this could include, for instance, lawyers and professional chambers, sectoral and economic interest groups as well as other interested legal experts, for example from other disciplines parallel to tax law.

The practical application part addresses primarily legal practitioners entrusted with solving concrete cases, such as generalists, specialised media and educational institutions. In addition to the previously mentioned target groups, this could include, for instance, tax consultants and tax officers of companies, philanthropy and administrative authorities, specialised publishers as well as specialised educational programmes in universities and colleges.

\section{Activities/Products}

This study intends to have a descriptive purpose in the sense that it attempts to respect and interpret the OECD MTC as it actually is (de lege lata). In particular it does not intend to have a normative purpose in the sense that it indicates any evaluative suggestion beyond the OECD MTC as it actually is (de lege ferenda). In the background of this general intention, the following concrete activities/products emerge as outcomes of this dissertation for the potential audiences mentioned before: 
Referring to the law-making audience, one aim of this thesis is to point to the conceptual limits, ruptures and weaknesses of the OECD MTC related to financial instruments and to critically challenge its capabilities and expedience. On the other hand, it should also be demonstrated which far-reaching possibilities an interdisciplinary and structural interpretation methodology offers in acceptance of these (possibly necessary or unavoidable) limits and weaknesses. In that regard, this dissertation is also intended to encourage acknowledging the findings of other areas of scientific research and to exploit these for the jurisprudence in an unconventional and value-adding way.

Referring to the law-interpreting audience, a further objective of this thesis is to develop a concrete tiebreaking test in order to distinguish shares yielding dividends pursuant to Art. 10(3) OECD MTC, debt-claims yielding interest pursuant to Art. 11(3) OECD MTC, capital gains pursuant to Art. 13(5) OECD MTC and other income pursuant to Art. 21(1) OECD MTC. This test shall be capable of solving the conceptually most ambiguous and controversial use cases discussed to date in research and practice; in doing so the main focus is on the systematic element of interpretation. For the target properties or characteristics of such a test reference is made to section 1.1.2.

Referring to the law-practicing audience, another goal of this thesis is to apply a concrete catalogue of those conceptually most ambiguous and controversial use cases based on that test. On the one hand, this should validate and demonstrate the capability and expedience of the self-developed test. On the other hand it should contribute a consistent own opinion on the tax treatment of the relevant financial instruments for the expert discussion.

\section{Innovation}

From the author's point of view, this dissertation draws its innovative character from several methodological approaches and techniques:

As a subject of tax law and thus of the OECD MTC, this study goes comparatively deep into the economic structure and dependencies of financial instruments (e.g. finance theory). This results, on the one hand, from the intentional and, secondly, the systematic element of interpretation of the OECD MTC, which aim both to address these relationships appropriately.

At this level of those relatively fundamental economic structure and dependencies, this thesis also draws analogies from other legal-like systems with similar problems (e.g. IAS / IFRS) by transferring their more advanced approaches and techniques to the OECD MTC. In addition, this paper also makes legal comparisons with some more advanced approaches and techniques of other tax laws (e.g. US federal tax law), which have already adopted the findings of those other research areas mentioned above and use them to solve the conceptual problems dealt with herein. 
A reverse approach from the perspective of European interpretation methodology also results from the "funnel approach" taken in this study: it starts with the general and fundamental principles, which are embedded in the systematic legal setting afterwards. The results are condensed or broken down to potential differentiators and only then are they interpretatively tested against the concrete legal texts.

Finally, this study also represents an attempt to conceptually and terminologically unlink the autonomously interpreted concepts and norms of the OECD MTC as well as components of them from the patterns of local tax laws to the maximum possible extent. Through this generic approach, the above-mentioned test and the differentiating criteria flowing into it should attain a particularly high degree of universality and objectivity.

For further aspects of the approach taken here reference is made to section 1.3.

\section{$5 \quad$ Implementation}

The aforementioned activities/products for the respective audiences could be implemented by the following examples:

Referring to the law-making readers, the conceptual limits and weaknesses of the OECD MTC identified in this thesis could be the subject of subsequent scientific studies. As part of a fundamental consideration of dogmatic and pragmatic arguments, these studies would at first have to clarify the normative question to what extent the possibilities for tax avoidance and tax structuring of financial instruments resulting from those weaknesses are acceptable. To the extent any need for change is identified, they could further derive technical and/or fundamental suggestions from this thesis for improving the capabilities and expedience of the OECD MTC.

Irrespective of these normative possibilities for further development, the structural inter-dependencies and criteria identified in this dissertation could be analogously applied to similar use cases. In particular, transactions cited herein are those such as insurance, letting and leasing, royalties and annuities, betting and gambling or those embedded in MTC taxonomy (e.g. business or employment). Such a transfer could potentially address also a variety of further research issues, as there are, for instance, the systematic relationship of Art. 10, 11, and 13 OECD MTC with those of other distributive articles (e.g. Art. 12 OECD MTC). Perhaps, such an analysis would ultimately lead to the fundamental question to what extent the OECD MTC that is tied in physical patterns is even capable to actually deal with economic substance. In other words: in which relation the material object (axiom) and the formal evidence (pragmatics) necessary for its recognition stand.

Also for the law-interpreting audience the tie-breaking test developed in this study could be further developed for both normative and descriptive purposes. Normative in a way that the structural interdependencies flowing into that test could be used for the design of revised income articles by developing the test back into a suggested wording. Descriptive in the sense that the identified differentiators could be amplified into a practice guide on the classification and treatment of financial instruments pursuant to international tax law. Irrespective of this, the test and possibly also those differentiators could eventually be used as guidelines for 
potential compatibility or harmonisation efforts where appropriate (e.g. between different domestic tax laws or with other disciplines such as accounting law).

For the law-practicing audience, the tie-breaking test and the differentiators can at first be used for tax structuring (in particular the development of innovative financial instruments), as long as the legislators continue to leave the fundamental problem of the legal discrepancy between the economic substance and its physical medium unsolved. In addition, the tie-breaking test developed in this thesis could be used as a guideline for a comparative study of the treatment of financial instruments under various domestic tax laws (e.g. in the form of a practitioner handbook). 


\section{Curriculum Vitae}

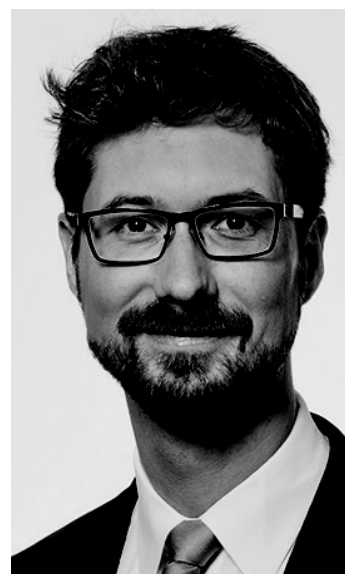

Jan Weissbrodt, born in Berlin (Germany) on 15 February 1979, graduated with an economic degree in Business Administration and Management at the University of Mannheim (Germany) with the specialisations in Corporate Tax, Accounting, Audit \& Valuation as well as Banking \& Finance.

While he was working as a tax advisor and assistant auditor for a tax, audit and advisory boutique in Frankfurt am Main (Germany), he was approved and admitted to the Chamber of Certified German Tax Consultants.

After having changed to Credit Suisse in Zurich (Switzerland) as an in-house tax specialist, he obtained his Masters degree (LL.M.) in International Tax Law at the University of Zurich (Switzerland).

During his work as a Senior Tax Manager for KPMG in Zurich (Switzerland), he started his dissertation in International Tax Law at the University of Mastricht (Netherlands). Today he holds a position as Global Head of Tax of the Sportradar Group in St. Gallen (Switzerland).

Jan Weissbrodt has published articles in renowned German and Swiss tax journals and held educational lectures in academic and professional programs. 